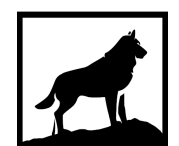

Michigan Technological

1 в 8 5 University
Michigan Technological University Digital Commons @ Michigan Tech

\title{
CHARACTERIZATION OF HYDRAULIC INTERACTIONS BETWEEN TORQUE CONVERTER AND TRANSMISSION DURING TRANSIENT EVENTS
}

Mark Woodland

Michigan Technological University, mtwoodla@mtu.edu

Copyright 2019 Mark Woodland

Recommended Citation

Woodland, Mark, "CHARACTERIZATION OF HYDRAULIC INTERACTIONS BETWEEN TORQUE CONVERTER AND TRANSMISSION DURING TRANSIENT EVENTS", Open Access Master's Thesis, Michigan Technological University, 2019.

https://doi.org/10.37099/mtu.dc.etdr/843

Follow this and additional works at: https://digitalcommons.mtu.edu/etdr

Part of the Automotive Engineering Commons 
CHARACTERIZATION OF HYDRAULIC INTERACTIONS BETWEEN TORQUE CONVERTER AND TRANSMISSION DURING TRANSIENT EVENTS

\title{
By
}

Mark T. Woodland

\begin{abstract}
A THESIS
Submitted in partial fulfillment of the requirements for the degree of MASTER OF SCIENCE

In Mechanical Engineering
\end{abstract}

MICHIGAN TECHNOLOGICAL UNIVERSITY

2019

(C) 2019 Mark T. Woodland 

This thesis has been approved in partial fulfillment of the requirements for the Degree of MASTER OF SCIENCE in Mechanical Engineering.

Department of Mechanical Engineering-Engineering Mechanics

Thesis Co-Advisor: Jason Blough

Thesis Co-Advisor: Darrell Robinette

Committee Member: Carl Anderson

Committee Member: Chuck Van Karsen

Department Chair: William W. Predebon 



\section{Table of Contents}

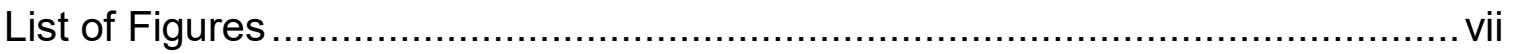

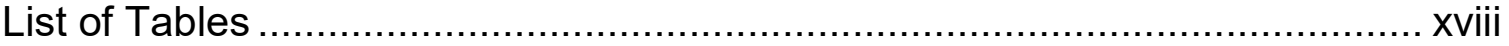

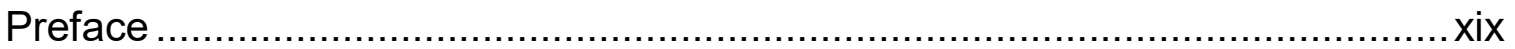

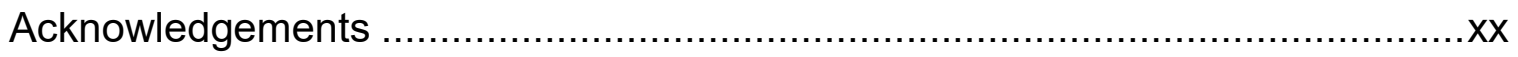

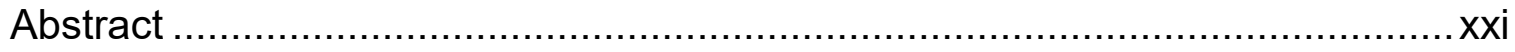

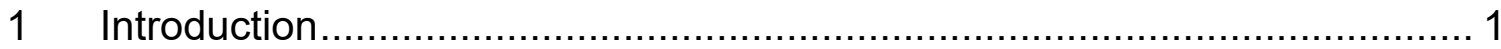

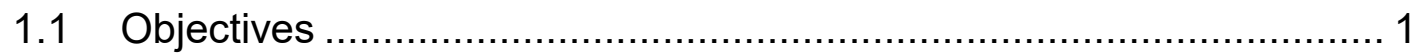

1.2 Torque Converter Basics ….................................................. 2

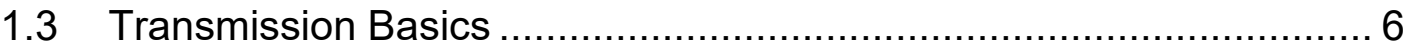

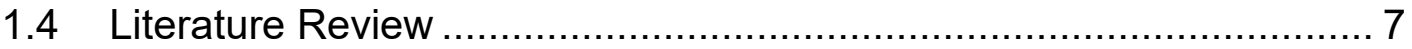

1.4.1 Torque Converter Experimentation ..................................... 8

1.4.2 Torque Converter Simulation ........................................... 10

1.4.3 Wet Friction Clutch Development..................................... 11

1.4.4 Transmission Development............................................ 11

1.4.5 Transmission Simulation ................................................ 12

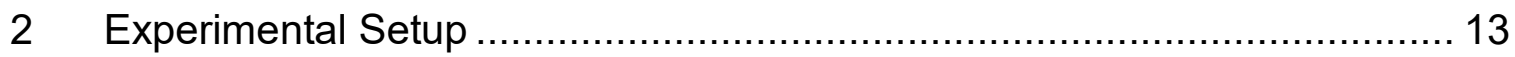

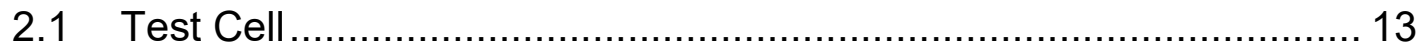

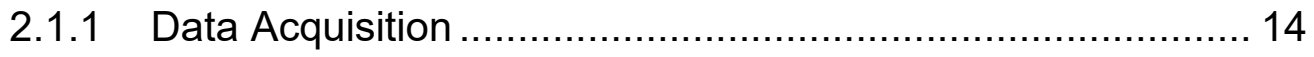

2.1.2 Dyno Controller .......................................................... 15

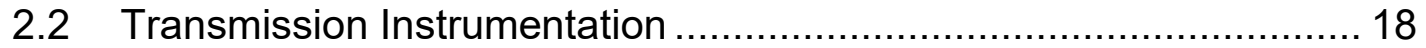

2.3 Transmission Controller .......................................................... 20

2.3.1 Universal Solenoid Driver II............................................. 20

2.3.2 Next Gen Transmission Controller .................................... 23 


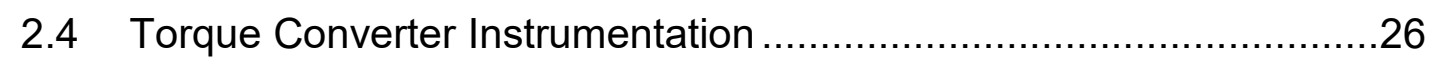

2.4.1 Impeller and Cover ......................................................27

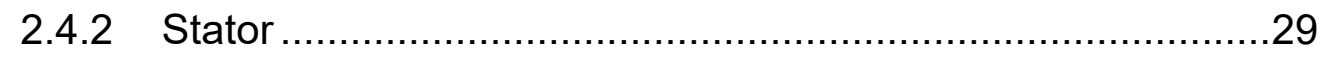

2.4.3 Turbine and Clutch Plate ...................................................31

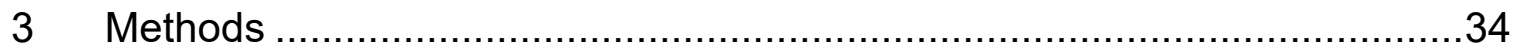

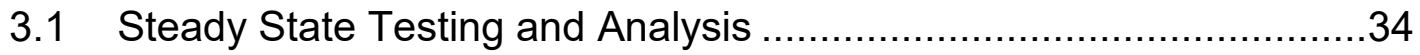

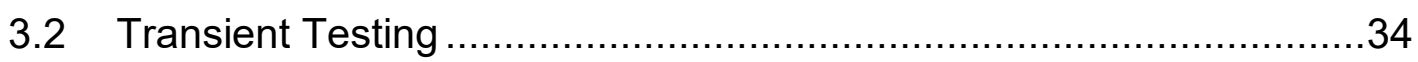

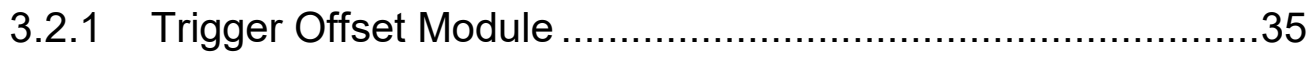

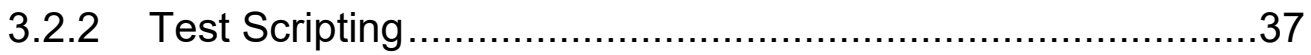

3.2.3 Data Acquisition Parameters …........................................37

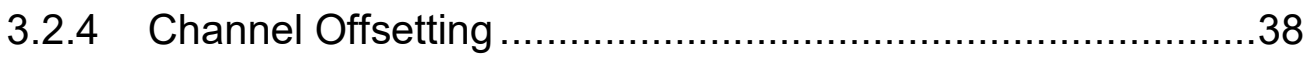

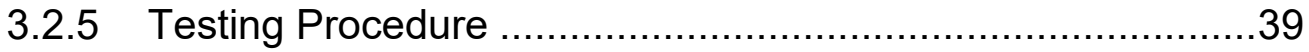

3.3 Transient Data Post Processing ………..................................... 41

3.3.1 Signal Dropout Removal ............................................... 41

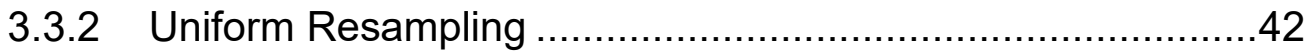

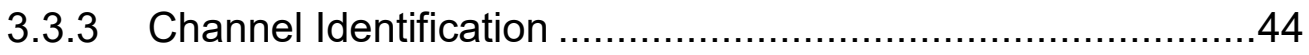

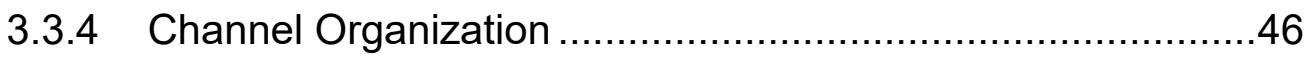

3.4 Back Drive Test Development …..............................................

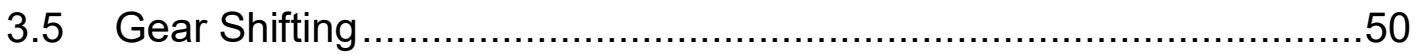

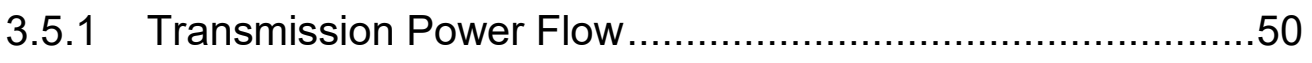

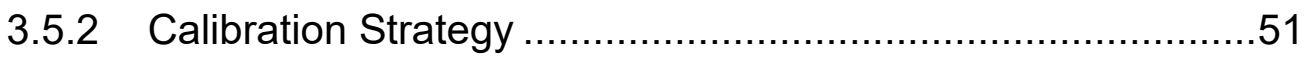

3.5.3 AmeSIM Transmission Model .........................................54

3.5.4 Dyno Torque Management ................................................59

3.6 Torque Converter Clutch Controls ................................................

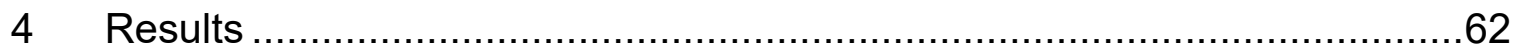

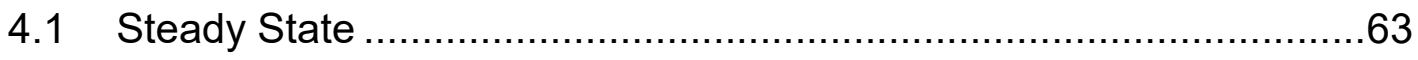


4.1.1 Torque Converter Performance Validation ........................... 63

4.1.2 Zero Load Pressure ............................................................ 64

4.1.3 TCC Control and Charge Pressure ................................... 72

4.1.4 Torque Converter Clutch Capacity and Friction Material

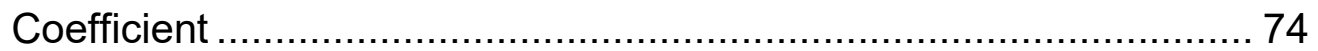

4.1.5 Clutch Pressures and Forces ......................................... 76

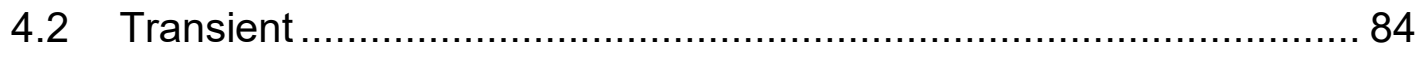

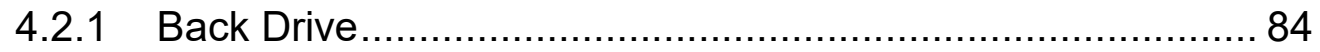

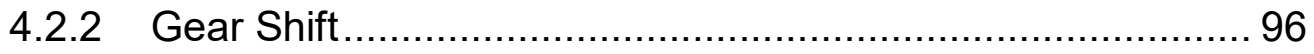

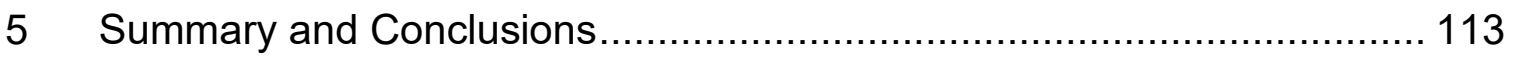

5.1 Steady State Results Summary ................................................ 113

5.2 Transient Results Summary ................................................... 113

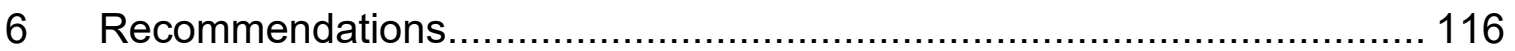

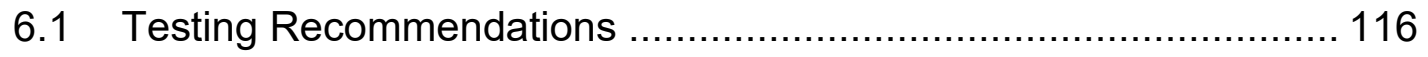

6.2 Instrumentation Recommendations............................................. 116

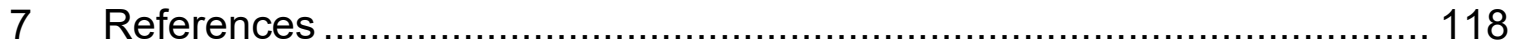

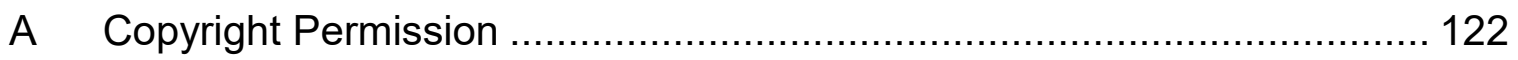

A.1 Edward De Jesus Rivera Dissertation Reference Permission......... 122

A.2 SAE Copyright agreement for Transient Testing in Methods

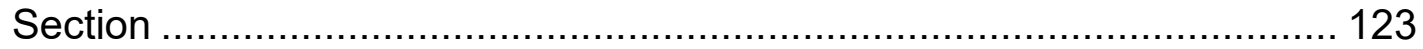




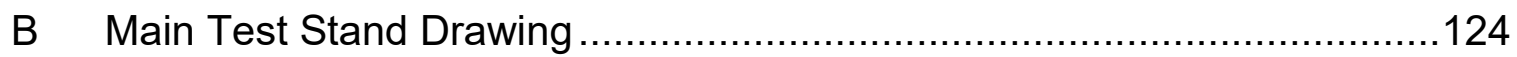

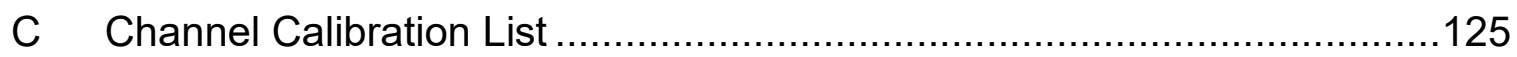

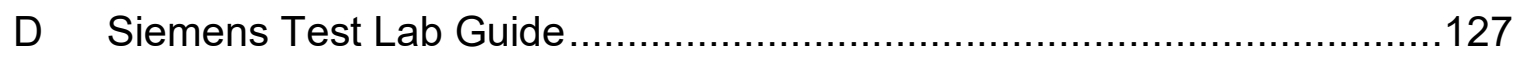

E Test Cell Startup and Operation Procedure .........................................133

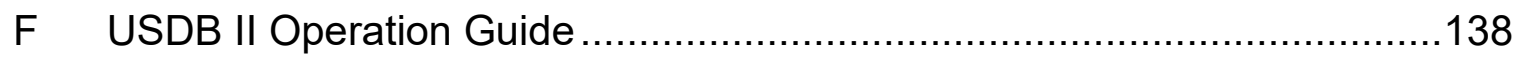

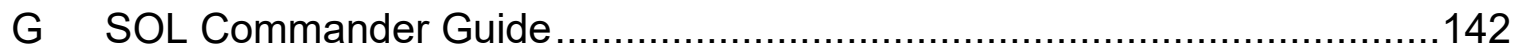

H Pressure Transducer Specifications ..................................................148

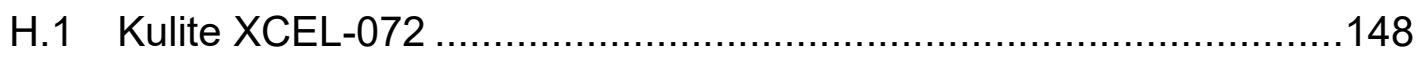

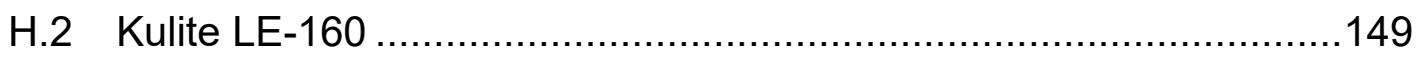

I Torque Converter Instrumentation Photos ............................................150

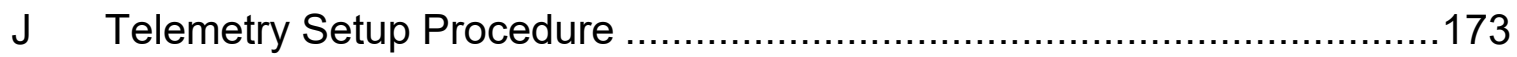

K Torque Converter Clutch Pressures ................................................178

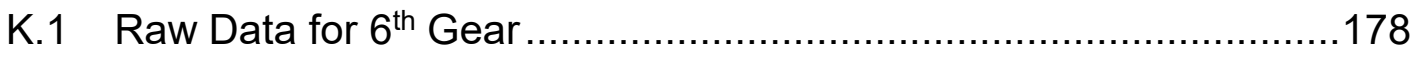

K.2 $5^{\text {th }}$ Gear TCC Pressure Graphics ...............................................179

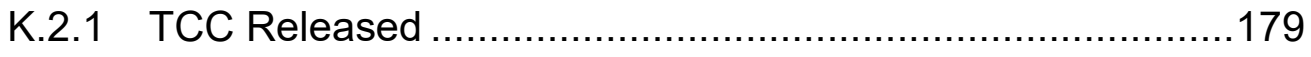

K.2.2 TCC Applied ...........................................................180

K.2.3 TCC Slip ............................................................... 181

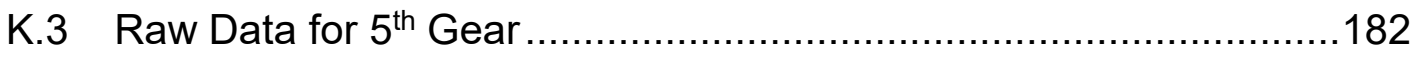

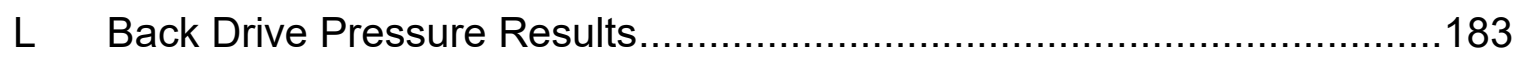

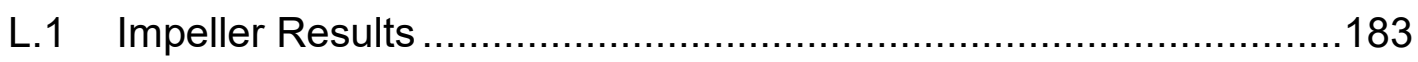

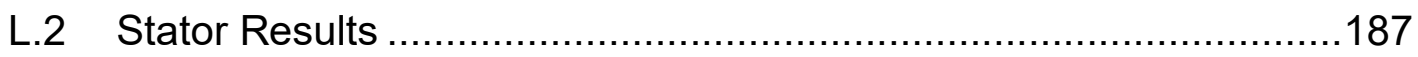




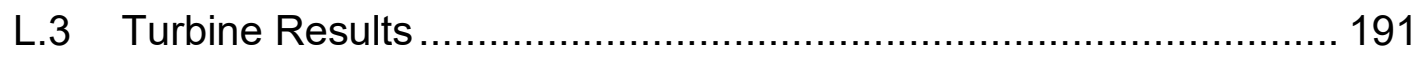

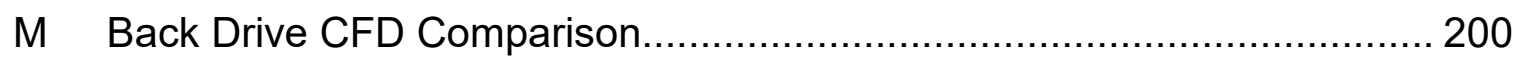

M.1 Impeller +45 Nm CFD Comparison .............................................. 200

M.2 Impeller -45 Nm CFD Comparison .............................................. 201

M.3 Stator +45 Nm CFD Comparison …....................................... 202

M.4 Stator -45 Nm CFD Comparison ................................................... 203

M.5 Turbine +45Nm CFD Comparison.............................................. 204

M.6 Turbine -45 Nm CFD Comparison.............................................. 205

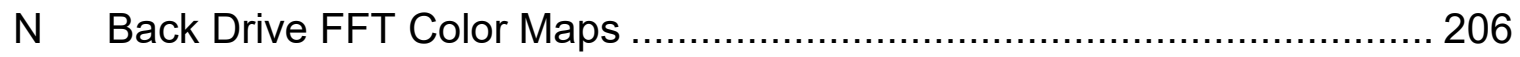

N.1 Impeller Color Maps .............................................................. 206

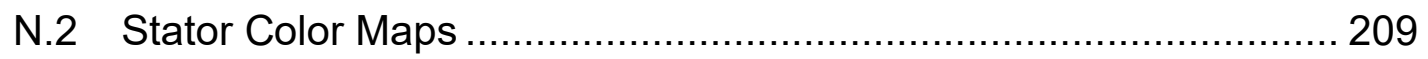

N.3 Turbine Color Maps.............................................................. 213

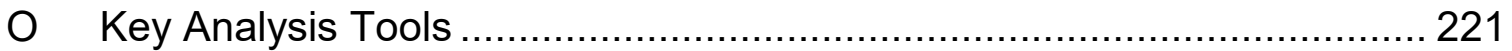

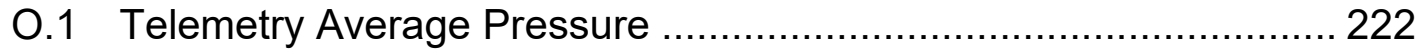

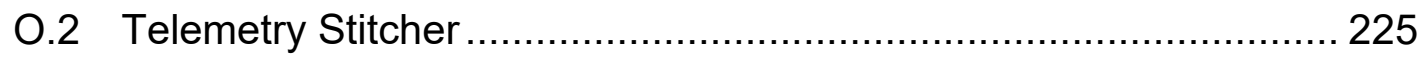

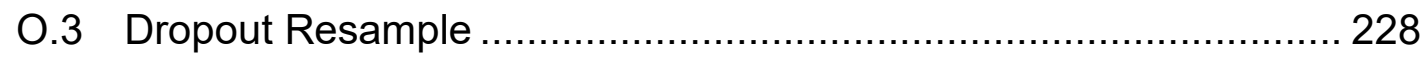

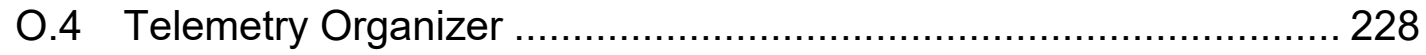

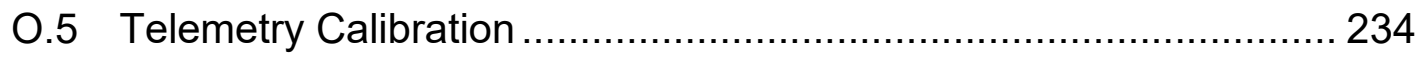

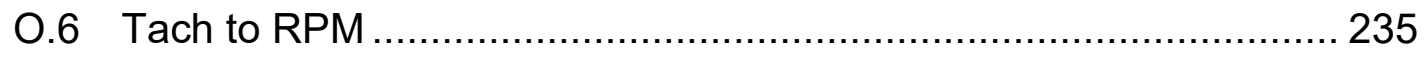

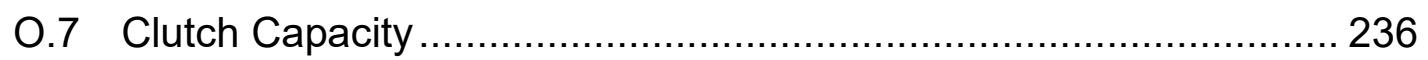

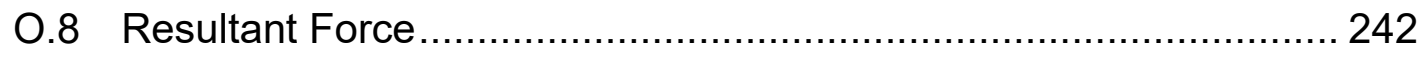

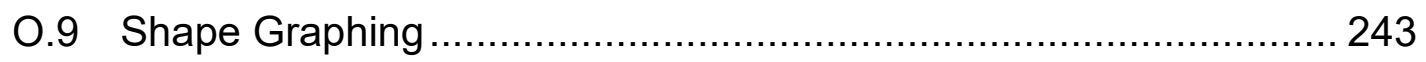


O.10 Text Graphing .

.245 


\section{List of Figures}

Figure 1-1. Torque converter components …........................................... 2

Figure 1-2 Torque converter power flow torque multiplication (Left), rigid connection (Right)............................................................................ 3

Figure 1-3. Torque converter performance example ................................... 5

Figure 1-4. Concept of clutch application timing with respect to impeller and turbine

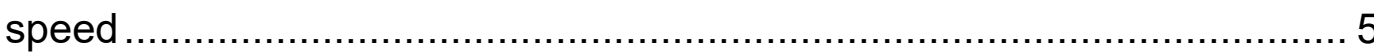

Figure 1-5. Transmission cross section and power flow ................................. 6

Figure 1-6. Normally low solenoid driver (left), Normally high solenoid driver (right) 7

Figure 2-1. Transmission test cell layout ..................................................... 13

Figure 2-2. Test cell measurement and communication layout ....................... 14

Figure 2-3. Dyno control VI status screen ................................................... 16

Figure 2-4. Dyno controller manual mode ................................................ 17

Figure 2-5. Dyno controller experimental mode ............................................. 18

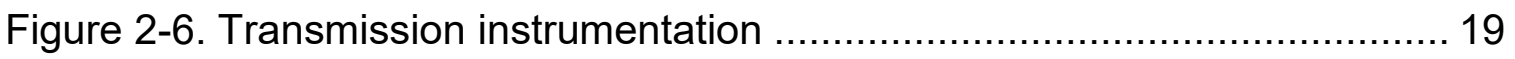

Figure 2-7. USD II and Next Gen solenoid drivers in tower instrumentation rack21

Figure 2-8. USD II control software main screen ........................................ 21

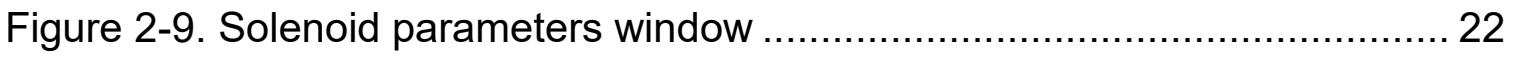

Figure 2-10. Individual solenoid control window .......................................... 24 
Figure 2-11. Solenoid shift schedule window .25

Figure 2-12. Shift profile and trigger activation window ................................26

Figure 2-13. Example multiplexed data stream for 7 channels [41] ..................27

Figure 2-14. Transmitter $A$ instrumentation locations [19] ..............................28

Figure 2-15. Transmitter A hardware for power supply and transmitter [24].......28

Figure 2-16. Transmitter B instrumentation locations [19] ............................29

Figure 2-17. Transmitter B induction coils and transmitter hardware [24] ...........30

Figure 2-18. Signal slot for transmitter B cut in impeller shell [24]...................30

Figure 2-19. Transmitter $\mathrm{C}$ instrumentation locations [19] ...............................

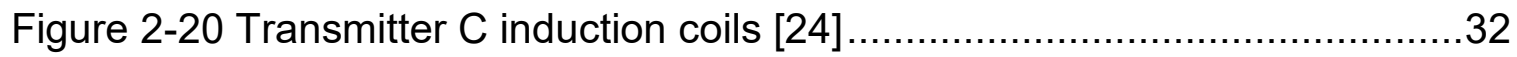

Figure 2-21. Transmitter $C$ induction coils and transmitter connections [24] .......32

Figure 2-22. Hardware for power and signal connections to transmitter B \& C

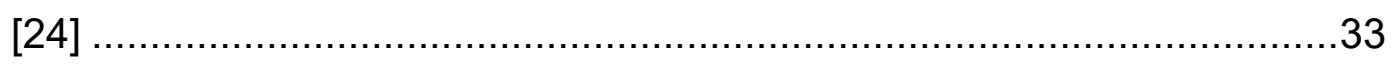

Figure 2-23. Signal slot for transmitter $\mathrm{C}$ cut in cover [24]............................33

Figure 3-1. Test cell measurement and communications with transient capabilities 35

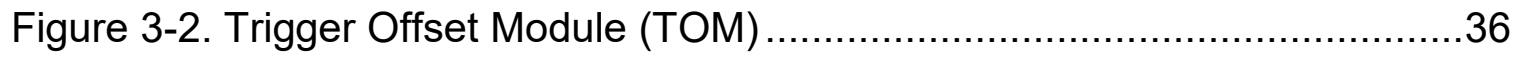

Figure 3-3. Phase error based on $11.5 \mathrm{kHz}$ sampling frequency .....................38

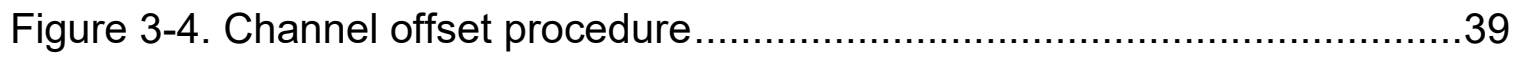

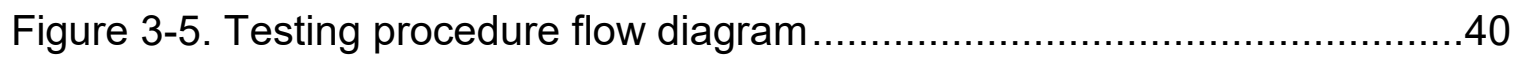


Figure 3-6. Raw data trace with dropouts (top), dropout removed trace (bottom)

Figure 3-7. IR Telemetrics signal evolution diagram [44].............................. 43

Figure 3-8. Telemetry sampling procedure [44] ...................................... 44

Figure 3-9. Channel groups (top), individual channel breakdown (bottom) ........ 45

Figure 3-10. Data removal from start and end of channel ............................. 46

Figure 3-11. Channel 1 from each run stitched into a time trace ..................... 46

Figure 3-12. Example of all channels for transmitter $A$ after post processing .... 47

Figure 3-13. FFT colormap of channel 2 from transmitter A ............................ 48

Figure 3-14. Dyno operation between positive and negative torque .................. 49

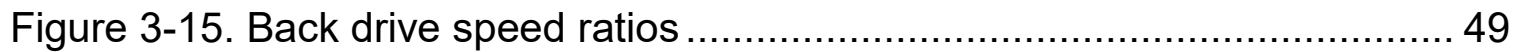

Figure 3-16. Stick diagram of transmission under study .............................. 50

Figure 3-17. Power-on upshift calibration strategy for constant input torque ...... 52

Figure 3-18. Power-on downshift calibration strategy for constant input torque . 53

Figure 3-19. Transmission 1-D model layout ................................................ 54

Figure 3-20. Current command conversion to pressure …............................ 55

Figure 3-21. Solenoid pressure conversion to friction clutch torque capacity .....56

Figure 3-22. Example current command profile for a normally low solenoid ......57

Figure 3-23. Example current command profile for a normally high solenoid .....57 
Figure 3-24. Example model results of a downshift from 6th to 5th gear

Figure 3-25. Upshift calibration strategy with torque management .59

Figure 3-26. Downshift calibration strategy with torque management. 60

Figure 4-1. Torque converter performance validation. .63

Figure 4-2. Zero load transmission pressure values for impeller and cover: top to bottom- TCC Released, TCC Applied, TCC Slipping.... .65

Figure 4-3. Zero load transmission pressure values for stator: top to bottom- TCC Released, TCC Applied, TCC Slipping 66

Figure 4-4. Zero load transmission pressure values for turbine and TCC: top to bottom- TCC Released, TCC Applied, TCC Slipping. 67

Figure 4-5. Line (top) and TCC control (bottom) pressures 68

Figure 4-6. Centripetal pressure for each impeller and cover channel 69

Figure 4-7. Calculation error for each channel compared to test results ...... .71

Figure 4-8. Impeller and cover centripetal pressures across multiple TCC control pressures .73

Figure 4-9. Stator centripetal pressures across multiple TCC control pressures.73

Figure 4-10. Turbine and TCC centripetal pressures across multiple TCC control pressures. .74

Figure 4-11. Torque converter clutch capacity ...... .75

Figure 4-12. Pressure profile across TCC .76

Figure 4-13. Force profile across TCC .77 
Figure 4-14. Pressure and resultant force acting on TCC example graphic

Figure 4-15. Pressure across TCC and resultant force for TCC released 81

Figure 4-16. Pressure across TCC and resultant force for TCC applied 82

Figure 4-17. Pressure across TCC and resultant force for 20 RPM slip ............ 83

Figure 4-18. 45 to $-45 \mathrm{Nm}$ test scenario for back drive ................................... 84

Figure 4-19. Speed ratio achieved during 45 to $-45 \mathrm{Nm}$ test ............................ 85

Figure 4-20. Back drive stitched time history for impeller and cover channels ... 86

Figure 4-21. Back drive stitched time history for stator channels..................... 86

Figure 4-22. Back drive stitched time history for turbine torus and clutch cavity channels

Figure 4-23. Back drive stitched time history for torque converter clutch channels 87

Figure 4-24. Impeller channel 2 pressures during back drive .......................... 88

Figure 4-25. Turbine channel 5 pressures during back drive.......................... 89

Figure 4-26. Stator channel 1 pressures during back drive ............................. 89

Figure 4-27. CFD comparison of test vs. steady state values to achieve -45

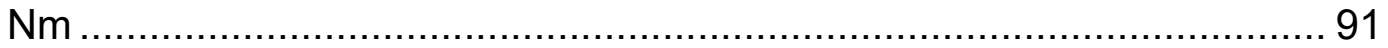

Figure 4-28. CFD correlation to high speed ratios .......................................... 92

Figure 4-29. Pressure distribution across stator blade for 45 and $-45 \mathrm{Nm}$......... 92

Figure 4-30. Stator speed identification using pressure data FFT color map ..... 94 
Figure 4-31. Hydraulic pump primary frequency

Figure 4-32. Multiple frequencies associated with the hydraulic pump .96

Figure 4-33. TCC slipping downshift repeatability verification .98

Figure 4-34. TCC slipping upshift repeatability verification .99

Figure 4-35. C35R current command profile comparison 100

Figure 4-36. CB26 current command profile 101

Figure 4-37. Low load, low speed downshift with TCC released- (top to bottom): transmission speeds, transmission torques, clutch pressures, stitched torque converter pressure time history 103

Figure 4-38. Low load, low speed downshift with TCC applied- (top to bottom): transmission speeds, transmission torques, clutch pressures, stitched torque converter pressure time history 104

Figure 4-39. Low load, low speed downshift with TCC slipping 20 RPM- (top to bottom): transmission speeds, transmission torques, clutch pressures, stitched torque converter pressure time history 105

Figure 4-40. Low load, low speed shift with TCC released pressure data comparison 107

Figure 4-41. Low load, low speed shift with TCC applied pressure data comparison 108

Figure 4-42. Low load, low speed shift with TCC slipping pressure data comparison 109

Figure 4-43. FFT of channel 7 measured pressure on the TCC for before, during, and after the shift 111 
Figure 4-44. FFT of channel 6 measured pressure on the TCC for before, during, and after the shift

Figure 4-45. FFT of Line pressure for the transmission for before, during, and after

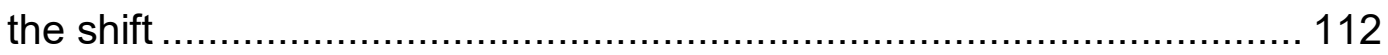

Figure D-1. Navigation pane for Test Lab.............................................. 127

Figure D-2. Navigation bar to select Test Lab window .............................. 128

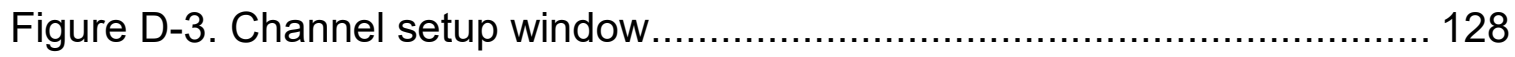

Figure D-4. Tracking setup window with turbine and output speed windows

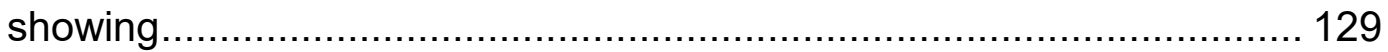

Figure D-5. Acquisition setup window pointing out sampling parameter

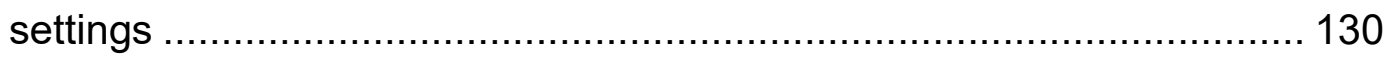

Figure D-6. Measurement window with pressure plot tab open ...................... 131

Figure D-7. Exporting data to Matlab in Navigator window........................... 132

Figure F-1. Solenoid driver and power supply mounted in transmission control

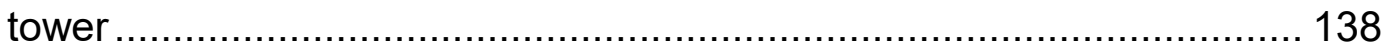

Figure F-2. Control window for USD II software ......................................... 139

Figure F-3. Solenoid command window for each solenoid ........................... 139

Figure F-4. Possible built in operations ................................................. 140

Figure F-5. Control window light up indicating commands are ready to send to

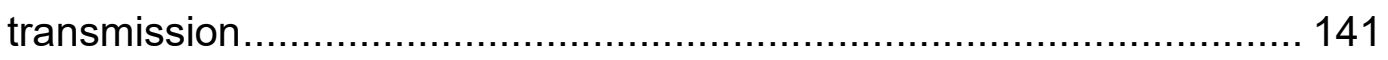


Figure F-6. Sequencer window to create a string of commands to run in a sequence.

Figure I-1. Left to right: shaft coupler, transmitter induction coil, head plate, receiver coil on flex plate

Figure I-2. Powering induction coil on head plate, receiving induction coil on flex plate. 150

Figure I-3. Transmitter coil and head plate placement on transmission housing 151

Figure I-4. Transmitter and hardware for turbine transmitter mounted on clutch plate. 151

Figure I-5. Kevlar patch on clutch plate for transmitter 152

Figure I-6. Power and signal pin arrays mounted to shell of turbine 152

Figure 1-7. Turbine torus 153

Figure I-8. Stator trailing edge side with receiver induction coil and transmitter hardware mounted in center. 153

Figure I-9. Stator leading edge side 154

Figure I-10. Stator laying on top of turbine 154

Figure I-11. Impeller with stator transmitter induction coil 155

Figure I-12. Stator laying on top of impeller. 155

Figure I-13. Impeller transmitter hardware mounted to cover. Kevlar patches to allow turbine transmitter signal to escape the torque converter 156 
Figure I-14. Turbine transmitter induction coil and Kevlar patches on inside of cover 156

Figure I-15. Impeller torus transducer locations........................................... 157

Figure I-16. Impeller channel 1 location, leading edge between blades ........... 157

Figure I-17. Impeller channel 2 location, between impeller and turbine........... 158

Figure I-18. Impeller channel 3 location, trailing edge between blades ........... 158

Figure I-19. Impeller channel 4 location, center between blades..................... 159

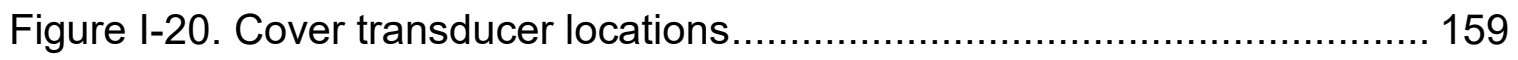

Figure I-21. Cover channels 5-7 locations …............................................ 160

Figure I-22. Stator transducer locations.................................................... 160

Figure I-23. Stator channel 1 location, leading edge/middle/pressure side ...... 161

Figure I-24. Stator channel 2 location, trailing edge/middle/pressure side ....... 161

Figure I-25. Stator channel 3 location, middle of blade/shell/pressure side ...... 162

Figure I-26. Stator channel 4 location, leading edge/core/pressure side ......... 162

Figure I-27. Stator channel 5 location, trailing edge/shell/pressure side.......... 163

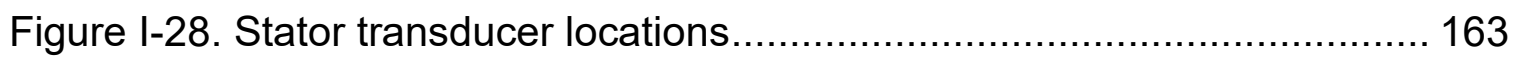

Figure I-29. Stator channel 6 location, leading edge/middle/suction side ......... 164

Figure I-30. Stator channel 7 location, trailing edge/middle/suction side ......... 164

Figure I-31. Turbine transducer locations ................................................. 165 
Figure I-32. Turbine channel 1 location, middle of blade suction side 165

Figure I-33. Turbine channel 2 location, trailing edge pressure side 166

Figure I-34. Turbine channel 3 location, leading edge pressure side 166

Figure I-35. Turbine channel 12 locations, trailing edge suction side 167

Figure I-36. Turbine channel 14 location, leading edge suction side. 167

Figure I-37. Turbine channel 15 location, middle blade pressure side 168

Figure I-38. Turbine channel 4 and 13 locations, back of turbine under plate ...168

Figure I-39. Clutch transducer locations 169

Figure I-40. Clutch channel 5 location, outer radius past friction material 169

Figure I-41. Clutch channel 9 location, middle radius 170

Figure I-42. Clutch channel 10 location, outer radius before friction material....170

Figure I-43. Clutch channel 11 location, inner radius 171

Figure I-44. Clutch plate transducer locations

Figure I-45. Clutch channel 6 location, middle radius 172

Figure I-46. Clutch channel 7 and 8 locations, inner and outer radius respectively.....

Figure I-1. Power supply for telemetry....

Figure I-2. Receivers for each transmitter 173

Figure I-3. Digital FV windows- chart display (top), receiver controller (middle), and receiver readout (bottom) 
Figure I-4. Receiver connected.

Figure I-5. Receiver showing signal strength and recording options .............. 176

Figure 1-6. Example of streamed data 177 


\section{List of Tables}

Table 2-1. Sampling parameters for each measurement type ….....................15

Table 2-2. Transmission gear ratio including final drive ................................19

Table 2-3. Transmission measured pressures ...........................................20

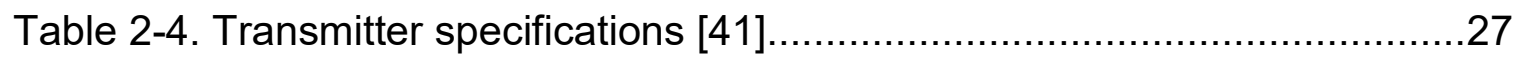

Table 3-1. Sampling frequency for each type of data ....................................38

Table 4-1. Summary of tests and operating conditions ...................................62

Table 4-2. Friction coefficient estimates for TCC friction material .....................76

Table 4-3. CFD parameters and results summary ......................................

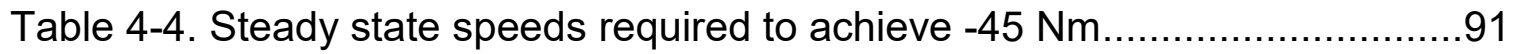

Table 4-5. Stator speeds for each speed ratio ...............................................93

Table 4-6. Gear shifts completed operating conditions ...................................96 


\section{Preface}

Multiple objectives were set to be accomplished for this research. First, is developing a test cell that has the capability to run a highly instrumented torque converter and transmission without changing the performance characteristics. A torque converter was instrumented with 29 pressure transducers and placed in a front wheel drive six-speed transmission instrumented to measure clutch and operating pressures. This gives the opportunity to mimic any maneuver that is seen in-vehicle, such as shifting gears.

Second, is developing a procedure for data collection and analysis. The instrumentation was designed for steady state testing, but the need to measure transient events was of interest. The methods that are used are also published through SAE to share the knowledge to others about the capabilities of capturing transient events with multiplexed data. Having this capability opens up the possibilities of what could be studied with the transmission and gives a better insight to where problems can arise.

Third, is creating test procedures that are relevant and that are similar to those in vehicle. The procedures that are covered are baselining the torque converter, gear shifting, and torque converter clutch being released, slipping, and applied. All test results were completed on the same torque converter and transmission. A noninstrumented transmission was used when developing shift and torque converter clutch profiles to avoid damaging the instrumented transmission.

Finally, is presenting the large data sets in a manner that is easy to interpret. By having a summary of the results that is simple improves the odds that additional work will be built off of the results and can be referenced during future development. This became a personal goal of mine to build my experience as well as ensuring that the work completed is stored in a simple and useful manner. 


\section{Acknowledgements}

Thank you to Ford Motor Company, for without their financial and technical support this project would not have been possible. I would like to specially thank, Steve Frait, Ram Sudarsan Devendran, Jeff Knutson, Soon Park, Mike Leads, and Tom Gochenour for all their time that they put into the project to ensure both the project and my personal success were achieved.

Thank you to all the professors that have impacted my education and taking time from their busy schedules to answer questions and discuss research challenges that I faced. I would also like to thank my committee members, Jason Blough, Darrell Robinette, Carl Anderson, and Chuck Van Karsen, for without their guidance and expertise, I would not be the engineer I am today.

Thank you to IR Telemetrics for providing the instrumented torque converter and technical support. Especially, when developing new procedures and methods when recording transient data.

Thank you to my family and friends for without their support I would not have been able to be successful at graduate school. A special thanks goes out to my girlfriend, Karina, for her unending support, patience, and traveling the graduate school path at Michigan Tech with me.

Finally, I would like to thank Edward De Jesus for his contribution to the project with the test cell development and educating me on torque converter design and operation. 


\section{Abstract}

A torque converter was instrumented with 29 pressure transducers to measure the torus, clutch plate, and torque converter cavities using telemetry to transfer the data. The torque converter was placed in a six-speed front wheel drive transmission and a test cell was built to drive and load the transmission to mimic in-vehicle performance.

Steady state tests were completed to establish a baseline for pressure performance of the torque converter. The transient events tested include back drive and gear shifting. Back drive showed how the pressure fluctuates across the speed ratios above 1 as well as identifying the stator speed. Gear shifting presented how large the pressure change can be between each gear state. Low speed downshifting, where hydraulic demand can possibly exceed pump capacity, resulted in showing the control over the torque converter clutch was still possible and reliable. These results can be used to improve future calibrations and designs. 



\section{Introduction}

Transmissions are complex architectures that transfer power from one location to another and are commonly used in the automotive industry. The constant drive to improve fuel economy causes a large interest in improving transmission efficiency. Transmissions also have an impact on the drive quality that is felt by the driver. Both fuel efficiency and drive quality are controlled by gear shift and torque converter design and calibration.

\subsection{Objectives}

The objective of this study is to gain an insight on how the torque converter interacts with the transmission through steady state operation and transient events. By understanding what is occurring inside the transmission and torque converter, better calibration techniques can be used to improve fuel efficiency and drive quality. All the measurements are taken using open loop controls, thus eliminating control variation showing only impacts due to the hardware and operation conditions. The information gained can then be applied to future designs.

To achieve this objective a test cell and control strategies had to be developed that was capable of running the transmission through a variety of scenarios. The transmission and torque converter were instrumented and ran through scenarios such as back drive and gear shifting with the torque converter clutch (TCC) applied, released, and slipping. The test scenarios were constructed to mimic, as closely as possible, in-vehicle performance. Data analysis techniques were also developed to handle both steady state and transient event post processing. All the development work and results are presented in the following sections. 


\subsection{Torque Converter Basics}

Torque converters are a turbomachine that transmit power from a driver to a driven component via a fluid interface. There are many different architectures of torque converters for a variety of applications, as seen by [1, 2]. A basic torque converter is made up of three elements, the impeller, turbine, and stator, making up the torus. The addition of a clutch plate allows for the input to be rigidly locked to the output resulting in almost $100 \%$ efficiency in power transmission. The torque converter used is this study is a three element, single stage, double phase torque converter as described above [3]. Single stage means the torque converter has a single turbine. The double phase means the torque converter can operate in two modes. The first, is torque multiplication with the stator being fixed. The second, the stator is allowed to freewheel via a one-way clutch. Figure 1-1 illustrates each of the components of the torque converter and the terminology that will be used throughout the rest of this document.

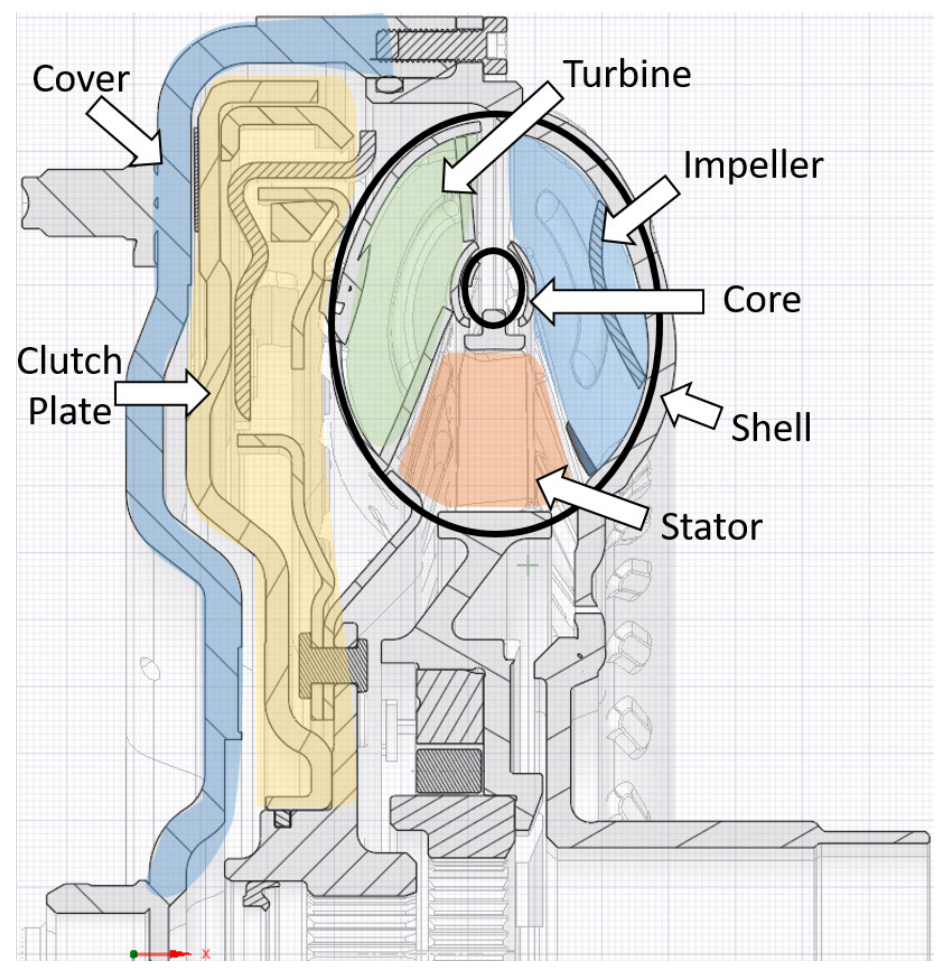

Figure 1-1. Torque converter components 
The impeller is attached to the cover that is then mounted to the flex plate and engine. The input power can be transmitted by a fluid or mechanical connection. When power is being transmitted via the fluid the power is transmitted from the impeller to the automatic transmission fluid [ATF] that then rotates the turbine. The flow exits the turbine to the stator which either can cause torque multiplication, during low speed ratios, or free wheel, during high speed ratios. The stator is mounted on a one-way clutch that locks the stator during low speed ratios but will free wheel during high speed ratios. The speed ratio is calculated by Equation 1-1, where $N_{o}$ is the output speed, $N_{i}$ is the input speed.

$$
S R=\frac{N_{o}}{N_{i}}
$$

When the power is being transmitted by mechanical coupling, the clutch plate is locked with the cover. This is done by pressurizing the clutch plate to engage the friction material on the clutch with the cover. During mechanical coupling the input and output speeds are the same. Figure 1-2 shows the power flow for fluid and mechanical coupling through the torque converter.
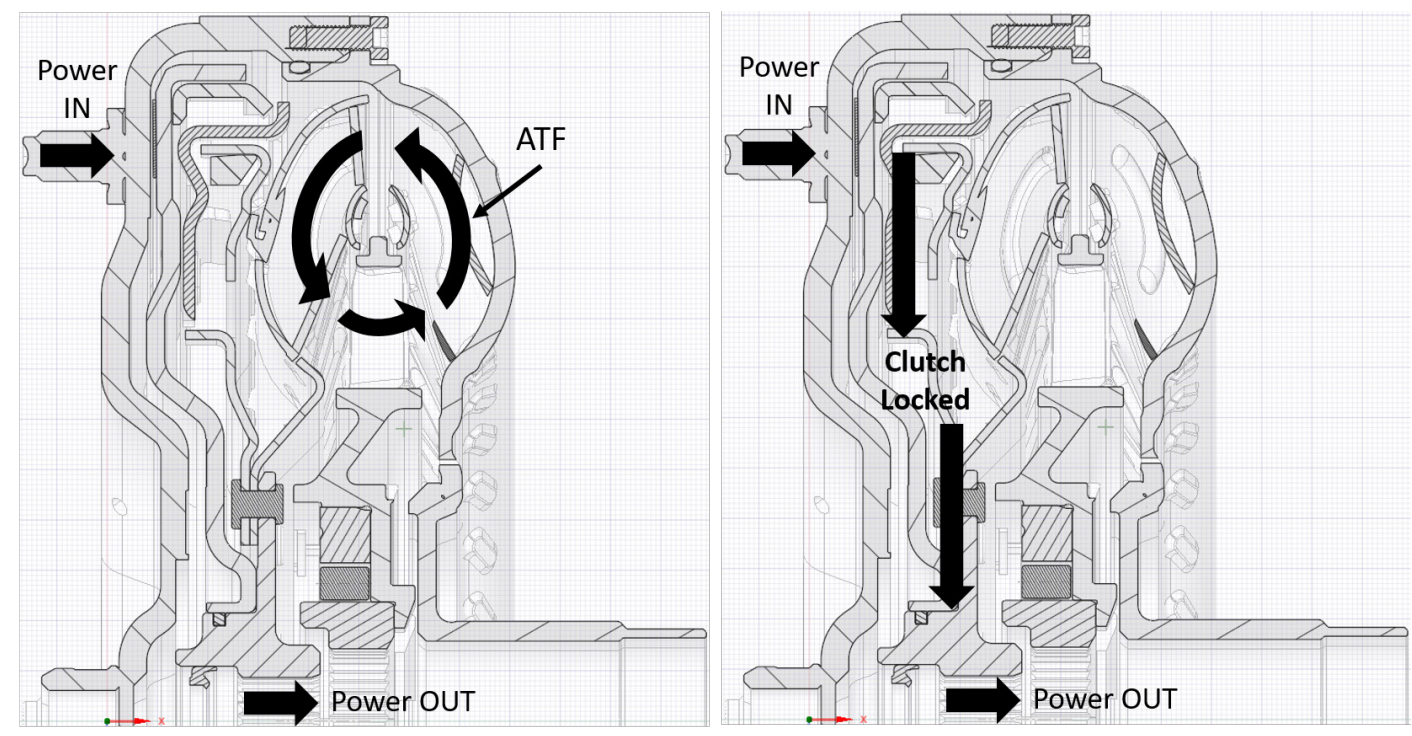

Figure 1-2 Torque converter power flow torque multiplication (Left), mechanical connection (Right) 
A torque converter performance is characterized by the $\mathrm{K}$-factor and torque ratio at each speed ratio, as illustrated in Equation 1-2 and Equation 1-3 respectively. The $\mathrm{K}$-factor is determined by the impeller speed $\mathrm{N}_{\mathrm{i}}$, and input torque $\mathrm{T}_{\mathrm{i}}$. The torque ratio is calculated by the output torque $T_{0}$ divided by the input torque $T_{i}$. The efficiency of the torque converter is based on the torque ratio multiplied by the speed ratio, as seen in Equation 1-4.

$$
\begin{gathered}
K F=\frac{N_{i}}{\sqrt{T_{i}}} \\
T R=\frac{T_{o}}{T_{i}} \\
E F F=T R * S R
\end{gathered}
$$

Equation 1-4

An example torque converter K-factor, torque ratio, and efficiency curve are shown in Figure 1-3. When the vehicle is not moving the torque converter is operating at stall or a speed ratio of zero. At stall the torque converter is $0 \%$ efficient because all the input power is converted to thermal energy and rejected via the ATF. As the torque converter increases in speed ratio so does the efficiency. Once the speed ratio is high enough that the stator begins to free wheel, also called the coupling point, the efficiency increases. 


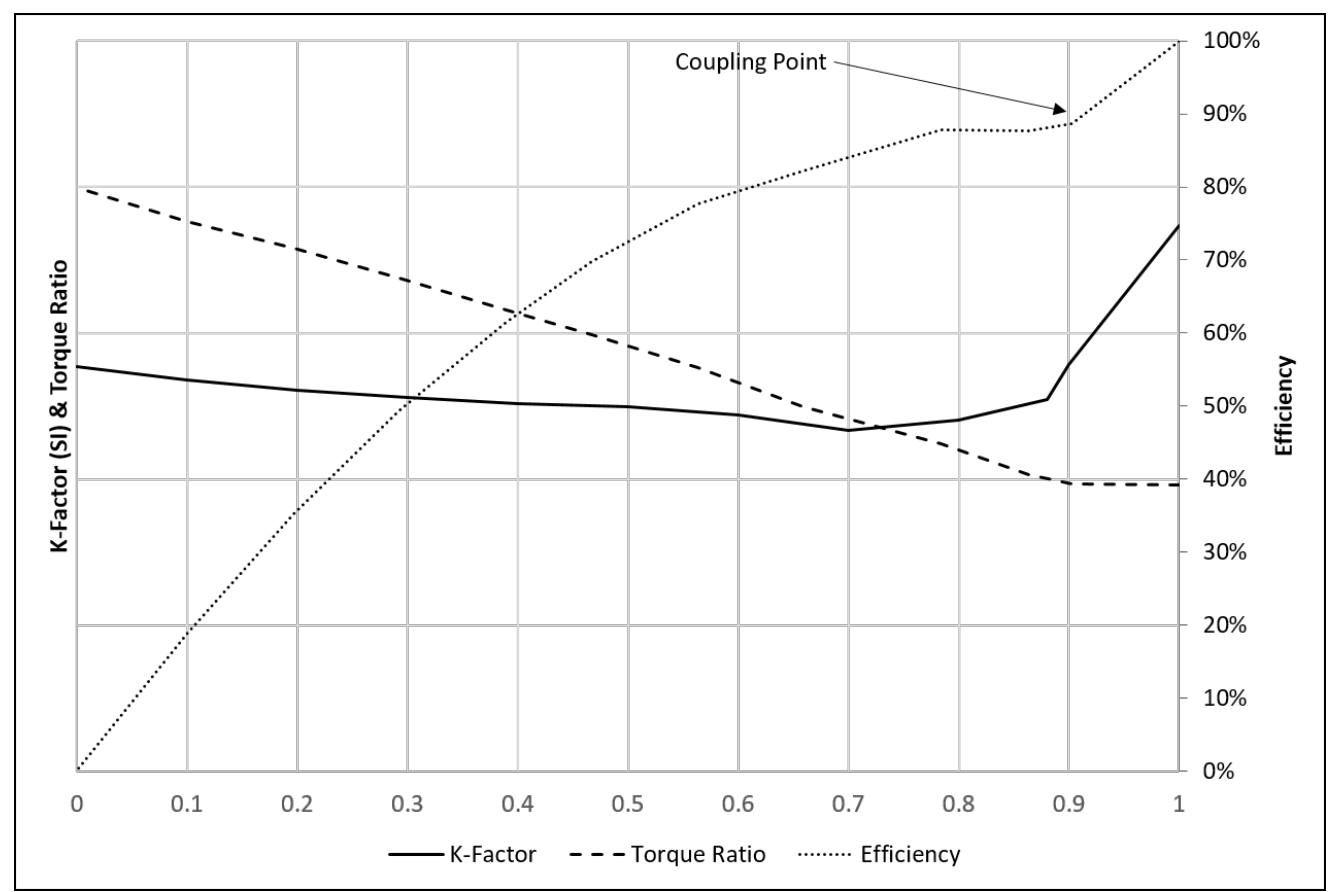

Figure 1-3. Torque converter performance example

When the impeller and turbine speeds converge the clutch plate can be applied and essentially $100 \%$ efficiency is achieved. This higher efficiency rate is the motivation to increase the amount of time that the torque converter clutch is applied during operation. Figure 1-4 illustrates how the speeds converge and the larger the speed difference the more energy the clutch has overcome. To large of speed difference can result in glazing or damaging the clutch.

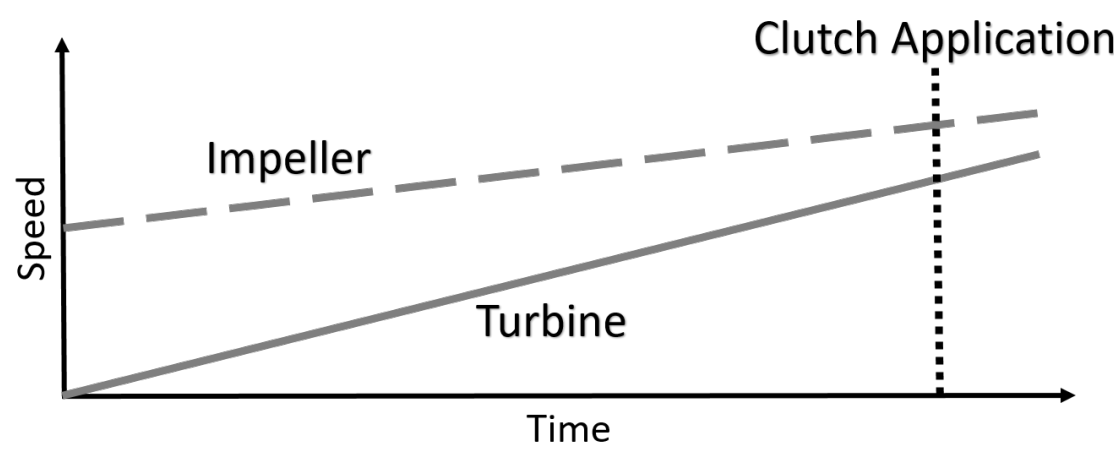

Figure 1-4. Concept of clutch application timing with respect to impeller and turbine speed 


\subsection{Transmission Basics}

The purpose of a transmission is to transmit power from one location to another, which can be accomplished in a variety of methods, such as gears, belts, and clutches [4]. The unit used in this study is a step gear transmission that is an automatic front wheel drive (FWD) 6-speed transmission. The power flow through the transmission under study is illustrated in Figure 1-5. The power from the torque converter is transferred through the transmission by planetary gears, a chain, final drive, and output shafts. The gear ratio is determined by the combination of the clutches and planetary gears.

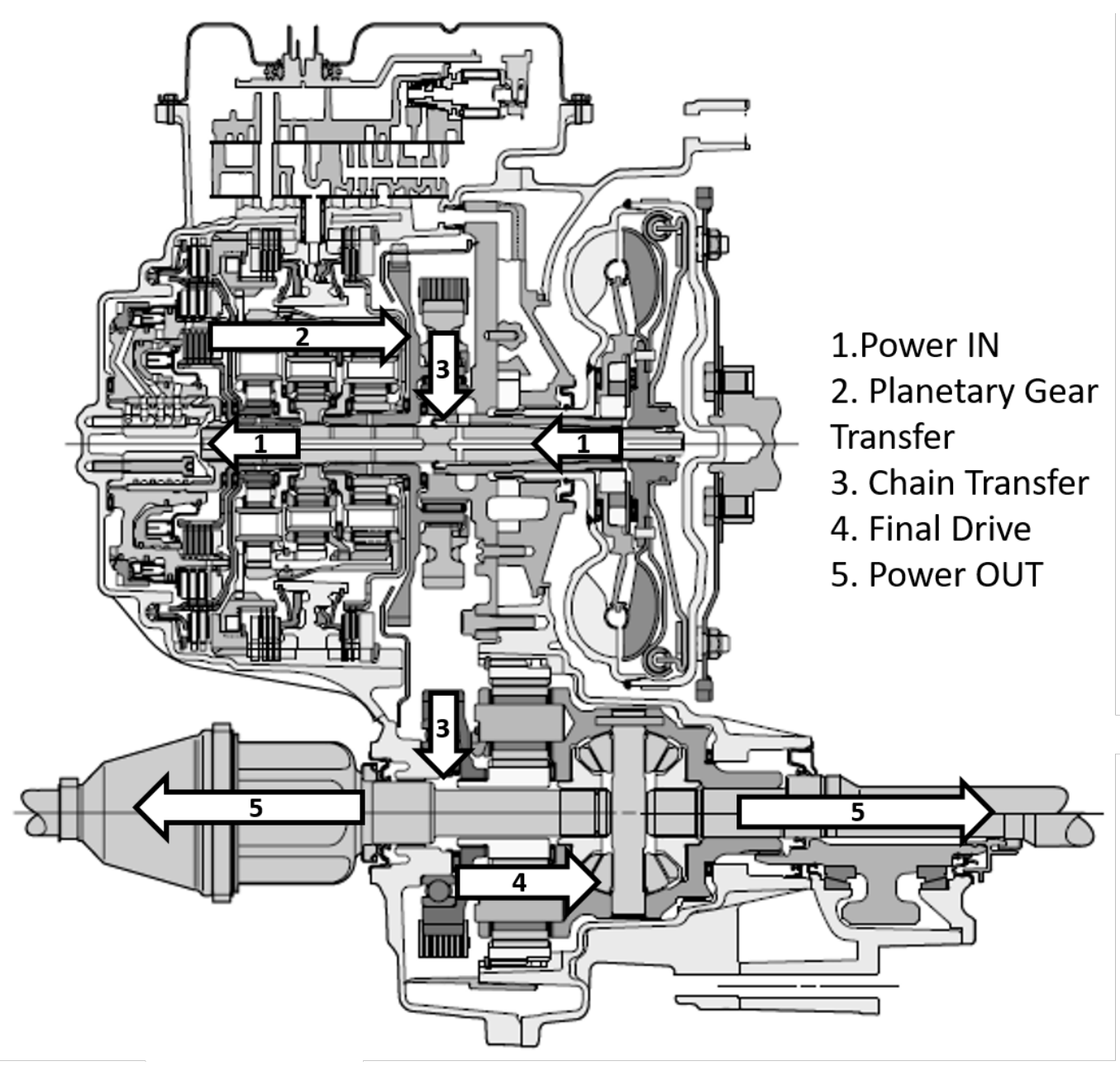

Figure 1-5. Transmission cross section and power flow 
The clutches are controlled by solenoid drivers where the pressure is determined by the amount of current sent to the solenoid, as illustrated in Figure 1-6. There are two types of drivers where one is normally low, meaning that when the current is 0 the pressure is also 0 . The second driver type is normally high, meaning when the current is 0 the pressures is max. For this research the transmission had to shift gears while under load, so clutch control and shift profiles had to be developed. Gear shift modeling, solenoid pressure profile generation, and dyno management development will be described in the methods section.

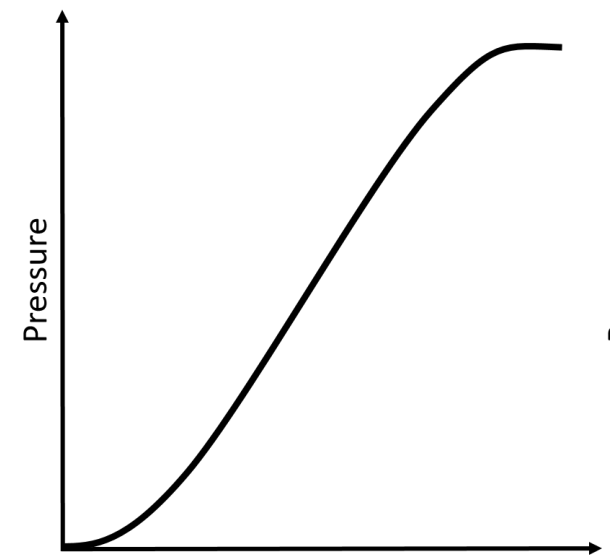

Current $[\mathrm{mA}]$

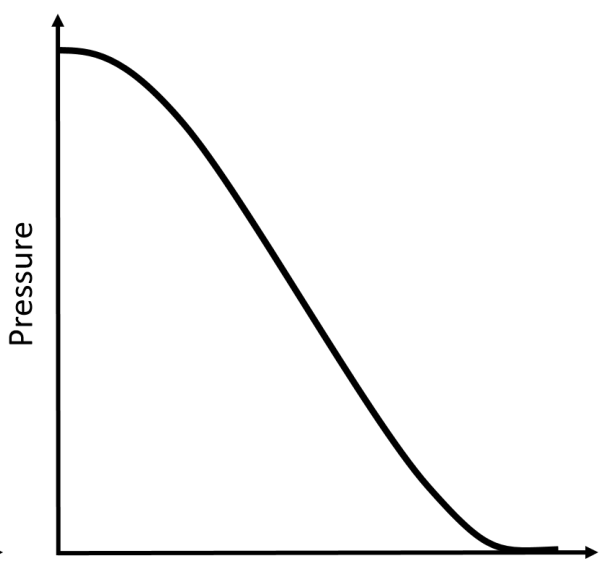

Current $[\mathrm{mA}]$

Figure 1-6. Normally low solenoid driver (left), Normally high solenoid driver (right)

\subsection{Literature Review}

A literature review was conducted to understand past related work and to determine where current research is needed. It was found that there has been extensive instrumentation done on torque converters measuring internal pressures on the torus, but there is a lack of knowledge on pressure measurements on the torque converter clutch. There also has been studies on torque converter and transmission interaction, but none with the torque converter containing specialty instrumentation that can also operate normally in a transmission. This opens up 
the possibilities for taking measurements that show how the transmission and torque converter interact. Multiple simulations have been done to predict performance and flow information. This study also allows the ability to improve torque converter simulations by providing a larger amount of data for validation. The following sections are summarizing of the literature review that was used for this study.

\subsubsection{Torque Converter Experimentation}

Torque converters have been instrumented and studied to improve efficiency and reduce package size. Each component of the torus has been instrumented with pressure transducers to visualize the flow field through the blades. The turbine has been instrumented with pressure transducers and strain gages to observe the loading of the blades $[5,6]$. The stator has been instrumented with 72 pressure transducers to measure the profile across the blade. All measurements were static, meaning that the stator was in a fixed position [7].

Flow visualization has also been performed by liquid resin techniques and laser velocimetry [8, 9]. The liquid resin is dotted along the blade and the working fluid is then passed over smearing the resin and showing the flow direction. Laser velocimetry used a Plexiglas torque converter with metallic coated glass particles throughout the working fluid. An argon ion laser was then used to determine the flow velocity during operation. All the above measurements are taken at a speed ratio of 0.8 or lower.

An extensive amount of work has been accomplished in identifying cavitation in torque converters [10-12]. The impeller and stator have both been instrumented with pressure taps to verify the operating conditions that cause cavitation and how cavitation impacts the torque converter performance. A nearfield acoustical technique was also used to identify when cavitation occurred without the need to instrument the torque converter. 


\subsubsection{Transient Torque Converter Testing}

Transient testing has been done on torque converters to determine the performance and reverse engineer the design parameters of the torque converter [13]. The transient results were used to validate a nonlinear model to predict torque converter performance. All the transient tests where done with the torque converter clutch released.

Dynamic characterization of the hydrodynamic operation of a torque converter has been tested by having a dynamic input torque [14]. A frequency response function was found to show the attenuation of oscillation when the torque converter is operating as in torque multiplication mode. A second study used the same approach of measuring the frequency response function of the torque converter clutch to improve fuel economy and noise, vibration, and harshness (NVH) [15]. No transient testing involving the torque converter clutch application and release was found.

\subsubsection{Torque Converter Clutch}

The torque converter clutch has been instrumented with thermal couples and pressure transducers to measure the temperature across the friction material [16]. The pressures transducers referenced each side of the friction material during slipping conditions. The friction coefficient and heat rejection rate of the ATF were calculated based on the data collected. The friction coefficient had a large spread due to the limited pressure measurements on the clutch plate. More information on wet clutch development and testing will be described in the following section.

The torque converter clutch operates in three conditions; released, applied, and slipping. Released is used for launching the vehicle from a stop and allows the engine to rotate when the vehicle is stationary. Applied is the most efficient operating condition because the input is mechanically transmitting all the power to 
the output, but can have increased NVH issues. Finally, slipping is when the clutch is being applied but is rotating at a slower speed than the input. Slipping the clutch is ideal for transient maneuvers because of the combination of improved efficiency, compared to released, while also having better NVH characteristics over applied. There are many effective strategies to achieve slip control, as seen in $[17,18]$.

\subsubsection{Torque Converter Telemetry Instrumentation}

Telemetry has previously been used for instrumenting individual torque converter components such as the impeller, stator, turbine and the clutch plate $[5,10,11$, 16]. The torque converter that is under study takes all previous instrumentation methods and combines them into a single torque converter with the impeller, stator, turbine, clutch plate, and cover all being instrumented. This torque converter has also been used for previous research for correlating internal pressures to a computational fluid dynamics (CFD) model [19].

\subsubsection{Torque Converter Simulation}

Numerical 3-D simulations of torque converters have become more accurate as CFD improve and the knowledge of torque converters continuously grows. The models are validated by comparing the $\mathrm{K}$-factor and TR to experimental data of that torque converter. The pressure and flow profiles are then assumed to be correct [20]. Other simulation studies have looked at blade passing and drive excitations and the correlations to drivetrain NVH [21, 22]. Flow fields and clutch lockup times have also been simulated to reduce clutch application time [23].

A previous study conducted by Edward De Jesus correlated a CFD model with experimental data from the instrumented torque converter used in this study. The model predicted $\mathrm{K}$-factor and TR within $6 \%$ of experimental. The pressure profiles across the blades were also found and compared to the pressure measurements that were taken throughout the torque converter. The model pressures were within 
$20 \%$ of the experimental results [24]. As experimentation on torque converters continue, the accuracy of models can also improve allowing for faster new development and improved prototyping.

\subsubsection{Wet Friction Clutch Development}

A wet clutch is when the friction material is bathed in a fluid, such as torque converters and step transmissions that are lubricated by ATF. A large variety of clutches have been developed for the use in automotive applications [25]. A single surface friction material clutch is used in the torque converter and multi disk clutches are used in the transmission under study. A major consideration during clutch design and testing is the thermal capacity before failure. By understanding the amount of slip time and energy absorption the clutch can withstand, and the limits are not exceeded, the clutch can have extended life [26].

Multiple studies have been conducted that investigated friction material characteristics during slip, clutch life cycle, and fluid interaction on friction performance [27-30]. All these studies isolate the friction material with the clutch or clutch pack to conduct the study. This is useful for initial research but understanding how the clutch performs with other components is of interest for this research.

\subsubsection{Transmission Development}

Transmissions have been under study for many years to improve efficiency and improve shift quality. Automatic transmissions have been developed from 4, 5, and 6-speed transmission to the more recent 8, 9 and 10-speed transmissions [31-33]. Methods have been developed to include the impact that transmissions have on engine operations. This was done by building upon Environmental Protection Agency (EPA) test cell capabilities to incorporate an engine transmission package to see the true fuel efficiency and emissions [34]. 


\subsubsection{Transmission Simulation}

Multiple simulations have been developed to predict transmission performance to reduce the amount of test and development time. Automatic transmission hydraulics are a complicated system that are made up of solenoid valves, pressure regulators, pressure control valves, and clutch actuator systems. Having numerous components results in a nonlinear system to predict dynamic characteristics. Studies have shown that models can be developed to predict steady state and dynamic characteristics by validating through experimental comparison $[35,36]$.

Basic models have also been developed to improve shift quality and estimate transmission response. Some of the methods from [4, 37-40] are used for understanding shifting techniques and development. Shifting will be described in further detail in the methods section. 


\section{Experimental Setup}

This research had the opportunity of starting with an empty test cell, so a goal was set to develop a test cell that has the capability to operate numerous models of transmissions. The following sections explain the development of the test cell, dynamometer controller, data acquisition, transmission instrumentation, transmission controller, and torque converter instrumentation.

\subsection{Test Cell}

A test cell was built to operate the $375 \mathrm{Nm}$ input torque capacity FWD 6-speed transmission. A General Electric $380 \mathrm{~kW}$ DC dynamometer was used to drive the transmission with a General Electric $540 \mathrm{~kW}$ AC dynamometer as the transmission output absorber. The differential in the transmission is welded to allow the absorbing dyno to control the output speed and torque. Figure 2-1 shows the layout of the test with the input dyno on the left, transmission in the middle, and output dyno on the right. The instrumentation will be described in a later section.

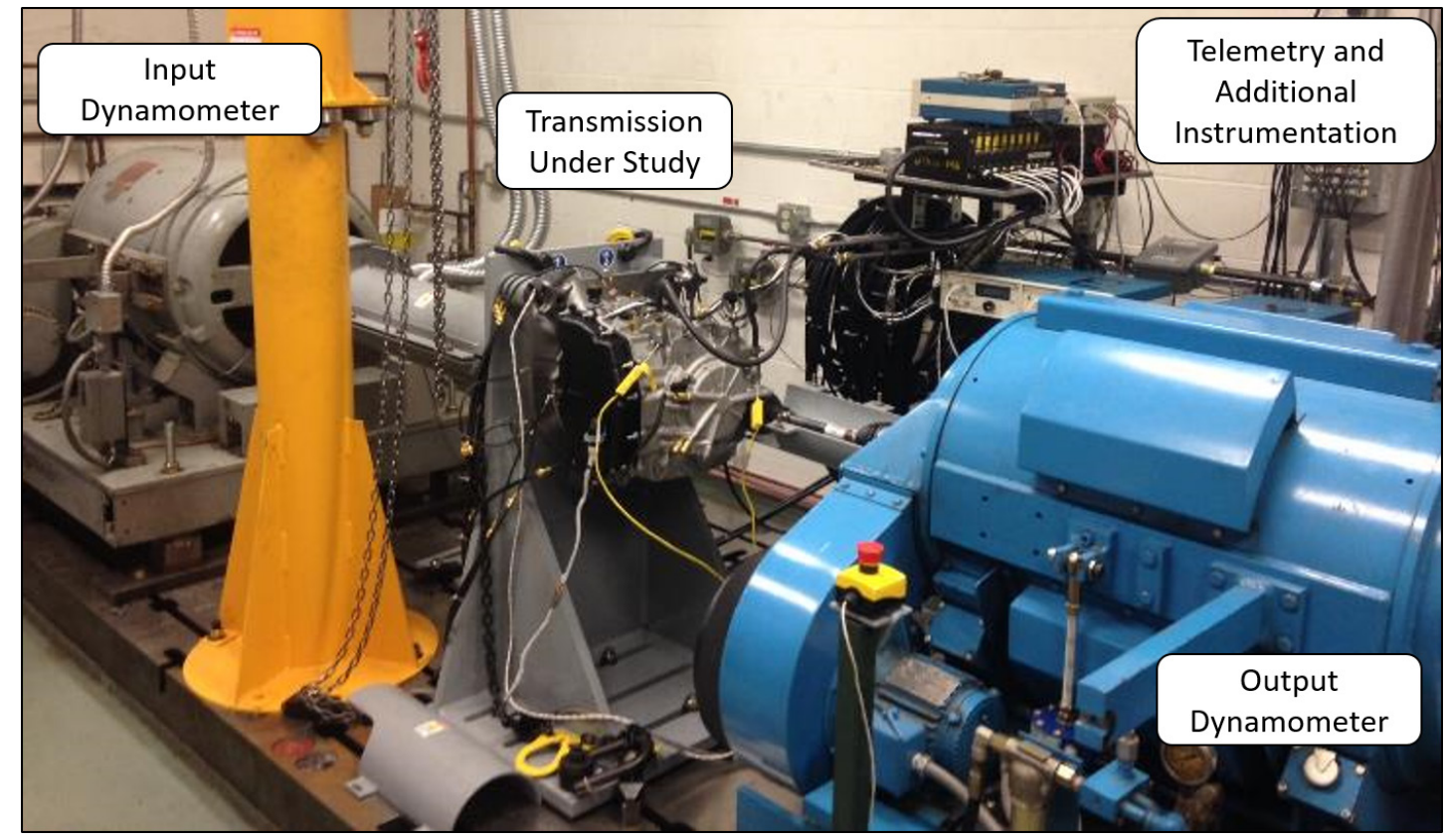

Figure 2-1. Transmission test cell layout 
The test stand hardware was designed by a previous graduate student with the main drawing in Appendix $B$ [24]. The test stand is designed so that only the head plate and shafting connections have to be customized to the transmission. A transmission installation, from drain to refill, can be accomplished in 3 hours.

\subsubsection{Data Acquisition}

The test cell has the capability to record a variety of measurements including pressures, temperatures, speeds, and torques. Figure 2-2 illustrates how each component is connected and where each measurement is recorded. In Figure 2-2 the shaded boxes represent physical hardware, while the white boxes are measurements and controls. Each of the lines represent the flow path of information for physical, electrical, and trigger connections by solid, long dashed, and short dashed lines respectively. The Universal data acquisition (DAQ), in the diagram, records all the measurements. Note, in later sections additions will be made to the layout to allow for transient measurements.

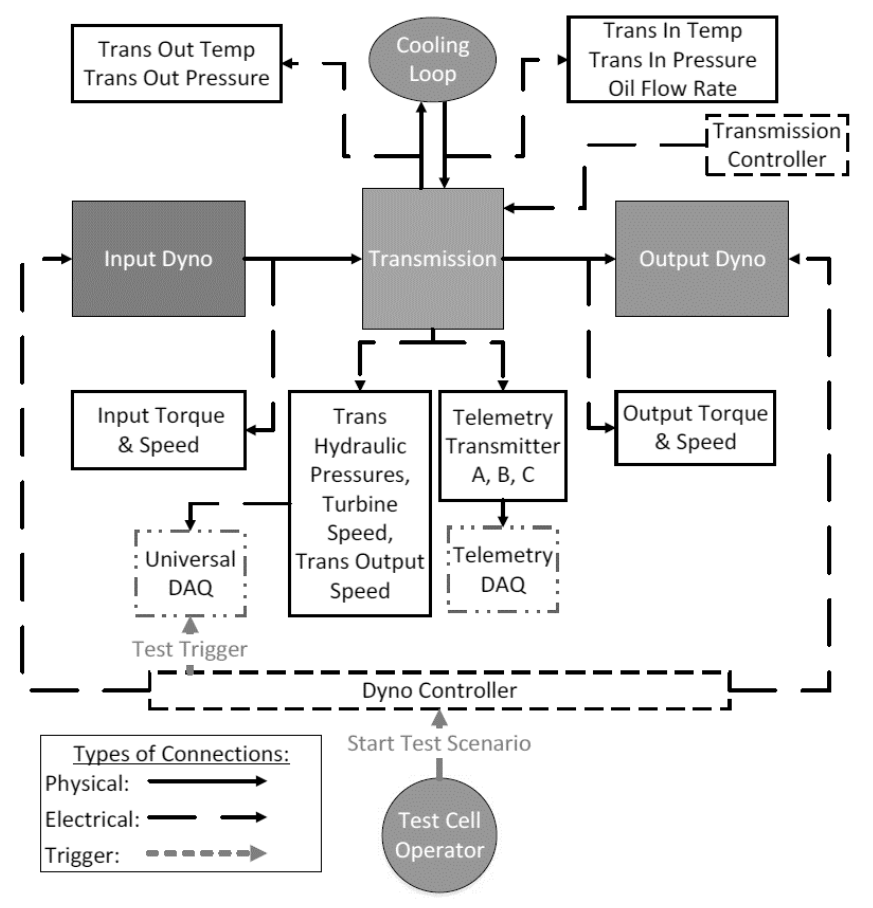

Figure 2-2. Test cell measurement and communication layout 
A Scadas III was used for data acquisition, referred to as the Universal DAQ. Each of the channel's calibrations can be found in Appendix C. The data was recorded using the parameters in Table 2-1. The speeds are sampled at a higher frequency because the measurements are a pulse train and the faster the signal is recorded the higher the accuracy. DAQ parameters dealing with transient measurements will be discussed in further detail in later sections. A detailed guide on how to use the DAQ software can be referenced in Appendix D.

Table 2-1. Sampling parameters for each measurement type

\begin{tabular}{|c|c|}
\hline Channel Type & Sampling Rate \\
\hline Speed & $51,200 \mathrm{~Hz}$ \\
\hline Torque & $6,400 \mathrm{~Hz}$ \\
\hline Pressure & $6,400 \mathrm{~Hz}$ \\
\hline Flow & $6,400 \mathrm{~Hz}$ \\
\hline Temperature & $10 \mathrm{~Hz}$ \\
\hline
\end{tabular}

\subsubsection{Dyno Controller}

The drive and absorbing dynamometers are controlled by a DYN-LOC IV and an AC2000 IGBT Digital Adjustable Speed Drive controller respectively. A custom LabVIEW Virtual Instruments $(\mathrm{VI})$ is used to communicate to the dyno controllers. The VI has three control windows, one for the test cell status, one for manual operation mode, and one for experiment operation mode. The status screen contains both dynamometer's speed and torque, the temperature and pressure of the inlet and outlet of the transmission, and the flow rate of the oil through the cooling loop. Figure 2-3 shows the layout for the status screen. 


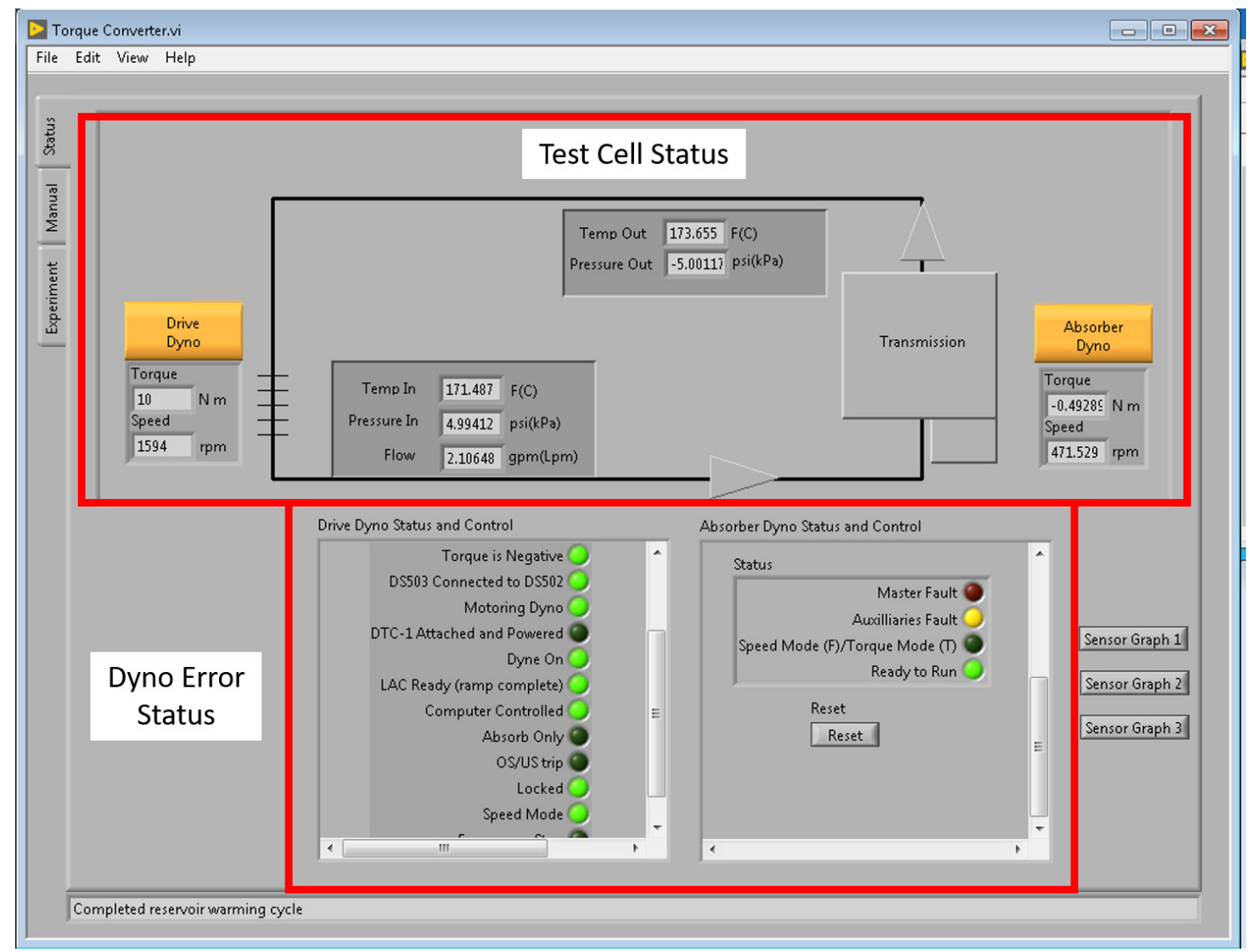

Figure 2-3. Dyno control VI status screen

The dynamometers can be controlled in manual or experimental mode. In manual mode, each dyno can be placed in speed or torque control. The user then inputs a speed or torque value and presses commit. Dyno data can be recorded manually by activating the start/stop button or by setting a time limit that automatically stops the recording. The manual tab also contains the error status of the dynos to show any current errors. Figure 2-4 shows the layout of the manual control tab. 


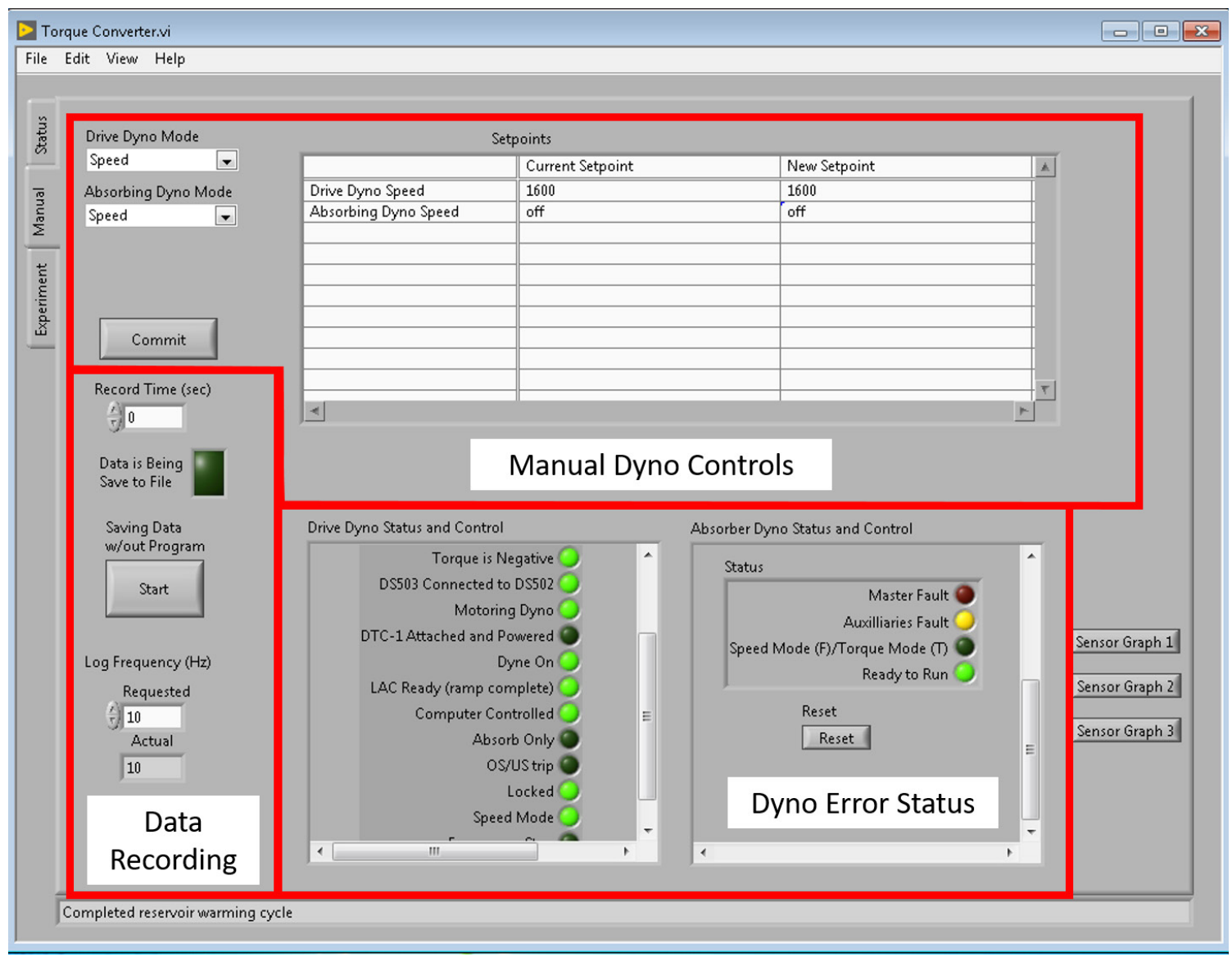

Figure 2-4. Dyno controller manual mode

The experimental mode automates the operation of the dyno commands. The user writes a script, prior to the test run, by defining speed or torque mode for each dyno, the control speed/torque command, and how long to hold conditions before proceeding. Each step can also issue a trigger and record data. Manual record and dyno status operate the same in manual mode. When running programs, the data is saved to a predefined file location and can automatically increment the test file name by selecting the "Auto-increment Filename". There is also warm up and cool down cycles built in by assigning a script to each button. Figure 2-5 shows the layout of the experimental control tab. This is a brief summary of the dyno software controller capabilities. For a detailed step by step guide reference Appendix E. 


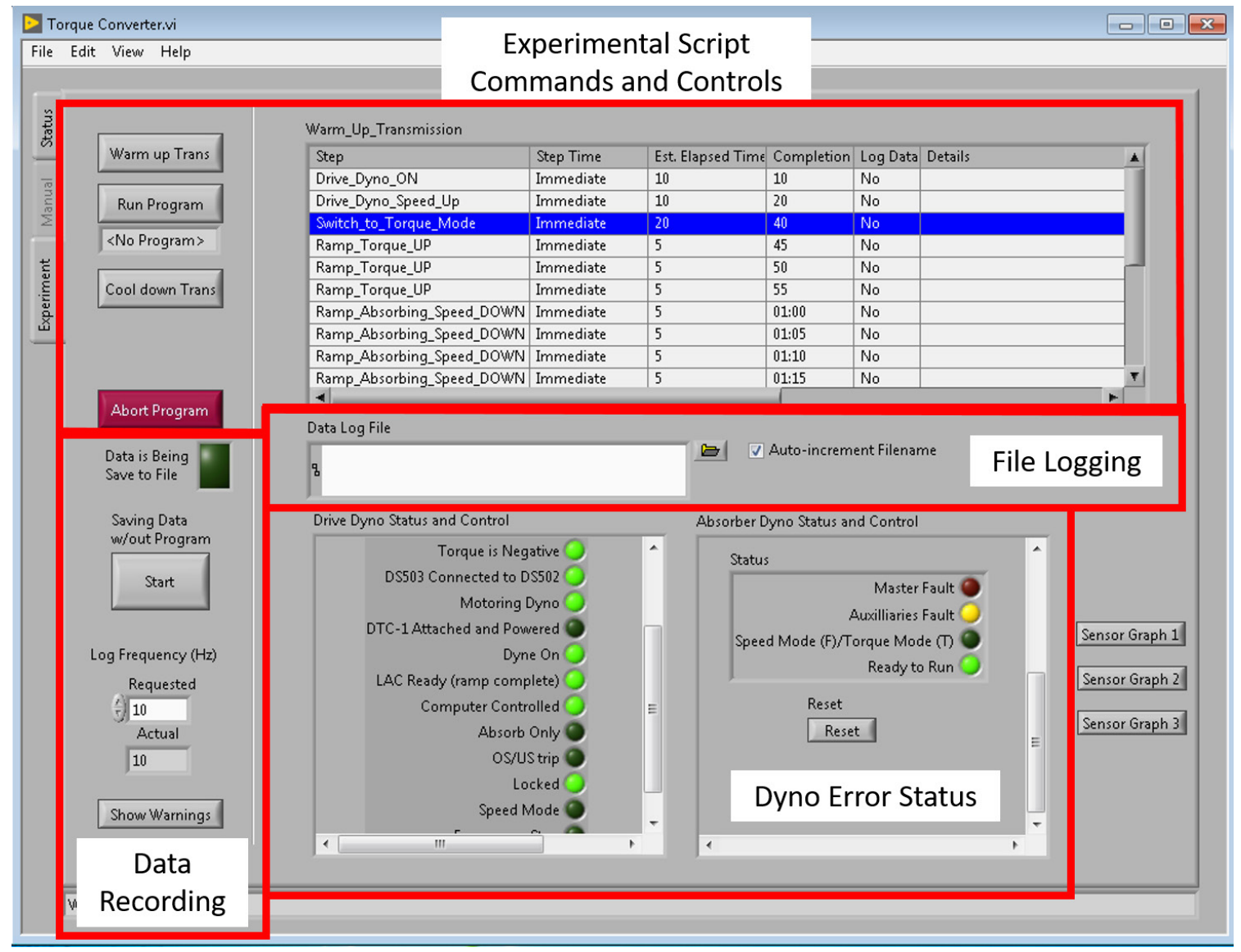

Figure 2-5. Dyno controller experimental mode

The transmission was operated by first starting the input dyno in speed mode with the output dyno turned off. This allows the transmission to pressurize the hydraulics before applying any load. Once the transmission is spinning the input and output can be changed to torque and speed mode respectively. Torque and speed mode was selected because it mimics how a vehicle operates with the driver requesting a certain vehicle speed via the throttle. Then the engine provides a torque based on that throttle and load from the transmission.

\subsection{Transmission Instrumentation}

The 6-speed FWD transmission has the gear ratios specified in Table 2-2. The majority of testing was completed using $5^{\text {th }}$ and $6^{\text {th }}$ gear to reduce the amount of 
output torque that had to be absorbed. The turbine shaft in the transmission and the hardware used to connect the transmission output shaft to the dyno are the weakest points in the system. A limit of $450 \mathrm{Nm}$ on the output dyno provides a safety factor of 2 for both components. The $450 \mathrm{Nm}$ was used as on operation limit when running tests.

Table 2-2. Transmission gear ratio including final drive

\begin{tabular}{|c|c|}
\hline Gear State & Gear Ratio \\
\hline 1st & 15.38 \\
\hline 2nd & 9.95 \\
\hline 3rd & 6.41 \\
\hline 4th & 4.85 \\
\hline 5th & 3.36 \\
\hline 6th & 2.50 \\
\hline Rev & -9.88 \\
\hline
\end{tabular}

Pressure transducers were added to the solenoid body and transaxle case to measure clutch, control, and line pressures, illustrated in Figure 2-6. The channels that are recorded from the transmission instrumentation are listed in Table 2-3, but the channels of interest are Line, TCC Apply, TCC Release, and all clutch pressures. The other pressures were used for monitoring purposes. All pressures in the transmission are measured downstream of their respective pressure regulators.
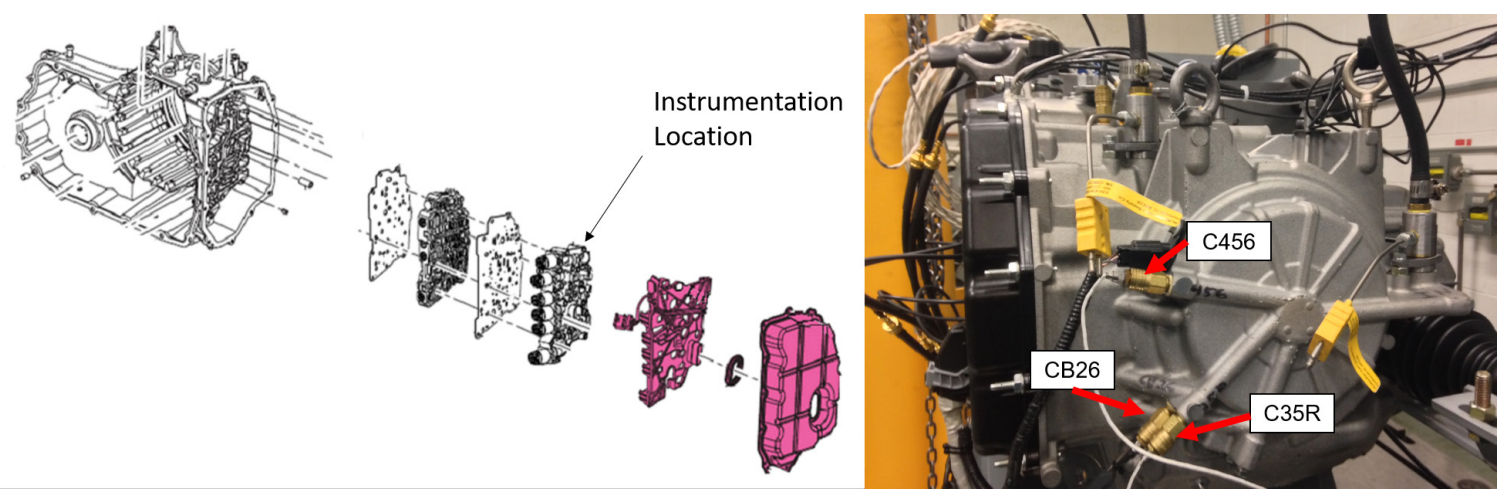

Figure 2-6. Transmission instrumentation 
Table 2-3. Transmission measured pressures

\begin{tabular}{|c|c|}
\hline Operation Pressures & $\begin{array}{c}\text { Clutch } \\
\text { Pressures }\end{array}$ \\
\hline $\begin{array}{c}\text { Transmission Inlet } \\
\text { Oil Pressure }\end{array}$ & CB1234 \\
\hline Transmission Outlet & C35R \\
\hline Line & CB26 \\
\hline $\begin{array}{c}\text { Variable Bleed } \\
\text { Solenoid TCC }\end{array}$ & C456 \\
\cline { 1 - 1 } $\begin{array}{c}\text { Variable Bleed } \\
\text { Solenoid Line }\end{array}$ & CBLR \\
\hline Solenoid Feed & \\
\hline \multicolumn{2}{|c|}{ TCC Apply } \\
\cline { 1 - 1 } TCC Release
\end{tabular}

\subsection{Transmission Controller}

A solenoid is an electrically controlled valve that controls fluid flow through the transmission for the purpose of clutch application and torque converter pressurization. To control the transmission a solenoid controller was required. A commercial solenoid controller was used at the beginning of the study, but additional functionality was required later, so a Next Gen controller was developed. Both control systems will be described to document their capabilities.

\subsubsection{Universal Solenoid Driver II}

The Universal Solenoid Driver (USD) II is a commercial solenoid controller that sends current to each of the solenoids. The USD II was used at the beginning of the research. A 12-volt power supply powers the USD II. Figure 2-7 shows the USD II and power supply mounted in the control tower. The male BNC connectors on the front of the USB II are the current outputs to each individual solenoid. 


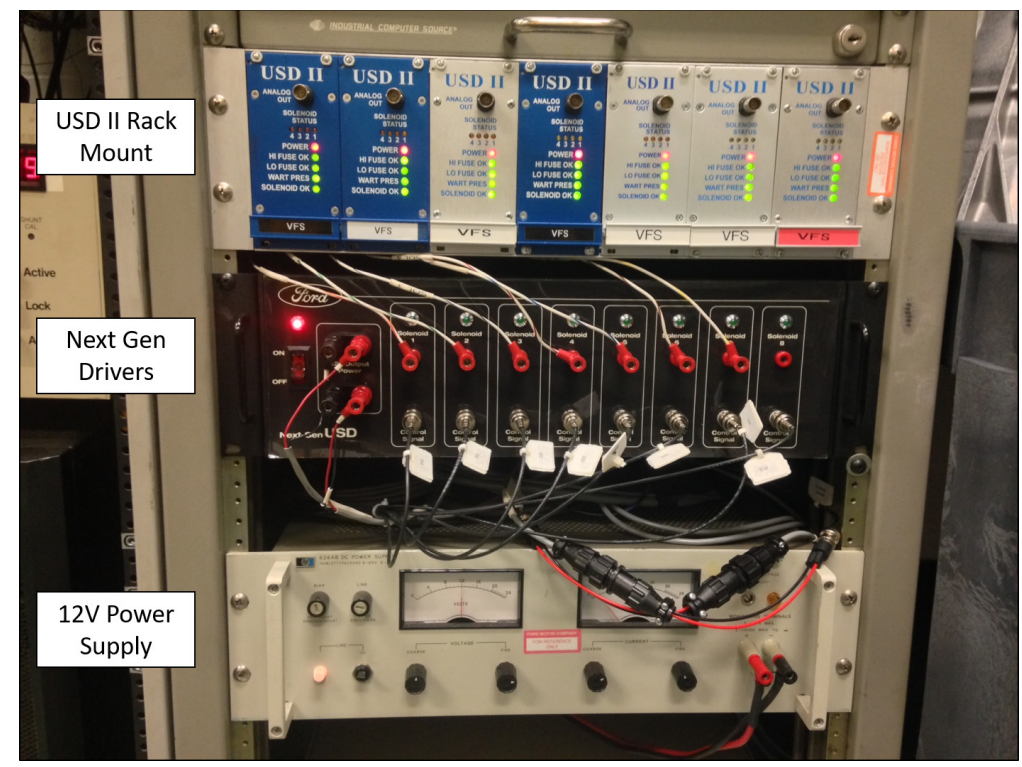

Figure 2-7. USD II and Next Gen solenoid drivers in tower instrumentation rack

The software used to control the drivers allows the user to manually operate each driver or run scripts for automation. In the software each driver has a separate control where the current command can be set between 0 to 255 counts ( 0 to 1000 $m A)$. Figure 2-8 is a screenshot of the software, where the boxes on the left are the controls for each driver and on the right are the command buttons.

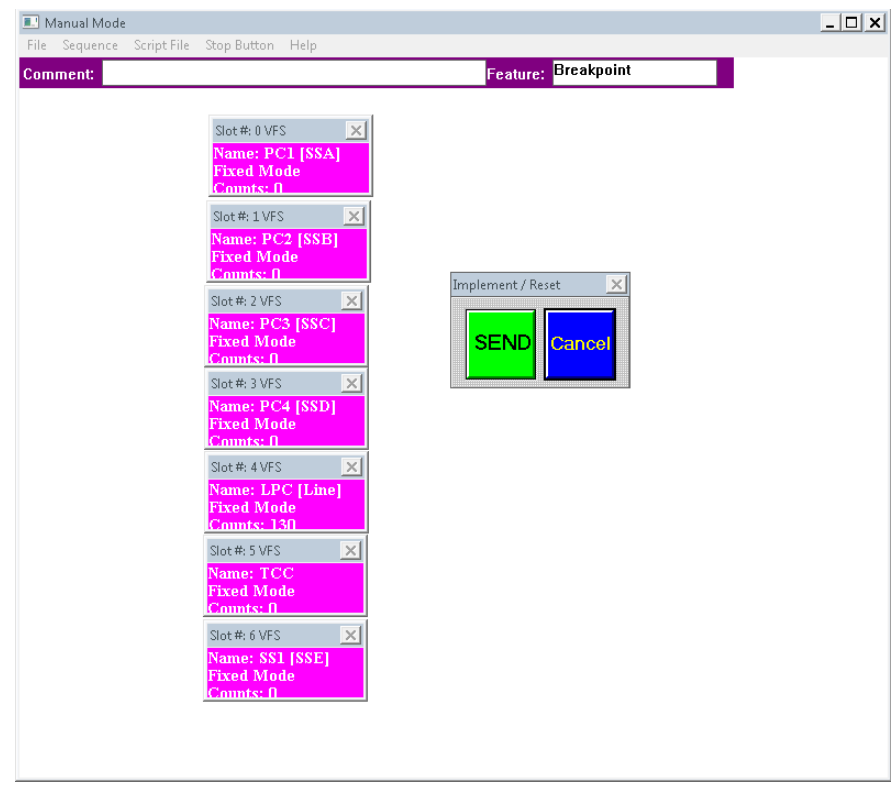

Figure 2-8. USD II control software main screen 
To open the solenoid parameters window, double click on one of the driver boxes. In the parameters window, the controls of interest are: mode selection, duty cycle, and frequency. The mode selection allows the user to select between a fixed current command to a built in operation, such a sweeps and steps. The duty cycle is where the 0 to 255 counts is used to command the desired current. A duty cycle is used to achieve the current level by changing the percentage the duty cycle is on. The frequency, set to $66.66 \mathrm{~Hz}$, is not a parameter that changes. Figure 2-9 is a snapshot of the solenoid parameter window. If additional information about operating the USD II controller is needed, reference Appendix F.

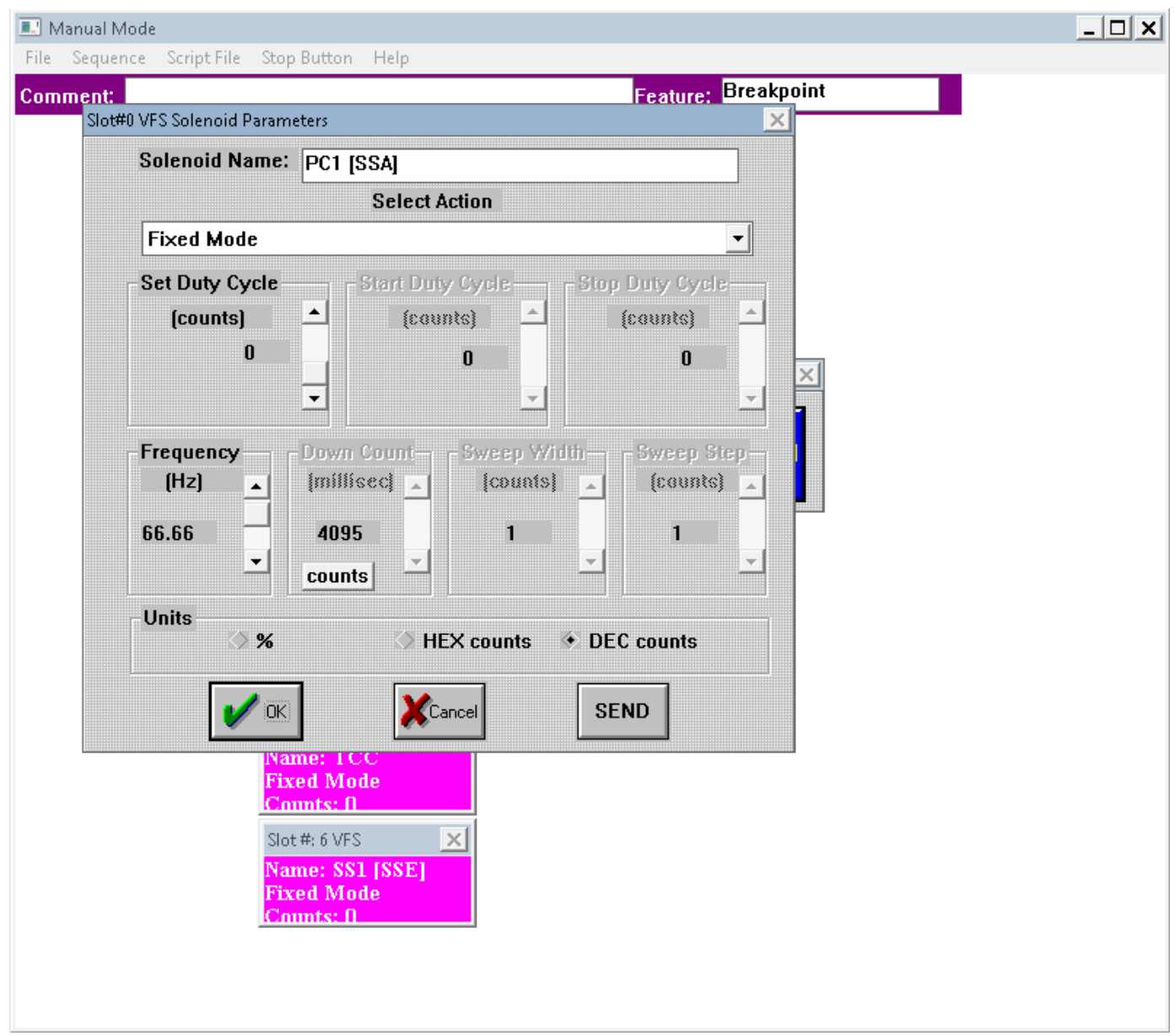

Figure 2-9. Solenoid parameters window 


\subsubsection{Next Gen Transmission Controller}

The USD II is a useful solenoid controller when the transmission is kept in a fixed gear, but having the capability to shift gears under load was of interest. Although, the USD II does have the capability to run scripts the software is time consuming to create new profiles and a more versatile software was necessary. The Next Gen transmission controller includes all the functionality of the USD II, but also allows for gear shifting and trigger activation.

The Next Gen solenoid driver and LabVIEW VI, called SOL Commander, was developed by Ford. SOL commander continued to undergo development throughout the project by both Ford and the MTU team. SOL Commander sends a command to the Next Gen solenoid driver box via a National Instruments card. An equivalent amount of current is then sent to the solenoid. The Next Gen driver is powered by the 12-volt power supply and both can be seen in Figure 2-7. The amount of current being sent to the solenoids was measured from BNC outputs on the driver.

Sol Commander started with the ability to control each solenoid separately to active a fixed gear, same as the USD II. Each solenoid can have a different high and low value and sweep between those values for a specified amount of time and repeat the sweep the predefined number of times. This is useful for solenoid control development, but for this research the sweep function was only used for TCC application and release. Figure 2-10 shows the layout of the solenoid control tab. The graph in the middle shows how the selected solenoid is operating. The stacked plots on the right show what each solenoid is doing based on the shift schedule that is loaded. The light and value indicators next to each of the graphs show which solenoid is active and the current command value. The commands can be implemented without sending to the transmission and this is done by selecting the ENGAGE/DISENGAGE button. 


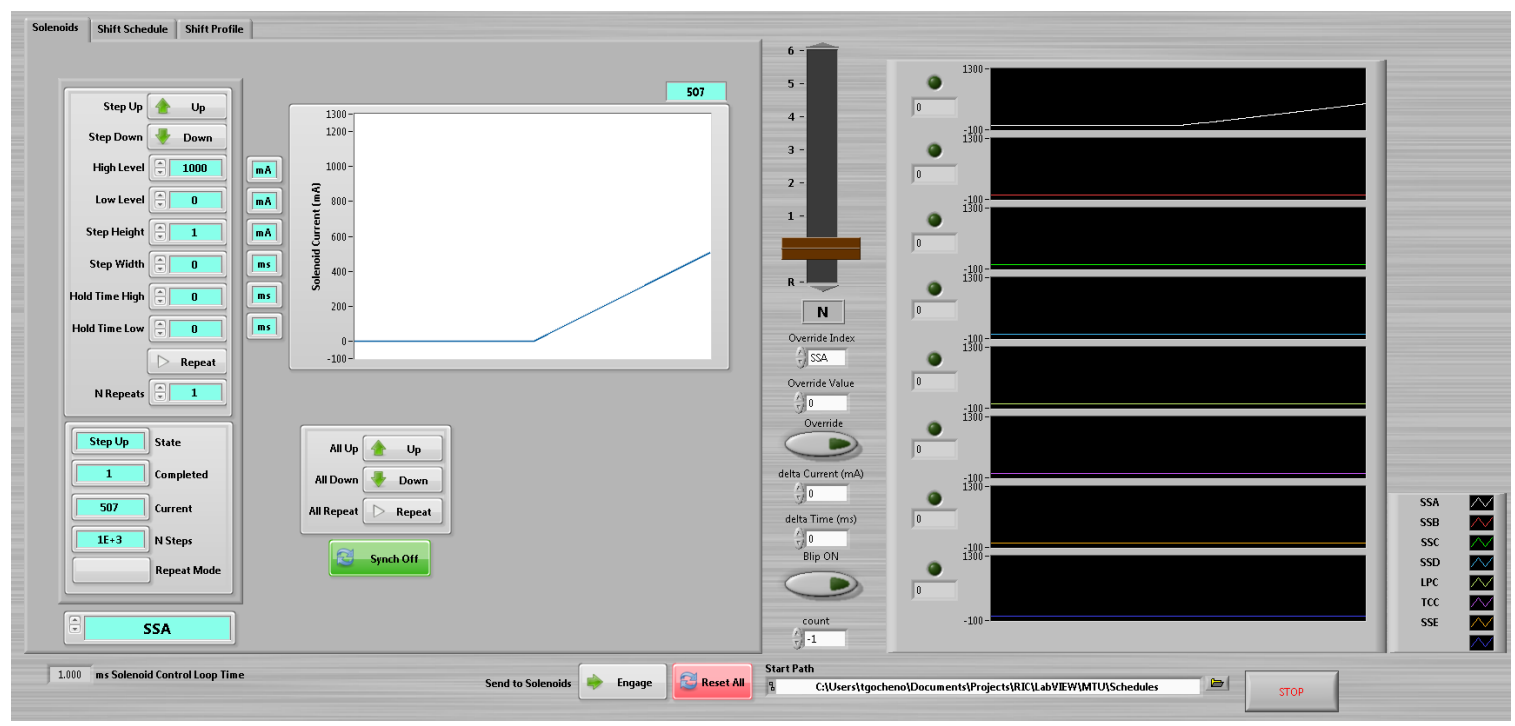

Figure 2-10. Individual solenoid control window

The second tab in the Sol Commander is the Shift Schedule selector and modifier. In the shift schedule window, a schedule can be made to select which solenoids are active for each gear. This schedule can be saved and reloaded for future use. The shifting lever, in the center, determines the gear state and selects which column of solenoids to activate. Loading the solenoid schedule is done prior to spinning the transmission. Figure 2-11 is an example of how a shift schedule will appear in the shift schedule tab. Both the solenoids and shift schedule tabs were developed and provided by Ford. 


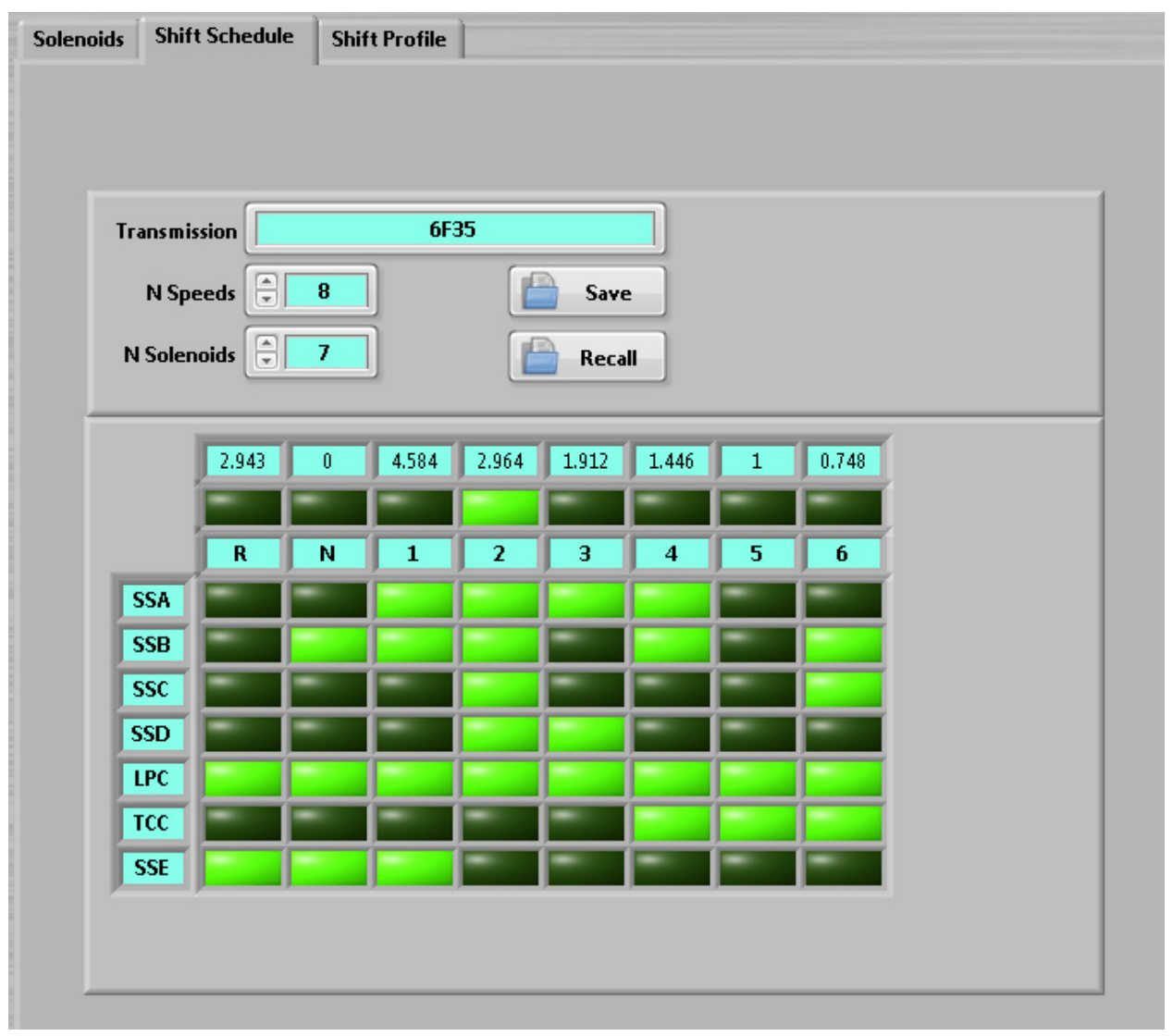

Figure 2-11. Solenoid shift schedule window

The additional capability to load solenoid profiles and activate based on a trigger were required to complete the research. These were additions made to the SOL Commander by the MTU team. An additional tab was added called Shift Profile. Under shift profile, a stack plot was added to show a profile of each solenoid. These profiles can be loaded for each gear having different profiles for upshifts and downshifts. Once profiles are loaded for each gear, the set can be saved as a group and reloaded for future use.

With the profiles loaded, they can be activated manually by moving the shifting lever or by using the trigger activation. The user specifies if an upshift or downshift should occur once the trigger is activated. The trigger activation is armed by pressing Activate on Trigger, which then disables majority of the controls, except the ability to cancel. This is a built in safety feature to ensure no unwanted changes 
are made while the SOL Commander waits for the trigger. Once the trigger is activated, the shift profiles run and hold the last value until a new command occurs. Figure 2-12 shows the layout of the shift profile tab. For a detailed operation guide of SOL Commander reference Appendix G.

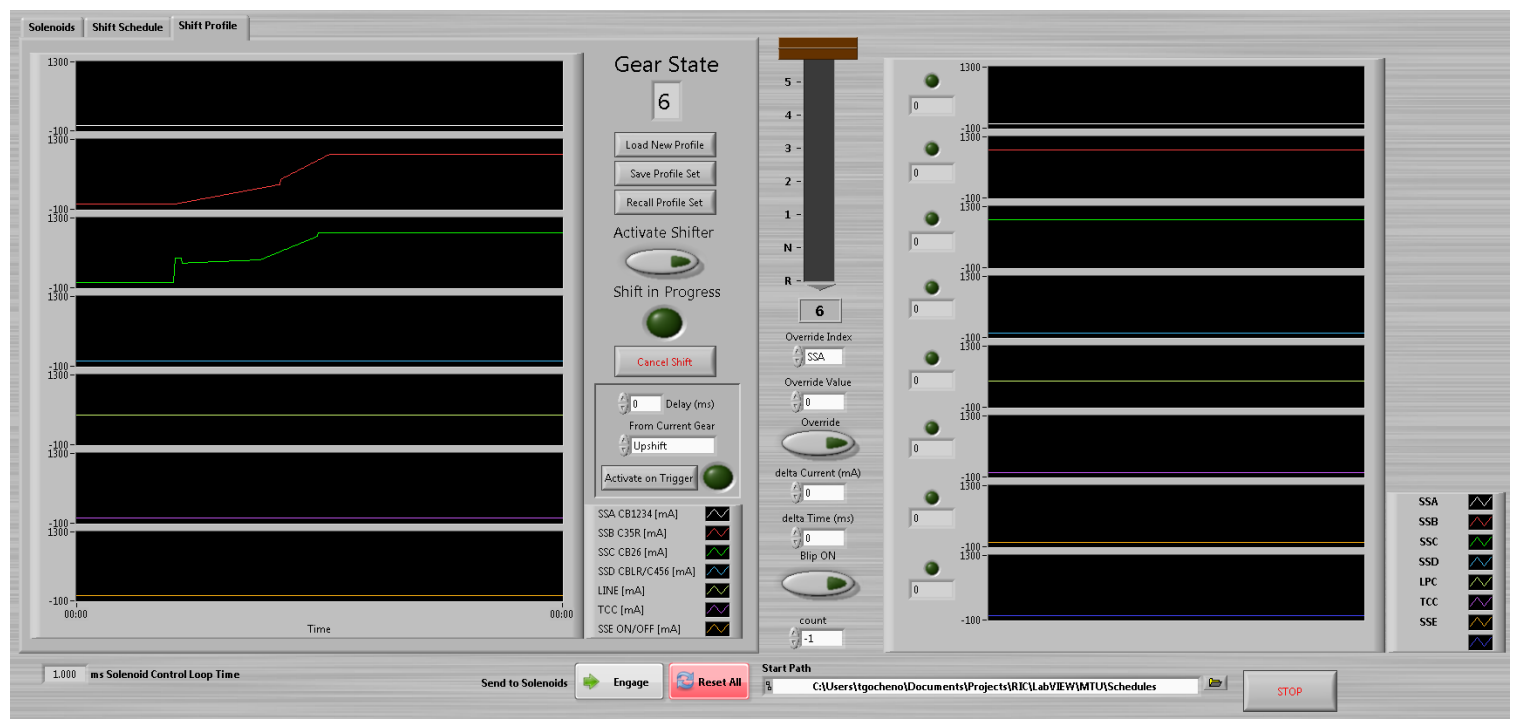

Figure 2-12. Shift profile and trigger activation window

\subsection{Torque Converter Instrumentation}

The torque converter was instrumented with 29 pressure transducers, 7 on the cover and impeller, 7 on the stator, and 15 on the turbine and clutch. Transducers were spread over multiple blades to reduce the impact the wiring and transducers has on the flow characteristics. Two types of pressure transducers were used on the torque converter. The Kulite XCEL-072 and Kulite LE-160 were used and can handle operating temperature up to $235^{\circ} \mathrm{C}$ and a maximum Full Scale Output (FSO) hysteresis of $\pm 0.5 \%$. For the transducer's specifications reference Appendix $\mathrm{H}$. Only three transmitters were used for all 29 transducers due to packaging limitations inside the torque converter. Each transmitter transmits multiplexed data for approximately 1 second for each transducer. Table 2-4 summarizes the specifications for each of the transmitters. 
Table 2-4. Transmitter specifications [41]

\begin{tabular}{|c|c|c|c|}
\hline Transmitter & $\begin{array}{c}\text { Number of } \\
\text { Channels }\end{array}$ & $\begin{array}{c}\text { Time Per Channel } \\
\text { [sec] }\end{array}$ & $\begin{array}{c}\text { Torque Converter } \\
\text { Instrumentation } \\
\text { Locations }\end{array}$ \\
\hline A & 7 & 1 & $\begin{array}{c}\text { Impeller and } \\
\text { Cover }\end{array}$ \\
\hline B & 7 & 1.013 & Stator \\
\hline C & 15 & 1.006 & $\begin{array}{c}\text { Turbine and } \\
\text { Clutch Plate }\end{array}$ \\
\hline
\end{tabular}

An example of how the multiplexed data appears is shown in Figure 2-13. The instrumentation was completed by IR Telemetrics located in Hancock, MI. Telemetry was used to transmit the data allowing the torque converter to operate normally in the transmission, which will be described in the following sections.

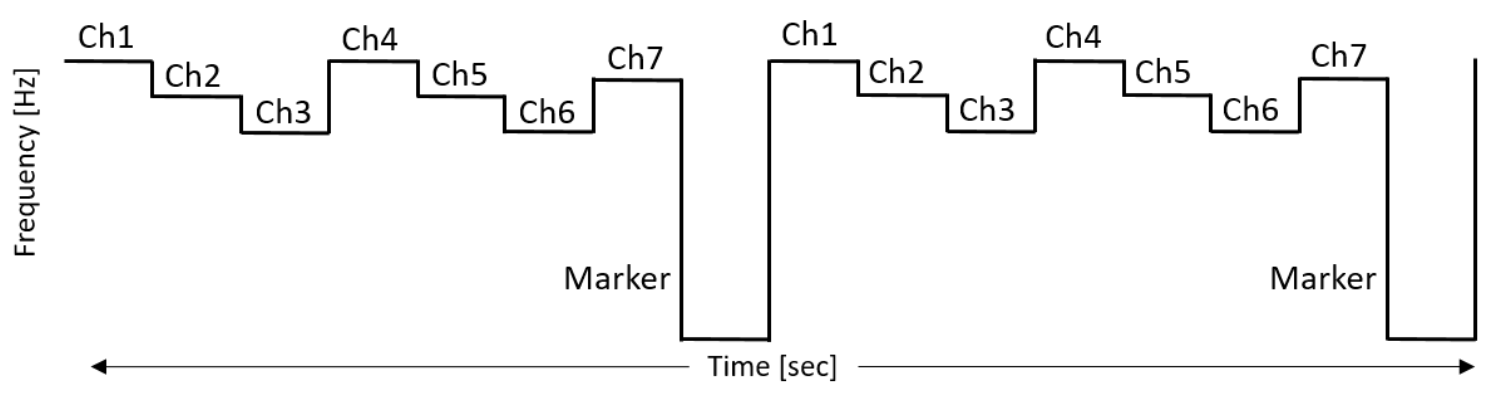

Figure 2-13. Example multiplexed data stream for 7 channels [41]

\subsubsection{Impeller and Cover}

Transmitter A includes 7 pressure transducers: 3 on the cover, 3 between the impeller blades, and 1 between the impeller and turbine. Figure 2-14 illustrates the instrumentation locations on the impeller and cover. The channel names with square boxes are measuring the clutch cavity while those with a chamfered box are measuring the impeller. 


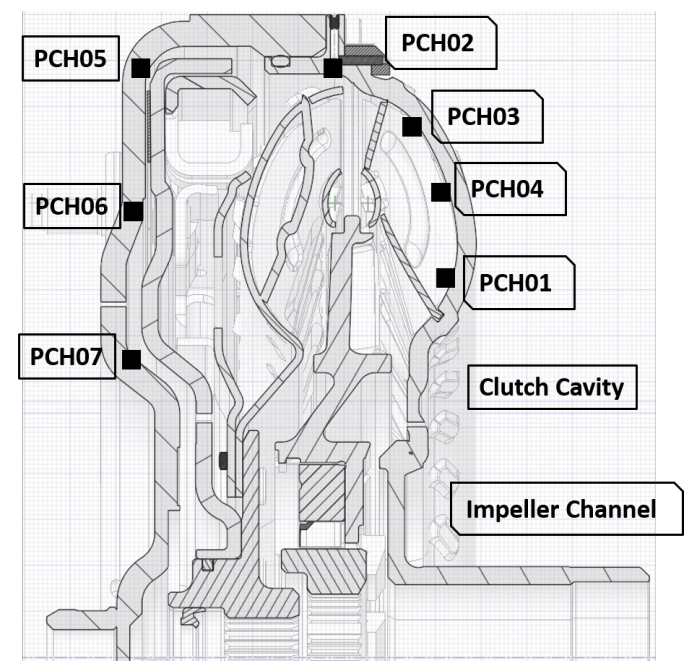

Figure 2-14. Transmitter A instrumentation locations [19]

Instrumentation hardware for transmitter A is located on the outside of the cover. This makes it the most reliable signal because the antennas in the bell house of the transmission can pick up the signal easily. Figure 2-15 shows the hardware located on the outside of the torque converter cover.

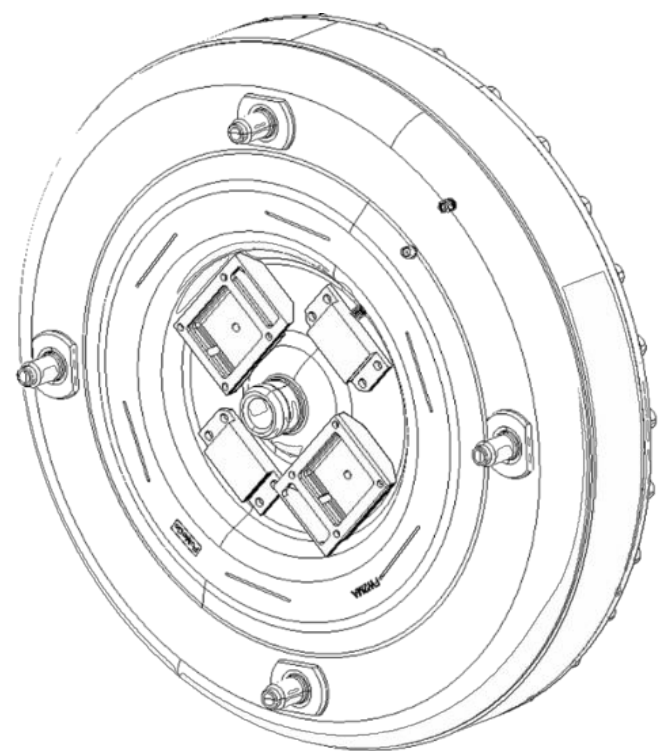

Figure 2-15. Transmitter A hardware for power supply and transmitter [24] 


\subsubsection{Stator}

Transmitter $\mathrm{C}$ includes 7 pressure transducers which are all located on the stator blades. Figure 2-16 illustrates the instrumentation locations on the stator. Three radial locations were measured across the blade. Channels near the core, blade middle, and shell are represented by square, dashed, and chamfered boxes respectively. Measurements were also taken on the pressure and suction side of the blade represented by solid and hollow circles respectively.

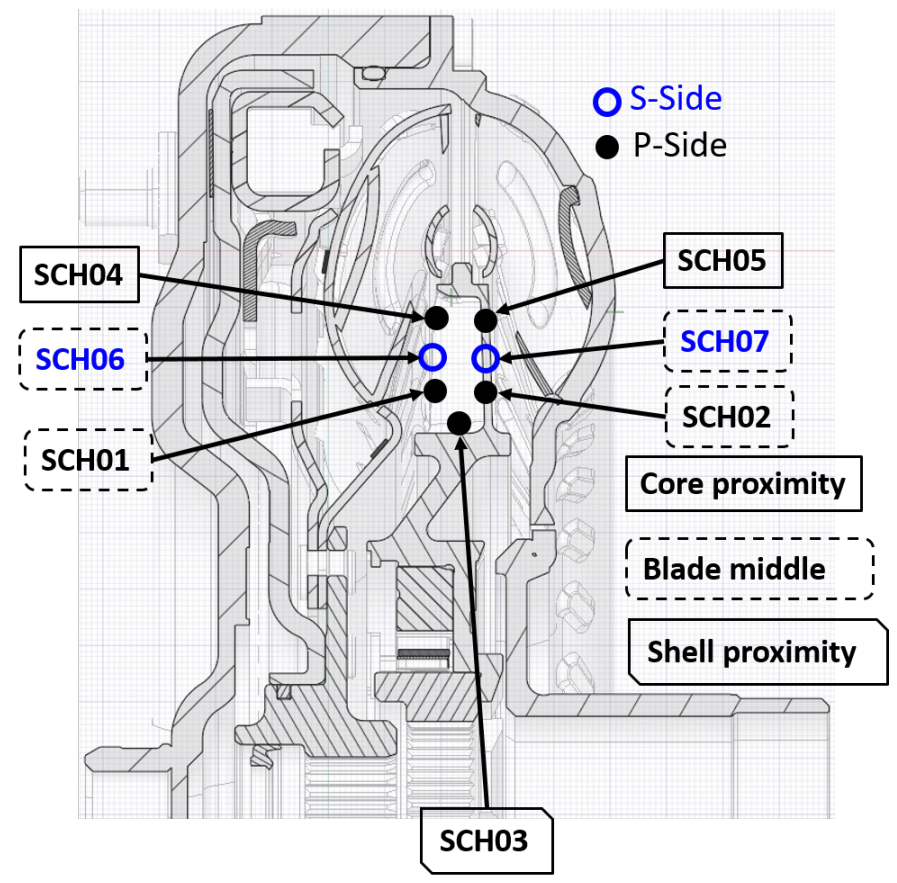

Figure 2-16. Transmitter B instrumentation locations [19]

All the transmitters are powered via induction coils which allows for a wireless power supply. This allows each component to spin normally without any wire interference. Transmitter B's induction coil is mounted below the stator blades, as seen in Figure 2-17. 


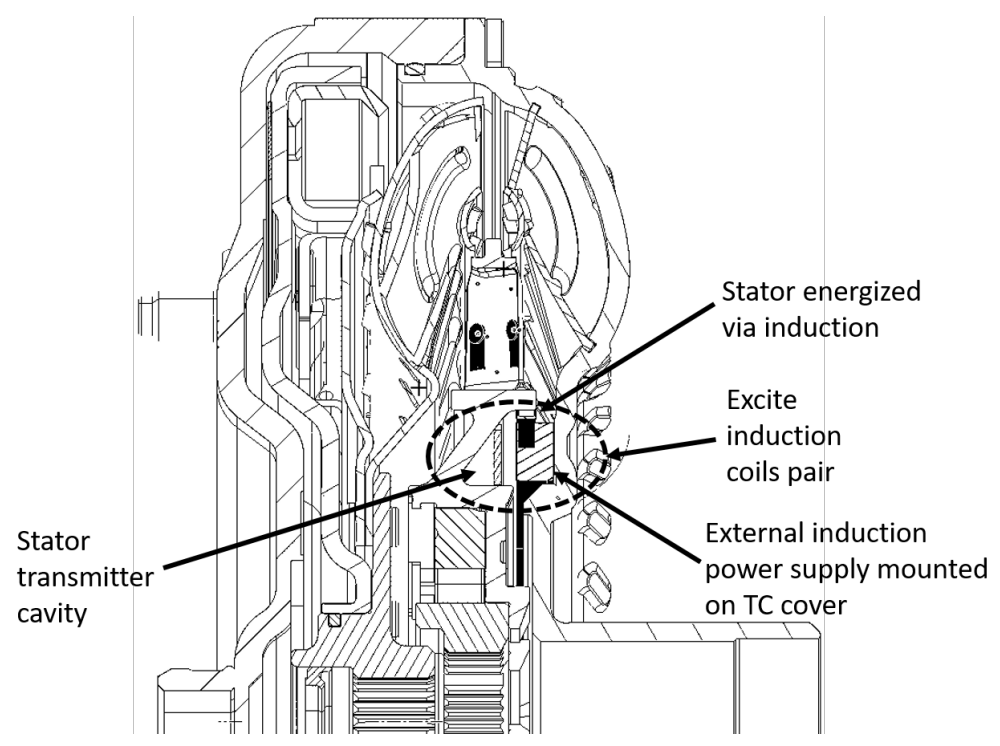

Figure 2-17. Transmitter B induction coils and transmitter hardware [24]

For the signal to be transmitted from the inside of the torque converter, multiple reradiating slots were cut into the impeller shell, as seen in Figure 2-18. The slot is covered by Kevlar sheets on both sides allowing for signal to transmit through without ATF leakage.

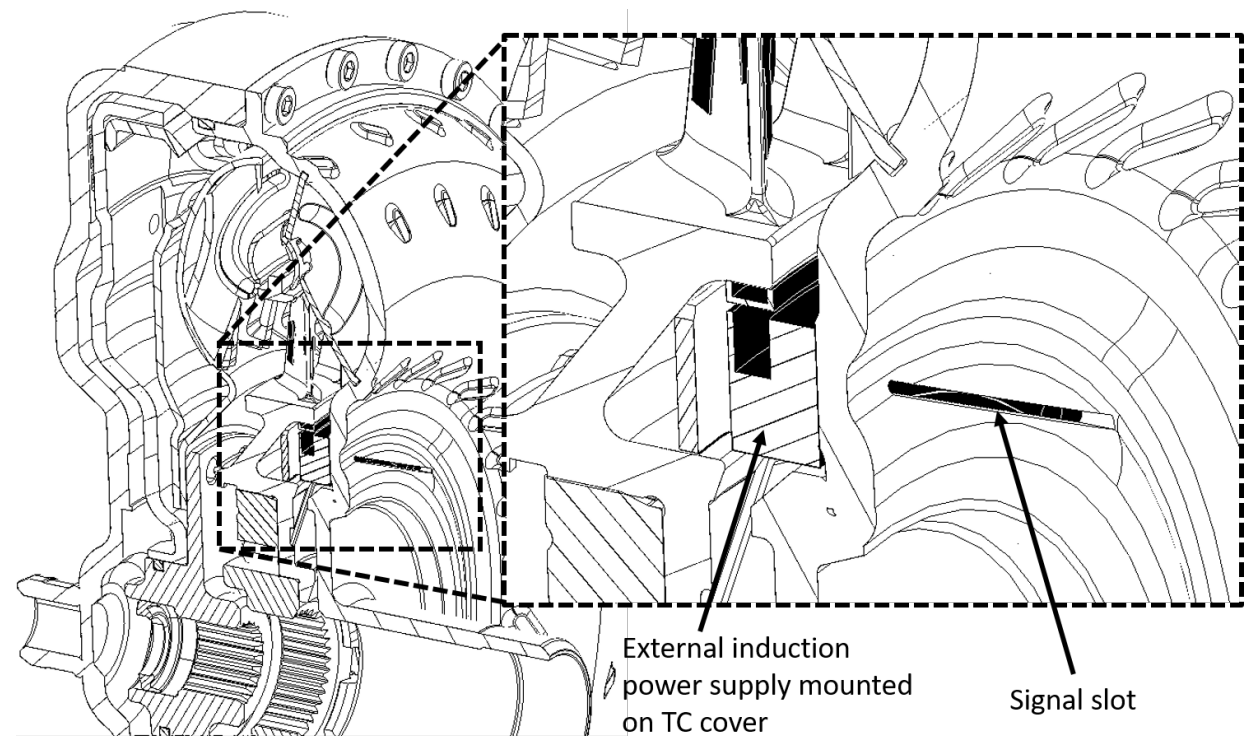

Figure 2-18. Signal slot for transmitter B cut in impeller shell [24] 


\subsubsection{Turbine and Clutch Plate}

Transmitter $\mathrm{C}$ includes 15 transducers, 6 on the turbine blades and 9 on the clutch plate/cavities. Figure 2-19 illustrates the instrumentation locations on the turbine and clutch plate. The transducers on the turbine blade are represented by chamfered boxes and solid and hollow triangles for pressure and suction sides of the blade respectively. The transducers measuring the clutch plate and cavities are represented by square and dashed boxes respectively.

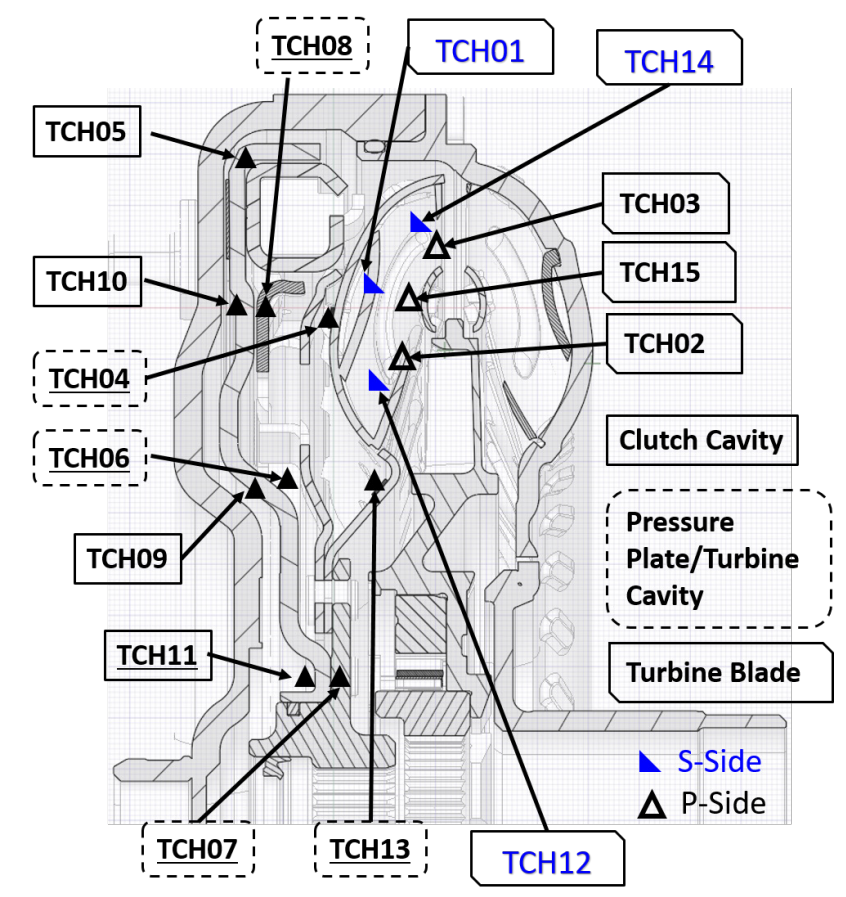

Figure 2-19. Transmitter C instrumentation locations [19]

Instrumentation of the turbine and clutch plate was the most complicated due to their location and functionality. Figure 2-20 shows the transmitters and induction coils mounted to the clutch plate. The instrumentation on the clutch plate is powered directly from the induction coil mounted to the plate, but the turbine required pin connections to transmit the power and signals. 


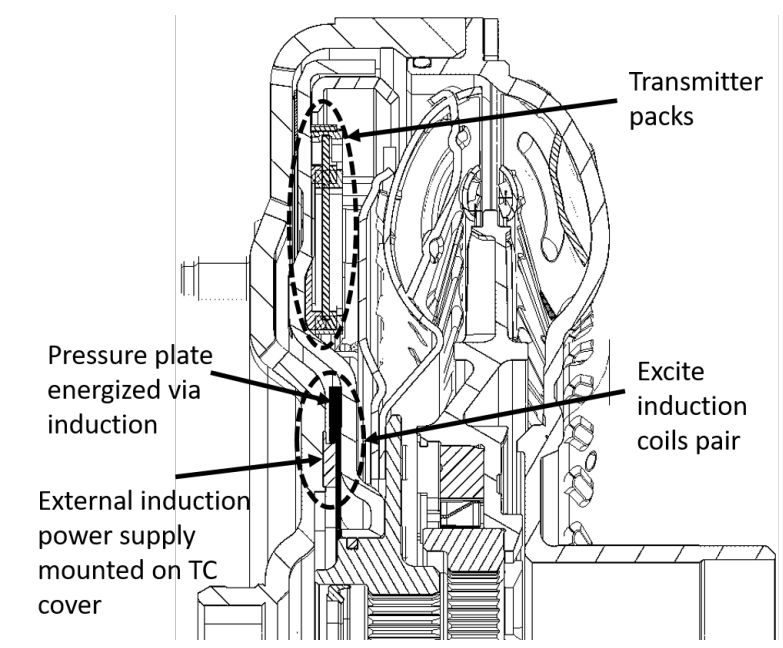

Figure 2-20 Transmitter $C$ induction coils [24]

Figure 2-21 shows the pin connections used to transmit power and communication with the turbine. These pins are designed to float allowing the clutch plate to move axially giving the ability to apply and disengage the clutch normally.

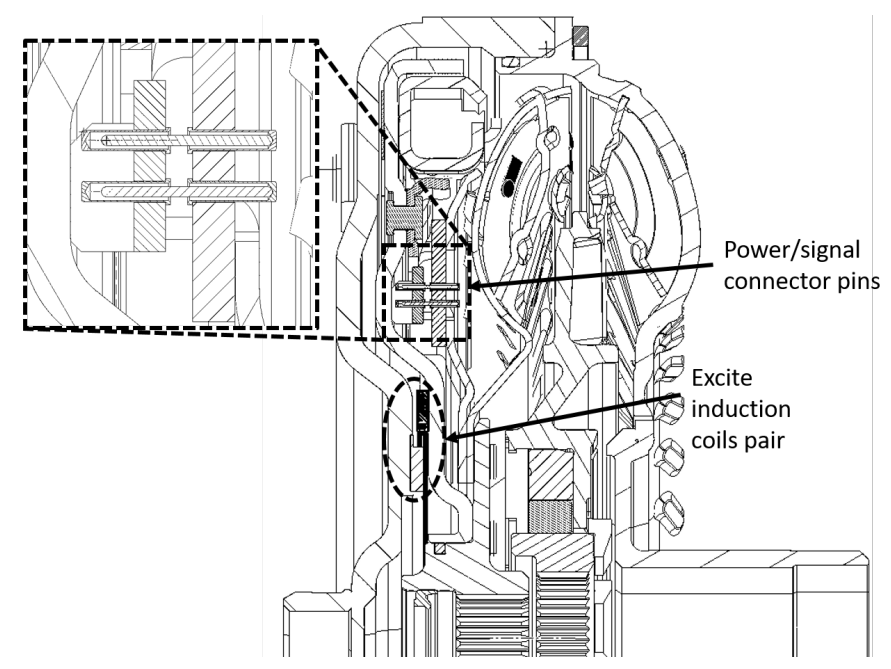

Figure 2-21. Transmitter $C$ induction coils and transmitter connections [24]

Two connector pin arrays were used to have redundancy, ensuring that power and communication will always be active. Figure 2-22 shows the pin arrays mounted to the shell of the turbine. 


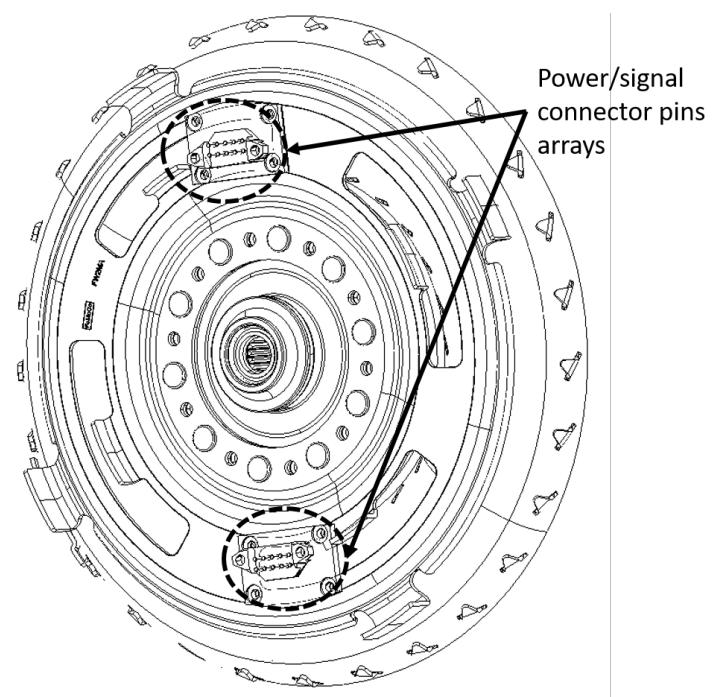

Figure 2-22. Hardware for power and signal connections to transmitter B \& C [24]

To transmit the data, slits had to be cut on the clutch plate and cover. Only one slit was required on the clutch plate because the transmitters are rigidly mounted to the plate. Multiple slits were cut around the cover providing a better opportunity for the signal to escape the torque converter and reach an antenna mounted to the transmission. All the slits are covered with the same Kevlar patches as on the impeller shell. Figure 2-23 shows the slit location on the clutch plate and cover. Photos of all the physical transducer locations and telemetry hardware can be found in Appendix I.

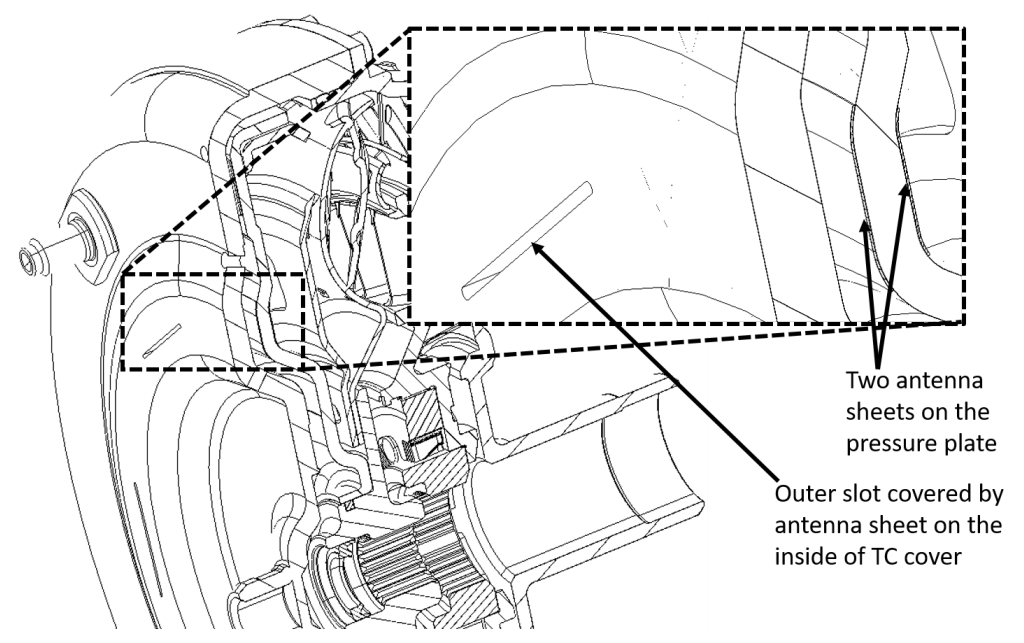

Figure 2-23. Signal slot for transmitter $\mathrm{C}$ cut in cover [24] 


\section{Methods}

Multiple procedures were developed throughout this study to improve test cell functionality and accuracy of mimicking in vehicle operation. The procedures are broken into steady state and transient testing. The following sections describes how each method was used and how the data is analyzed.

\subsection{Steady State Testing and Analysis}

Steady state testing was implemented first in the test cell to better understand the operation of the transmission and torque converter. The instrumentation in the torque converter is also ideal for steady state testing because of the multiplexed data. This is because when running at steady state the conditions are assumed to be constant and only one cycle through the channels are required to get the pressure measurements. The software, provided by IR Telemetrics, also outputs a document with the steady state pressure values for each channel. With the pressure values broken up by channel, the analysis becomes trivial. The steady state tests were used as a datum for TCC pressures, but the measurements of real interest were transient maneuvers.

\subsection{Transient Testing}

To be able to take transient measurements with the multiplexed pressure data, a method to repeat the transient event, shift the telemetry recording time, and the ability to sync the operational and pressure data was required. The following sections described the procedure and hardware that was developed to achieve transient testing. 


\subsubsection{Trigger Offset Module}

The hardware and electronics that must be able to communicate to achieve transient maneuvers include the transmission, dynamometer controls, telemetry system, and universal DAQ. Figure 3-1 shows the flow of information between all the above components with the solid, long dashed, and red short dashed lines representing physical, electrical, and trigger connections respectively. Note that the trigger offset module (TOM) and the delayed trigger communications are the additions to the test cell from the previous layout that allows the test cell to acquire transient data. Without these components, the test cell would only be capable of collecting steady state data.

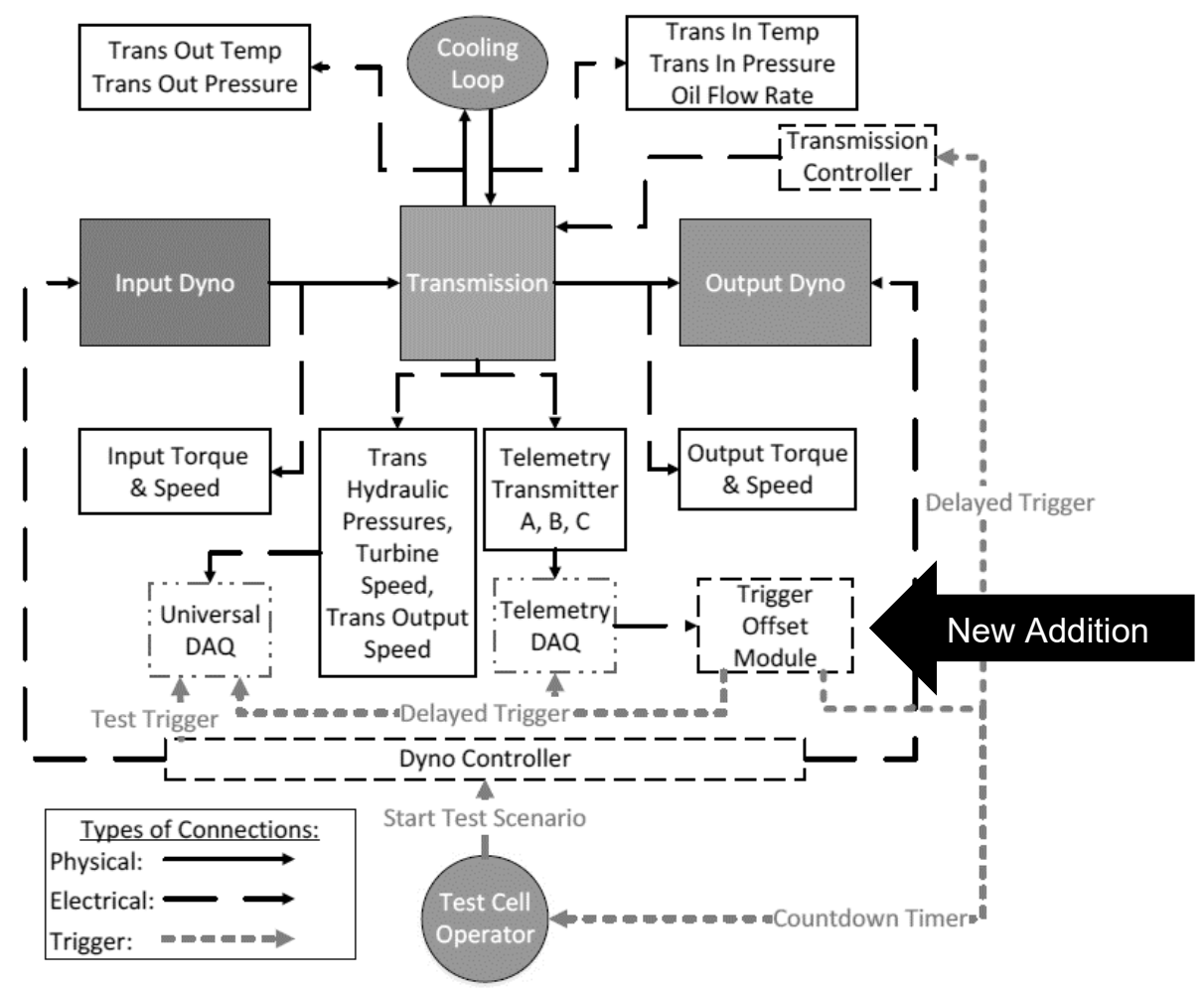

Figure 3-1. Test cell measurement and communications with transient capabilities 
The TOM consists of an Arduino Mega 2560, a liquid crystal display (LCD), keypad, and three BNC jacks. The module is shown in Figure 3-2 with each of the components labeled. The signal from transmitter $A$ is fed into the input BNC jack where the Arduino monitors the signal for a marker. When a marker is identified a countdown is displayed on the LCD for the predefined time that was inputted through the keypad (ex. $1 \mathrm{sec}, 2 \mathrm{sec}, 3 \mathrm{sec}$ ). When the countdown completes, a trigger is sent to the telemetry DAQ and transmission controller.

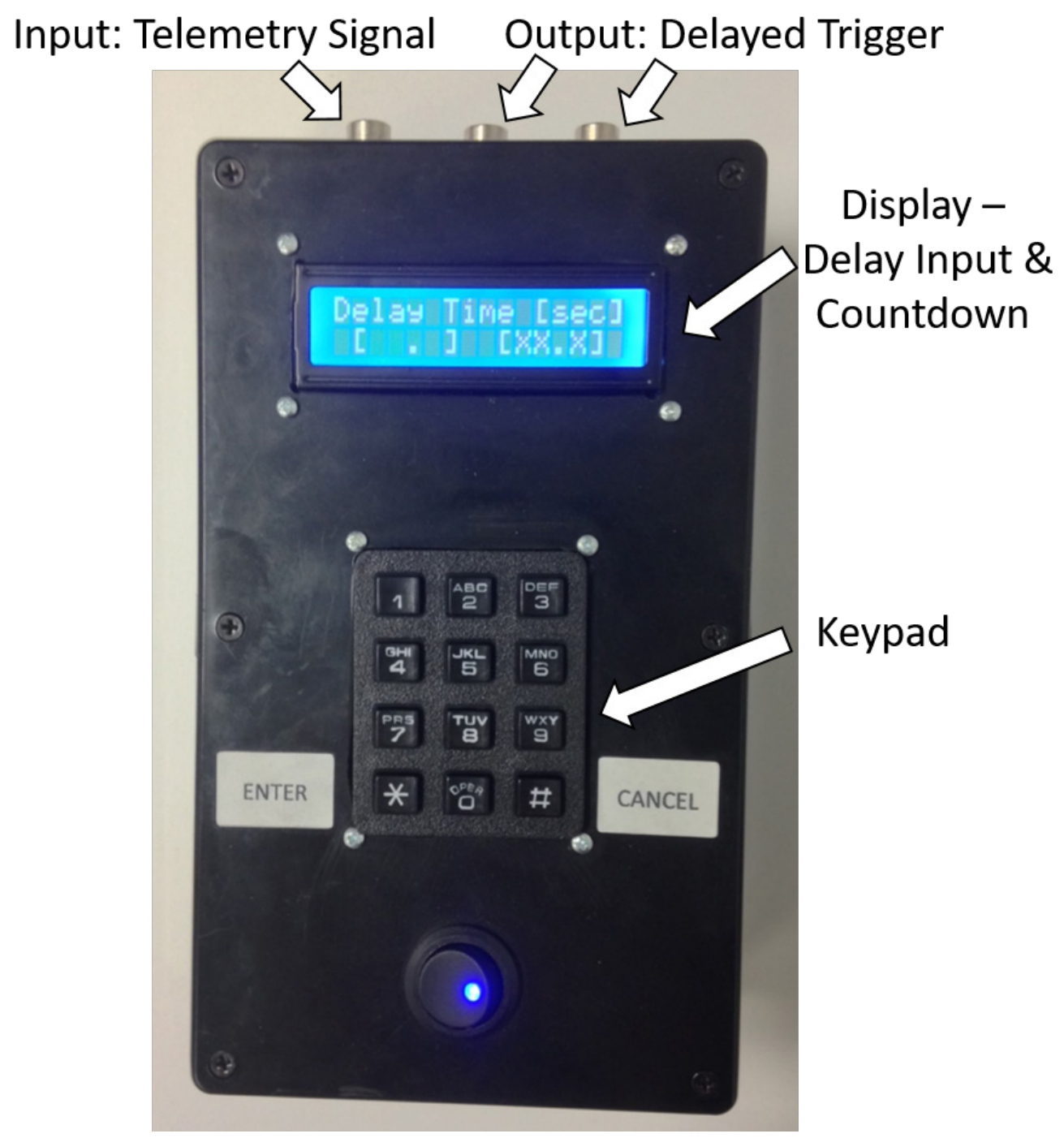

Figure 3-2. Trigger Offset Module (TOM) 


\subsubsection{Test Scripting}

A test script allows the transient event to be repeated by commanding either dynamometer, transmission, or a combination of the two to complete a maneuver. Manual operation can be done for very basic maneuvers, but is not recommended because the possibility for repeatability error increases. The test script can vary from a basic script, such as only sweeping input speed, to a complicated script, where the input and output dynamometers change speed or torque with the transmission shifting gears.

\subsubsection{Data Acquisition Parameters}

When working with triggered transient events, extra consideration and understanding is necessary to preserve the integrity and quality of the measurement. Ideally, the event channel sampling should be 180 samples per cycle of the highest frequency of interest [42]. As the frequency of importance increases towards Nyquist, the phase error will increase. The phase error in transient acquisition is related to the sensing of the trigger event since an event cannot be identified until the delta-t after it occurred. Phase errors due to triggering will cause an offset between each of the channels in post processing. If timing between channels is important the triggering error must be minimized. The acquisition of channels which are not transient in nature can be sampled at a reduced rate to improve data storage efficiency. Table 3-1 describes the parameters used for testing. The maximum error that can be seen due to trigger accuracy at $51.2 \mathrm{kHz}$ is 20 microseconds. This is doubled to 40 microseconds due to the use of two triggers per transient event. A maximum 40 microsecond delay with the slowest telemetry sampling frequency of $11.5 \mathrm{kHz}$ results in the phase error shown in Figure 3-3. Frequencies of interest in this study are below $100 \mathrm{~Hz}$ where the phase error is minimal thus no significant errors due to triggering are anticipated. 
Table 3-1. Sampling frequency for each type of data

\begin{tabular}{|c|c|}
\hline $\begin{array}{c}\text { Transient Event } \\
\text { Data }\end{array}$ & $51.2 \mathrm{kHz}$ \\
\hline Monitoring Data & $6.4 \mathrm{kHz}$ \\
\hline Telemetry Data & $11.5-32 \mathrm{kHz}$ \\
\hline
\end{tabular}

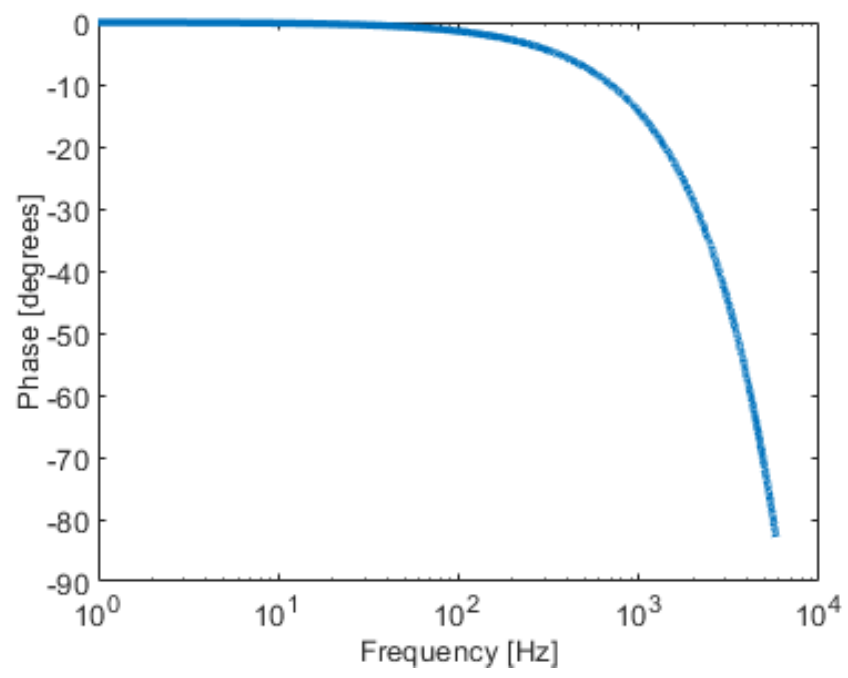

Figure 3-3. Phase error based on $11.5 \mathrm{kHz}$ sampling frequency

\subsubsection{Channel Offsetting}

Channel offsetting is the process of shifting the start time when the telemetry records data with respect to the start of the transient event. This gives the ability to change which channel is the first in the data set. The test is repeated 16 times to capture the transient maneuver on all the channels. 16 tests are required because transmitter $C$ has 15 channels plus 1 marker. Transmitter $A$ and $B$ only require 8 repetitions of the test due to 7 channels plus 1 marker. Figure 3-4 illustrates a transient maneuver of sweeping input speed and how each test run is offset by 1 channel. By changing which channel the maneuver begins on, different channels will observe different portions of the transient event. The transient event can be any length of time because the telemetry will continue to repeat recording until the end of the test. A transient event of 0.5 or 30 seconds will require the same number of test runs to capture the total event on every channel. 


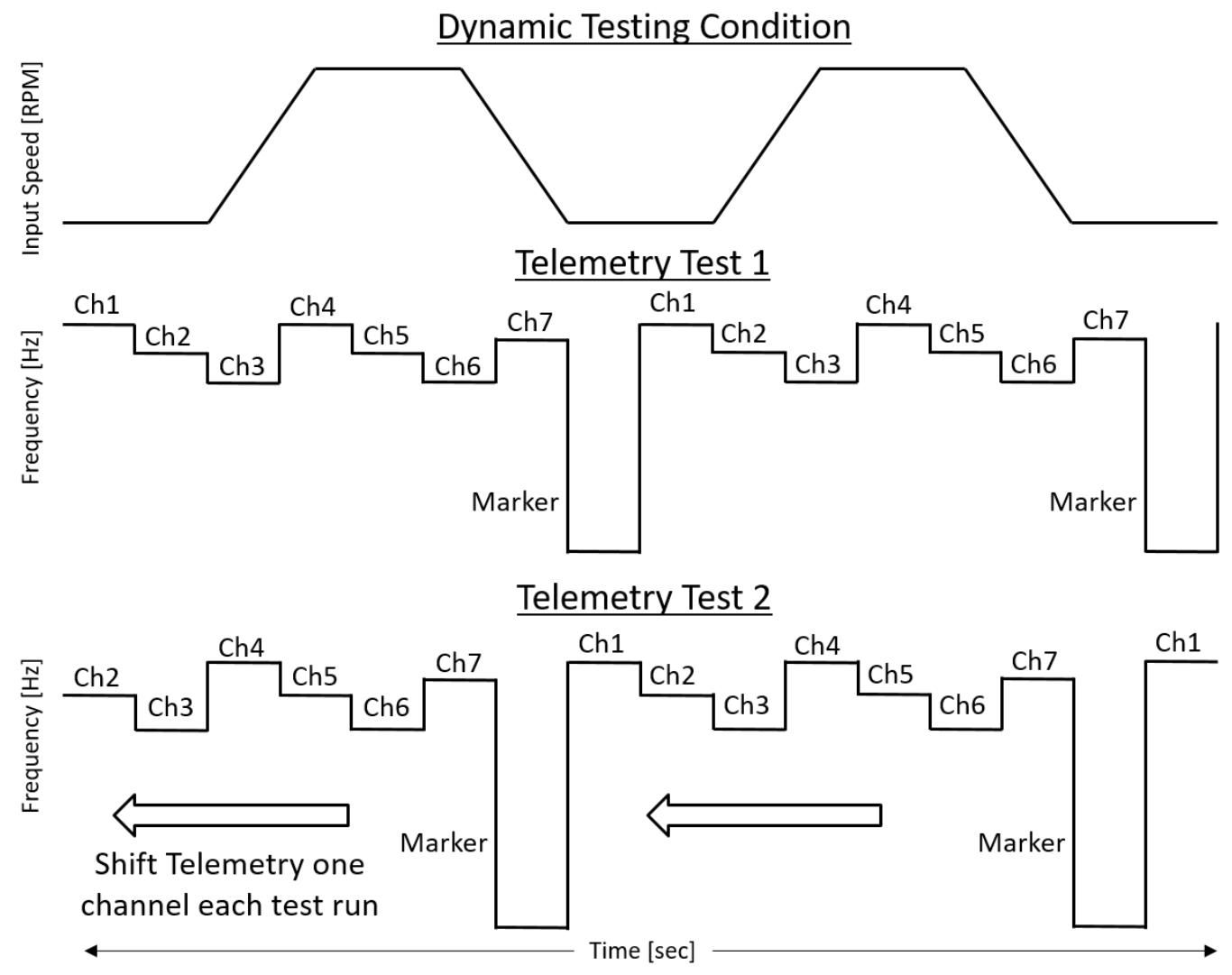

Figure 3-4. Channel offset procedure

\subsubsection{Testing Procedure}

To collect a data set, a six step process occurs for each test run. Before running, the test script must be ready to start and the TOM must have the required trigger delay for that run. The six step process is broken down into a flow chart shown in Figure 3-5. The first step is to sync the three transmitters by power cycling the system. All three transmitters run off a single power supply allowing for all three transmitters to be turned on simultaneously. To fully discharge the transmitters a two-minute power off cycle is required, which is due to capacitors throughout the system. This causes the transmitters to start on the same channel every time. If this step is skipped, the telemetry data will start on a random channel and capturing the transient event on every channel will not be possible. 


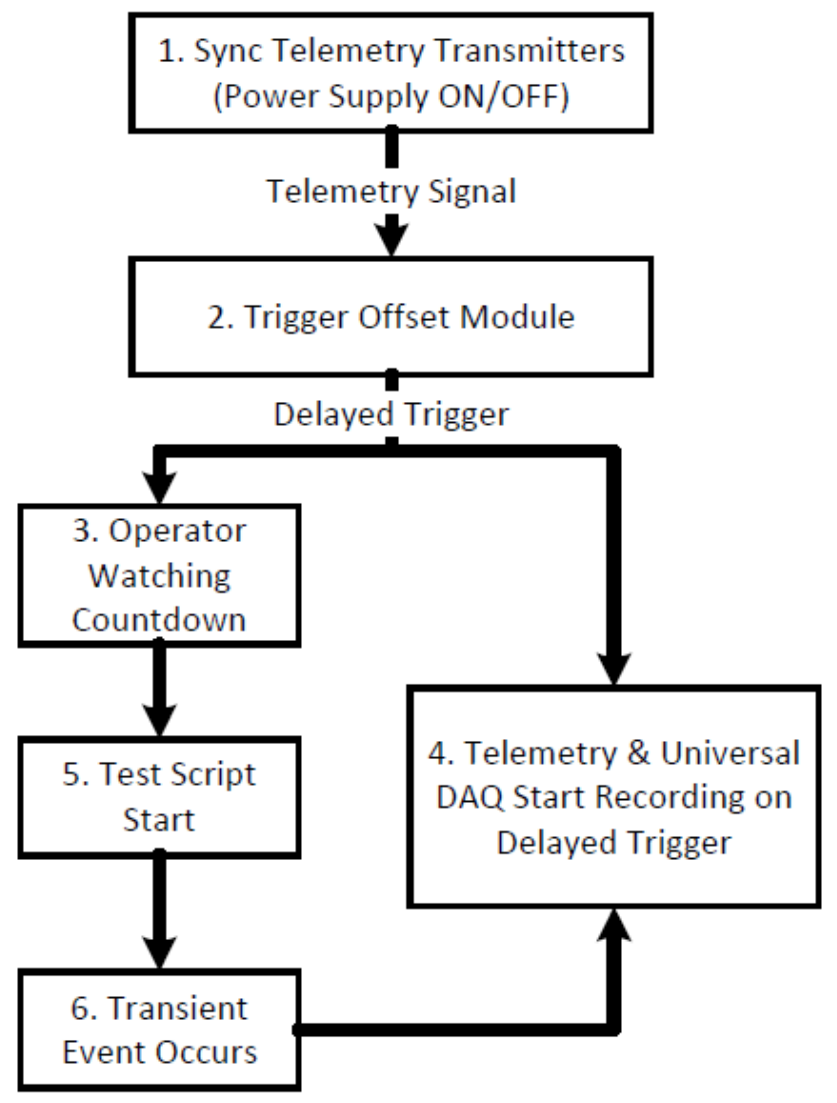

Figure 3-5. Testing procedure flow diagram

Once the transmitters are synched and powered back on, one telemetry signal is monitored by the TOM looking for the first marker. The telemetry signal used in this case was transmitter A because it contained the fewest number of dropouts, reducing the possibility of false markers.

When a marker occurs, the TOM will countdown the predefined delay time. Once the countdown is complete, triggers are sent to the telemetry receivers and universal DAQ to begin recording for a specified amount of time. The operator also starts the test script from watching the LCD on the TOM upon completion of the countdown. The test script will begin to run and initiate the transient event, which is then captured on the telemetry receiver and universal DAQ. This process is then repeated the 16 times to fully capture the transient event by shifting the TOM delay time by $1 \mathrm{sec}$ per run. 


\subsection{Transient Data Post Processing}

Once a full set of test runs have been completed the data must go through multiple processing steps to create a useable time history. This process involves dropout removal, uniform resampling, channel identification, and a channel stitching process.

\subsubsection{Signal Dropout Removal}

Dropouts are the loss of signal in the telemetry data which results in a false recorded signal. These dropouts are caused by the transmitted signal having to pass through the reradiating slots through the clutch plate and cover. Transmitter A has the least amount of dropouts because the transmitted signal is on the outside of the cover. The dropouts are one to three data points in length averaging 0.1 milliseconds of signal loss.

To remove dropouts, all data points outside of 3 standard deviations of the local mean were identified. A 3 standard deviation range was chosen because statistically $99.7 \%$ of the possible mean values will fall in this range [43]. No issues were found with using this technique for the transition between channels. Once the dropouts were identified, they were removed and replaced with the local mean. Figure 3-6 is an example of transmitter B's raw data stream and the dropout removal processed data. 

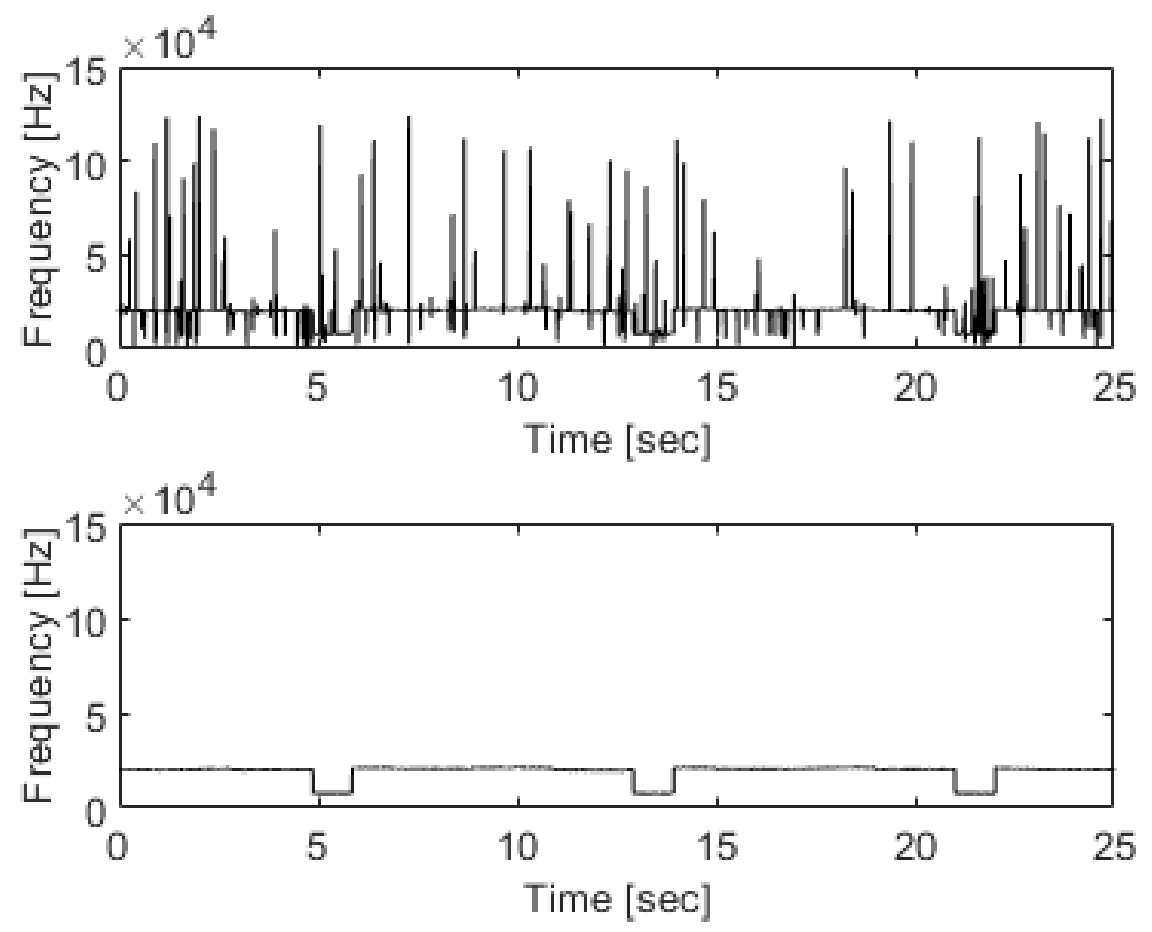

Figure 3-6. Raw data trace with dropouts (top), dropout removed trace (bottom)

\subsubsection{Uniform Resampling}

The instrumented torque converter was developed by IR Telemetrics with their patented telemetric signal evolution process. Figure 3-7 illustrates how the signal is measured by the transducer, converted to a pulse width modulated (PWM) signal, and transmitted as a microwave signal. The square wave frequency is then recorded and reconstructed back to the original signal. 


\section{IR Telemetrics Signal Evolution Diagram}

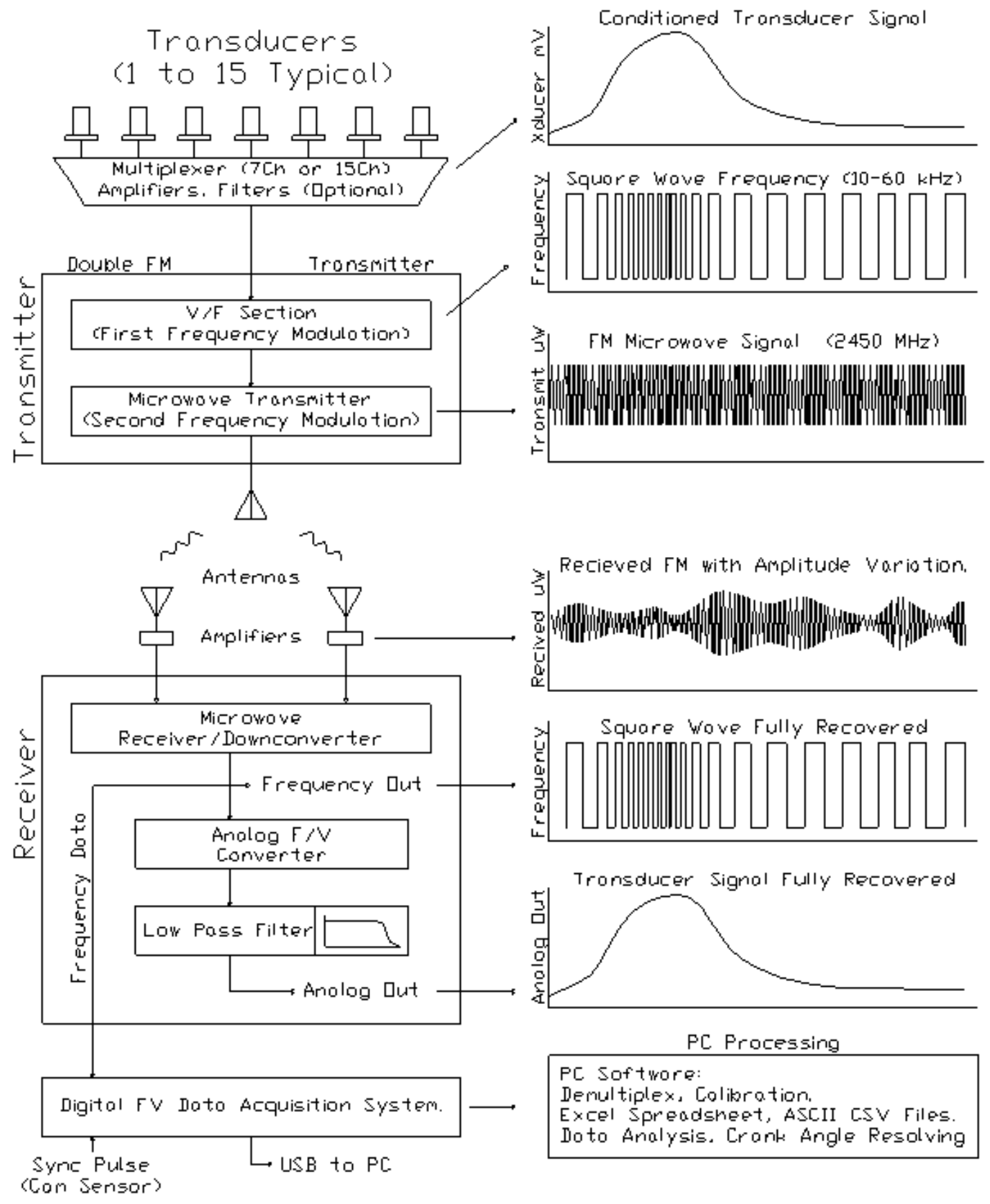

Figure 3-7. IR Telemetrics signal evolution diagram [44] 
The reconstructed signal does not have a uniform sampling rate because a sample is taken on every rising edge of the square wave. The frequency of the square wave is directly proportional to the measured pressure, so as the pressure increases so does the frequency. Figure 3-8 is an example of where the samples are taken on the square wave, represented by stars, and shows how the sampling rate varies with frequency.

The data was resampled to a constant sampling frequency of $52 \mathrm{kHz}$ by using a cubic spline interpolation. A uniform time vector was made and a value was interpolated at each new time interval. The uniform resampling allows for easier manipulation of the data for later processing and analysis.

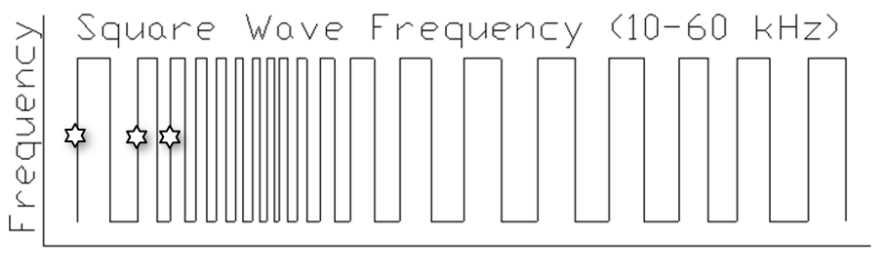

Figure 3-8. Telemetry sampling procedure [44]

\subsubsection{Channel Identification}

To identify each of the channels, the marker starts and ends are required. The channel length can be calculated by determining the marker length from the marker start and end values for that transmitter. This accounts for the slight time per channel variation between each of the transmitters. The data goes through a twostep process where full channel sets are processed first and then partial channel sets second. The full channel sets are when all 7 or 15 channels were recorded, this is determined by a marker end to marker start. The channel set is then broken into individual channels based on the marker length. Finally, $1 \%$ of the data points are removed from the ends of each channel to ensure that no false data is saved from the channel transitions. Figure 3-9 shows the channel sets and how the channels appear after channel identification processing. 

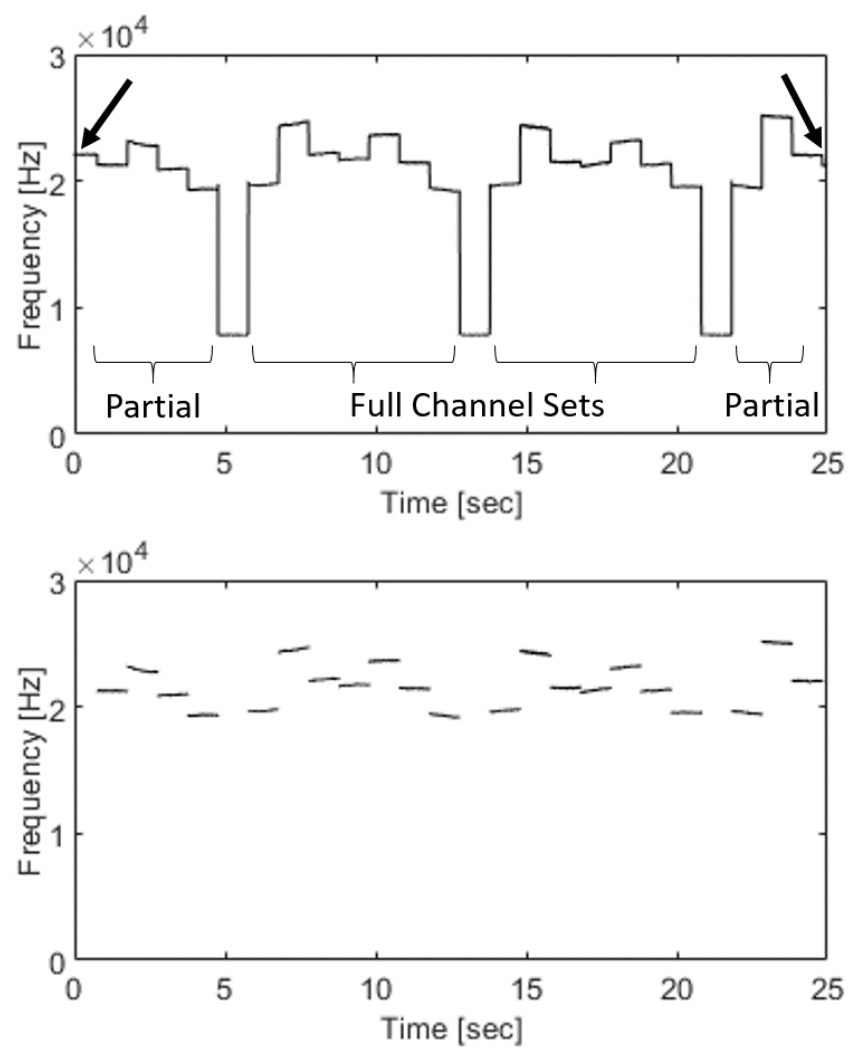

Figure 3-9. Channel groups (top), individual channel breakdown (bottom)

The partial channel sets are only going to occur at the beginning and end of the test run. The partial channel sets go through a similar process as the full sets, but instead of using the marker start and end values, the beginning and end time of the data set are used. The number of complete channels are then calculated using the length of the marker. Then, all the complete channels are split based off of the first and last marker for the beginning and end partial sets respectively. Again, 1\% of the data on each of the channels are removed, as illustrated in Figure 3-10. 


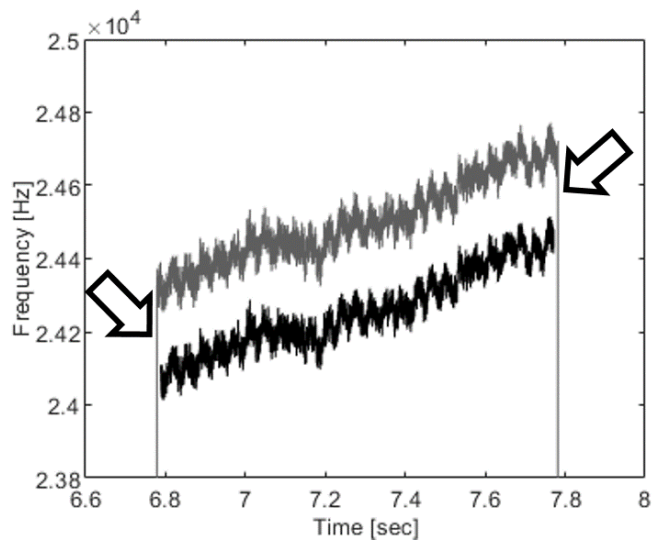

Figure 3-10. Data removal from start and end of channel

\subsubsection{Channel Organization}

The channel identification process is completed with each test run, which consists of separating all the channels from a test run into their respective channels. For example, all the channel 1's and 2's will be grouped separately into their two respective groups. Once all the channels have been organized into the proper groups, an ordering process is applied. The ordering is determined by the time vectors that are associated with each of the individual channels and organized chronologically. This ordering connects each channel creating a "continuous" time trace. Figure 3-11 shows an example of how channel 1 was pulled from each of the test runs and organized in the proper order.

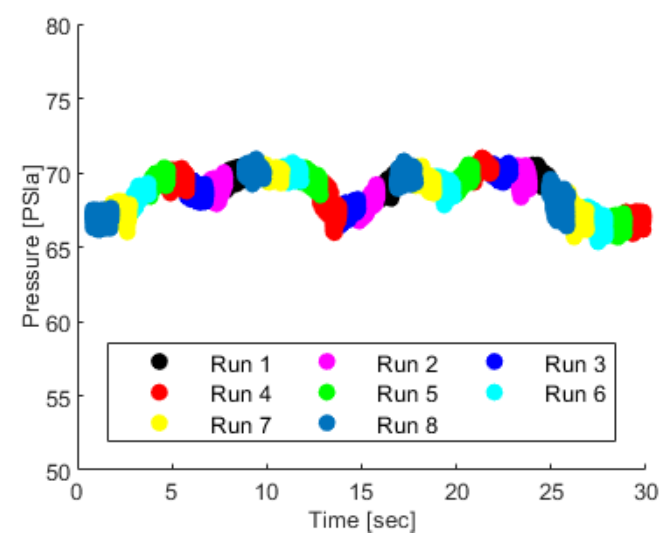

Figure 3-11. Channel 1 from each run stitched into a time trace 
The data processing will produce 7 or 15 individual traces depending on the number of channels for that transmitter. Figure 3-12 shows the fully processed data for all 7 channels of transmitter $A$. It is important to note that each of the channel time histories appear to be continuous, but there are still discontinuities in the data and cannot be treated as one continuous data set. This is mainly a concern if additional post processing on the data is of interest, such as converting to the frequency domain. The time histories can then be synced to the universal DAQ data for further processing and analysis.

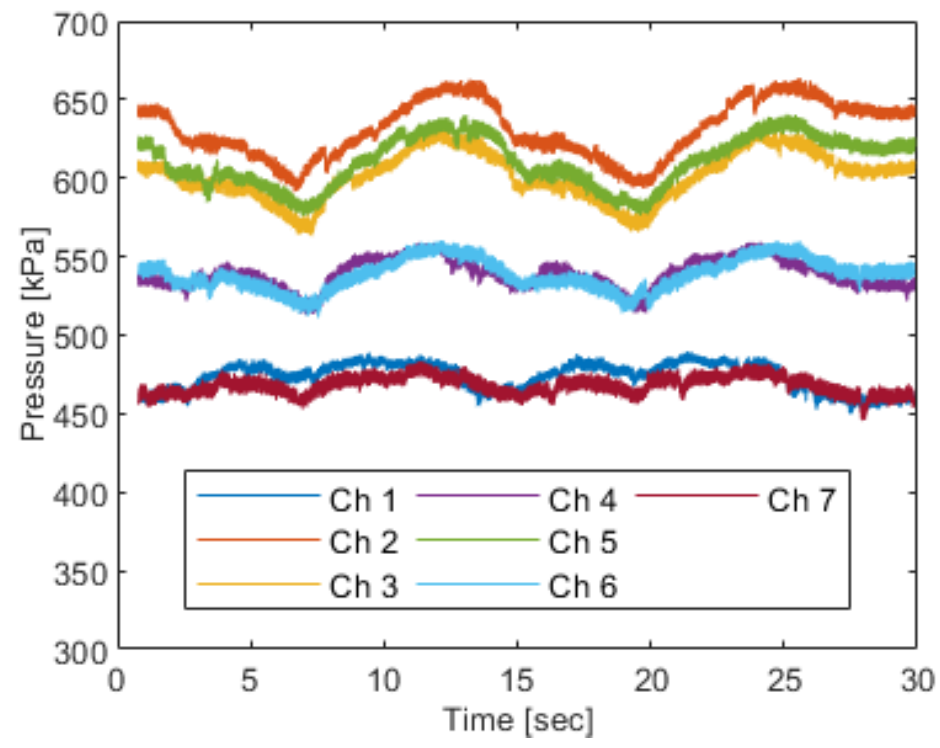

Figure 3-12. Example of all channels for transmitter $A$ after post processing

The data can still be converted to the frequency domain as long as data blocks from the original 1 second recording are used and do not span across runs. Figure 3-11 illustrates the blocks of data that can be used for converting to the frequency domain. Figure 3-13 is an example Fast Fourier Transform (FFT) colormap that was created using channel 2 from transmitter $A$. 


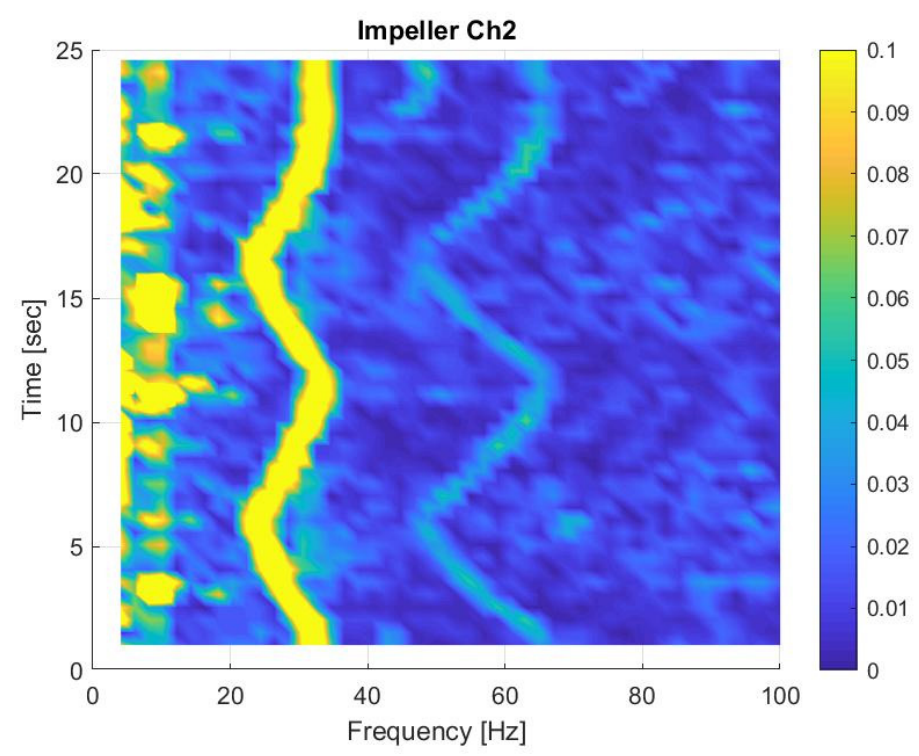

Figure 3-13. FFT colormap of channel 2 from transmitter A

\subsection{Back Drive Test Development}

Back driving occurs when the power flow in the transmission is reversed where the output is driving the input. This can occur when cruising down a hill without applying the brakes or throttle. The vehicle speed increases down the hill due to the weight of the vehicle instead of power generated by the engine. The engine is at idle speed but since the output of the transmission is going faster than the input a back drive condition occurs. During back drive an open torque converter can see speed ratios larger than 1 , while a locked torque converter will drive the input engine speed up.

To create a back drive condition in the test cell, the drive dyno was set to torque mode and the absorbing dyno to speed mode. The absorbing dyno was set to a constant output speed, while the drive dyno oscillated between a positive and negative torque representing engine driving the transmission and transmission driving the engine respectively. The drive dyno did not have the capability to operate at a constant negative torque due to being a DC dyno. Figure 3-14 is an 
example of a positive 45 to $-45 \mathrm{Nm}$ test where the dashed lines represent the input and output torque and the solid lines representing the impeller and turbine speed. All the back drive tests were completed in $5^{\text {th }}$ gear.

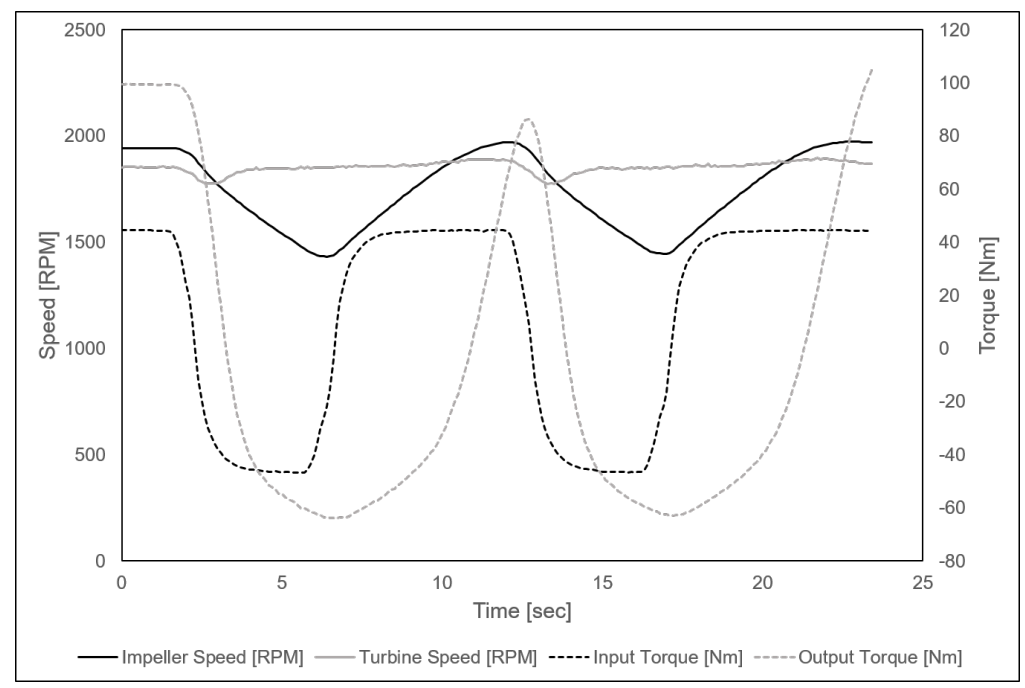

Figure 3-14. Dyno operation between positive and negative torque

Using this back drive method, speed ratios between 0.96 and 1.3 can be achieved. Figure 3-15 shows the speed ratios that are achieved from the test scenario shown in Figure 3-14. By creating test scripts, as described earlier, the speed ratios can be reproduced repeatability.

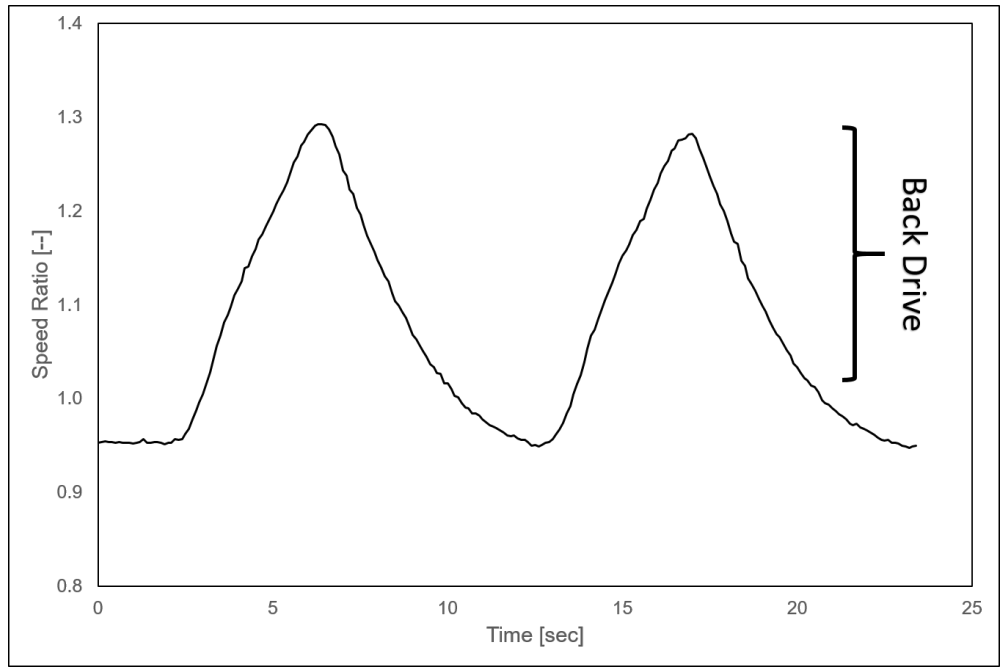

Figure 3-15. Back drive speed ratios 


\subsection{Gear Shifting}

\subsubsection{Transmission Power Flow}

Before calibrating for a gear shift an understanding of the layout and power flow of the transmission is required. Figure 3-16 is a stick diagram of the 6 speed transmission understudy. There are three planetary gear sets and six clutches. The power flow starts on the left from the turbine shaft as the input of the transmission. Depending on the combination of clutches the power will be transmitted across the three planetary gear sets creating different gear ratios. The output is a chain drive to the final drive ending on the left of Figure 3-16. By visualizing the transmission power flow, an understanding between oncoming and off-going clutches for calibration becomes clearer.

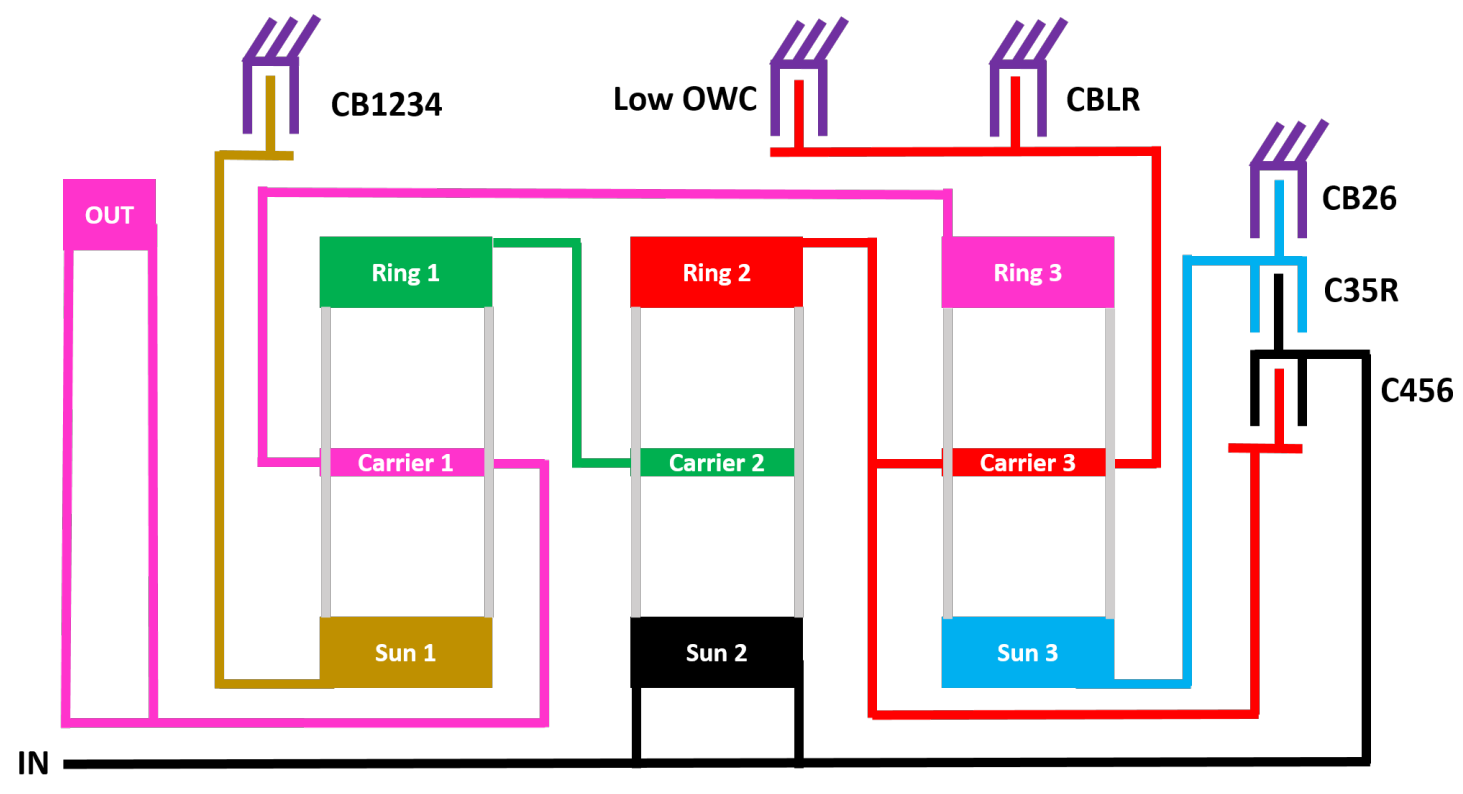

Figure 3-16. Stick diagram of transmission under study 


\subsubsection{Calibration Strategy}

The work done with gear shift calibration was to mimic previous vehicle shift maneuvers as closely as possible. It is important to note that the calibrations used for these tests where modified to accommodate the test cell and were not developed by a transmission calibration engineer. This results in calibrations that are good for representing the hydraulic interaction during a shift but may not be vehicle quality shifts.

The combination of clutches that are on and off determines the gear ratio of the planetary gear sets. The simplest strategy to transition from one gear to the next is by having one off-going clutch and one oncoming clutch. Off-going and oncoming mean that a clutch is losing or gaining capacity to hold torque, which is controlled by the clutch pressure. There are four shifts types that can occur in an automatic transmission: power-on upshift, power-on downshift, power-off upshift, and power-off downshift [4]. Power-on means that the input driver is applying power to the transmission, while power-off is low or no throttle conditions where there is no power to the transmission. This study only looked at power-on upshifts and downshifts. Each shifting strategy uses similar principles but there are some slight differences.

During a shift there are two phases that occur, torque and inertia phase. Torque phase is when the torque is being transferred from one clutch to another without having an input speed change. Inertia phase is when the input speed changes from the starting gear speed to the ending gear speed. During inertia phase, the inertia of the input is playing a role in the final amount of transitional torque that the on-coming clutch must carry.

For this study the input torque and output speed were held constant. Having a constant output speed is not abnormal during a gear shift because of the large vehicle mass, but ideally the input torque would have additional torque 
management to get a constant output torque. Having a constant input torque was done to simplify the maneuver and reduce calibration time, but still retained the key hydraulic information of interest. An example of a typical power-on upshift calibration strategy, used for this study, is shown Figure 3-17. During the torque phase the off-going clutch decreases to zero while the on-coming clutch increases to hold input torque capacity. At the end of torque phase, the end gear state is achieved and the output torque decreases to the end gear state torque value. Once inertia phase begins the input speed decreases causing a large torque fluctuation in the output torque. The oncoming clutch has to increase torque capacity to accommodate the output torque fluctuation until the input speed reaches the end gear speed. At the end of inertia phase, the oncoming torque capacity is reduced because the output torque is reduced.

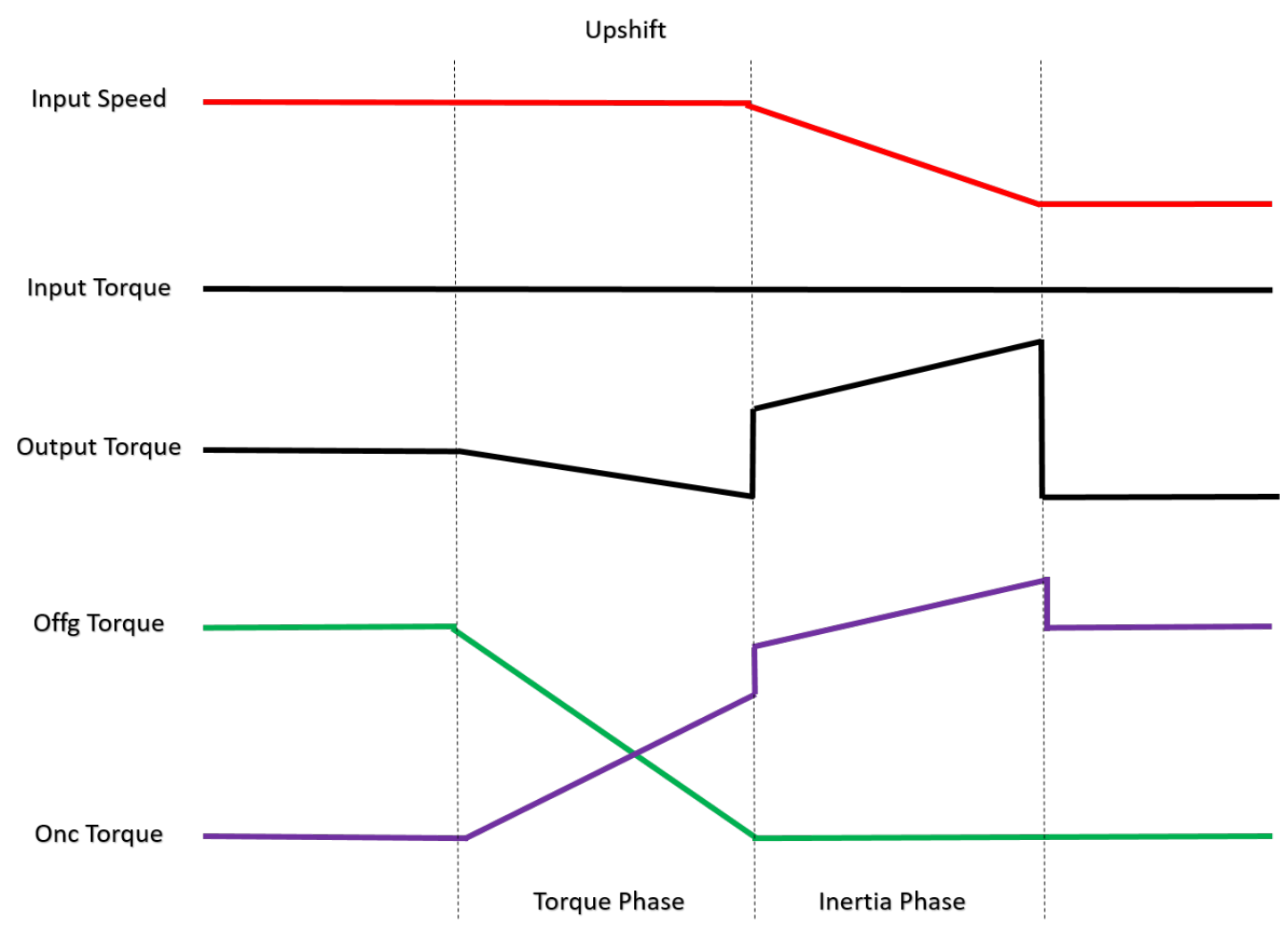

Figure 3-17. Power-on upshift calibration strategy for constant input torque 
A power-on downshift is the reversed process of completing a power-on upshift. The downshift first begins with the inertia phase with an input speed increase. Due to a constant input torque, the output torque drops caused by a reduction in offgoing clutch torque capacity to allow input speed to increase. At start of torque phase, the input speed has reached the end gear state speed. The off-going clutch torque capacity increases to stop the input speed from increasing. The off-going clutch then reduces torque capacity as the on-coming clutch torque capacity increases. The output torque increases with the oncoming clutch until the end gear has been reached. Figure 3-18 illustrates the calibration strategy for a power-on downshift.

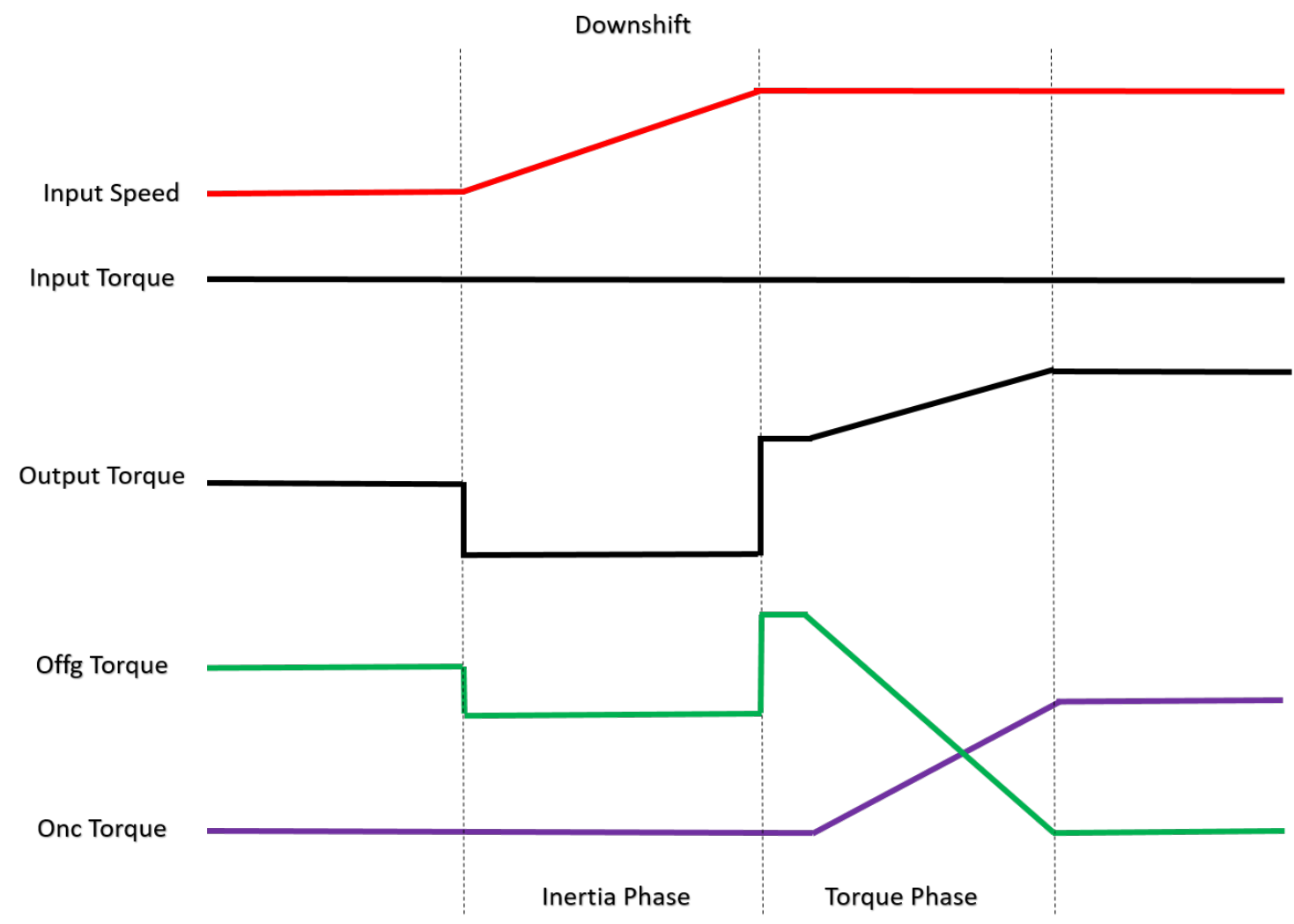

Figure 3-18. Power-on downshift calibration strategy for constant input torque 


\subsubsection{AmeSIM Transmission Model}

A 1-D model of the transmission was built in LMS Amesim to develop shift profiles before attempting with the hardware. The model consists of the transmission inertias, stiffness, damping, planetary gears, and friction clutches. The component connection layout can be seen in Figure 3-19. This model does not contain a torque converter model, so the shift represents what occurs when the TCC is applied. Having the TCC applied is the worst case scenario for torque fluctuation during a gear shift because the large input dyno inertia has a big impact on the torque fluctuation during the inertia phase of the shift. When the torque converter is open, the input and output dynos are not mechanically coupled and free to transition slowly. The model was used to reduce the fluctuation while mimicking the shift calibration profile from the vehicle data.

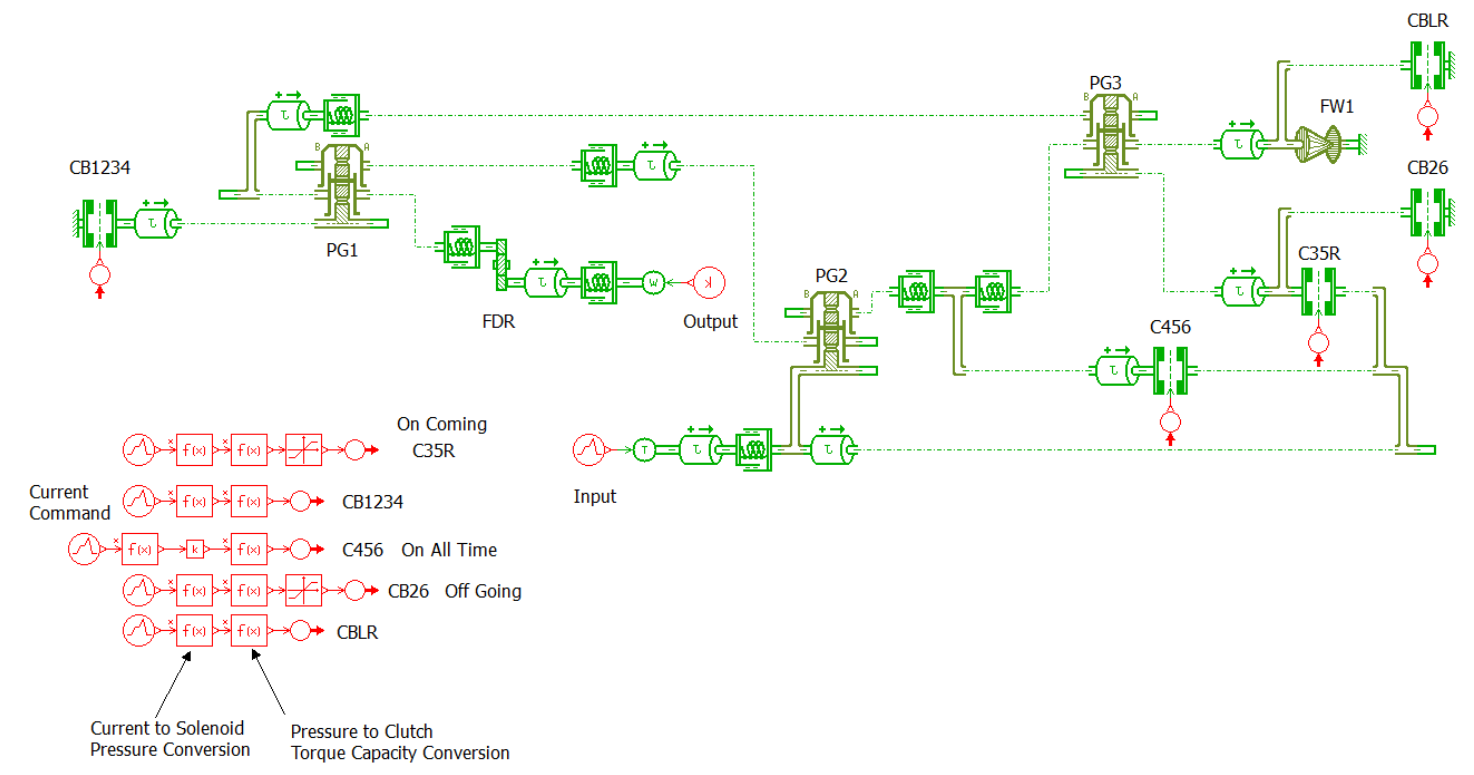

Figure 3-19. Transmission 1-D model layout 


\subsubsection{Shift Model Parameters}

The parameters that were used in the model are estimates for mass and stiffness of the transmission components. To control the clutches, a conversion from electrical current command to pressure and then pressure to clutch friction torque was done. Figure 3-20 show the calibration curves that were used for both normally low and high solenoids to convert from a current command to a pressure.

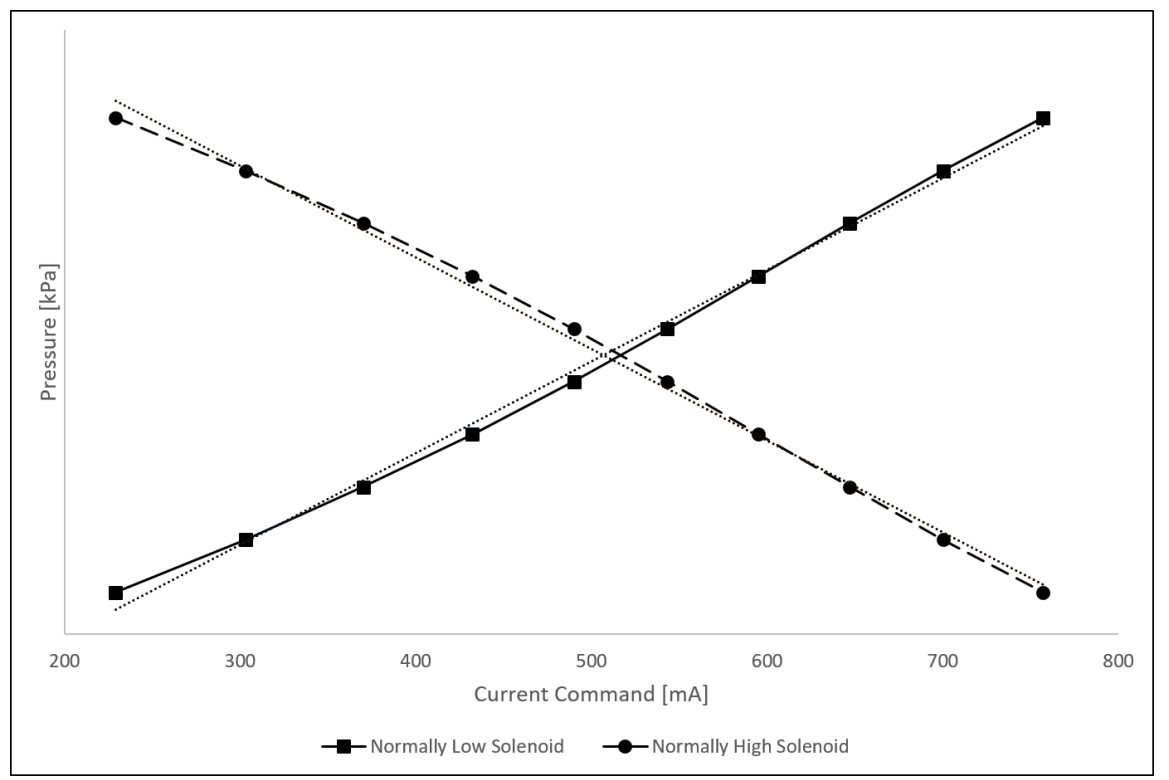

Figure 3-20. Current command conversion to pressure

The pressure is then fed into a calibration curve for each clutch. The calibration curves are dependent on the gear state because each clutch has to hold a different amount of torque based on the gear ratio. Figure 3-21 are the calibration curves for clutches $\mathrm{C} 456$ and CB26 for $6^{\text {th }}$ gear. 


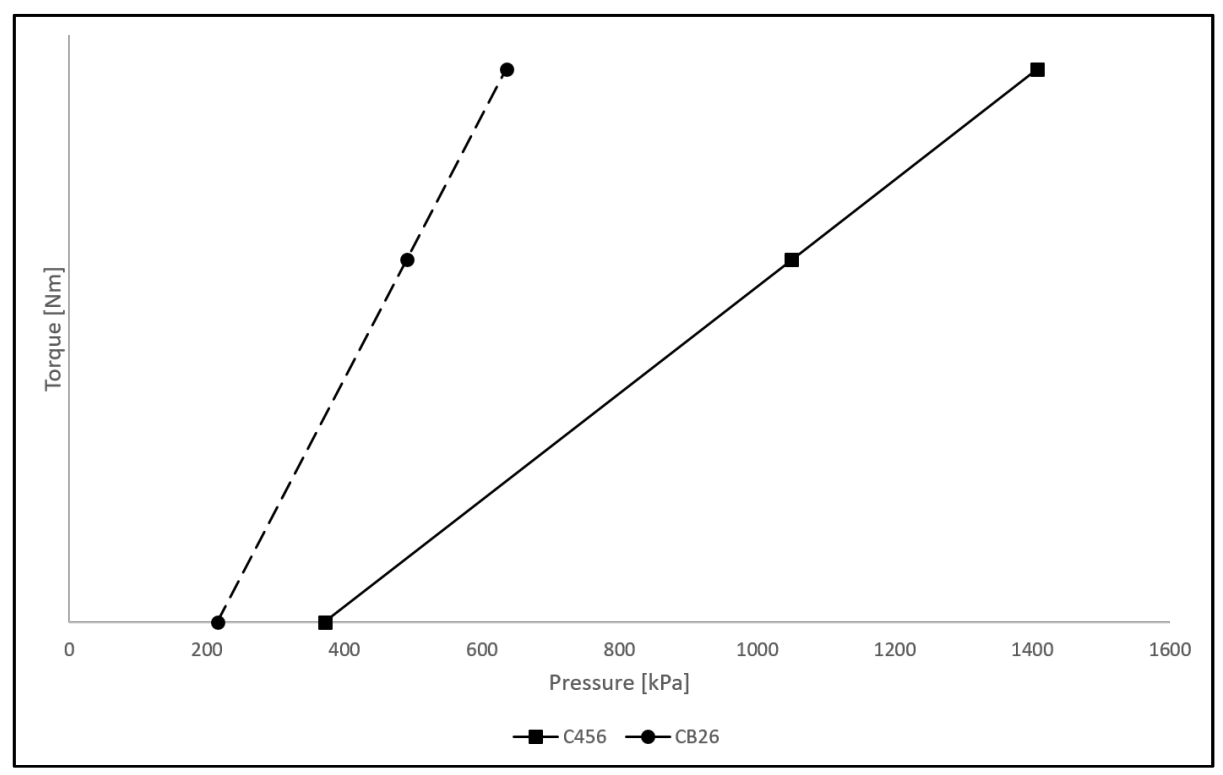

Figure 3-21. Solenoid pressure conversion to friction clutch torque capacity

\subsubsection{Shift profiles}

The starting shifting profiles were taken from vehicle data based off the regulator pressure. Multiple shifts from the data were averaged to get a general shift profile. The pressure was then converted to a current command. A profile was made for each of the clutches. Figure 3-22 and Figure 3-23 are example current command profiles for the oncoming clutch controlled by a normally low or high solenoid respectively. The off-going clutches were calibrated to decrease capacity linearly during the torque phase following the same calibration strategies that were discussed above in Figure 3-17 and Figure 3-18. 


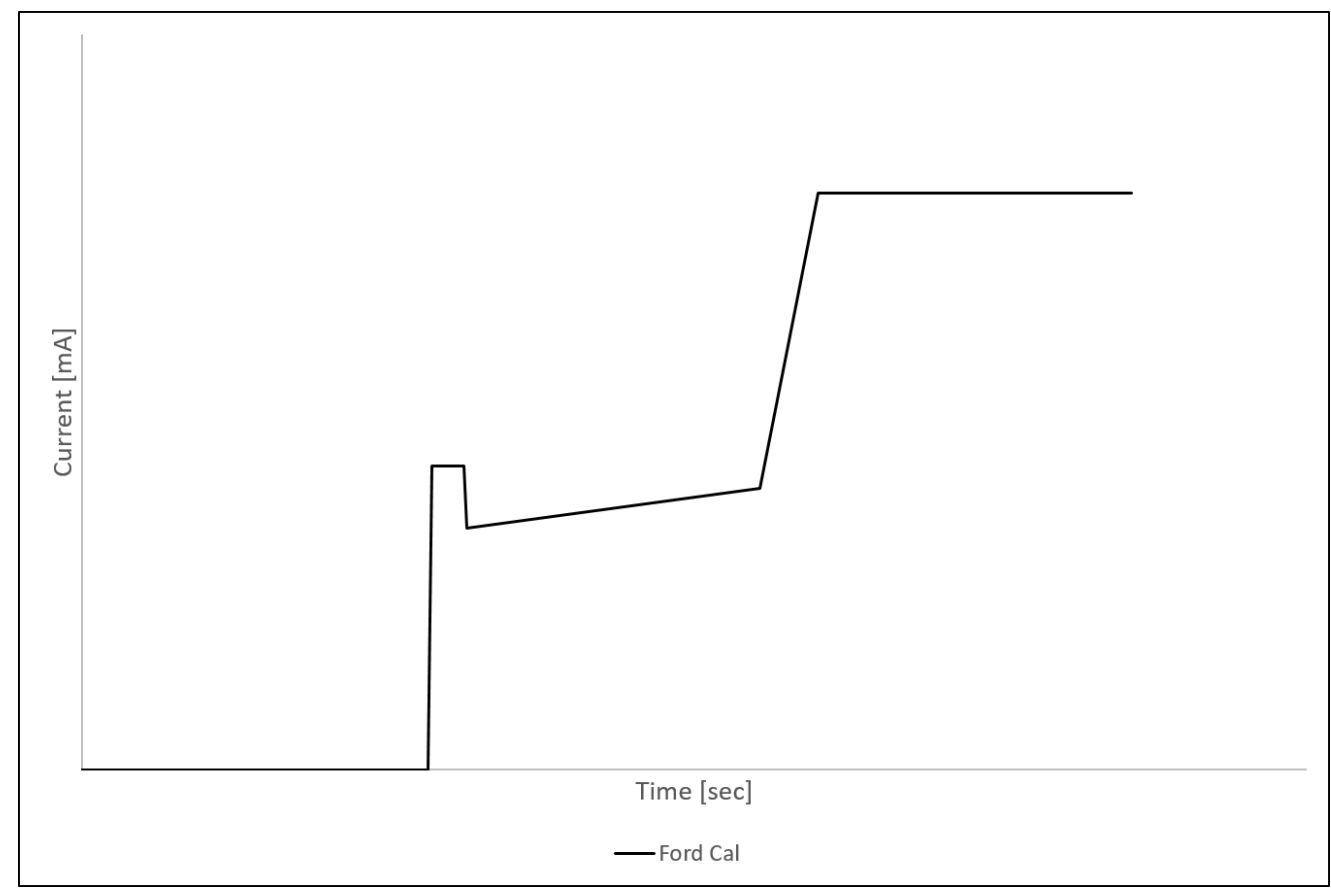

Figure 3-22. Example current command profile for a normally low solenoid

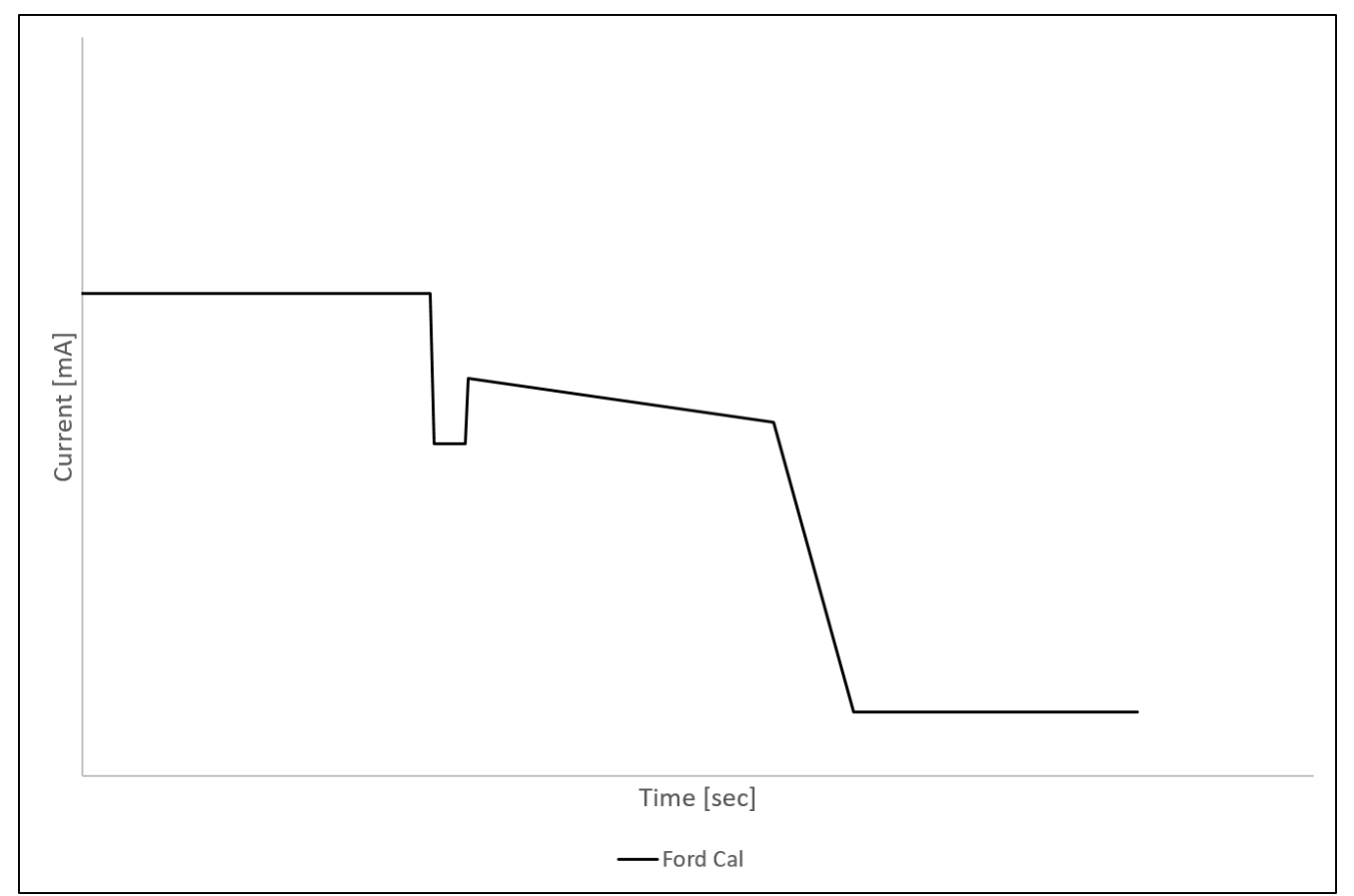

Figure 3-23. Example current command profile for a normally high solenoid 


\subsubsection{Shift Model Results}

Both speed and torque for the input and output are taken from the model to verify that the shift is properly calibrated. The output torque is the main concern to ensure that the limit of $450 \mathrm{Nm}$ is not exceeded. The input speed is also of interest to see how long the shift takes. Ideally the transition period for the input speed should take between 0.3-0.6 seconds. Due to the large inertia from the input dyno these times were not met but kept in mind to get the shift as short as possible without damaging the transmission. Figure 3-24 are the results from the model for a downshift.
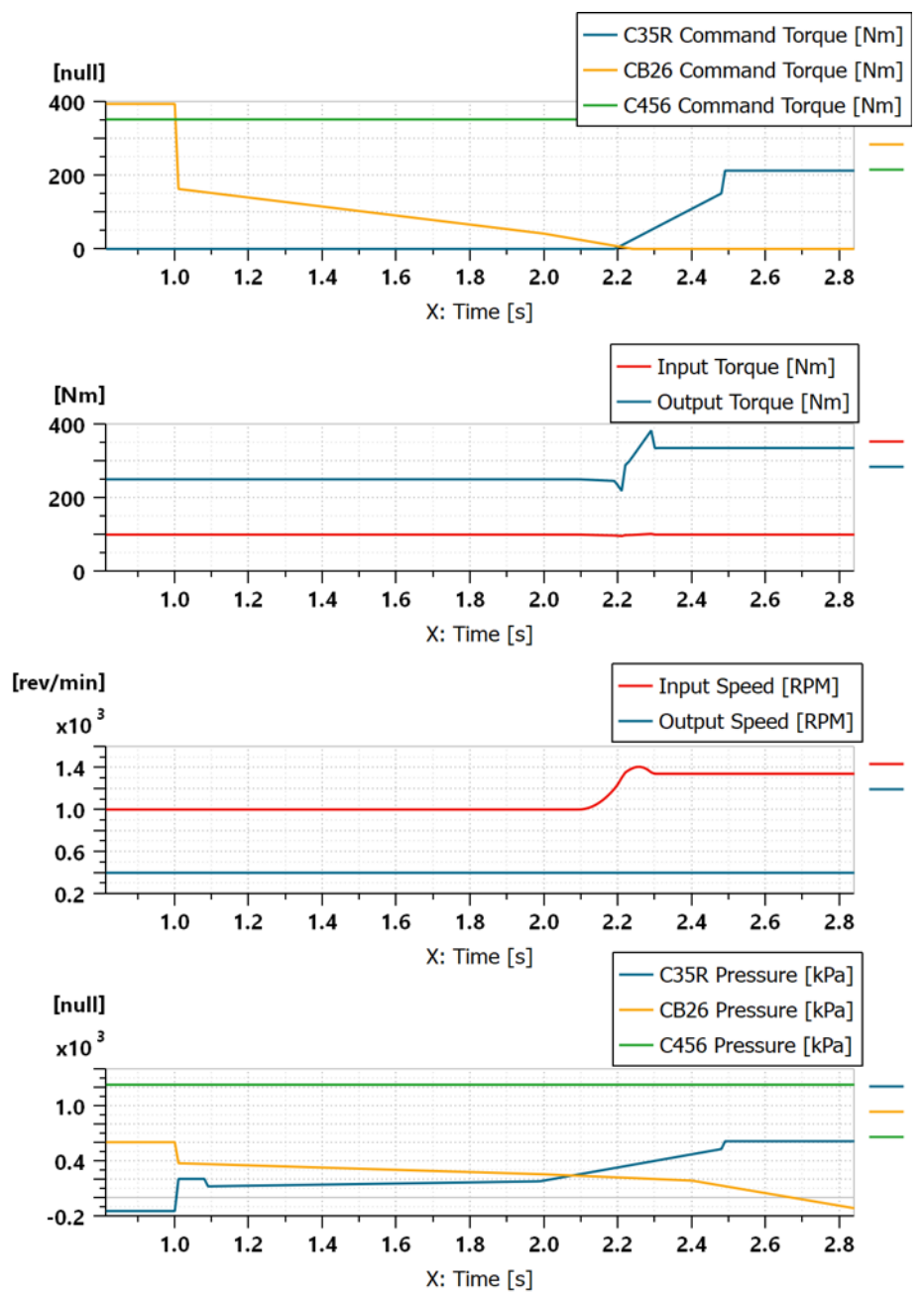

Figure 3-24. Example model results of a downshift from 6th to 5th gear 


\subsubsection{Dyno Torque Management}

Once the shift profile is finalized, the profile is then taken to the test cell to verify the shift is occurring properly. Torque management was also developed to compensate for the large output fluctuation that was seen in the above shift calibration strategy. Torque management is accomplished by writing a script that changes the input dyno torque as the transmission is shifting. The torque management and shift are synced by a trigger that activates the shift once the dyno script has been initiated. With torque management the output torque can be reduced to a smooth transitional torque reduction. Figure 3-25 illustrates the calibration strategy for adding torque management to an upshift. During an upshift the input torque is reduced during the inertia phase to help decrease the input speed. Once inertia phase is over the input torque returns to the starting torque value.

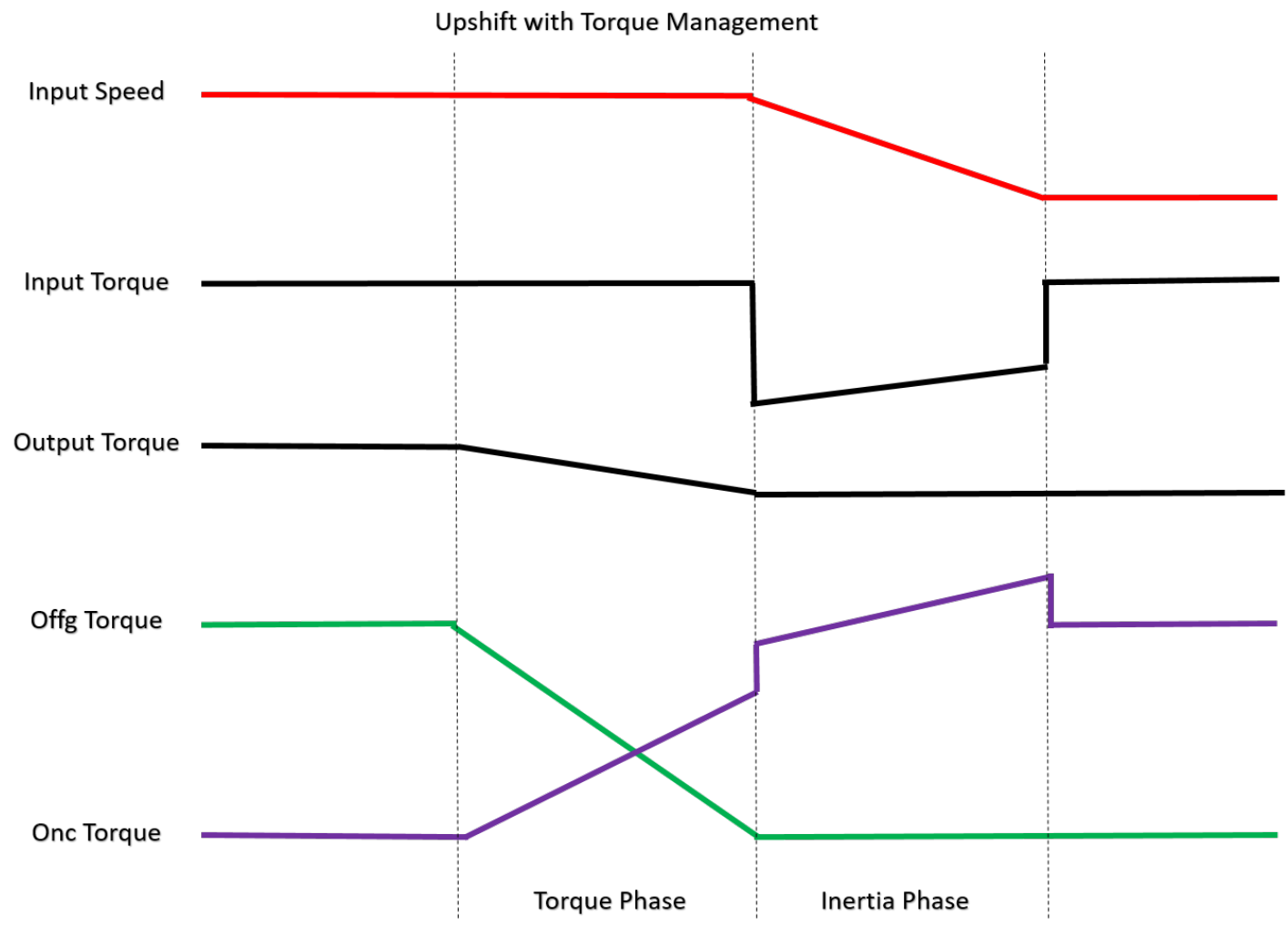

Figure 3-25. Upshift calibration strategy with torque management 
A similar torque management strategy is used for downshifts. The difference is during the inertia phase, instead of an input torque reduction there is a torque increase. By increasing the input torque this helps increase the input speed. Once inertia phase is completed, the input torque returns to the starting torque through the torque phase. Note for vehicle shift calibration the ideal output torque is kept constant throughout for drivability and driver comfort. The output torque was not kept constant for the tests because the more complex torque management strategy could not be replicated well due to the slow response of the dynamometers.

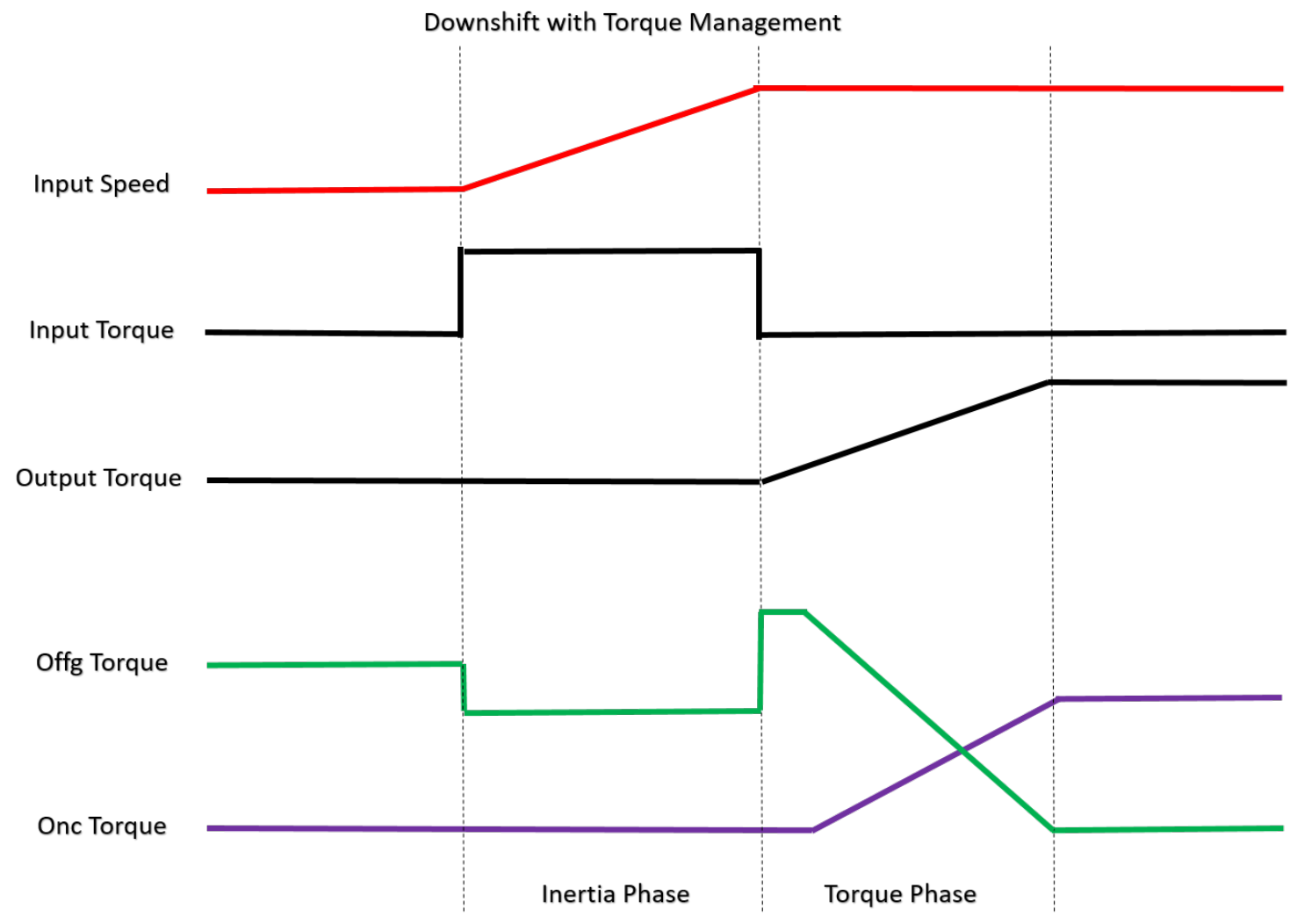

Figure 3-26. Downshift calibration strategy with torque management 


\subsection{Torque Converter Clutch Controls}

The TCC was controlled by using the SOL Commander software. SOL Commander has the capability to do steady state and transient TCC testing. For the scope of this research all TCC testing was done as steady state in released, slipping, or applied. The slipping conditions were determined manually by adjusting the slip between the input and turbine speed until the desired amount of slip was met. The command current needed to get a specific amount of slip under certain load is repeatable and can be used with the transient testing methods that were discussed in previous sections. 


\section{Results}

A variety of test scenarios were completed for this study. A summary of the tests that are presented in the following sections are given in Table 4-1.

Table 4-1. Summary of tests and operating conditions

\begin{tabular}{|c|c|c|c|c|}
\hline \multirow[b]{2}{*}{ Test Name } & \multirow[b]{2}{*}{ Purpose } & \multicolumn{2}{|c|}{ Operating Conditions } & \multirow[b]{2}{*}{$\begin{array}{c}\text { Transmission } \\
\text { Gear State }\end{array}$} \\
\hline & & $\begin{array}{c}\text { Input Dyno } \\
\text { [Speed or Torque } \\
\text { Mode] }\end{array}$ & $\begin{array}{c}\text { Output Dyno } \\
\text { [Speed or Torque } \\
\text { Mode] }\end{array}$ & \\
\hline \multicolumn{5}{|c|}{ Steady State Tests } \\
\hline Zero Load Pressure & \begin{tabular}{|c|} 
To acquire a baseline \\
pressure for each channel \\
without loading effects, only \\
charge and centripetal \\
pressure.
\end{tabular} & $\begin{array}{l}\text { Speed Mode- } \\
500-3000 \text { RPM }\end{array}$ & Freewheeling & 5 th \\
\hline $\begin{array}{c}\text { Control and } \\
\text { Application Pressure }\end{array}$ & $\begin{array}{c}\text { To ensure that a constant } \\
\text { relationship occurs between } \\
\text { control pressure at the } \\
\text { regulator to the application } \\
\text { pressure in the TC }\end{array}$ & $\begin{array}{l}\text { Torque Mode- } \\
20-120 \mathrm{Nm}\end{array}$ & $\begin{array}{c}\text { Speed Mode- } \\
\text { Constant } 400 \text { RPM }\end{array}$ & 6th \\
\hline $\begin{array}{c}\text { TCC Clutch Capacity } \\
\text { and Friction Material } \\
\text { Coeffcient }\end{array}$ & \begin{tabular}{|c|} 
To validate the pressure \\
measurements on the TCC \\
compared to preivious work \\
and design requirements \\
\end{tabular} & $\begin{array}{l}\text { Torque Mode- } \\
20-120 \mathrm{Nm}\end{array}$ & $\begin{array}{c}\text { Speed Mode- } \\
\text { Constant } 400 \text { RPM }\end{array}$ & 6th \\
\hline Centripetal Pressure & $\begin{array}{l}\text { To understand the centripetal } \\
\text { impact on the measurements } \\
\text { and to see how consistent } \\
\text { the centriptal pessure is } \\
\text { across a variety of conditions }\end{array}$ & $\begin{array}{l}\text { Torque Mode- } \\
30-100 \mathrm{Nm}\end{array}$ & $\begin{array}{l}\text { Speed Mode- } \\
\text { 100-400 RPM }\end{array}$ & 5th, 6th \\
\hline $\begin{array}{l}\text { Clutch Pressures } \\
\text { and Force }\end{array}$ & $\begin{array}{l}\text { To visualize the pressure } \\
\text { profile across the TCC and } \\
\text { calculate the resultant force } \\
\text { acting on the TCC }\end{array}$ & $\begin{array}{l}\text { Torque Mode- } \\
30-100 \mathrm{Nm}\end{array}$ & $\begin{array}{l}\text { Speed Mode- } \\
\text { 100-400 RPM }\end{array}$ & 5 th, 6th \\
\hline \multicolumn{5}{|c|}{ Transient Tests } \\
\hline Back Drive & $\begin{array}{c}\text { To understand how an open } \\
\text { TC pressures can fluctuate } \\
\text { when turbine is driving } \\
\text { impeller }\end{array}$ & $\begin{array}{l}\text { Torque Mode- } \\
45 \text { to }-45 \mathrm{Nm}\end{array}$ & $\begin{array}{c}\text { Speed Mode- } \\
\text { Constant } 500 \text { RPM }\end{array}$ & 5 th \\
\hline $\begin{array}{l}\text { Cruising Speed } \\
\text { Power-on Up and } \\
\text { Downshifts }\end{array}$ & $\begin{array}{c}\text { Baseline shift events where } \\
\text { transmission hyrdualics have } \\
\text { enough capacity to feed all } \\
\text { systems properly }\end{array}$ & $\begin{array}{l}\text { Torque Mode- } \\
\quad 30 \mathrm{Nm}\end{array}$ & $\begin{array}{c}\text { Speed Mode- } \\
\text { Constant } 500 \text { RPM }\end{array}$ & 5th-6th \\
\hline $\begin{array}{l}\text { Low Speed Power- } \\
\text { on Up and } \\
\text { Downshifts }\end{array}$ & $\begin{array}{c}\text { To observe possible } \\
\text { hyrdualic deficiencies and } \\
\text { what systems may have } \\
\text { reduced capacity }\end{array}$ & $\begin{array}{l}\text { Torque Mode- } \\
30 \text { and } 100 \mathrm{Nm}\end{array}$ & $\begin{array}{c}\text { Speed Mode- } \\
\text { Constant } 400 \text { RPM }\end{array}$ & 5th-6th \\
\hline
\end{tabular}




\subsection{Steady State}

Steady state testing was conducted to build a base understanding of the systems normal operating conditions. The steady state results provide a datum to compare to the transient tests to see if abnormalities occur and if relations can be connected.

\subsubsection{Torque Converter Performance Validation}

To validate that the torque converter was operating according to specification a performance test was conducted. Speed ratios were tested from 0.1-0.9 by keeping a constant $75 \mathrm{Nm}$ input torque and changing the output speed with the transmission in $5^{\text {th }}$ gear. Figure 4-1 shows the results for the torque converter performance test. The lower solid curve is the K-factor specifications with the tolerance limits shown by dashed lines with the test data overlaid as the gray line with circle markers. The upper curve is the torque ratio using the same formatting as the K-factor for specification and tolerance limits. Both curves are within the tolerance limits so the torque converter was deemed to be operating properly.

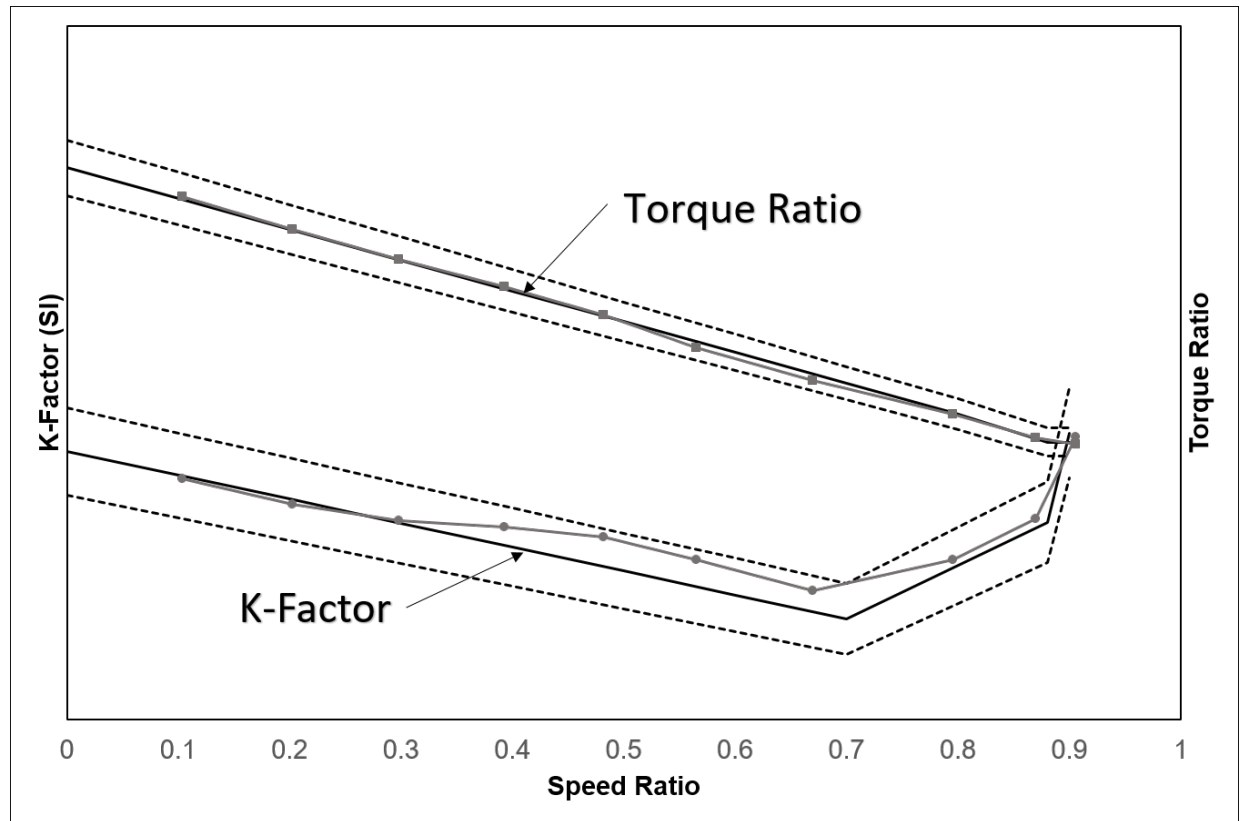

Figure 4-1. Torque converter performance validation 


\subsubsection{Zero Load Pressure}

Determining the pressures of the torque converter when the transmission is in zero load condition provides the baseline for pressure based on charge and centripetal pressure. This baseline can be compared to loaded conditions to compare variations in the pressure. The transmission was placed in neutral with a constant line pressure current command. The input speed was swept from 750-3000 RPM with the output dynamometer freewheeling. Results for TCC released, slipping, and applied can be seen in Figure 4-2, Figure 4-3, and Figure 4-4 for the impeller, stator and turbine respectively. Each figure contains the line and charge pressure where the line pressure is the feed pressure for the whole transmission and the charge pressure is the feed pressure for only the torque converter. As the speed increases so does the pressure which is due to the centripetal pressure change. 


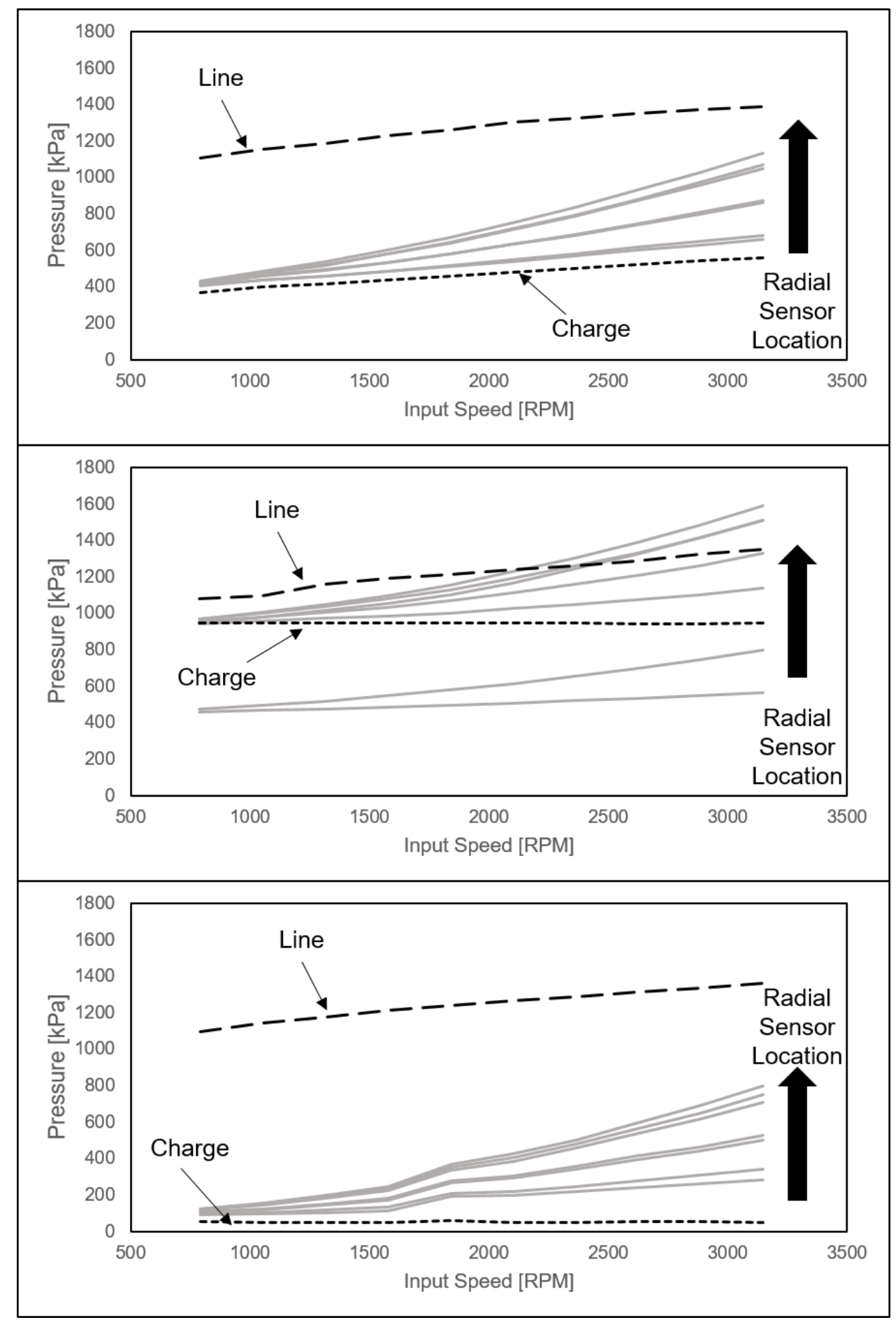

Figure 4-2. Zero load transmission pressure values for impeller and cover: top to bottom- TCC Released, TCC Applied, TCC Slipping 


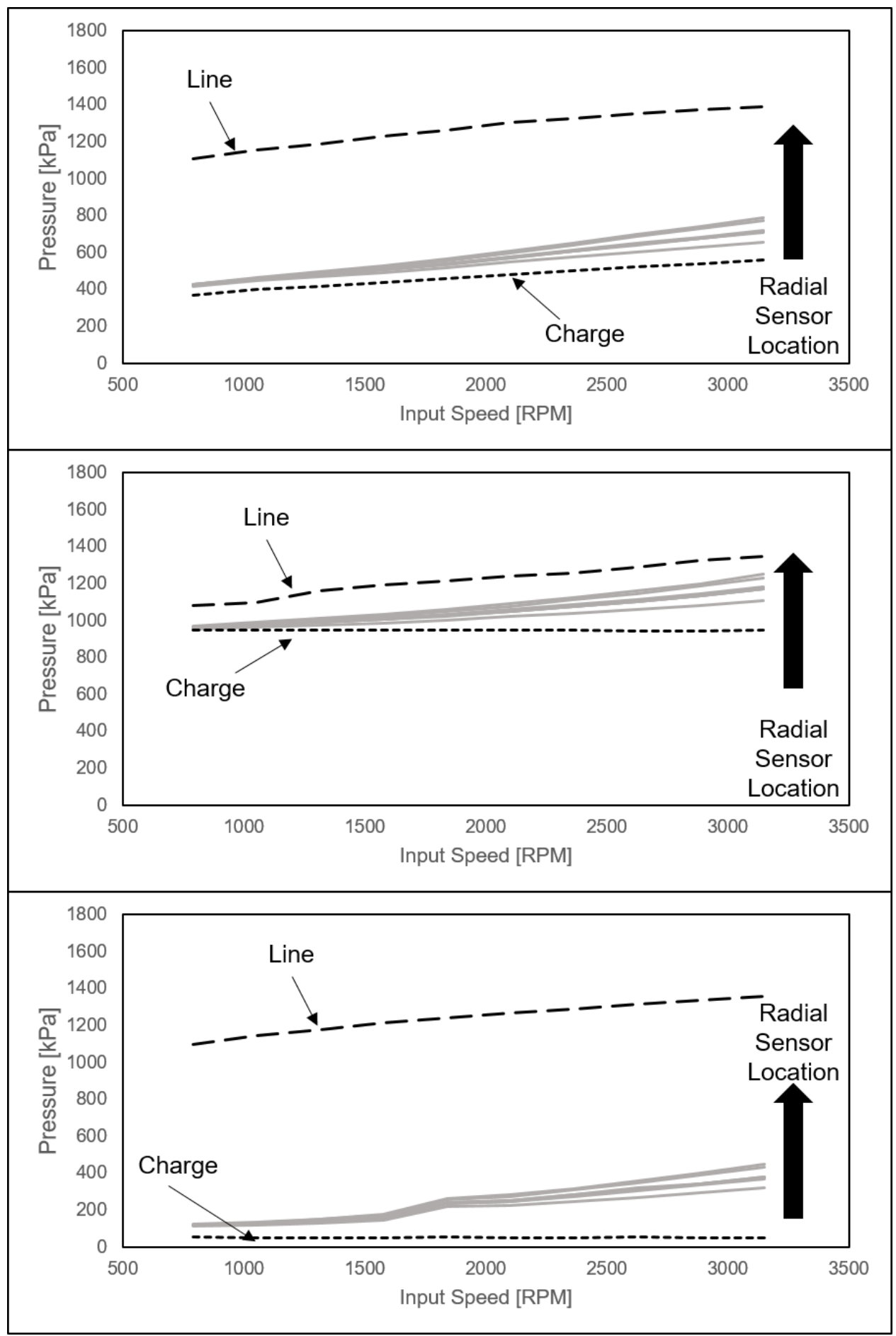

Figure 4-3. Zero load transmission pressure values for stator: top to bottom- TCC Released, TCC Applied, TCC Slipping 


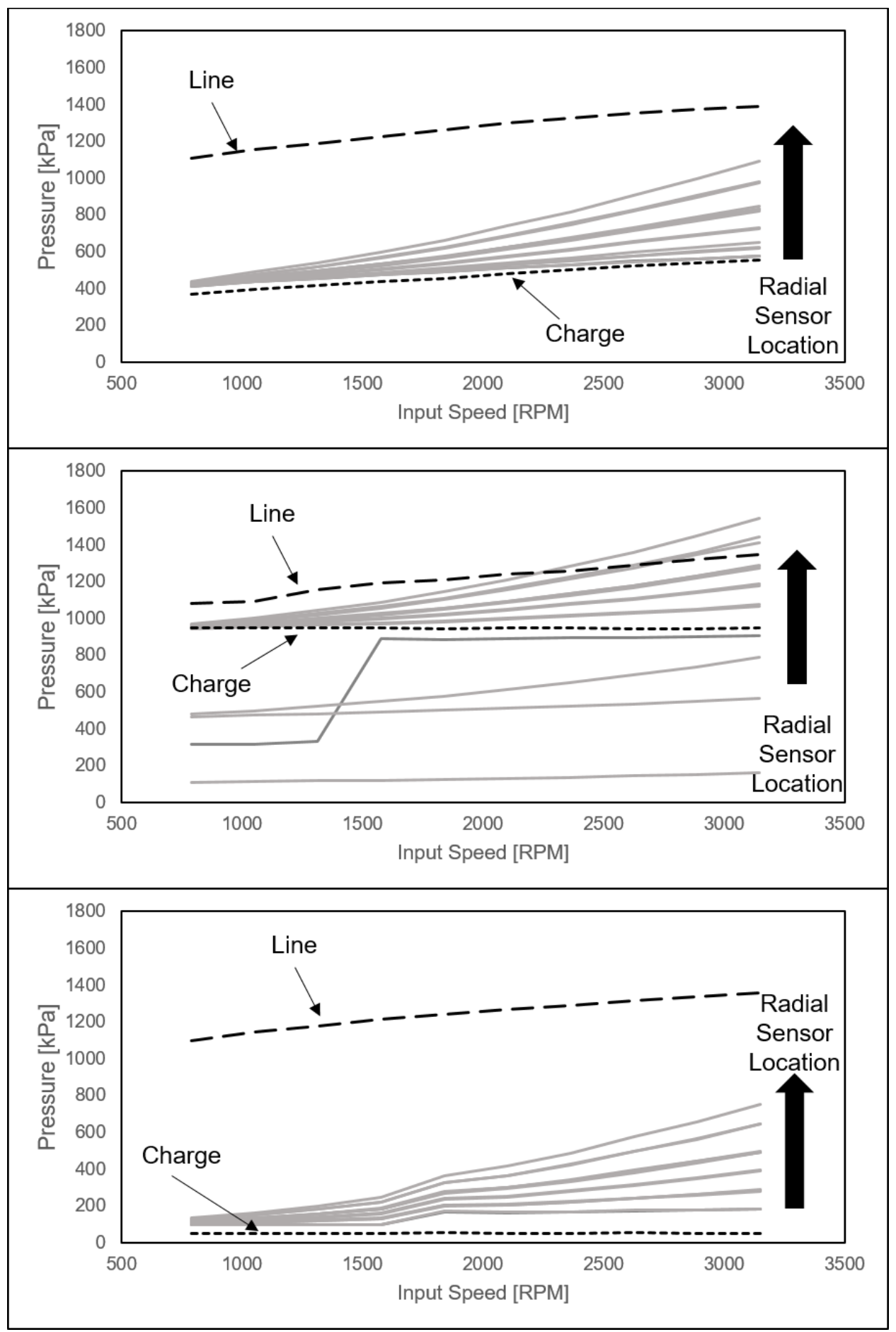

Figure 4-4. Zero load transmission pressure values for turbine and TCC: top to bottom- TCC Released, TCC Applied, TCC Slipping 


\subsubsection{Centripetal Pressure}

A test was done to see how the much variation there is in the charge pressure when running a constant current command instead of a constant pressure. This is of interest because the transmission controls are open looped and have no feedback. Without any feedback the pressure would have to be manually adjusted for each test condition. Figure 4-5 shows the results of the pressure change for line and TCC control as a function of speed. The target line pressure was 1172 $\mathrm{kPa}(170 \mathrm{PSI})$ and was set for 1500 RPM as majority of the testing will occur between 1000-2000 RPM. At 500 RPM the charge pressure is low and this is due the system not having the capability to pressurize the torque converter. This is not a concern because this is below idle speed of an engine and will not be an area of testing.

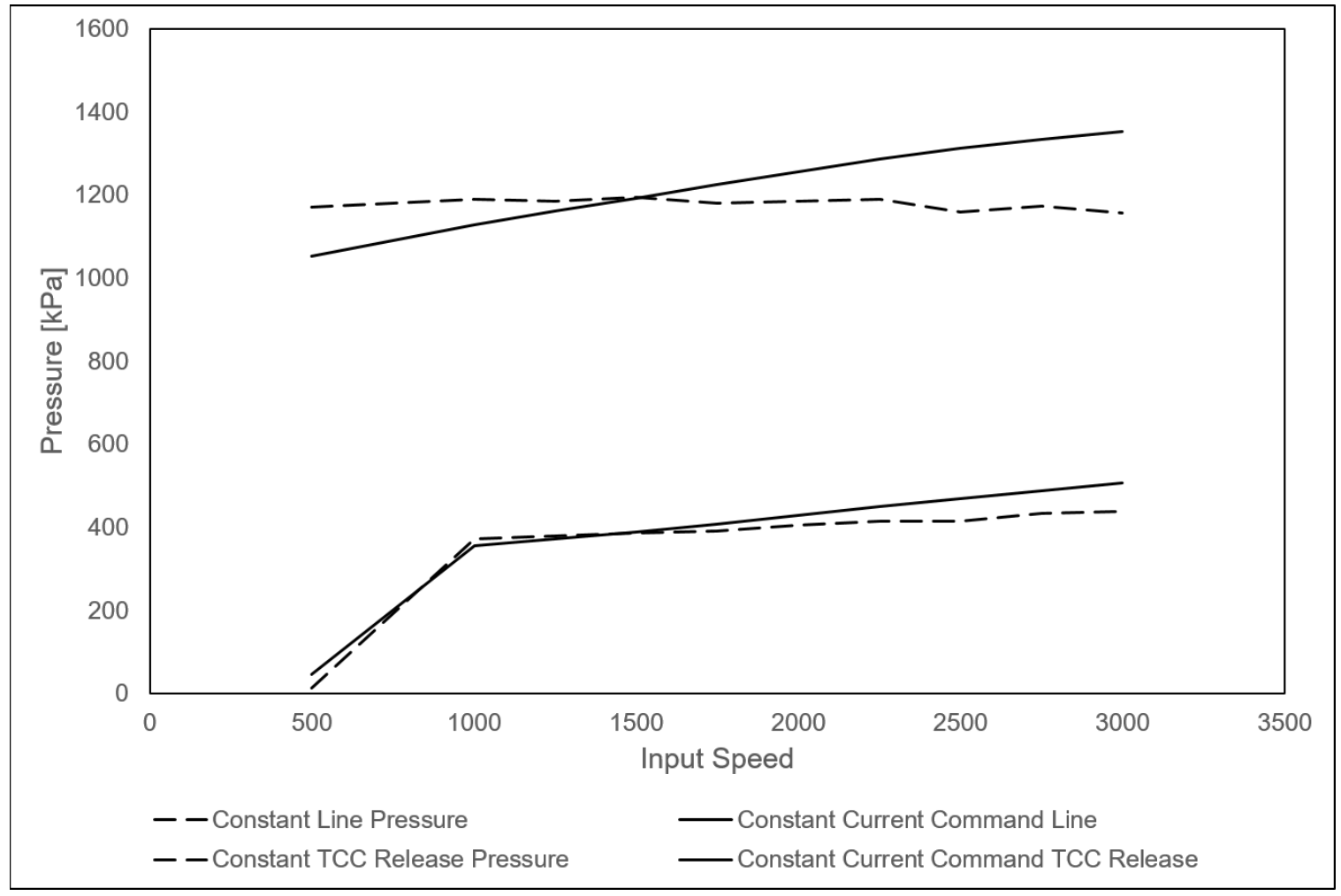

Figure 4-5. Line (top) and TCC control (bottom) pressures 
To normalize the data, the charge pressure was removed to show the centripetal component of the pressure. Figure 4-6 is an example of how the centripetal pressures are radially and speed dependent. The larger the radial location and speed the higher the centripetal pressure. This trend follows for all other sensors on the stator, turbine, and TCC.

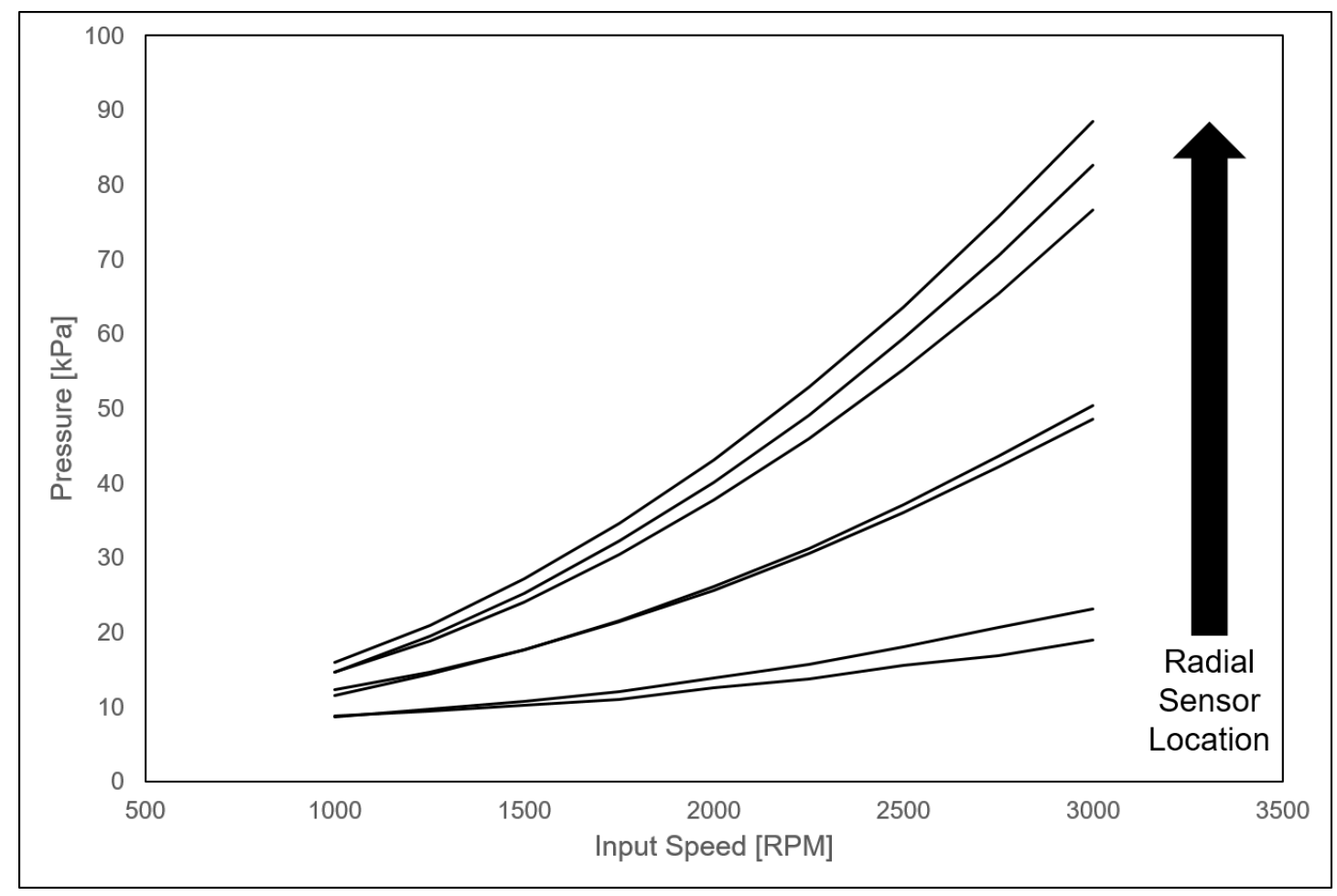

Figure 4-6. Centripetal pressure for each impeller and cover channel

\subsubsection{Centripetal Pressure Calculation and Accuracy}

The centripetal pressure was calculated using Equation 4-1 and Equation 4-2. Equation 4-1 calculates the pressure at each radius based on the oil density $\rho$, radial location $r$, oil feed starting radius $r_{0}$, charge pressure $P_{\text {charge, }}$ and the angular velocity $\omega$. The angular velocity is calculated using Equation 4-2 where $\mathrm{N}$ is rotational speed in revolutions per minute. Note that the angular velocity and radial location are squared which is seen in the centripetal pressure results seen in Figure 4-6. 


$$
\begin{array}{cc}
P(r)=\frac{1}{2} \rho \omega^{2}\left(r^{2}-r_{o}^{2}\right)+P_{\text {charge }} & \text { Equation 4-1 } \\
\omega=N * \frac{2 \pi}{60} & \text { Equation 4-2 }
\end{array}
$$

A pressure was calculated for each instrumented location and compared to the test results. The associated error for each channel can be seen in Figure 4-7. In summary the calculated pressures are within $\pm 15 \%$ of measured value. The errors show an underestimate in pressure at lower speeds and overestimate in pressure at higher speeds. This calculation can be used for initial design to give estimate pressures because of how quick results can be calculated. For final designs a more technical model should be used for final pressure values. This equation will be used as a comparison in later analyzes as a design comparison.

It is important to note that these calculations are valid for when the torque converter is operating past the coupling point and not in torque multiplication mode. In torque multiplication there are additional fluid dynamics that contribute to the pressure. 


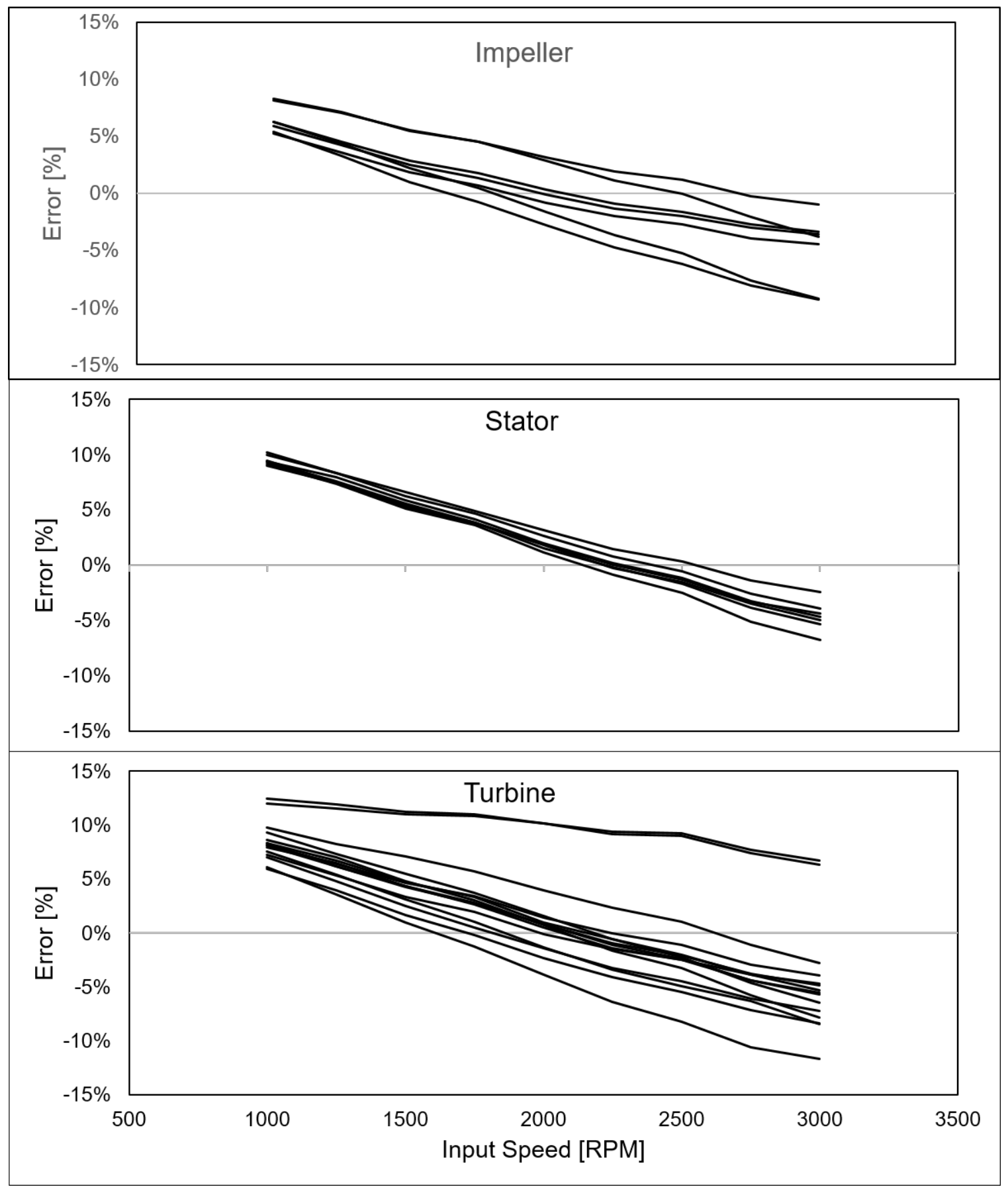

Figure 4-7. Calculation error for each channel compared to test results 


\subsubsection{TCC Control and Charge Pressure}

A study was conducted to characterize the interaction of the TCC control pressure and the pressures seen in the torque converter. This test was completed with the TCC slipping at a constant 20 RPM varying input torque from $20-120 \mathrm{Nm}$ and a constant output speed of 400 RPM in $6^{\text {th }}$ gear. The test showed that the torque converter internal pressure is constant in relationship to the charge pressure at a constant output speed. This was done as a validation study to ensure that the understanding of how the torque converter may vary was recorded. The results for all three transmitters are shown in Figure 4-8, Figure 4-9, and Figure 4-10 are the results of the measured pressure minus the charge pressure for the impeller/cover, stator, and turbine/TCC respectively. The dashed lines are the channels that are in the torus or between the TCC and turbine shell. The solid lines are the channels between the TCC and cover. The results show that the dashed line pressures have a constant centripetal pressure across the range of charge pressures, while the solid line pressures decrease. This is due to the charge pressure is only seen by the dashed line channels because the TCC is applied cutting off the charge pressure from the solid line pressures. Since the charge pressure increases a larger difference is seen when compared to the solid line pressures. 


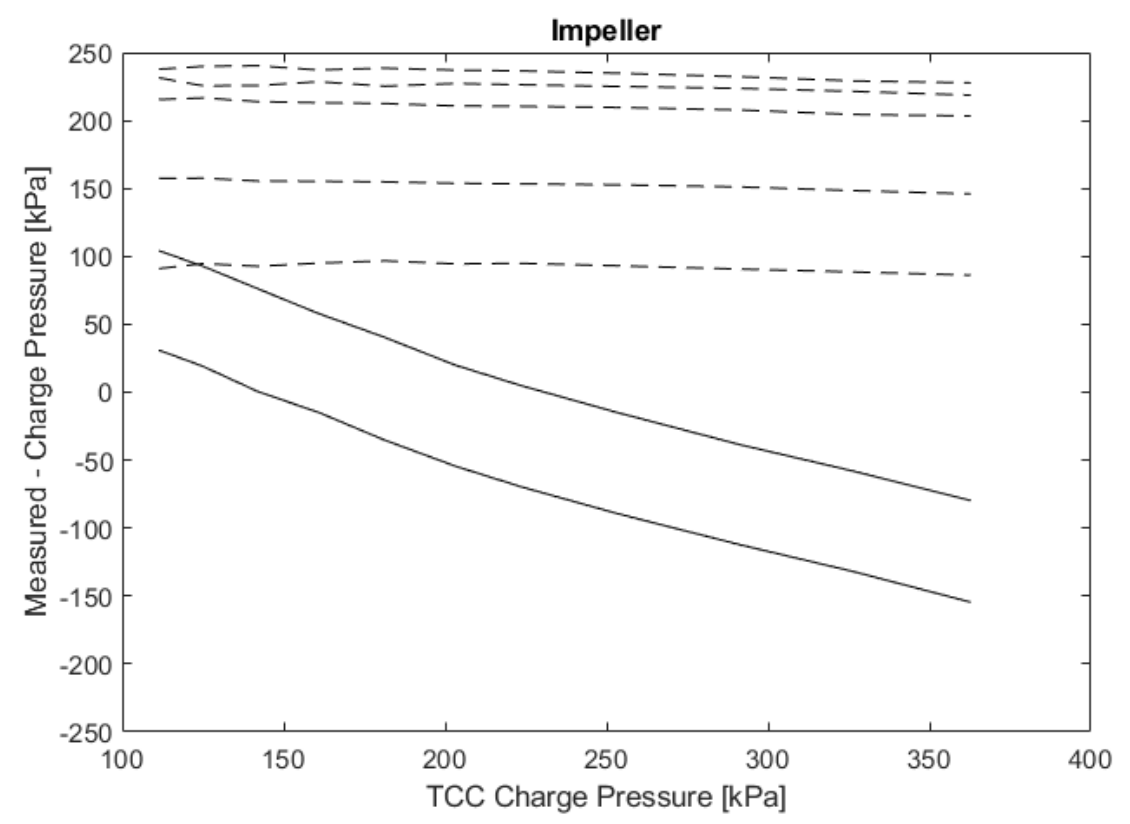

Figure 4-8. Impeller and cover centripetal pressures across multiple TCC control pressures

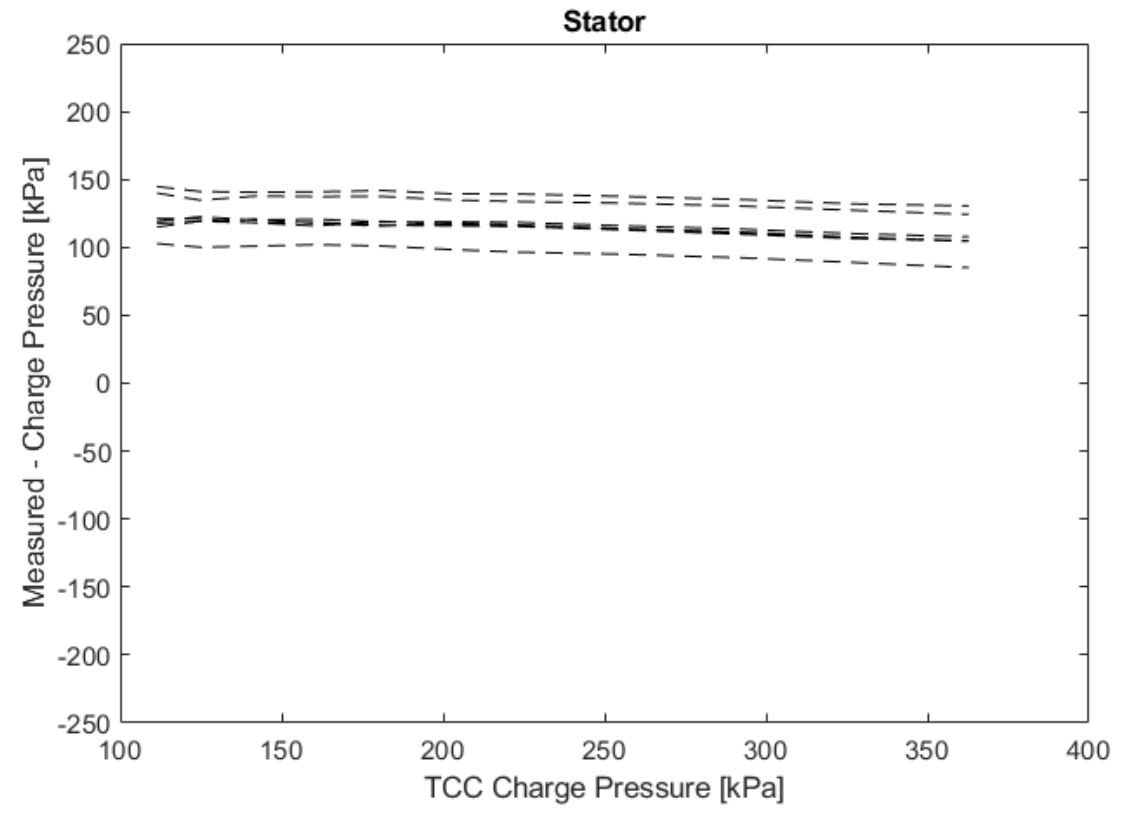

Figure 4-9. Stator centripetal pressures across multiple TCC control pressures 


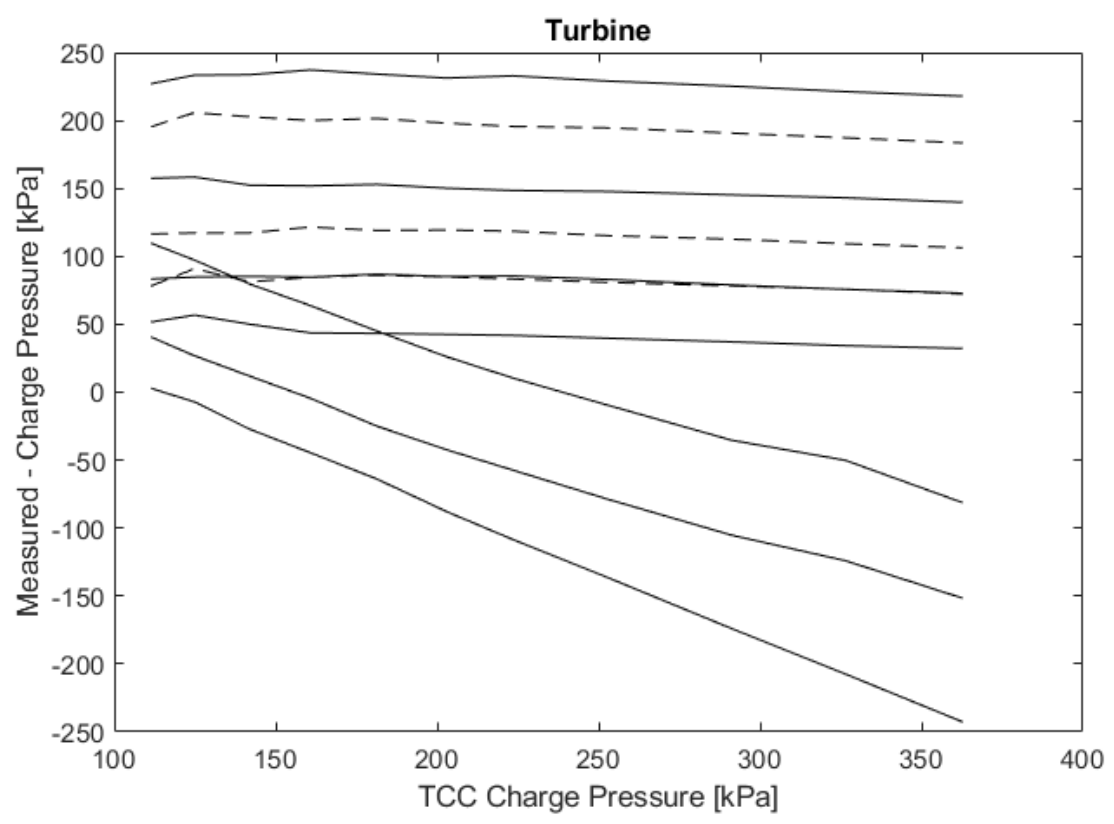

Figure 4-10. Turbine and TCC centripetal pressures across multiple TCC control pressures

\subsubsection{Torque Converter Clutch Capacity and Friction Material Coefficient}

Testing the TCC capacity and friction material coefficient was of interest to characterize the TCC in comparison to other literature and design parameters. The TCC capacity should have a linear trend, so as the charge pressure increases so does the amount of torque the clutch can transmit. This was tested by sweeping input torque from $20-120 \mathrm{Nm}$ with a constant output speed of $400 \mathrm{RPM}$ in $6^{\text {th }}$ gear. The charge pressure was increased until the clutch begins to drive the input speed down. Figure 4-11 shows the results of the clutch capacity test and how there is a linear correlation between charge pressure and clutch capacity. 


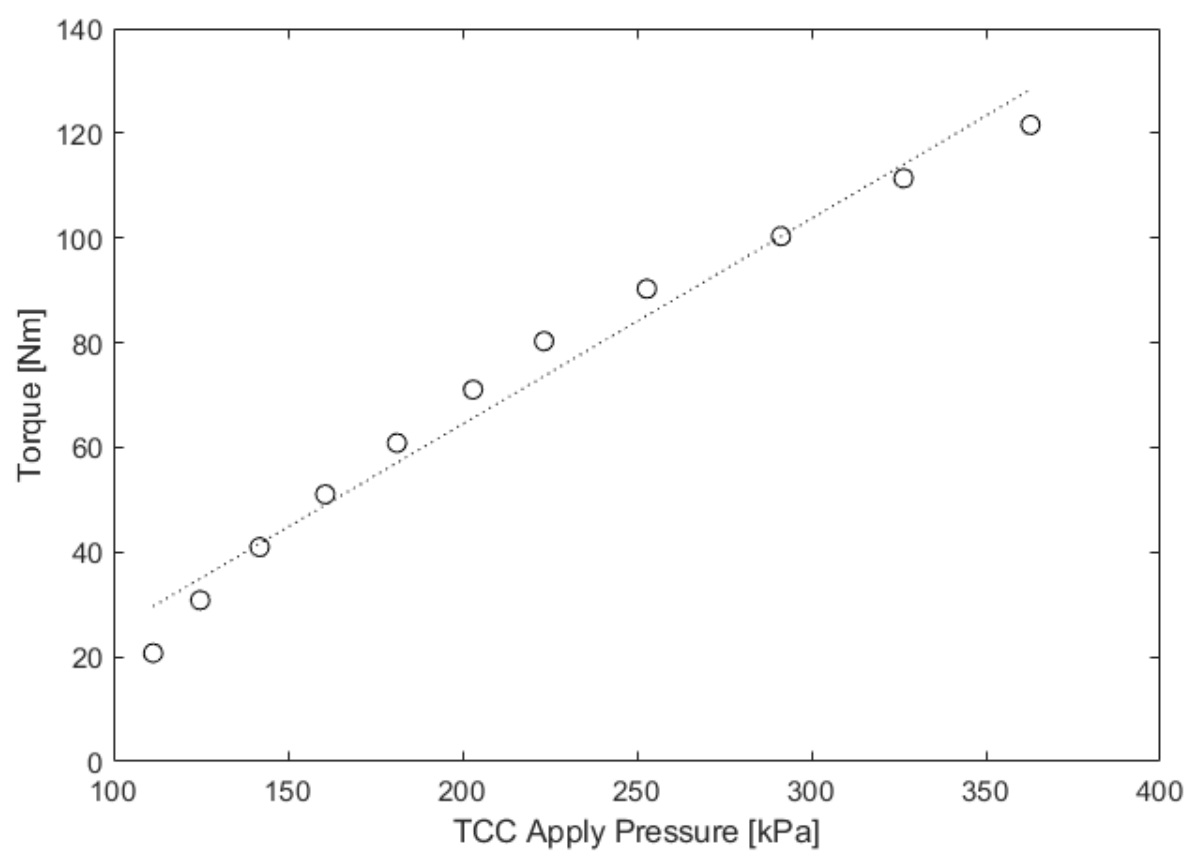

Figure 4-11. Torque converter clutch capacity

This agrees with [4] when slip across a frictional clutch is small there is a linear correlation to the capacity. This can be explained by Equation 4-3 were $T$ is torque capacity, $p$ is pressure across the surface, $\mu$ is friction coefficient of friction material, $r$ is radius along the surface, integrated between $r_{0}$ outer radius and $r_{i}$ inner radius. There is a linear correlation between torque capacity and pressure.

$$
T=\int_{r_{i}}^{r_{o}} 2 \pi p \mu r^{2} d r \quad \text { Equation 4-3 }
$$

The friction coefficient for the TCC was determined by running three different tests to cover the areas of operation for a TCC. The TCC was tested during slip of 5-10 RPM, when the clutch begins to make contact with the cover and pull the input speed down, and when the clutch is disengaging from the cover and releasing torque capacity. The friction coefficient was calculated by using Equation 4-3 and then averaged for each condition. The friction coefficient for the TCC was found to be an average of 0.19 , which is in the range for possible friction coefficients of paper material [45]. 
Table 4-2. Friction coefficient estimates for TCC friction material

\begin{tabular}{|c|c|}
\hline Test Condition & Friction Coefficient \\
\hline Slip 5-10 RPM & 0.0605 \\
\hline Start of Contact with Cover & 0.3132 \\
\hline Releasing Contact with Cover & 0.2057 \\
\hline
\end{tabular}

\subsubsection{Clutch Pressures and Forces}

The clutch pressures across the TCC, channels 5-11, were used to determine the resultant force acting on the TCC during slipping and applied conditions. A quadratic curve fit was applied to the pressure measurements on each side of the TCC. The pressures were subtracted between the front and rear of the TCC to get a pressure profile representing the acting pressure across the clutch. An example pressure profile can be seen in Figure 4-12 with the circles representing the pressure measurements with the dotted line being the curve fix to the data. The dashed line is showing the resulting pressure profile across the clutch with the solid lines indicating the location of the friction material. It is assumed that the pressure across the friction material is negligible because only a small amount of ATF can travel across the friction material.

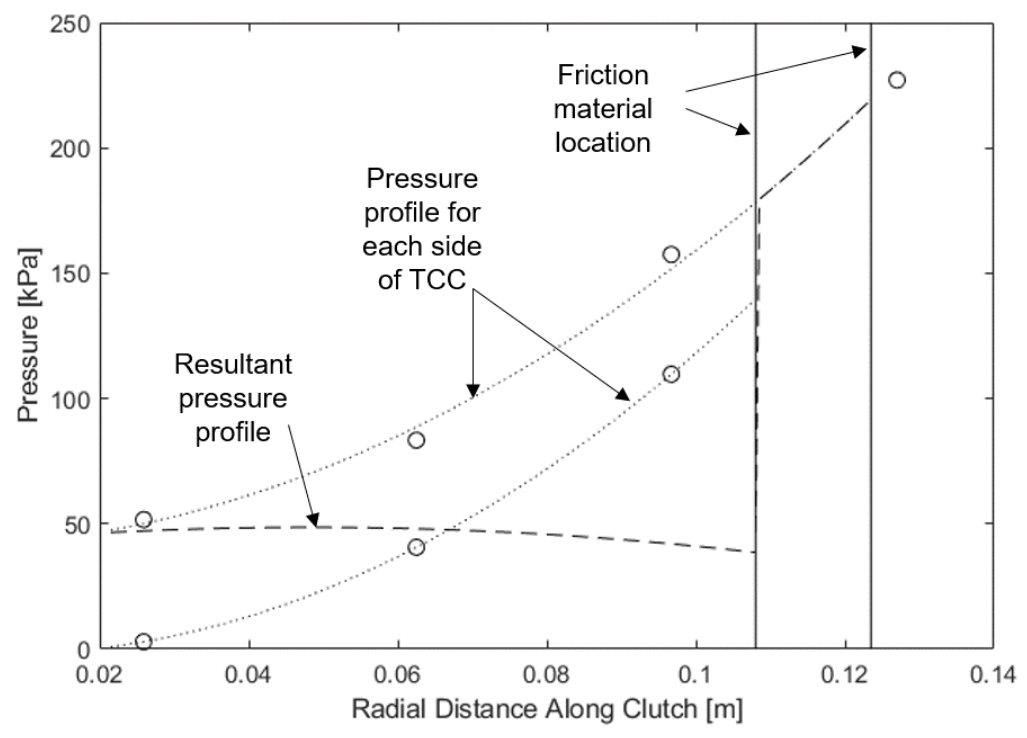

Figure 4-12. Pressure profile across TCC 
The force due to pressure is calculated at each radius along the clutch by using Equation 4-4. Equation 4-4 uses all the same parameters as Equation 4-1 above.

$$
F(r)=\pi r^{2}\left[\rho \omega^{2}\left(\frac{r^{2}}{4}-\frac{r_{o}^{2}}{2}\right)+P_{i n t}\right]
$$

An example force profile is given in Figure 4-13 with the dashed line showing the force profile and the solid line is where the resultant force is acting. The resultant force is where there is an equal amount of force on each side of the line.

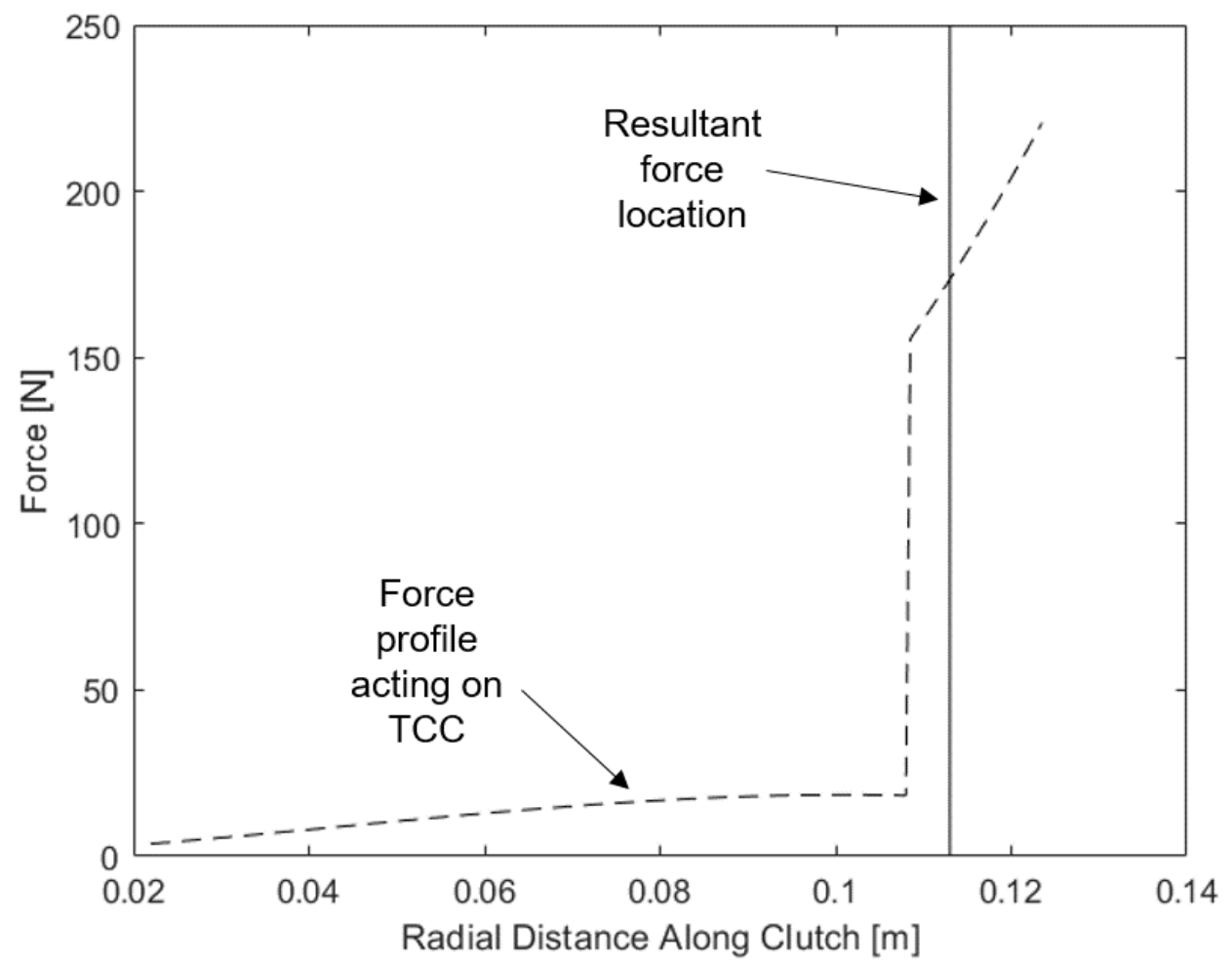

Figure 4-13. Force profile across TCC

The pressure profiles and resultant force were measured at 30 and $100 \mathrm{Nm}$ in $6^{\text {th }}$ gear across $300-500$ RPM. The results are illustrated by an example graphic shown in Figure 4-14 with a summary on interpretation listed below. 


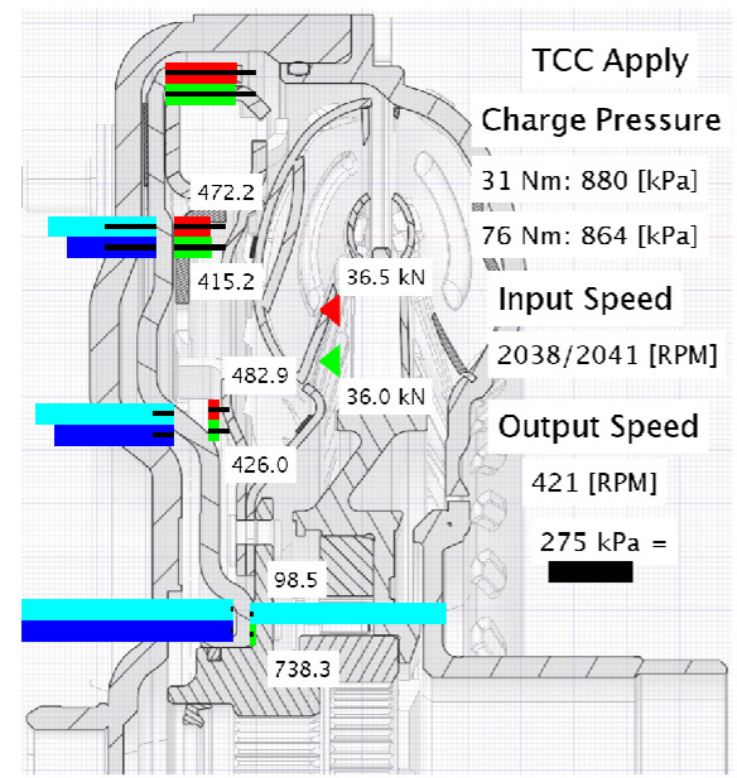

Figure 4-14. Pressure and resultant force acting on TCC example graphic

\section{- Colored Bars}

- All pressures are relative to charge pressure

- Sensor pressure - charge pressure $=\Delta P$

- Positive Pressure $(+\Delta \mathrm{P})$

- Red-30 Nm input torque (low load)

- Green- $100 \mathrm{Nm}$ input torque (medium load)

- Negative Pressure $(-\Delta \mathrm{P})$

- Cyan- $30 \mathrm{Nm}$ input torque (low load)

- Blue -100 Nm input torque (medium load)

- Text next to color bar

- Shows value for $\Delta \mathrm{P}$ between each side of clutch plate

- Black color bars

- Calculated pressure at each sensor location based on input speed and charge pressure

- $275 \mathrm{kPa}(40 \mathrm{PSI})$ reference bar in right bottom corner for scale comparison

- Colored Arrows

- Shows location of resultant force with magnitude

- Red- low load

- Green - medium load

- Text on Right

- Provides operating conditions of test 
Clutch pressures and resultant force were measured for with the TCC released, slipping $20 \mathrm{rpm}$, and applied. Figure 4-15 show the results for TCC released. Looking at the pressures between the front and back of the clutch, the pressures are equally opposed causing the clutch to be open. This is expected and the resultant forces mean nothing in the case of TCC released because the clutch is not touching the cover.

In the case when the TCC is applied the resultant force location is of importance. When the TCC is applied, the pressures on the front of the clutch have a lower pressure than the charge pressure. Since the TCC is applied the input speed is decreased, compared to the TCC released case, and has less centripetal pressure impact. There is also a large pressure difference across the clutch causing the TCC to be applied. The resultant forces were found to be located towards the center of the TCC with similar magnitudes of application force. This shows that since the charge pressures were the same the input torque has no impact on the resultant force. The results can be seen in Figure 4-16

The area of really interest is when the TCC is slipping because minor changes in operating points and charge pressure can have a large impact on TCC slip. Remember the goal is to apply the clutch as quickly as possible while also maintaining good drive quality with low $\mathrm{NVH}$. By having the TCC slip the clutch can be partially applied through changing operating conditions, such as gear shifting. Figure 4-17 show the results for the TCC slipping 20 RPM. The charge pressure changes from $103.4 \mathrm{kPa}$ (15 PSI) for low loads to $262 \mathrm{kPa}$ (38 PSI) for medium loads to be able to handle the higher torque capacity. This causes a large pressure difference across the clutch for the medium loaded case compared to the low load. For the medium load case the resultant force is located at the center of the clutch, like when the TCC is applied, but the low load case shows that the resultant force is located at a large radius. By using the friction coefficient found from above the torque capacity of the clutch for each force is found to be equal to the 30 and 100 
$\mathrm{Nm}$ input torque. The thing of interest is that if the resultant force is located a larger radius and moves when a larger torque occurs there will be a delay for the transition and slip control may fluctuate. Further analysis is required to understand the possible impacts.

Additional cases were completed in $5^{\text {th }}$ gear showing similar results as in $6^{\text {th }}$ gear drawing the same conclusions. The $5^{\text {th }}$ gear results can be seen in Appendix $\mathrm{K}$ along with the raw data values for each case. 

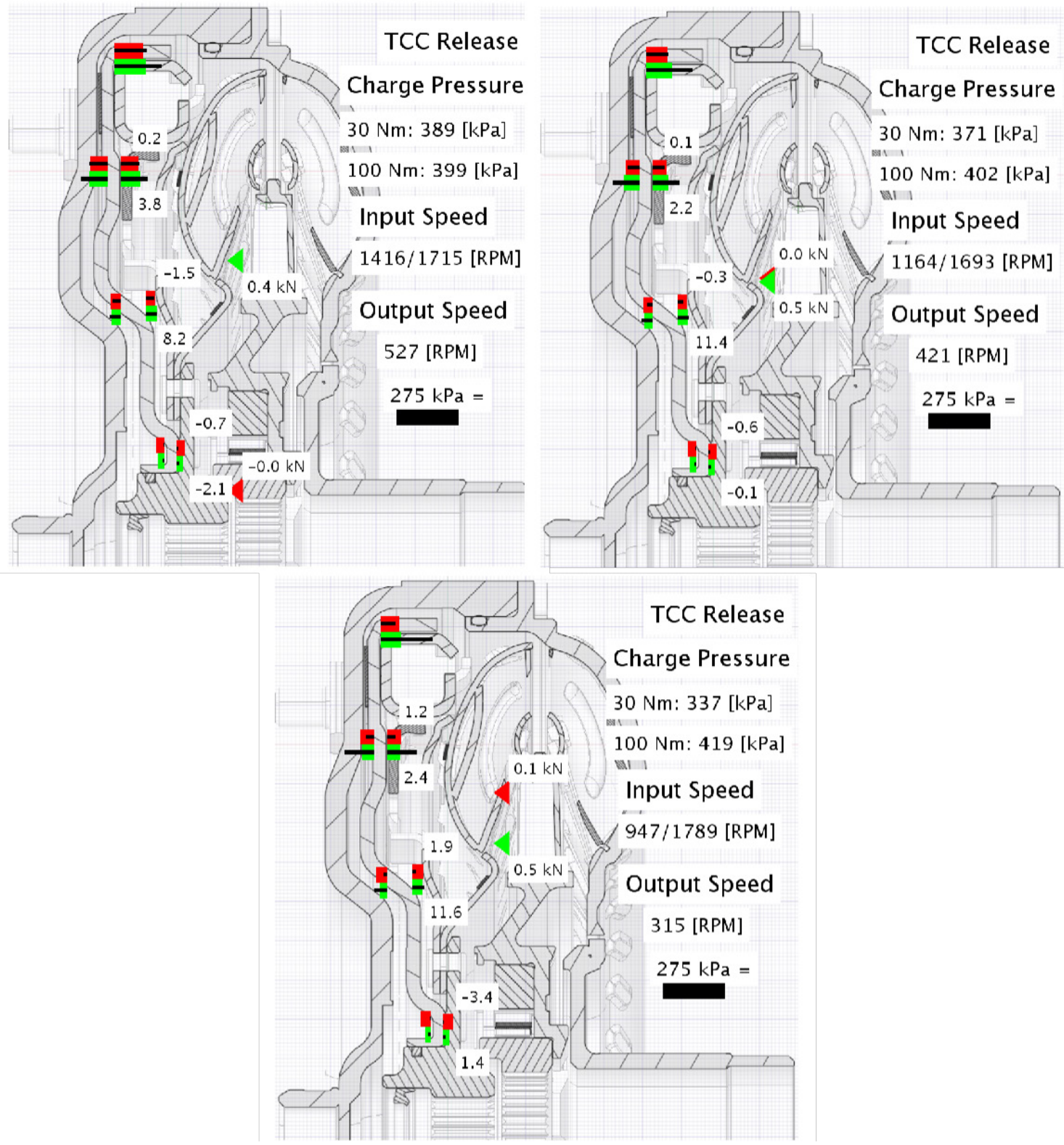

Figure 4-15. Pressure across TCC and resultant force for TCC released 


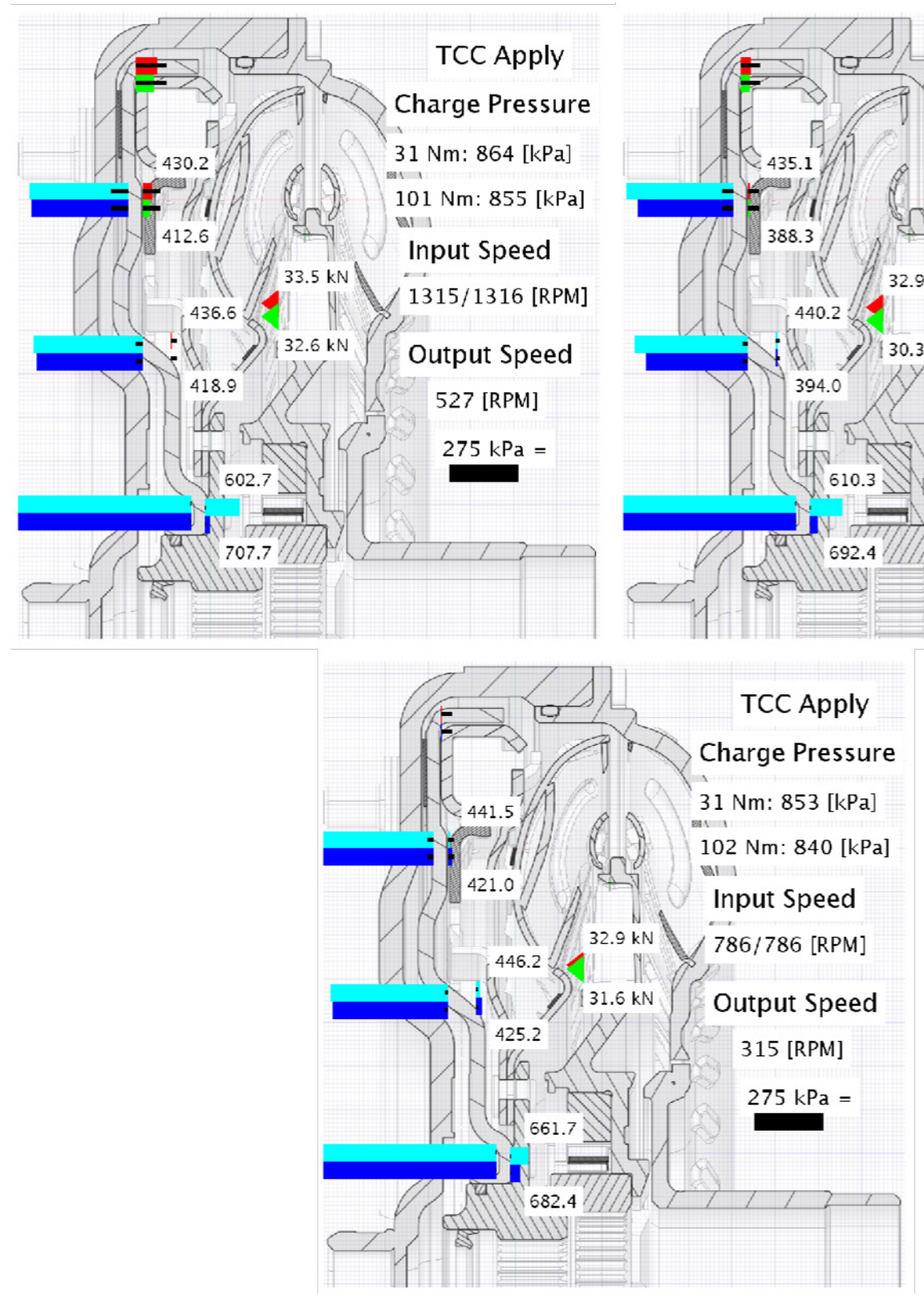

Figure 4-16. Pressure across TCC and resultant force for TCC applied 


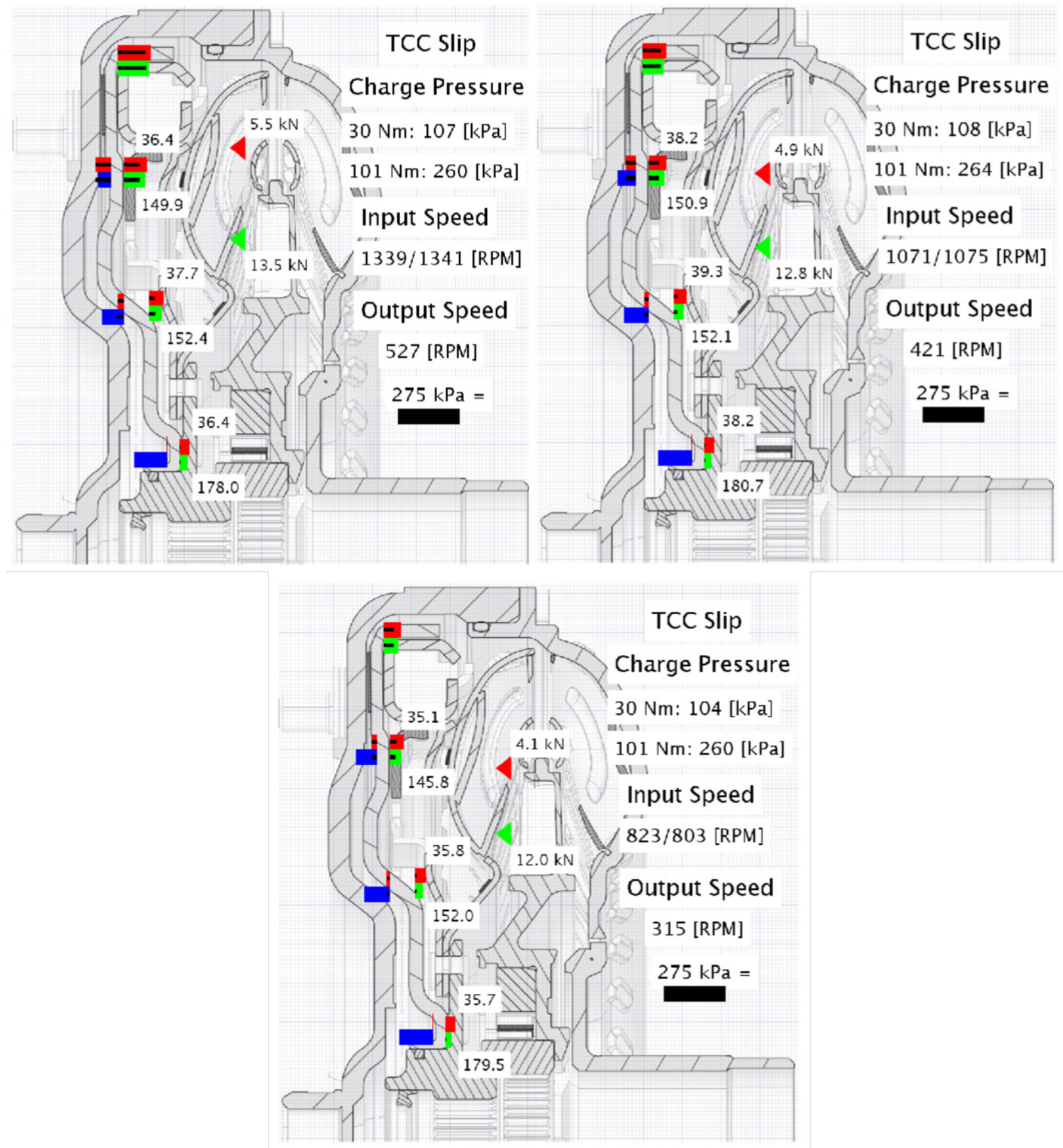

Figure 4-17. Pressure across TCC and resultant force for 20 RPM slip 


\subsection{Transient}

Transient events are the main interest in this study because controllability of transient events can be challenging. By increasing the knowledge about a transient event better calibration or hardware design can be implemented. Two main transient events were studied: back driving the transmission and gear shifting.

\subsubsection{Back Drive}

Back drive was completed with the TCC released with the input torque sweeping between 45 to $-45 \mathrm{Nm}$ with a constant output speed $550 \mathrm{RPM}$ in $5^{\text {th }}$ gear. The back drive tests used the transient testing methodology described in chapter 3. Methods. Figure 4-18 and Figure 4-19 show the test conditions for the 45 to -45 $\mathrm{Nm}$ sweep scenario and the resulting speed ratios throughout the test respectively. Back drive tests were also completed for 35 to $-35 \mathrm{Nm}, 25$ to $-25 \mathrm{Nm}$, and 15 to $15 \mathrm{Nm}$ sweeps. The torque levels used are low to represent the back drive scenario where the engine is not driving or creating small amounts of torque.

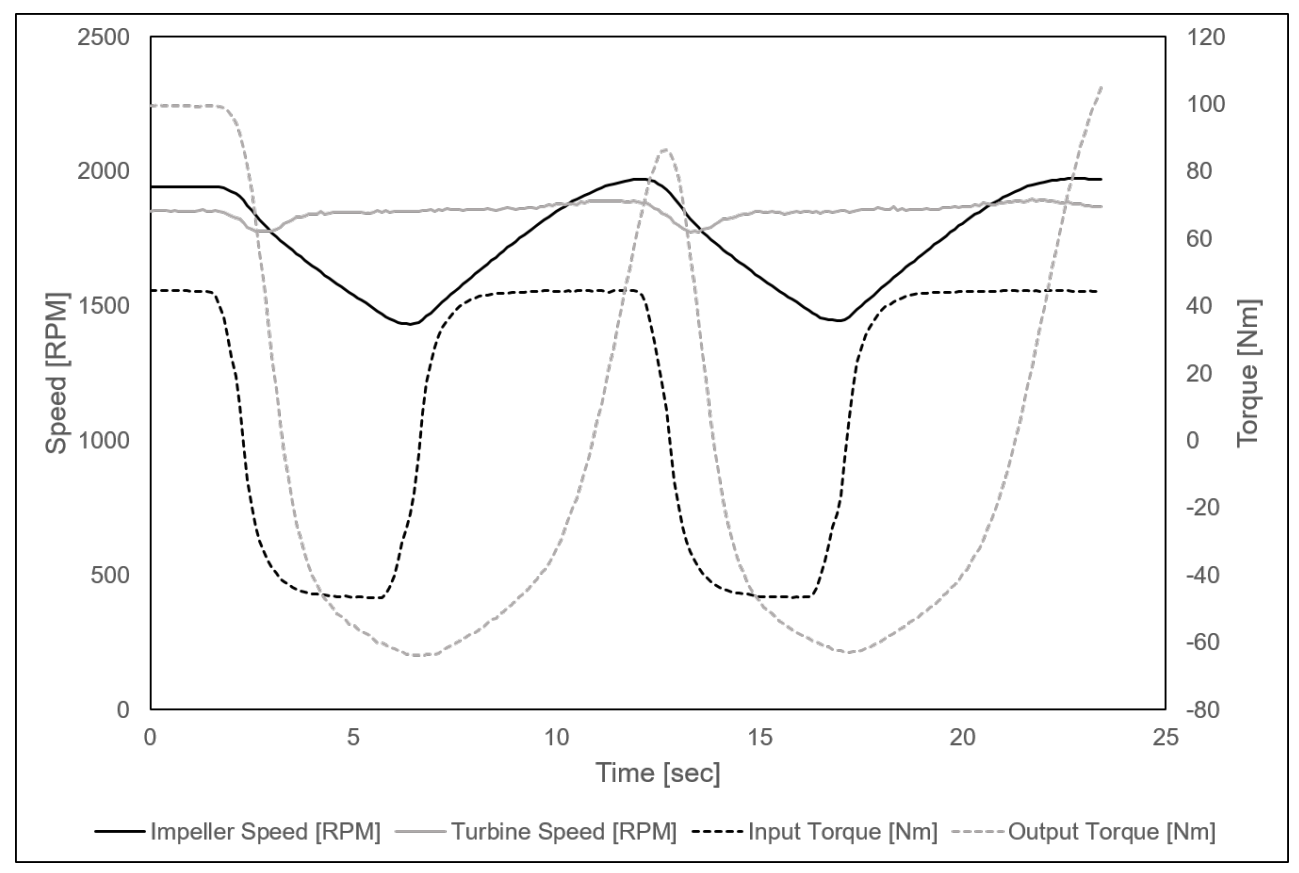

Figure 4-18. 45 to $-45 \mathrm{Nm}$ test scenario for back drive 


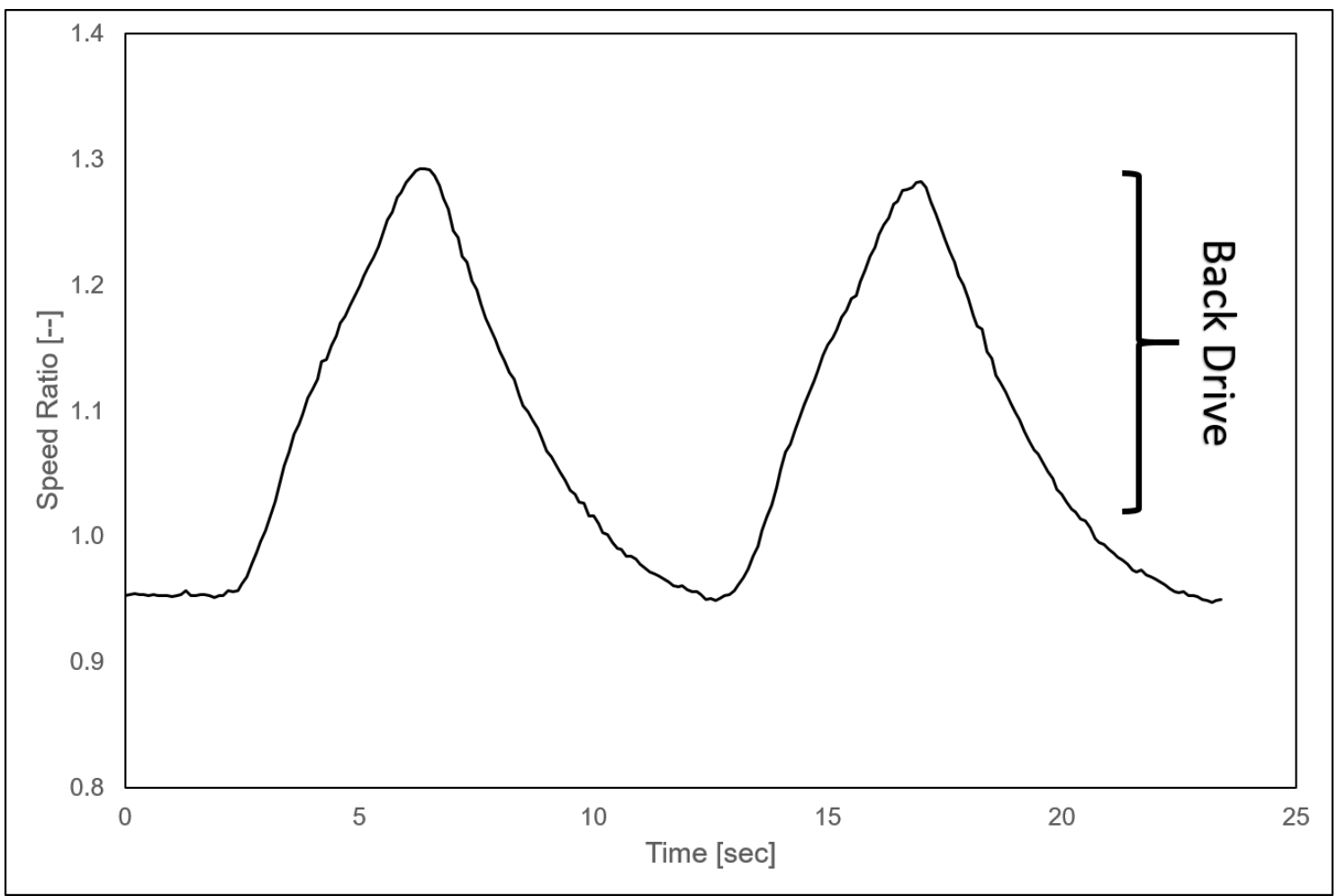

Figure 4-19. Speed ratio achieved during 45 to $-45 \mathrm{Nm}$ test

The stitched time histories for the 45 to $-45 \mathrm{Nm}$ for the impeller/cover, stator, turbine, and TCC are given in Figure 4-20, Figure 4-21, Figure 4-22, and Figure 4-23 respectively. Each channel's time history has arrows pointing to the sensor's location in the torque converter. The gray areas on the time history plots represent the time when the input torque is negative. The pressures in the impeller, turbine, and TCC see a decrease in pressure as the speed ratio increases from 0.95 to 1.3 while the pressure on the stator increases. The reason for increased pressure across the stator will be explained in a later section. 


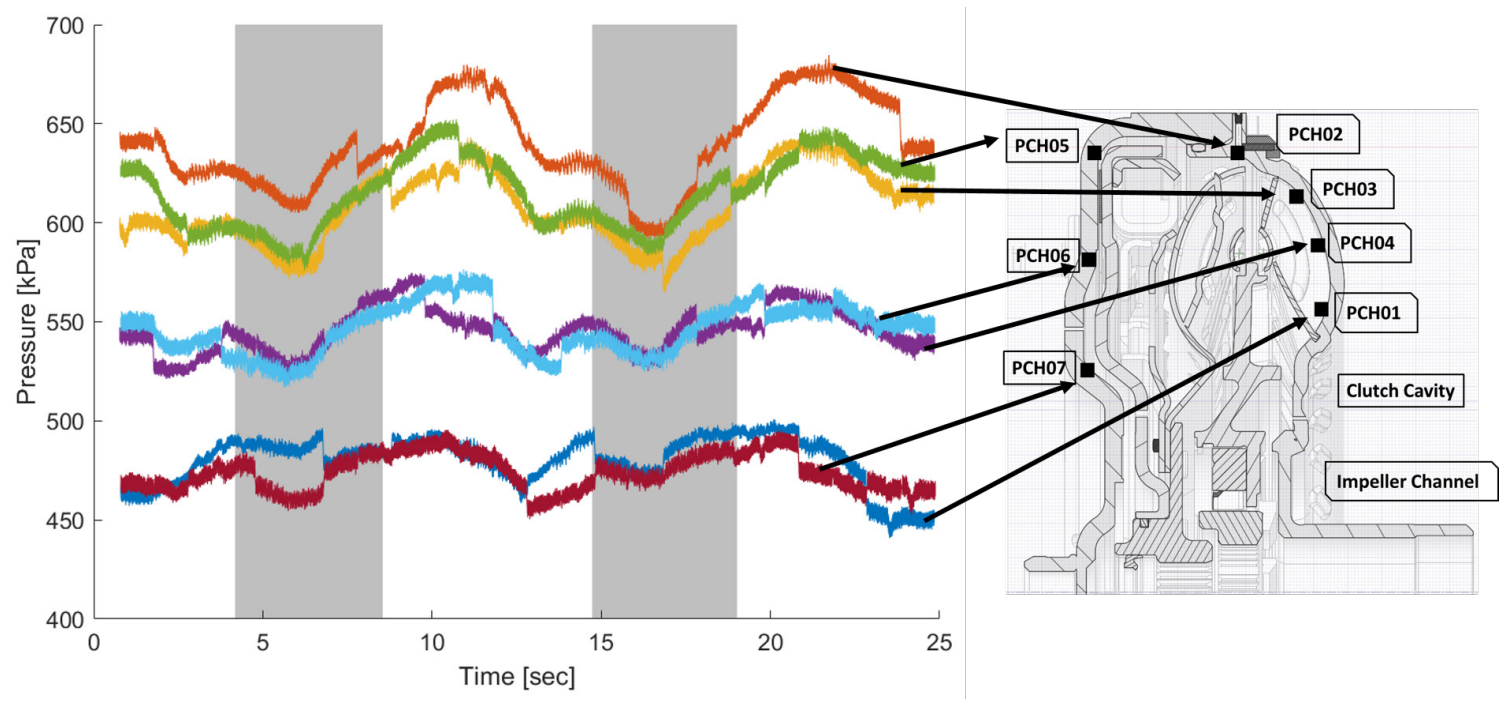

Figure 4-20. Back drive stitched time history for impeller and cover channels

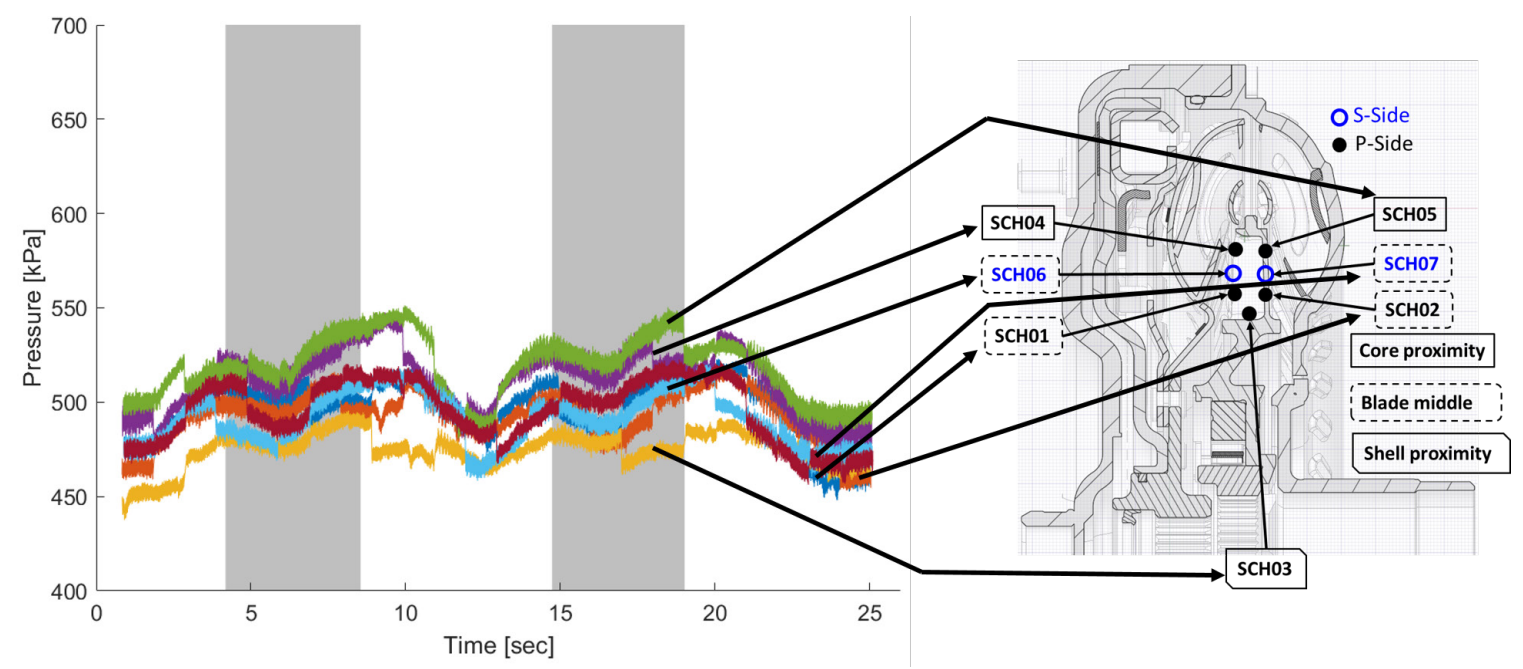

Figure 4-21. Back drive stitched time history for stator channels 


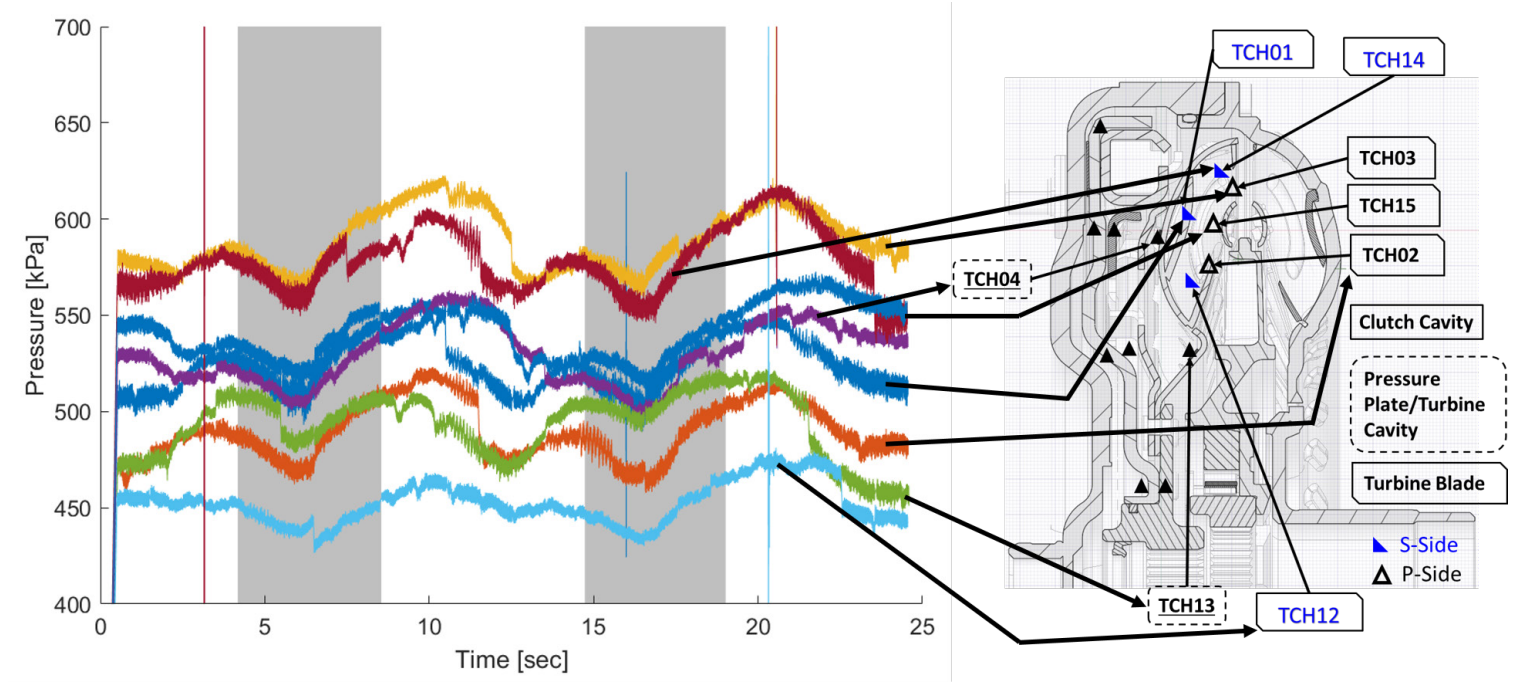

Figure 4-22. Back drive stitched time history for turbine torus and clutch cavity channels

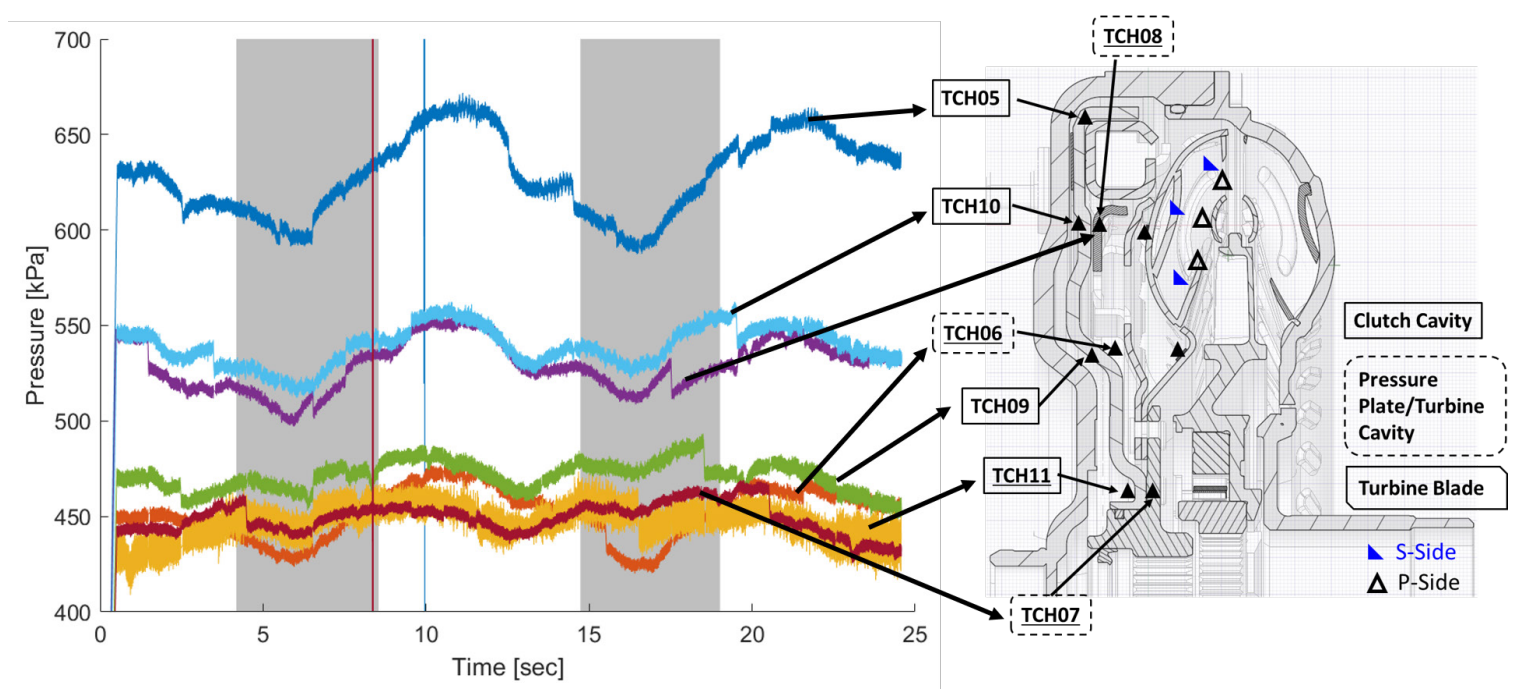

Figure 4-23. Back drive stitched time history for torque converter clutch channels

The pressures were pulled from the time history at speed ratios of $0.98,1.1$, and 1.2 and the mean pressures at each speed ratio were averaged for both positive and negative torques. This was done for all torque sweeps and complied for each channel to show the change in pressure across positive and negative torques. Figure 4-24, Figure 4-25, and Figure 4-26 are channels from the impeller, stator, and turbine respectively that were selected to show the effects at each location 
through the torque converter. Each graph is split up for each speed ratio and for a reference the neutral pressure for TCC open are shown on the right. The neutral pressures provide a range of how much the input speed can affect the pressure at that location. The impeller and turbine show how the pressure decreases as the speed ratio increases and as the torque decreases. The stator shows the opposite where the pressure increases slightly as speed ratio increases but no change is seen based on torque. The results for each channel can be seen in Appendix L.

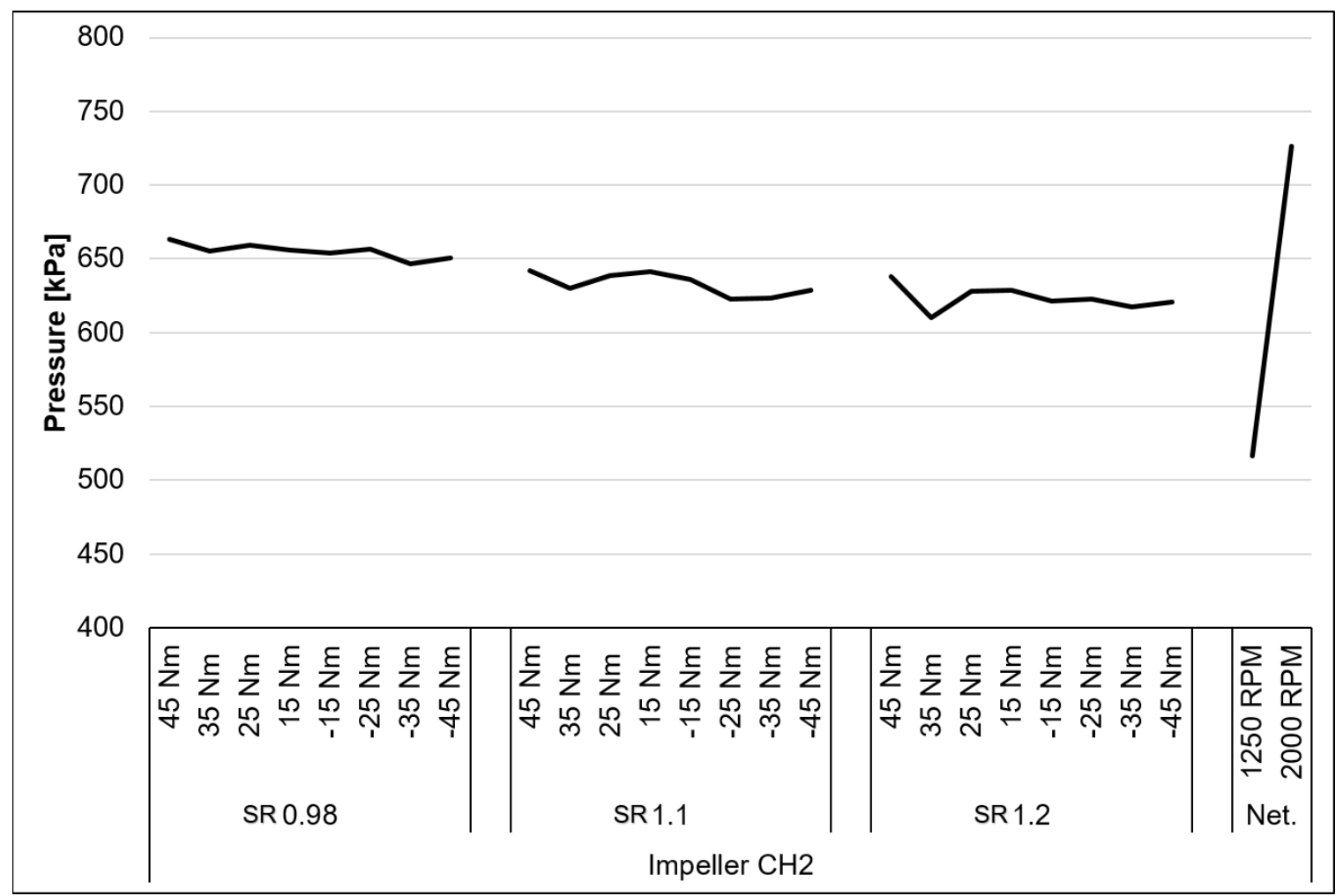

Figure 4-24. Impeller channel 2 pressures during back drive 


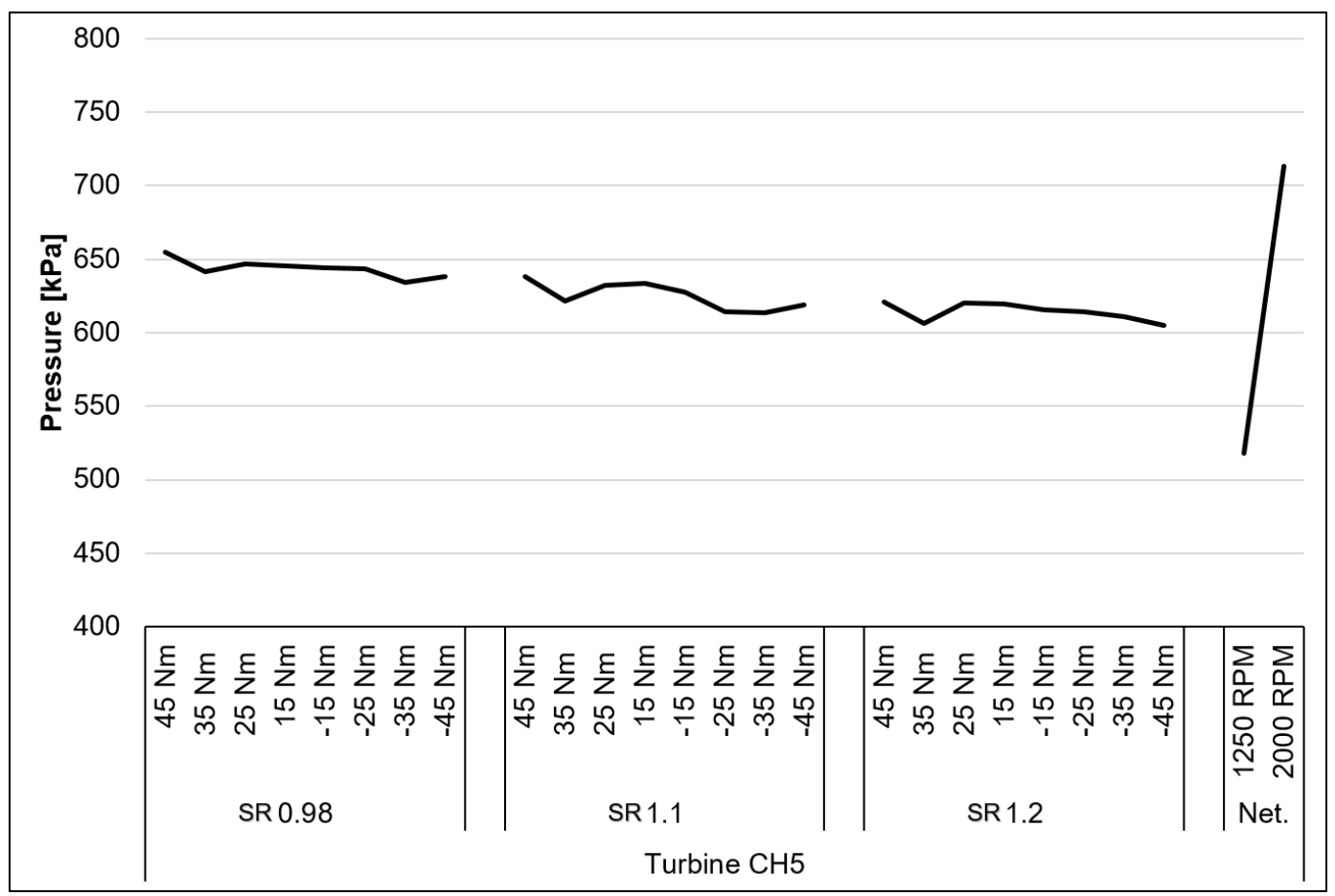

Figure 4-25. Turbine channel 5 pressures during back drive

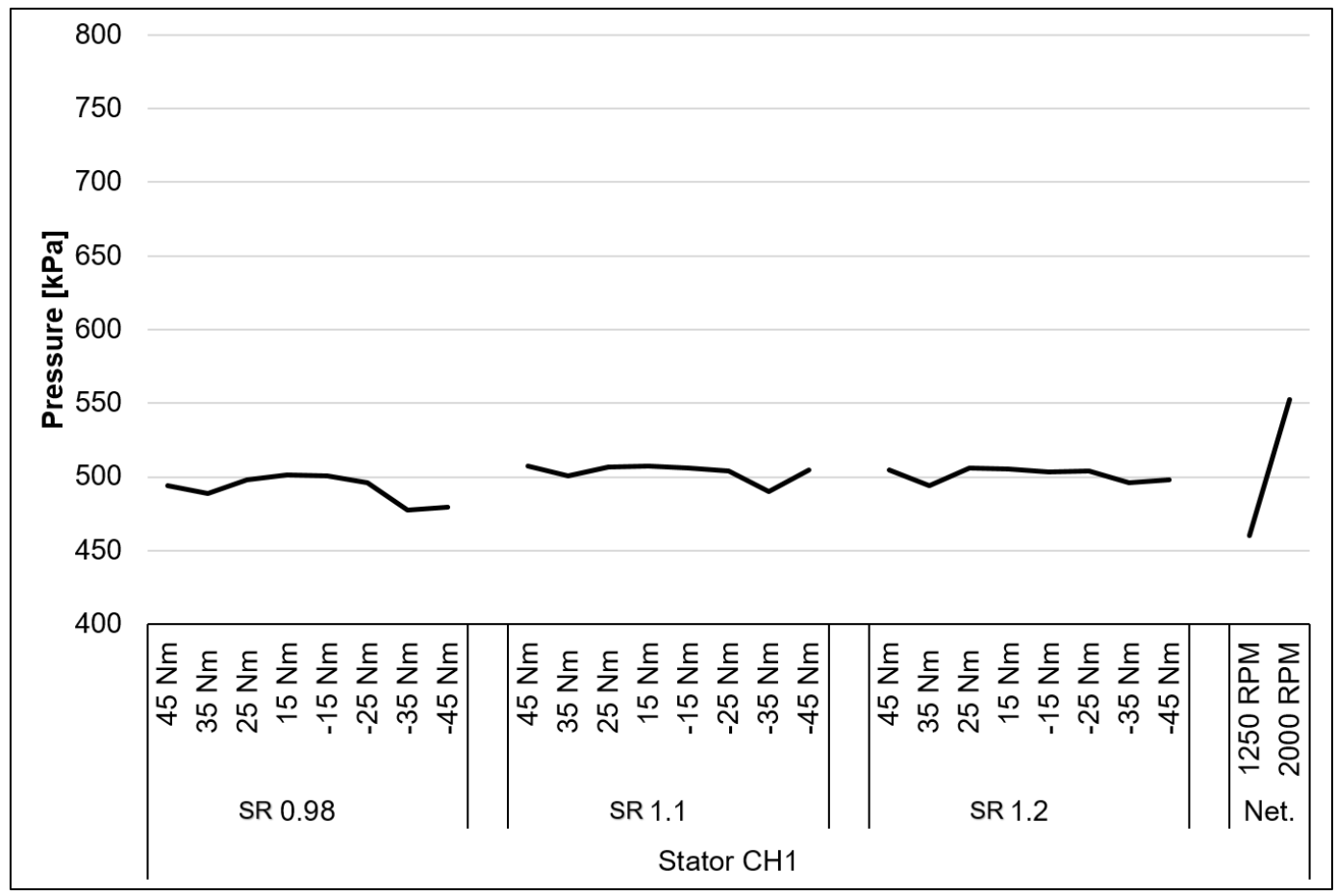

Figure 4-26. Stator channel 1 pressures during back drive 


\subsubsection{CFD Correlations}

The CFD correlations were completed with another graduate student that built the model of the torque converter. It was of interest to simulate the back drive tests to show how well the model correlates to high speed ratios. This is an addition to the research that was completed by [24].

The 45 to $-45 \mathrm{Nm}$ case was used as the parameters for the $0.98,1.1$, and 1.2 speed ratios. The impeller, turbine, and stator speeds were used as the input parameters to the model. The torque on each element is an output. The stator speed was estimated by finding the speed where there is zero torque on the stator because it is freewheeling at these speed ratios. The parameters and results are summarized in Table 4-3.

Table 4-3. CFD parameters and results summary

\begin{tabular}{|c|c|c|c|c|c|c|c|}
\hline $\begin{array}{c}\text { Test } \\
\text { Torque } \\
\text { Direction }\end{array}$ & $\mathrm{SR}$ & $\begin{array}{c}\text { Impeller } \\
\text { Speed } \\
{[\mathrm{RPM}]}\end{array}$ & $\begin{array}{c}\text { Turbine } \\
\text { Speed } \\
{[\mathrm{RPM}]}\end{array}$ & $\begin{array}{c}\text { Stator Speed } \\
\text { Estimate [RPM] }\end{array}$ & $\begin{array}{c}\text { CFD Impeller } \\
\text { Torque [Nm] }\end{array}$ & $\begin{array}{c}\text { CFD Turbine } \\
\text { Torque [Nm] }\end{array}$ & $\begin{array}{c}\text { CFD Stator } \\
\text { Torque [Nm] }\end{array}$ \\
\hline$+45 \mathrm{Nm}$ & 0.98 & 1806 & 1890 & 1703 & -4 & 4 & -0.01 \\
\hline$-45 \mathrm{Nm}$ & 0.98 & 1933 & 1777 & 1717 & -8 & 8 & -0.04 \\
\hline$+45 \mathrm{Nm}$ & 1.10 & 1663 & 1836 & 2079 & 9 & -10 & -0.08 \\
\hline$-45 \mathrm{Nm}$ & 1.10 & 1693 & 1860 & 2090 & 10 & -10 & -0.04 \\
\hline$+45 \mathrm{Nm}$ & 1.20 & 1535 & 1846 & 2141 & 12 & -12 & 0.01 \\
\hline$-45 \mathrm{Nm}$ & 1.20 & 1555 & 1860 & 2172 & 12 & -12 & -0.07 \\
\hline
\end{tabular}

The torques seen in the CFD results show a lower torque than what is seen by the test data. This is due to the CFD being a steady state calculation instead of a transient. To achieve a steady state condition of $-45 \mathrm{Nm}$ the speed would have to be much higher and this can be determined by using the affinity law given in Equation 4-5. Table 4-4 show the speeds required to achieve $-45 \mathrm{Nm}$ at the higher speed ratios. 


$$
\text { Speed }_{\text {desired }}=\text { Speed }_{\text {known }} *\left(\frac{\text { Torque }_{\text {desired }}}{\text { Torque }_{\text {known }}}\right)^{\frac{1}{2}}
$$

Table 4-4. Steady state speeds required to achieve $-45 \mathrm{Nm}$

\begin{tabular}{|c|c|c|}
\hline Speed Ratio & Impeller & Turbine \\
\hline 1.1 & 3652 RPM & 4017 RPM \\
\hline 1.2 & 2993 RPM & 3591 RPM \\
\hline
\end{tabular}

A comparison between the pressures for the test and $-45 \mathrm{Nm}$ steady state for the impeller, turbine, and stator are shown in Figure 4-27 for 1.1 and 1.2 speed ratios. Transducer 7 on the turbine is not shown because in the model the measurement location is deadheaded against another surface where fluid cannot be modeled.
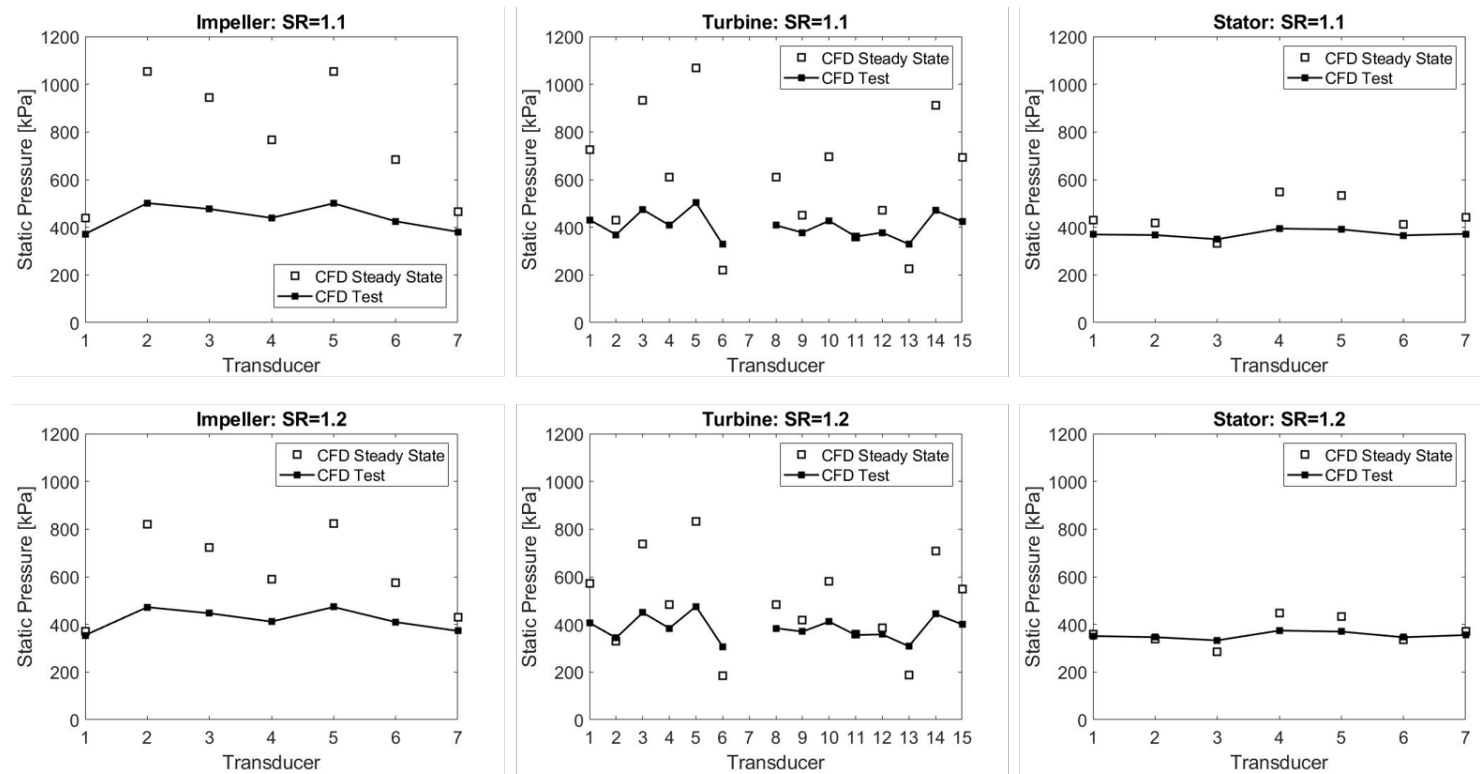

Figure 4-27. CFD comparison of test vs. steady state values to achieve $-45 \mathrm{Nm}$

Figure 4-28 shows the how well the CFD correlates to the test data. As the speed ratio increases the CFD error increases. To see the results for all channels reference Appendix M. One key point to illustrate for the results is how the flow changes across the stator blade. Figure 4-29 shows the pressures across the stator blade for the test and CFD results for 45 and $-45 \mathrm{Nm}$. The test results are 
higher than the CFD but the CFD does capture how the fluid field is acting across the blade. This is shown by looking at the middle of the blade and seeing how the pressures cross one another creating a figure 8 pattern between the pressure and suction sides of the blade. This can be seen in the test and the CFD meaning that the CFD can be used for stator blade design and development.
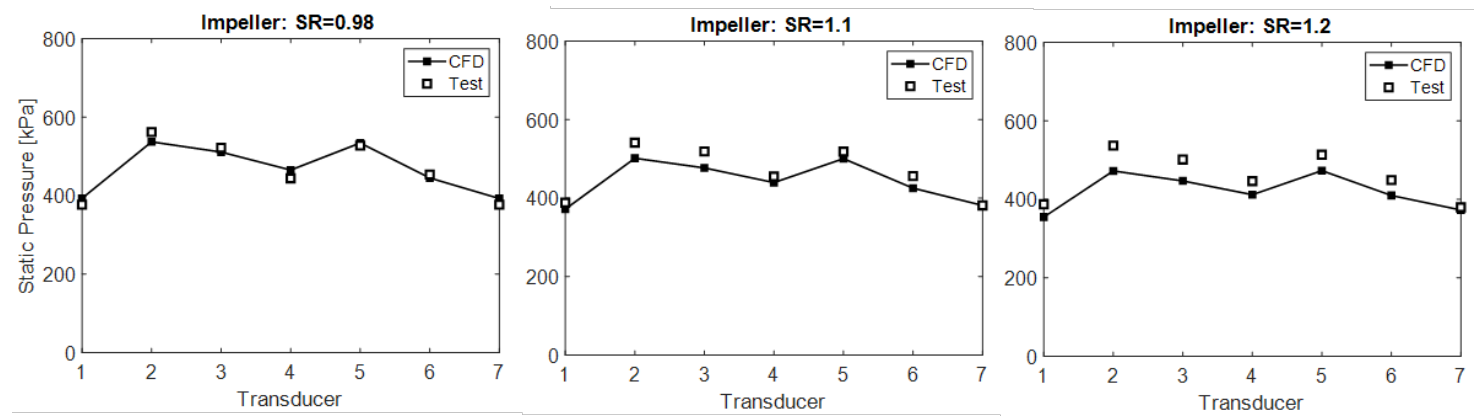

Figure 4-28. CFD correlation to high speed ratios
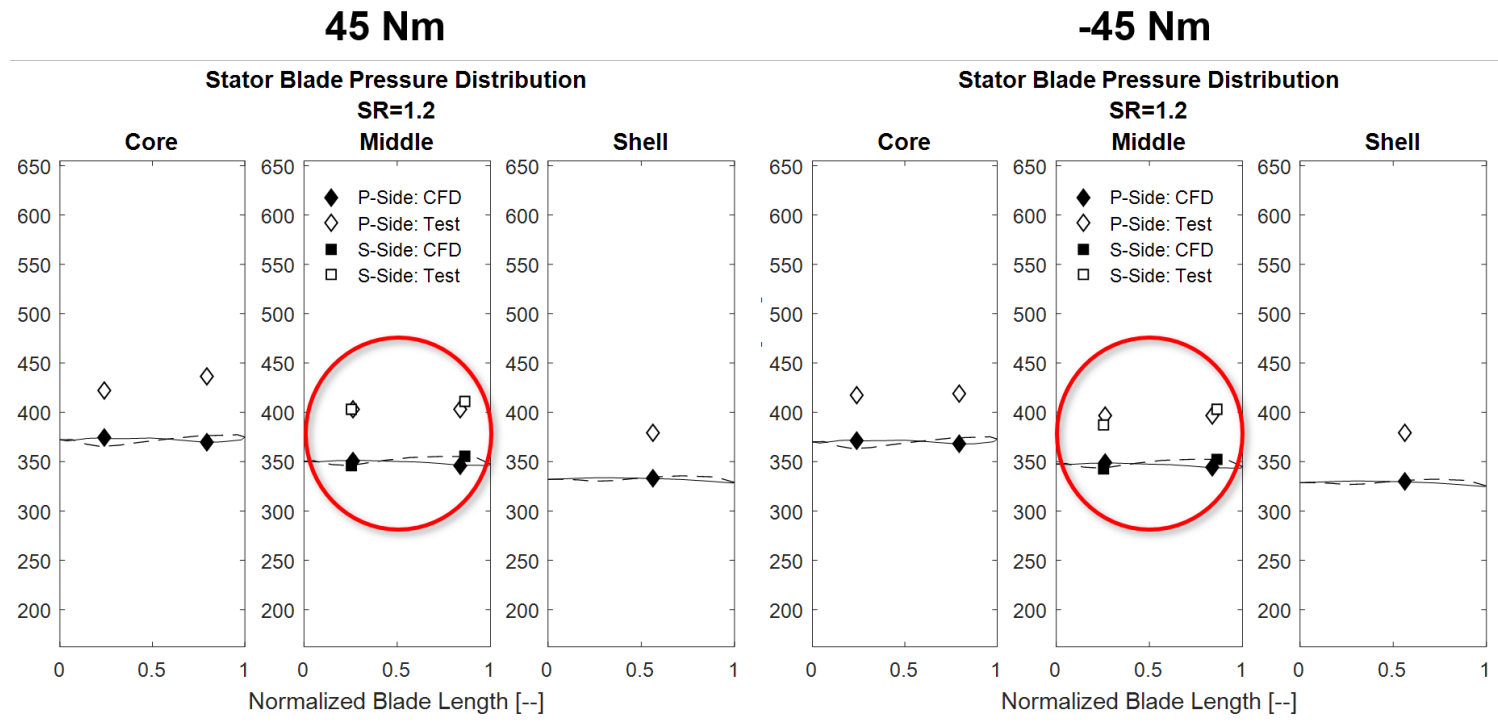

Figure 4-29. Pressure distribution across stator blade for 45 and $-45 \mathrm{Nm}$ 


\subsubsection{Stator Speed Identification}

The key information used from the CFD relevant to the transient testing research is the stator speed estimates, provided in Table 4-5. These values were used to compare to the test data to determine the stator speed when looking at a FFT color map.

Table 4-5. Stator speeds for each speed ratio

\begin{tabular}{|c|c|c|}
\hline Speed Ratio & Impeller Speed [RPM] & $\begin{array}{c}\text { Stator Speed CFD } \\
\text { Estimate }\end{array}$ \\
\hline $0.98 \star$ & 1865 & $\sim 1700(28.3 \mathrm{~Hz})$ \\
\hline $1.10 \star$ & 1675 & $\sim 2080(34.7 \mathrm{~Hz})$ \\
\hline $1.20 \star$ & 1550 & $\sim 2150(35.8 \mathrm{~Hz})$ \\
\hline
\end{tabular}

Identifying the stator speed is of interest because understanding what happens to the stator at high speed ratios can drive innovation and calibration techniques. To identify the stator speed using the pressure data the stitched time history was split into blocks. Only the data that was recorded continuously can be placed in a block. Data blocks cannot contain data where stitching occurs. An FFT was taken on each of these blocks to create a color map showing the frequency on the $\mathrm{x}$-axis and time on the y-axis. The primary frequency of the stator can be found by applying this process on one of the stator channels, as seen in Figure 4-30. The primary frequency is determined by Equation 4-6 where $\mathrm{N}$ is the rotational speed in RPM and $\mathrm{F}$ is the primary frequency in $\mathrm{Hz}$. The stator speeds obtained from the CFD are indicated by stars along the color map. This verifies that expensive instrumentation is not needed to estimate stator speed instead cheaper models can be used.

$$
F=\frac{N}{60}
$$

Equation 4-6 


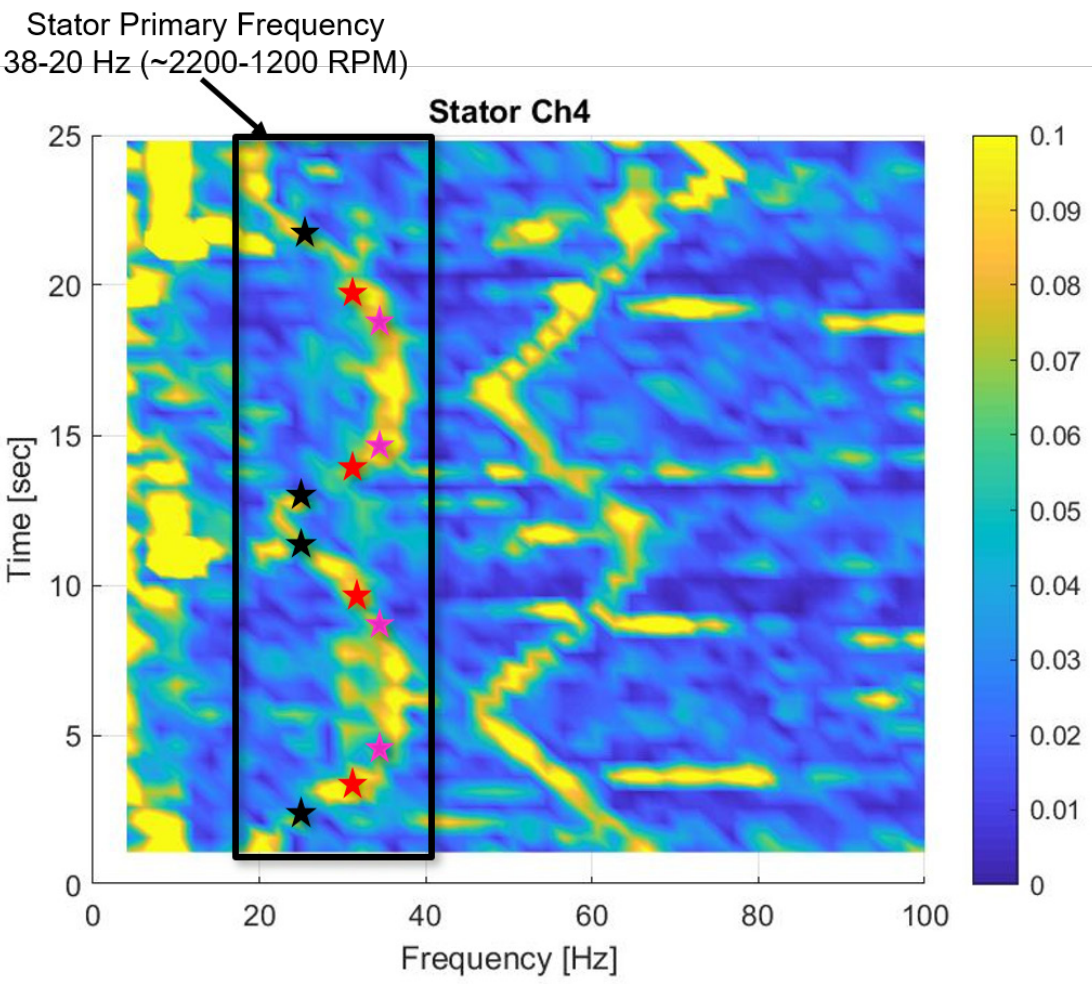

Figure 4-30. Stator speed identification using pressure data FFT color map

\subsubsection{Hydraulic Pump Frequency Content}

A frequency was noticed to appear on all channel color maps and was identified to be the hydraulic pump. Figure 4-31 shows the color map for the line pressure measurement where the hydraulic pump has the largest impact. The hydraulic pump primary frequency was identified to be between $24-32.5 \mathrm{~Hz}$, which is also the impeller primary frequency because the pump in concentrically driven by the impeller. The second order of the hydraulic pump primary frequency is $48-65 \mathrm{~Hz}$ as seen in Figure 4-31. This second order from the hydraulic pump is what can be seen across all other channels in the torque converter. Seeing the hydraulic pump appear on the other color maps is not a surprise since the hydraulic pump is the primary excitation to the ATF. This means modifications made to the hydraulic pump performance, such as changing the number of lobes on gerotor gear, can be seen and impact the pressures in the torque converter. 


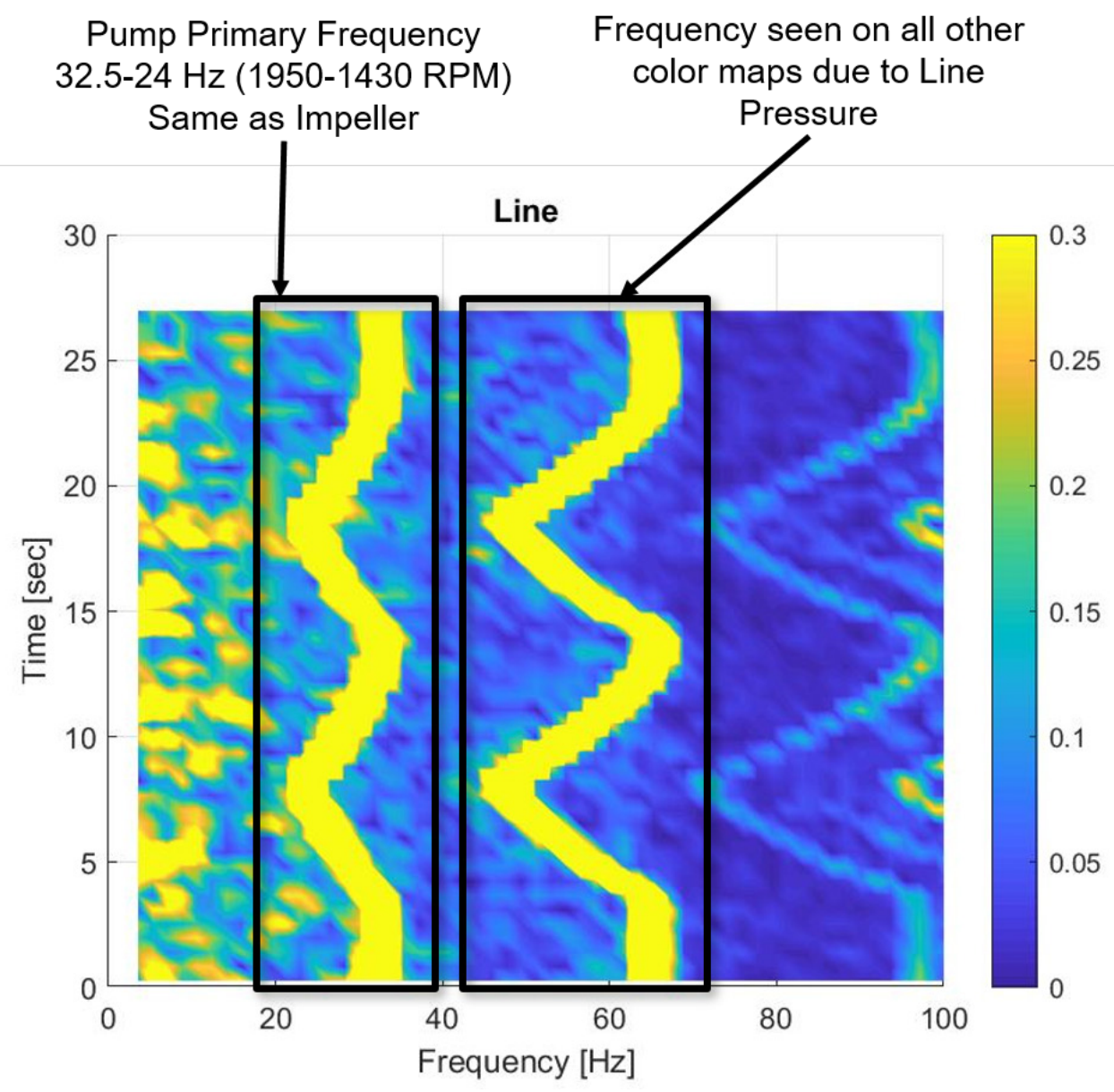

Figure 4-31. Hydraulic pump primary frequency

Additional frequencies caused by the hydraulic pump were found at higher frequencies ranging from $95-260 \mathrm{~Hz}$. The frequency with the highest amplitude is gear mesh frequency of the inner rotor of the gerotor hydraulic pump. Multiple other frequencies were also seen for different number of lobes. These frequencies are identified on the color map seen in Figure 4-32. Additional research is required to better understand the frequencies caused by the gerotor pump. All channel color maps can be found in Appendix N. 


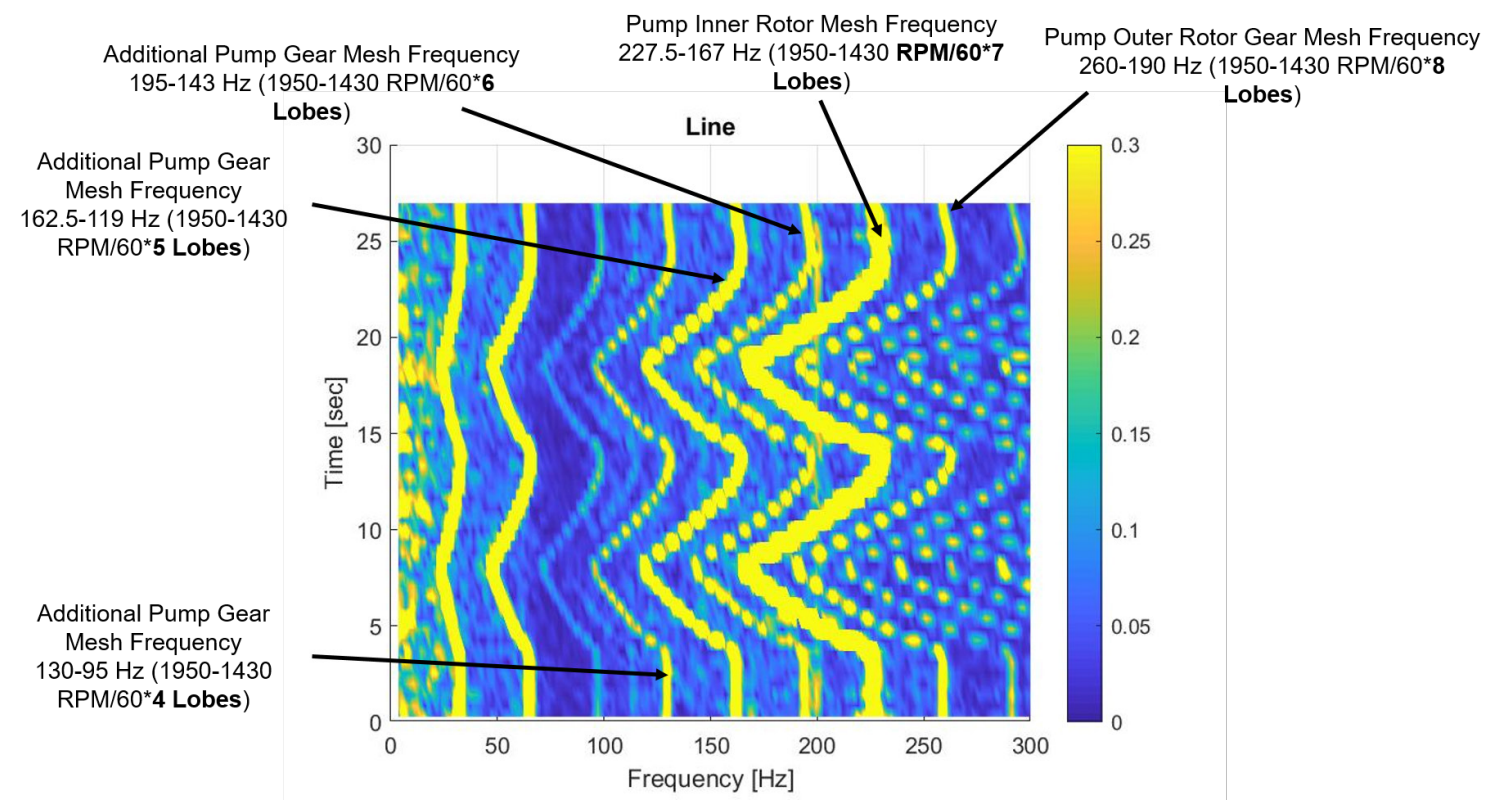

Figure 4-32. Multiple frequencies associated with the hydraulic pump

\subsubsection{Gear Shift}

Being able to achieve gear shifting while under load was of interest to study how the hydraulics from the transmission interact with the torque converter during the shift. Both power-on upshifts and downshifts were completed for a medium and low load input torque at both cruising and low speeds. The operating conditions for each shift scenario are summarized in Table 4-6.

Table 4-6. Gear shifts completed operating conditions

\begin{tabular}{|c|c|c|}
\hline Case & Input Torque & $\begin{array}{c}\text { Vehicle Speed } \\
\text { Equivalent }\end{array}$ \\
\hline $\begin{array}{c}\text { Low Load, Cruising } \\
\text { Speed }\end{array}$ & $30 \mathrm{Nm}[22.1 \mathrm{ft}-\mathrm{lb}]$ & $88.5 \mathrm{kph}[55 \mathrm{mph}]$ \\
\hline $\begin{array}{c}\text { Medium Load, Low } \\
\text { Speed }\end{array}$ & $100 \mathrm{Nm}[73.7 \mathrm{ft}-\mathrm{lb}]$ & $48.3 \mathrm{kph}[30 \mathrm{mph}]$ \\
\hline Low Load, Low Speed & $30 \mathrm{Nm}[22.1 \mathrm{ft}-\mathrm{lb}]$ & $48.3 \mathrm{kph}[30 \mathrm{mph}]$ \\
\hline
\end{tabular}




\subsubsection{Test Repeatability}

To be able use the multiplexed telemetry transient data method that was developed the shift must be repeatable so the pressure time history can be stitched together properly. Each shift maneuver was verified to be repeatable and the pressure data can be stitched together. Figure 4-33 and Figure 4-34 are 16 test runs overlapped showing the test repeatability. The figures include the dyno speeds, TCC slip speed, dyno torques and clutch pressures. Note there is some variation in the output dyno torque and this is due to the transmission triggering activating a delta time after seeing the trigger event. The output torque variation is noticeable because by changing when the shift occurs in relationship to the torque management a smaller or larger output torque can occur. This variation in output torque was considered acceptable and the shift strategy was used.

The torque management used for down and upshift can be seen on the input torque in Figure 4-33 and Figure 4-34. The torque does not match the step response examples that were described in the methods because the dyno controls take time to adjust for the inertia. This creates a smoother torque curve. To compensate the torque management is started prior to the shift to allow the dyno to reach the proper torque to achieve the shift safely.

During the shift the TCC slip varies from the control of 20 RPM. This is due to the control pressure is being held constant throughout the shift without any feedback controls. By having a constant charge pressure the TCC does not have the capacity to hold the fluctuating torque. Once the shift is completed and the torque returns to its starting value, the TCC has the capacity to maintain 20 RPM of slip once again. 

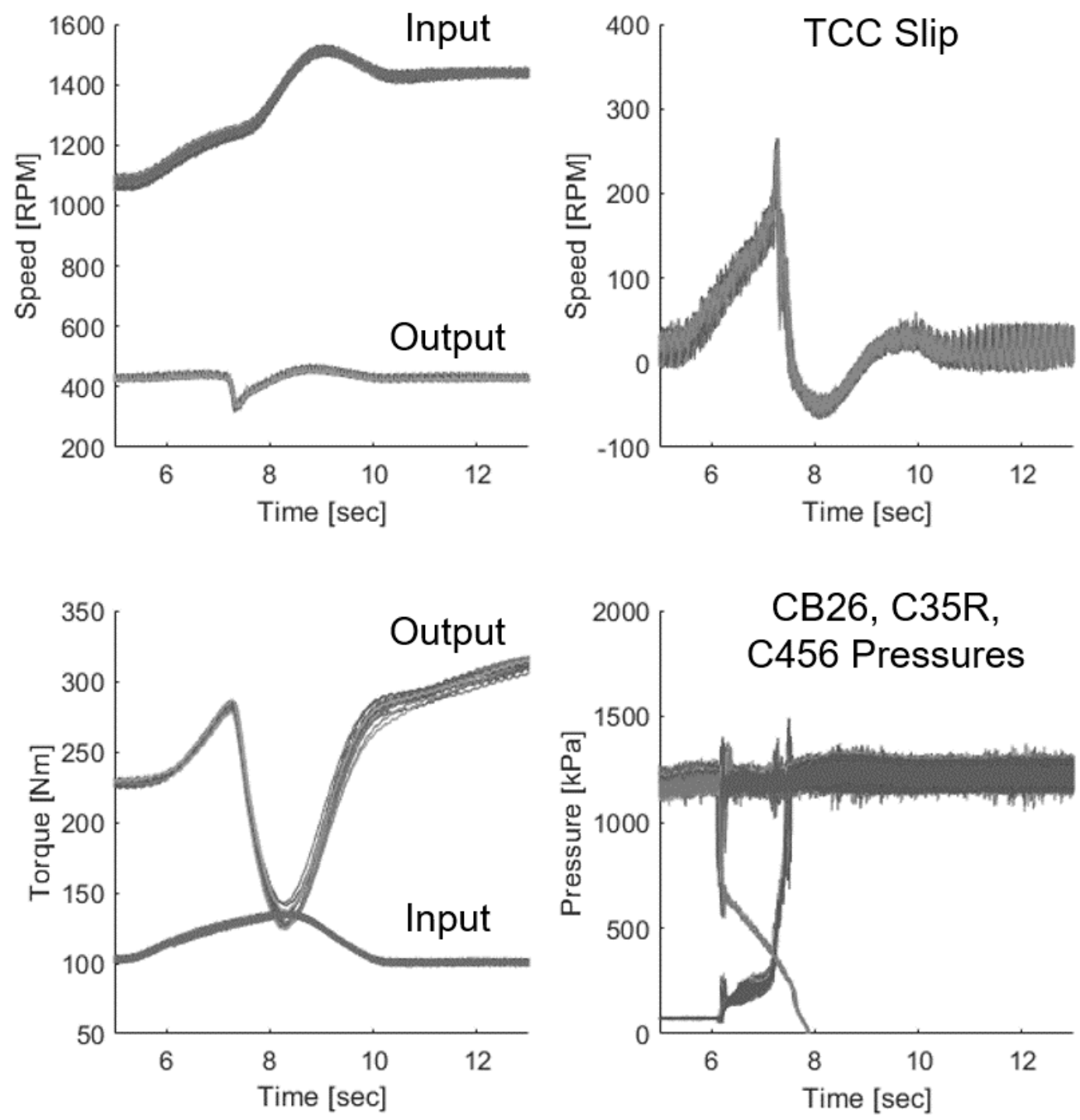

Figure 4-33. TCC slipping downshift repeatability verification 

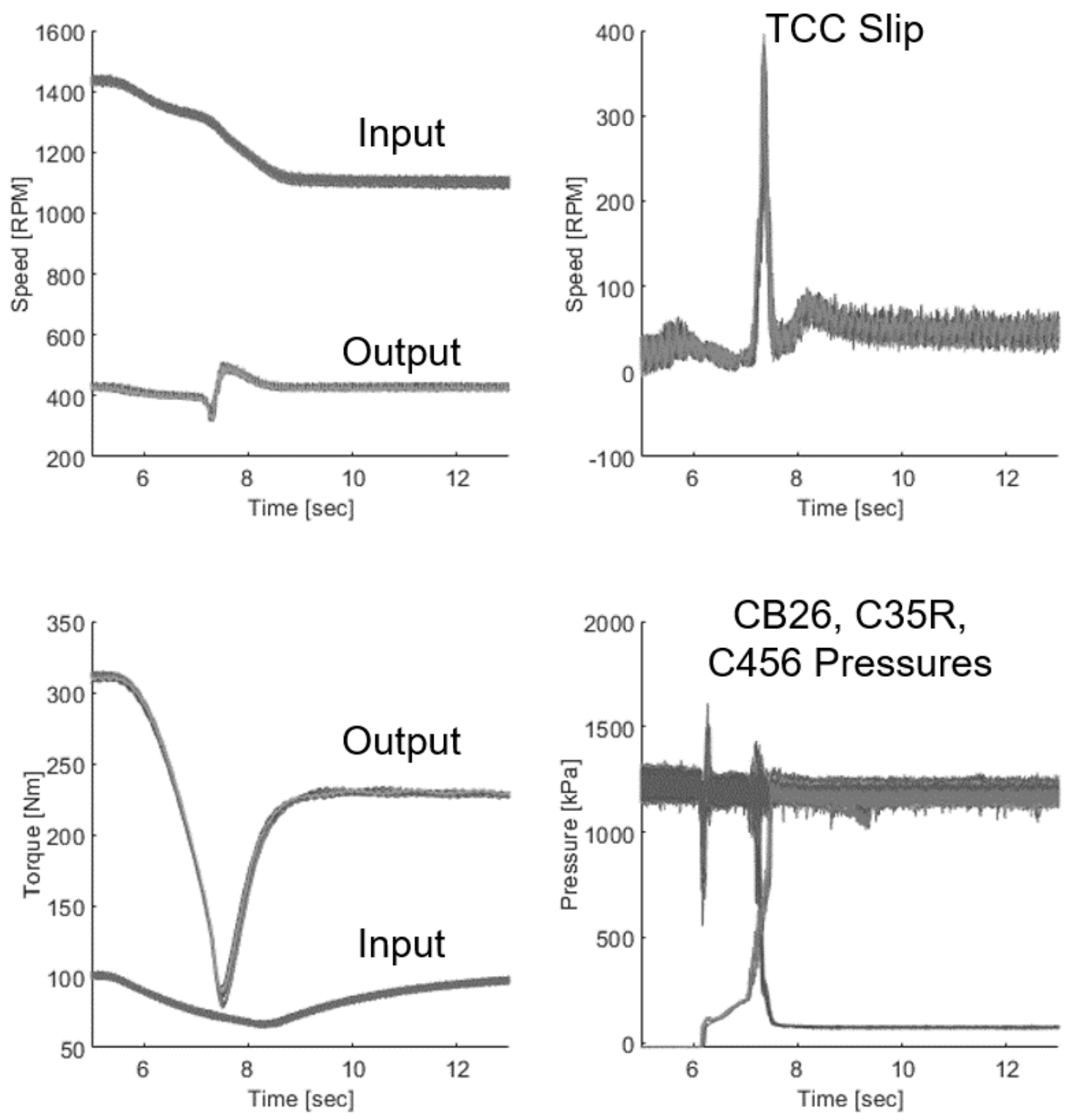

Figure 4-34. TCC slipping upshift repeatability verification 


\subsubsection{Shift Command Profile Comparison}

To ensure that the shifts used in this study were comparable to in-vehicle performance an average pressure profile was used to validate the profiles. Vehicle data for clutch pressures during a shift were averaged together for each gear state and converted to a current profile. The averaged current profile and test current profile were overlaid to validate that the pressure measurement would represent the shift properly. Figure 4-35 and Figure 4-36 show the current command profiles for the in-vehicle and test calibration. Majority of the current command profile was identical other than the end of the shift. The test calibration has a shallower slope to aid in accommodating for the large input inertia from the dynamometer. By having a less aggressive inertia phase the output torque fluctuation will be less. This variation at the end of the shift was considered acceptable because the clutch fill and torque phase pressures would mimic in-vehicle performance properly.

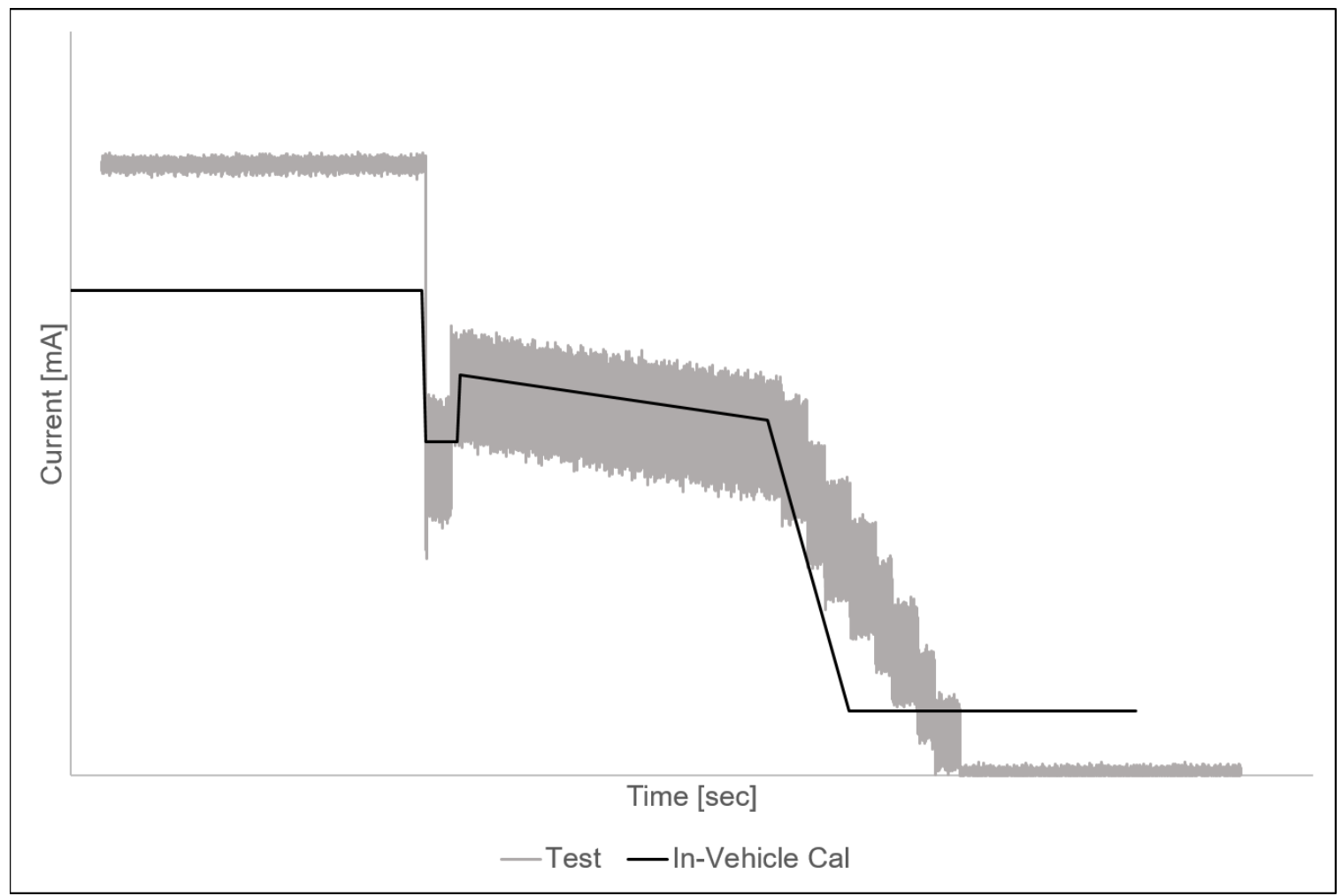

Figure 4-35. C35R current command profile comparison 


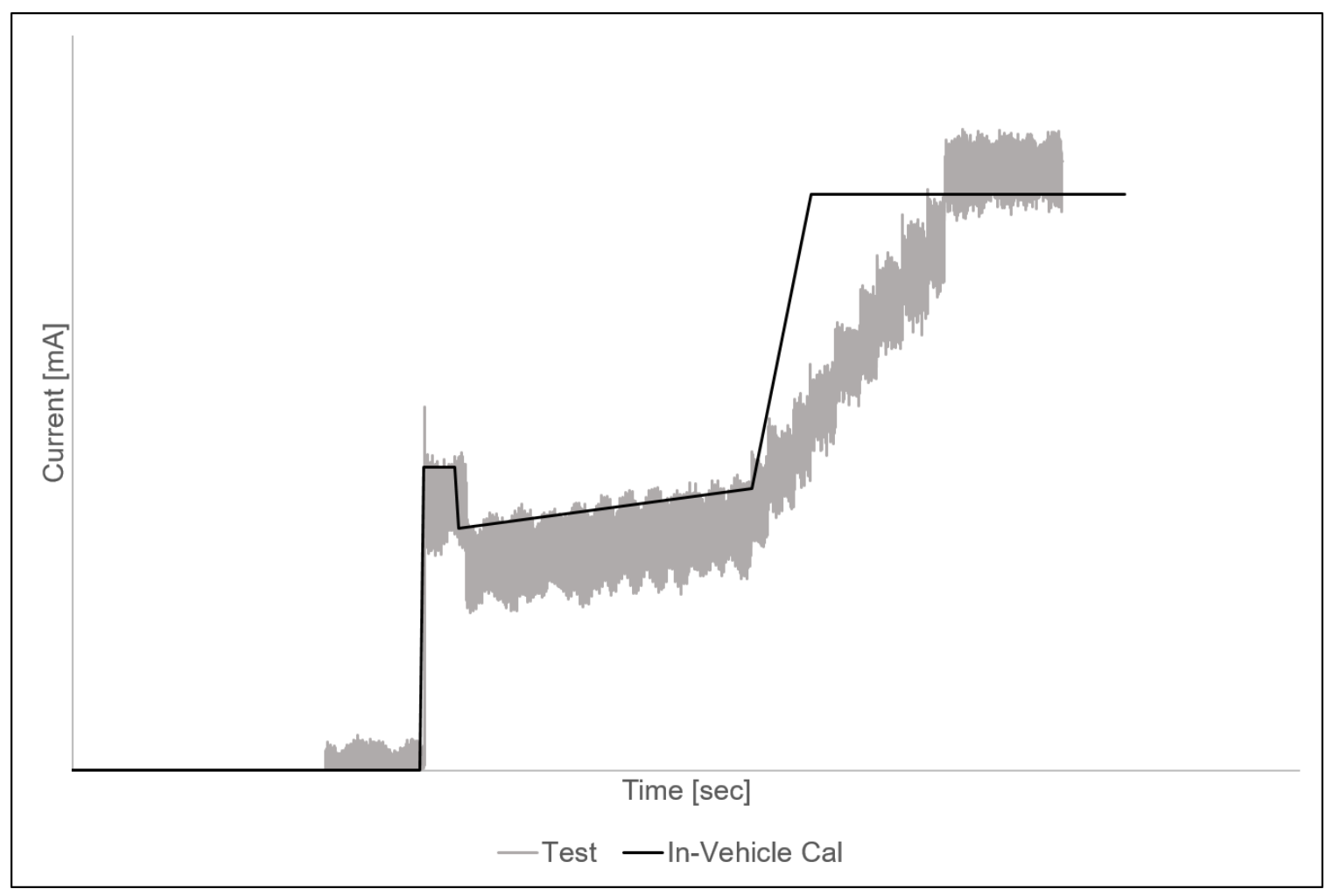

Figure 4-36. CB26 current command profile

\subsubsection{Low Speed Shifting}

Only the low load, low speed downshift results are presented here because these test conditions are the most likely to induce low hydraulic capacity to the torque converter. The low load, low speed upshift was tested but not reported here because calibrating for an upshift that results in an engine speed of approximately 1000 RPM is not common, but it is possible for a downshift if the vehicle is slowing down. All other testing conditions presented in Table 4-6 were used to develop a base understanding of what the pressures may appear to look like when the system has enough hydraulic capacity to feed all clutches and torque converter.

Figure 4-37, Figure 4-38, and Figure 4-39 are the results for a low load, low speed downshift with the TCC released, applied, and slipping respectively. When the TCC is released the input and output dynamometer are not mechanically 
connected, which allows the input dyno to transition slowly during the shift event. This can be seen in Figure 4-37 where the turbine speed has completed the shift but the input is slowly ramping up to the final speed. The torque fluctuation seen during the shift is low with the TCC open because the torque is being transmitted via the ATF instead of a mechanical connection through the TCC. There is a fluctuation on the line pressure due to the change in gear clutch pressures and the fluctuation can be seen on the clutch pressures, but is not seen on the charge or torque converter pressures. All the torque converter pressures are higher than the charge pressure because all locations in the torque converter are affected by the charge pressure when the TCC is released.

When the TCC is applied the input and turbine speeds are identical with little to no slip across the TCC. The torque fluctuation is the largest when the TCC is applied because the dynamometers are mechanically connected via the TCC and the output dyno has to compensate for the additional inertia on the input to achieve the commanded control speed. A similar line pressure fluctuation is seen as compared to having the TCC open. The torque converter pressures now have channels that are lower than the charge pressure. These channel locations are between the TCC and cover where the charge pressure does not impact. All other torque converter pressures are above the charge pressure.

When the TCC is slipping the input and turbine speed were held at a constant 20 RPM slip for the starting conditions. When the torque management for the shift was active the slip speed increases because the clutch capacity is held constant but the input torque increases and cannot maintain the 20 RPM slip. Once the shift and torque management are complete the slip across the TCC returns to 20 RPM. The torque fluctuation during the shift is lower because the TCC is not transmitting all the torque between the dynamometers resulting in a smoother torque profile. The torque converter pressures are seen to be lower because the charge pressure is low, compared to TCC applied and released, to achieve a slipping clutch 
condition. It was determined that the transmission still had the hydraulic capacity at low speed, low load to control the TCC properly.
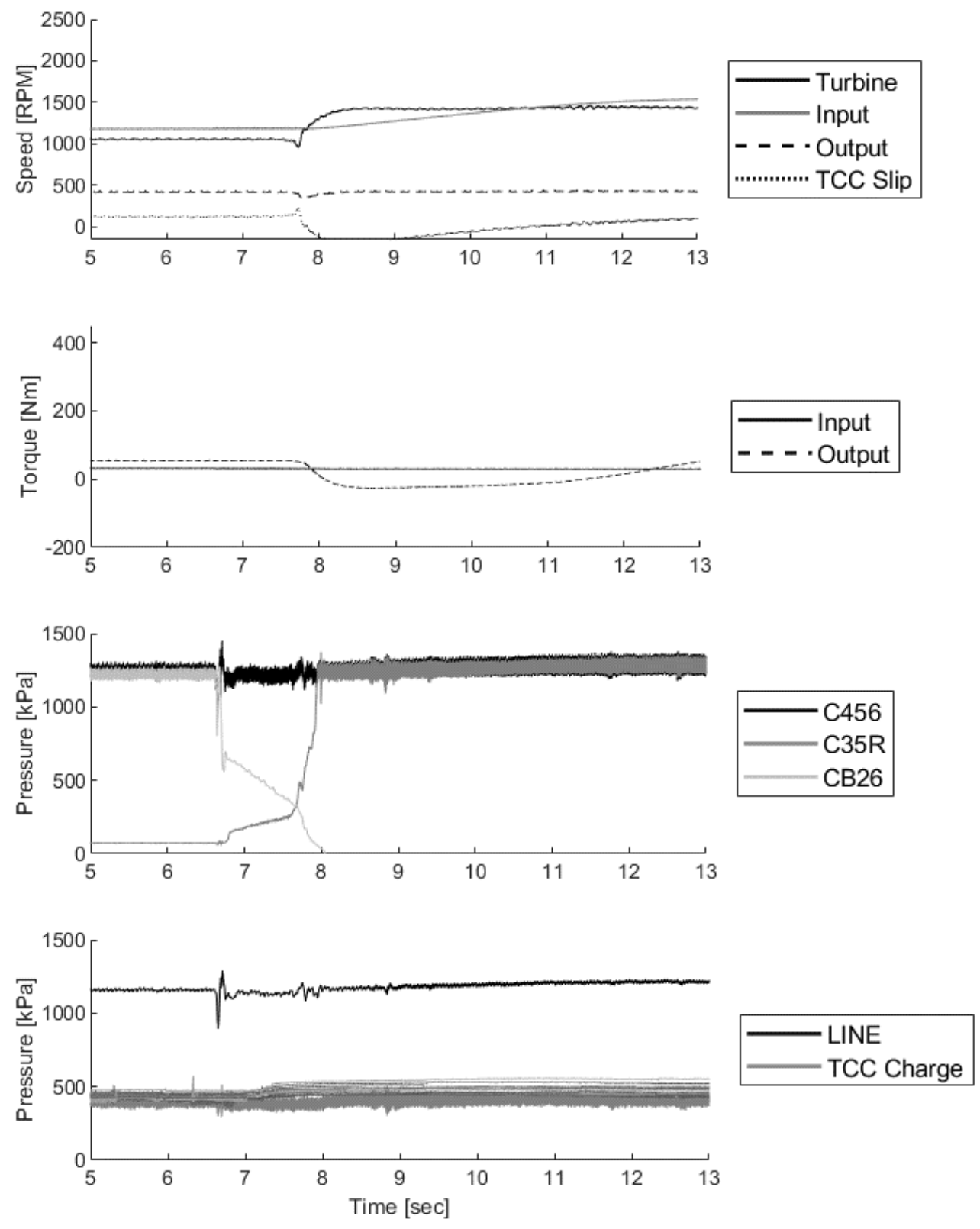

Figure 4-37. Low load, low speed downshift with TCC released- (top to bottom): transmission speeds, transmission torques, clutch pressures, stitched torque converter pressure time history 

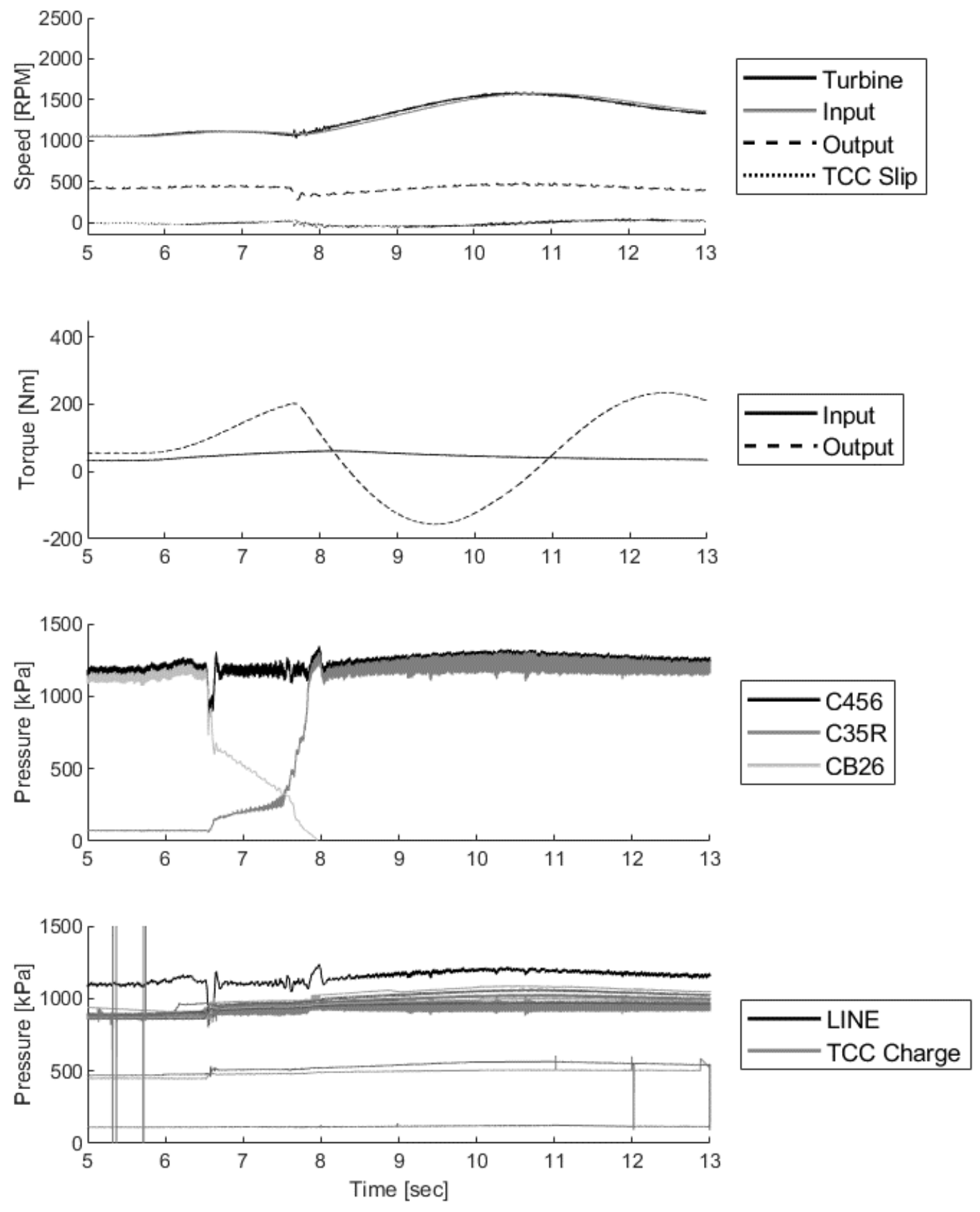

Figure 4-38. Low load, low speed downshift with TCC applied- (top to bottom): transmission speeds, transmission torques, clutch pressures, stitched torque converter pressure time history 

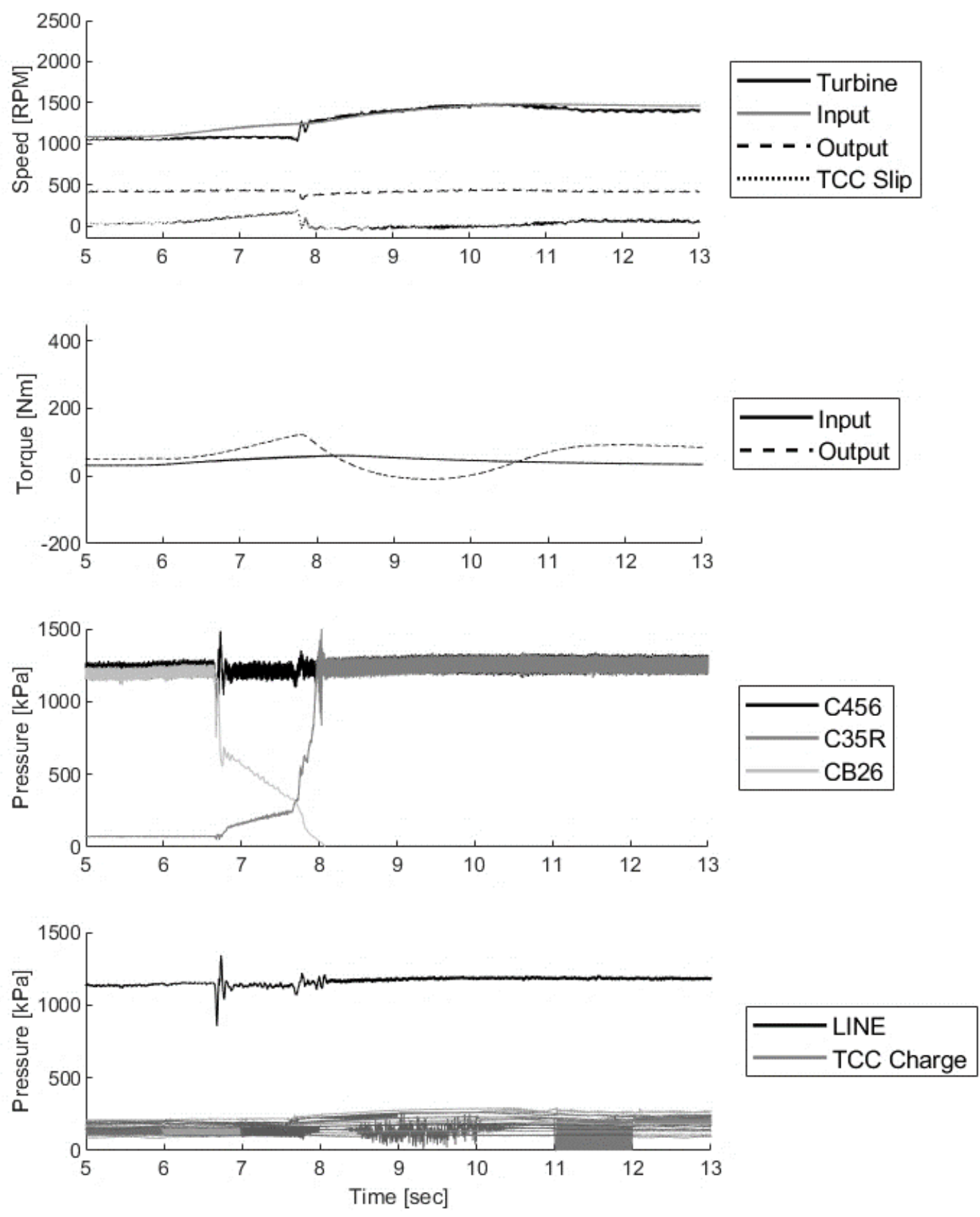

Figure 4-39. Low load, low speed downshift with TCC slipping 20 RPM- (top to bottom): transmission speeds, transmission torques, clutch pressures, stitched torque converter pressure time history 


\subsubsection{Pressure Shift Profiles Using Zero Load Estimates}

Shift profiles were estimated by using the zero load pressure measurements are shown in Figure 4-2, Figure 4-3, and Figure 4-4. The estimate pressure profiles were compared to the test results for the low load, low speed downshift to see if there is a correlation between speed, load, and pressure.

The estimated pressure profile for when the TCC is released is illustrated in Figure 4-40. The turbine speed was used as the estimation speed because the input speed has a long transition period and does not follow the speed of the shift quickly. The turbine speed can be used because all the zero load data is steady state with a high speed ratio of 0.95 or higher. By using the turbine speed a decent correlation is seen between the zero load estimate and the measured pressure results. The measure pressures have the change in pressure earlier than the estimated profile, which is attributed to the pressures changes occur first and the then the speed follows. The estimated pressure matches well with the measured pressure when in $5^{\text {th }}$ gear, but underestimates the pressure when in $6^{\text {th }}$. This could mean that each gear has different zero load pressures, but additional research is required to verify this hypothesis. 

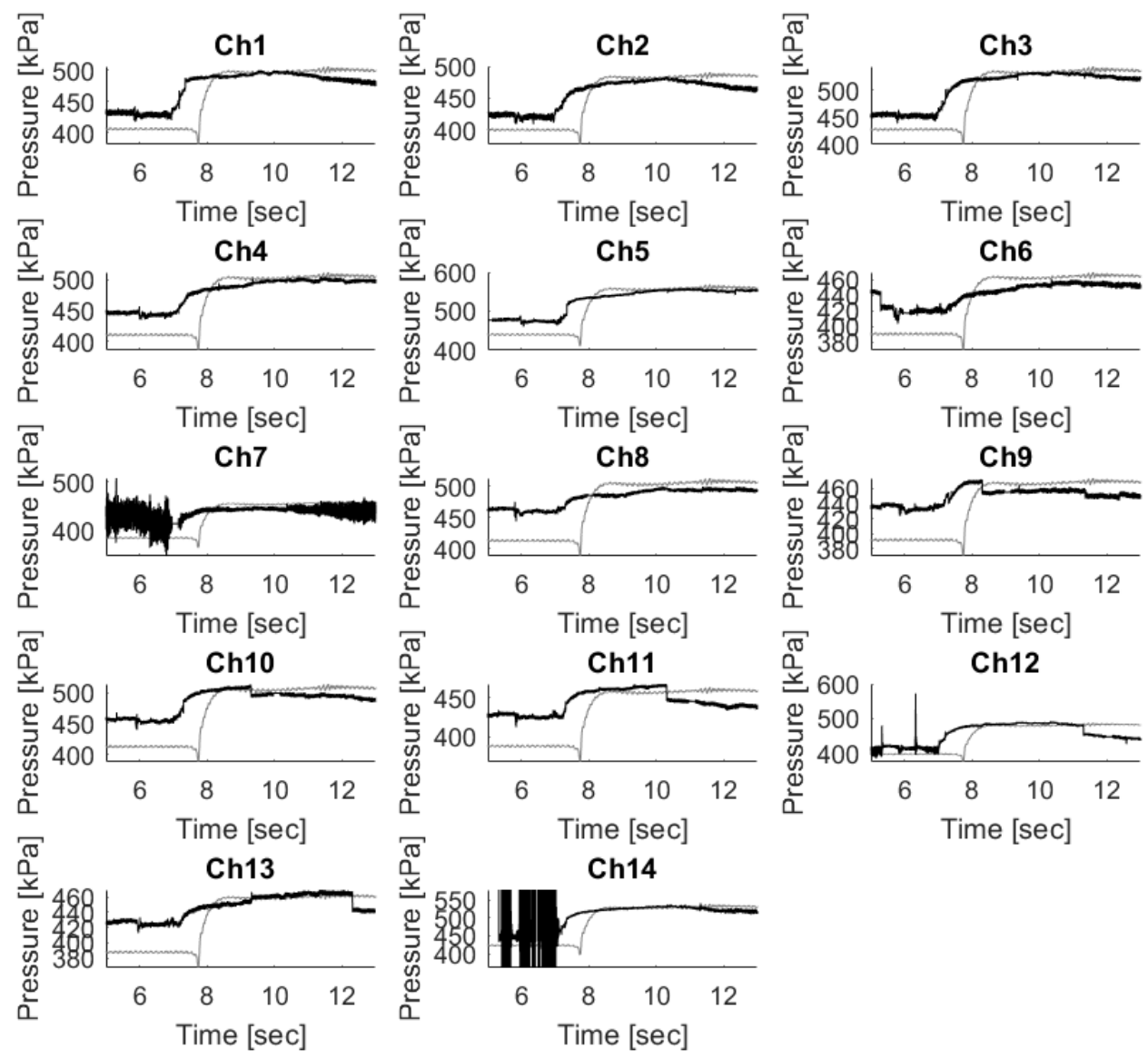

Figure 4-40. Low load, low speed shift with TCC released pressure data comparison

The comparison between the zero load estimate profile and the measured pressures for when the TCC is applied can be seen in Figure 4-41. Since the TCC is applied the input and turbine have the same speed and the input can be used to estimate the pressure profile. Again, the pressure estimate profiles match the measured pressures when in $5^{\text {th }}$ gear, but now overestimate the pressure when in $6^{\text {th }}$ gear. 

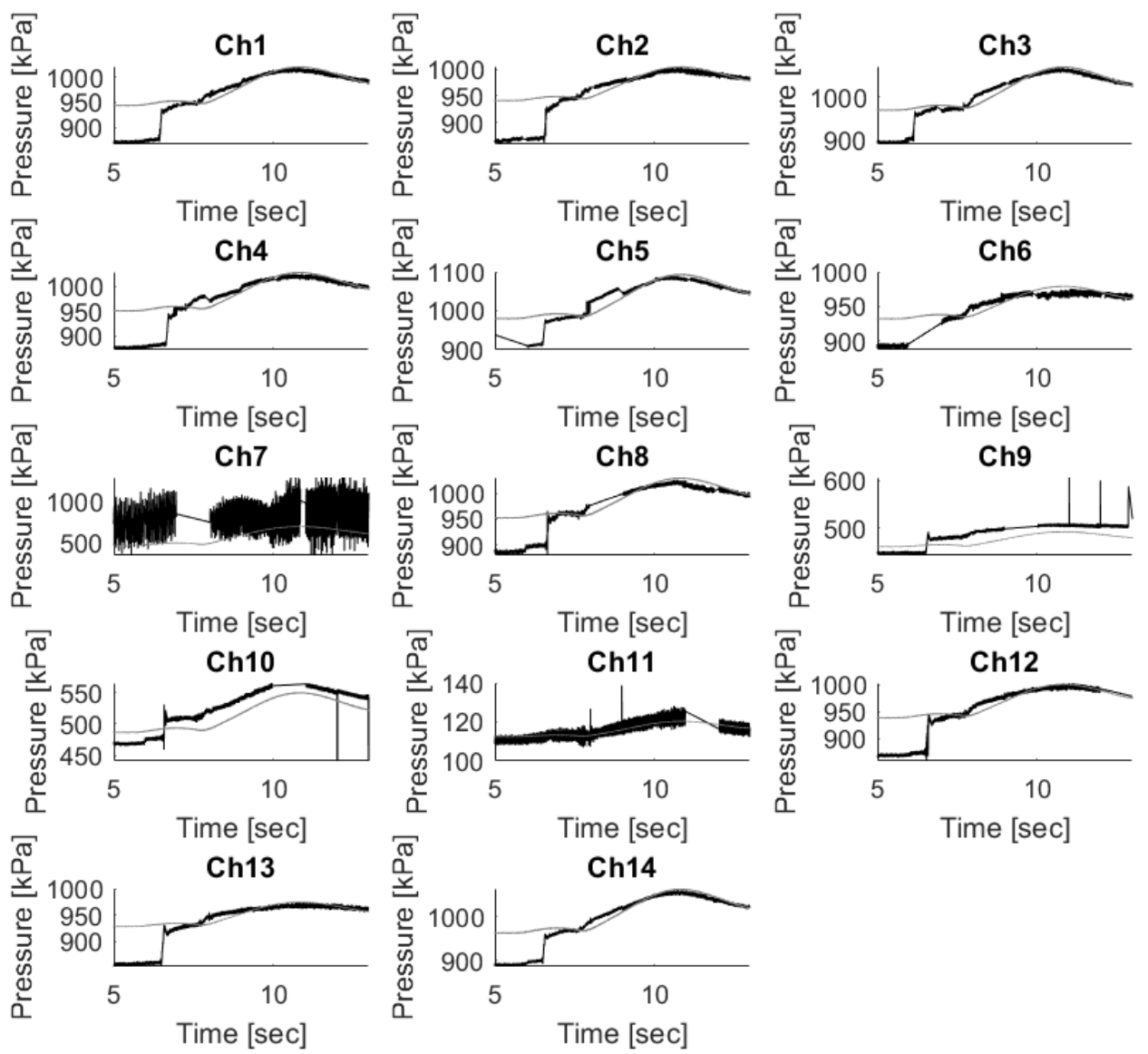

Figure 4-41. Low load, low speed shift with TCC applied pressure data comparison

The pressure profile comparison for when the TCC is slipping can be seen in Figure 4-42. The estimated pressure appears to underestimate the measured pressure, which can be attributed to the how the zero load slip pressures were measured. Since there is zero load it is difficult to cause the clutch to slip because torque is required to break the clutch away from the cover. To achieve slip in a zero load condition only a small amount of charge pressure is required, thus giving lower pressure estimates. Although the pressures are lower than measured the estimated profile follows the same trend as the measured. 

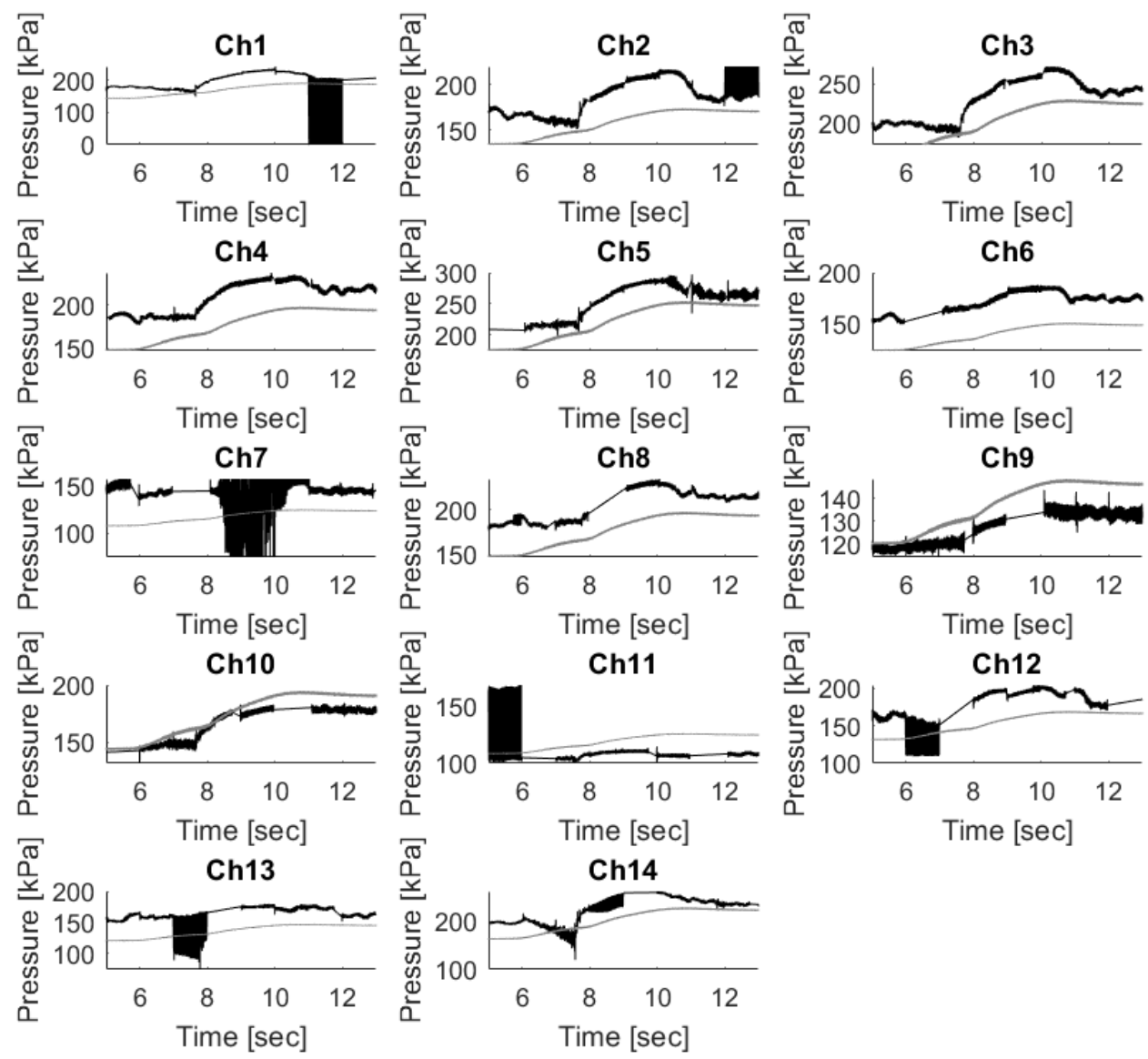

Figure 4-42. Low load, low speed shift with TCC slipping pressure data comparison

By knowing that the zero load pressures can an estimate the pressures during a shift only one measurement is required. A shift can be measured once and by using the input and turbine speed estimate the profile shape and magnitude. This would reduce the measurement time from 16 repeated runs to a single shift measurement. Further research should be conducted on other gears to validate this method and reduce the errors seen in $6^{\text {th }}$ gear. 


\subsubsection{TCC Oscillation}

Oscillation was seen on every channel caused by the hydraulic pump, but channel 7 had a larger magnitude than the others when the TCC was applied. An FFT, using a hanning window on the data, was computed for channel 7 , channel 6 , and the line pressure for the low load, low speed downshift, shown in Figure 4-43, Figure 4-44, and Figure 4-45 respectively. Channel 6 was selected because it is the next closest measured location to channel 7. An FFT was computed before, during, and after the shift to see how the frequency may change across the shift profile. In each of the figures the primary operating frequency of the impeller is shown by a $\left(^{*}\right)$. Note each figure has different y axis magnitudes to be able to identify the frequency content.

Both Figure 4-43 and Figure 4-44 show that the primary frequency has the largest magnitude. The primary frequency can be seen in Figure 4-45 for the line pressure but is smaller in magnitude compared to the gerotor pump equivalent gear mesh frequency that was identified in the back drive results. Although the mesh frequency can be identified on the line pressure, channel 7 and 6 show little no excitation for that frequency.

Channel 7 can be a channel of interest because if the clutch is oscillating between applied and released the oscillation would be noticeable as a frequency not associated with the gerotor pump. This tool should be used for future analysis when testing power-off downshifts where TCC controllability may be reduced. 

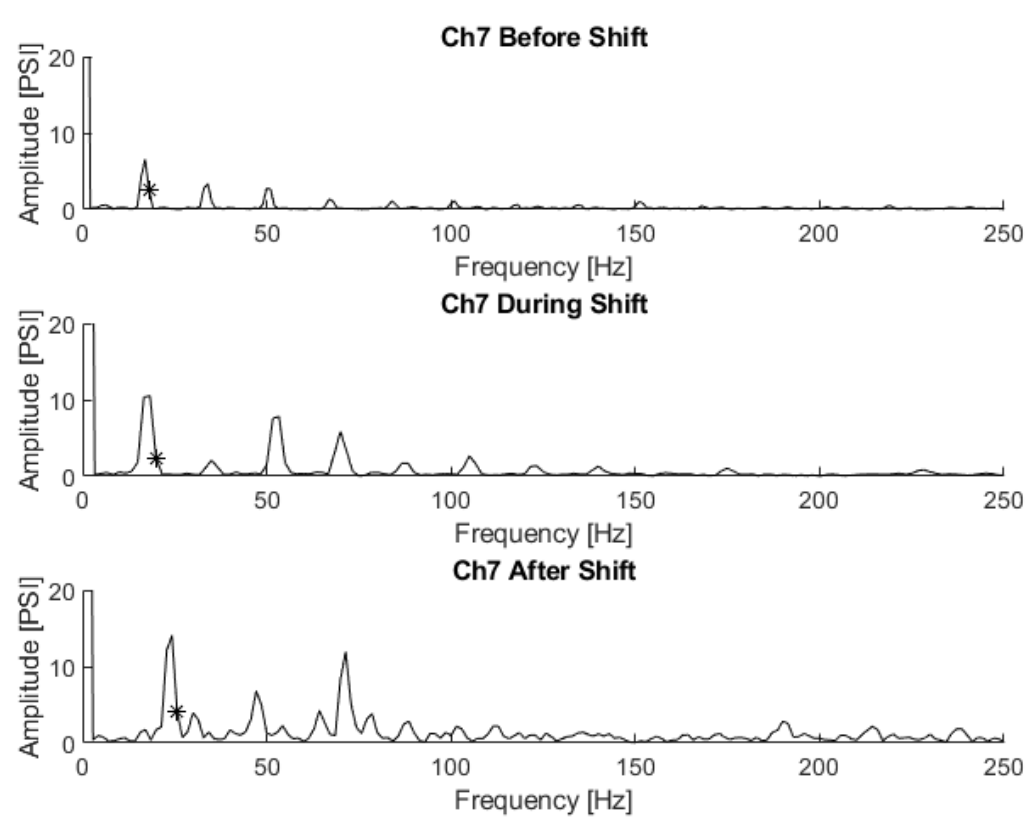

Figure 4-43. FFT of channel 7 measured pressure on the TCC for before, during, and after the shift
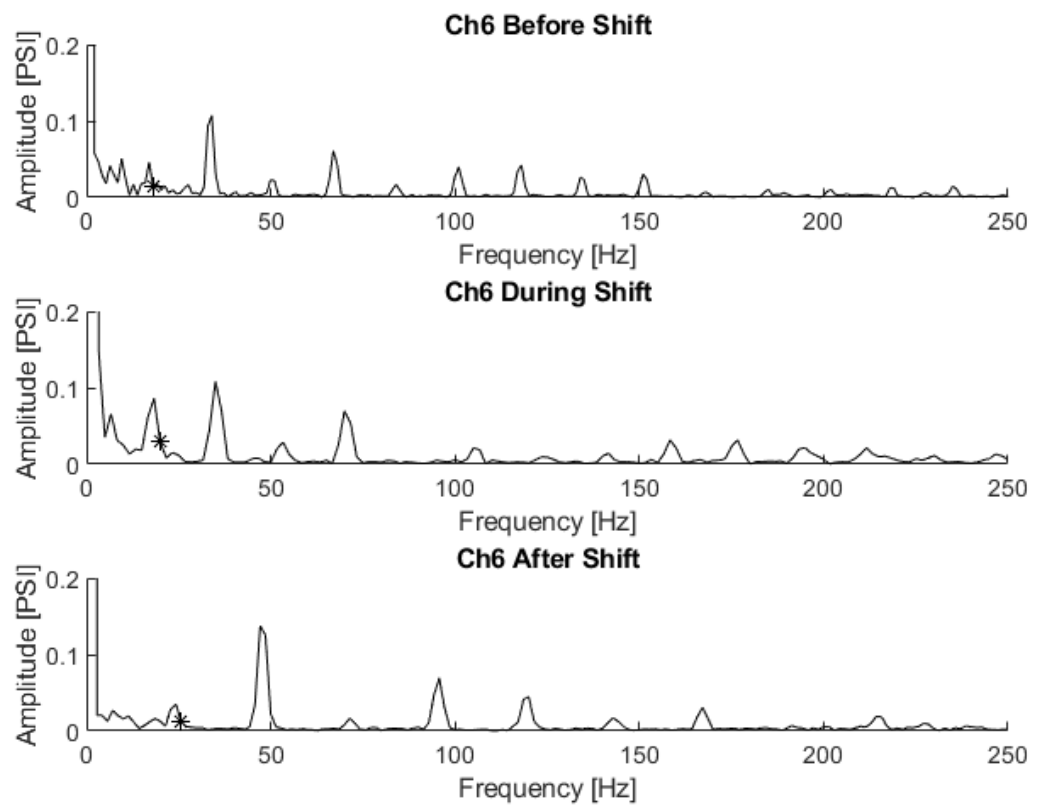

Figure 4-44. FFT of channel 6 measured pressure on the TCC for before, during, and after the shift 

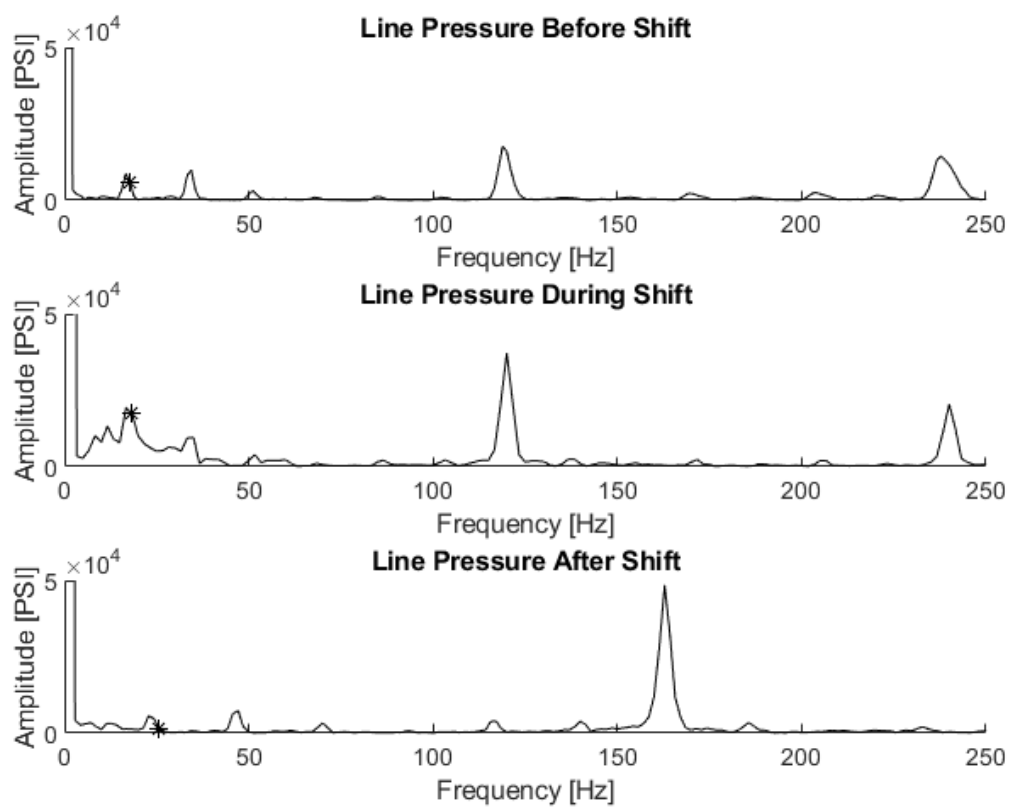

Figure 4-45. FFT of Line pressure for the transmission for before, during, and after the shift 


\section{Summary and Conclusions}

\subsection{Steady State Results Summary}

- Centripetal pressure can be calculated to be within $\pm 15 \%$ of true pressure and can be used for quick design calculations or estimates.

- There is a constant relationship between charge pressure and internal torque converter pressure. As the charge pressure increases at a constant speed the torque converter pressures will increase the identical amount. If the TCC is applied the pressure between the cover and clutch will not be affected by the charge pressure.

- The TCC capacity was verified to follow a linear trend, as charge pressure increases the more torque capacity available. The friction coefficient was found to be 0.19 which is within the range for design specifications and other literature.

- The pressure profiles acting on the TCC were characterized and the resultant force was found to act on the center of the clutch. When the TCC is slipping the resultant force acts on the center when under medium loads of torque (similar to TCC applied), but under low loads the force was found to be acting at a larger radial location closer to the friction material. This transition of resultant force location between medium and low loads may have an impact when calibrating transitional points.

\subsection{Transient Results Summary}

- A procedure to use multiplexed telemetry data for transient events was developed and implemented. The procedure allows for the $1 \mathrm{sec}$ channels to capture different portions of a transient event and then are stitched together to 
show a full time history of the event. The data may appear to be continuous but the time history is POINT DATA and must be treated as separate blocks.

- A back drive scenario was achieved to have the turbine drive the impeller resulting in speed ratios up to 1.3. The impeller and turbine pressures were found to decrease in pressure during the high speed ratios (1-1.2) while the stator increased in pressure. This is due to the stator inlet changing from the turbine to the impeller.

- A CFD model, created by [24], was correlated to the back drive test results showing good pressure estimate at SR 0.98 and increased in error as speed ratio increased. The torque results were underestimated by the CFD because the CFD is a steady state calculation, while the test is a transient measurement. Using the CFD stator speeds were estimated and used for verification.

- The stator speed was identified by using a FFT color map created from the pressure measurements taken on the stator. The stator speed was verified by comparing the speed estimates acquired from the CFD results. By being able to identify the stator speed and verify that the CFD can estimate the speed accurately future development can use the model results reliably.

- The pressure oscillations created in the gerotor hydraulic pump were identified throughout the whole torque converter. Changes made to the hydraulic pump will have an impact on torque converter pressures.

- Gear shifting while under load was achieved using the dynamometers as a driver and absorber to the transmission. The hydraulic shift profile was implemented to mimic in vehicle shifting strategies as close as possible. Limitations to completing the shift as quickly as in vehicle were found due to the large inertia for the input dynamometer. 
- The shift events were repeatable to allow for the telemetry transient procedure of repeating the test 16 times could be used.

- Power-on up and downshifts with the TCC released, slipping, and applied were completed. The results showed that the hydraulic system is capable of keeping the system saturated during medium and low load. The TCC was able to be controlled properly during all maneuvers tested.

- Zero load pressures were compared to the measured pressures during a shift to show that by using the input and turbine speed the pressure profile can be estimated. Good correlation was found when in $5^{\text {th }}$ but not in $6^{\text {th }}$ gear. By using the zero load pressure profile estimates only one test run is required to estimate the pressures during the shift instead of the current 16 repeated test runs. Additional research is needed to see how zero load pressures change between gears.

- A large pressure oscillation was found on the sensor between the clutch plate and turbine output wall when the TCC is applied. At this location the ATF is blocked and the frequencies from the hydraulic pump can be seen, such as in the back drive color maps. The lower frequencies were found to be present while the higher were not. This is not a concern at the moment but should be an area to continue looking as future research is conducted. 


\section{Recommendations}

\subsection{Testing Recommendations}

- Reduce the amount of time that the instrumented torque converter is ran. The torque converter instrumentation has a finite life and it has been seen that channel 15 on the turbine is already intermittent. Run test scenarios on the non-instrumented torque converter and then repeat test on the instrumented.

- Install a smaller inertia drive dynamometer and apply similar control strategy as developed for torque converter research [46]. This setup would allow for oscillating excitation as an input instead of a constant drive torque. An oscillating input torque would mimic closer to that of an engine and may open the window for more detailed analysis of the hydraulic interaction between the torque converter and transmission.

- Continued shift profile development is necessary as only a selected few were studied. Other operating conditions may show additional insight to the hydraulics. Power-off shifts was determined to be a point of interest late into the research and was not able to be part of this study.

- Replace the NI 9234 card that is currently being used for triggering the shift events with a NI card that has built in triggering capabilities, such as NI 9205 or 9206. Purchase this for the test cell if continued testing is of interest because NI 9234 is on loan from Dr. Blough.

\subsection{Instrumentation Recommendations}

- On future instrumentation projects, the addition of thermal couples for the inlet and outlet of the torque converter would provide additional insight. By 
knowing the temperature for the torque converter a better understanding of what the instrumentation is experiencing can give a better estimation on instrumentation life.

- When dealing with transient testing, try to get as many key transducers to be simultaneous. It is understood that packaging is the reason for the multiplexed transmitted data. When packaging limitations are not restricted simultaneous channels should be used. For example, since the transmitter for the impeller and cover are on the outside of the torque converter cover. By having simultaneous channels, the number of times to repeat a test can be reduced and additional correlations, such as cross-spectrums and frequency response functions, can be calculated.

- When multiplexed transmitted data is required use the same number of channels, preferably all 7 channel transmitters instead of 15 , to reduce the number of times a test has to be reran. It was also found that the 7 channel transmitters take less time to power down to resync than the 15 channel transmitter, thus reducing the total test time. 


\section{References}

1. Hachisuwa, I., et al., Development of Compact Torque Converter with New Multiple Disk Clutch for Toyota New FWD Eight-Speed Transmission Direct Shift$8 A T$. 2017, SAE International.

2. Robinette, D. and T. Skrzycke, A Dual Clutch Torque Converter for Dual Input Shaft Transmissions. 2013, SAE International.

3. The Design of a Single-Stage Three-Element Torque Converter. 1961, SAE International.

4. Bai, S., J. Maguire, and H. Peng, Dynamic Analysis and Control System Design of Automatic Transmissions. 2013: SAE International.

5. De Jesus Rivera, E., Blade Induced Tipe Loading on a $310 \mathrm{~mm}$ Torque Converter Turbine Blade, in Mechanical Engineering. 2003, Michigan Technological University.

6. Sweger, P.O., C.L. Anderson, and J.R. Blough, Measurements of Strain on $310 \mathrm{~mm}$ Torque Converter Turbine Blades. International Journal of Rotating Machinery, 2004. 10(1): p. 55-63.

7. By, R.R. and B. Lakshminarayana, Static Pressure Measurement in a Torque Converter Stater. 1991, SAE International.

8. Numazawa, A., et al., An Experimental Analysis of Fluid Flow in a Torque Converter. 1983, SAE International.

9. Brun, K. and R.D. Flack, The Flow Field Inside an Automotive Torque Converter: Laser Velocimeter Measurements. 1996, SAE International.

10. Anderson, C.L., et al., Experimental Investigation of Cavitation Signatures in an Automotive Torque Converter Using a Microwave Telemetry Technique. International Journal of Rotating Machinery, 2003. 9(6).

11. Mekkes, J.A., Carl \& Narain, Amitabh, Static Pressure Measurements and Cavitation Signatures on the Nose of a Torque Converters Stator Blades. 2004.

12. Robinette, D.L., Detecting and predicting the onset of cavitation in automotive torque converters. 2007: Thesis (Ph.D.)--Michigan Technological University, 2007.

13. Pohl, B., Transient Torque Converter Performance, Testing, Simulation and Reverse Engineering. 2003, SAE International. 
14. Robinette, D., M. Grimmer, and R. Beikmann, Dynamic Torque Characteristics of the Hydrodynamic Torque Converter. SAE International Journal of Passenger Cars - Mechanical Systems, 2011. 4(2): p. 1023-1032.

15. Robinette, D., et al., Torque Converter Clutch Optimization: Improving Fuel Economy and Reducing Noise and Vibration. 2011, SAE International.

16. Throop, M.J. and D.G. McWatt, Slipping Torque Converter Clutch Interface Temperature, Pressure and Torque Measurements Using Inductively Powered Radiotelemetry. 1997, SAE International.

17. Otanez, P., et al., Aggressive Torque Converter Clutch Slip Control and Driveline Torsional Velocity Measurements. 2008, SAE International.

18. Kono, K., et al., Torque Converter Clutch Slip Control System. 1995, SAE International.

19. Rivera, E.D.J., et al., CFD Correlation of a Torque Converter with 29 Pressure Transducers.

20. Chen, J. and G. Wu, Numerical Investigation of Jet-Wake and Secondary Flows in a Hydrodynamic Torque Converter. 2017, SAE International.

21. Sawkar, N.A., P. Modi, and M. Fingerman, Numerical Investigation of Flow Induced Excitations in a Torque Converter. 2017, SAE International.

22. Tsangarides, M.C., W.E. Tobler, and C.R. Heermann, Interactive Computer Simulation of Drivetrain Dynamics. 1985, SAE International.

23. Yamaguchi, T. and K. Tanaka, Transient Flow Field Analysis Around a Lockup Clutch Inside a Torque Converter. 2012, SAE International.

24. Rivera, E.D.J., Pressure Measurements Inside Multiple Cavities of a Torque Converter and CFD Correlation, in Mechanical Engineering. 2018, Michigan Technological University.

25. CHASE, H., PRACTICE AND THEORY IN CLUTCH DESIGN. 1921, SAE International.

26. Dundore, M.W. and R.C. Schneider, Clutch Energy - A Criteria of Thermal Failure. 1968, SAE International.

27. Mohire, S., et al., Derivation of Test Schedule for Clutch Using Road Load Data Analysis and Energy Dissipation as Basis. 2018, SAE International. 
28. Devlin, M., et al., Effect of Fluid Flow through Clutch Material on Torque Fluctuations in Clutches. 2016, SAE International.

29. Iqbal, S., et al., Experimental Characterization of Drag Torque in Open MultiDisks Wet Clutches. 2013, SAE International.

30. Okamoto, D., A Study on Friction Characteristics at Low Pressure Slip Condition of Wet - Clutch. 2014, SAE International.

31. Martin, B., et al., 62TE 6-Speed Transaxle for Chrysler Group. 2007, SAE International.

32. Ota, H., et al., Toyota's World First 8-Speed Automatic Transmission for Passenger Cars. 2007, SAE International.

33. Scherer, H., M. Bek, and S. Kilian, ZF New 8-speed Automatic Transmission $8 H P 70$ - Basic Design and Hybridization. SAE International Journal of Engines, 2009. 2(1): p. 314-326.

34. Stuhldreher, M., et al., Testing and Benchmarking a 2014 GM Silverado 6L80 Six Speed Automatic Transmission. 2017, SAE International.

35. Watechagit, S. and K. Srinivasan, Modeling and Simulation of a Shift Hydraulic System for a Stepped Automatic Transmission. 2003, SAE International.

36. Zheng, Q. and K. Srinivasan, Transmission Clutch Pressure Control System: Modeling, Controller Development and Implementation. 2000, SAE International.

37. Robinette, D., et al., Performance Characterization of Automatic Transmission Upshifts with Reduced Shift Times. SAE International Journal of Engines, 2015. 8(3): p. 1359-1373.

38. Robinette, D., A Two Degree of Freedom, Lumped Inertia Model for Automatic Transmission Clutch-to-Clutch Shift Dynamics. SAE International Journal of Passenger Cars - Mechanical Systems, 2014. 7(3): p. 1163-1174.

39. Deur, J., et al., Modeling of Wet Clutch Engagement Including a Thorough Experimental Validation. 2005, SAE International.

40. Yin, X., et al., Shift Quality Improvement through Integrated Control of Dual Clutches Pressure and Engine Speed for DCT. 2014, SAE International.

41. Woodland, M., et al., Testing Methods and Signal Processing Strateqies for Automatic Transmission Transient Multiplexed Pressure Data. SAE International, 2019. 
42. Blough, J.R., S.M. Dumbacher, and D.L. Brown, Time Scale Re-Sampling to Improve Transient Event Averaging. 1997, SAE International. p. 3028-3036.

43. Mendenhall, W. and T. Sincich, Statistics for the Engineering and Computer Sciences. 1984: Dellen Publishing Company.

44. IR Telemetrics, I.-G.L.B., P.E., IR Telemetrics Signal Evolution.

45. Juvinall, R.C. and K.M. Marshek, Fundamentals of Machine Component Design. Vol. 3rd. John Wiley \& Sons, Inc.

46. Mordorski, E., Development of Dynamic Torsional Actuator for Torque Converter Clutch Characterization, in Mechanical Engineering. 2018, Michigan Technological University.

47. SAE No. 2 Friction Test Machine Durability Test. 2012, SAE International. 


\section{A Copyright Permission}

\section{A.1 Edward De Jesus Rivera Dissertation Reference Permission}

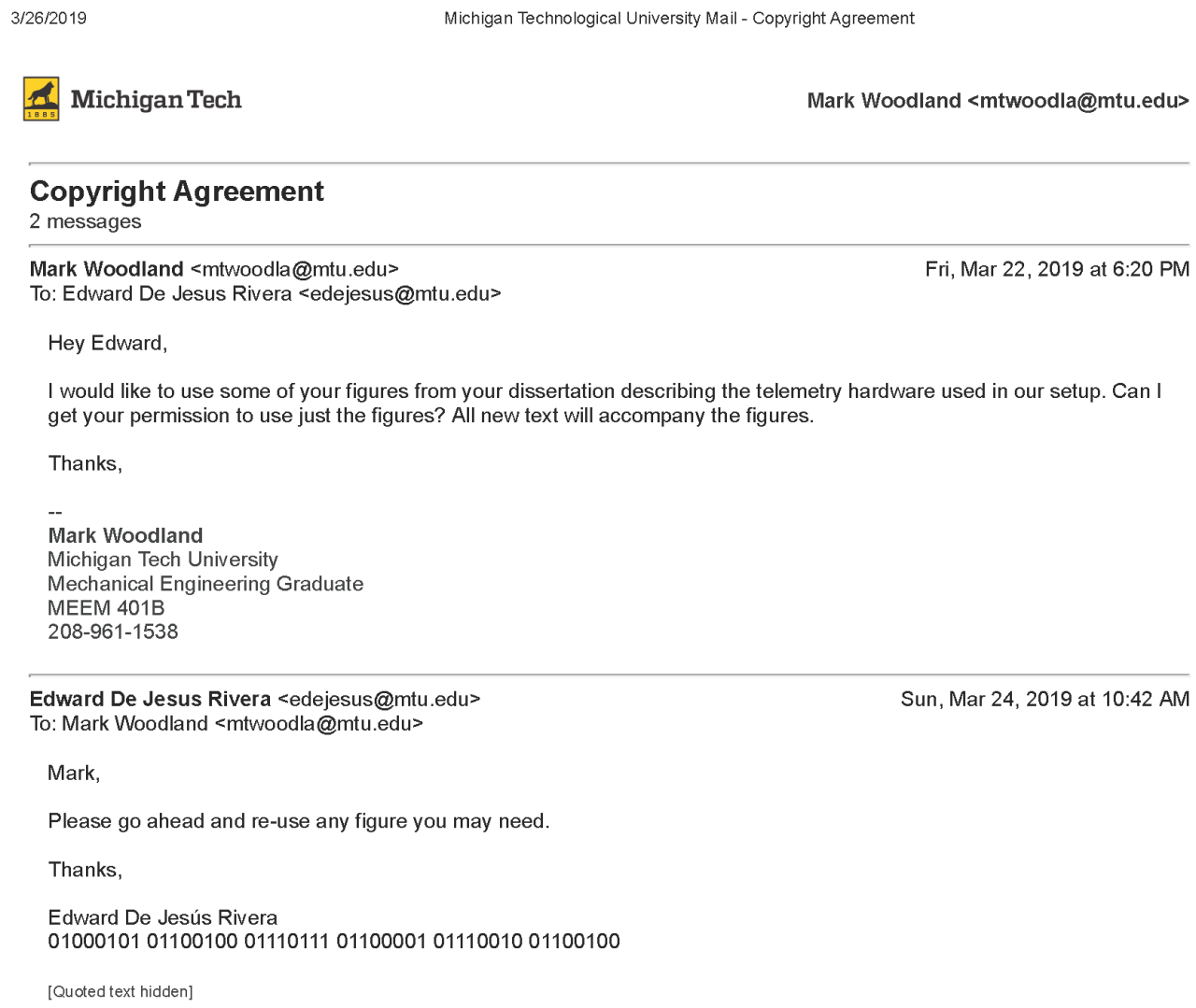

Mark Woodland <mtwoodla@mtu.edu> 


\section{A.2 SAE Copyright agreement for Transient Testing in Methods Section}

("Work"). If the Work is a work-made-for-hire pursuant to 17 USC Â§ 101 of the Copyright Act, then such undersigned entity (e.g. employer) shall be deemed the Author for purposes of this Assignment.

Assignor represents, warrants and guarantees, either individually or on behalf of all co-authors, that (1) the Work is an original unpublished work; (2) Assignor is the sole and exclusive owner and claimant of all right, title and interest in and to the Work, including all copyrights therein unless otherwise documented through a permissions release, and neither the Work nor copyrights have been assigned, transferred or otherwise encumbered; (3) the Work contains no material whose publication would violate any copyright or other personal or proprietary right of any person or entity; (4) the Work is not a work made for the United States Government; and (5) Assignor has the authority to transfer the rights to Assignee and cause this Agreement to be executed as of the date first written above.

Assignor further represents, warrants and guarantees, to the best of Assignor's knowledge and ability, that the Work is NOT controlled for export from the United States to any non-U.S. person or any other nation under the International Traffic in Arms Regulations (22 CFR Parts 120-130) or the Export Administration Regulations (15 CFR Parts 730-774) and, accordingly, may be modified, used, copied, distributed or circulated by SAE, in whole or in part, without any export licenses under the foregoing regulations.

Assignor hereby assigns to SAE all rights, titles and interest in and to Assignor's copyright in the Work in the exclusive rights: (1) to reproduce the Work in all media now known or hereinafter devised; (2) to distribute copies of the Work in all media now known or hereinafter devised; and (3) to prepare derivative works based upon the Work including, for example, but not limited to, the right with respect to all or part of the Work to edit, annotate, comment, format/reformat and abstract the Work or incorporate it into a compilation collection or other work. No other exclusive rights in the Work are hereby assigned.

Assignor agrees that it shall not dispute, contest, or aid or assist others in disputing or contesting, either directly or indirectly, SAE's exclusive right, title and interest in the Work and in any and all compilations, collective works and derivative works based on the Work, including copyrights therein or other proprietary rights therein claimed by SAE.

Assignor agrees that, for no additional compensation, Assignor will execute any and all documents that may be necessary to assist SAE to register, perfect and enforce SAE's rights in and to the Work and any and all compilations, collective works and derivative works based on the Work.

SAE hereby grants Assignor the nonexclusive right to reproduce and publicly distribute the Work in print/film format for one (1) year and in electronic/optical media for five (5) years following a six (6) month embargo after first publication, either in print or digitally, by SAE. Any such reproduction or distribution of the Work shall include the SAE copyright notice thereon and shall not be offered for sale or used to imply endorsement by SAE of a service or product. The Assignor may also post an electronic version of the accepted Work to an institutional repository, but not the final typeset Work. Nothing herein shall prohibit Assignor's reproduction and noncommercial distribution of the Work for its own use. 


\section{B Main Test Stand Drawing}

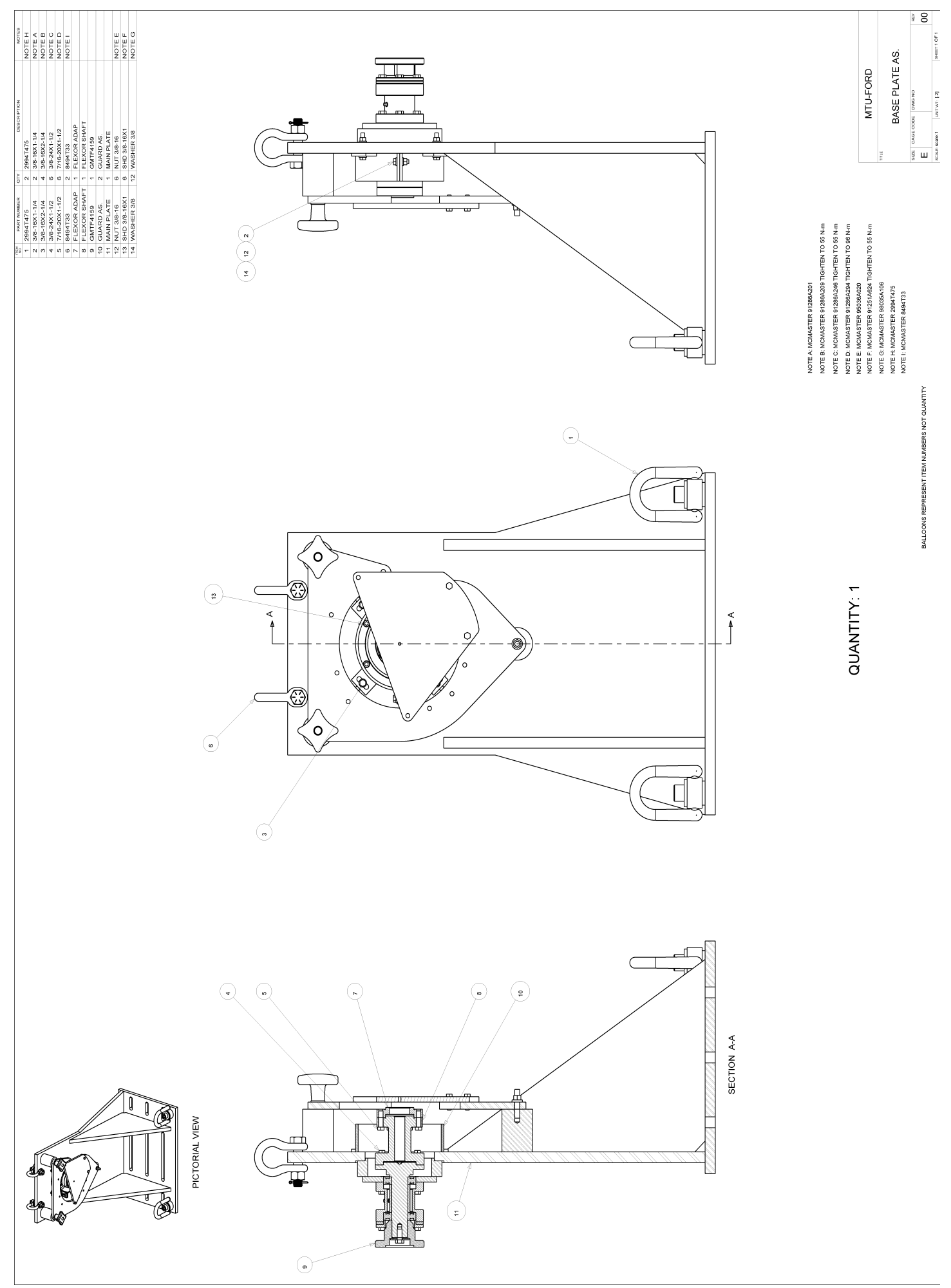




\section{Channel Calibration List}

\begin{tabular}{|c|c|c|c|c|c|}
\hline $\begin{array}{l}\text { Channel } \\
\text { Number }\end{array}$ & Channel Name & DAQ Name & Sensitivity & Units & Offset \\
\hline 3 & $\begin{array}{c}\text { Tachometer- Input } \\
\text { Dyno }\end{array}$ & DC_Tach & 1.001 & $\mathrm{mV/RPM}$ & 35.836 \\
\hline 4 & $\begin{array}{l}\text { Tachometer- } \\
\text { Output Dyno }\end{array}$ & AC_Tach & -1.033 & $\mathrm{mV} / \mathrm{RPM}$ & 41.423 \\
\hline 5 & Torque- Input Dyno & DC_Torque & -4.936 & $\mathrm{mV} / \mathrm{Nm}$ & $\overline{-}$ \\
\hline 6 & $\begin{array}{l}\text { Torque- Output } \\
\text { Dyno }\end{array}$ & AC_Torque & 1.2147 & $\mathrm{mV} / \mathrm{Nm}$ & 0.2309 \\
\hline 7 & $\begin{array}{l}\text { Tachometer- } \\
\text { Turbine Speed } \\
\text { Sensor }\end{array}$ & TSS_Tach & \multicolumn{3}{|c|}{36 pusles per revolution } \\
\hline 8 & $\begin{array}{l}\text { Tachometer- } \\
\text { Output Speed } \\
\text { Sensor }\end{array}$ & OSS_Tach & \multicolumn{3}{|c|}{24 pusles per revolution } \\
\hline 9 & $\begin{array}{l}\text { Pressure- } \\
\text { Transmission Inlet }\end{array}$ & Trans_IN_Pressure & 33.3163 & $\mathrm{mV} / \mathrm{PSI}$ & 0 \\
\hline 10 & $\begin{array}{c}\text { Pressure- } \\
\text { Transmission Outlet }\end{array}$ & Trans_OUT_Pressure & 33.3 .3156 & $\mathrm{mV} / \mathrm{PSI}$ & 0 \\
\hline 11 & Pressure- Line & LINE_Pressure & 33.317 & $\mathrm{mV} / \mathrm{PSI}$ & 0 \\
\hline 12 & $\begin{array}{c}\text { Pressure- Variable } \\
\text { Bleed Solenoid } \\
\text { TCC }\end{array}$ & VBS_TCC_Pressure & 33.27 & $\mathrm{mV} / \mathrm{PSI}$ & 0 \\
\hline 13 & CB26 Pressure & CB26_Pressure & 33.33 & $\mathrm{mV} / \mathrm{PSI}$ & 0 \\
\hline 14 & $\begin{array}{c}\text { Pressure- Solenoid } \\
\text { Feed }\end{array}$ & SOL_FEED_Pressure & 33.335 & $\mathrm{mV} / \mathrm{PSI}$ & 0 \\
\hline 15 & Pressure- CB 1234 & CB1234_Pressure & 36.116 & $\mathrm{mV} / \mathrm{PSI}$ & 0 \\
\hline 16 & Pressure- CBLR & CBLR_Pressure & 33.587 & $\mathrm{mV} / \mathrm{PSI}$ & 0 \\
\hline 17 & $\begin{array}{l}\text { Pressure- TCC } \\
\text { Apply }\end{array}$ & TCC_APPLY_Pressure & 31.97 & $\mathrm{mV} / \mathrm{PSI}$ & 0 \\
\hline 18 & $\begin{array}{l}\text { Pressure- TCC } \\
\text { Release }\end{array}$ & TCC_REL_Pressure & 32.299 & $\mathrm{mV} / \mathrm{PSI}$ & 0 \\
\hline 19 & $\begin{array}{c}\text { Solenoid Driver- } \\
\text { SSA }\end{array}$ & SD1_SSA & 1000 & $\mathrm{mV} / \mathrm{V}$ & 0 \\
\hline 20 & $\begin{array}{l}\text { Solenoid Driver- } \\
\text { SSB }\end{array}$ & SD2_SSB & 1000 & $\mathrm{mV} / \mathrm{V}$ & 0 \\
\hline 21 & $\begin{array}{l}\text { Solenoid Driver- } \\
\text { SSC }\end{array}$ & SD3_SSC & 1000 & $\mathrm{mV} / \mathrm{V}$ & 0 \\
\hline 22 & $\begin{array}{l}\text { Solenoid Driver- } \\
\text { SSD }\end{array}$ & SD4_SSD & 1000 & $\mathrm{mV} / \mathrm{V}$ & 0 \\
\hline 23 & $\begin{array}{c}\text { Solenoid Driver- } \\
\text { Line }\end{array}$ & SD5_Line & 1000 & $\mathrm{mV} / \mathrm{V}$ & 0 \\
\hline 24 & $\begin{array}{l}\text { Solenoid Driver- } \\
\text { TCC }\end{array}$ & SD6_TCC & 1000 & $\mathrm{mV} / \mathrm{V}$ & 0 \\
\hline 25 & $\begin{array}{l}\text { Solenoid Driver- } \\
\text { SSE }\end{array}$ & SD7_SSE & 1000 & $\mathrm{mV} / \mathrm{V}$ & 0 \\
\hline 26 & Flow Meter & Flow_Meter & 1000 & $\mathrm{mV} / \mathrm{V}$ & 0 \\
\hline
\end{tabular}




\begin{tabular}{|c|c|c|c|c|c|}
\hline 27 & $\begin{array}{c}\text { Tachometer- } \\
\text { Output Dyno Extra } \\
\text { tach for transient } \\
\text { events }\end{array}$ & AC_Tach2 & \multicolumn{3}{|c|}{60 pulses per revolution } \\
\hline 28 & Dyno Trigger & Dyno_Trigger & 1000 & $\mathrm{mV} / \mathrm{V}$ & 0 \\
\hline 29 & TOM Trigger & Arduino_Trigger & 1000 & $\mathrm{mV} / \mathrm{V}$ & 0 \\
\hline 31 & C35R Pressure & C35R_Pressure & 33.33 & $\mathrm{mV} / \mathrm{PSI}$ & 0 \\
\hline 32 & C456 Pressure & C456_Pressure & 33.33 & $\mathrm{mV} / \mathrm{PSI}$ & 0 \\
\hline 33 & $\begin{array}{c}\text { One Pulse Per } \\
\text { Revolution } \\
\text { Tachometer- Input } \\
\text { Dyno (DC) }\end{array}$ & DC_One_Tach & \multicolumn{3}{|c|}{1 pulse per revolution } \\
\hline 34 & $\begin{array}{c}\text { One Pulse Per } \\
\text { Revolution } \\
\text { Tachometer- } \\
\text { Output Dyno (AC) }\end{array}$ & AC_One_Tach & \multicolumn{3}{|c|}{1 pulse per revolution } \\
\hline
\end{tabular}




\section{Siemens Test Lab Guide}

DISCLAIMER: Test Lab has numerous functionalities and a variety of ways to achieve the same task. This guide is only to describe the methods that were used to acquire data for this research. A previous understanding about digital signal processing is required to set all parameters properly as this guide does not cover every setting in detail. It is very likely that there is additional functionality built into Test Lab that was missed and not used.

1. Turn on Scadas III DAQ and open Signature Acquisition on main desktop. The DAQ may take a few moments to initialize before the software will connect.

2. A new project is started when Signature Acquisition opens.

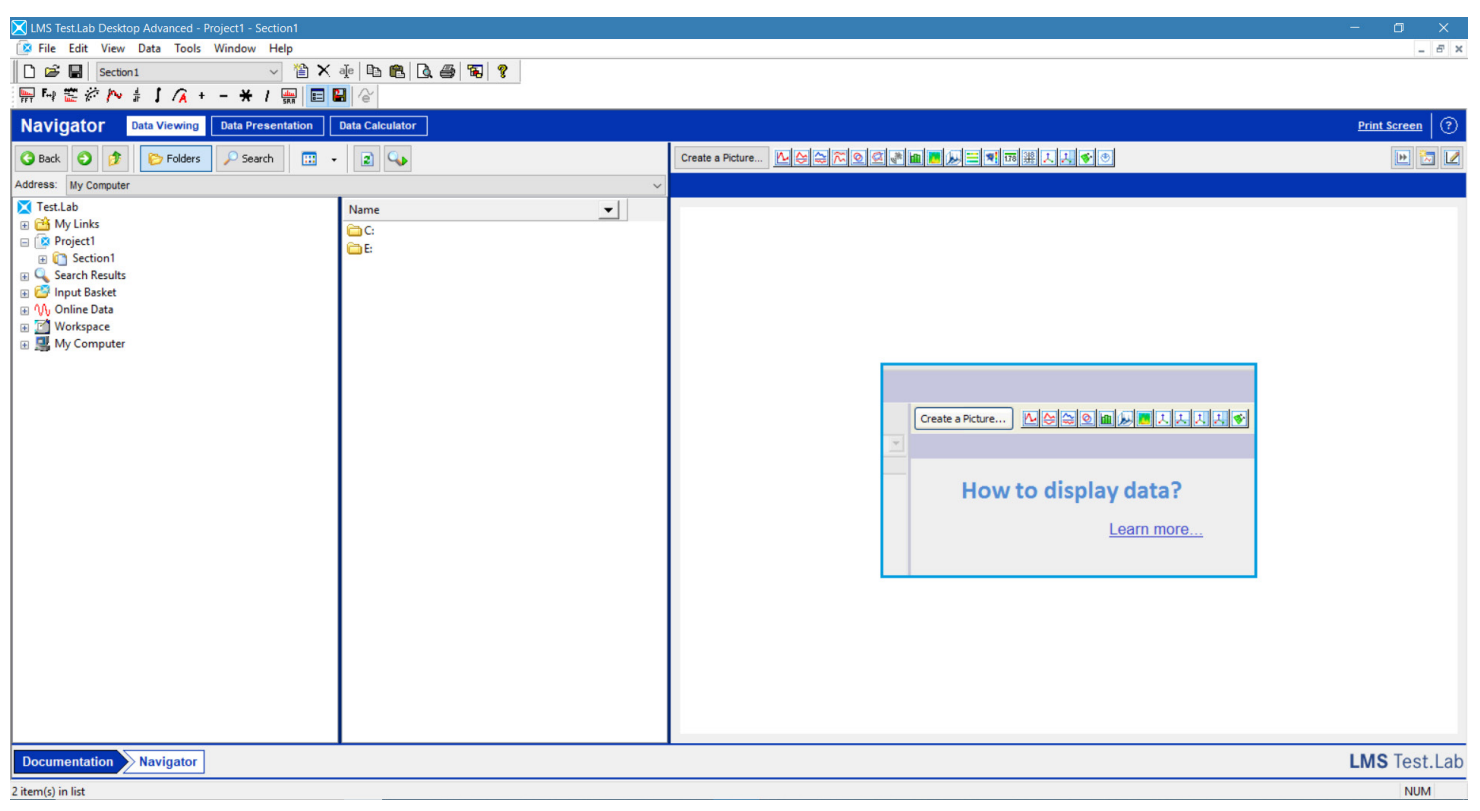

Figure D-1. Navigation pane for Test Lab

3. Open Transmission DAQ Setup saved in the Testing folder. At the bottom of the page there is a tab selector that switches between windows 


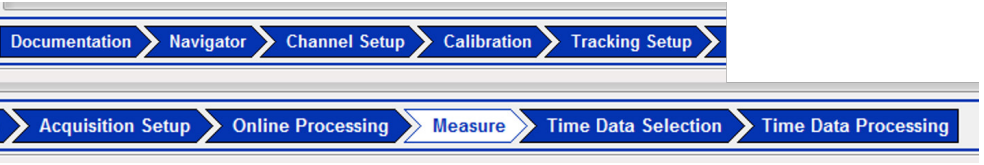

Figure D-2. Navigation bar to select Test Lab window

4. To setup new or edit existing channels select Channel Setup

5. In the channel setup the channels can be toggled on/off, names assigned, coupling type (AC, DC, ICP) selected, calibration values set, units applied and voltage operation range of the signal.

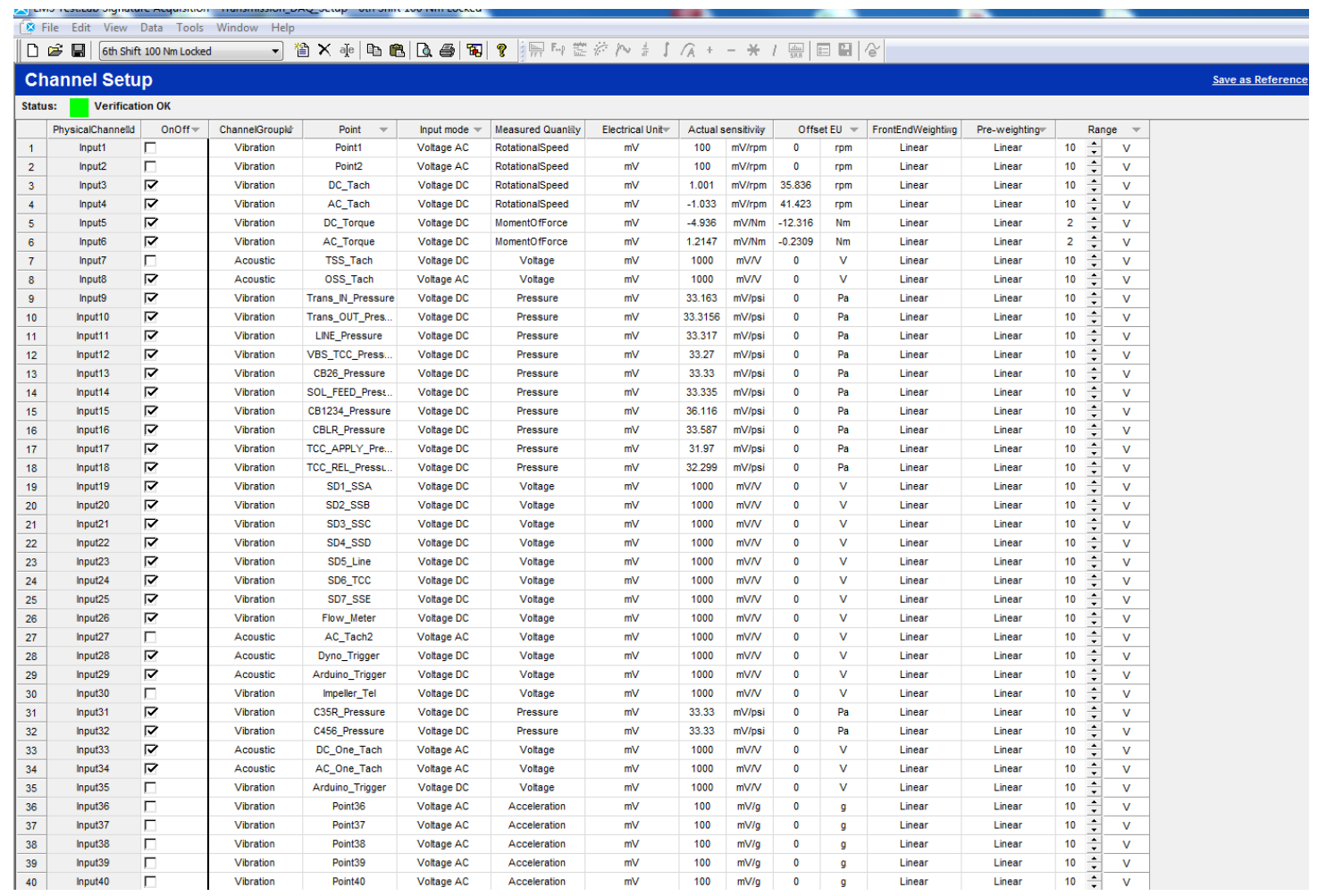

Figure D-3. Channel setup window

6. The calibration type is used if sensors are being calibrated live with Test Lab or, if the calibration values are known, the values can just be set in channel setup.

7. Under Tracking Setup, tachometer channels can be setup, such as turbine and output speed. The parameters are assigned using the controls on the 
right. For each tach channel the number of pulses per revolution must to get an RPM value.

8. The desired time length for recording data is set under Duration. To have recording set for trigger activation select Use Triggered Start. The recording can also end by a second trigger instead of a time limit by activating Use Triggered Stop.

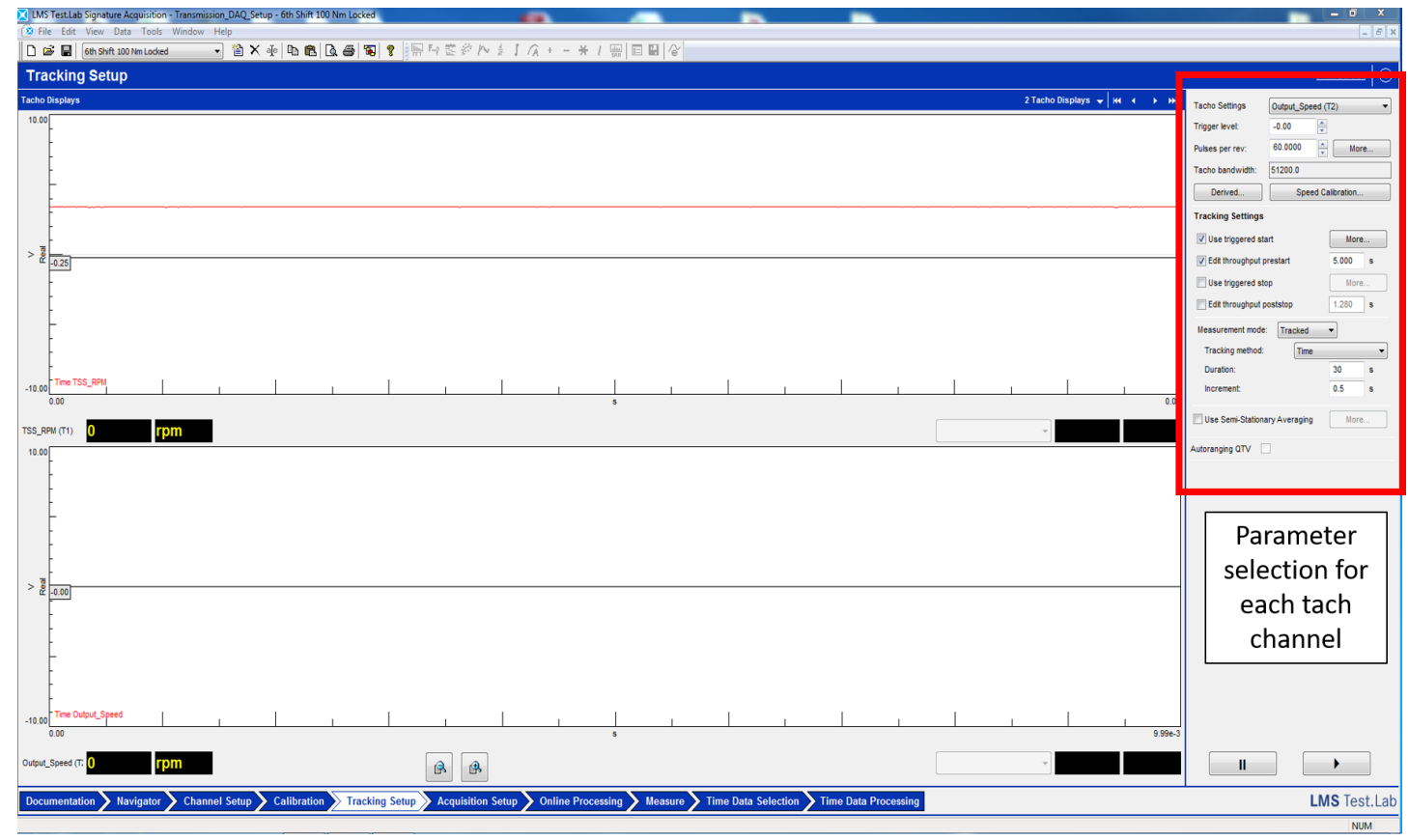

Figure D-4. Tracking setup window with turbine and output speed windows showing

9. Under Acquisition Setup window the sampling rate can be set for each channel type (Vibration, Acoustic, or Other). The current setup has the vibration and acoustic channels set to 6400 and $51200 \mathrm{~Hz}$ respectively. Acoustic channels include tachometer channels that are not measured using the tach card. 


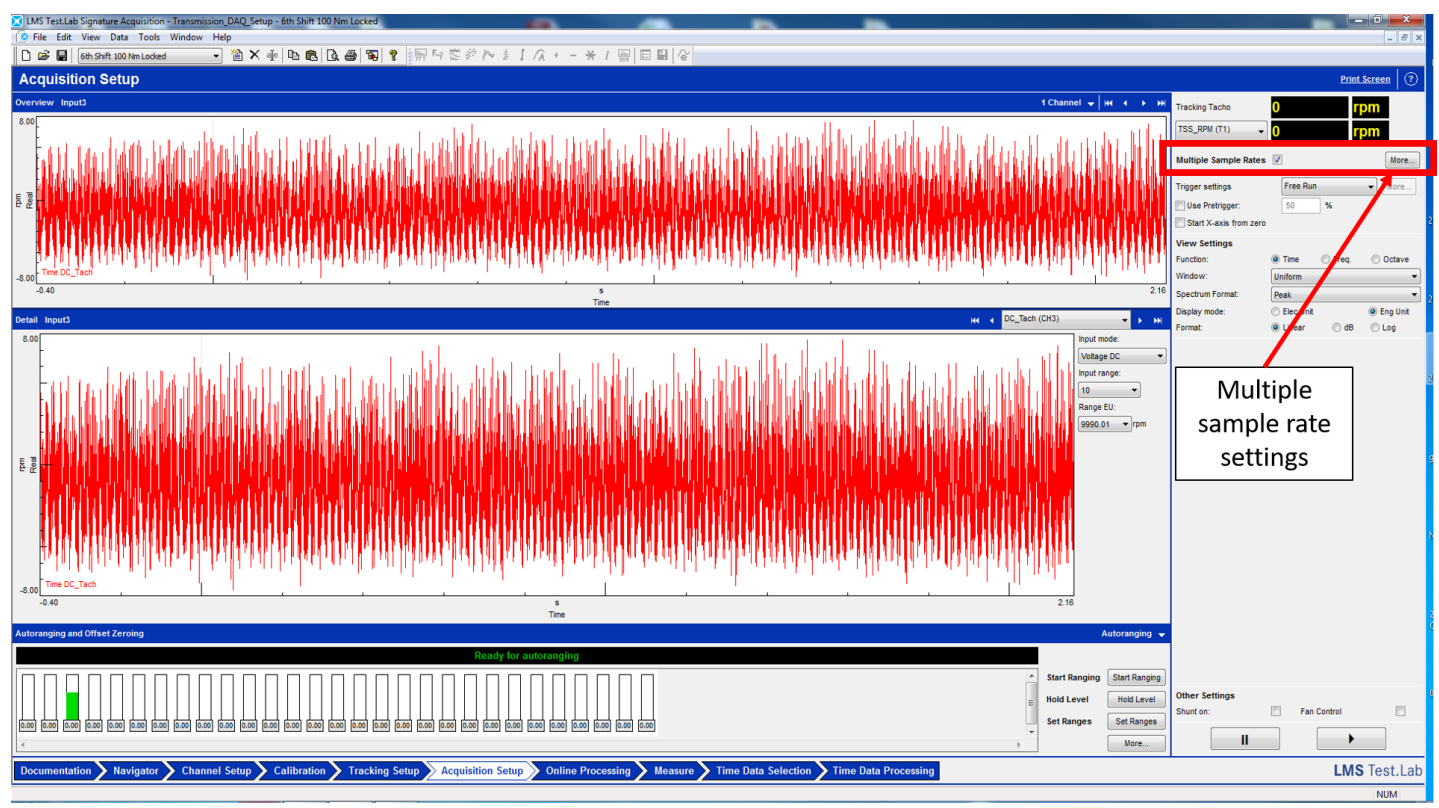

Figure D-5. Acquisition setup window pointing out sampling parameter settings

10. The Measure window is the most used when testing. This is where data is monitored and acquired. Once arming the DAQ the data will begin to stream across the plots. No data is recorded until commanded. Labeling in the green blocks describes what the system is currently doing and provides warnings. 


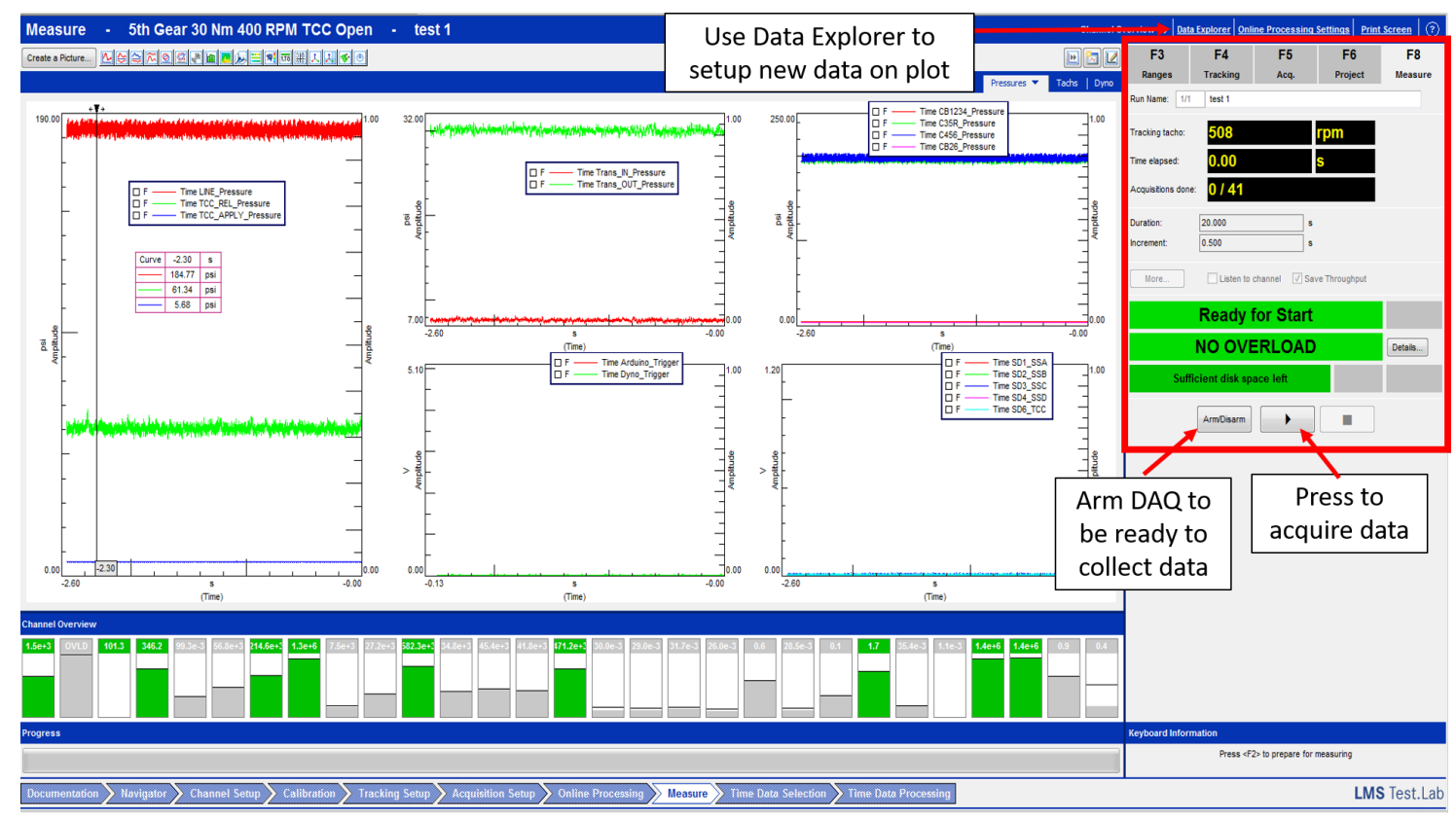

Figure D-6. Measurement window with pressure plot tab open

11. There are 3 tabs with different plots of data. First is pressure, second tachometers, and third dyno data. Additional or new channels can be added through Data Explorer.

12. Once data has been collected it can be analyzed in Test Lab or exported to Matlab. In the navigator window, select the Throughput from the test run and right click to export to Matlab. Figure D-7 shows the export process. Currently, each test run has to be exported individually, but a better method of exporting may be a worthwhile exploration. 


\begin{tabular}{|l|l|l|l|l|}
\hline LMS Test.Lab Desktop Advanced - Low_Speed_Shifting - 6th Shift 100 Nm Locked \\
\hline File Edit View Data Tools Window Help \\
\hline Navigator
\end{tabular}

34 item(s) in list

Figure D-7. Exporting data to Matlab in Navigator window 


\section{E Test Cell Startup and Operation Procedure}

1. Connect transmission output shaft to absorbing dyno and bolt shaft guard.

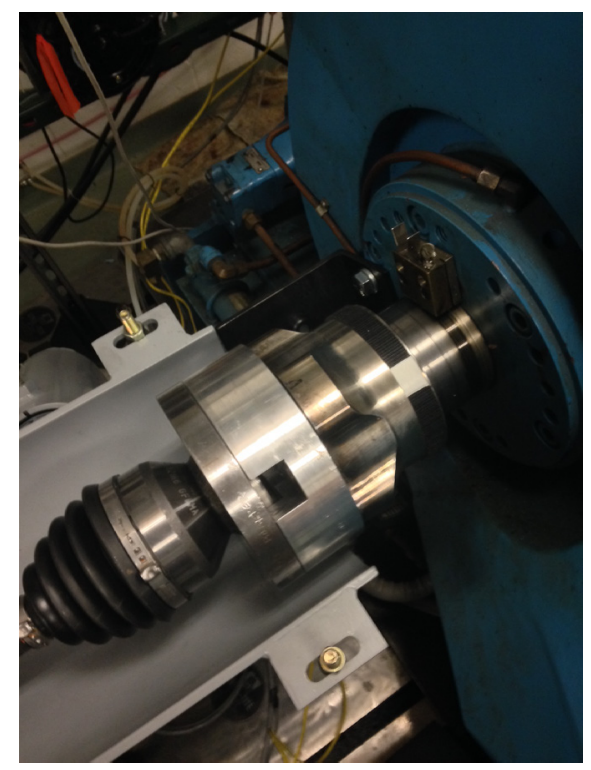

2. Turn on dyno power cabinets on upstairs.

3. Check oil pressure gauge on blue AC Dyno that journal bearings are pressurized.

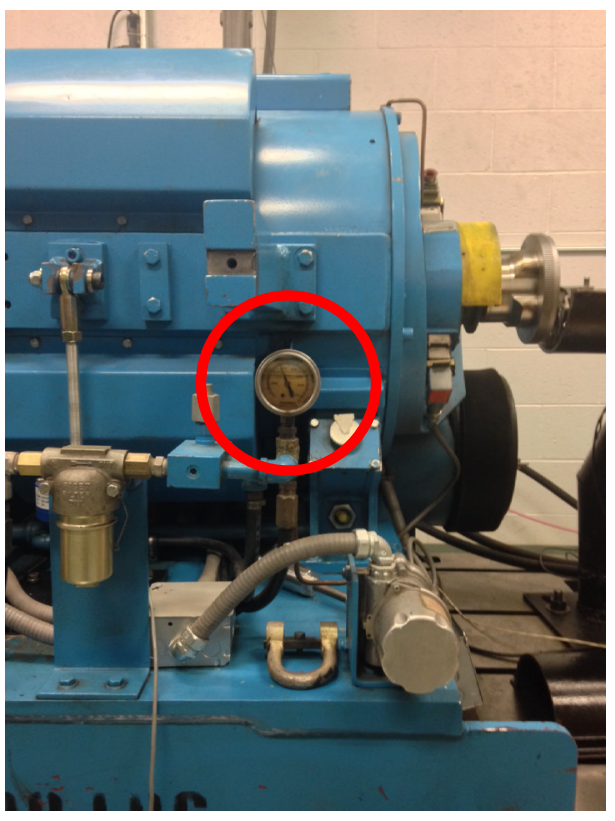


4. Check oil pressure through looking glasses on each end of tan DC Dyno. Small drops of oil should be dripping if oil pressure is on.

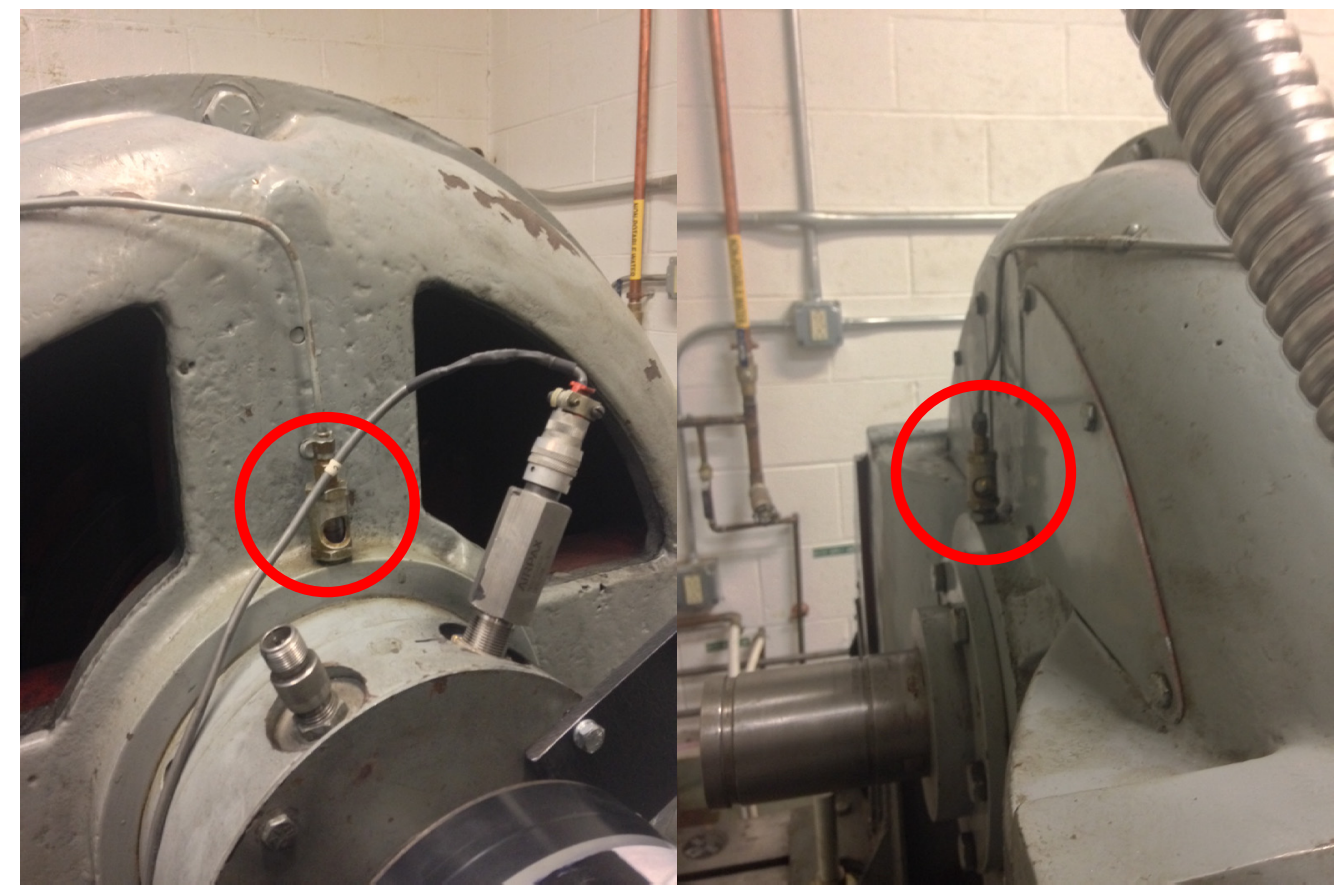

5. Set AC dyno direction to FORWARD on control tower.

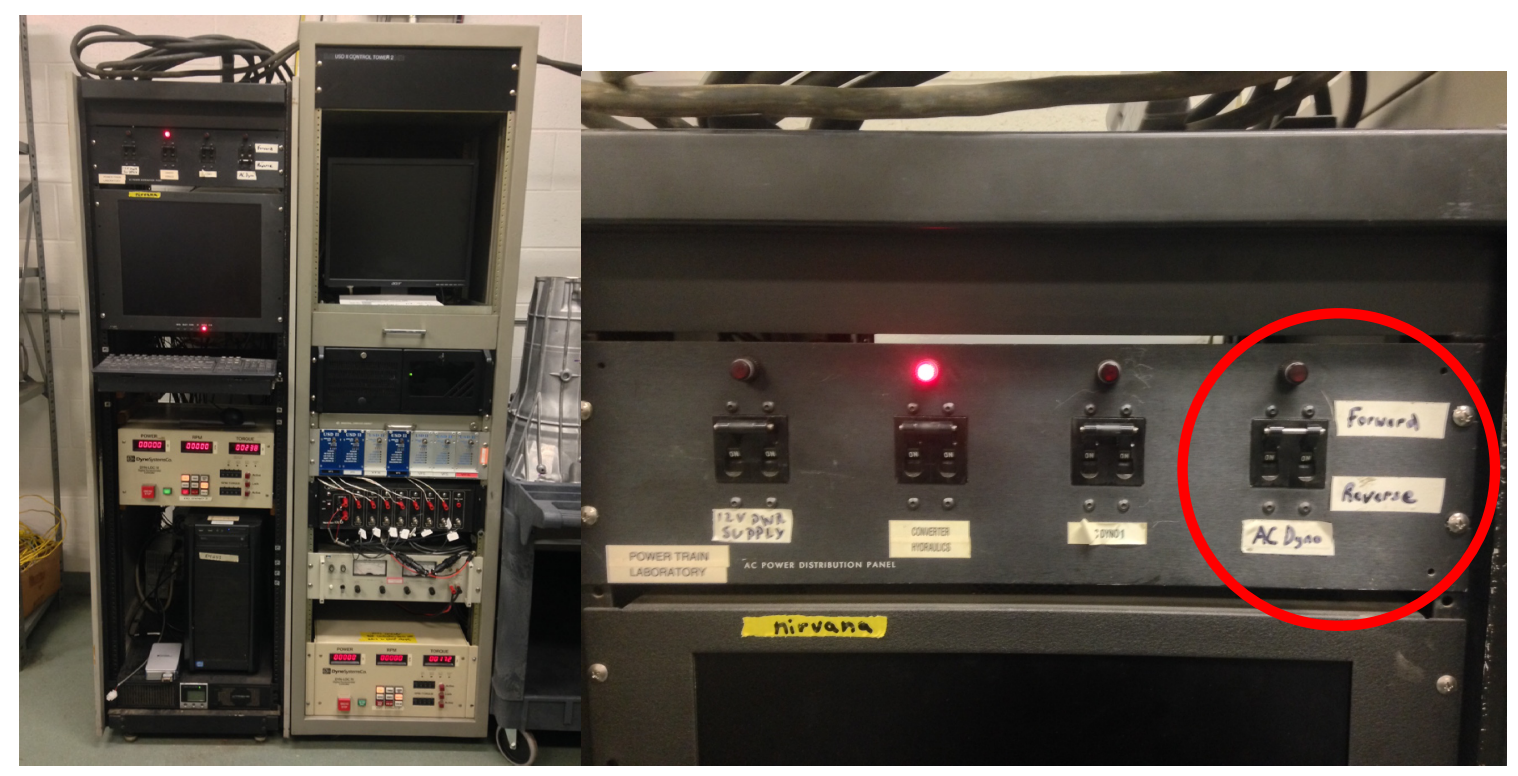


6. Turn power supply $\mathrm{ON}$, then transmission controller on transmission control tower.

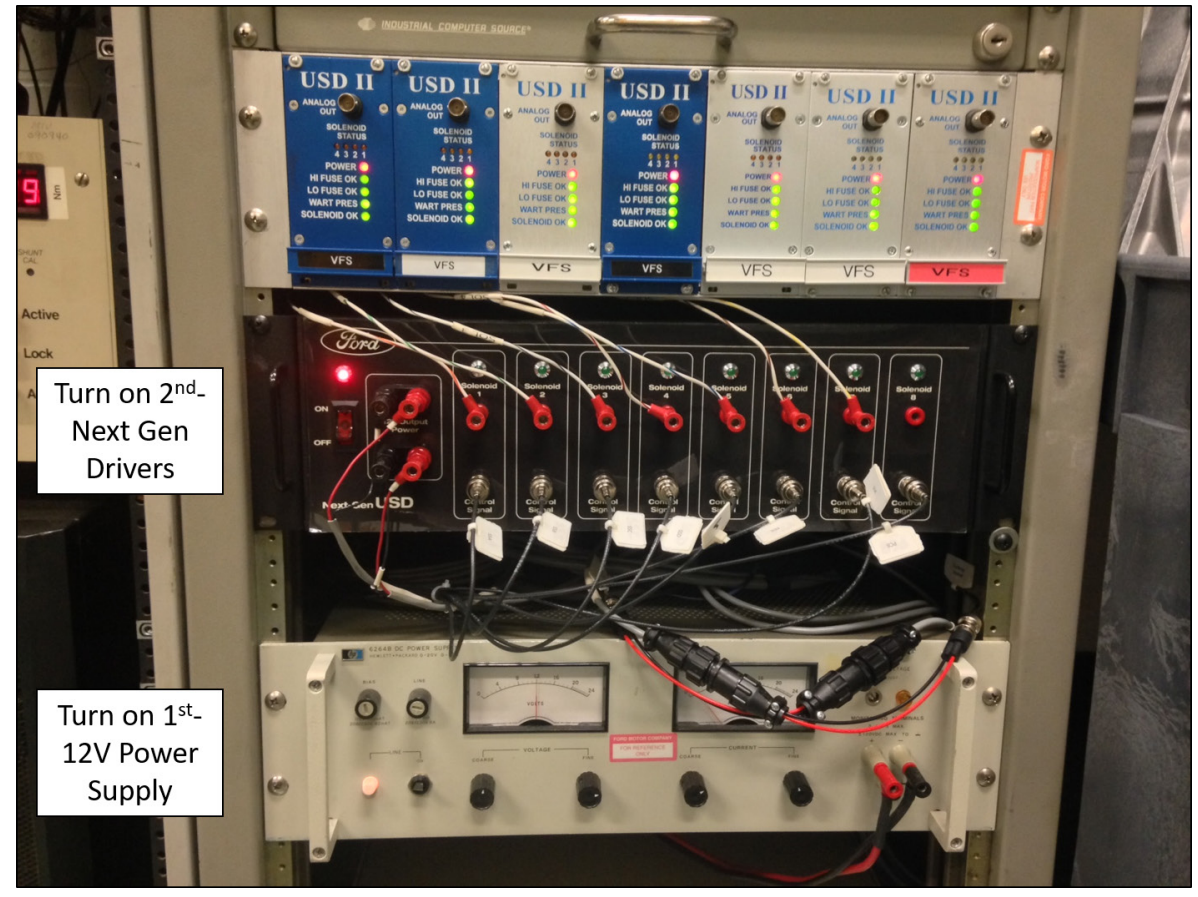

7. Turn instrumentation ON sitting on shelf

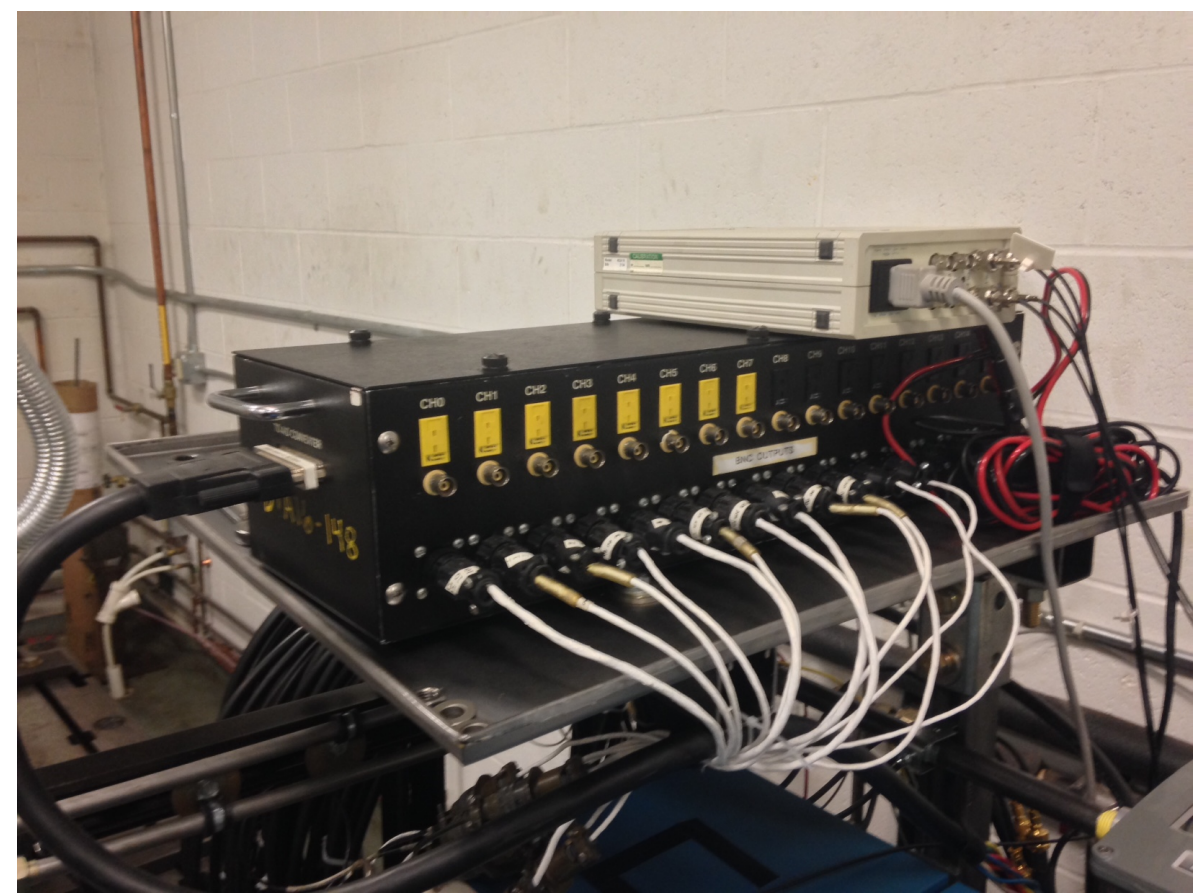


8. Remote desktop in to dyno control tower computer on middle computer.

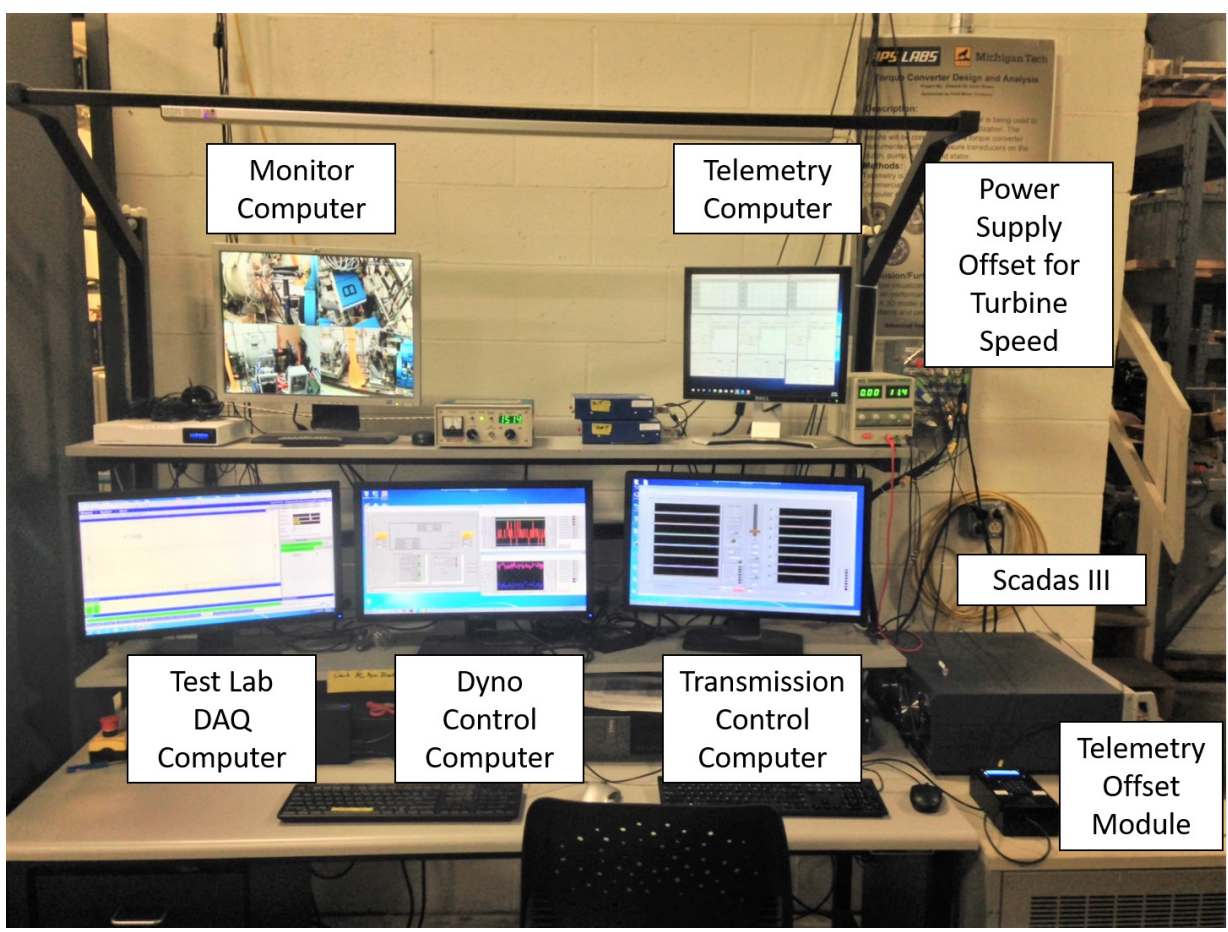

\section{Open Transmission LabVIEW VI.}

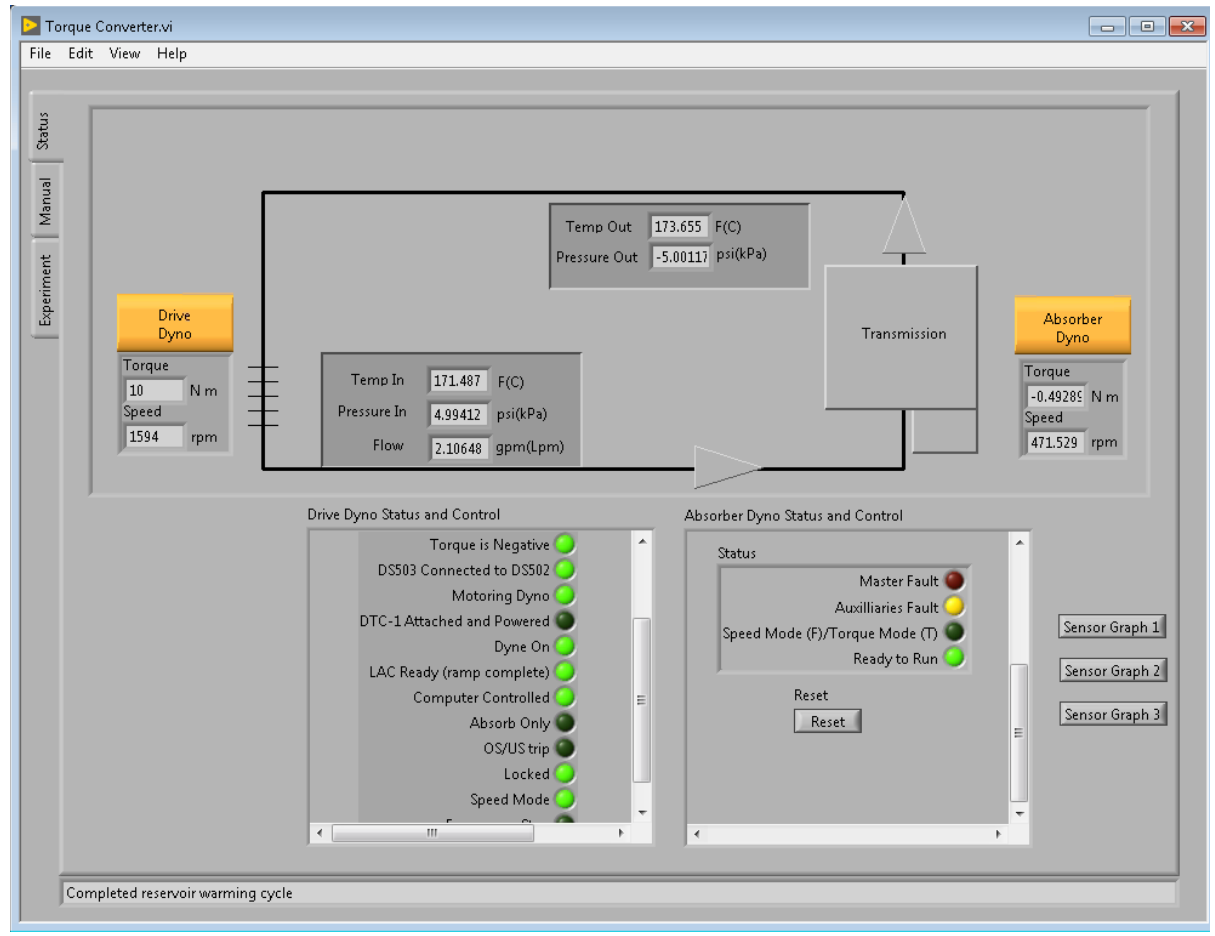


10. Turn top computer monitor $\mathrm{ON}$ for test cell cameras.

11. Turn power supply and Scadas III frontend system ON.

12. Open Signature Acquisition Test Lab on left computer.

13. Once channels are checked ON in Test Lab, verify channels are ready by looking for green lights on Scadas frontend.

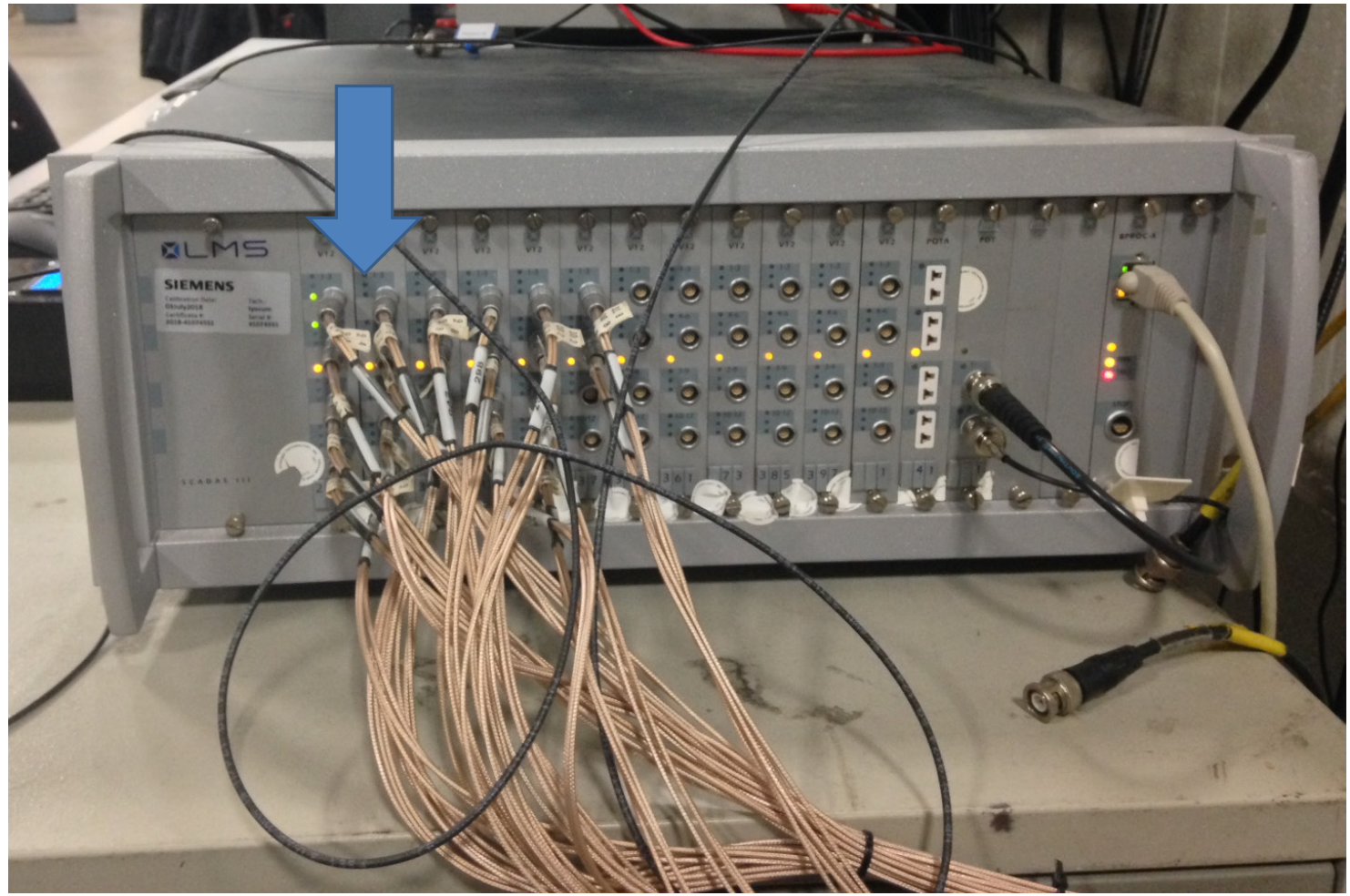

14. On far right computer remote desktop into Transmission Control tower computer and open Transmission Controller LabVIEW VI.

15. Transmission is ready to operate. Use manual or experiment mode to run. 


\section{F USDB II Operation Guide}

1. Connect the USD II rack mount to the transmission and turn on the power supply

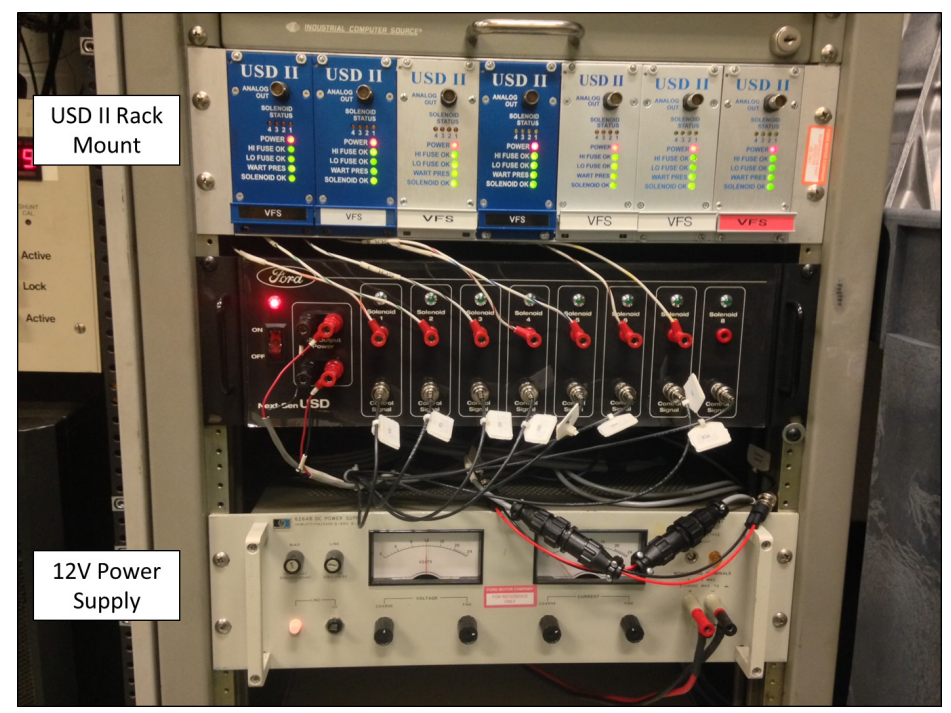

Figure F-1. Solenoid driver and power supply mounted in transmission control tower

2. Open Univ9600 on the remote desktop to the transmission control tower

3. The USD II will open a window with a control box for each solenoid on the left and command buttons on the right. 


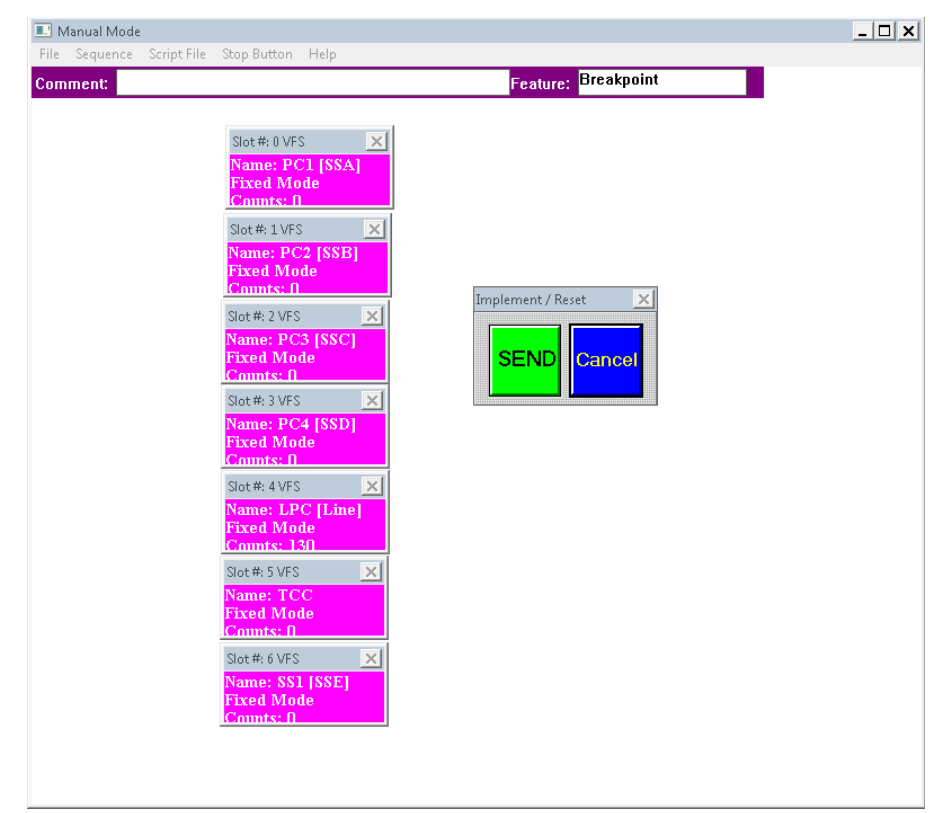

Figure F-2. Control window for USD II software

4. Set the pressure level by using SET DUTY CYCLE. Count range is 0 to 255 for off to max pressure, depending on if normally low or high solenoid.

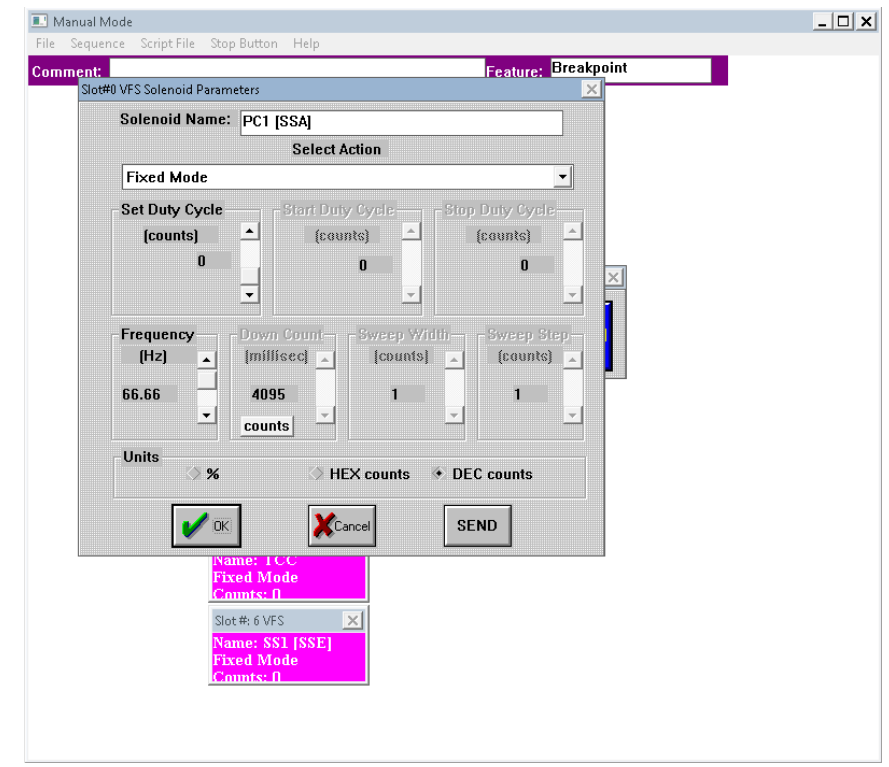

Figure F-3. Solenoid command window for each solenoid 
5. The default action for each of the drivers is FIXED MODE. Multiple modes can be selected from the list of built in operations. Each mode has a variety of commands that need to be filled in.

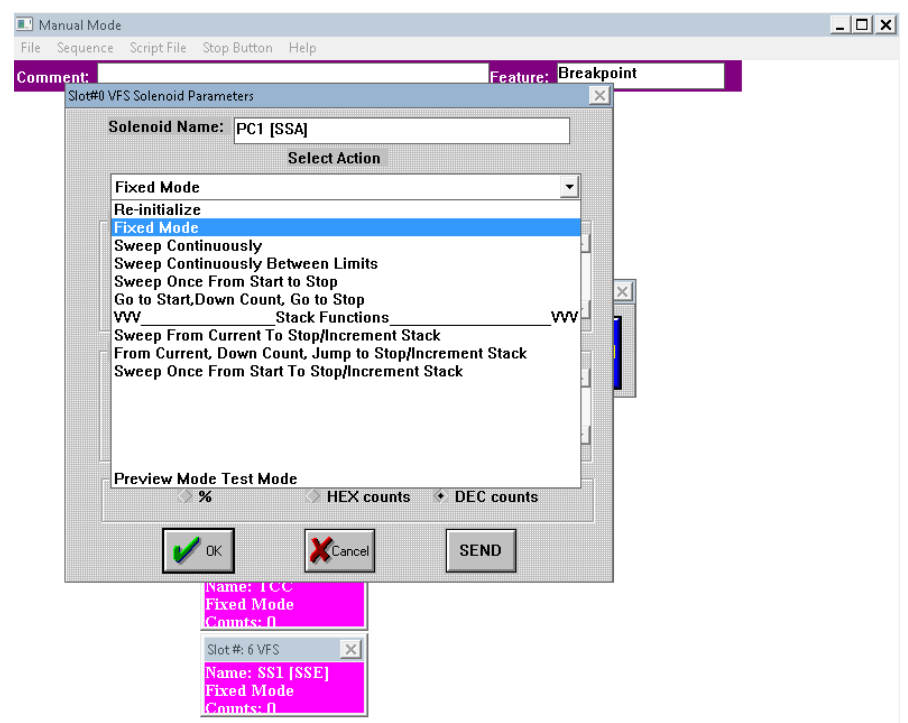

Figure F-4. Possible built in operations

6. The window will light up to indicate that commands are on standby to be sent to the transmission. Multiple commands can be stacked to be sent all at one time. 


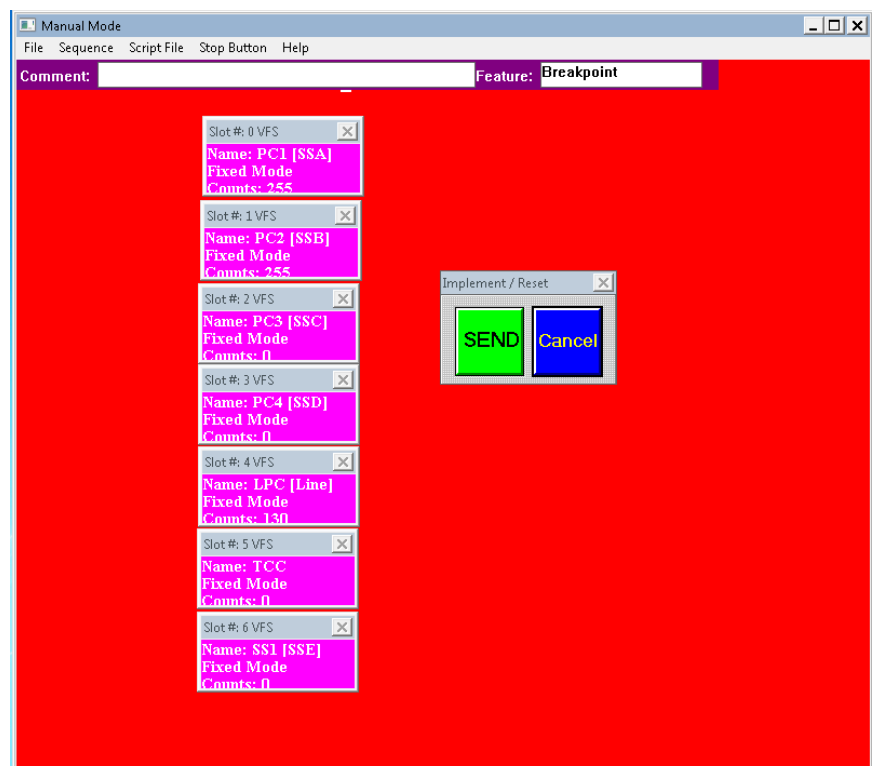

Figure F-5. Control window light up indicating commands are ready to send to transmission

7. Use the sequencer to write scripts to run multiple commands in a string. The sequence can be saved to be used later.

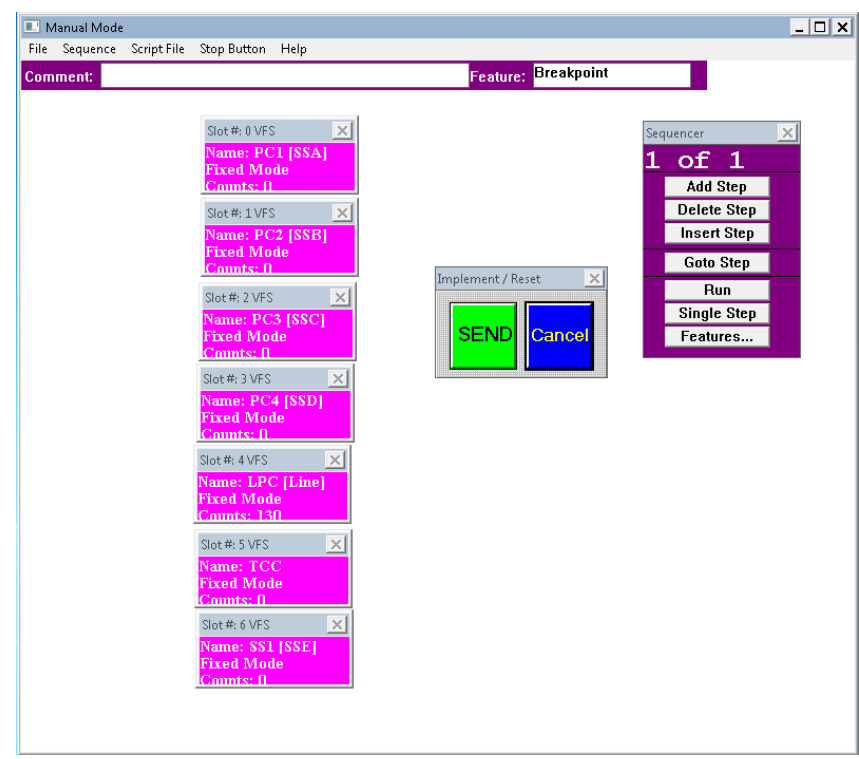

Figure F-6. Sequencer window to create a string of commands to run in a sequence. 


\section{G SOL Commander Guide}

There are three tabs in SOL Commander. Each that have unique controls that are used dependent on the necessary operation. The first control window is SOLENOIDS, which has similar capabilities as those of the USDB. Here each solenoid can be controlled individually and set to a specified current. A high and low limit can be set to have the solenoid sweep between the two values. All the solenoids can be synched together to have them sweep together. The sweep can be repeated by specifying the number of times to repeat the maneuver. The monitor window only shows the currently selected solenoid command. None of the commands are sent to the transmission until the ENGAGE button is activated. These controls are good for fixed gear testing.

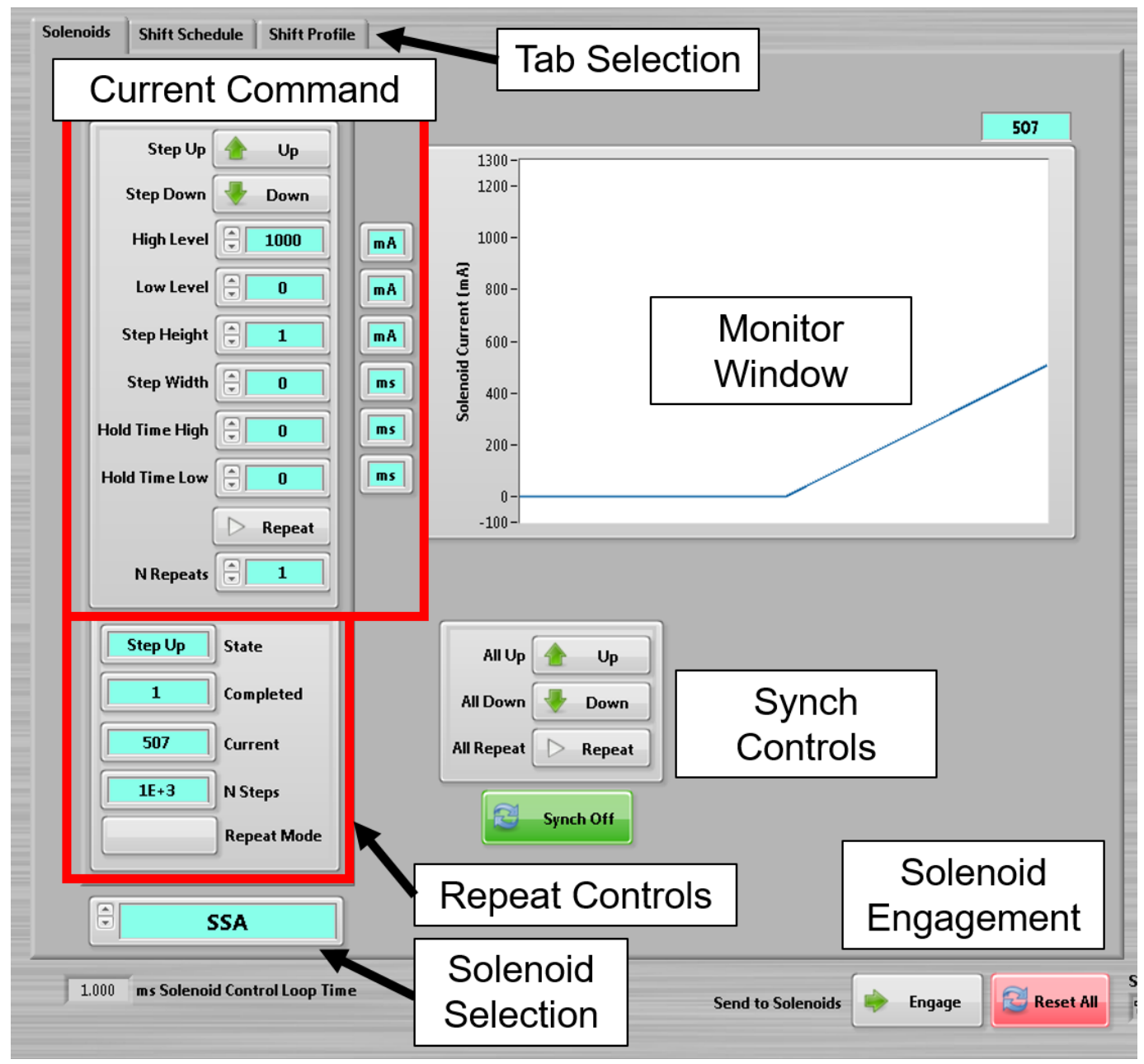


The second control window is SHIFT SCHEDULE. These controls specify which solenoid will be active for each gear state. First the number of speeds and solenoids are set for the application. Each solenoid is activated by turning the indicator ON/OFF for the respective gear. Labels can be added to identify the solenoids and gears for ease of array selection. Once a shift schedule is made it can be saved and reused for later testing.

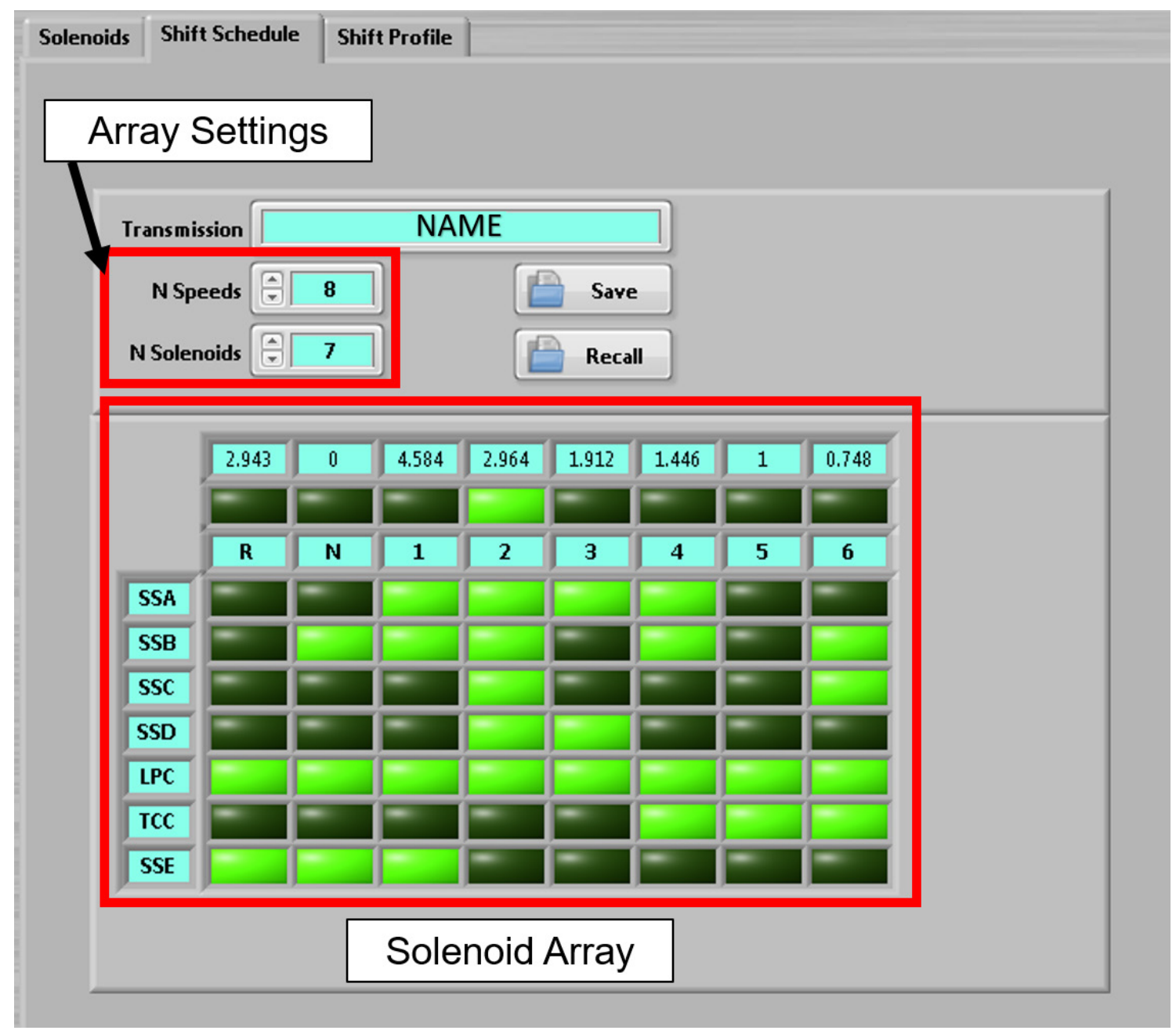


The final control window is called SHIFT PROFILE. This window is where shift profiles can be sent to the transmission and complete a shift during operation without damaging the transmission. The profiles are placed in a text file with the values and time steps for each of the solenoids, as shown in the table below. The table of values can be loaded by using the LOAD NEW PROFILE and a profile can be set for each gear by using the shift lever (described in detail in later section). Only one profile can be loaded for each gear so only an upshift or downshift can be accomplished for that gear. (Additional development should be done so both upshift and downshift profiles can be loaded simultaneously). When profiles have been loaded for each gear they can be saved as a group and reloaded for reuse. The profiles will be loaded back to their respective gears as when they were saved. The profiles can be seen in the profile viewer and will show the profiles associated with selected gear state.

\begin{tabular}{|r|r|r|r|r|r|r|r|}
\hline Time [sec] & SSA CB1234 [mA] & SSB C35R [mA] & SSC CB26 [mA] & SSD CBLR/C456 [mA] & LINE [mA] & TCC [mA] & SSE ON/OFF [mA] \\
\hline 0.00 & 0.00 & 1000.00 & 1000.00 & 0.00 & 500.00 & 0.00 & 0.00 \\
\hline 0.01 & 0.00 & 1000.00 & 1000.00 & 0.00 & 500.00 & 0.00 & 0.00 \\
\hline 0.02 & 0.00 & 1000.00 & 1000.00 & 0.00 & 500.00 & 0.00 & 0.00 \\
\hline 0.03 & 0.00 & 1000.00 & 1000.00 & 0.00 & 500.00 & 0.00 & 0.00 \\
\hline 0.04 & 0.00 & 539.00 & 698.40 & 0.00 & 500.00 & 0.00 & 0.00 \\
\hline 0.05 & 0.00 & 539.00 & 696.80 & 0.00 & 500.00 & 0.00 & 0.00 \\
\hline 0.06 & 0.00 & 539.00 & 695.20 & 0.00 & 500.00 & 0.00 & 0.00 \\
\hline 0.07 & 0.00 & 539.00 & 693.60 & 0.00 & 500.00 & 0.00 & 0.00 \\
\hline 0.08 & 0.00 & 539.00 & 692.00 & 0.00 & 500.00 & 0.00 & 0.00 \\
\hline 0.09 & 0.00 & 539.00 & 690.40 & 0.00 & 500.00 & 0.00 & 0.00 \\
\hline 0.10 & 0.00 & 539.00 & 688.80 & 0.00 & 500.00 & 0.00 & 0.00 \\
\hline 0.11 & 0.00 & 539.00 & 687.20 & 0.00 & 500.00 & 0.00 & 0.00 \\
\hline 0.12 & 0.00 & 645.84 & 685.60 & 0.00 & 500.00 & 0.00 & 0.00 \\
\hline 0.13 & 0.00 & 645.04 & 684.00 & 0.00 & 500.00 & 0.00 & 0.00 \\
\hline
\end{tabular}

To send the profile command to the solenoids both the ENGAGE and ACTIVATE SHIFTER must be pressed. The ENGAGE button sends the command to the solenoids while ACTIVATE SHIFTER enables the shift lever to run the profile when the shift lever changes. A shift can be done manually, using the shift lever, or by having a trigger activation. To have the shift activate on a trigger, select to have an UP or DOWNSHIFT from the current gear occur when the trigger is seen. When the settings are satisfactory press ACTIVATE TRIGGER, which will gray out and 
disable all controls so no changes can be made at this point. When the trigger is seen the profile commands will be sent and the shift will be completed. Once the shift is complete all controls will be re-enabled and further testing can be completed.

*Cancel button currently returns transmission to neutral, so be wary when using. Further development needs to be completed to improve cancel operations.

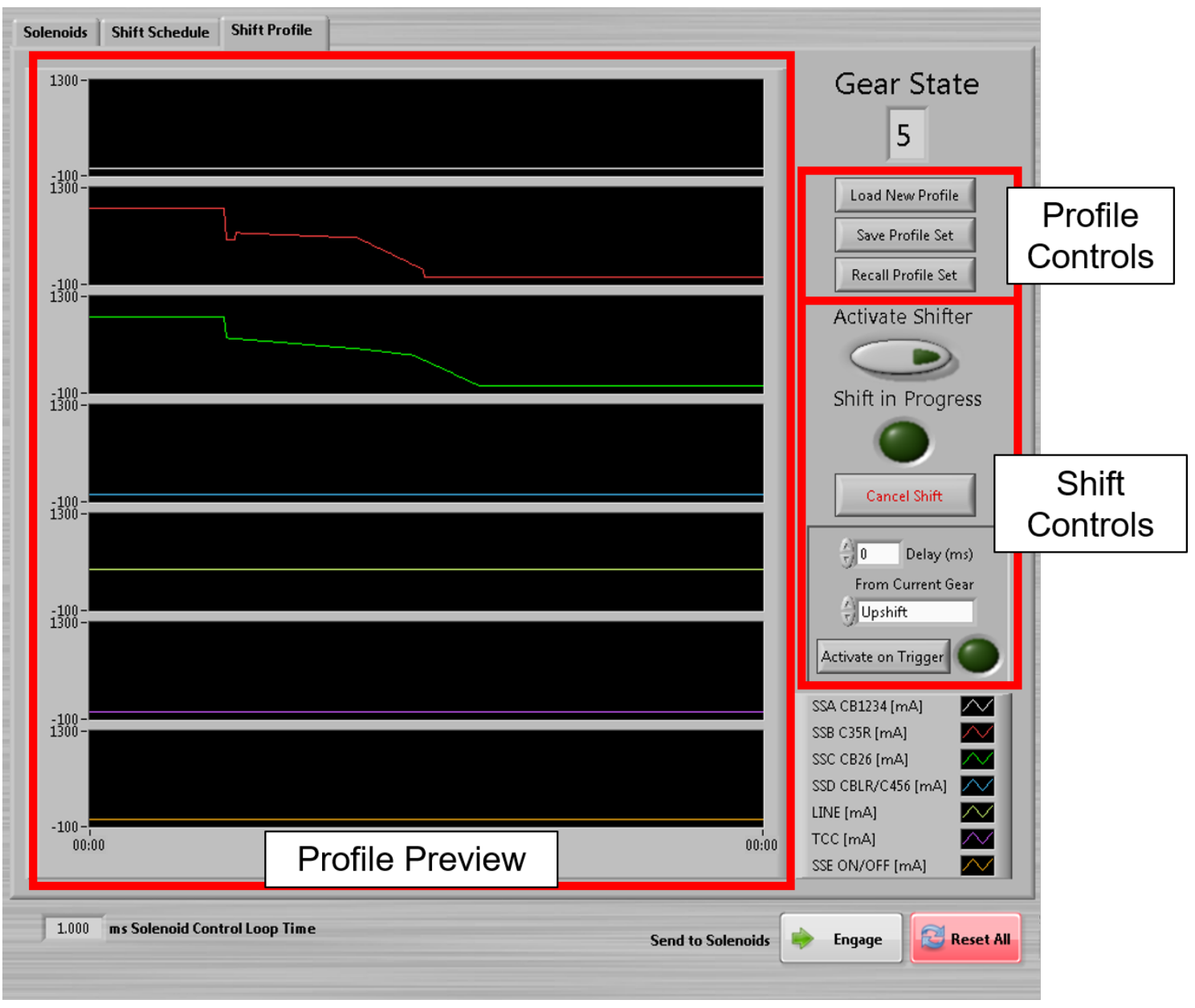


The image below shows how the window appears during a trigger activated shift. All controls are grayed out so no changes can be made. When the shift is activate, the SHIFT IN PROGRESS and trigger indicator will light up.

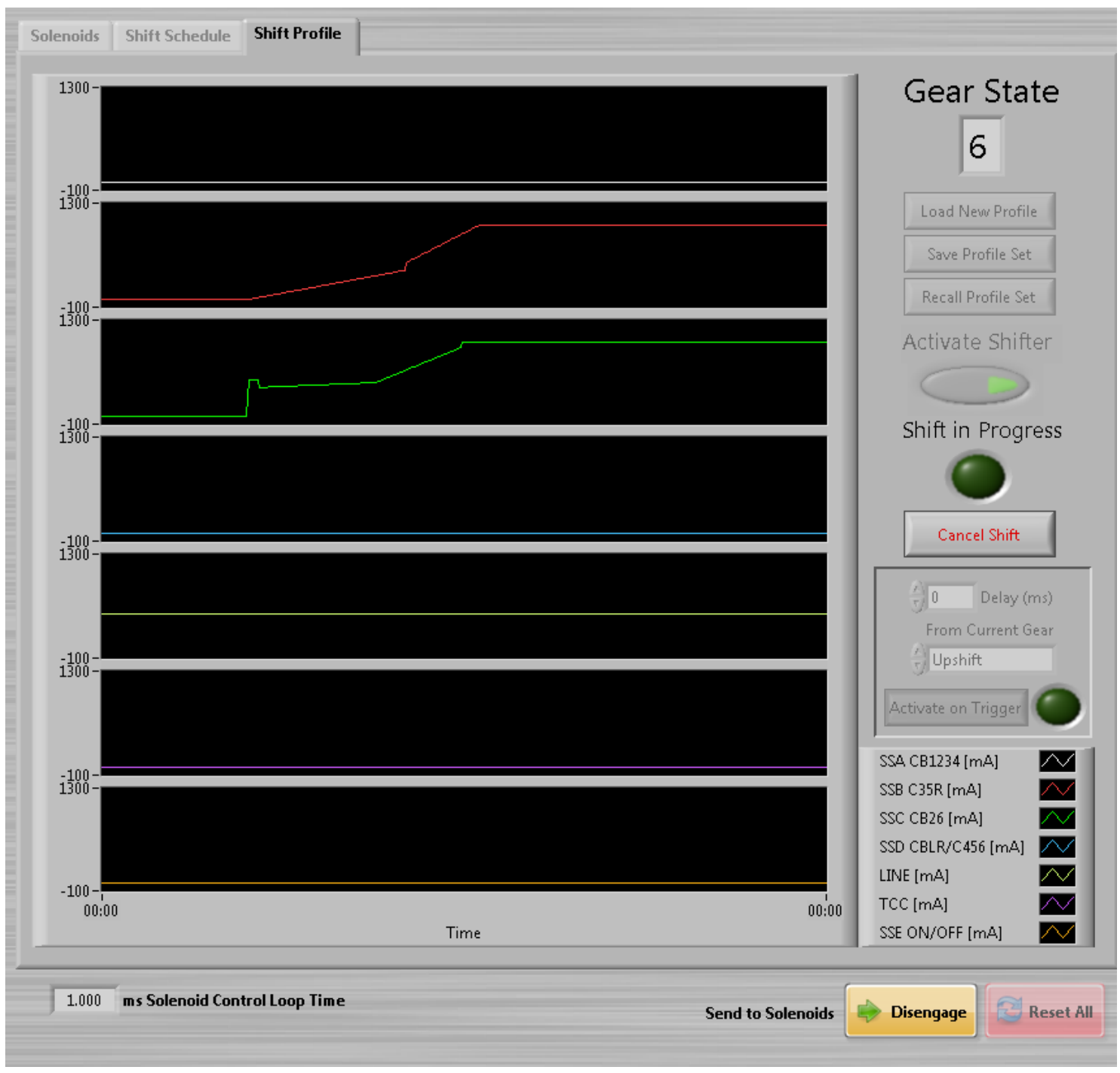


Next to all the windows are universal controls and solenoid status screen. The profile viewer shows the commands for all solenoids at the same time. These commands are not sent to the solenoids until the ENGAGE button is activated. The indicators and values next to the command viewer shows the current value of the solenoid. It is possible for the solenoid status and command viewer values to not be equal. When the ENGAGE button is activate, the solenoid status and command viewer values will match. When the ENGAGE button is disabled, the solenoid status will show the last values sent to the controller and the the command viewer will show the current commands sent from the software.

The shift lever is used to change gears and view/load profiles in the SHIFT PROFILE window. Value override allows the user to change a single solenoid value on the fly. This was mainly used to set the TCC slip conditions before a shift. The "Blip" override commands an addition of current for a specified amount of time. These controls were used to see the sensitvity of the TCC pressure .

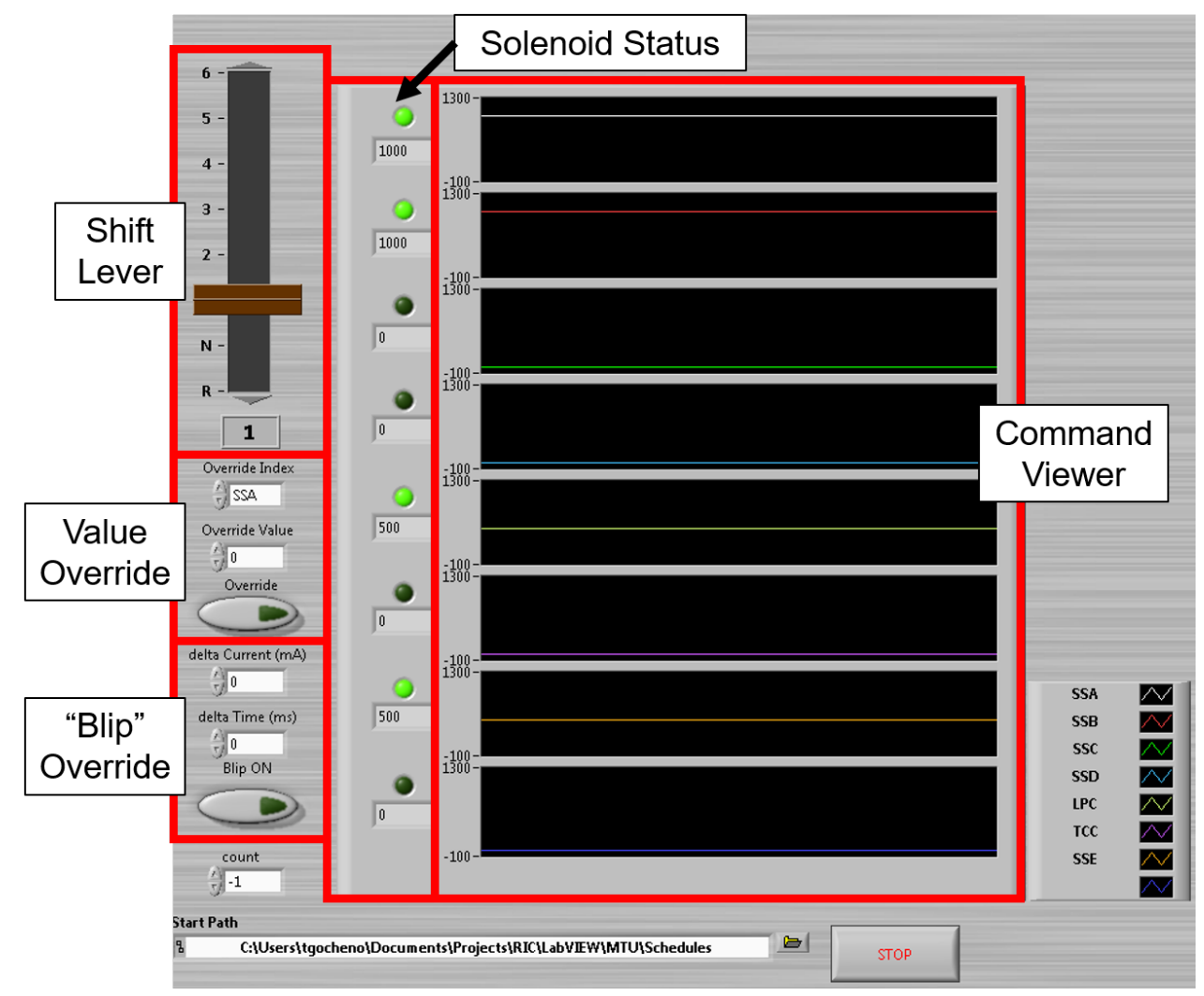




\section{H Pressure Transducer Specifications}

\section{H.1 Kulite XCEL-072}

\section{(-). kulite}

HIGH TEMPERATURE

MINIATURE PRESSURE TRANSDUCER

XCEL-072 SERIES

- Wide Temperature Capability $-65^{\circ} \mathrm{F}$ To $525^{\circ} \mathrm{F}$

- Designed For Harsh Environments

- Ideal For Turbine Engine Probes and Wind Tunnel Applications

- Patented Leadless Technology VIS ${ }^{2}$

- Designed For Both Static and Dynamic Response

- Suitable For Use in Most Conductive Liquids and Gases

The XCEL-072 design features Kulite's patented leadless technology. This allows for a very rugged

package suited for probes, pressure rakes and other similar test set ups. This transducer is well suited

(a)

areas of Industry.

Kul ite recommends the KSC-2 signal conditioner to maximize the measurement capability of the XCEL-072 transduce
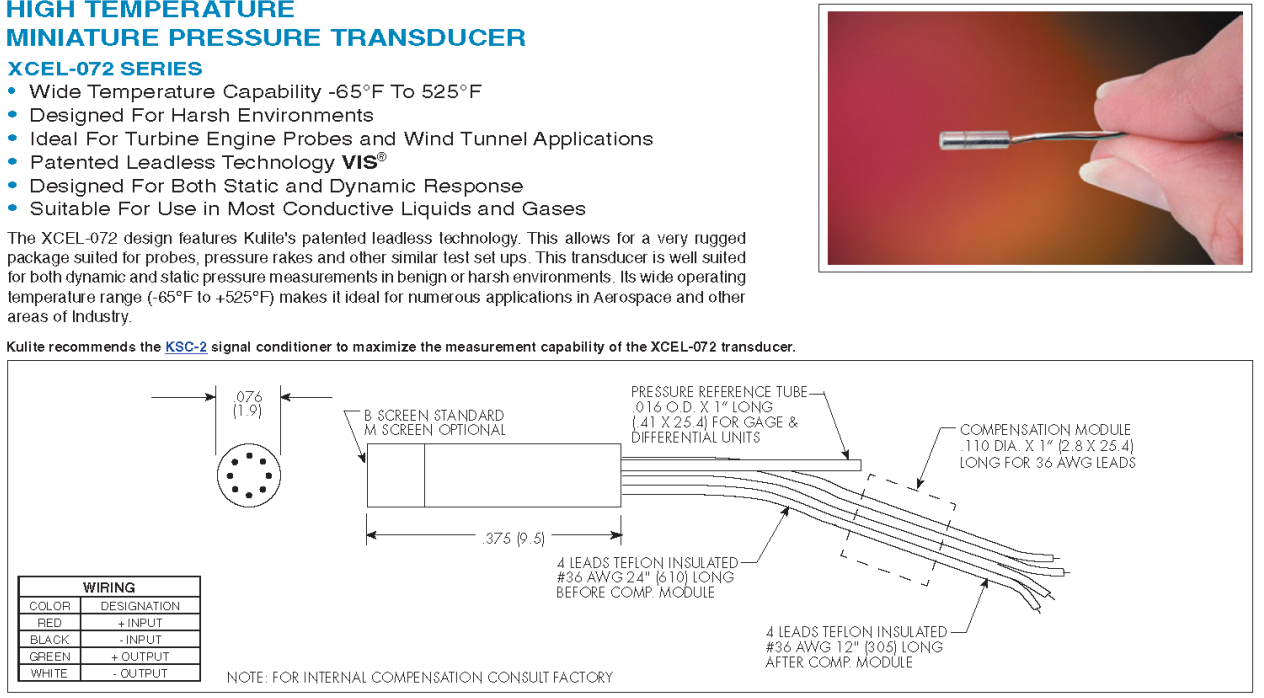

\begin{tabular}{|c|c|c|c|c|c|c|c|c|c|c|}
\hline \multirow{8}{*}{$\frac{5}{3}$} & Pressure Range & $\begin{array}{c}0.7 \\
10\end{array}$ & $\begin{array}{l}1.0 \\
15\end{array}$ & $\begin{array}{l}17 \\
25\end{array}$ & $\begin{array}{l}3.5 \\
50\end{array}$ & $\begin{array}{c}7 \\
100\end{array}$ & $\begin{array}{c}14 \\
200\end{array}$ & $\begin{array}{c}21 \\
300\end{array}$ & $\begin{array}{c}35 \\
500\end{array}$ & $\begin{array}{r}70 \mathrm{BAR} \\
1000 \mathrm{PSI}\end{array}$ \\
\hline & Operational Mode & \multicolumn{2}{|c|}{$\begin{array}{c}\text { Absolute, Gage, } \\
\text { Differential }\end{array}$} & \multicolumn{3}{|c|}{$\begin{array}{c}\text { Absolute, Gage, Sealed Gage, } \\
\text { Differential }\end{array}$} & \multicolumn{4}{|c|}{ Absolute, Sealed Gage } \\
\hline & Over Pressure & \multicolumn{9}{|c|}{2 Times Rated Pressure } \\
\hline & Burst Pressure & \multicolumn{9}{|c|}{3 Times Rated Pressure } \\
\hline & Pressure Media & \multicolumn{9}{|c|}{ Most Conductive Liquids and Gases - Please Consult Factory } \\
\hline & Rated Electrical Excitation & \multicolumn{9}{|c|}{$10 \mathrm{VDC} / \mathrm{AC}$} \\
\hline & Maximum Electrical Excitation & \multicolumn{9}{|c|}{ 12VDC/AC } \\
\hline & Input Impedance & \multicolumn{9}{|c|}{$1000 \mathrm{ohms}$ (Min) } \\
\hline \multirow{8}{*}{ } & Output Impedance & \multicolumn{9}{|c|}{$1000 \mathrm{ohms}$ (Nom.) } \\
\hline & Full Scale output (FSO) & \multicolumn{9}{|c|}{$100 \mathrm{mV}(\mathrm{Nom})$} \\
\hline & Residual Unbalance & \multicolumn{9}{|c|}{ $\pm 5 \mathrm{mV}(\mathrm{Typ}$ ) } \\
\hline & $\begin{array}{l}\text { Combined Non-Linearity, Hysteresis } \\
\text { and Repeatability }\end{array}$ & \multicolumn{9}{|c|}{ $\pm 0.1 \%$ FSO BFSL (Typ.), $\pm 0.5 \%$ FSO (Max.) } \\
\hline & Resolution & \multicolumn{9}{|c|}{ Infinitesimal } \\
\hline & $\begin{array}{l}\text { Natural Frequency of Sensor } \\
\text { without Screen (KHZ) (Typ) }\end{array}$ & 175 & 200 & 240 & 300 & 380 & 550 & 575 & 700 & 1000 \\
\hline & $\begin{array}{l}\text { Acceleration Sensitivity \% FS/g } \\
\text { Perpendicular }\end{array}$ & $1.0 \times 10^{-3}$ & $6.5 \times 10^{-4}$ & $5.0 \times 10^{-4}$ & $3.0 \times 10^{-4}$ & $1.5 \times 10^{-4}$ & $1.1 \times 10^{-4}$ & $9.0 \times 10^{5}$ & $6.0 \times 10^{5}$ & $4.0 \times 10^{-5}$ \\
\hline & Insulation Resistance & \multicolumn{9}{|c|}{100 Megohm Min @ 50 VDC } \\
\hline \multirow{6}{*}{ 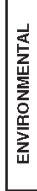 } & Operating Temperature Range & \multicolumn{9}{|c|}{$-65^{\circ} \mathrm{F}$ to $+525^{\circ} \mathrm{F}\left(-55^{\circ} \mathrm{C} 10+273^{\circ} \mathrm{C}\right)$} \\
\hline & Compensated Temperature Range & \multicolumn{9}{|c|}{$+80^{\circ} \mathrm{F}$ to $+450^{\circ} \mathrm{F}\left(+25^{\circ} \mathrm{C}\right.$ to $\left.+235^{\circ} \mathrm{C}\right)$} \\
\hline & Thermal Zero Shift & \multicolumn{9}{|c|}{ $\pm 1 \%$ FS $/ 100^{\circ} \mathrm{F}$ (Тур ) } \\
\hline & Thermal Sensitivity Shitt & \multicolumn{9}{|c|}{ $\pm 1 \% / 100^{\circ} \mathrm{F}$ (Typ) } \\
\hline & Steady Acceleration & \multicolumn{9}{|c|}{$10,000 \mathrm{~g}(\mathrm{Max})$} \\
\hline & Linear Vibration & \multicolumn{9}{|c|}{$10-2000 \mathrm{~Hz}$ Sine, $100 \mathrm{~g}$ (Max) } \\
\hline \multirow{3}{*}{\begin{tabular}{|l}
$\frac{d}{d}$ \\
$\frac{0}{w}$ \\
$\frac{\vec{c}}{2}$ \\
\end{tabular}} & Electrical Connection & \multicolumn{9}{|c|}{4 Leads 36 AWG 36 "Long } \\
\hline & Weight & \multicolumn{9}{|c|}{2 Gram (Nom.) Excluding Module and Leads } \\
\hline & Pressure Sensing Principle & \multicolumn{9}{|c|}{ Fully Active Four Arm Wheatstone Bridge Dielectrically Isolated Silicon on Silicon Patented Leadless Technology } \\
\hline
\end{tabular}




\section{H.2 Kulite LE-160}

\section{(0)kulite}

MICROLINE STRESS ISOLATED SURFACE MOUNT

PRESSURE TRANSDUCER

LQ-160 SERIES LE-160 SERIES

- Designed For Direct Blade Surface Mounting

- Silicon on Silicon Integrated Sensor VIS

- High G Loading

- Low Base Strain Sensitivity

- High Natural Frequency

- High Temperature Operation Up To $450^{\circ} \mathrm{F}$ (LE Series)

The LQ/LE-160 Series microline pressure transducer represents the latest build standard in a long line of

sensors designed and developed for direct mounting onto engine blades. Using a unique isolation lechnique to

reducosase slain and denth

inaccessible will a packing density previously impossible.

Kulite recommends the KSC-2 signal conditioner to maximize the measurement capability of the LQ-160 and LE-160 transducer

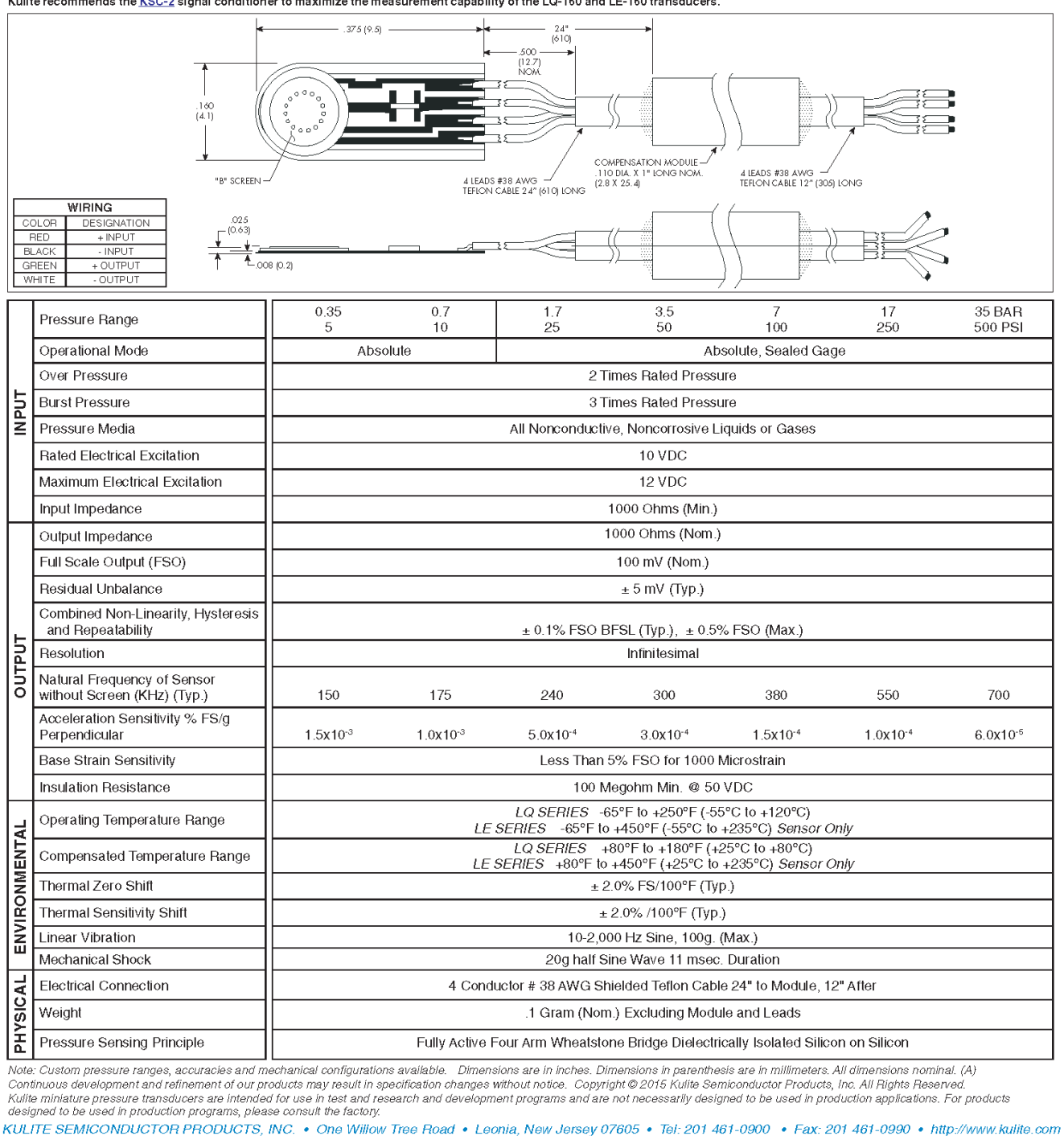




\section{Torque Converter Instrumentation Photos}

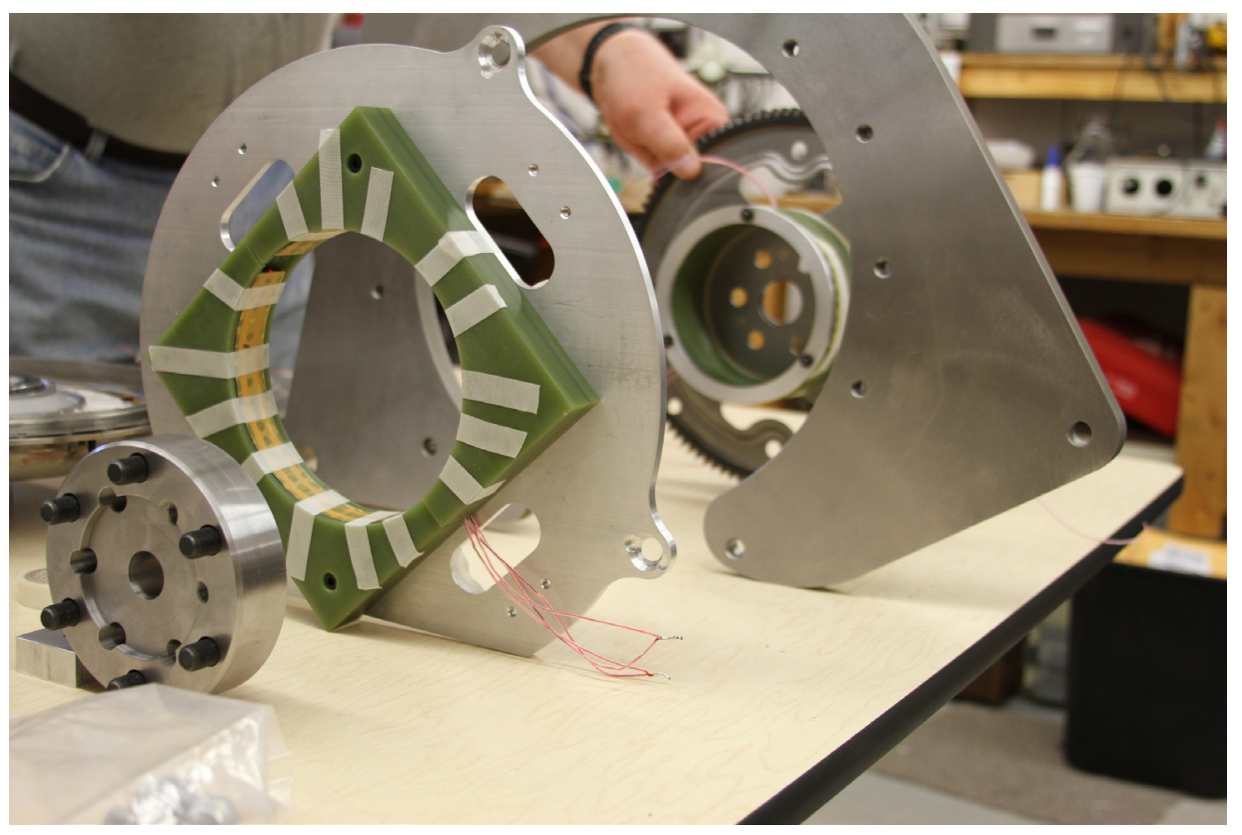

Figure I-1. Left to right: shaft coupler, transmitter induction coil, head plate, receiver coil on flex plate

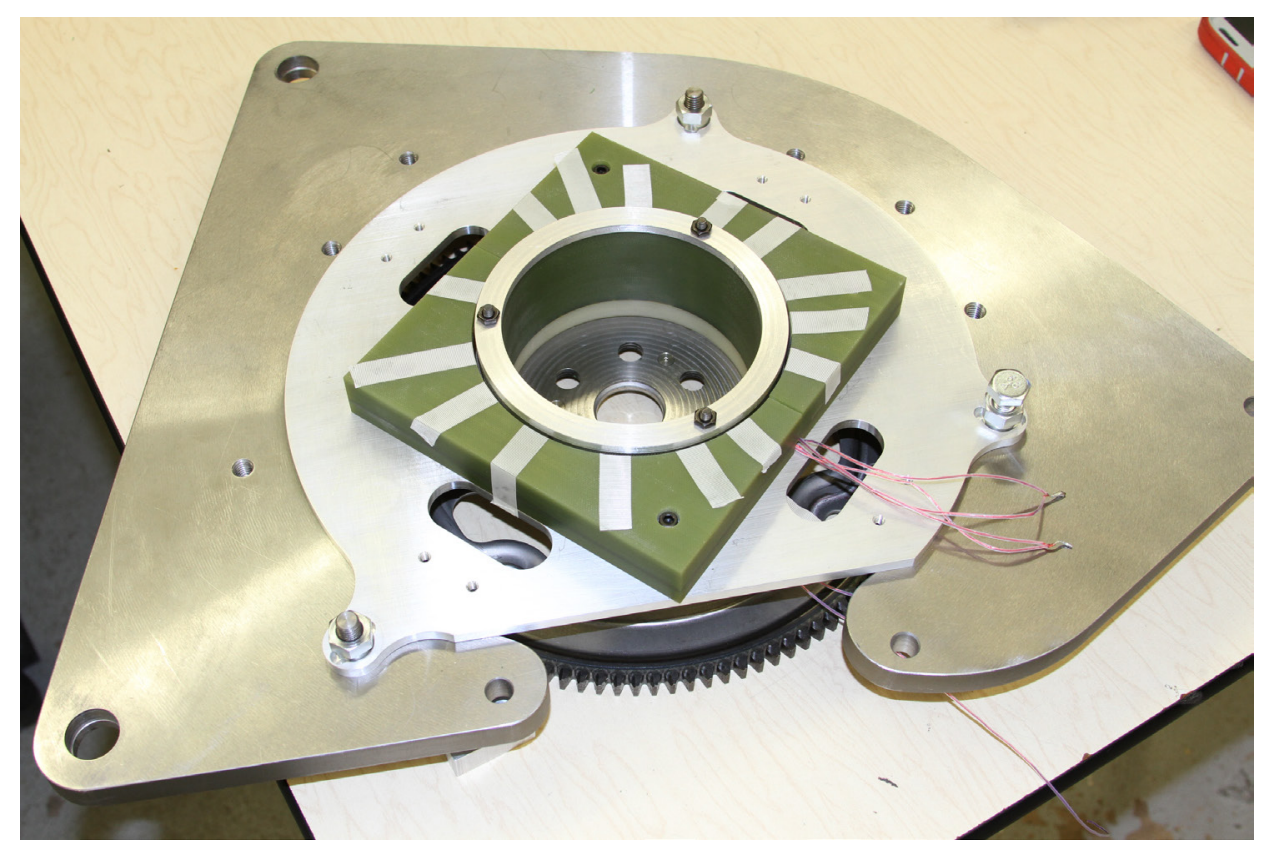

Figure I-2. Powering induction coil on head plate, receiving induction coil on flex plate 


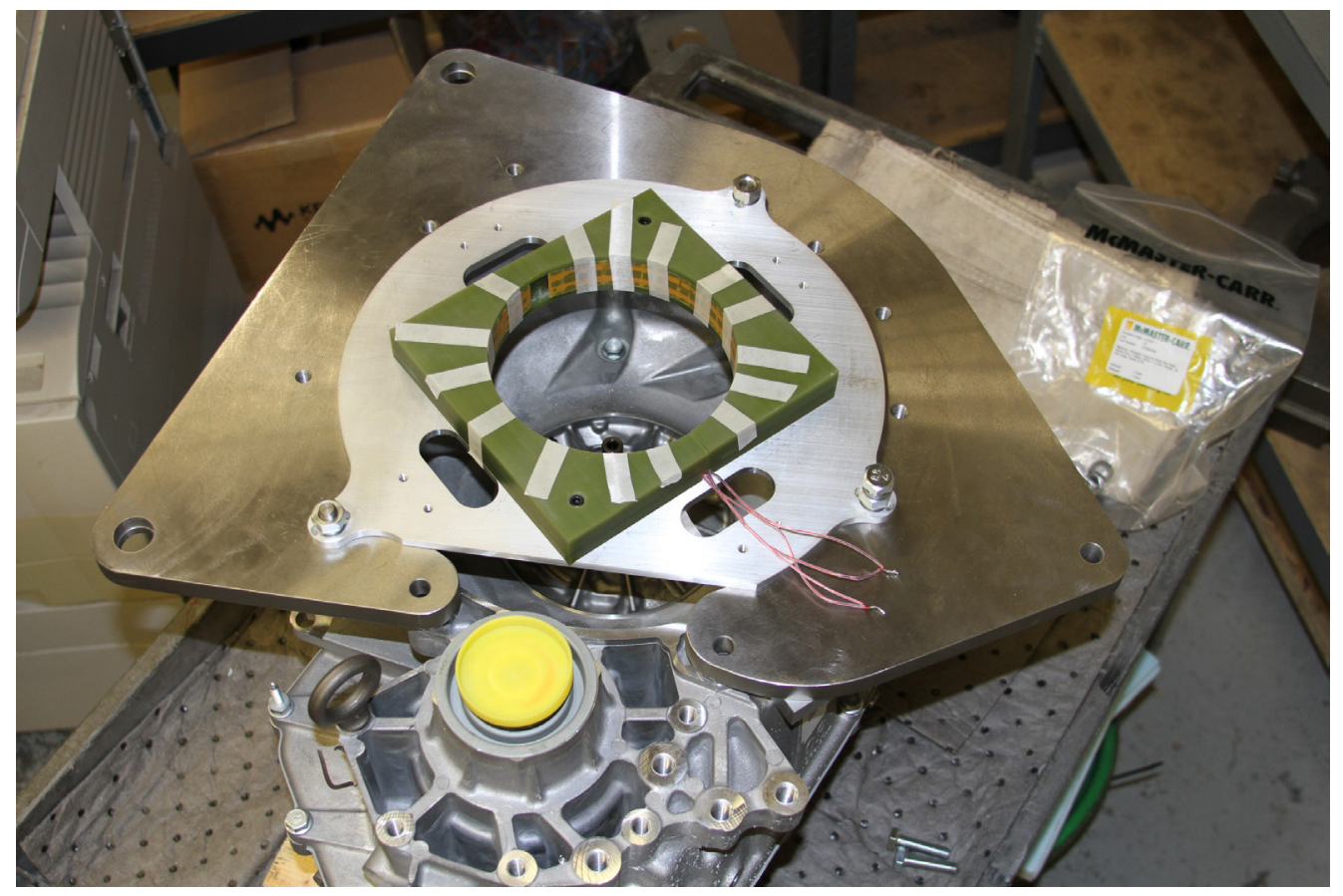

Figure I-3. Transmitter coil and head plate placement on transmission housing

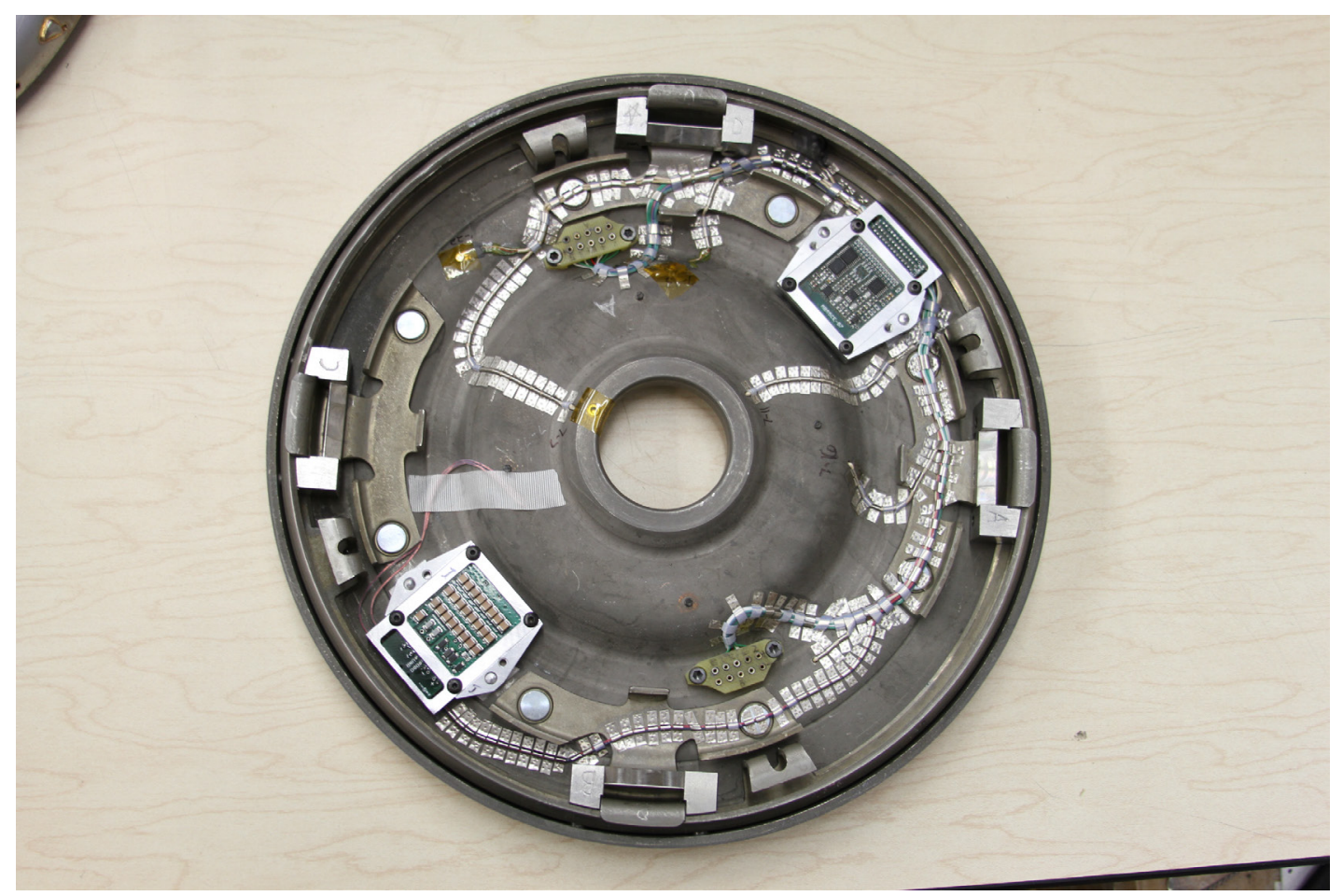

Figure I-4. Transmitter and hardware for turbine transmitter mounted on clutch plate 


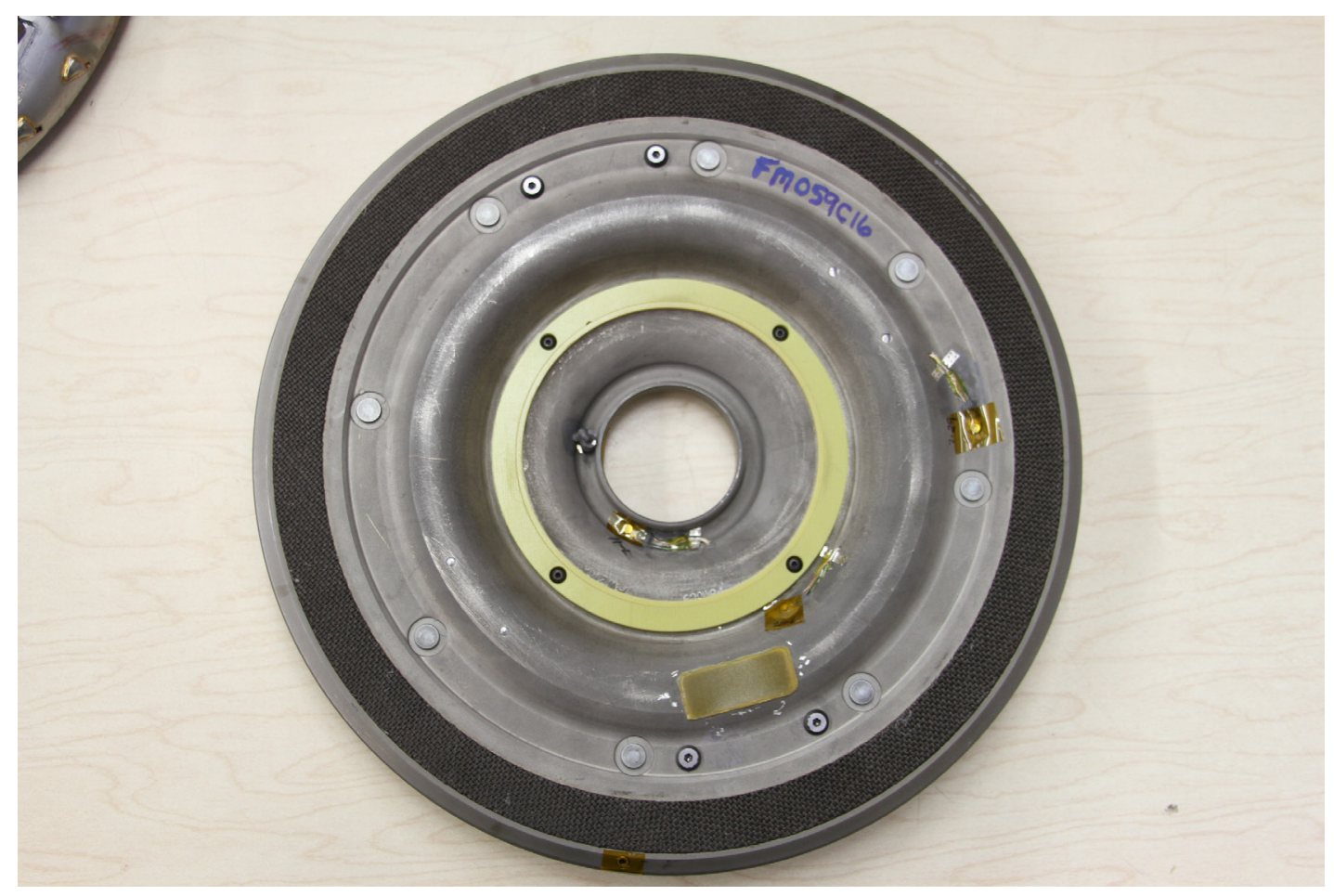

Figure I-5. Kevlar patch on clutch plate for transmitter

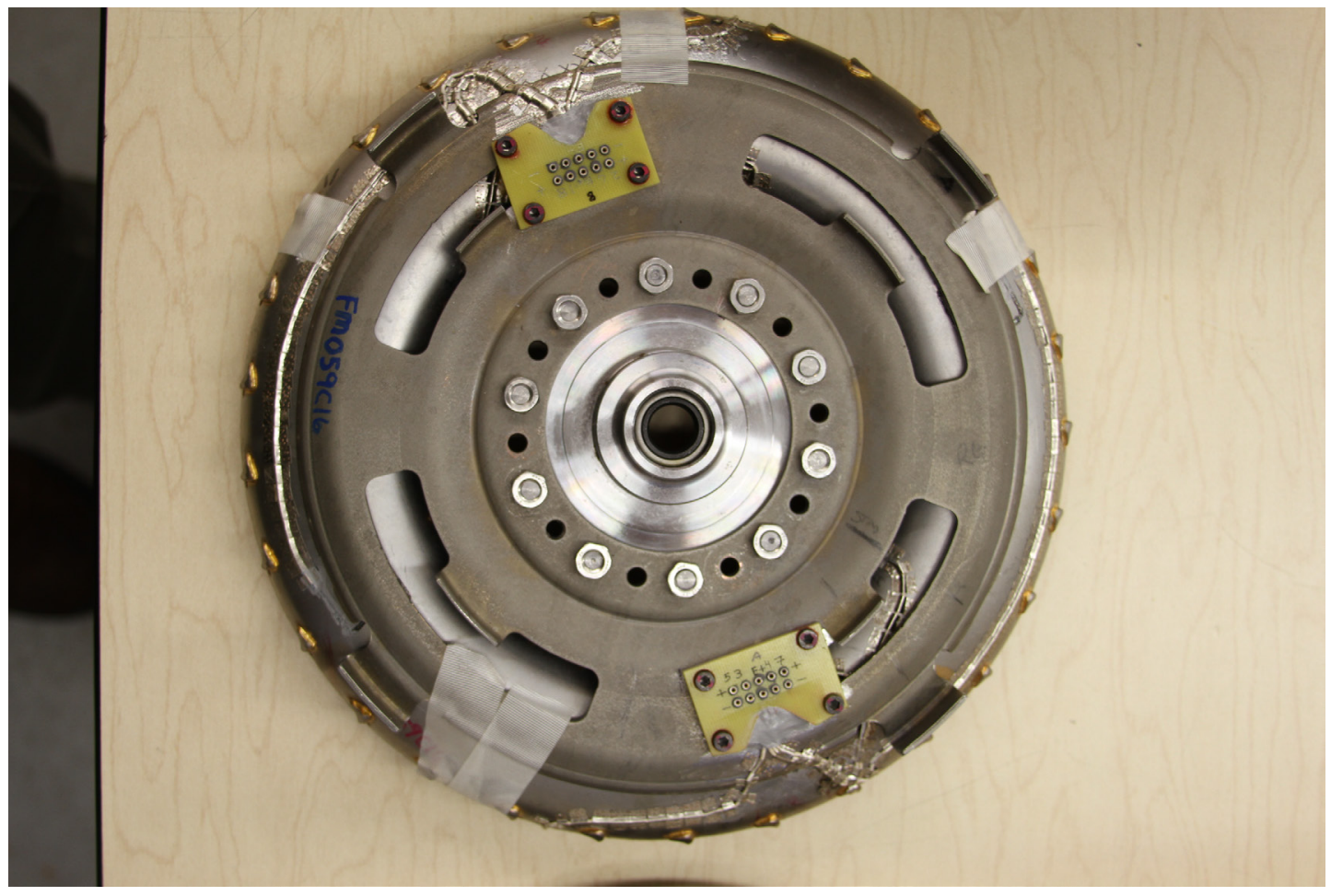

Figure I-6. Power and signal pin arrays mounted to shell of turbine 


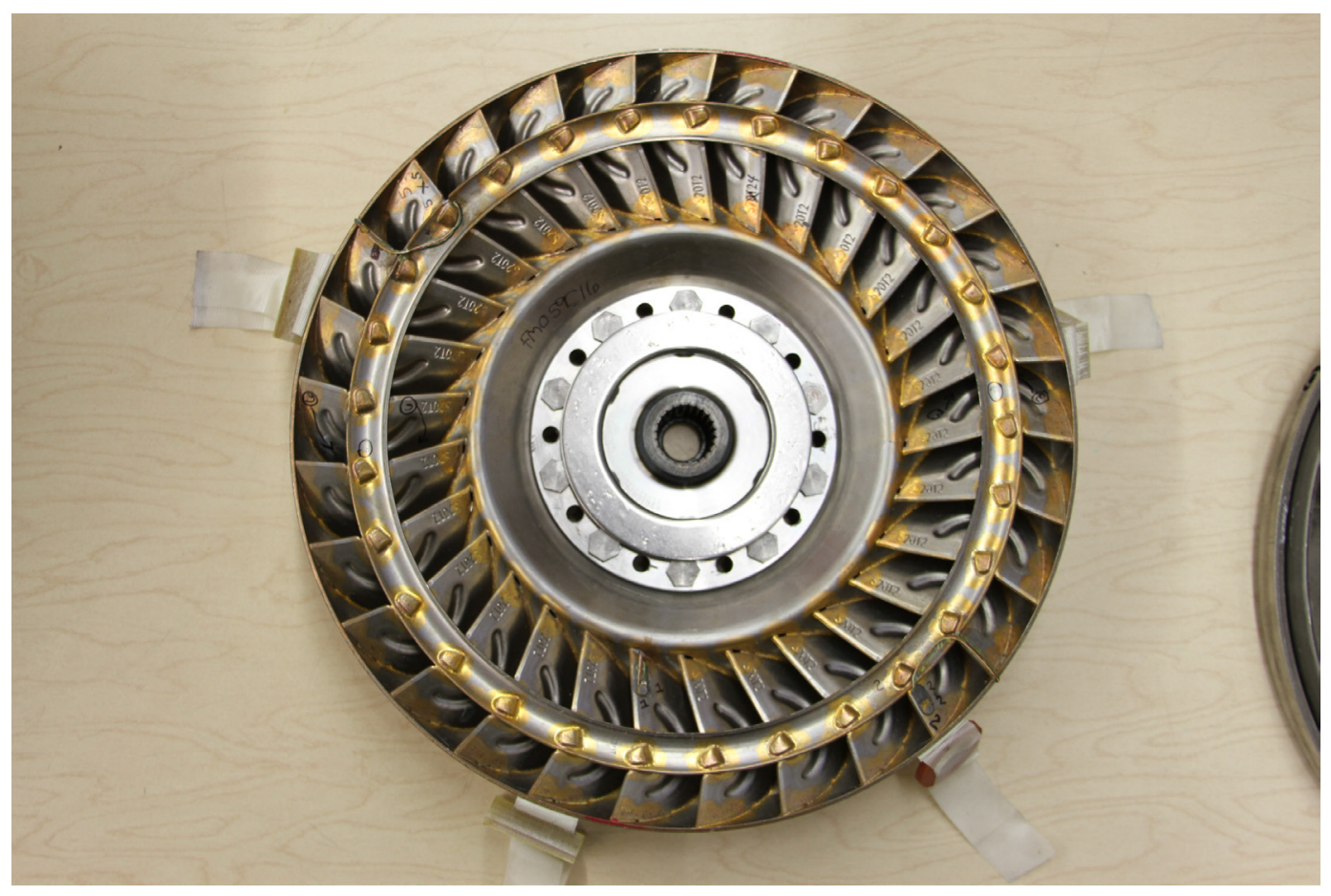

Figure I-7. Turbine torus

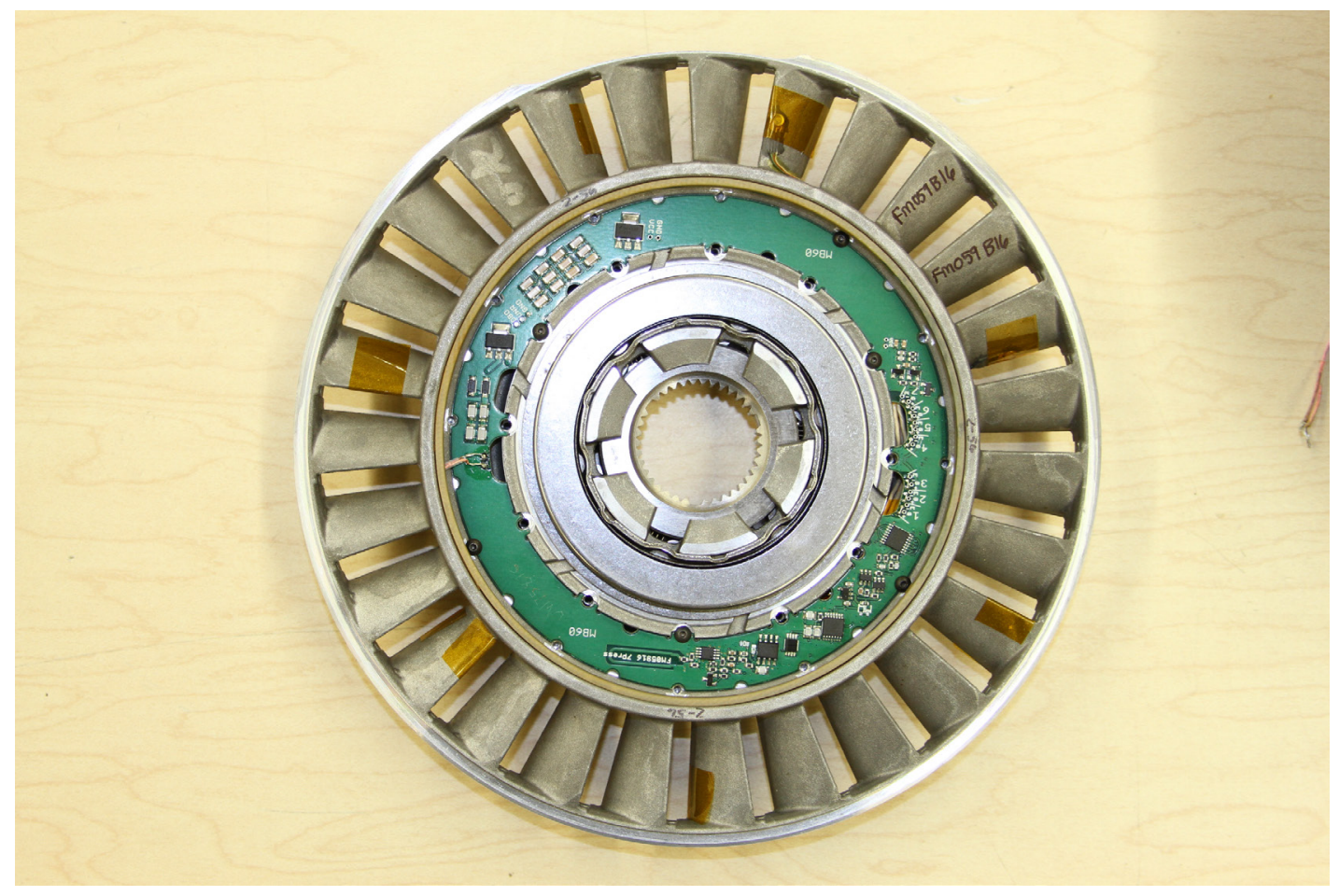

Figure I-8. Stator trailing edge side with receiver induction coil and transmitter hardware mounted in center 


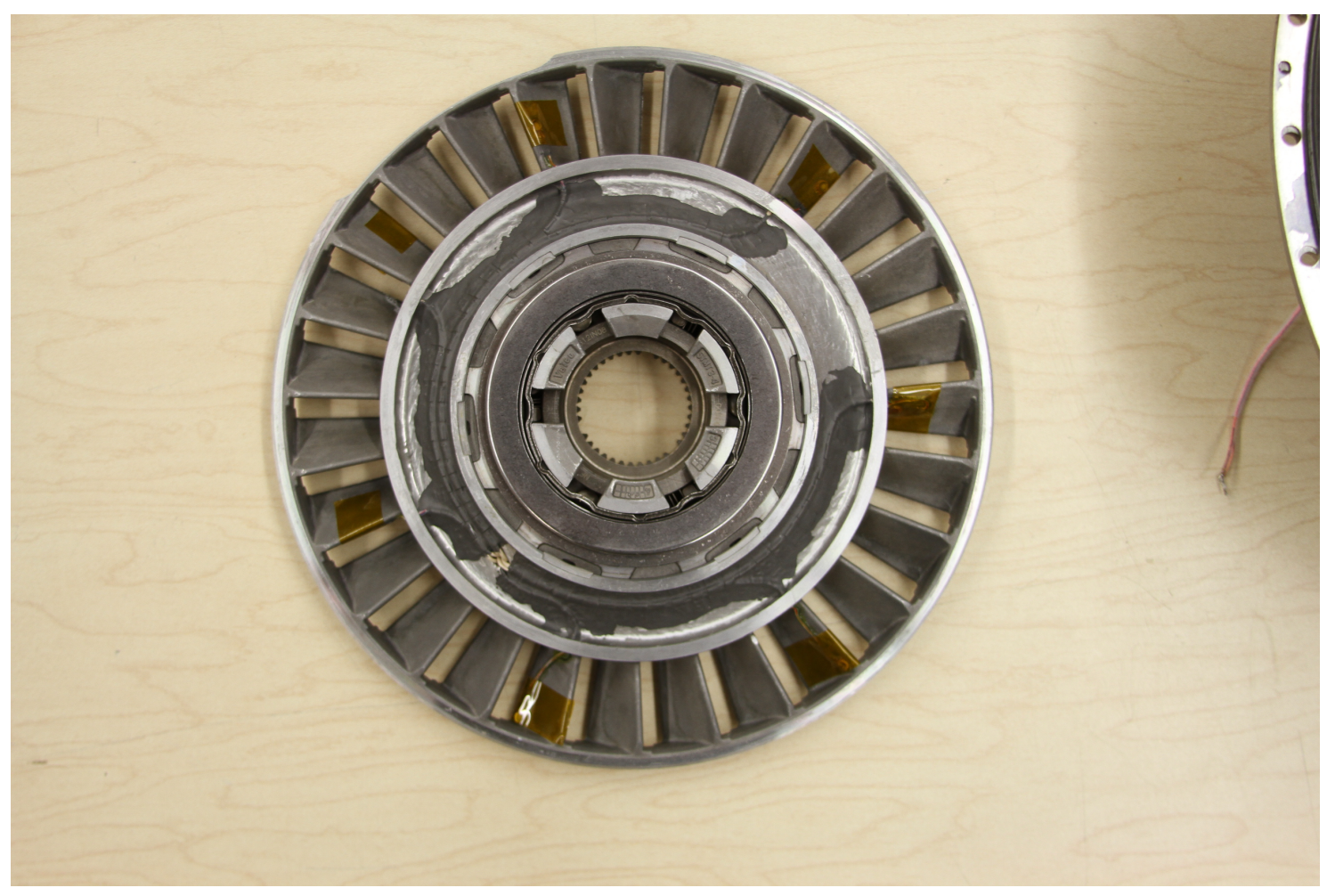

Figure I-9. Stator leading edge side

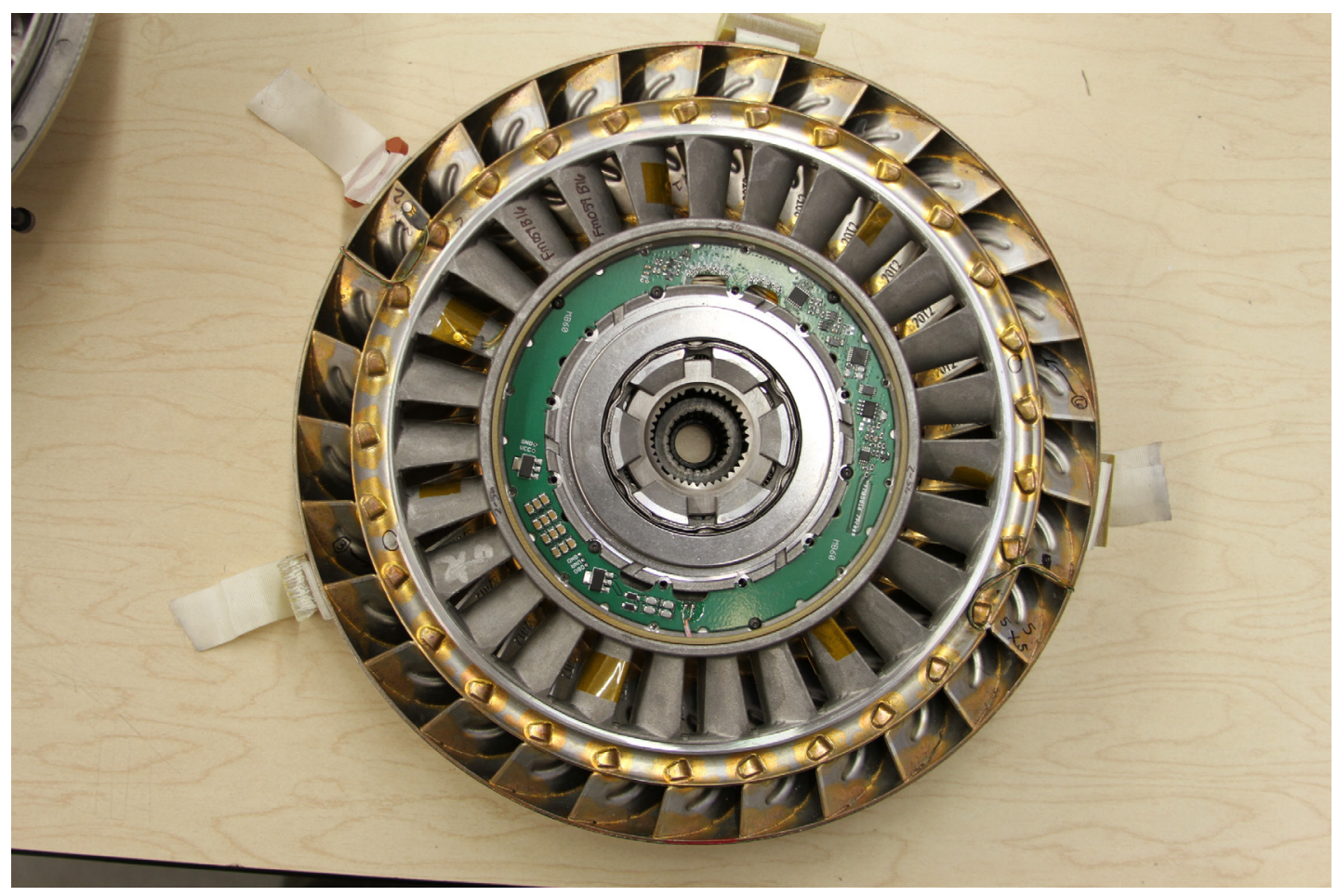

Figure I-10. Stator laying on top of turbine 


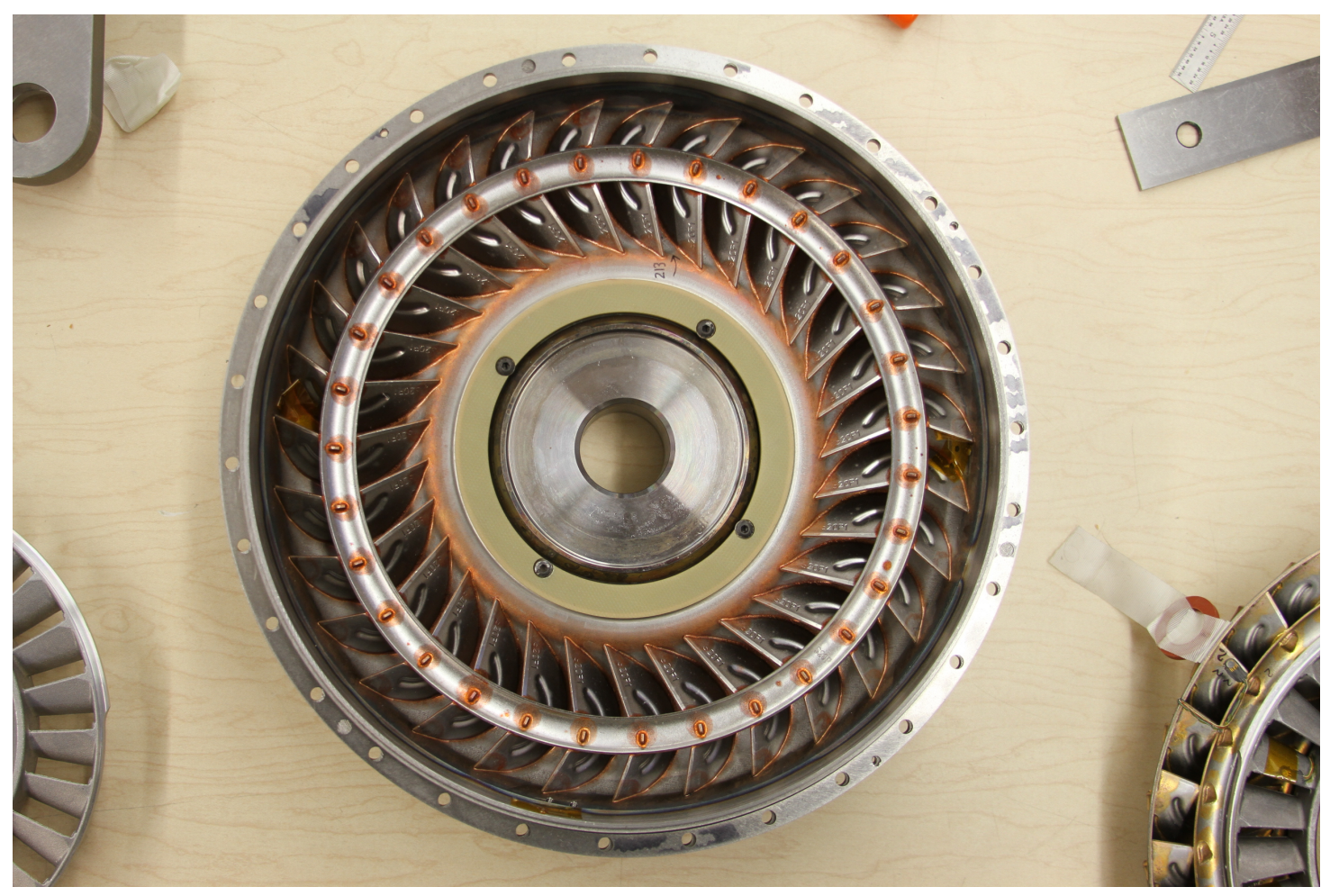

Figure I-11. Impeller with stator transmitter induction coil

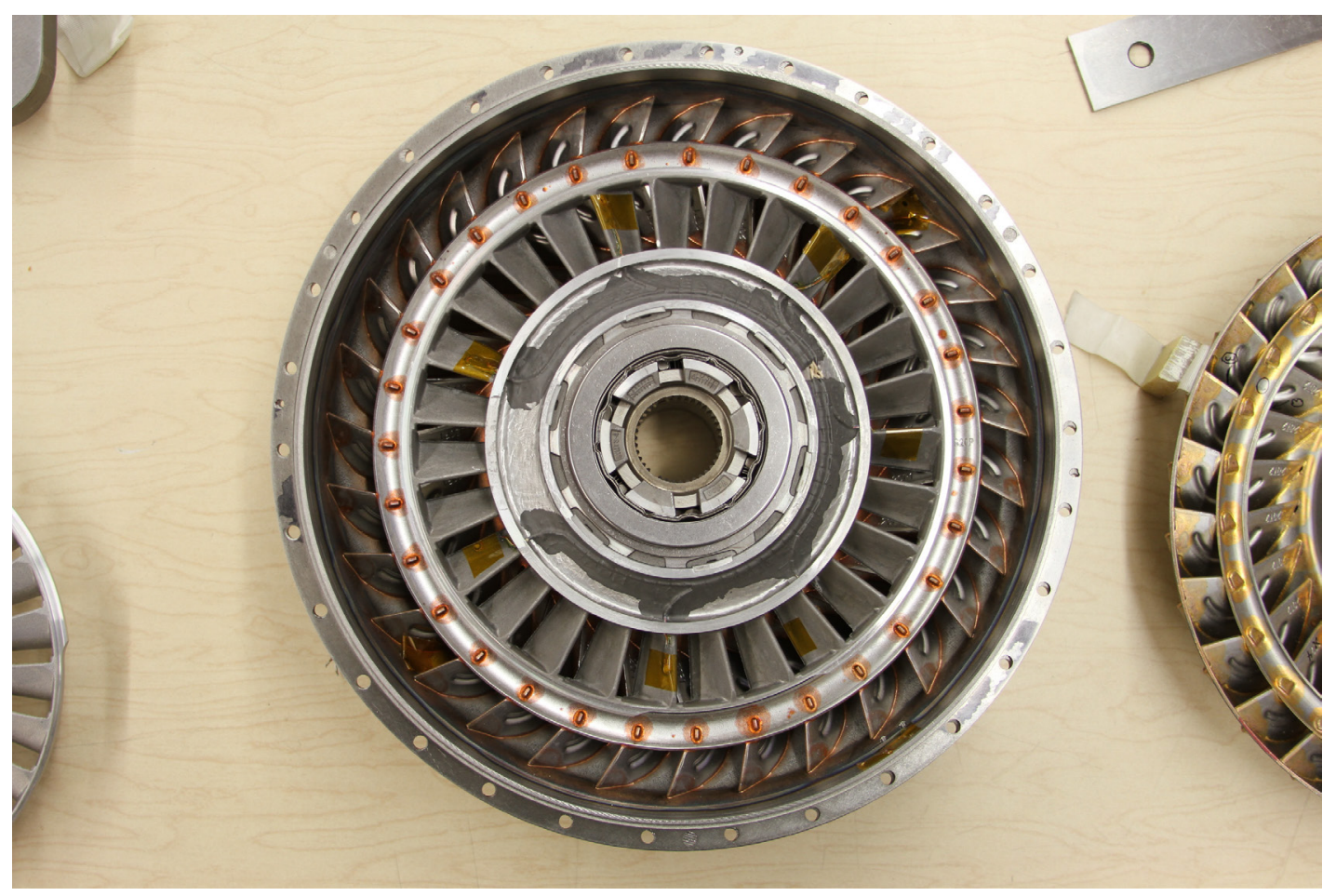

Figure I-12. Stator laying on top of impeller 


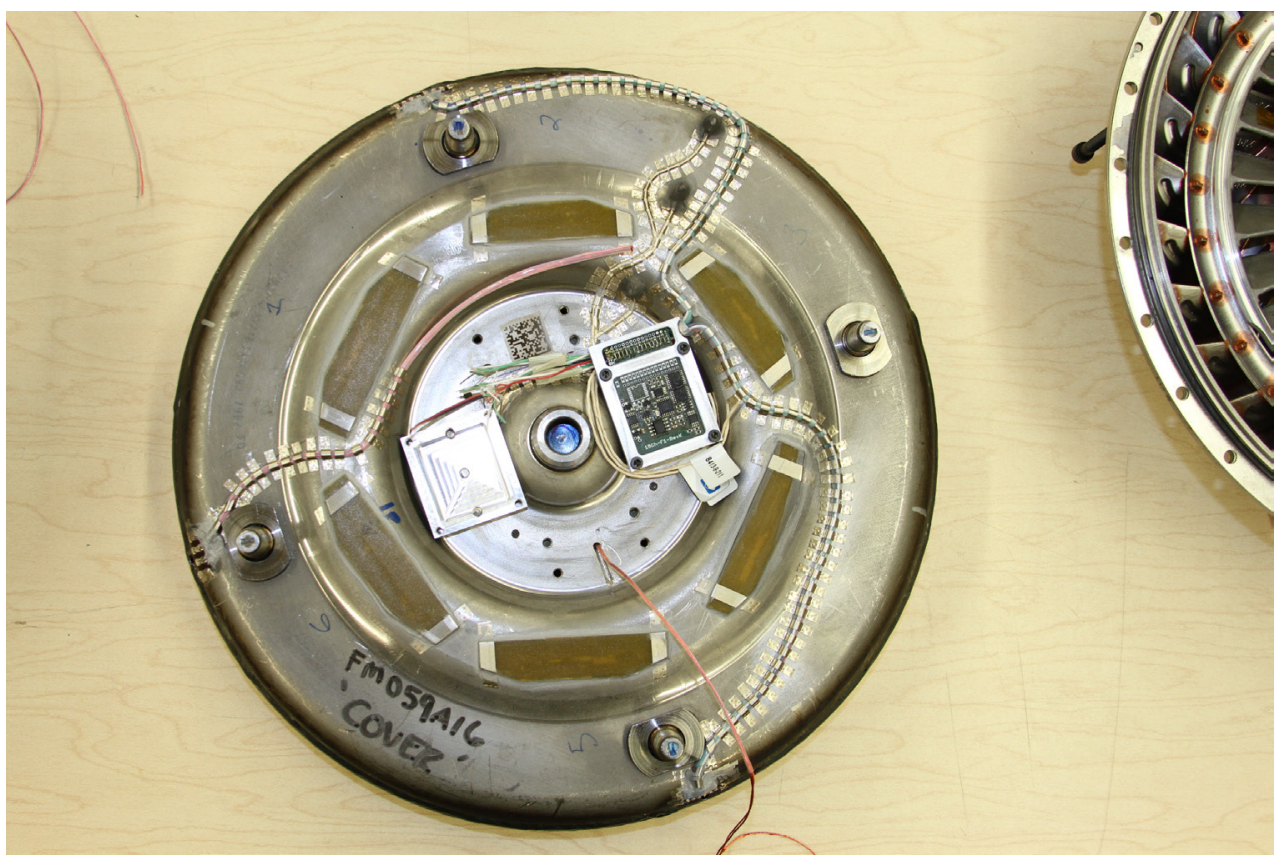

Figure I-13. Impeller transmitter hardware mounted to cover. Kevlar patches to allow turbine transmitter signal to escape the torque converter

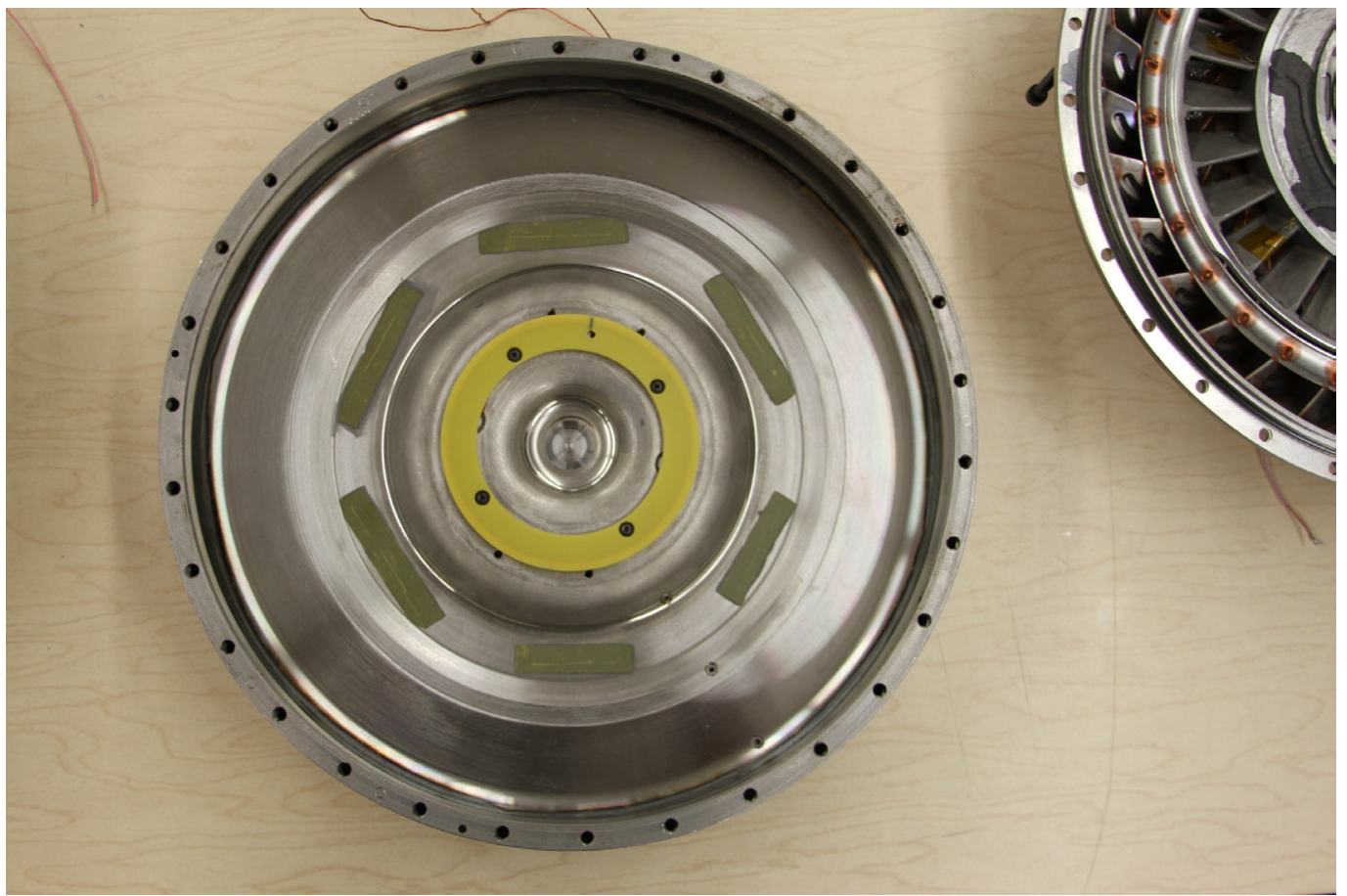

Figure I-14. Turbine transmitter induction coil and Kevlar patches on inside of cover 


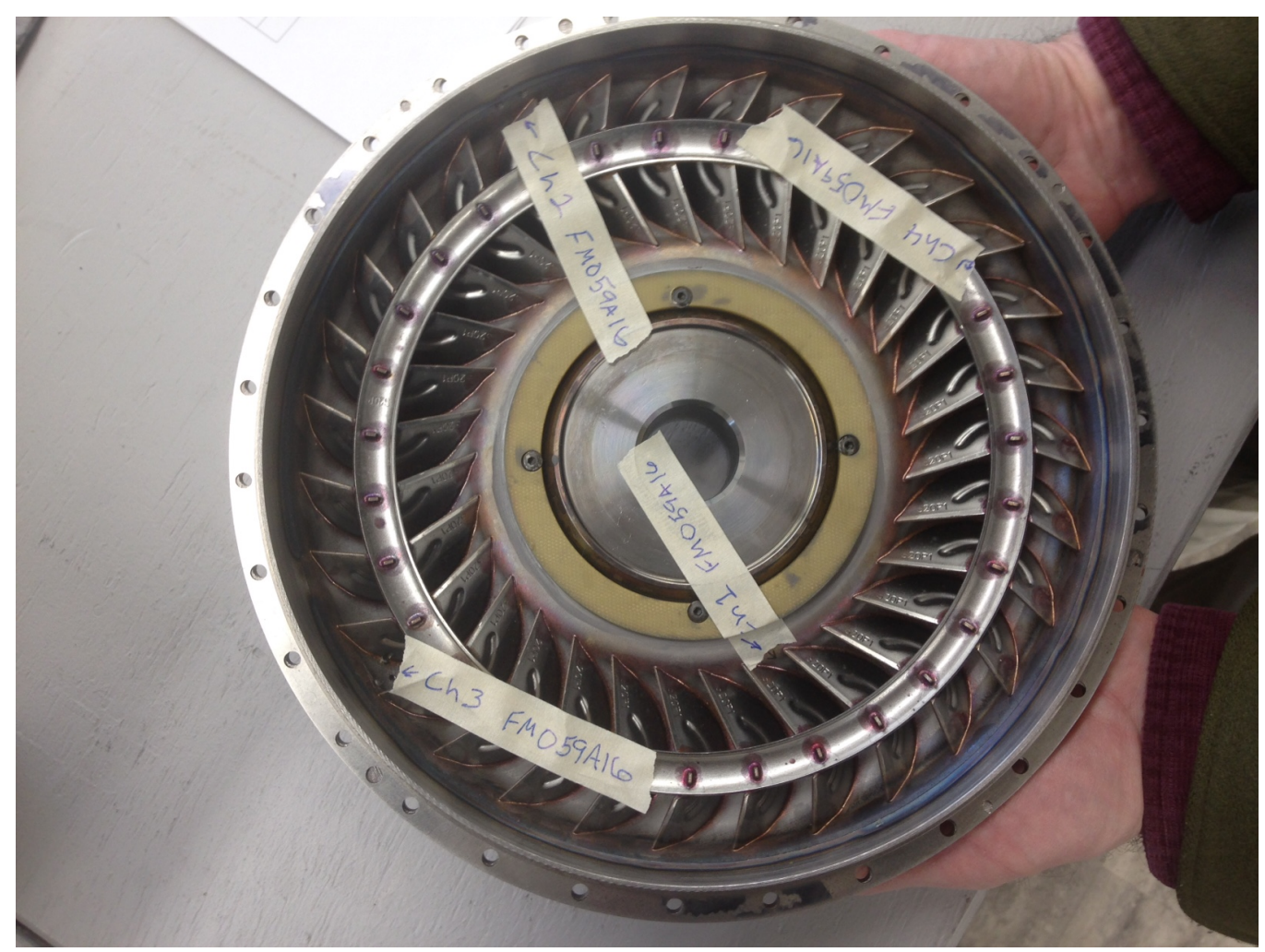

Figure I-15. Impeller torus transducer locations

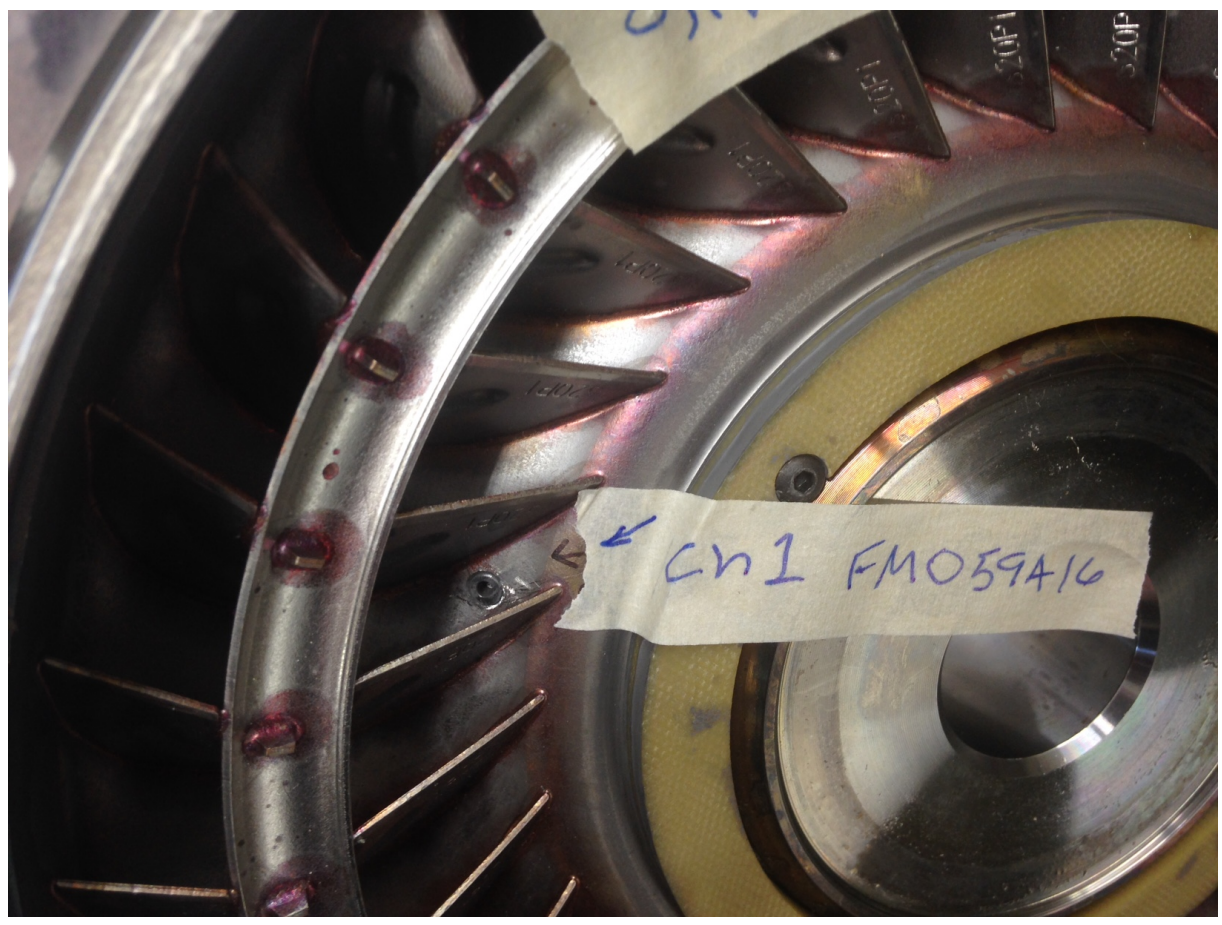

Figure I-16. Impeller channel 1 location, leading edge between blades 


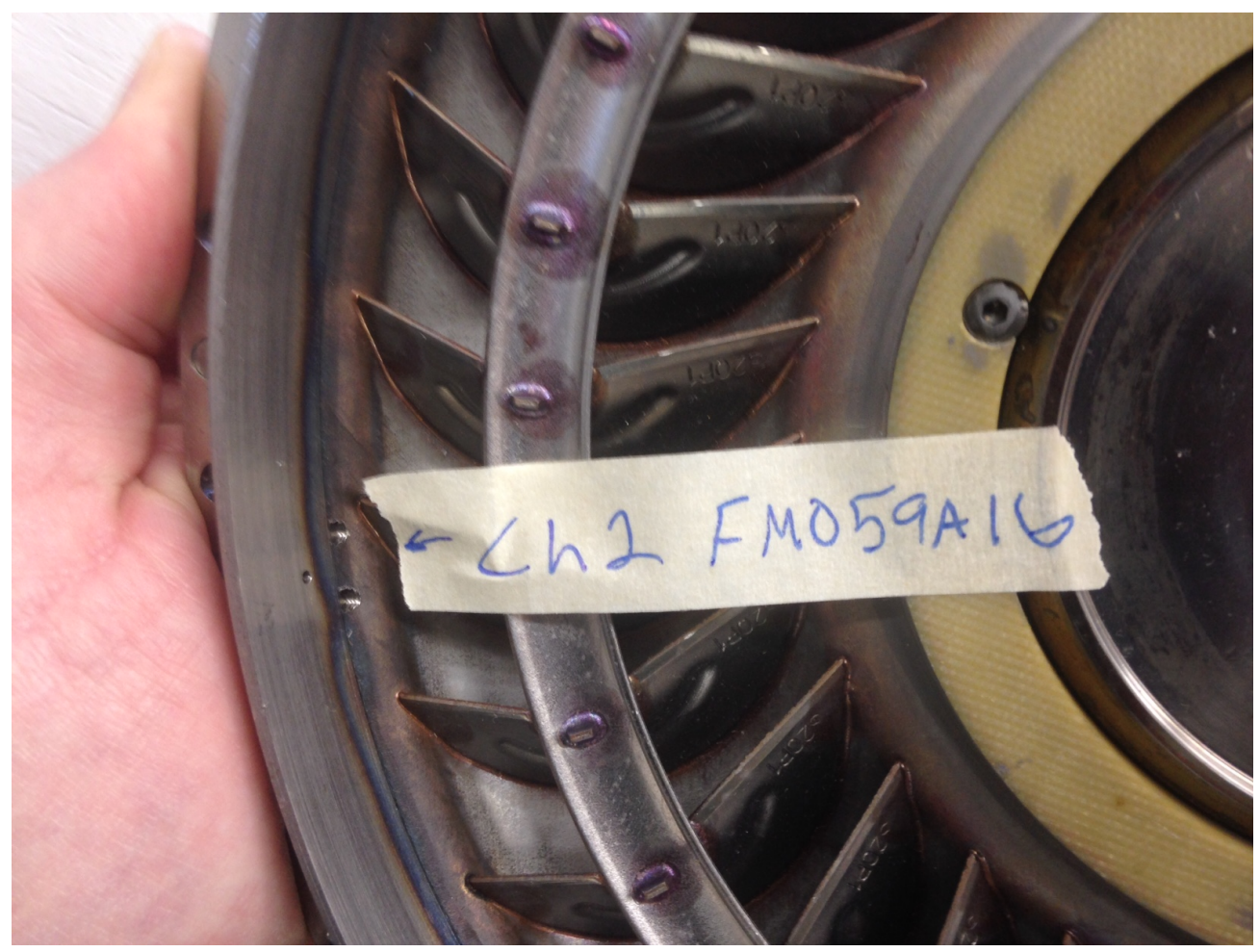

Figure I-17. Impeller channel 2 location, between impeller and turbine

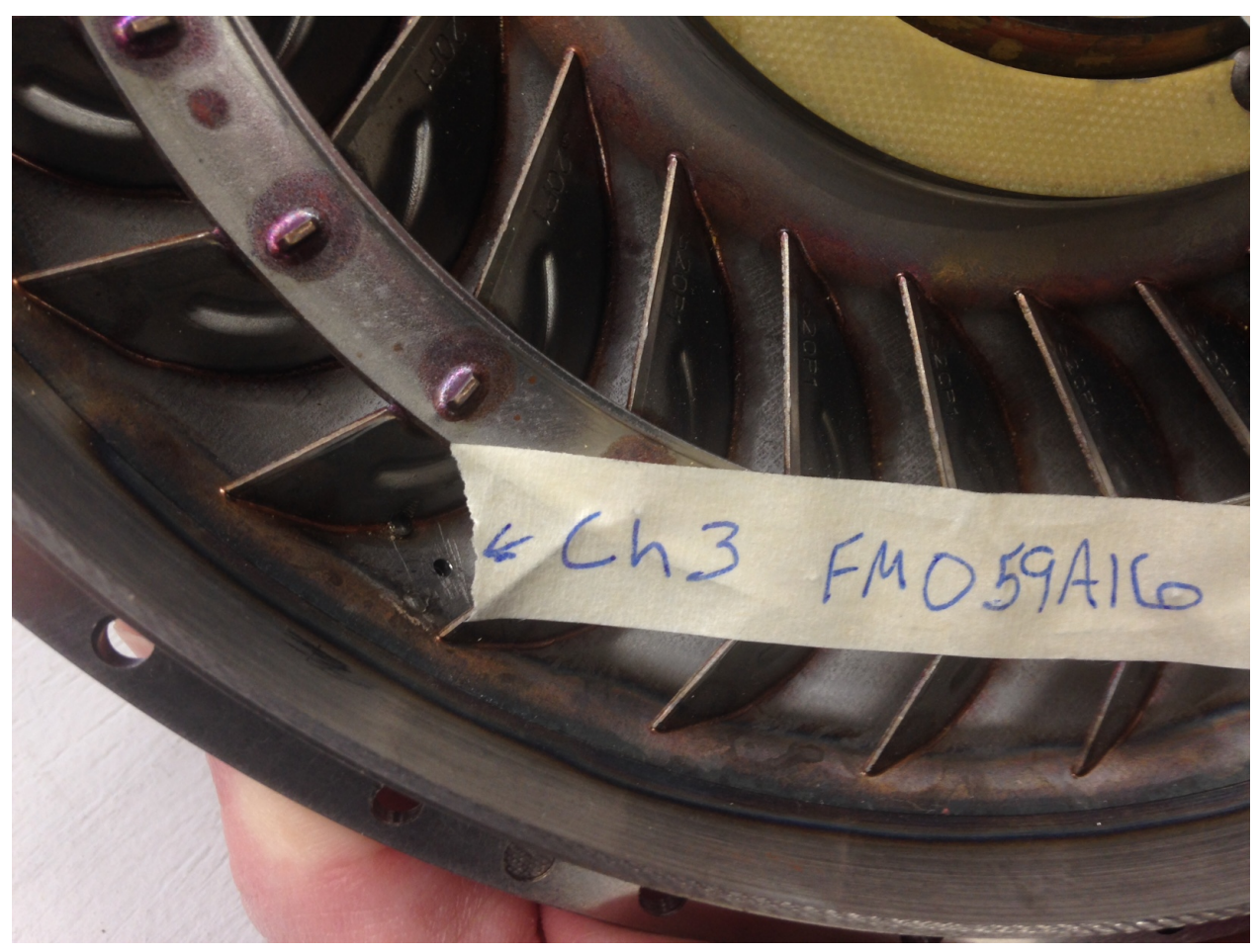

Figure I-18. Impeller channel 3 location, trailing edge between blades 


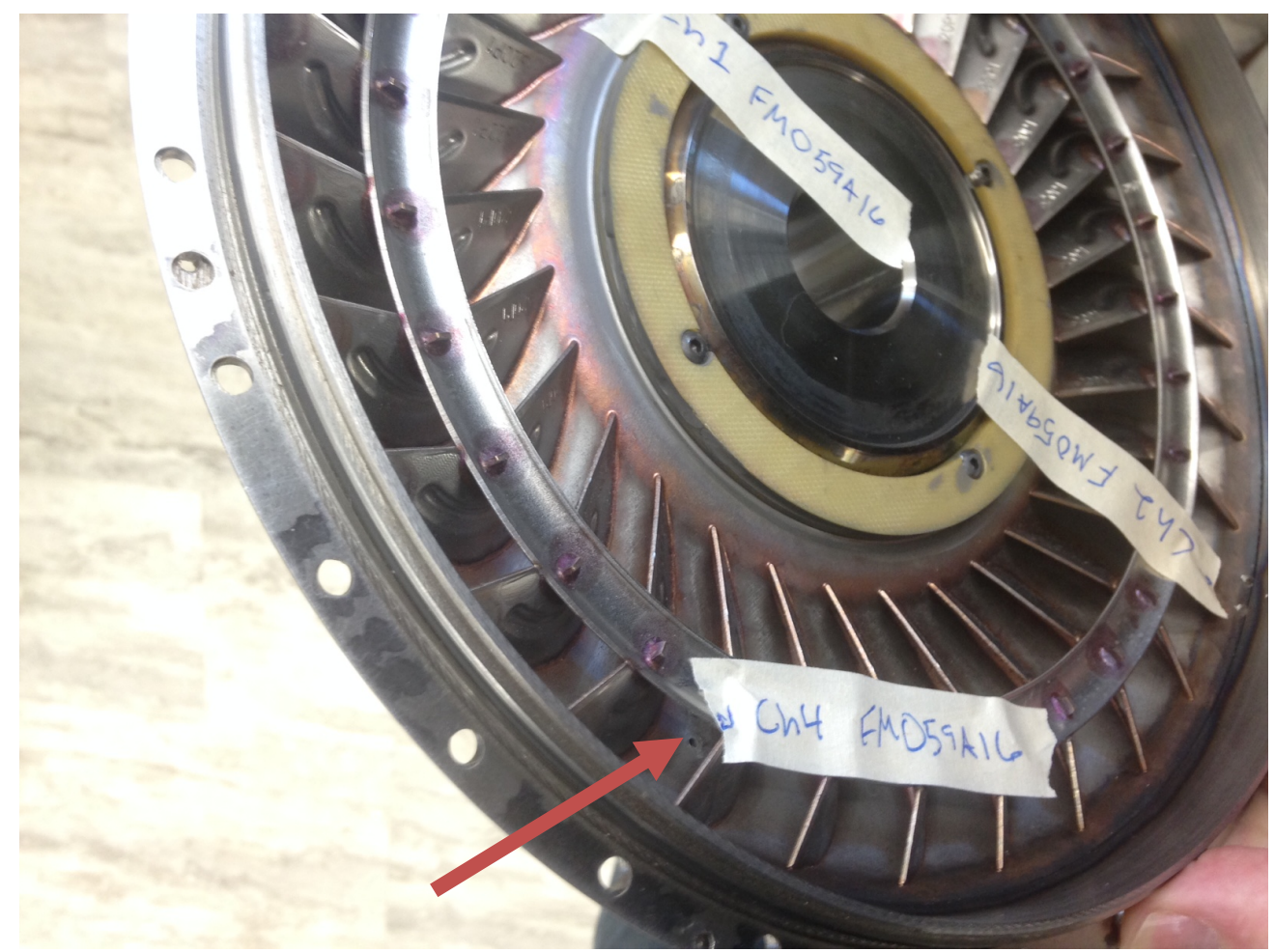

Figure I-19. Impeller channel 4 location, center between blades

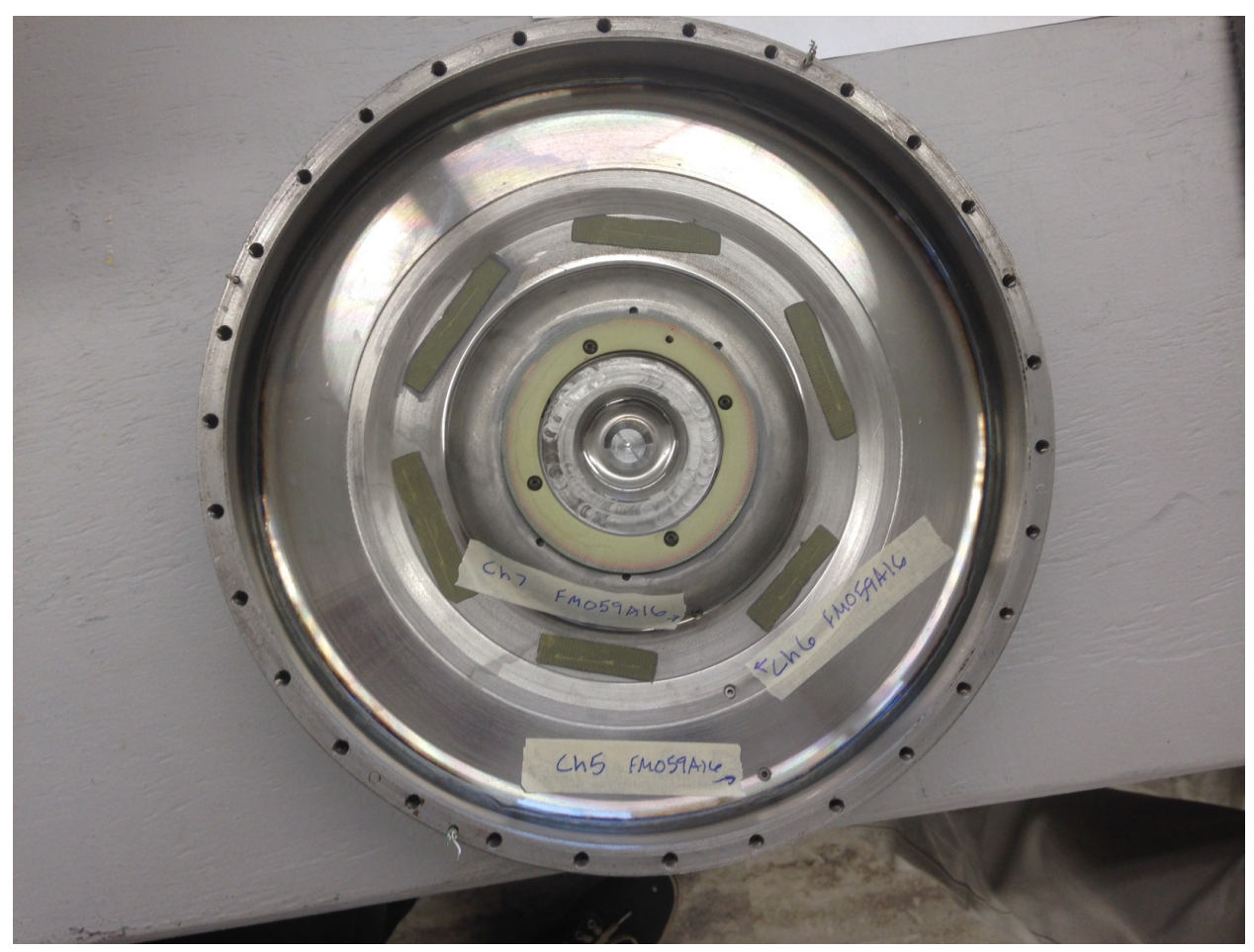

Figure I-20. Cover transducer locations 


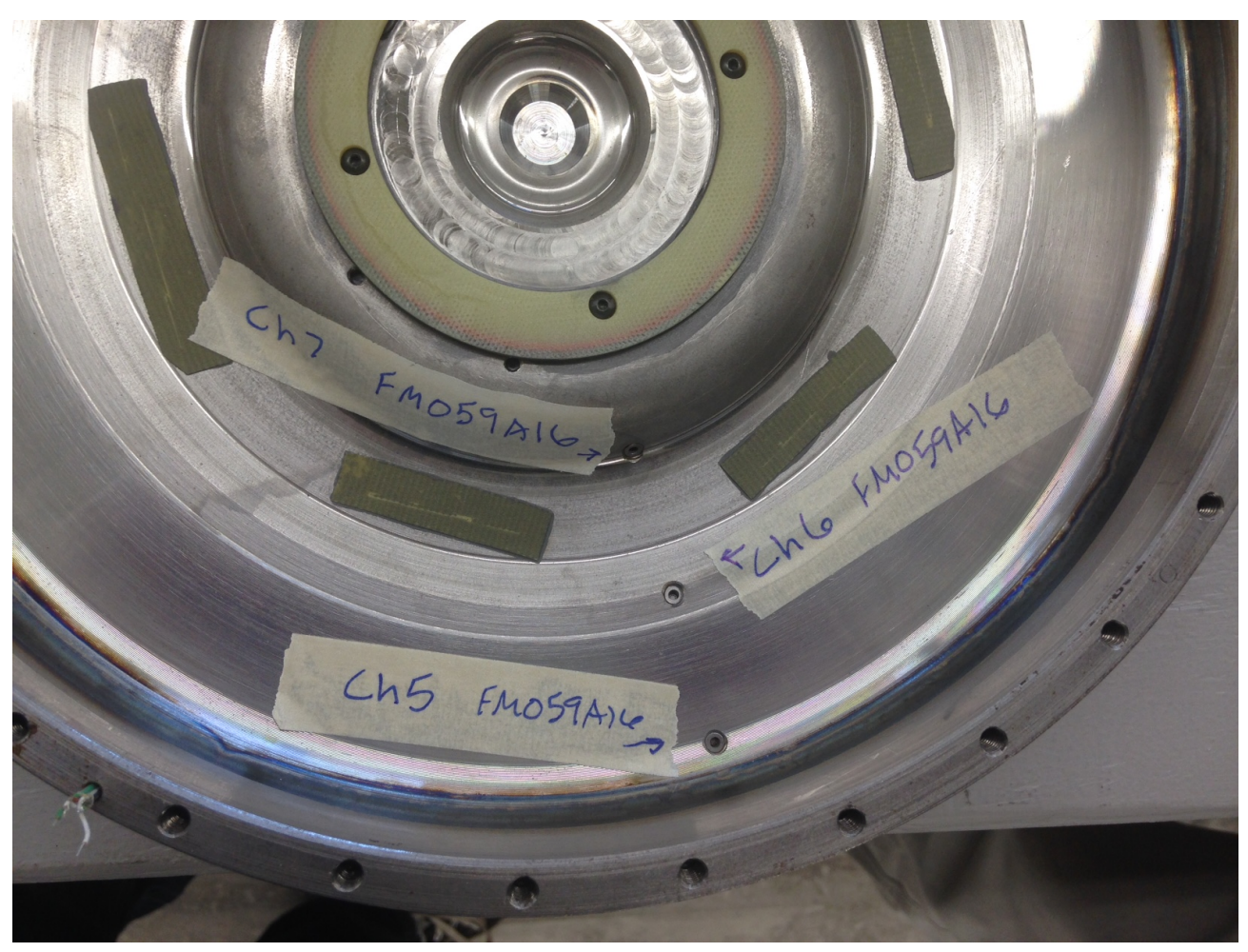

Figure I-21. Cover channels 5-7 locations

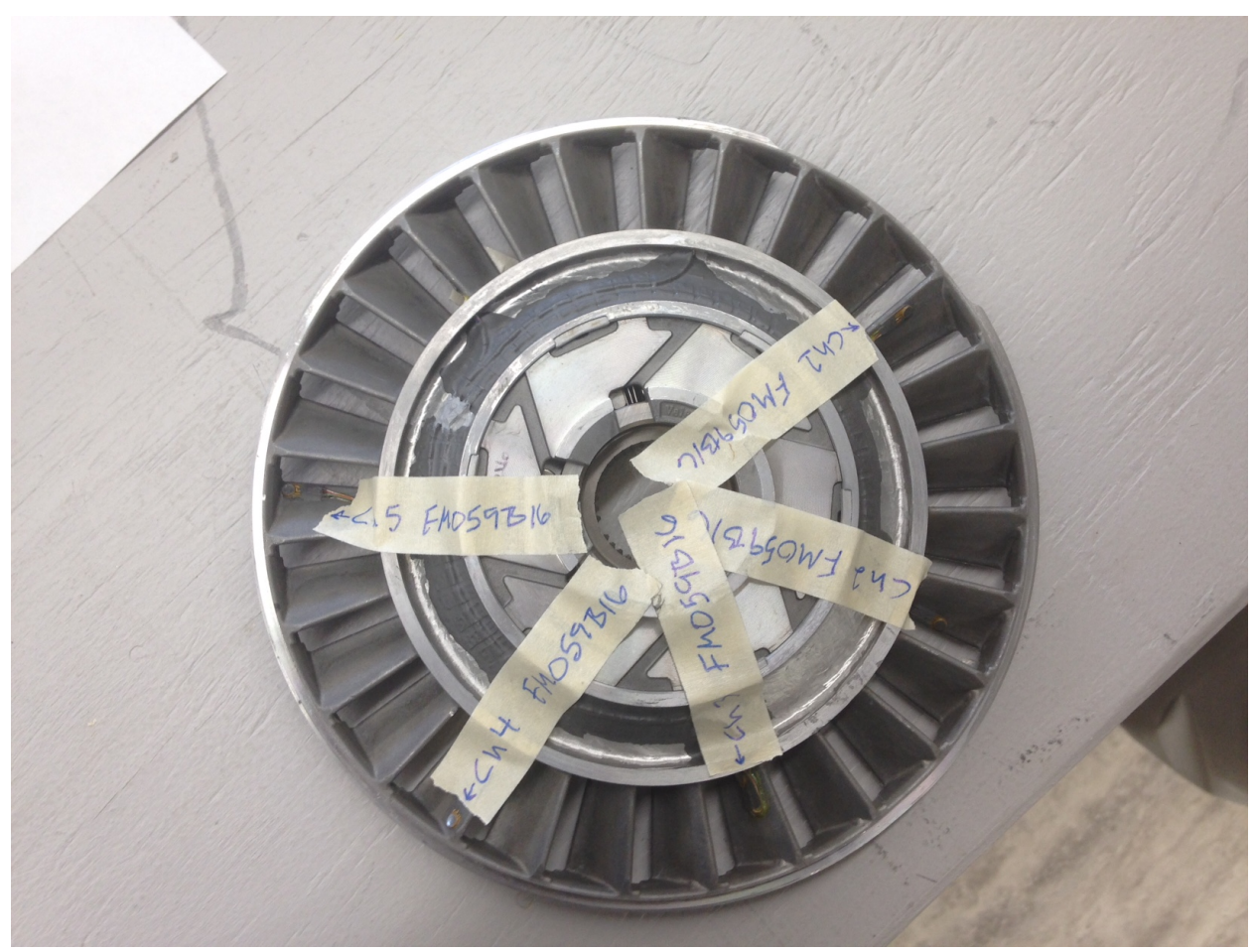

Figure I-22. Stator transducer locations 


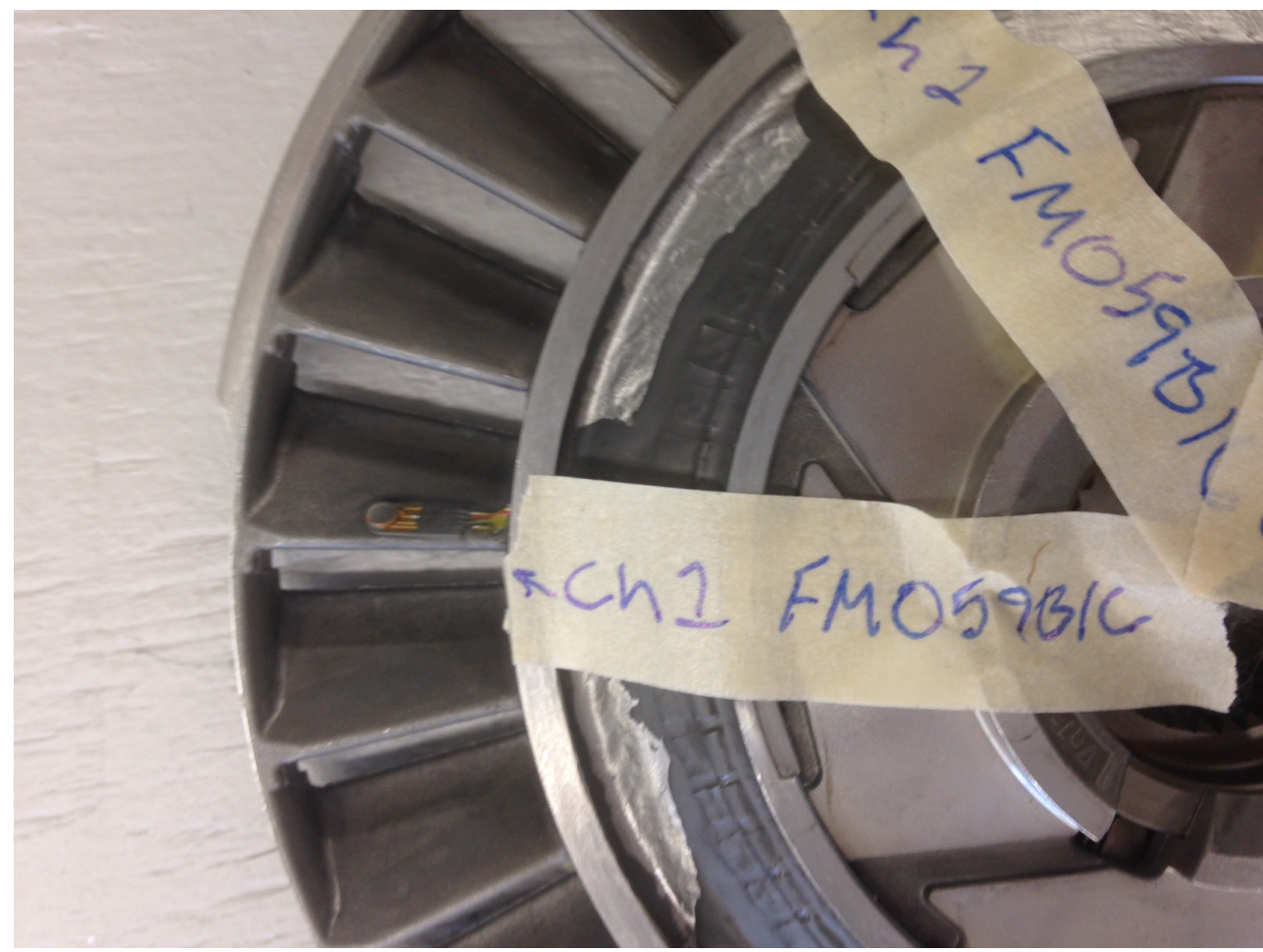

Figure I-23. Stator channel 1 location, leading edge/middle/pressure side

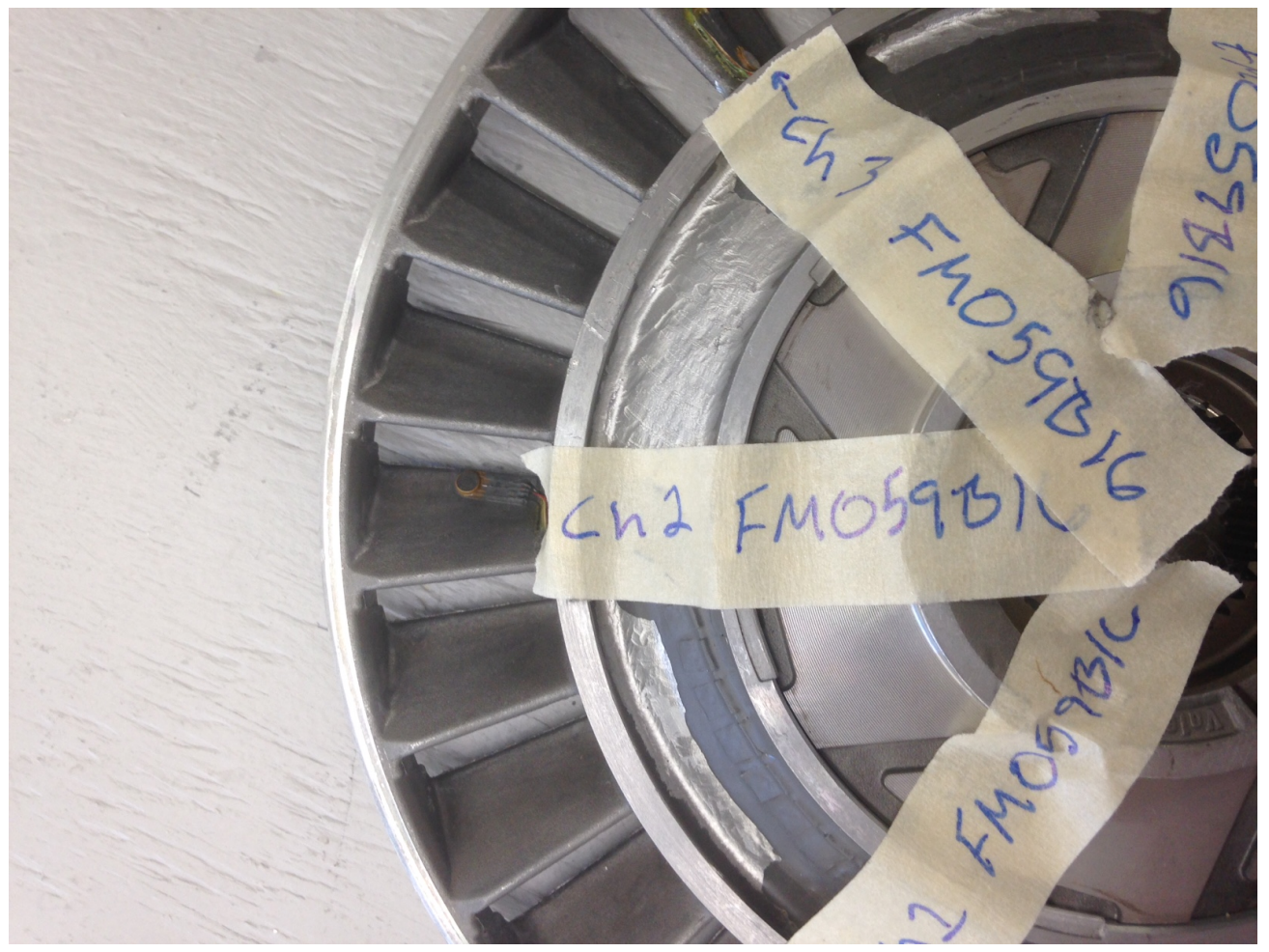

Figure I-24. Stator channel 2 location, trailing edge/middle/pressure side 


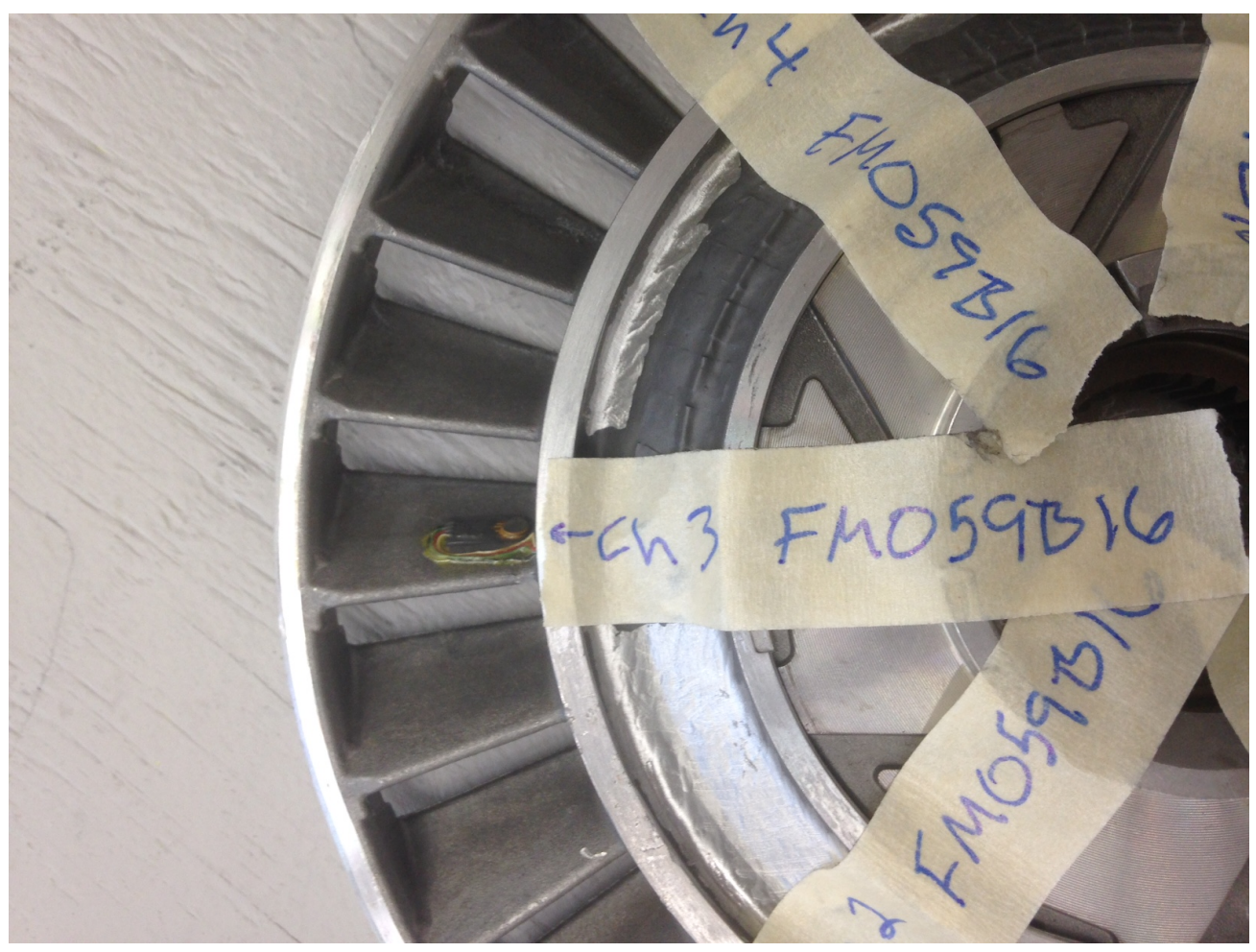

Figure I-25. Stator channel 3 location, middle of blade/shell/pressure side

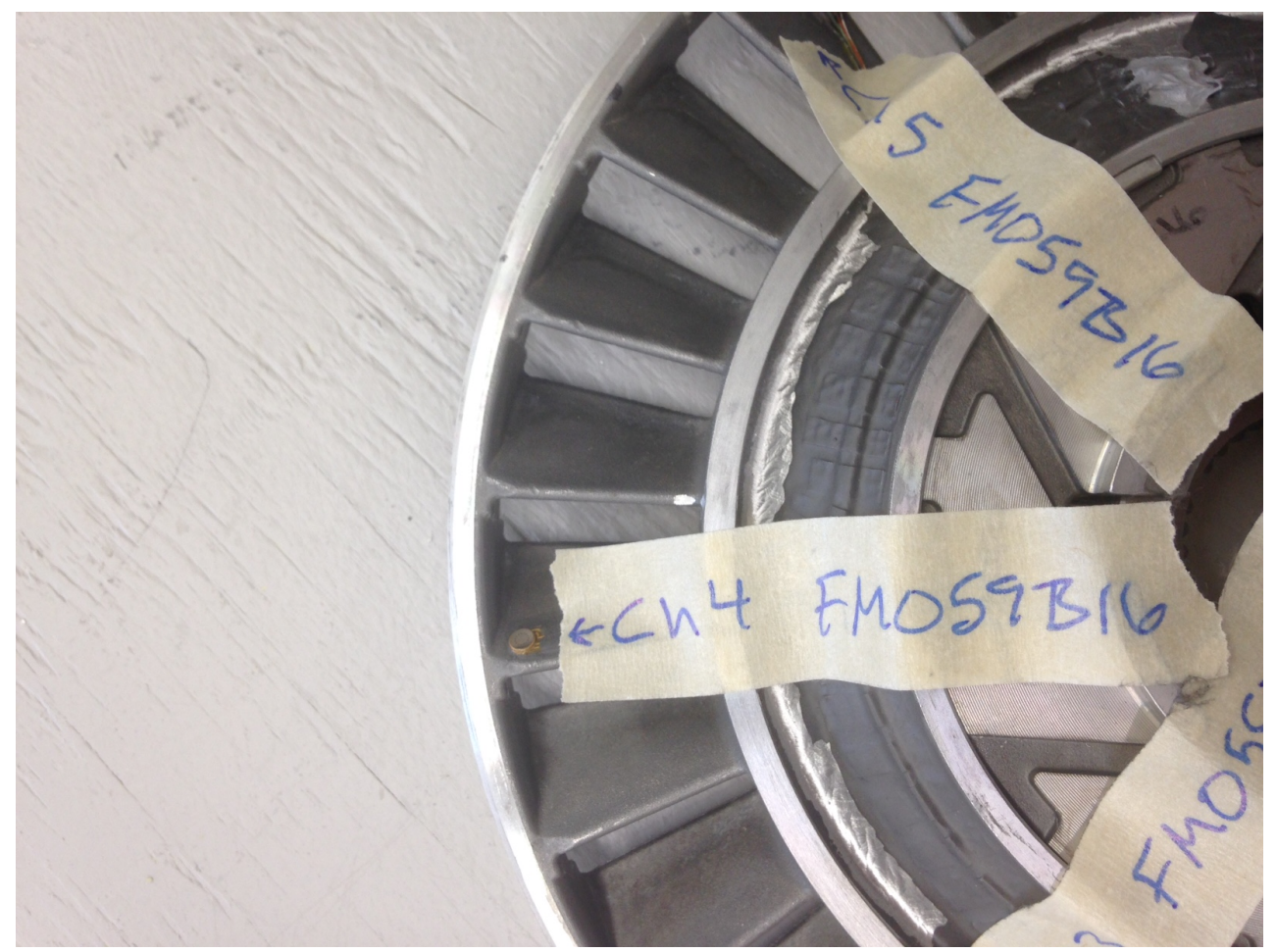

Figure I-26. Stator channel 4 location, leading edge/core/pressure side 


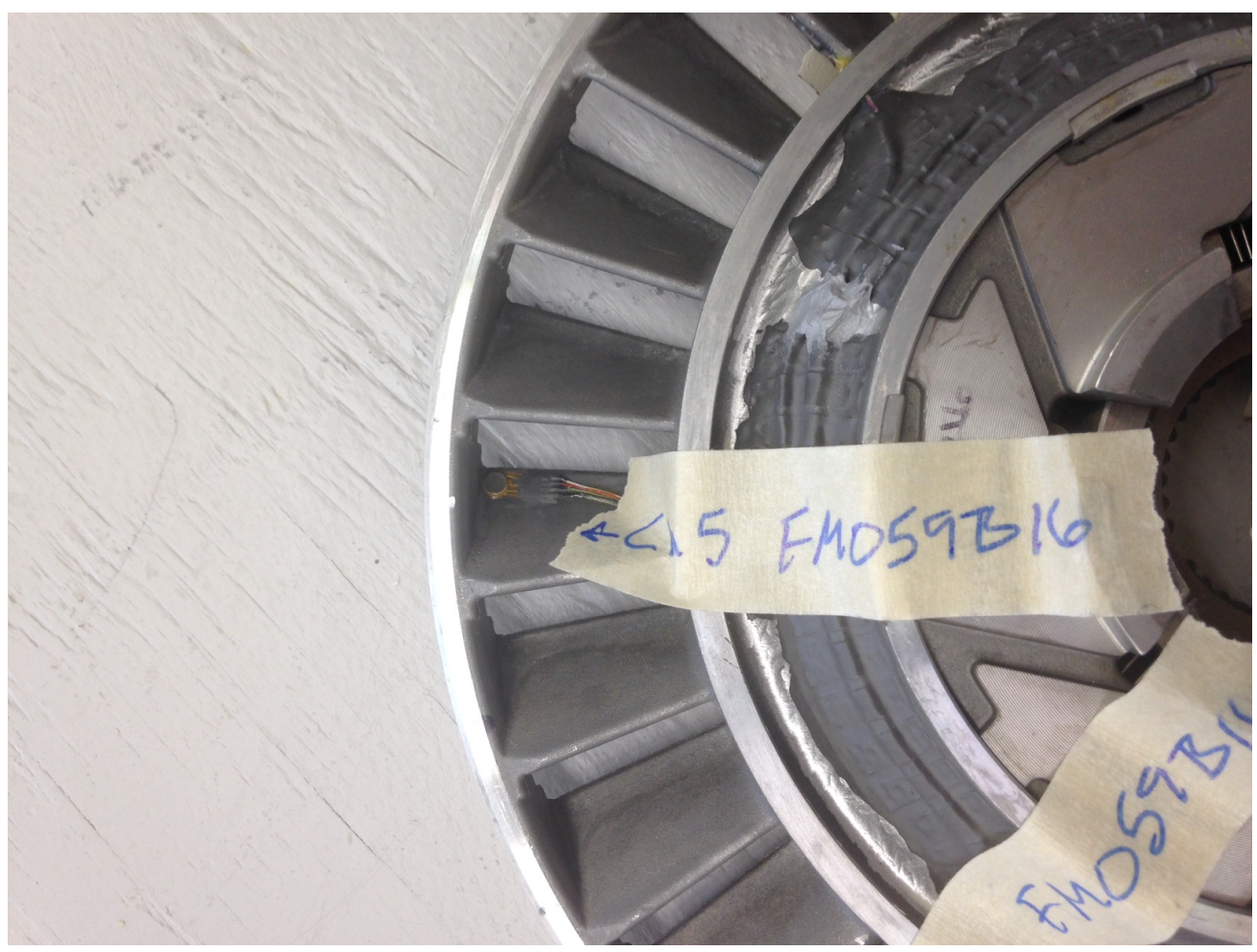

Figure I-27. Stator channel 5 location, trailing edge/shell/pressure side

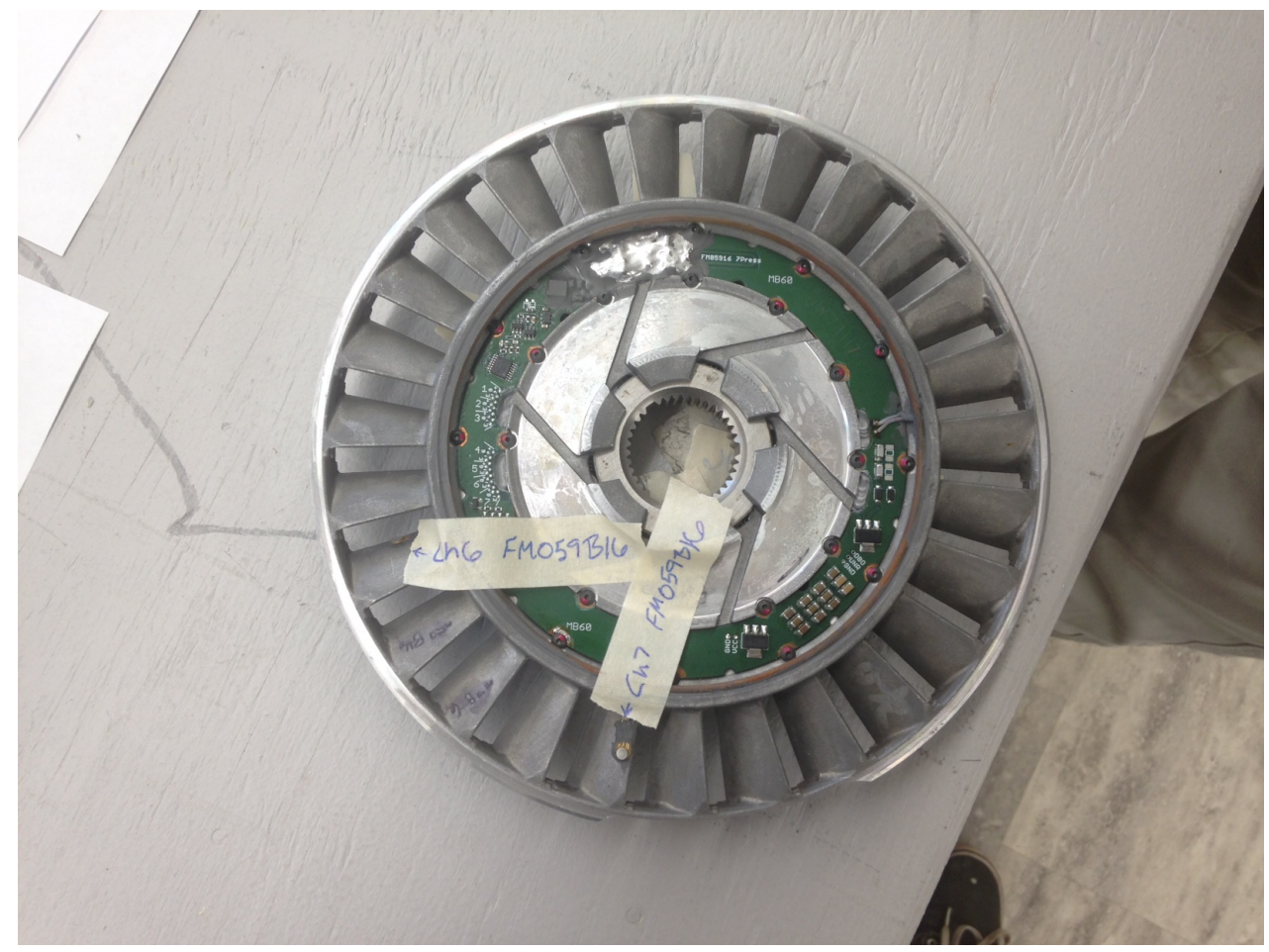

Figure I-28. Stator transducer locations 


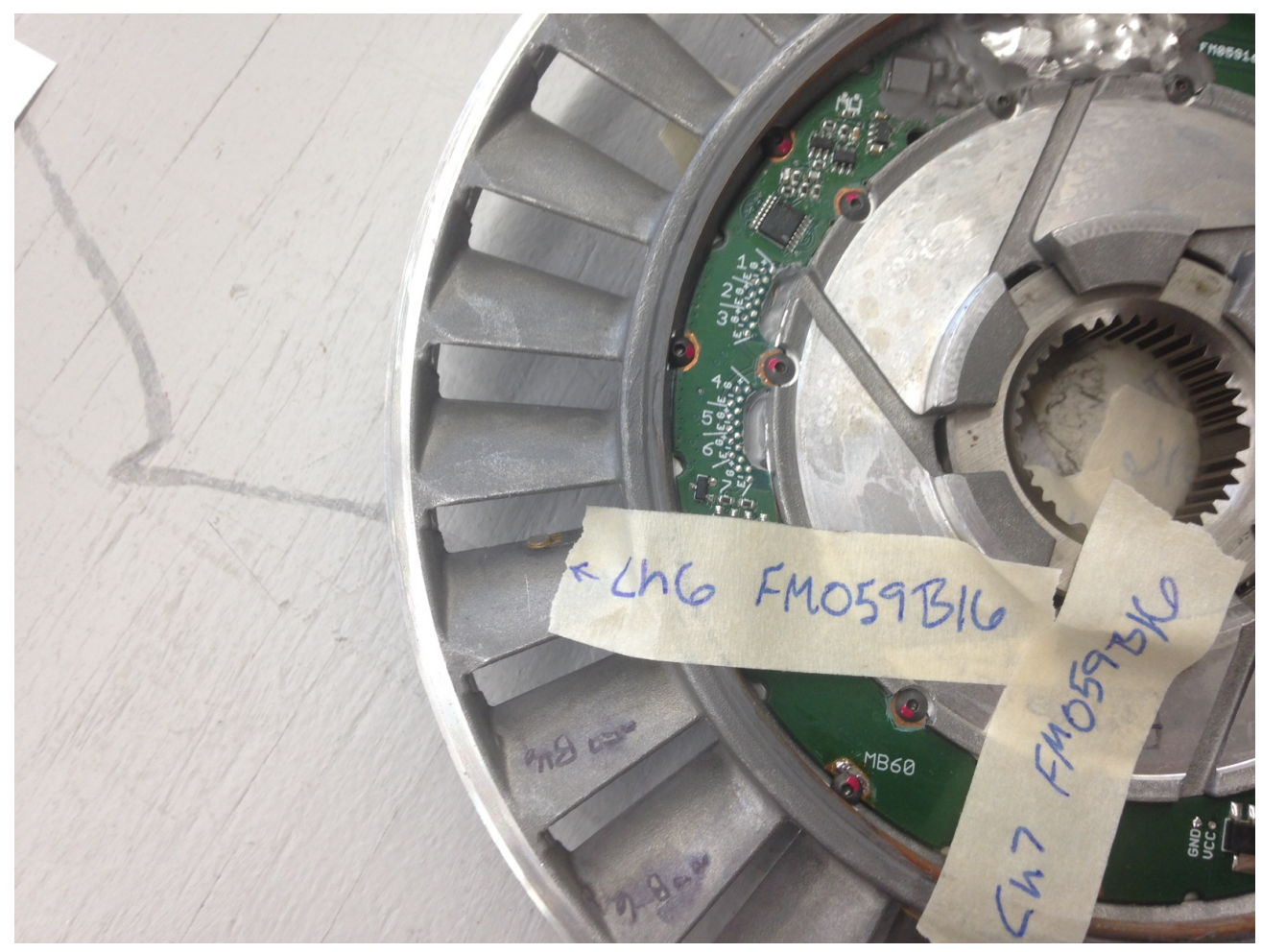

Figure I-29. Stator channel 6 location, leading edge/middle/suction side

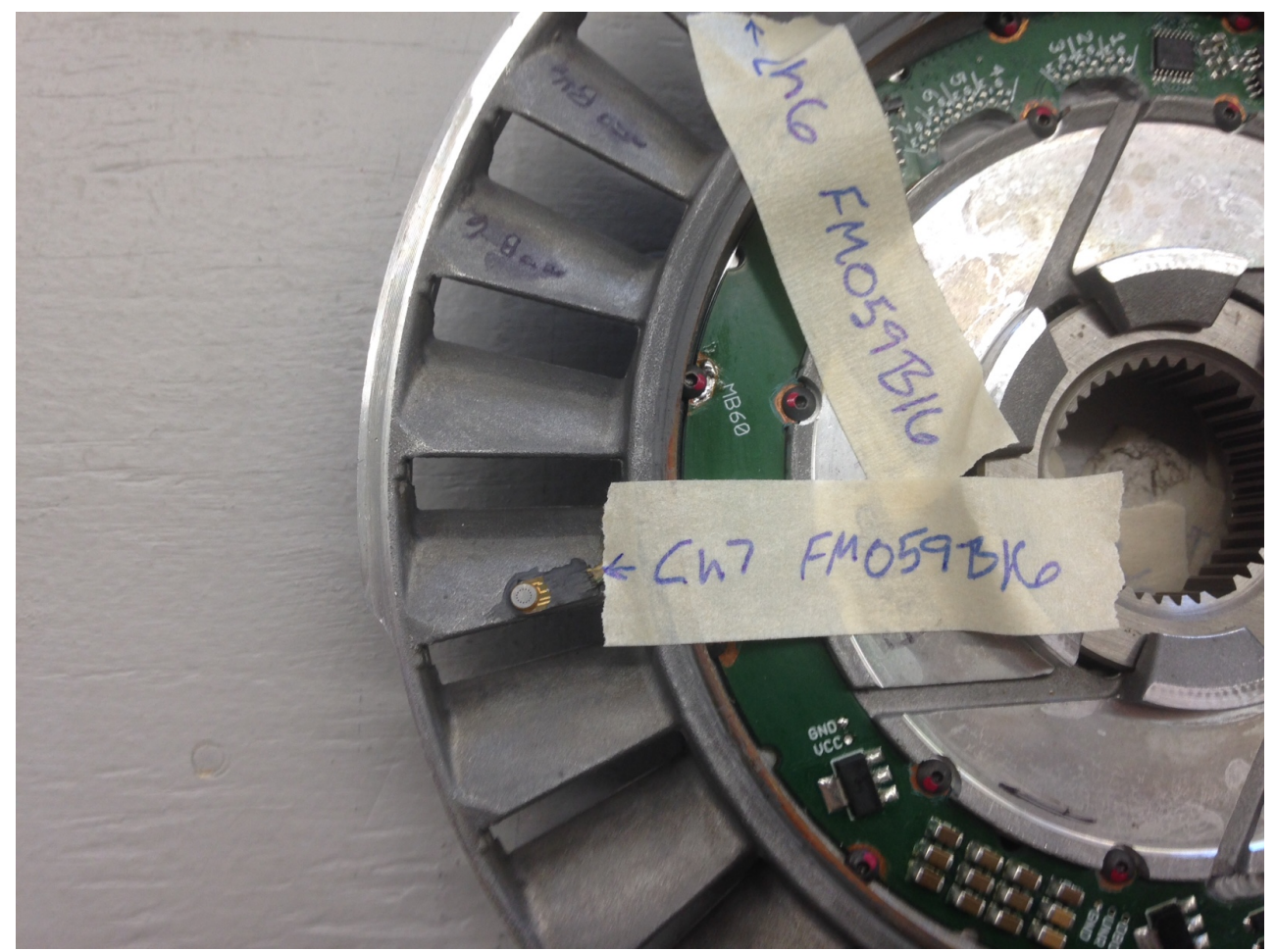

Figure I-30. Stator channel 7 location, trailing edge/middle/suction side 


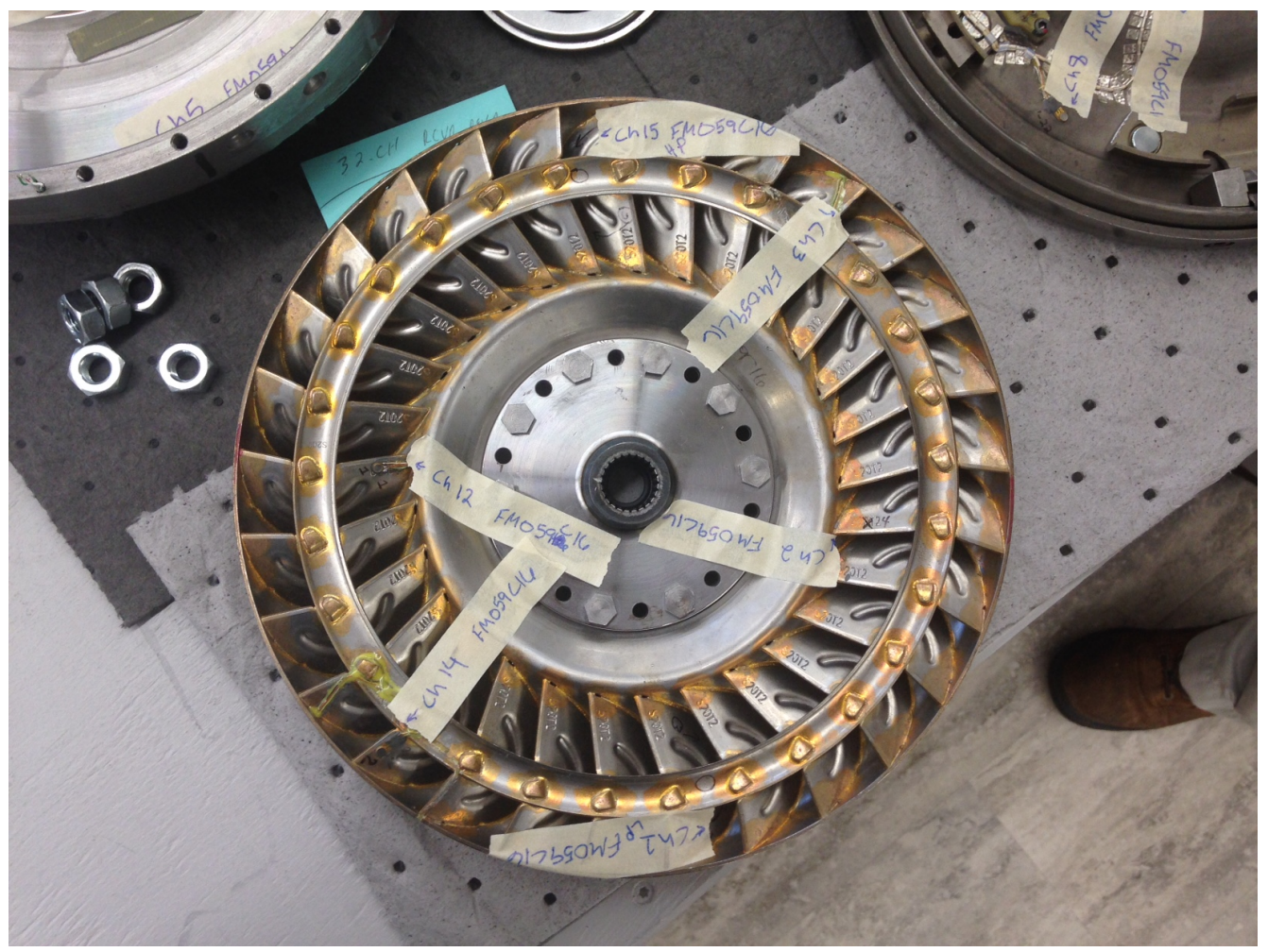

Figure I-31. Turbine transducer locations

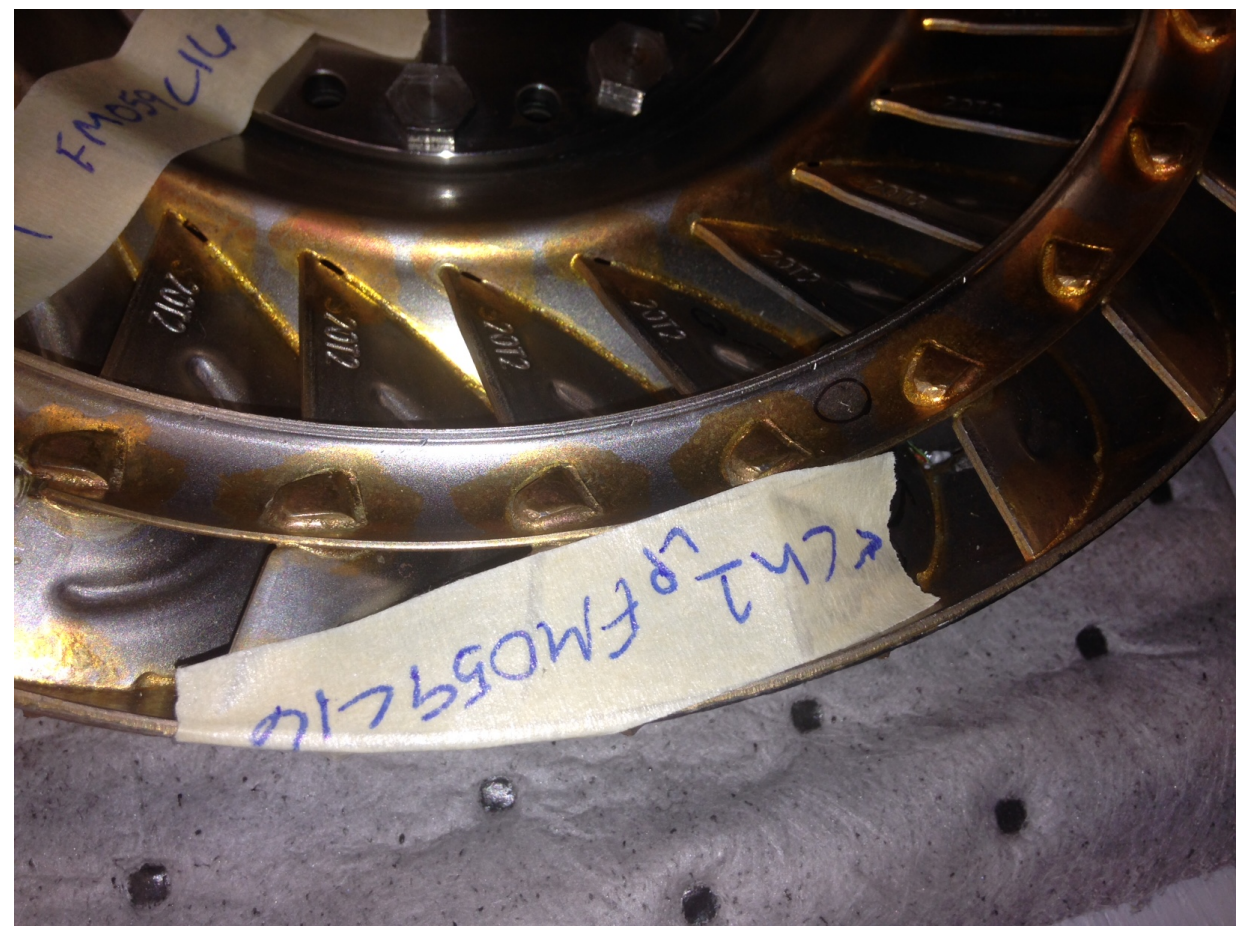

Figure I-32. Turbine channel 1 location, middle of blade suction side 


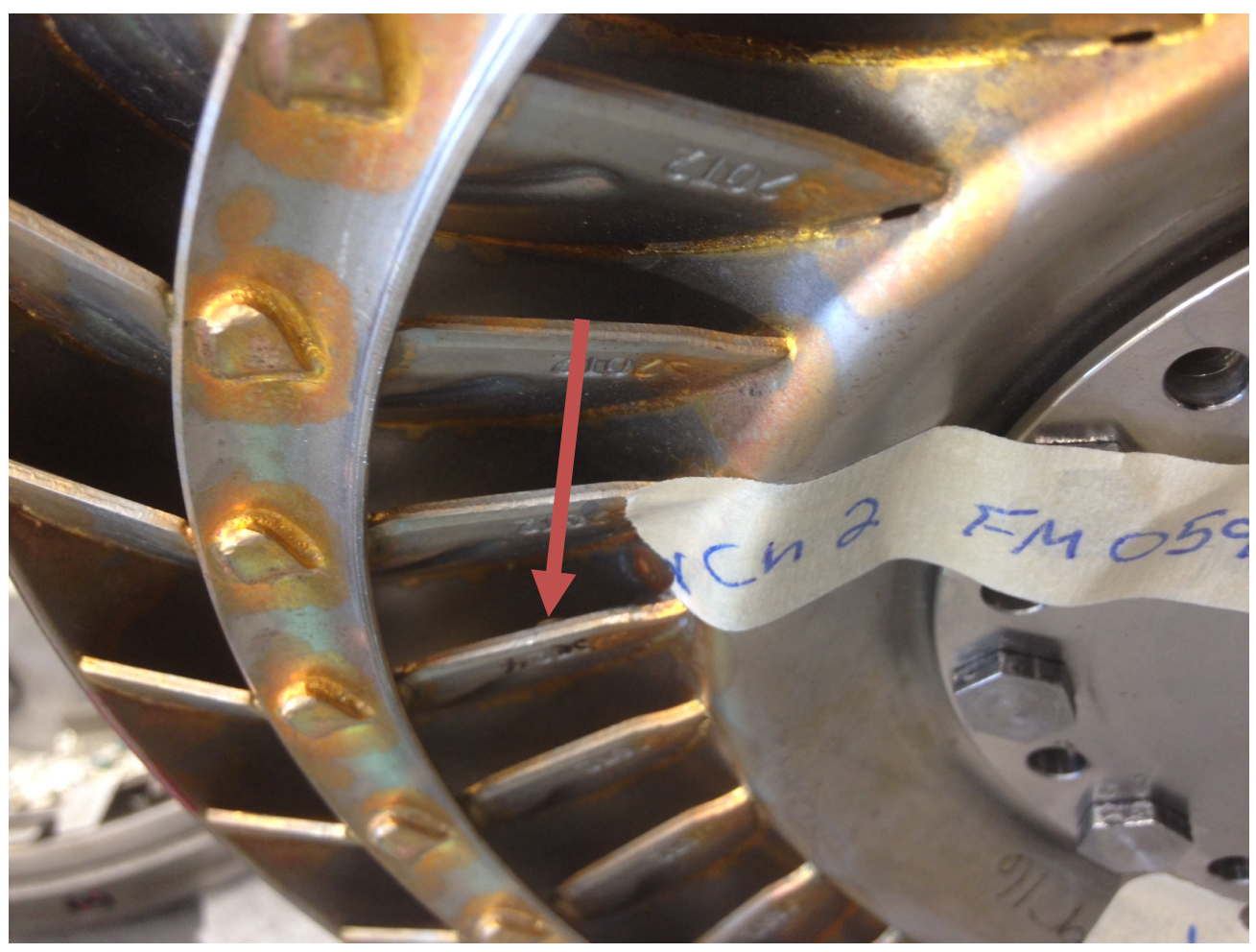

Figure I-33. Turbine channel 2 location, trailing edge pressure side

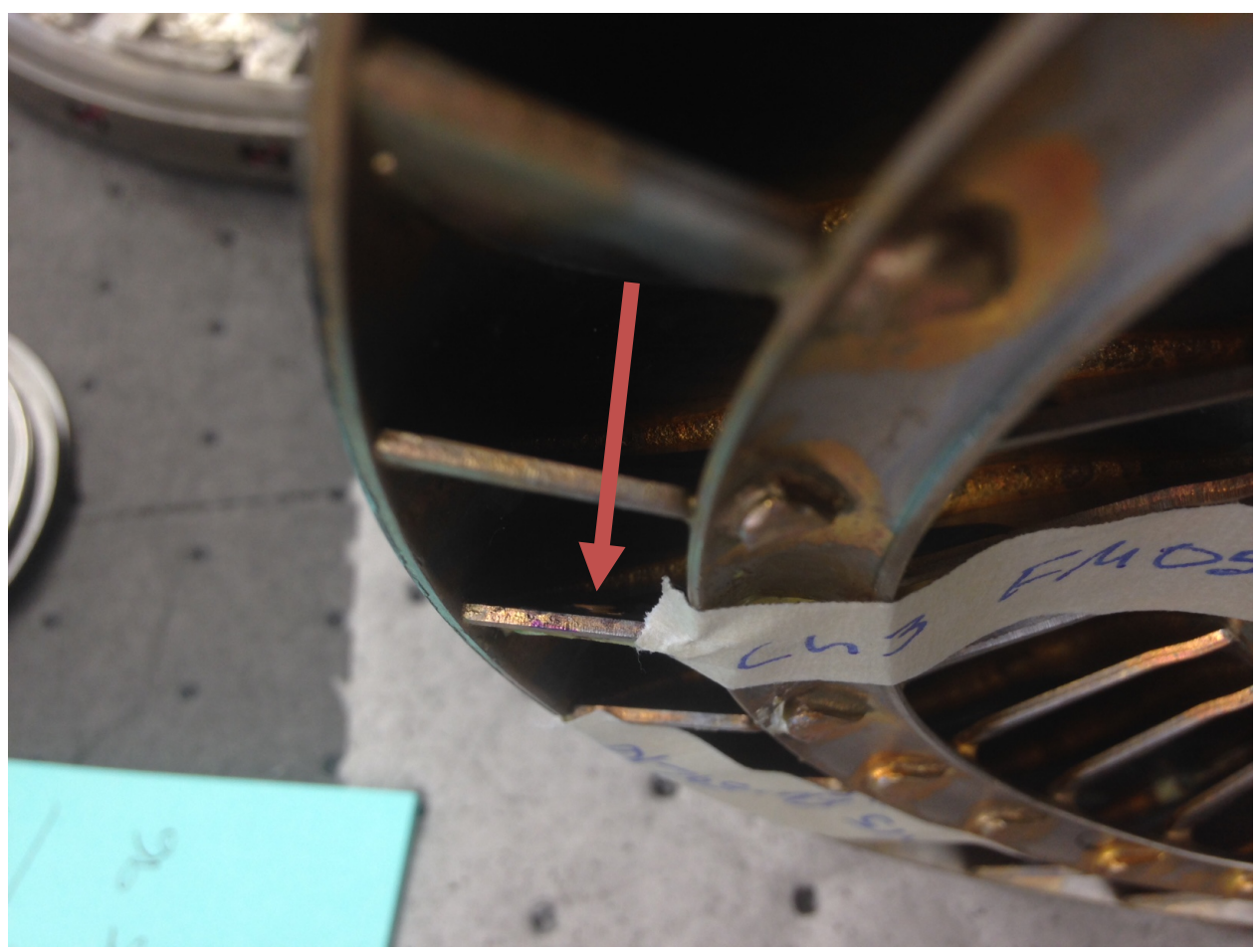

Figure I-34. Turbine channel 3 location, leading edge pressure side 


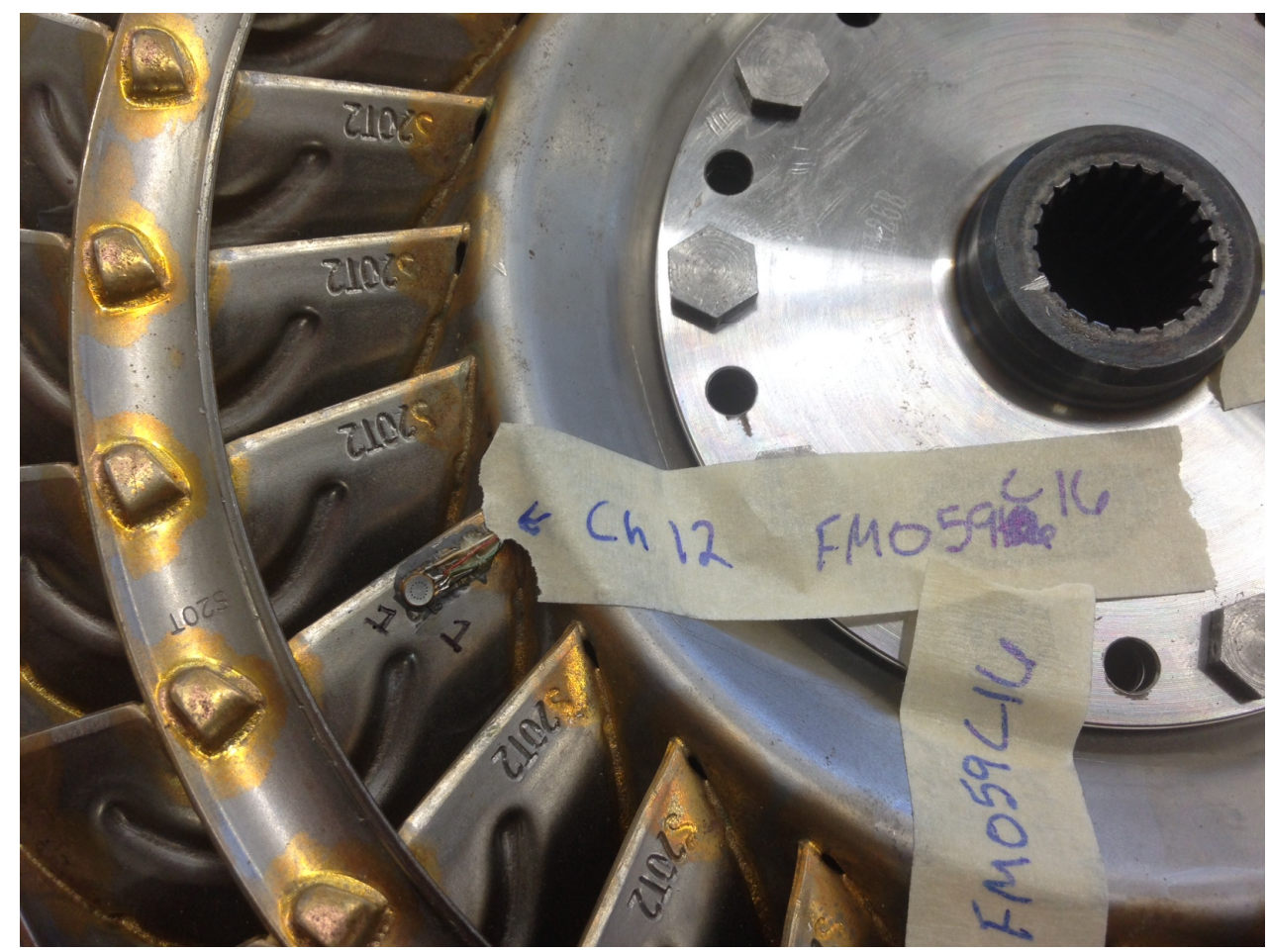

Figure I-35. Turbine channel 12 locations, trailing edge suction side

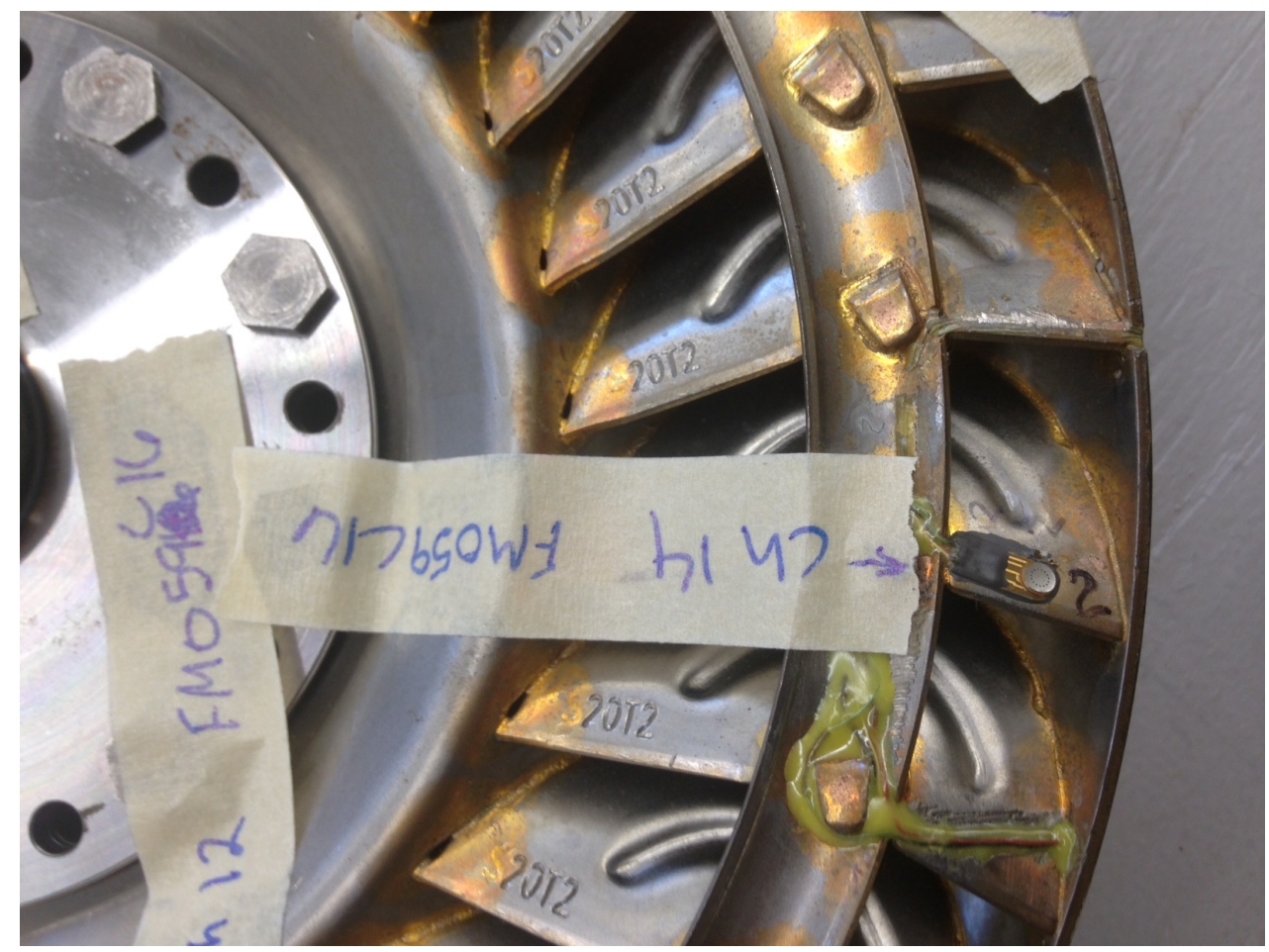

Figure I-36. Turbine channel 14 location, leading edge suction side 


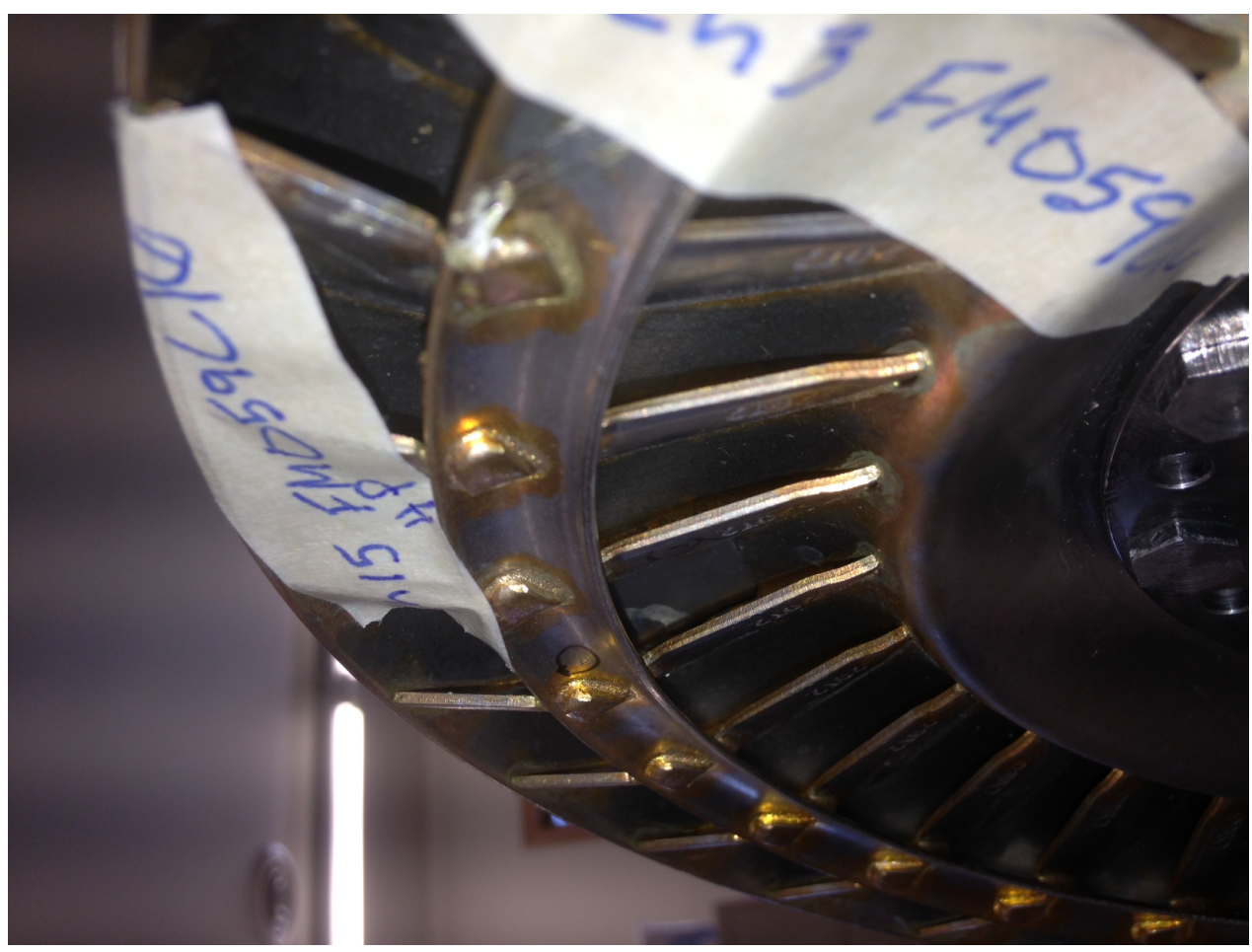

Figure I-37. Turbine channel 15 location, middle blade pressure side

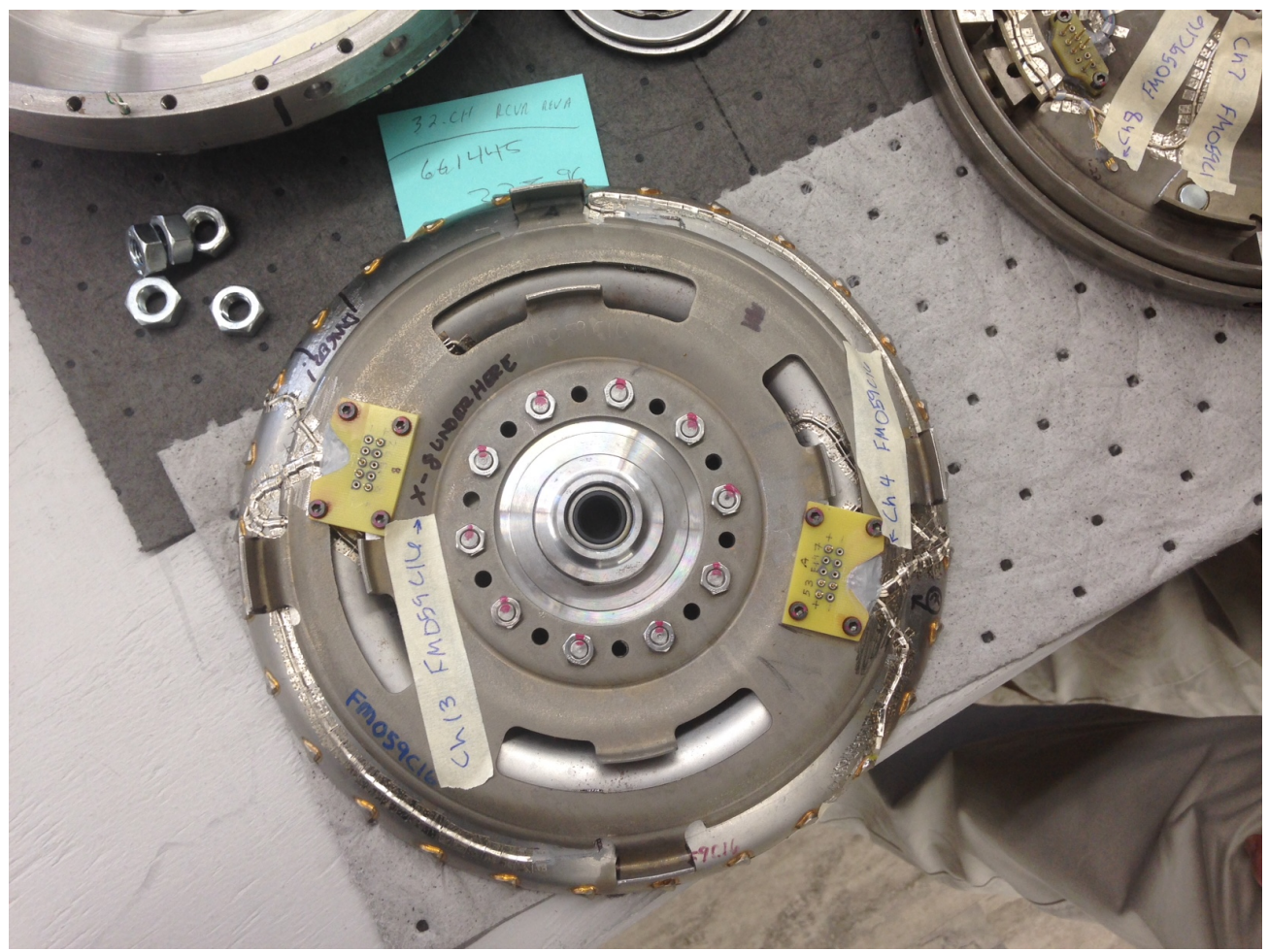

Figure I-38. Turbine channel 4 and 13 locations, back of turbine under plate 


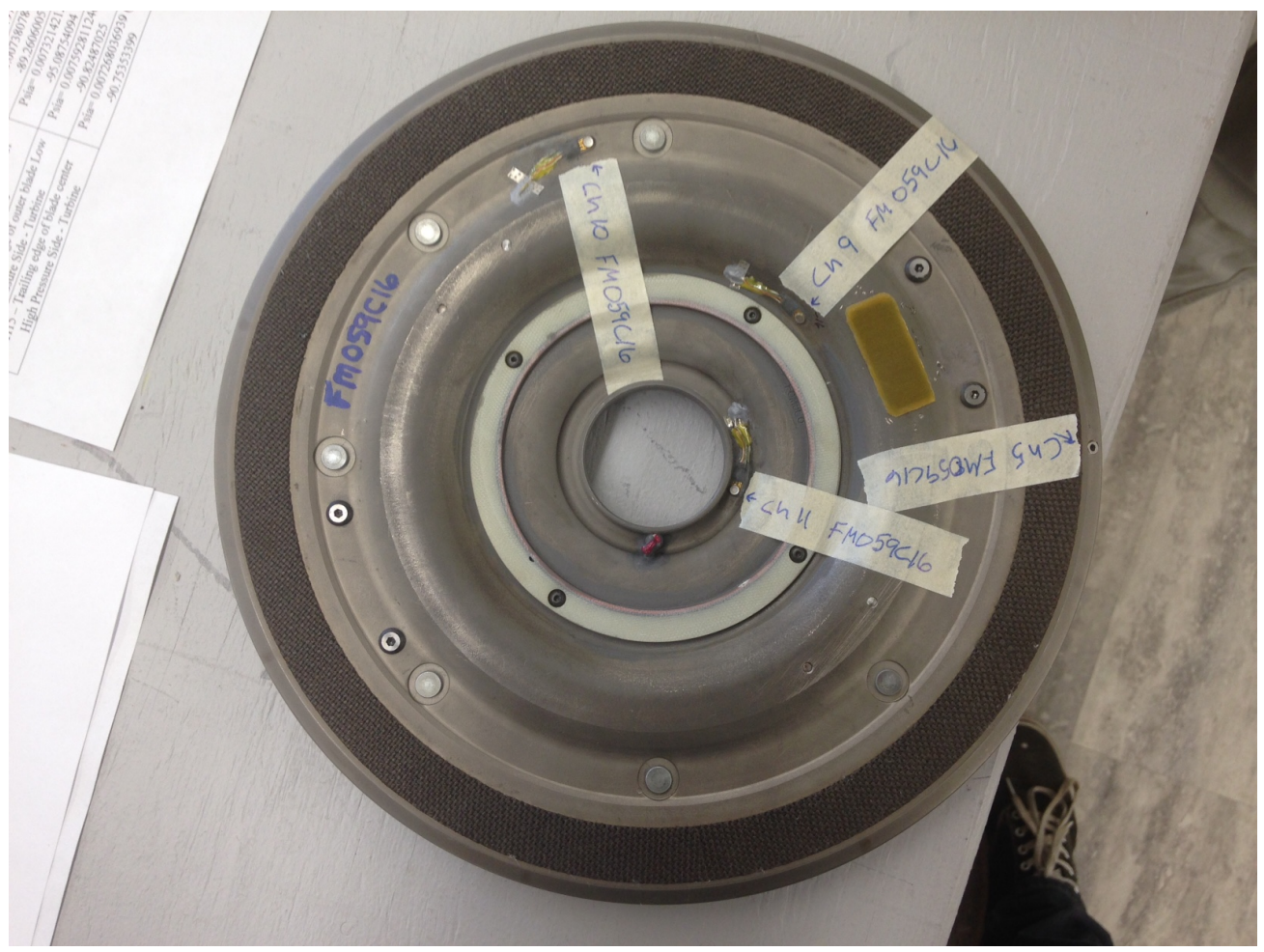

Figure I-39. Clutch transducer locations

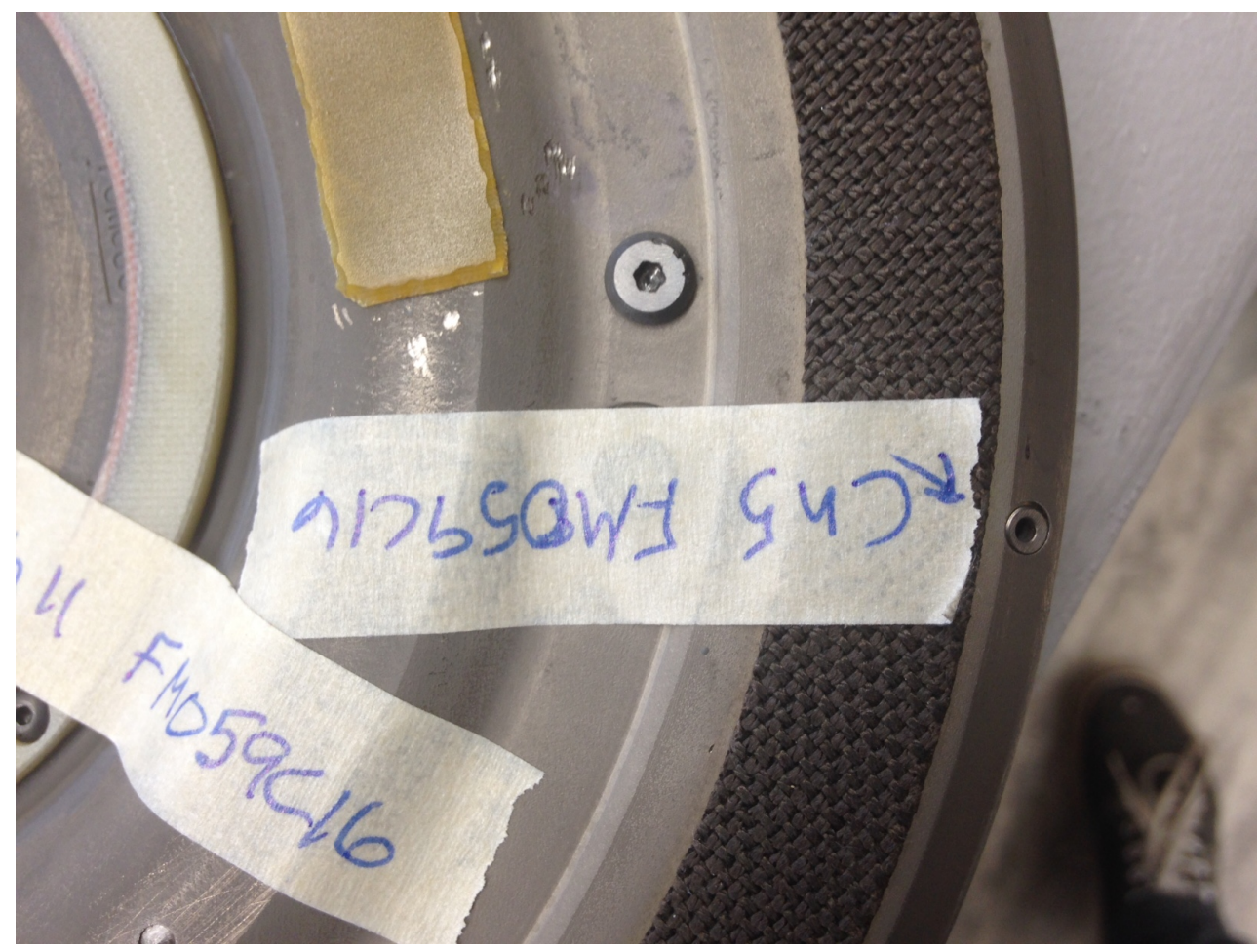

Figure I-40. Clutch channel 5 location, outer radius past friction material 


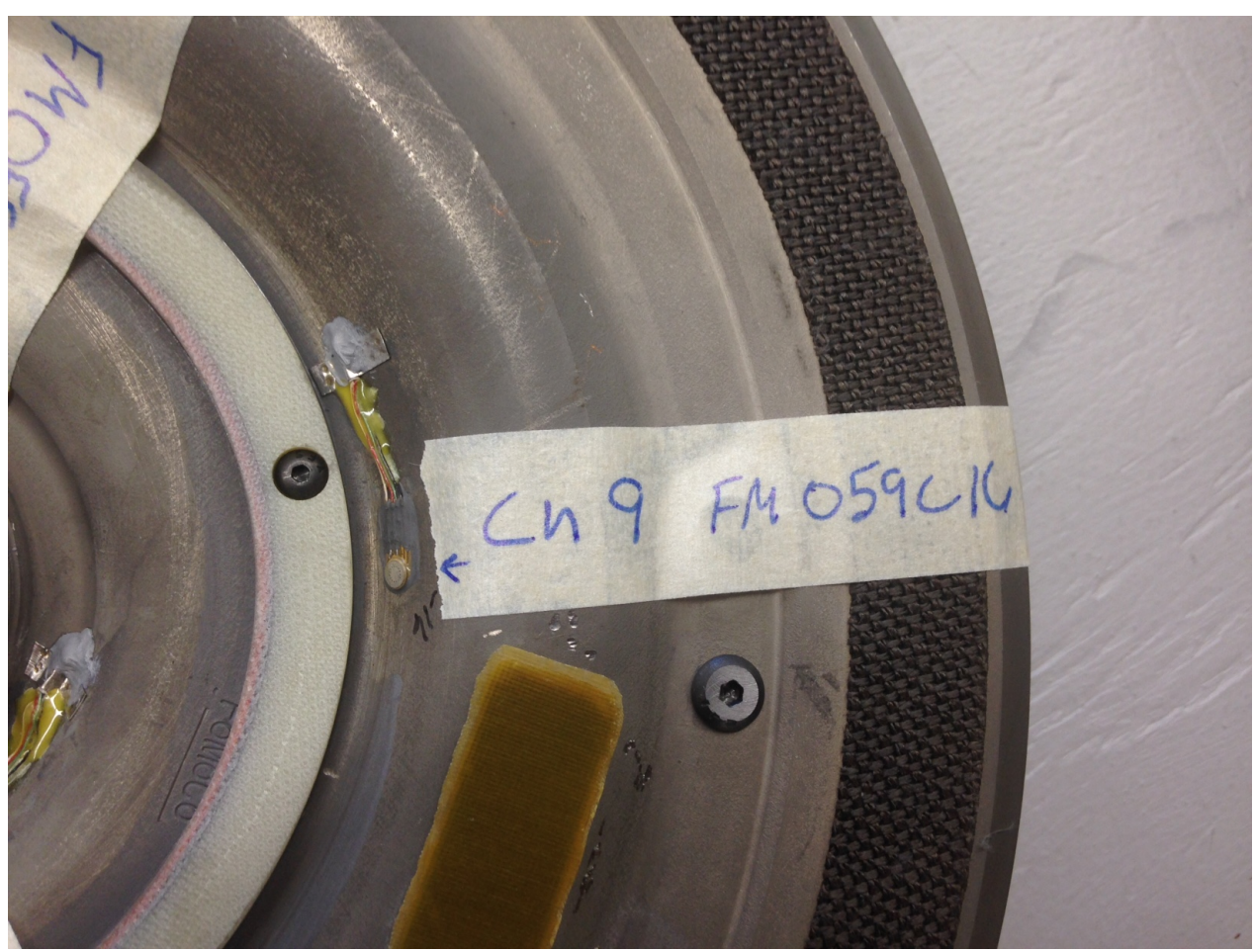

Figure I-41. Clutch channel 9 location, middle radius

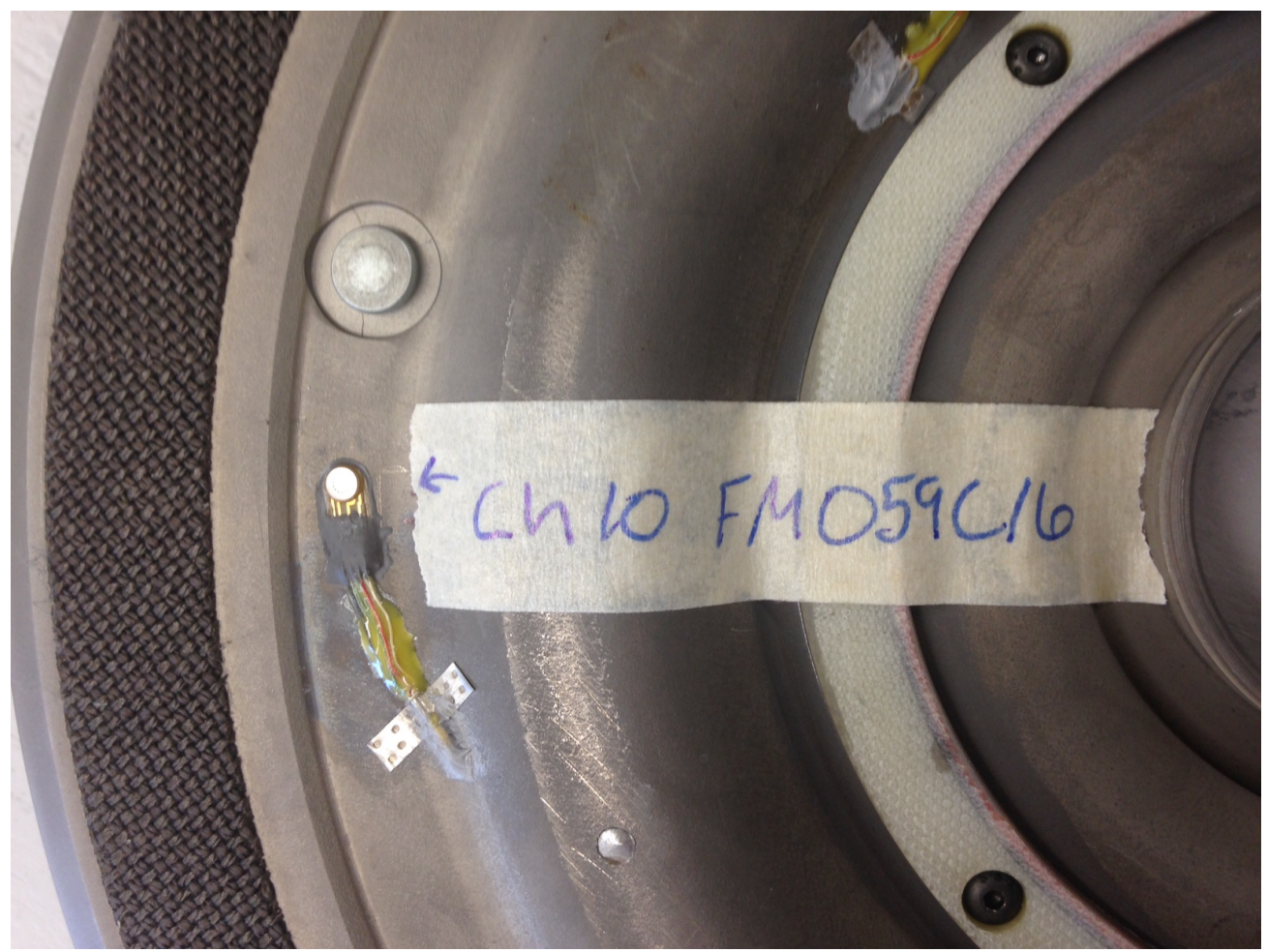

Figure I-42. Clutch channel 10 location, outer radius before friction material 


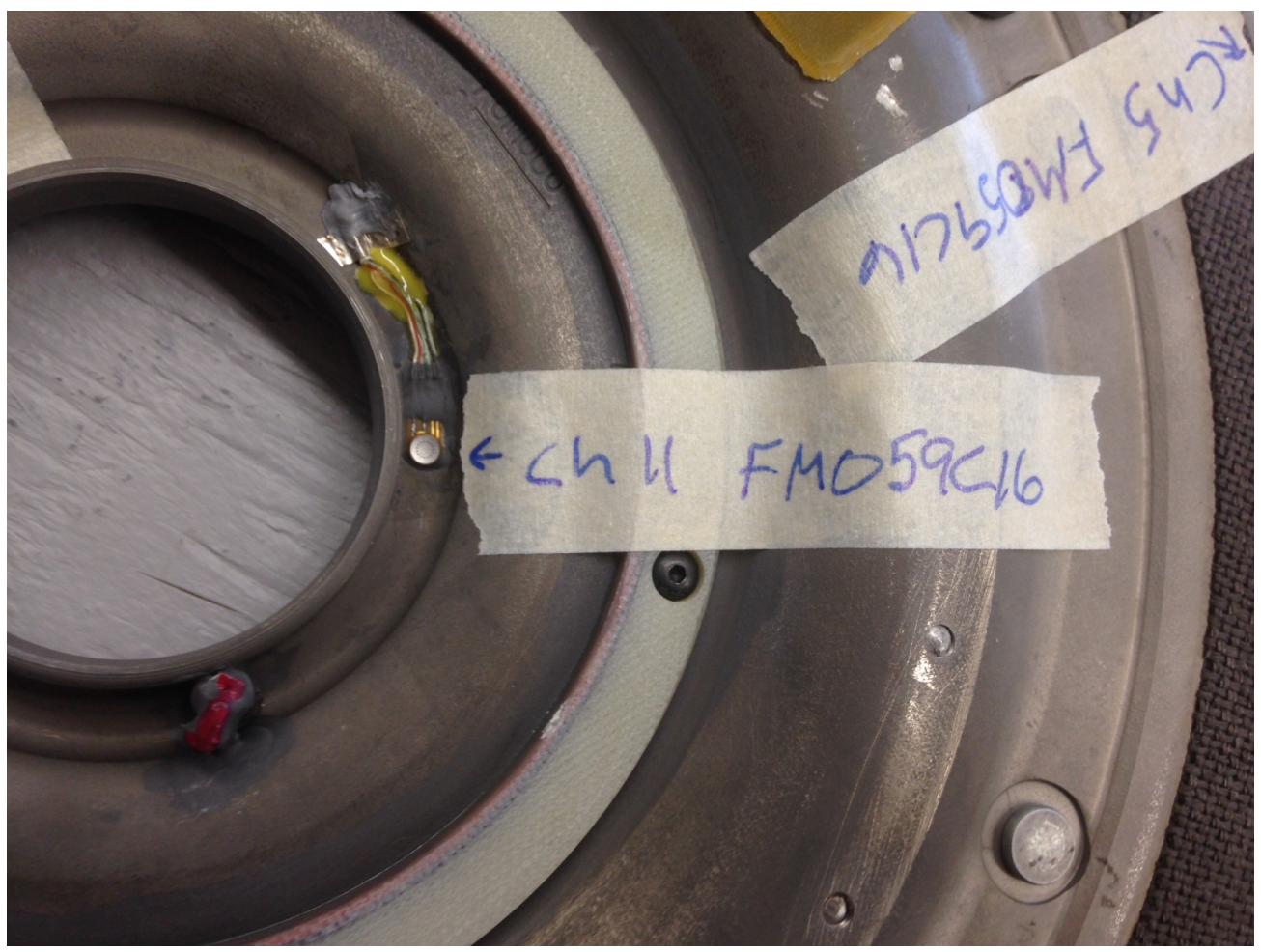

Figure I-43. Clutch channel 11 location, inner radius

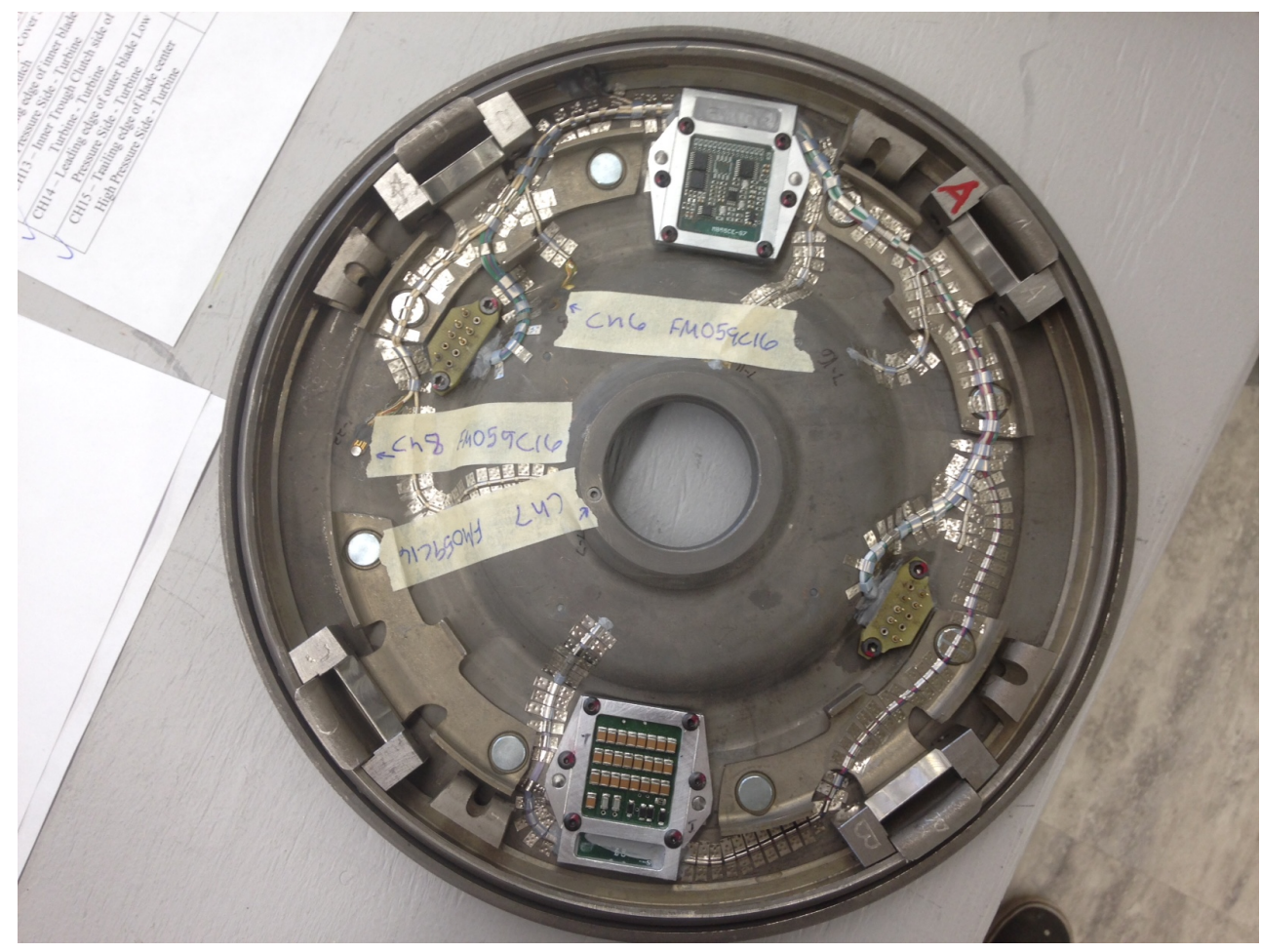

Figure I-44. Clutch plate transducer locations 


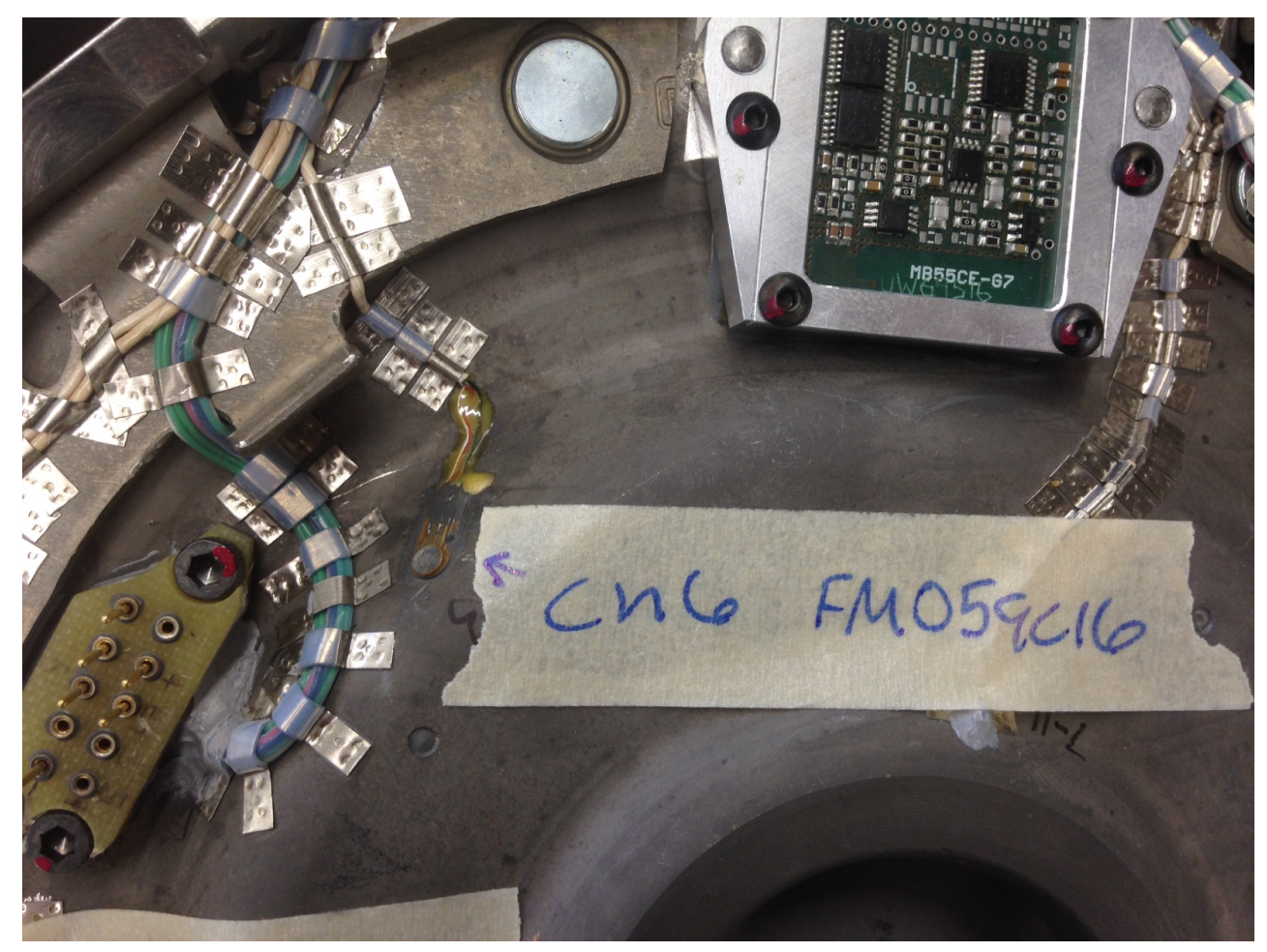

Figure I-45. Clutch channel 6 location, middle radius

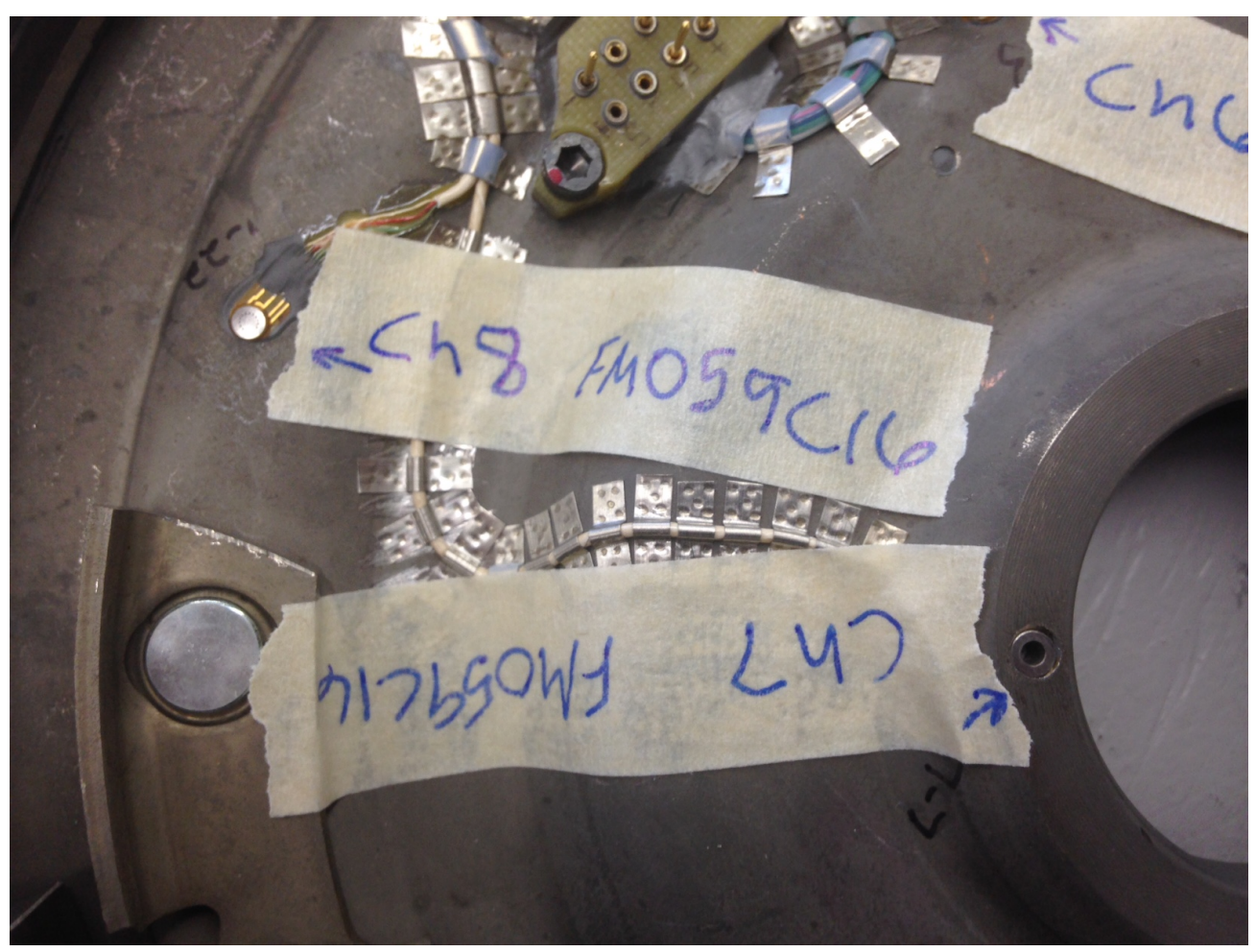

Figure I-46. Clutch channel 7 and 8 locations, inner and outer radius respectively 


\section{J Telemetry Setup Procedure}

1. Connect extension cable from transmission to power supply on computer control stand outside and power on.

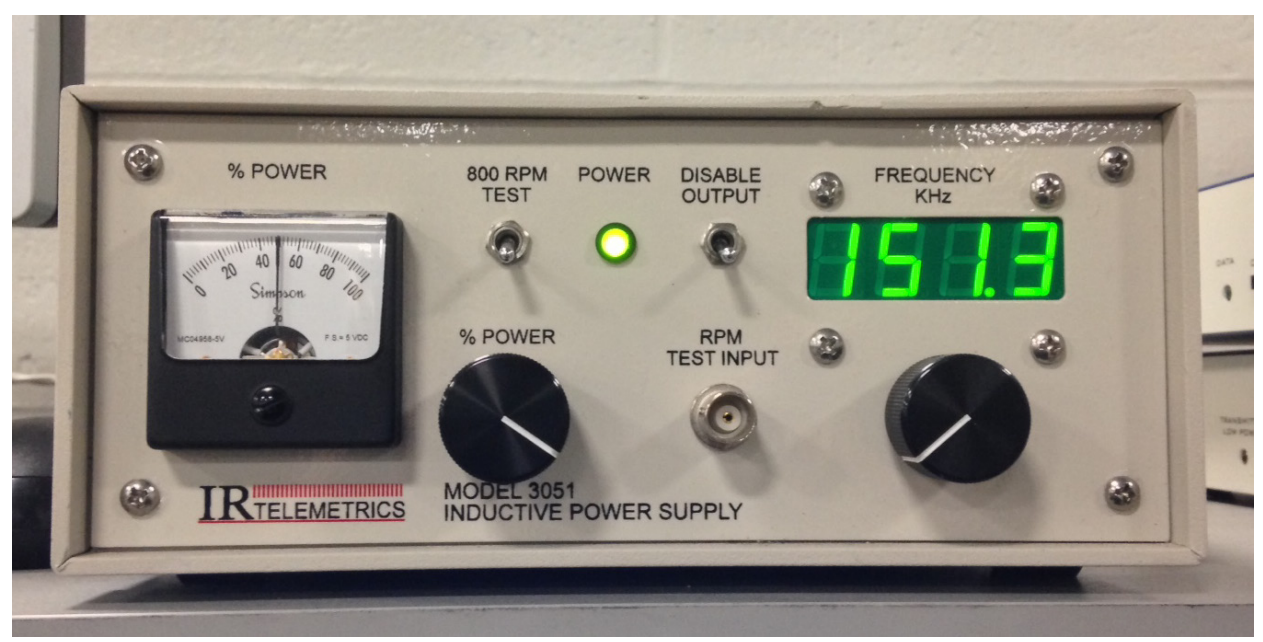

Figure I-1. Power supply for telemetry

2. Turn on the three receivers, one at a time, in the test cell.

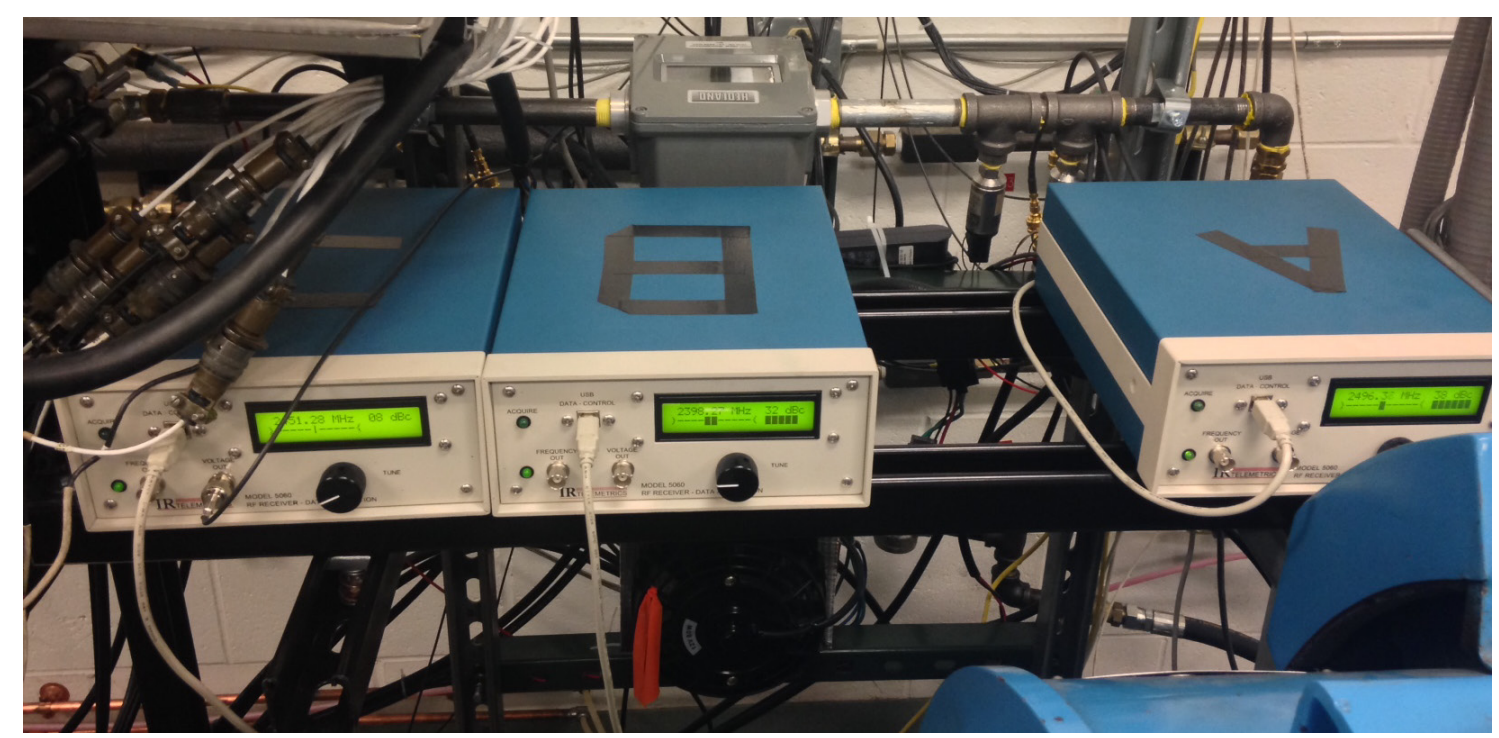

Figure I-2. Receivers for each transmitter

3. Open three Digital FV software windows. 
4. Connect the DFV 2 window to each of the receivers.

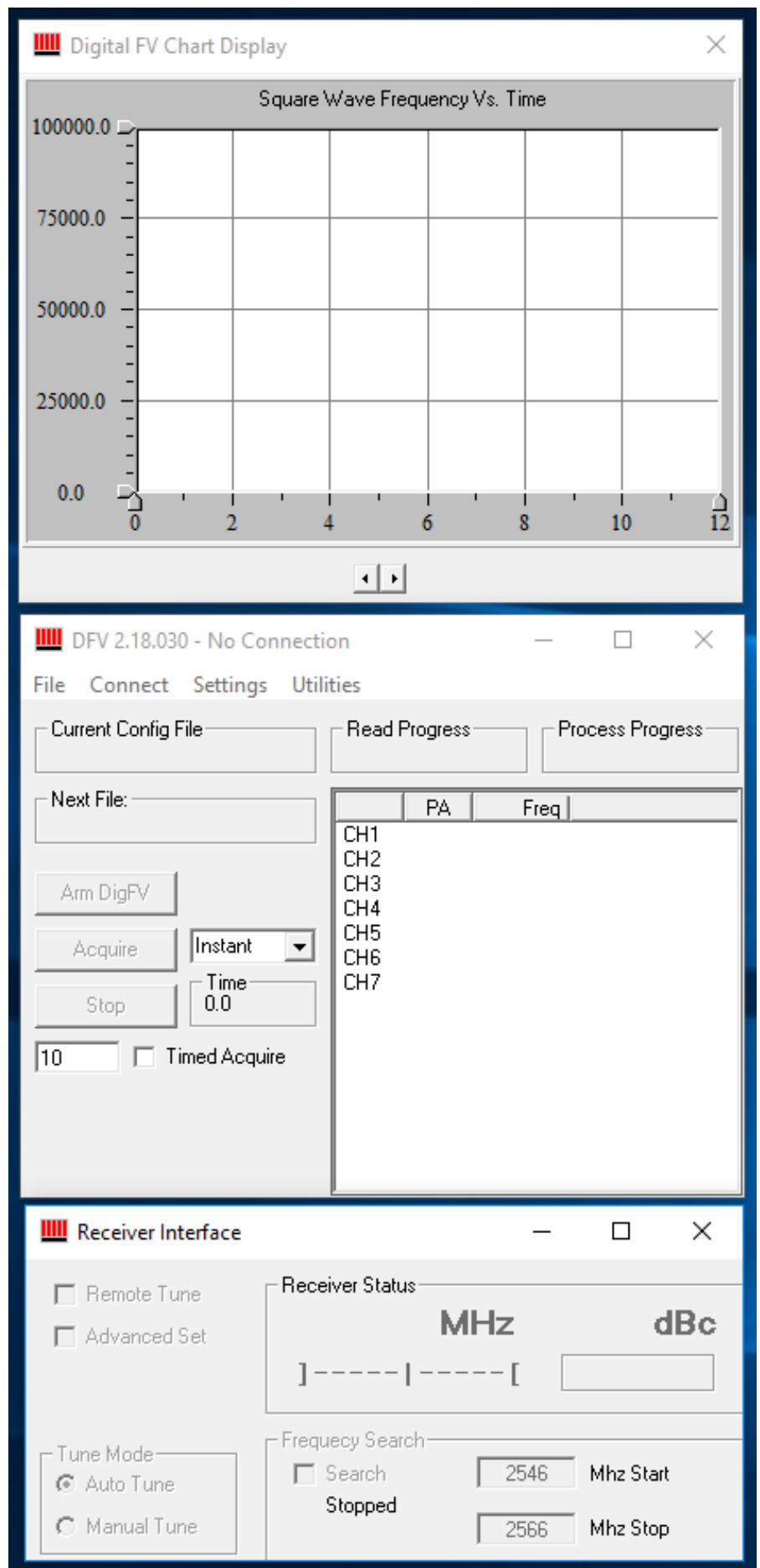

Figure I-3. Digital FV windows- chart display (top), receiver controller (middle), and receiver readout (bottom) 
5. Open configuration file associated with each receiver by selecting File > Open Configuration

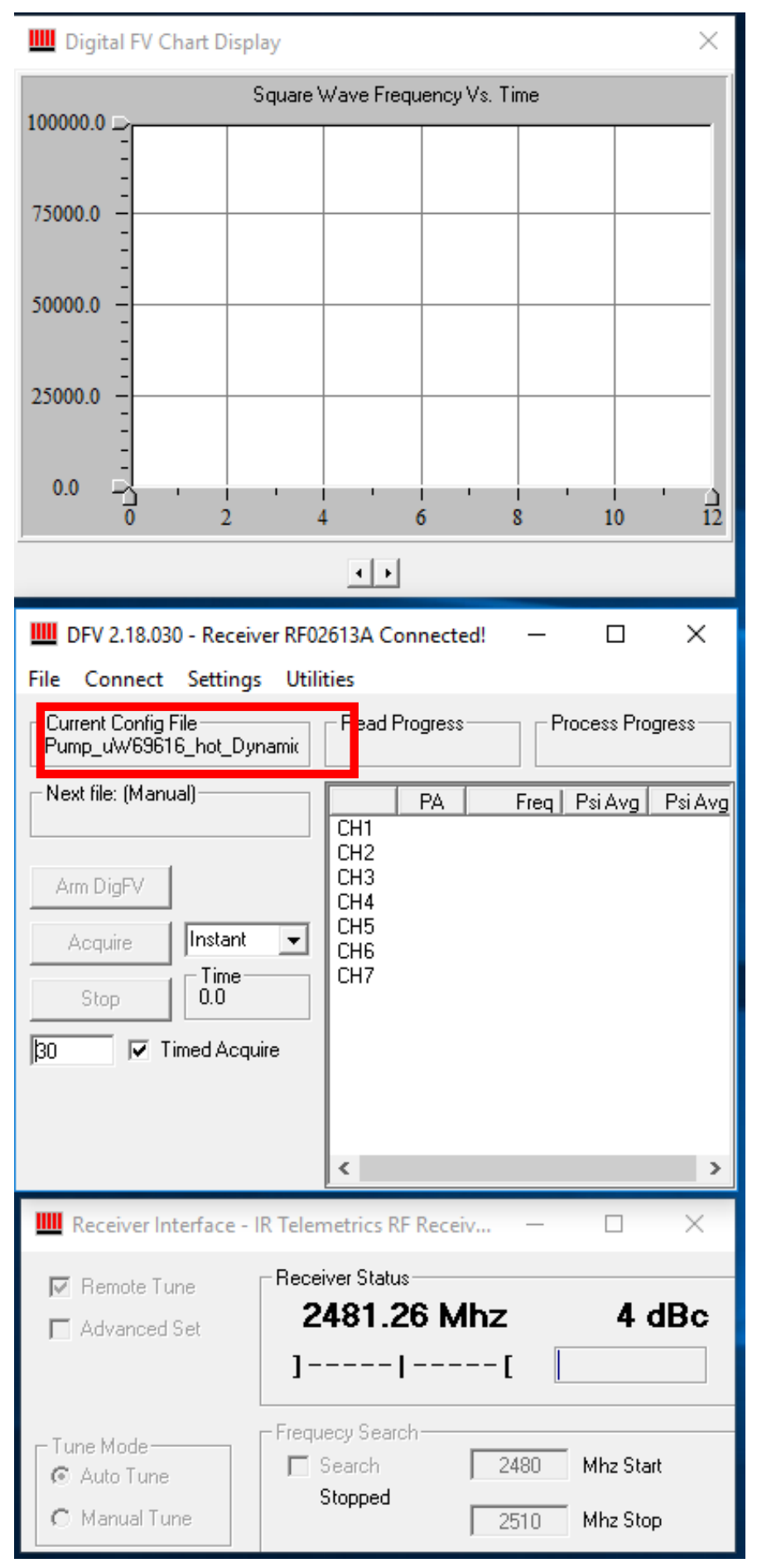

Figure I-4. Receiver connected 
6. Use dropdown menu and select streaming or on sync depending on test scenario. Streaming for steady state, On Sync for transient. Signal strength can be monitored on Receiver Interface window.

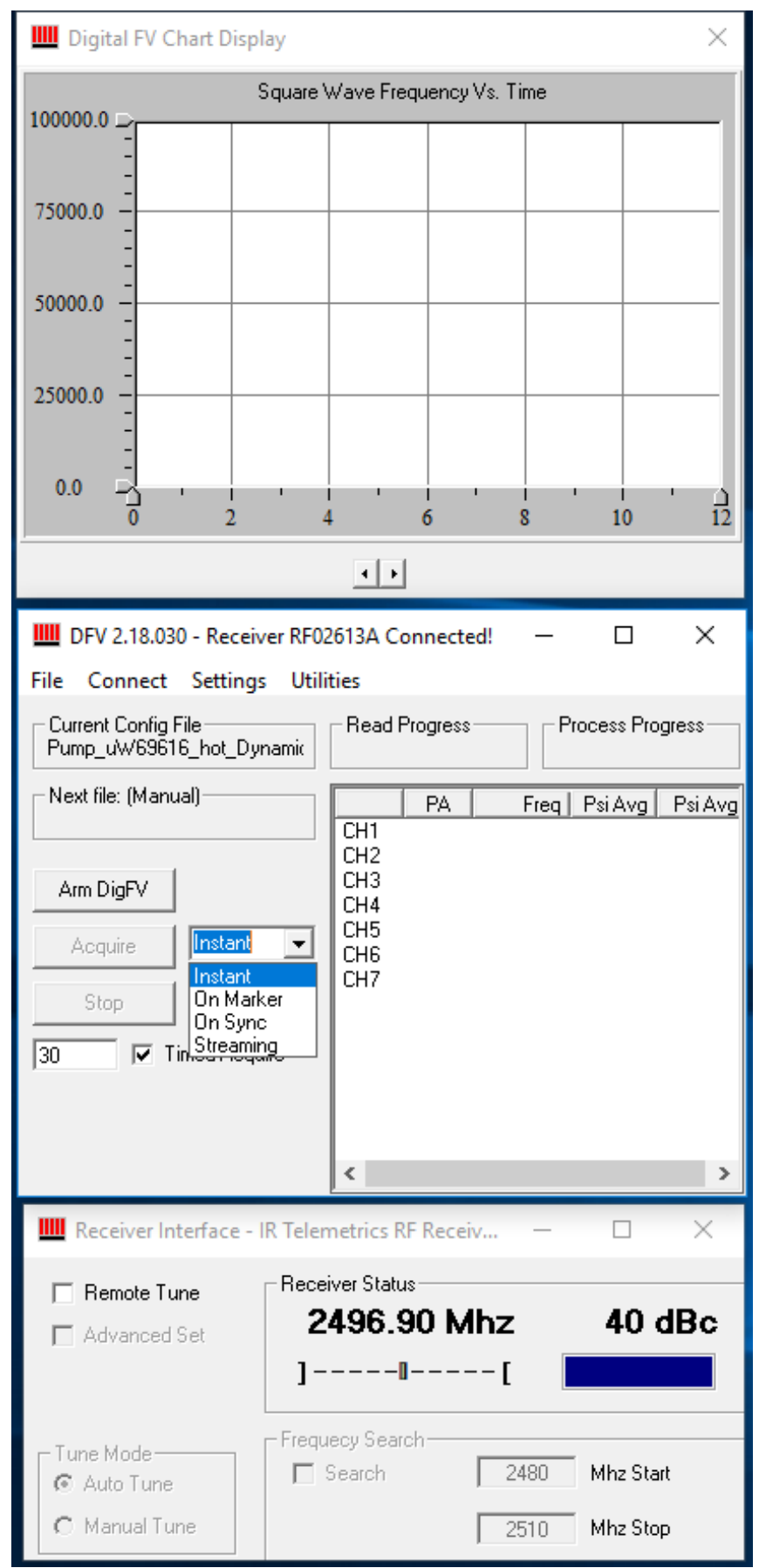

Figure I-5. Receiver showing signal strength and recording options 
7. Under Settings > File Options to set the filename to auto increment. Set record time to stop after specified time by checking Timed Acquire and typing the amount of times. Record telemetry data by pressing Arm DigFV and then Acquire.

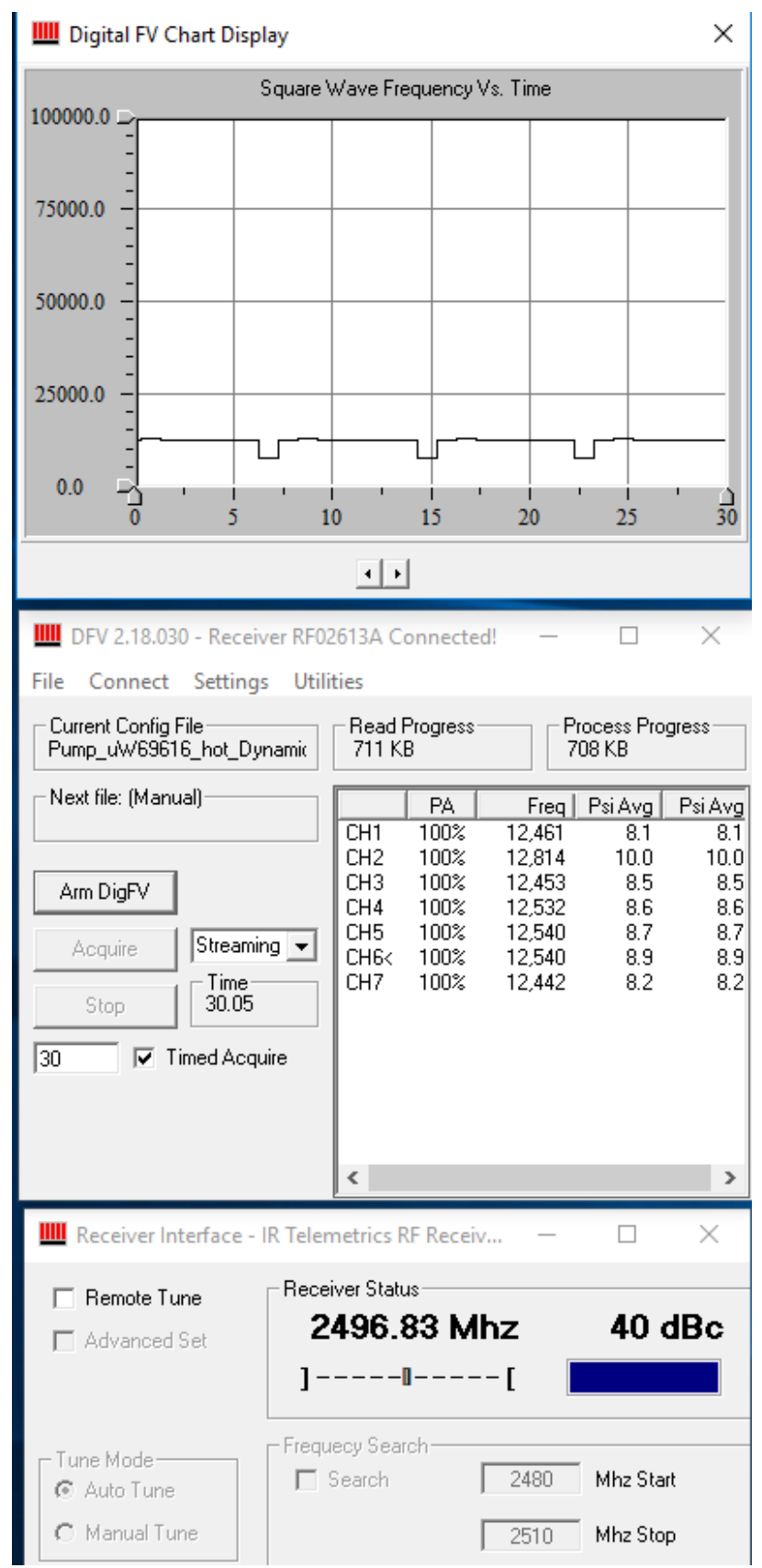

Figure I-6. Example of streamed data 


\section{K Torque Converter Clutch Pressures}

\section{K.1 Raw Data for $6^{\text {th }}$ Gear}
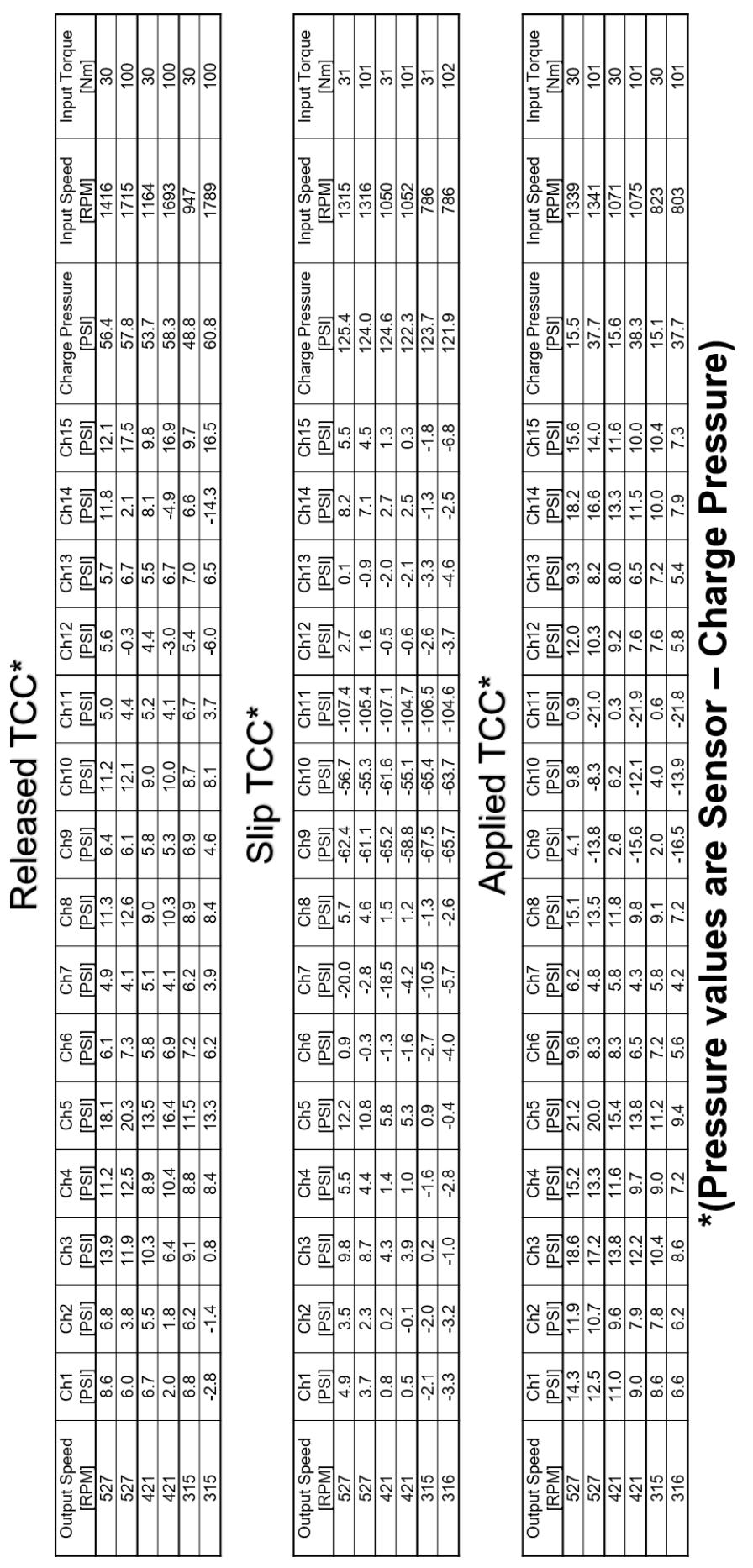


\section{K.2 $5^{\text {th }}$ Gear TCC Pressure Graphics}

\section{K.2.1 TCC Released}
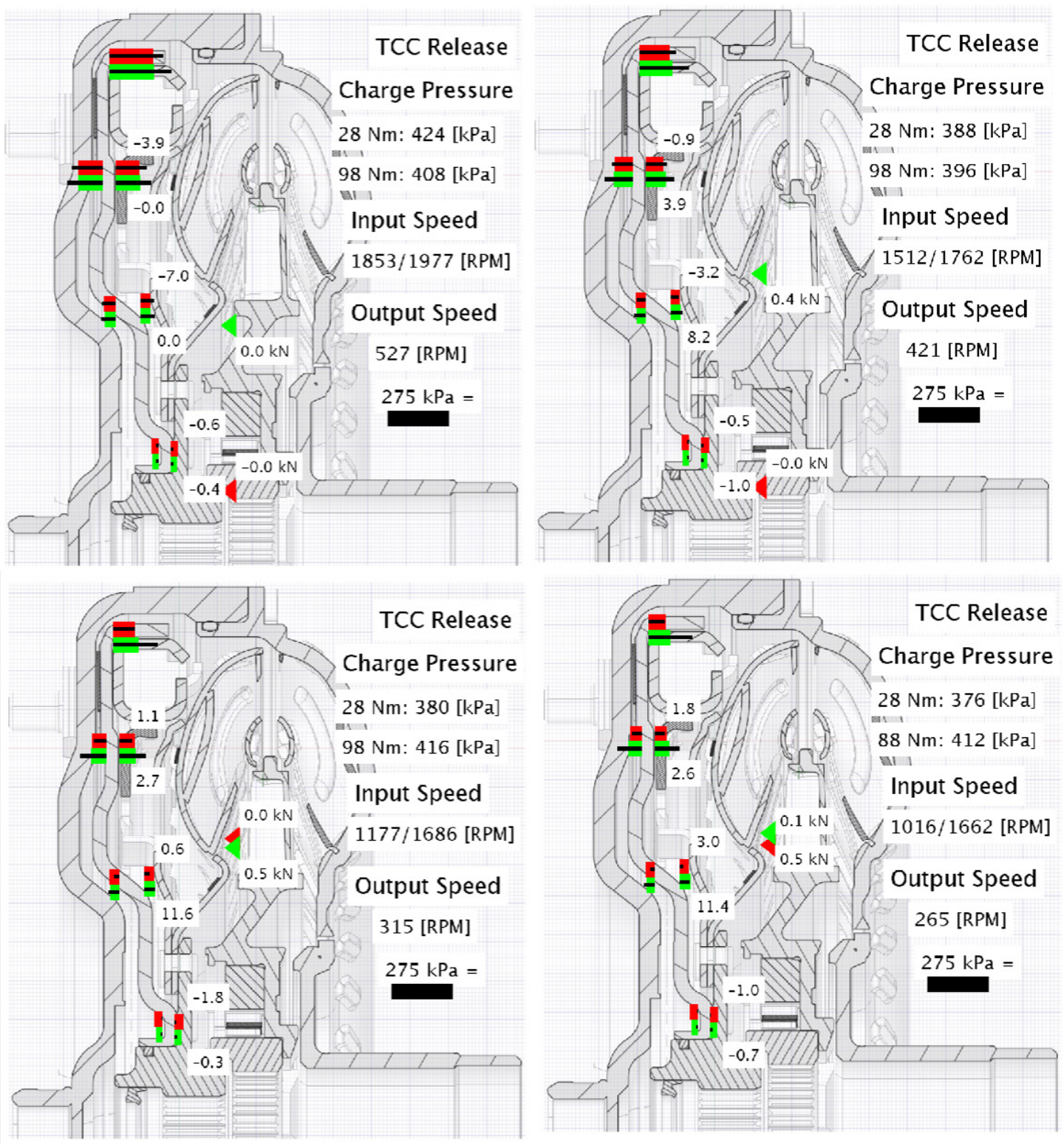


\section{K.2.2 TCC Applied}

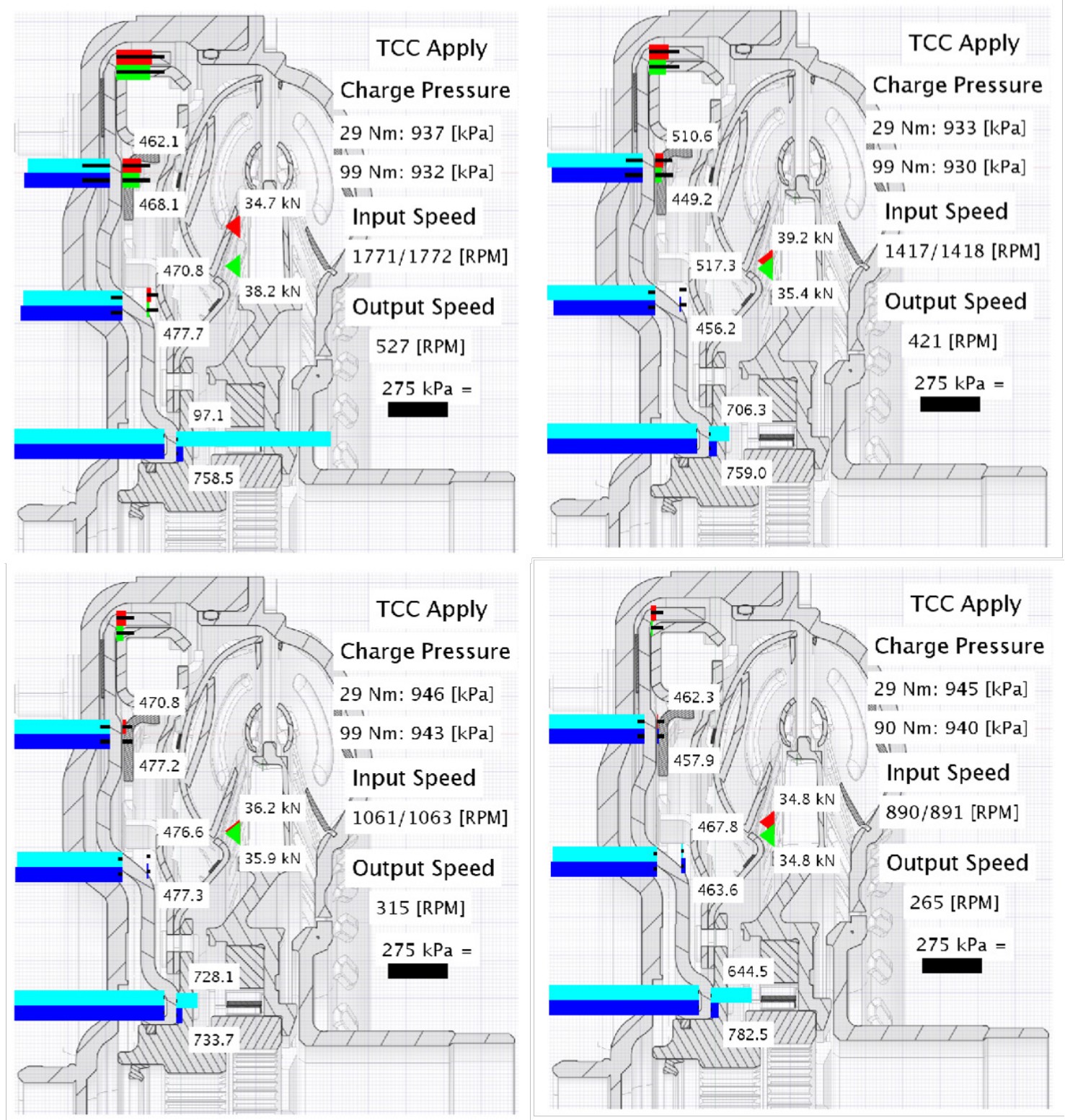




\section{K.2.3 TCC Slip}
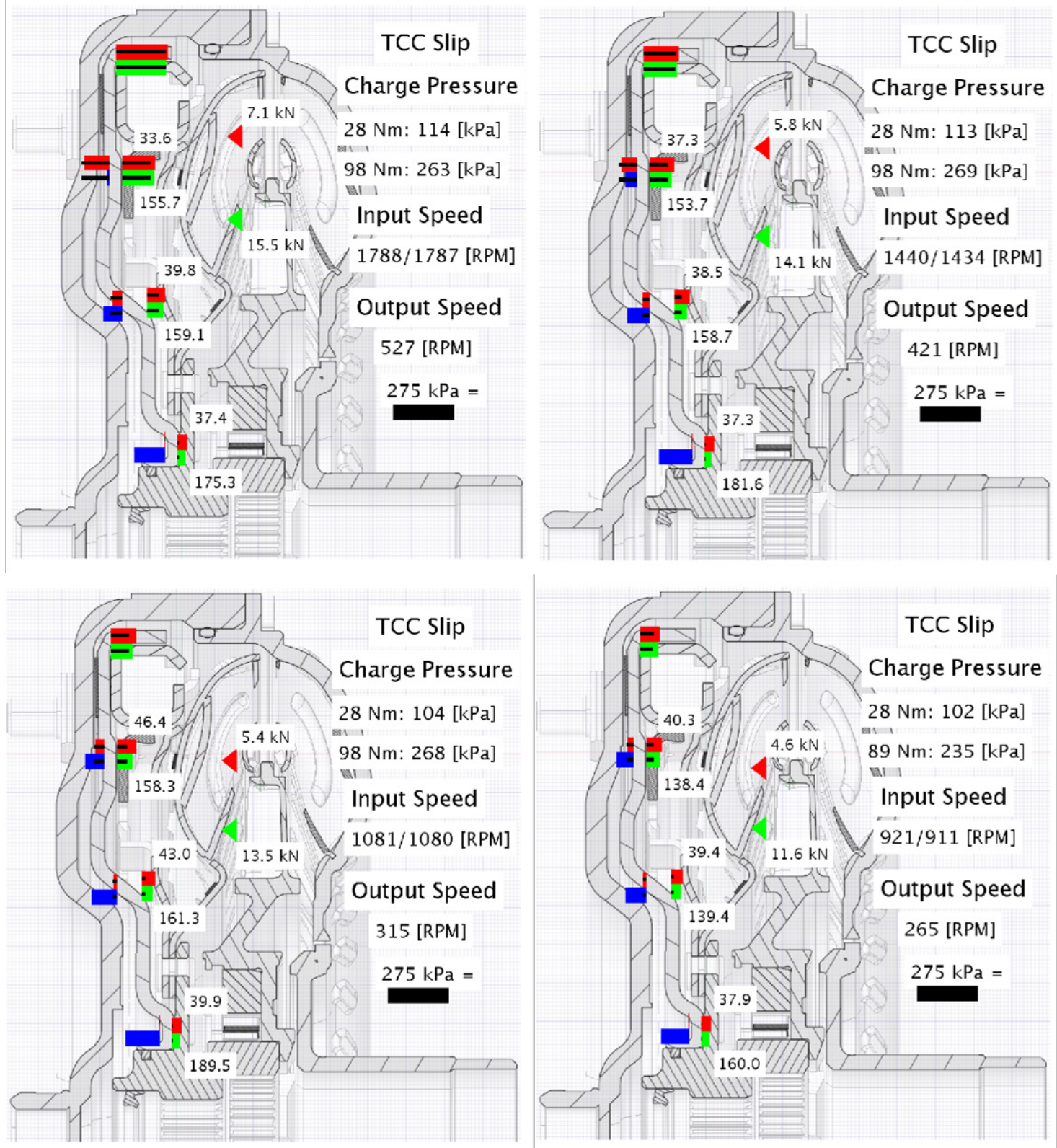


\section{K.3 Raw Data for $5^{\text {th }}$ Gear}
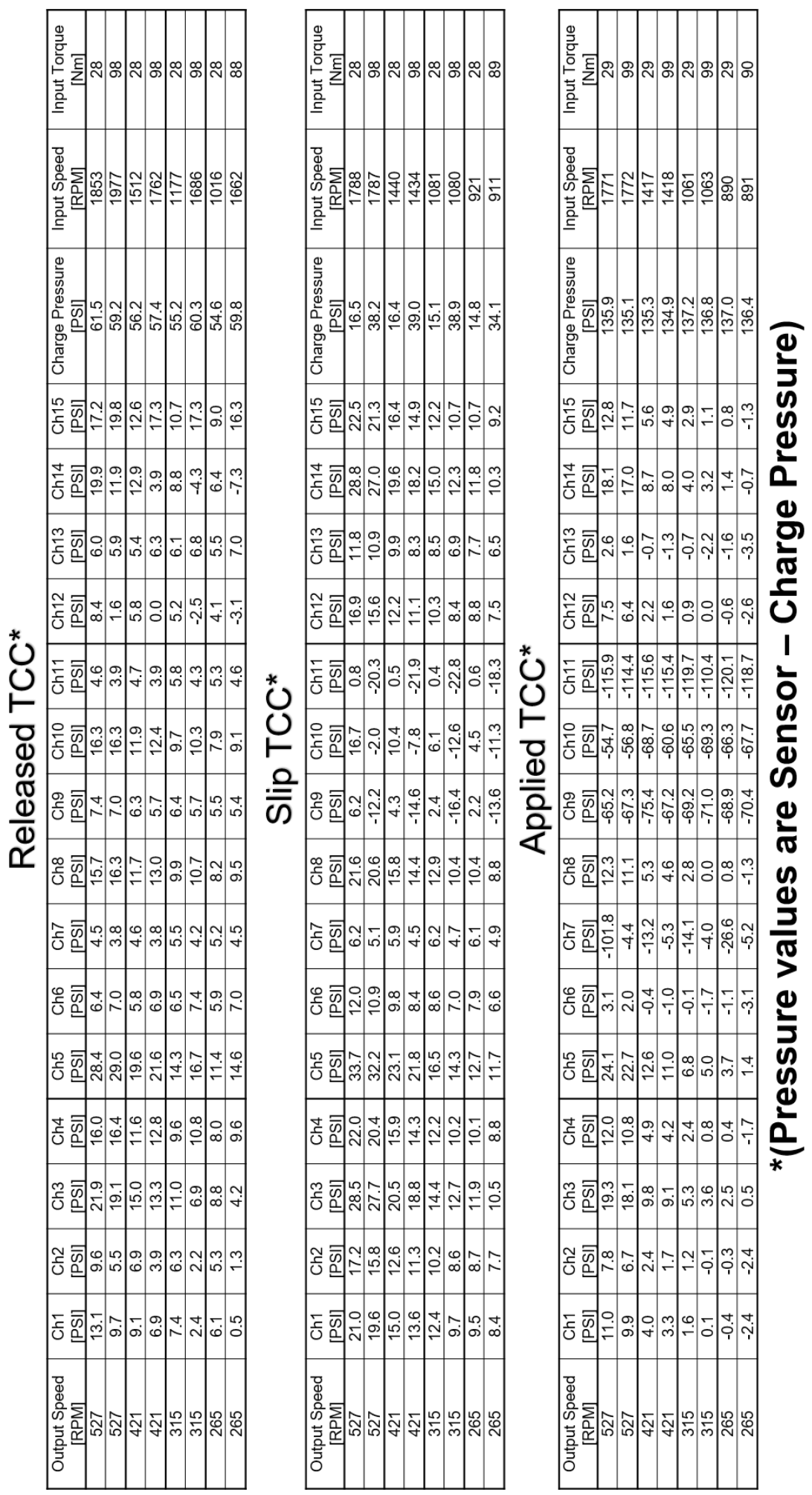

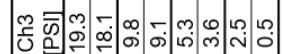

กิ

कृष

- $=0.0 \mathrm{~m} 0 .+4$

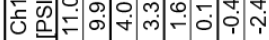

ఫ

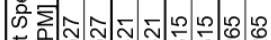

o

ठ̀ 


\section{Back Drive Pressure Results}

\section{L.1 Impeller Results}
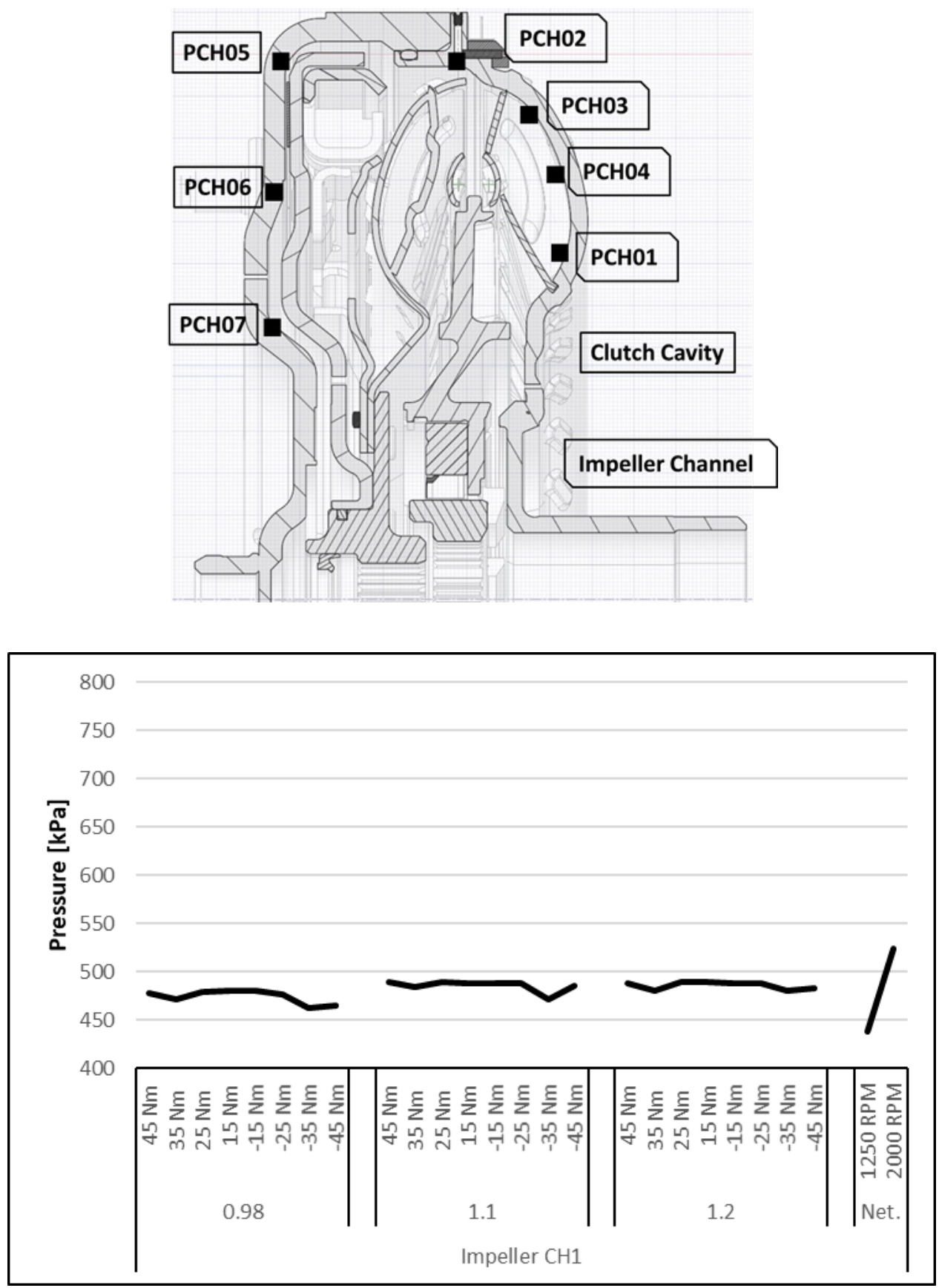

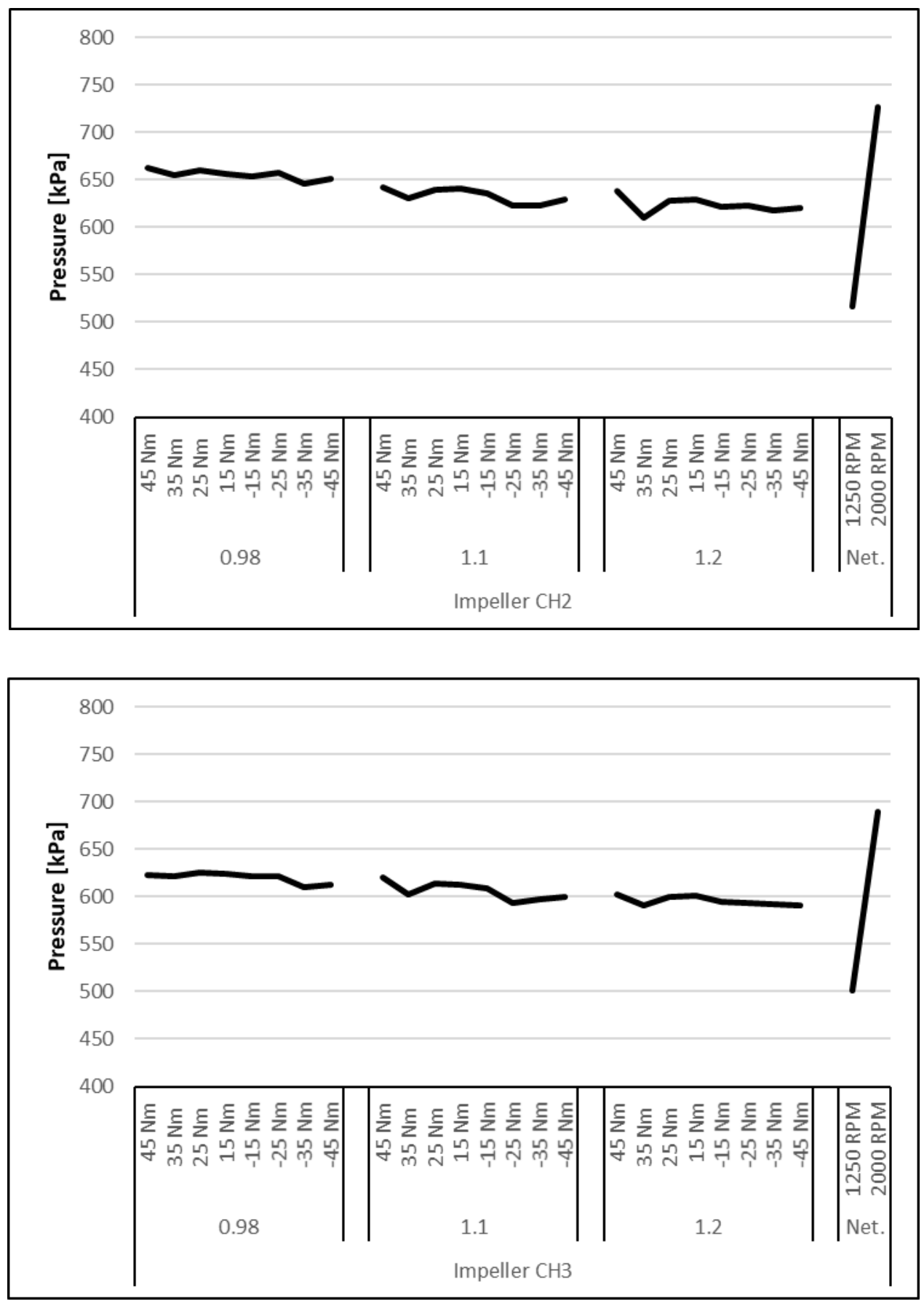

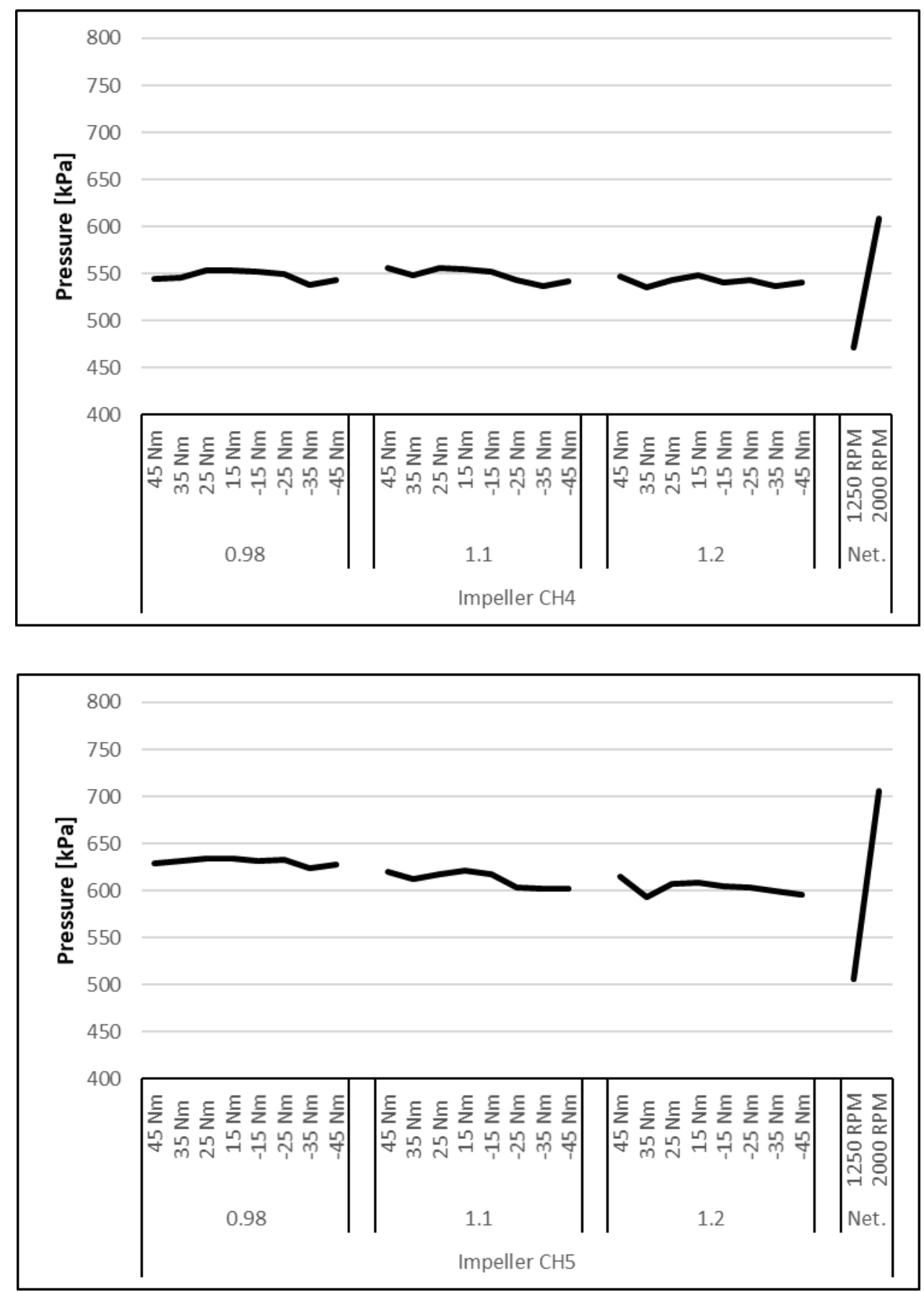

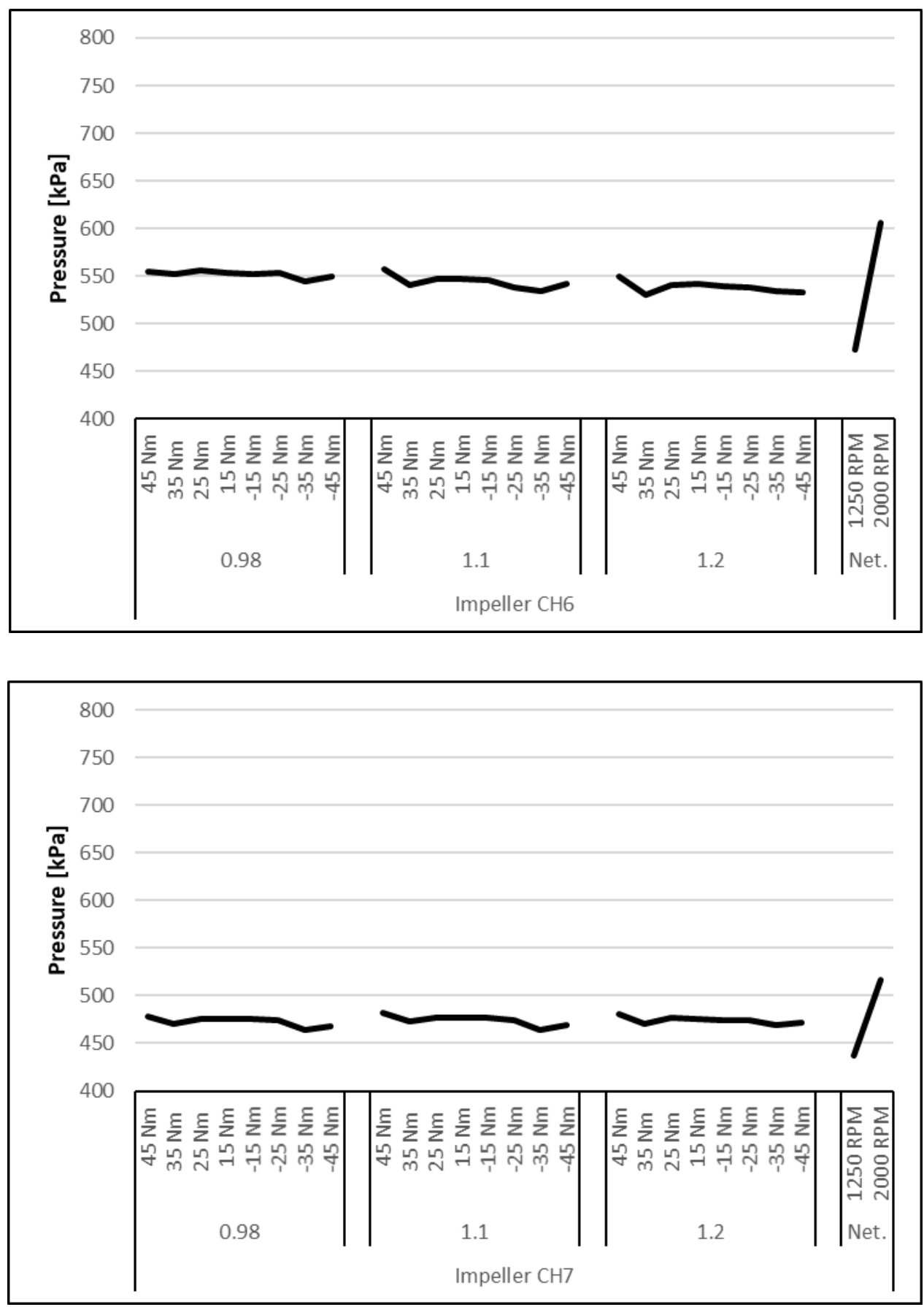


\section{L.2 Stator Results}
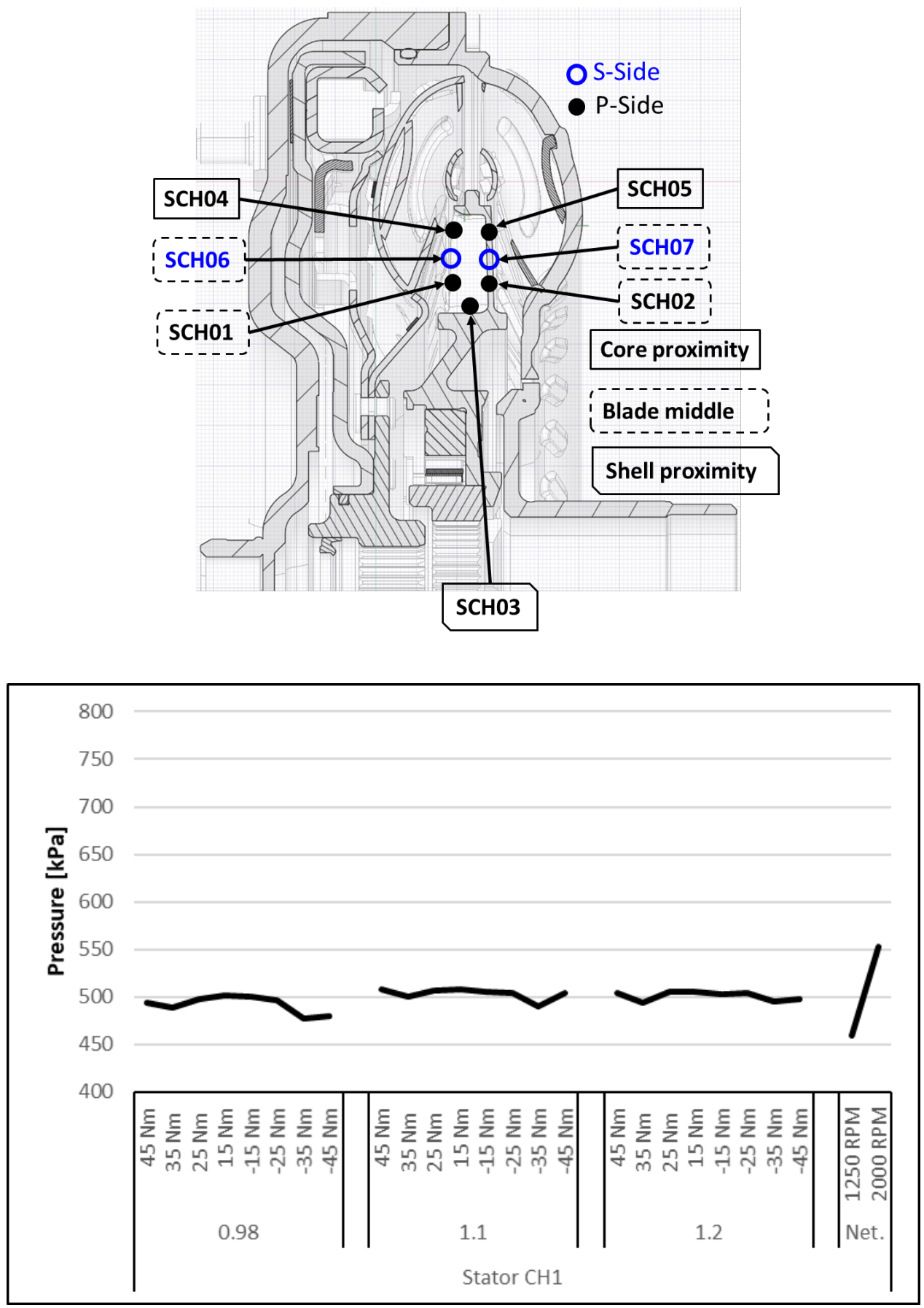

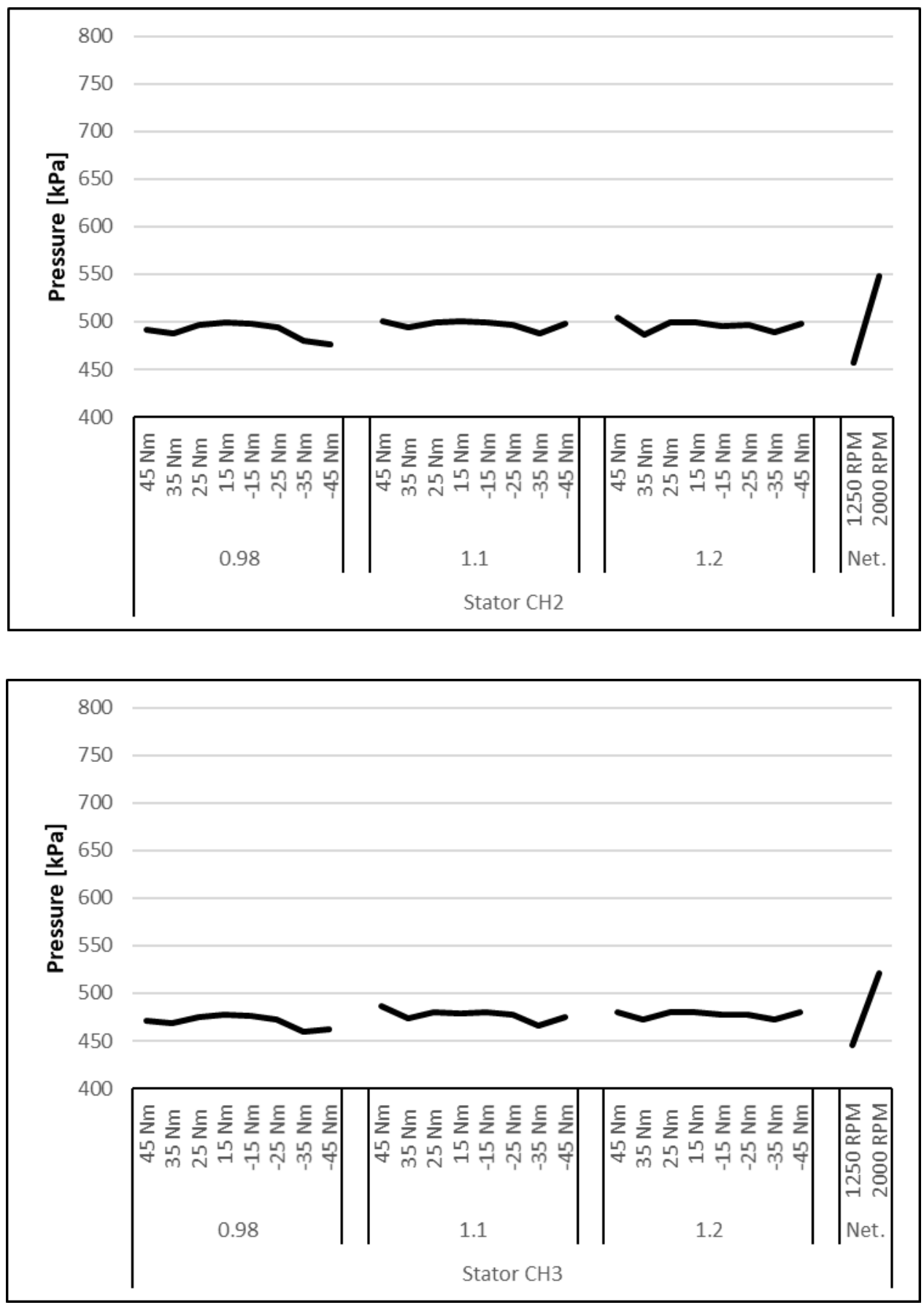

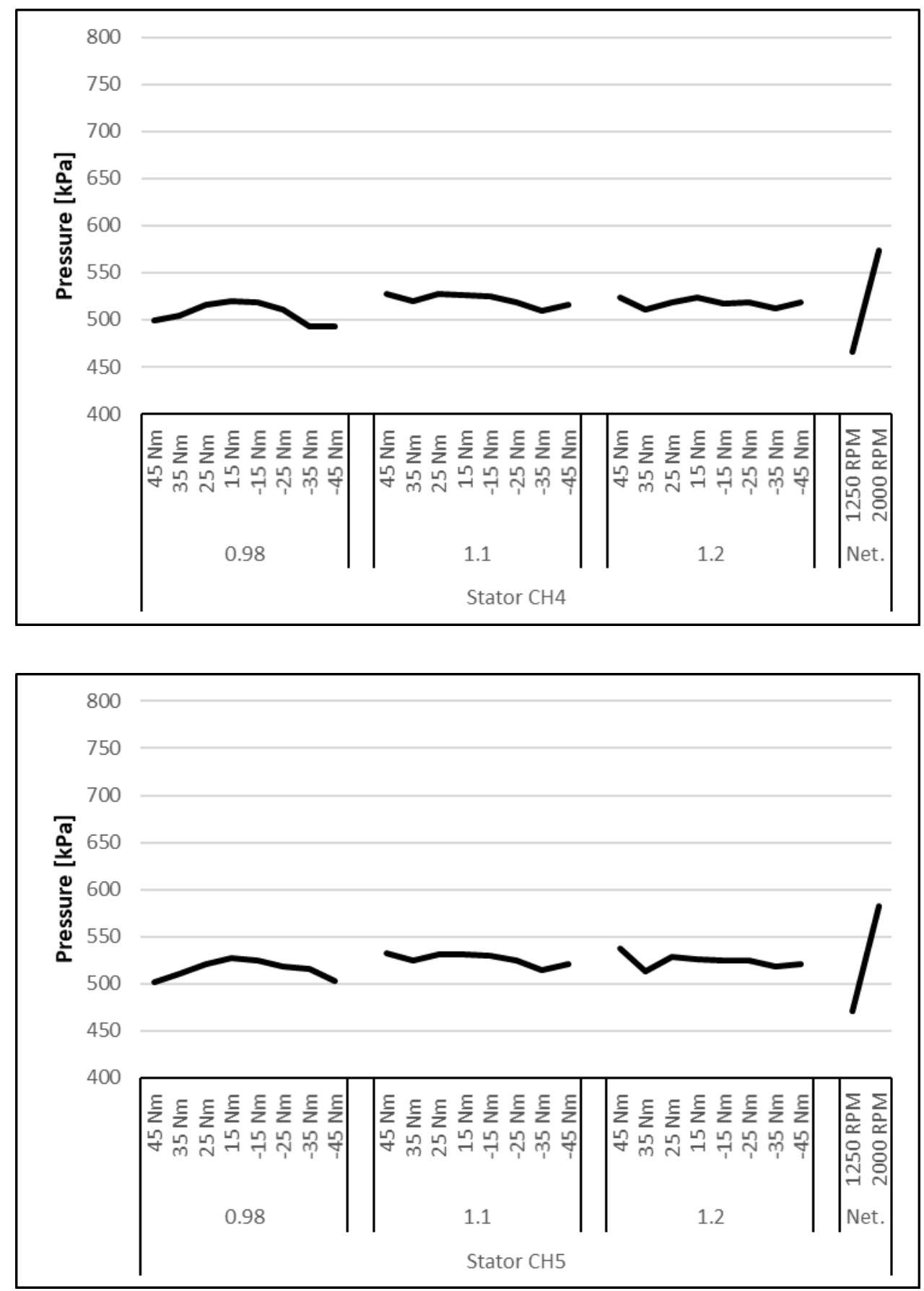

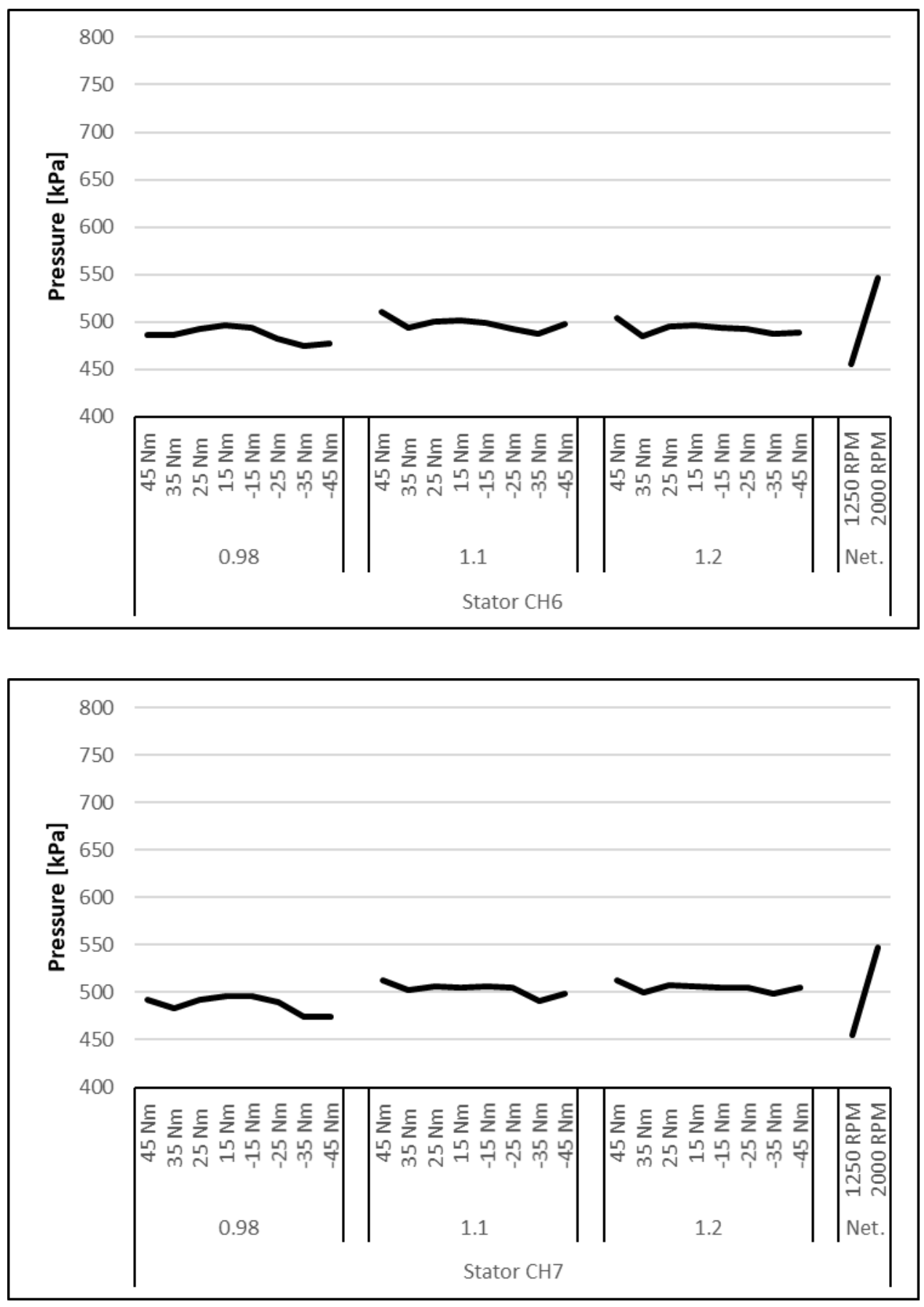


\section{L.3 Turbine Results}
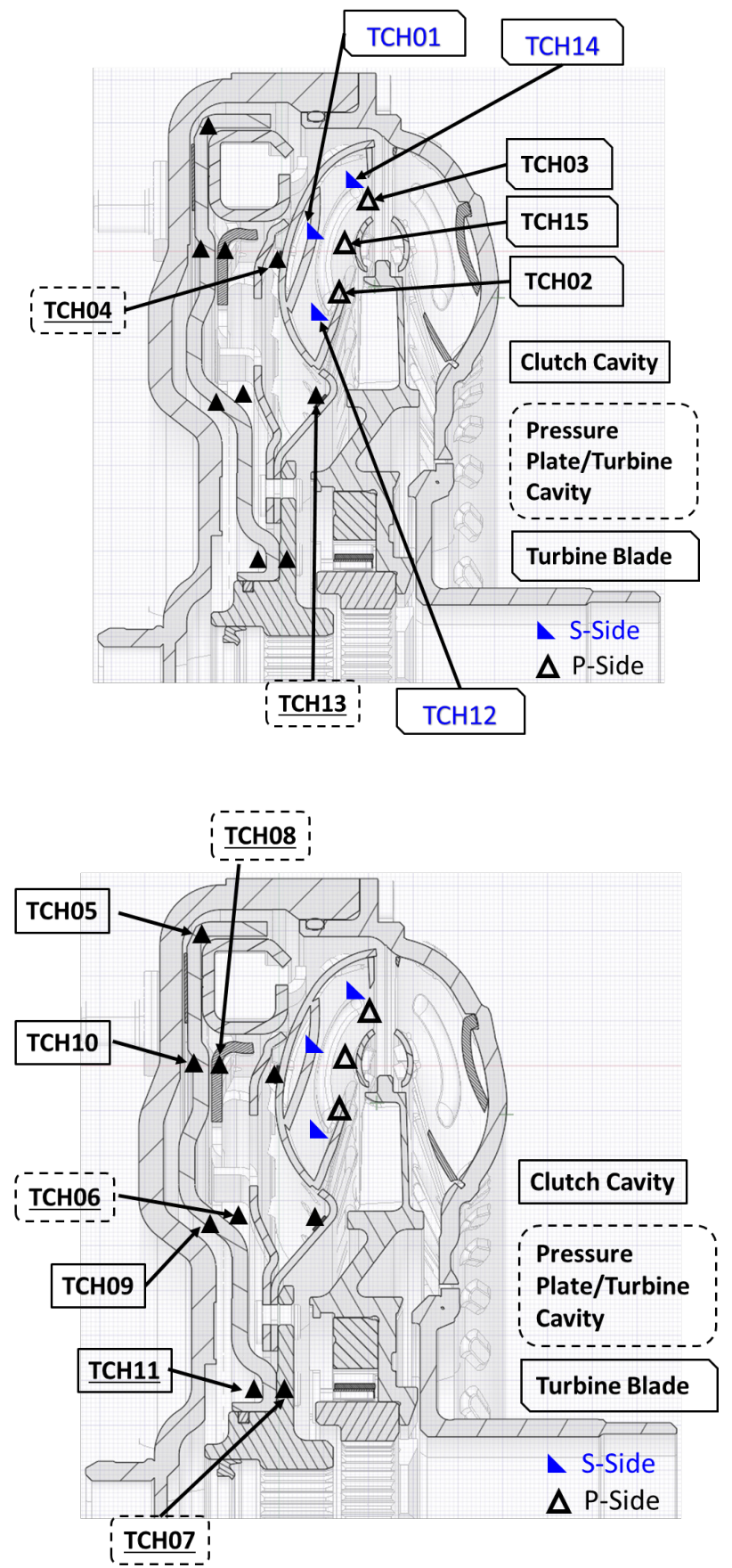

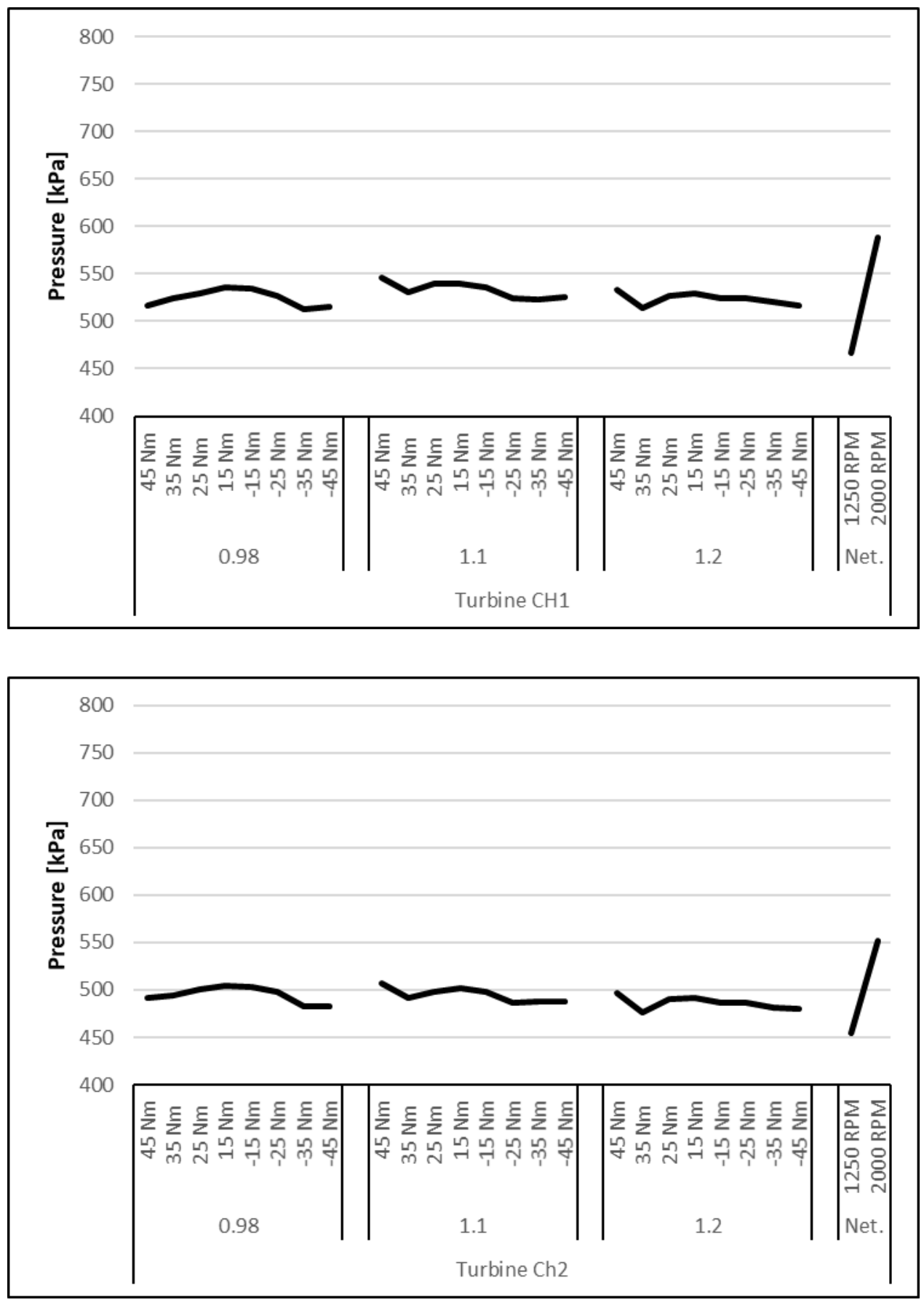

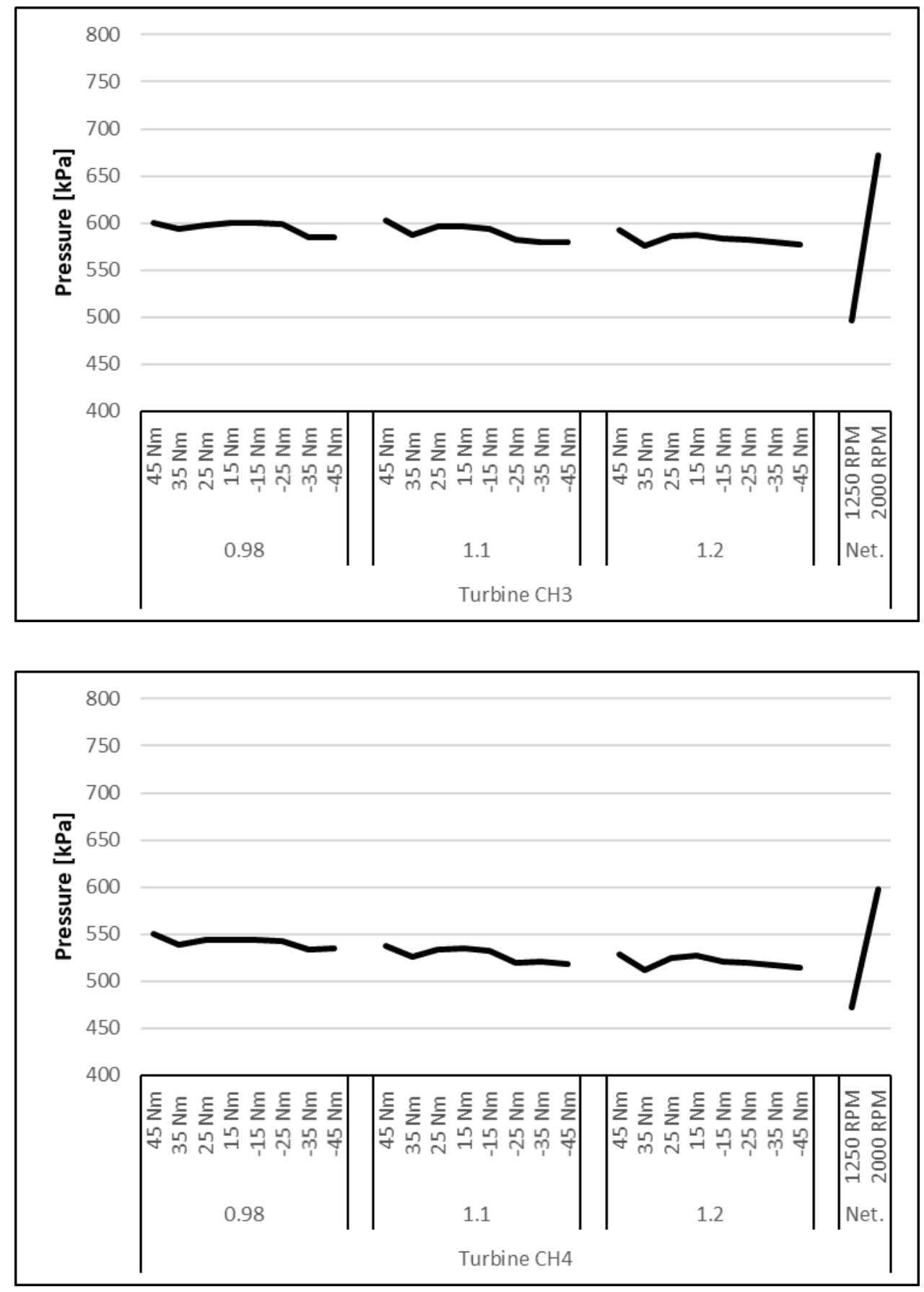

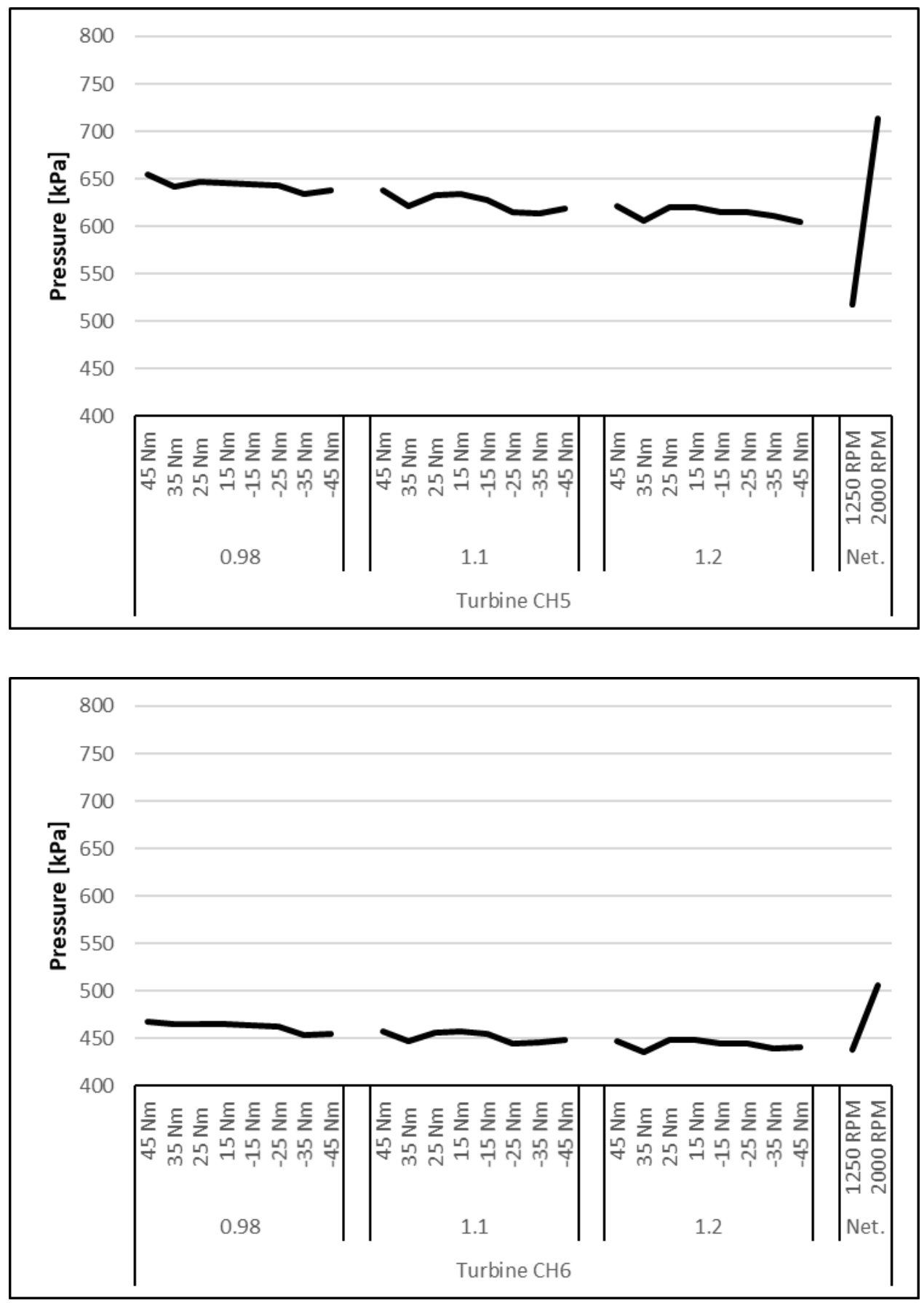

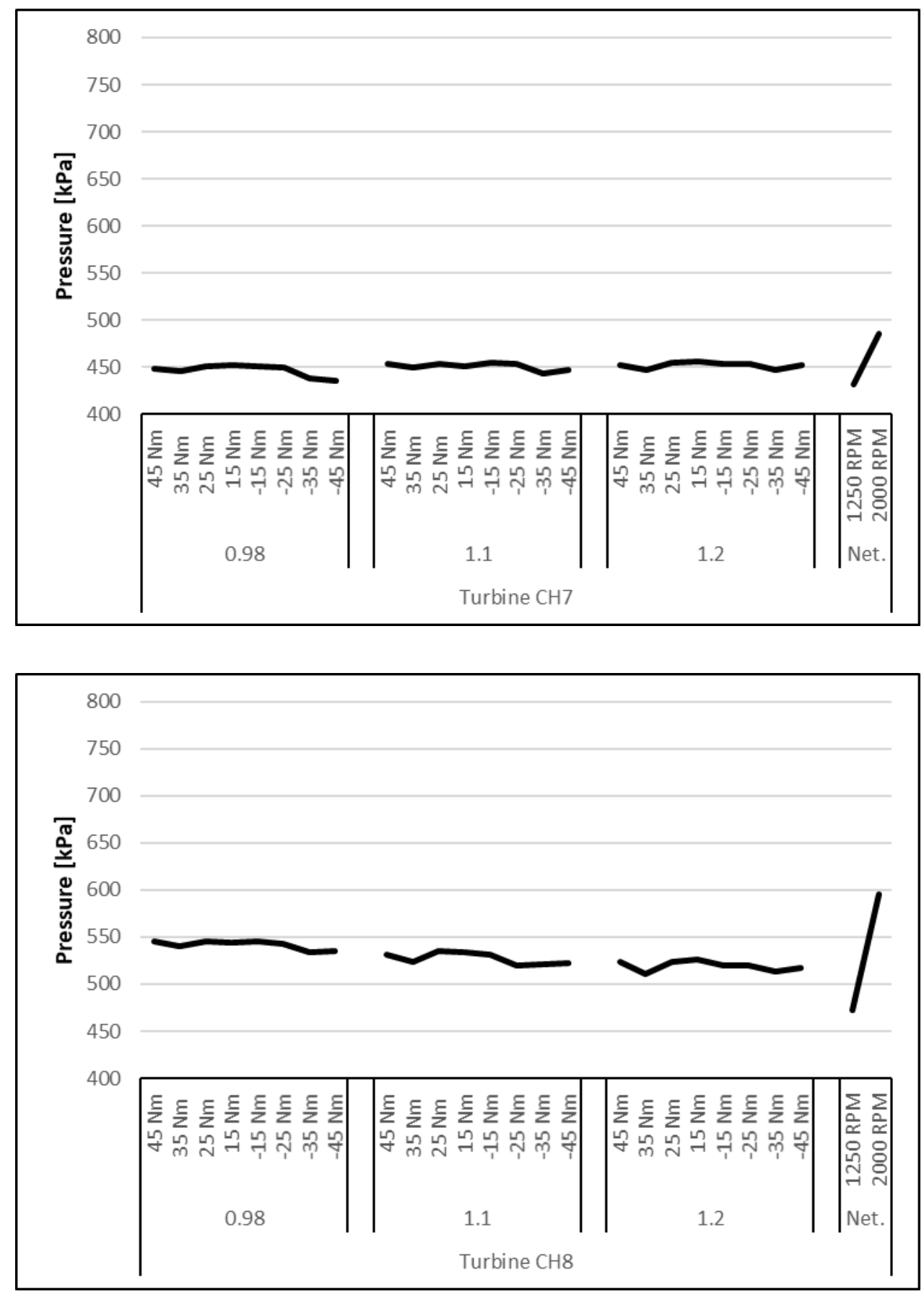

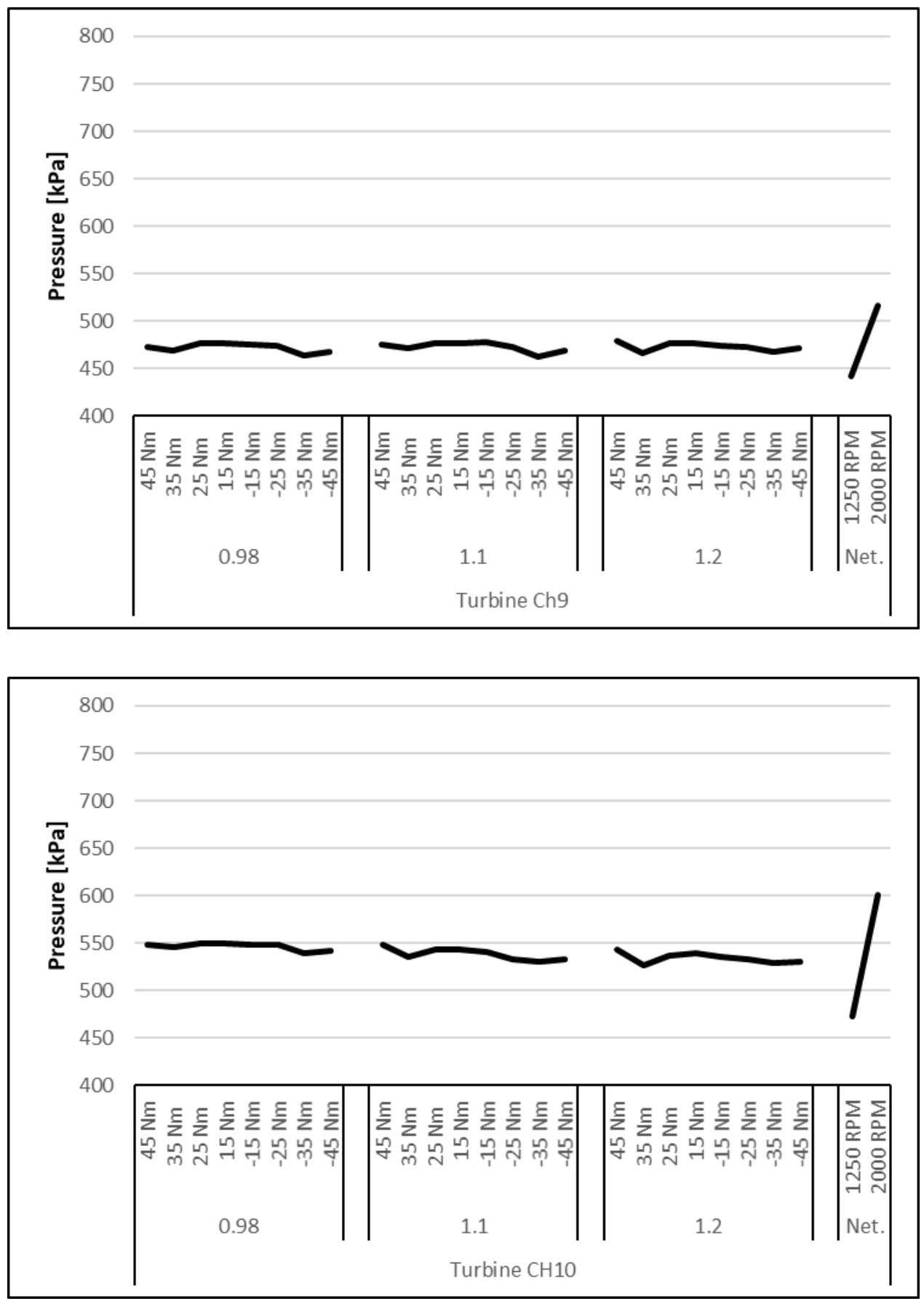

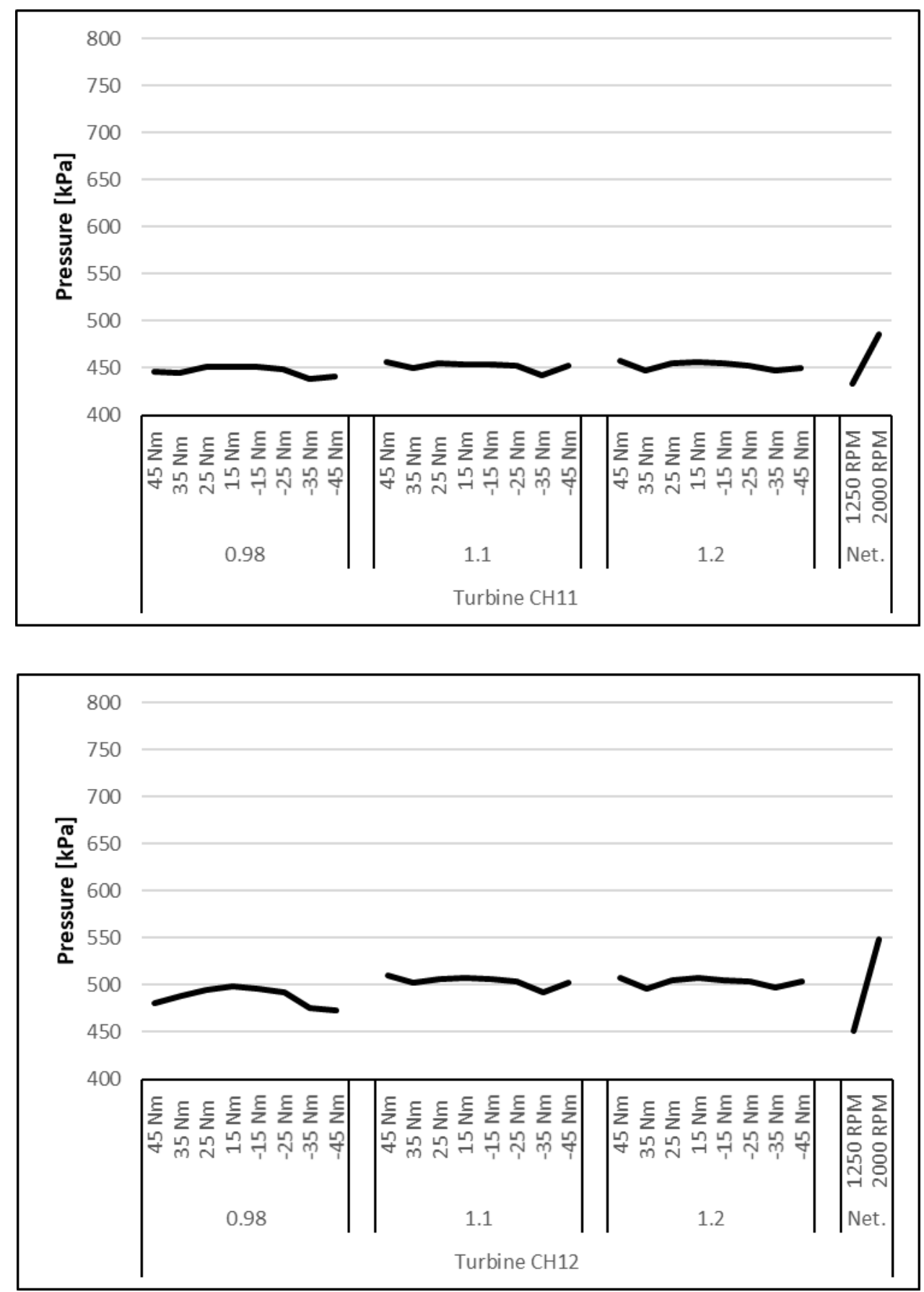

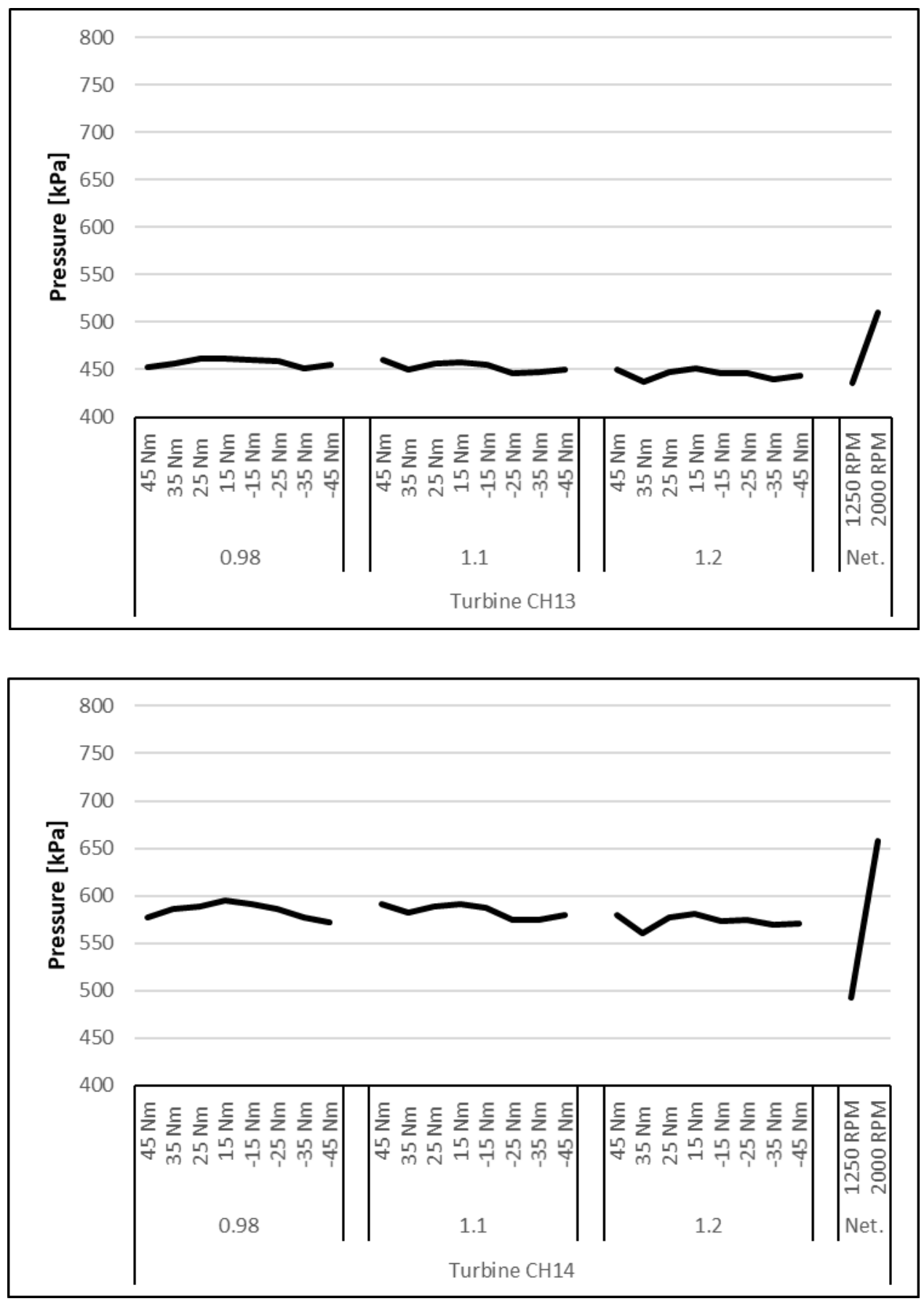


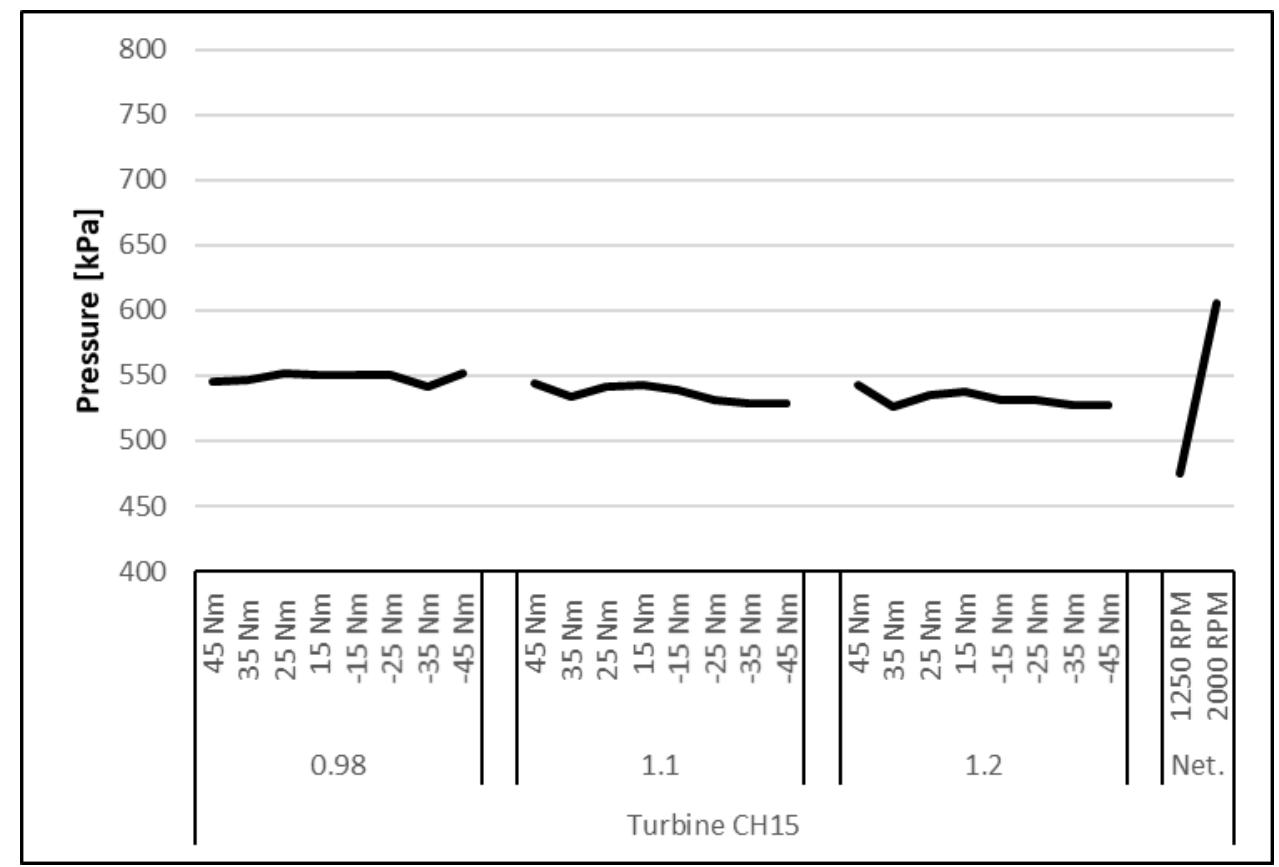




\section{Back Drive CFD Comparison}

\section{M.1 Impeller +45 Nm CFD Comparison}
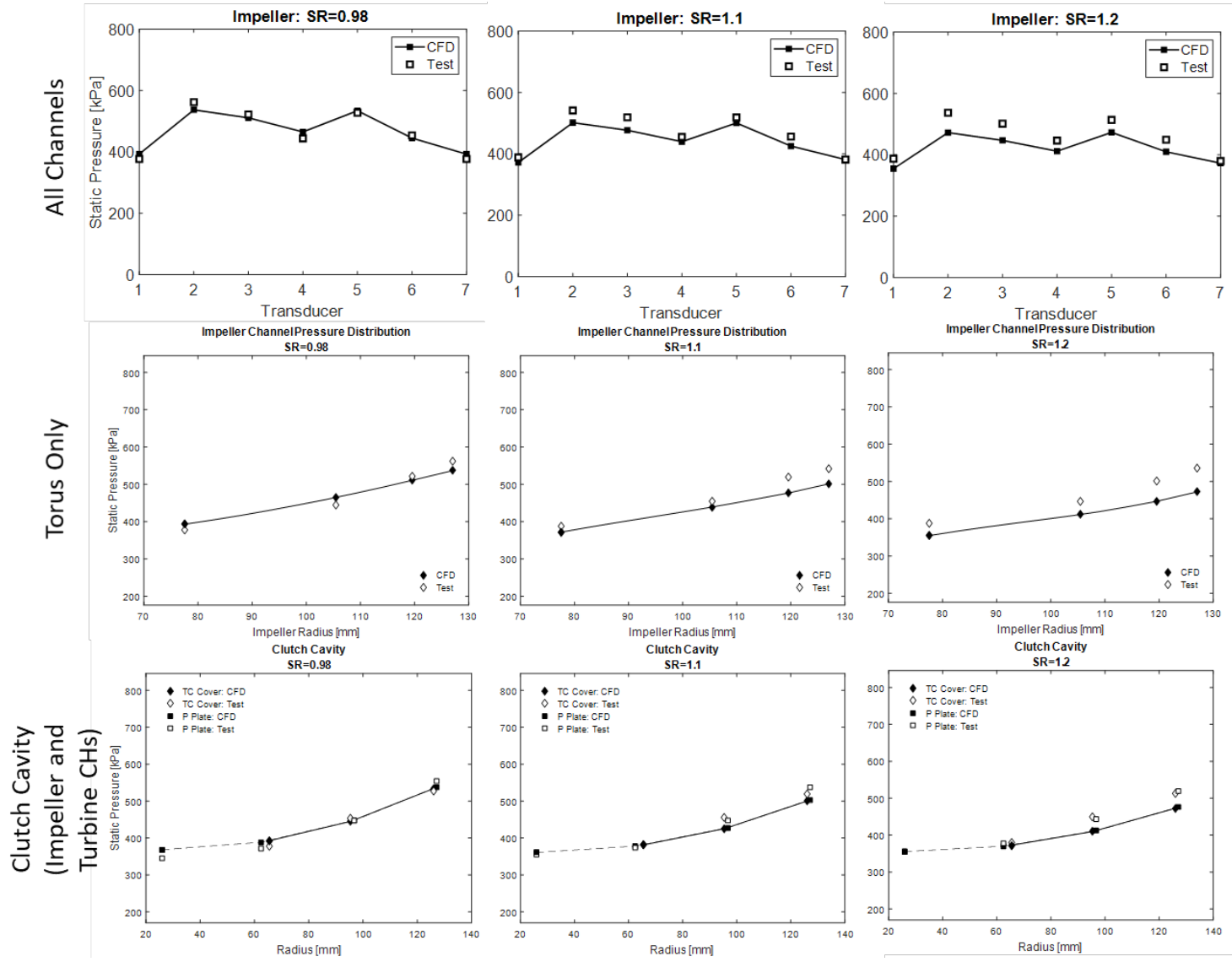


\section{M.2 Impeller -45 Nm CFD Comparison}
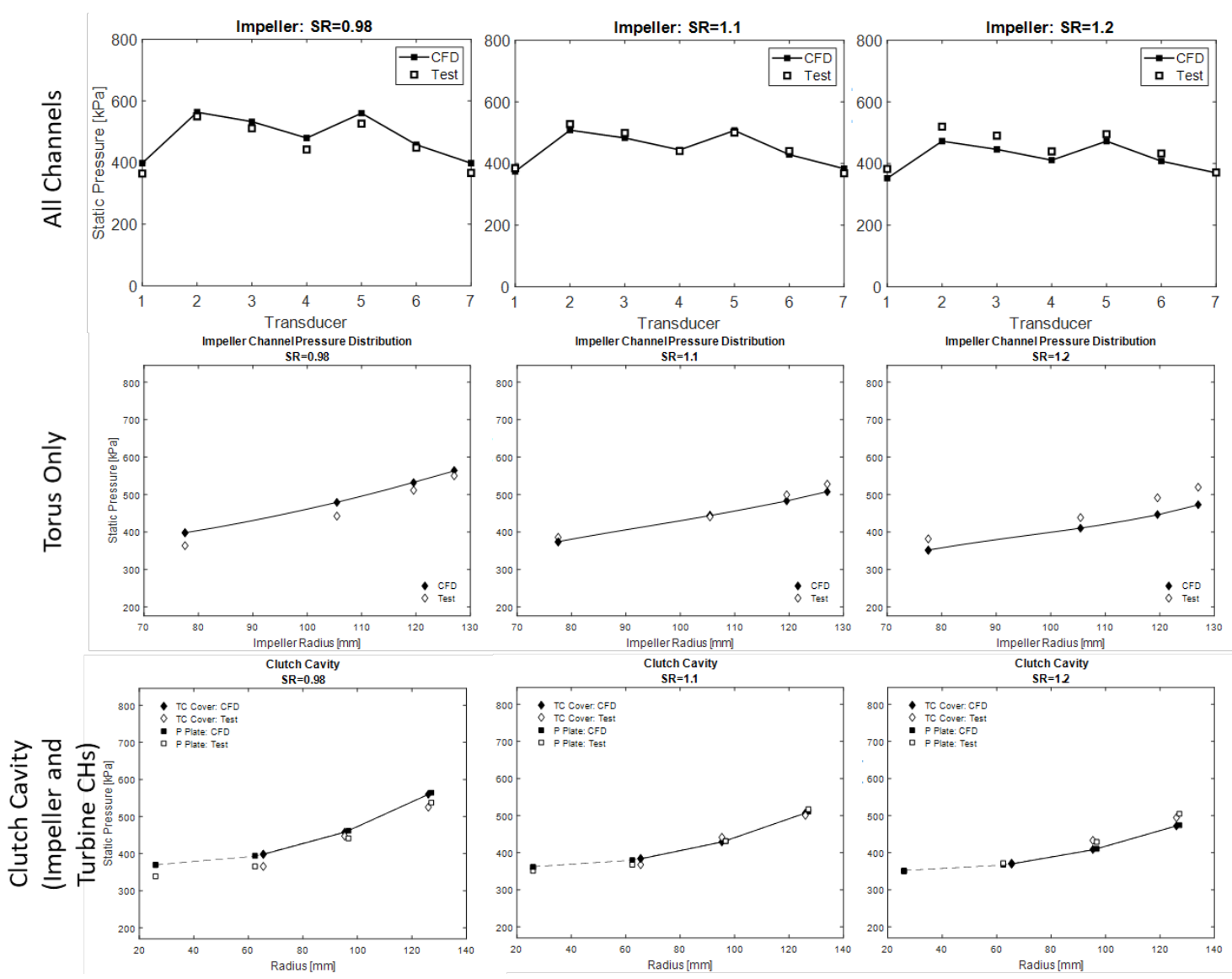


\section{M.3 Stator +45 Nm CFD Comparison}
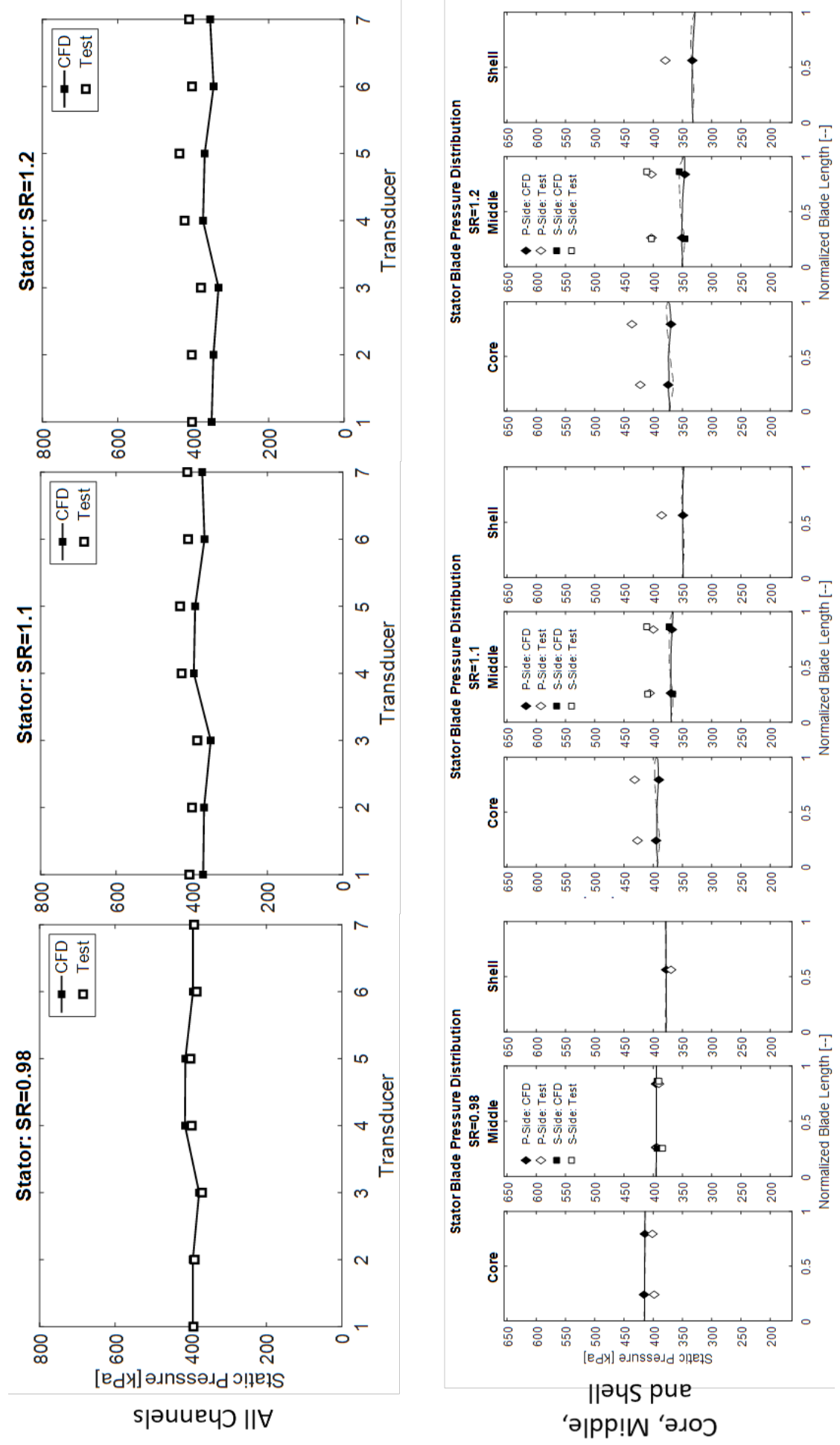


\section{M.4 Stator -45 Nm CFD Comparison}
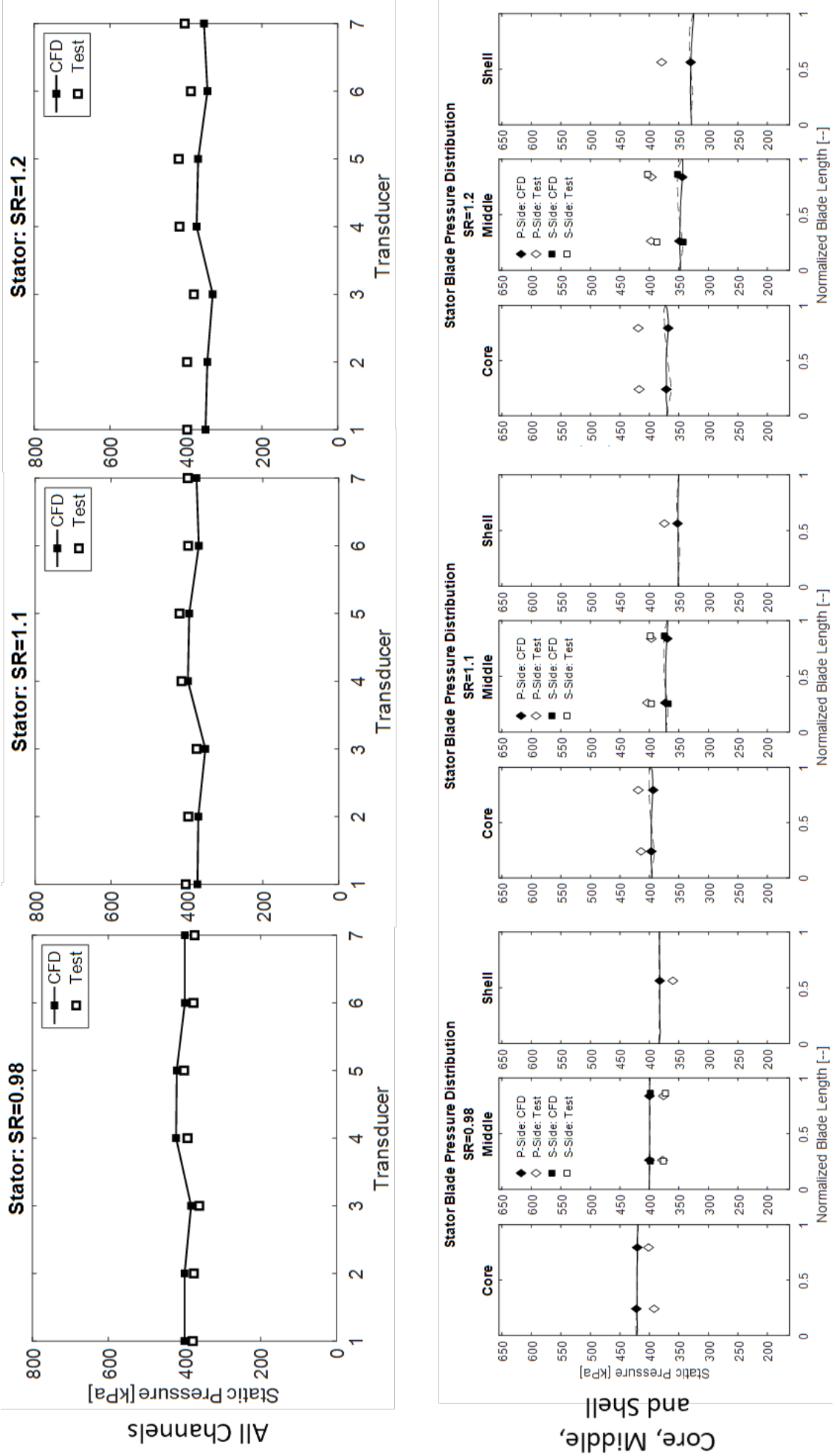


\section{M.5 Turbine $+45 \mathrm{Nm}$ CFD Comparison}
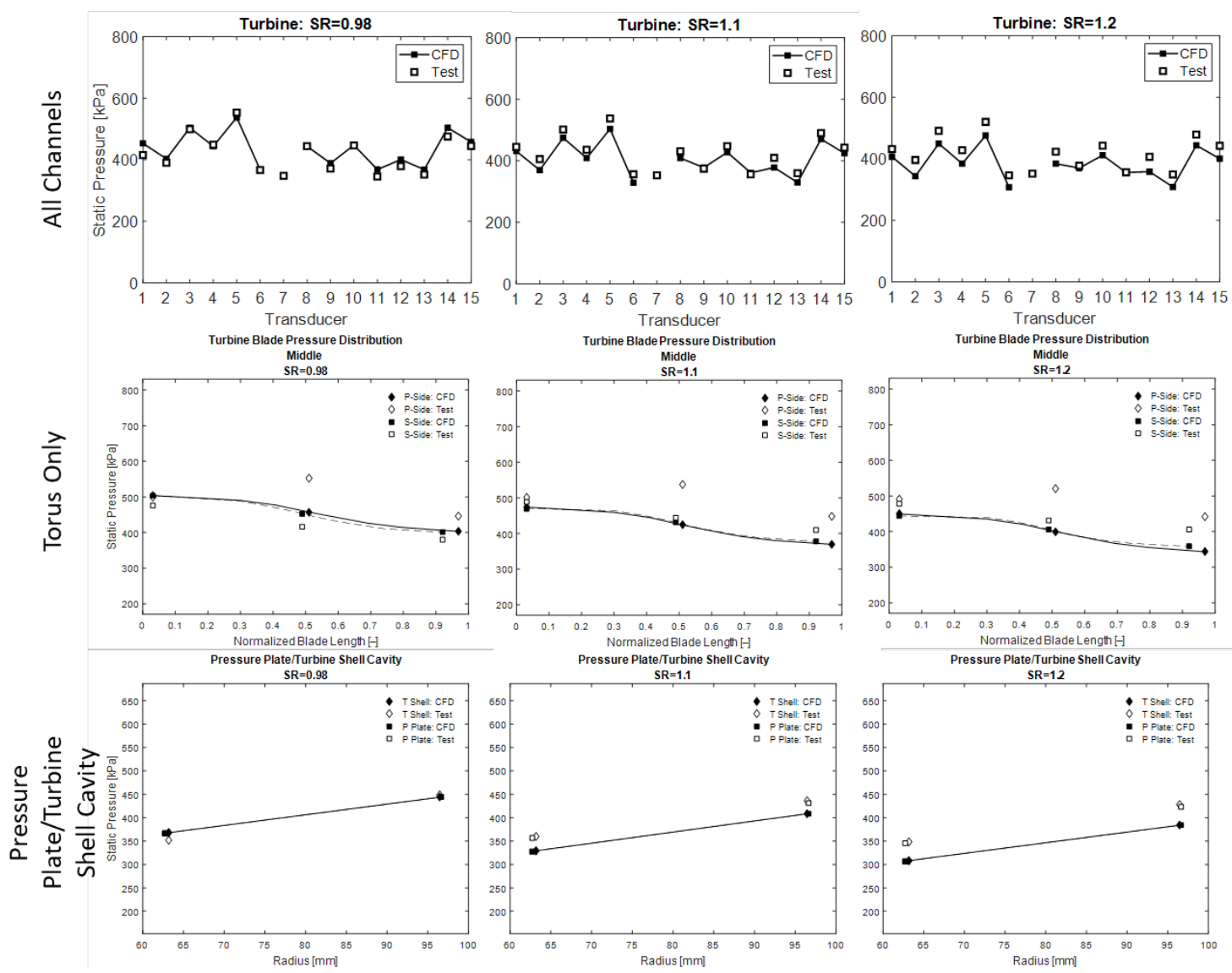


\section{M.6 Turbine -45 Nm CFD Comparison}
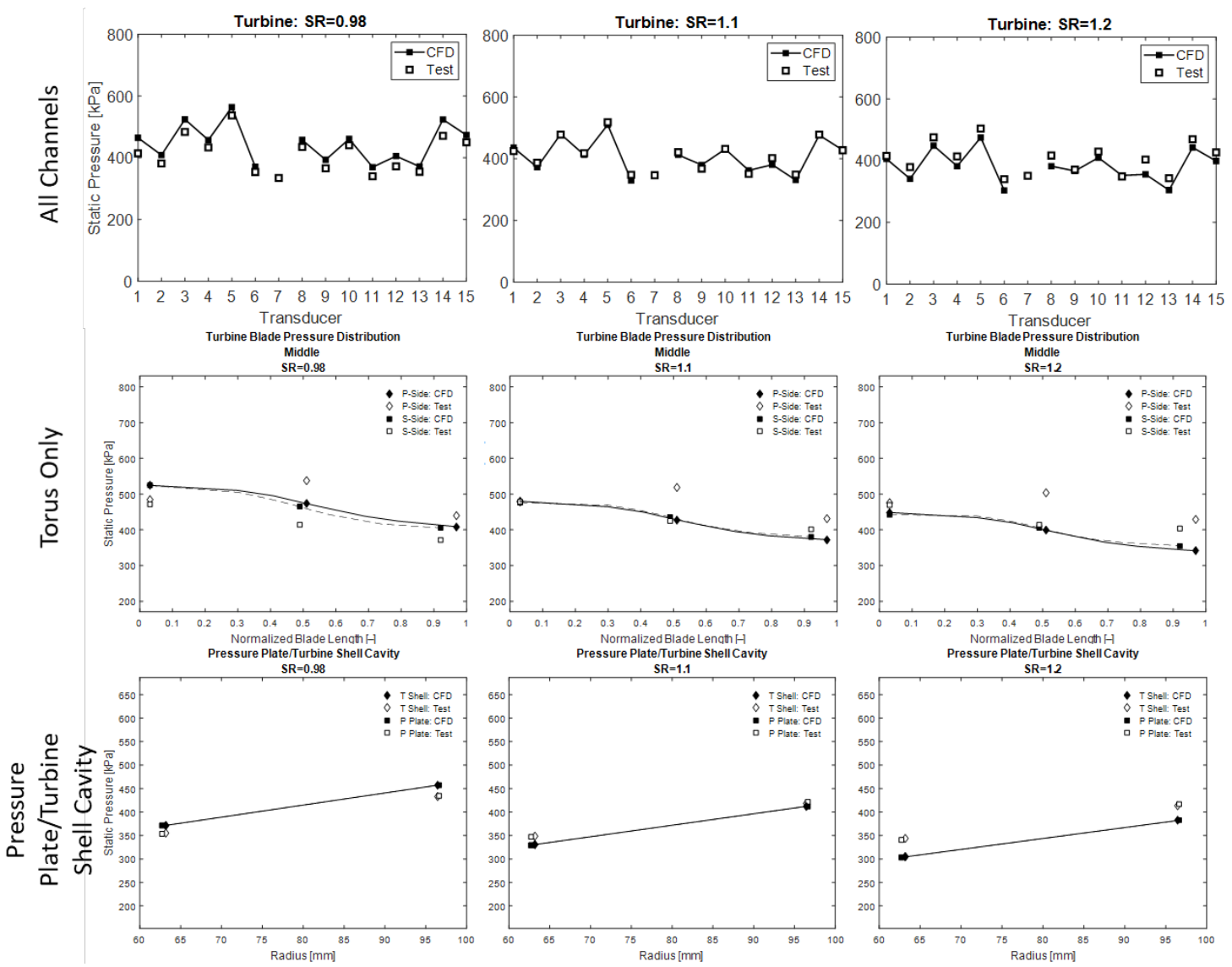


\section{N Back Drive FFT Color Maps}

\section{N.1 Impeller Color Maps}
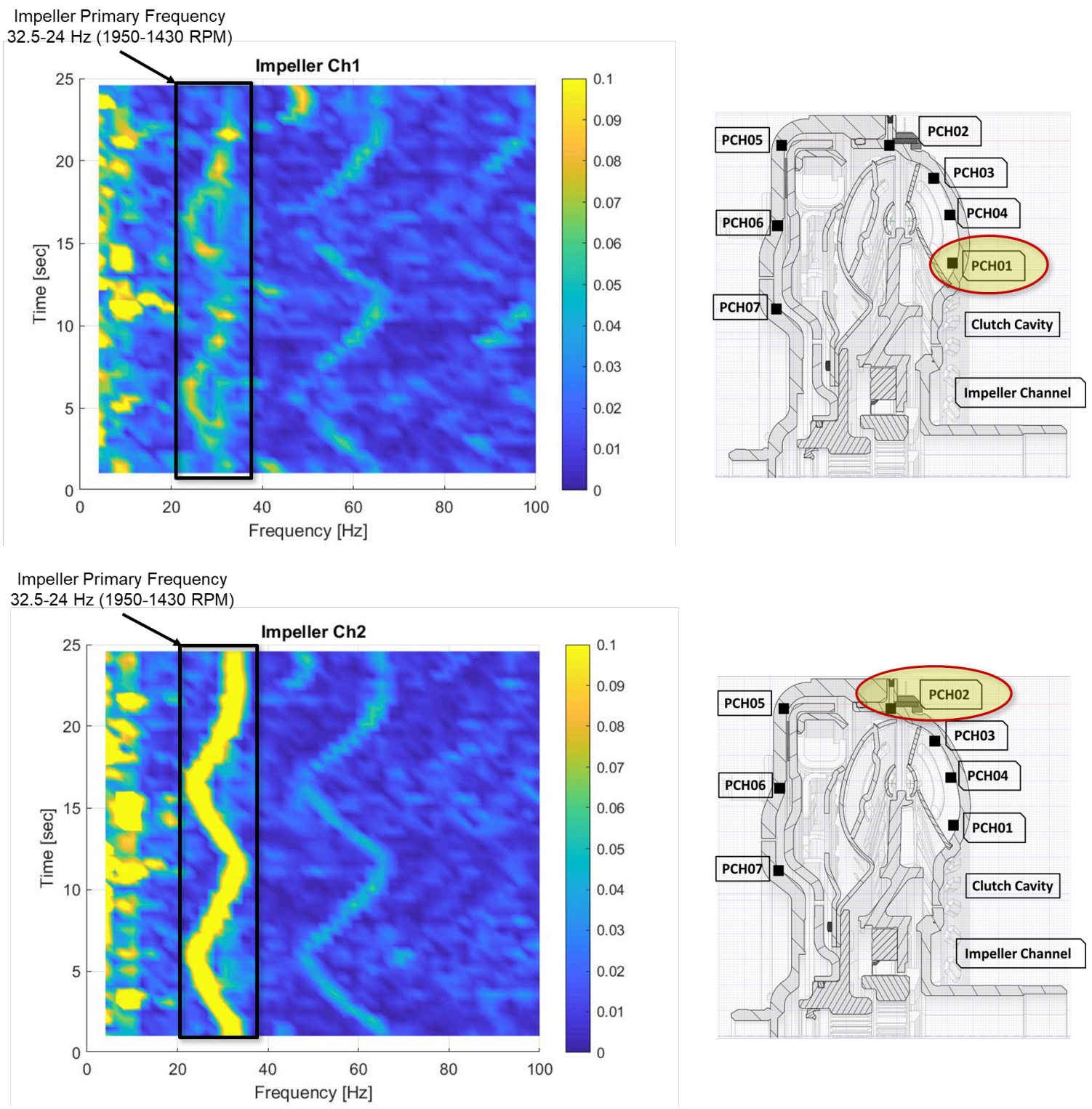

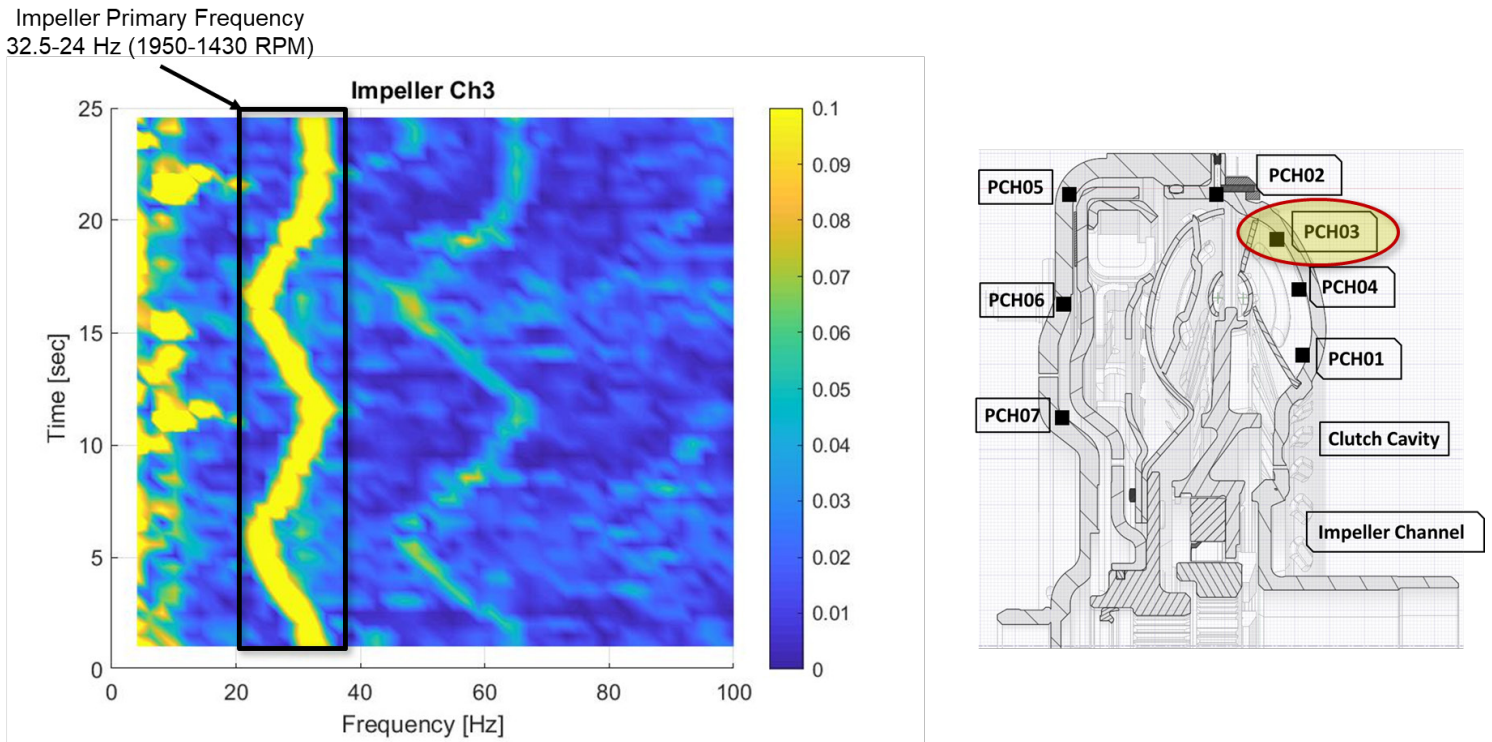

Impeller Primary Frequency 32.5-24 Hz (1950-1430 RPM)
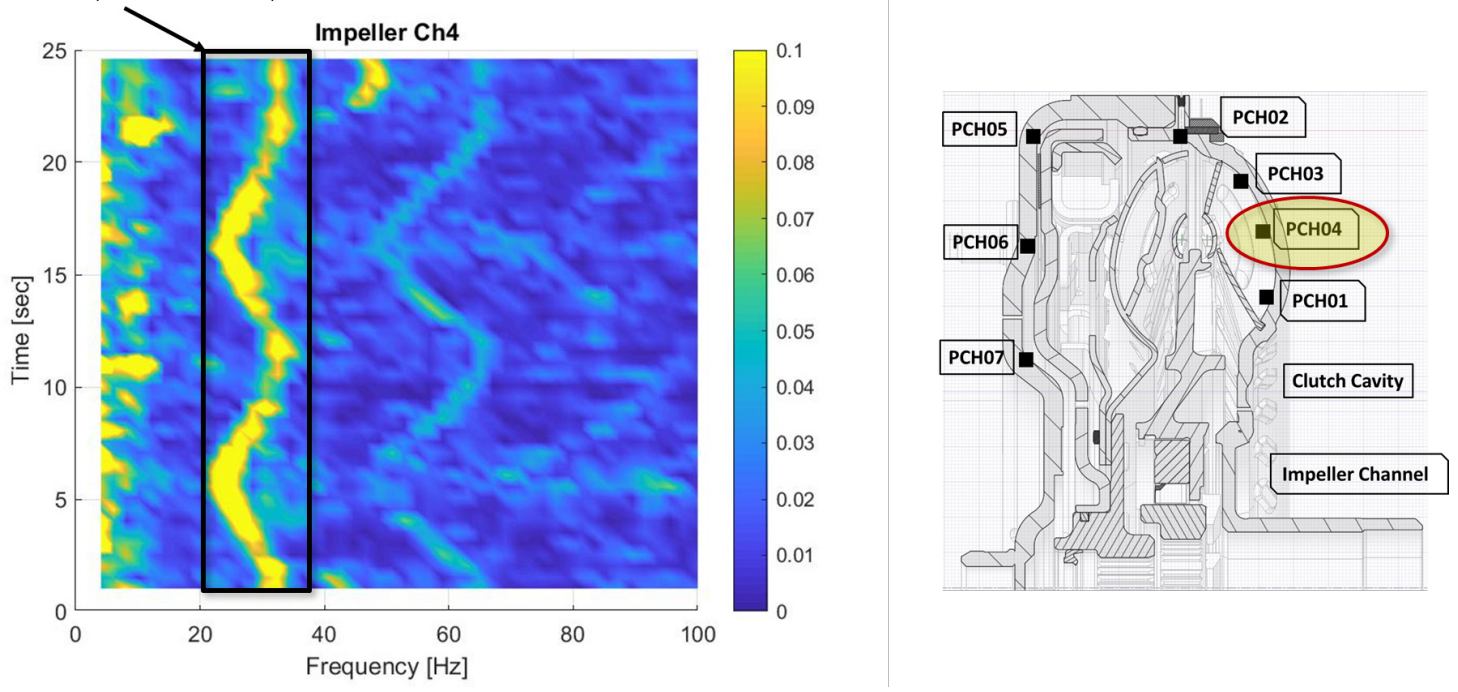

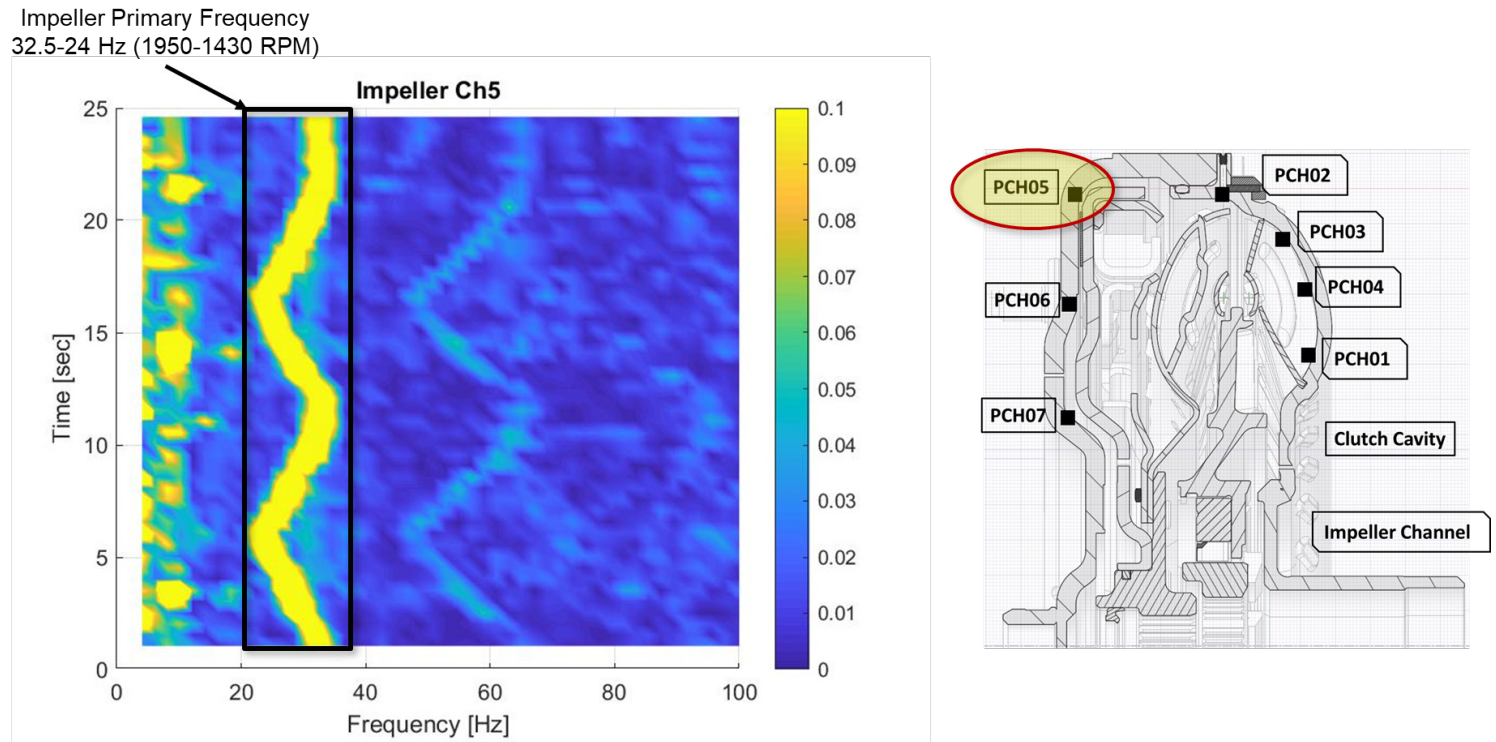

Impeller Primary Frequency

32.5-24 Hz (1950-1430 RPM)
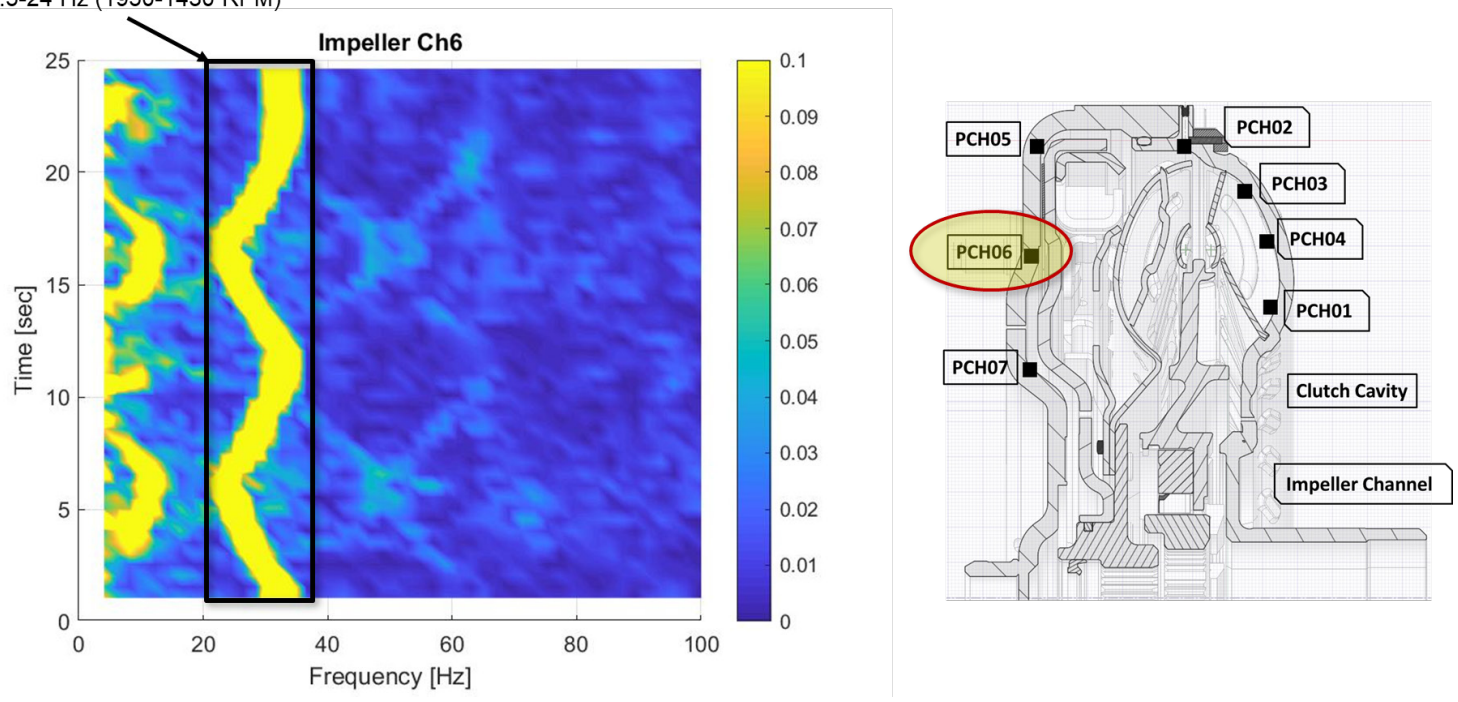

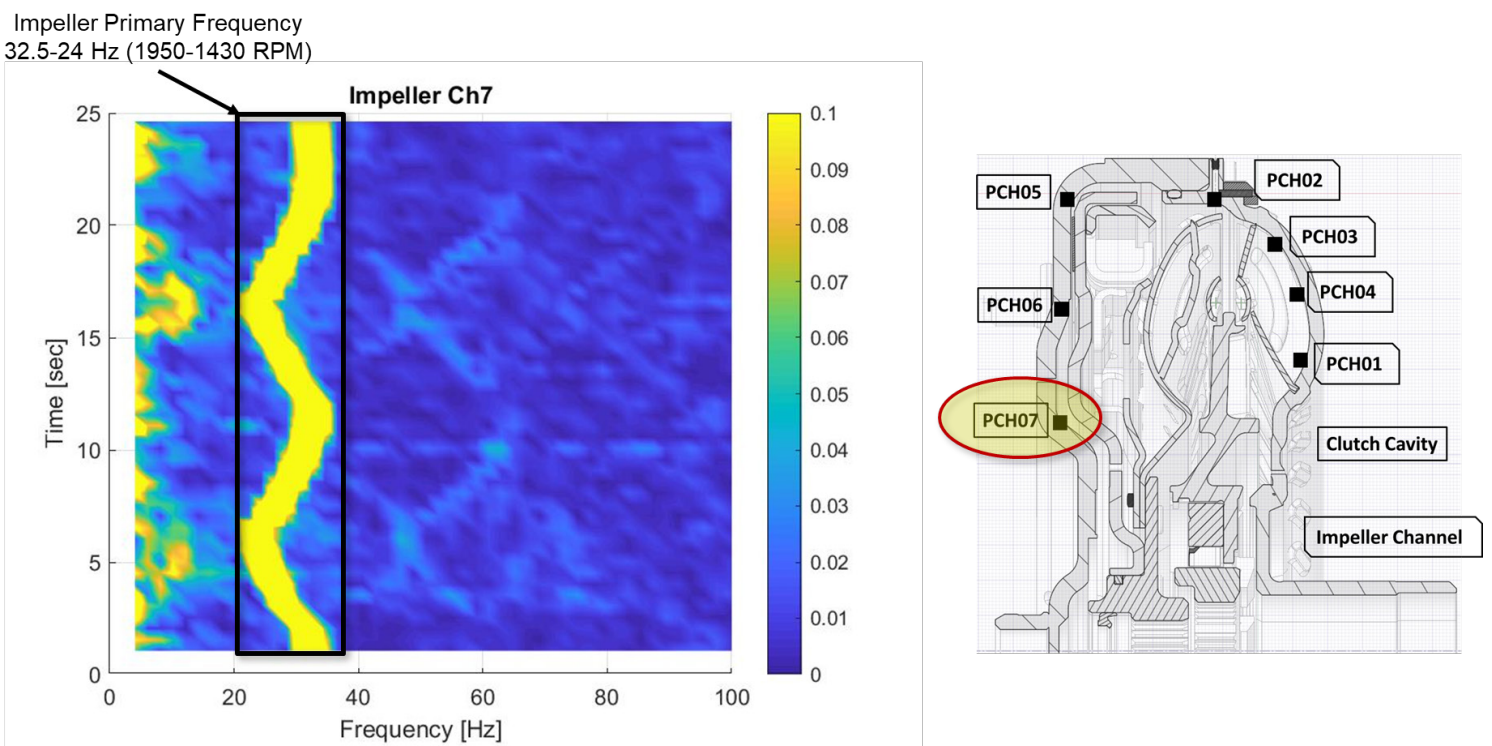

\section{N.2 Stator Color Maps}
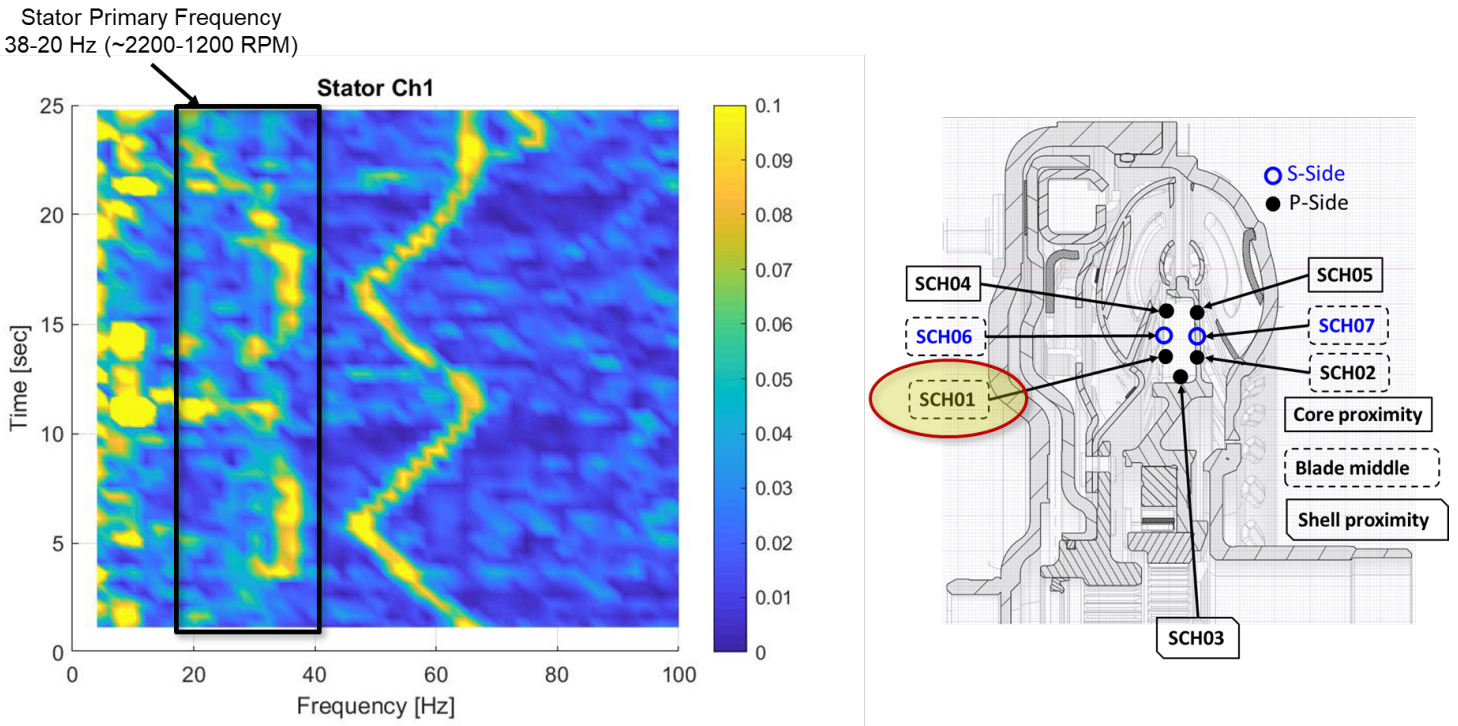
Stator Primary Frequency

$38-20 \mathrm{~Hz}$ ( 2200-1200 RPM)
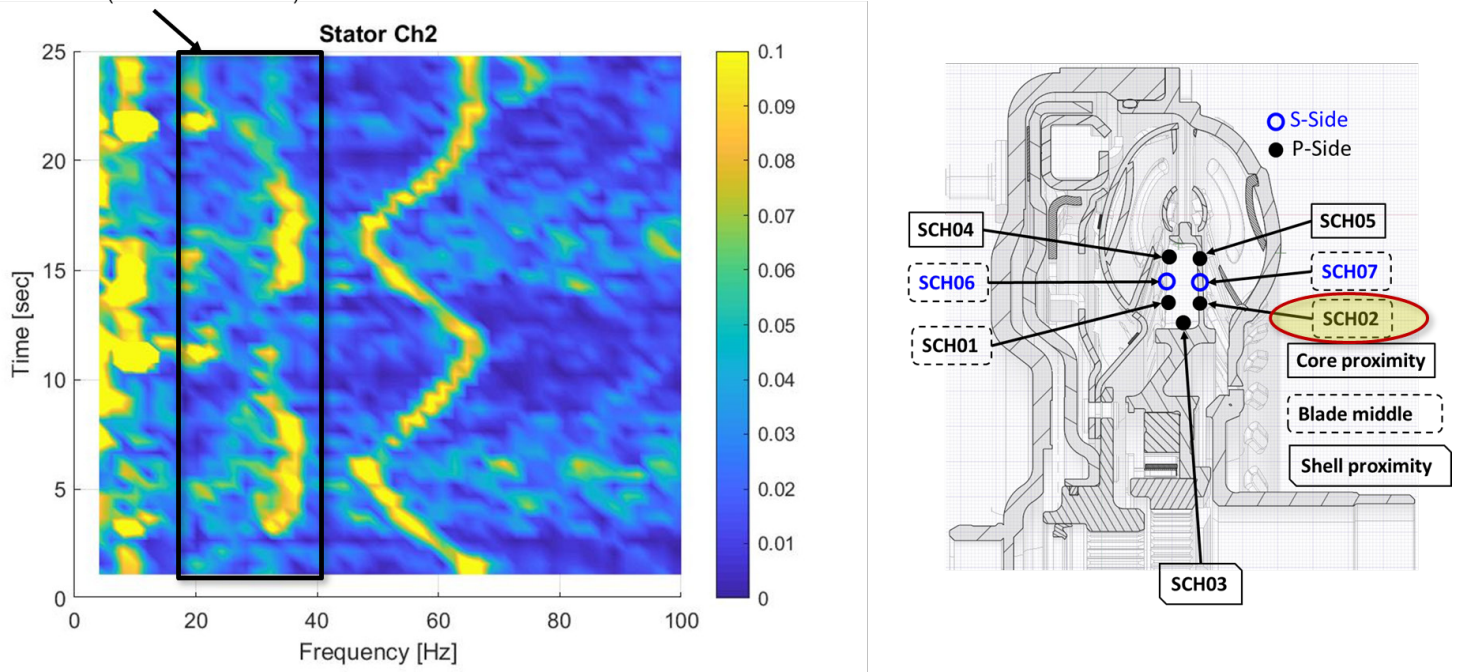

Stator Primary Frequency
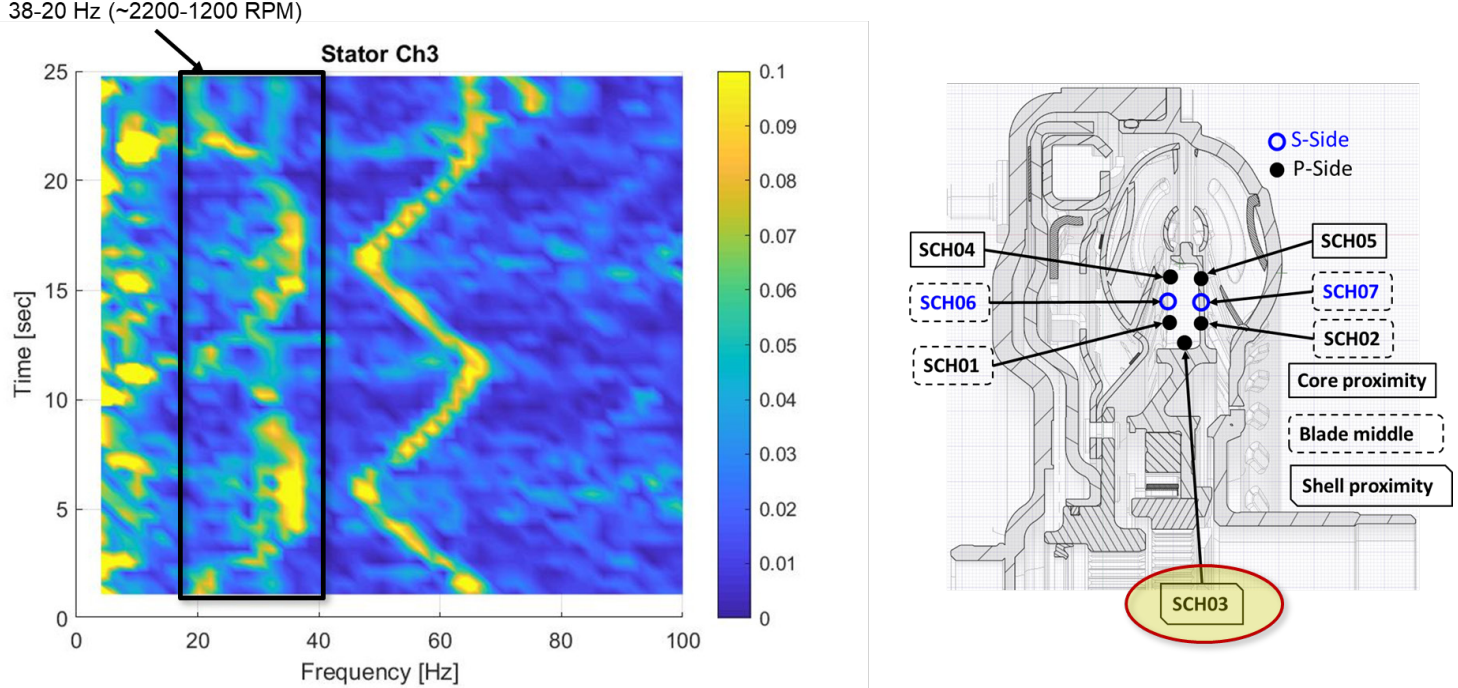
Stator Primary Frequency

$38-20 \mathrm{~Hz}$ ( 2200-1200 RPM)
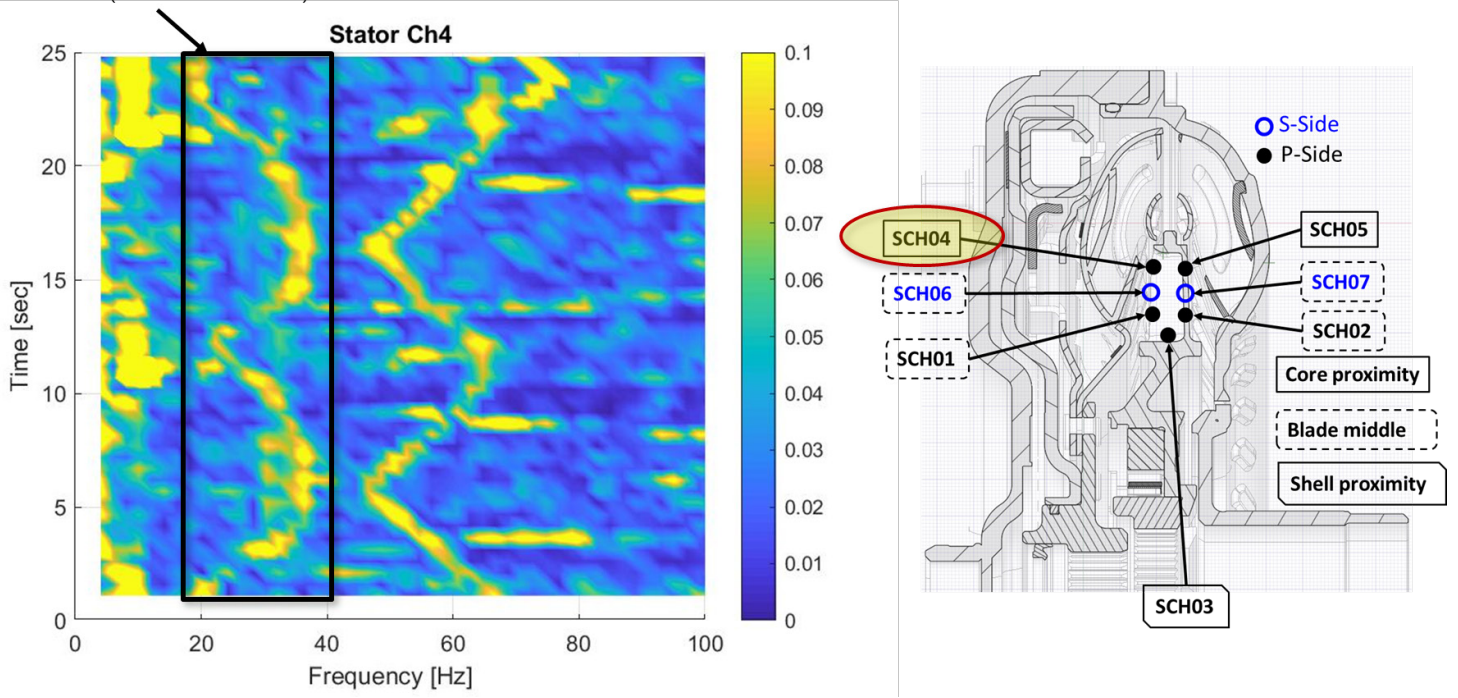

Stator Primary Frequency

$38-20 \mathrm{~Hz}$ ( 2200-1200 RPM)
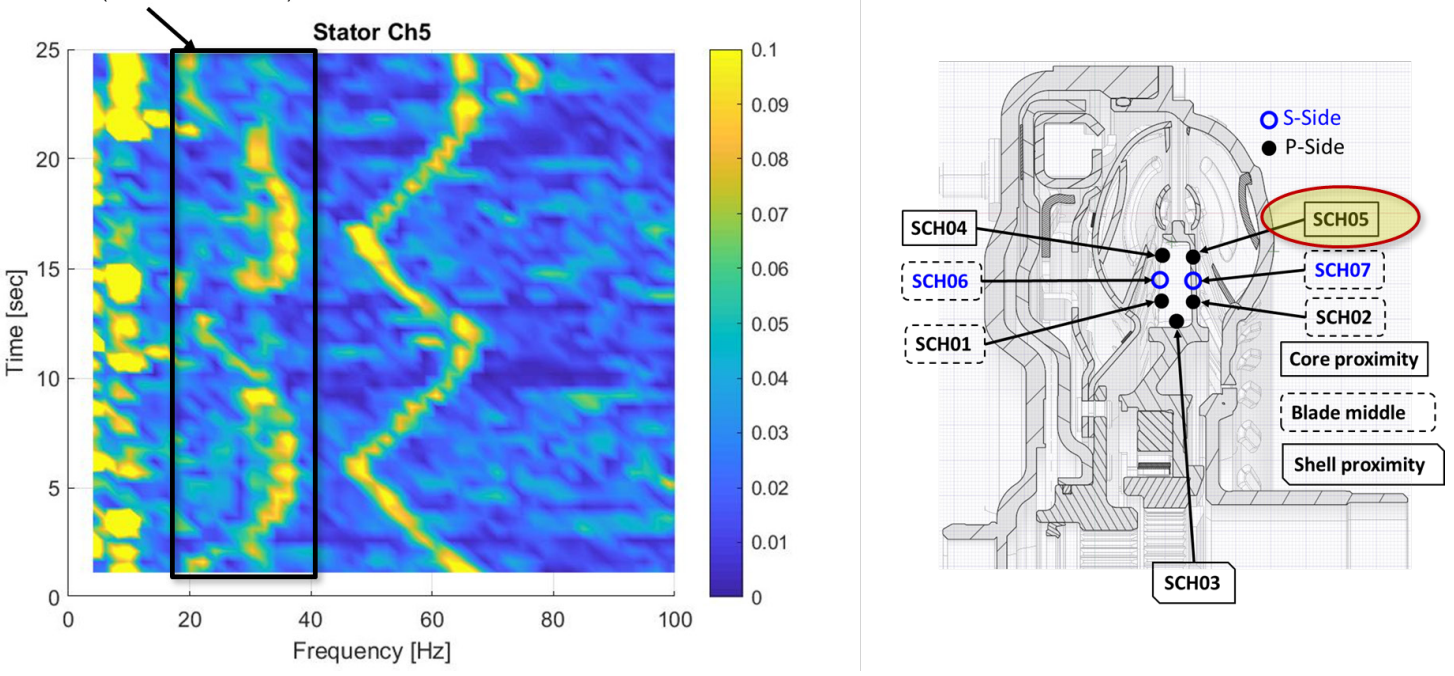
Stator Primary Frequency

$38-20 \mathrm{~Hz}$ ( 2200-1200 RPM)
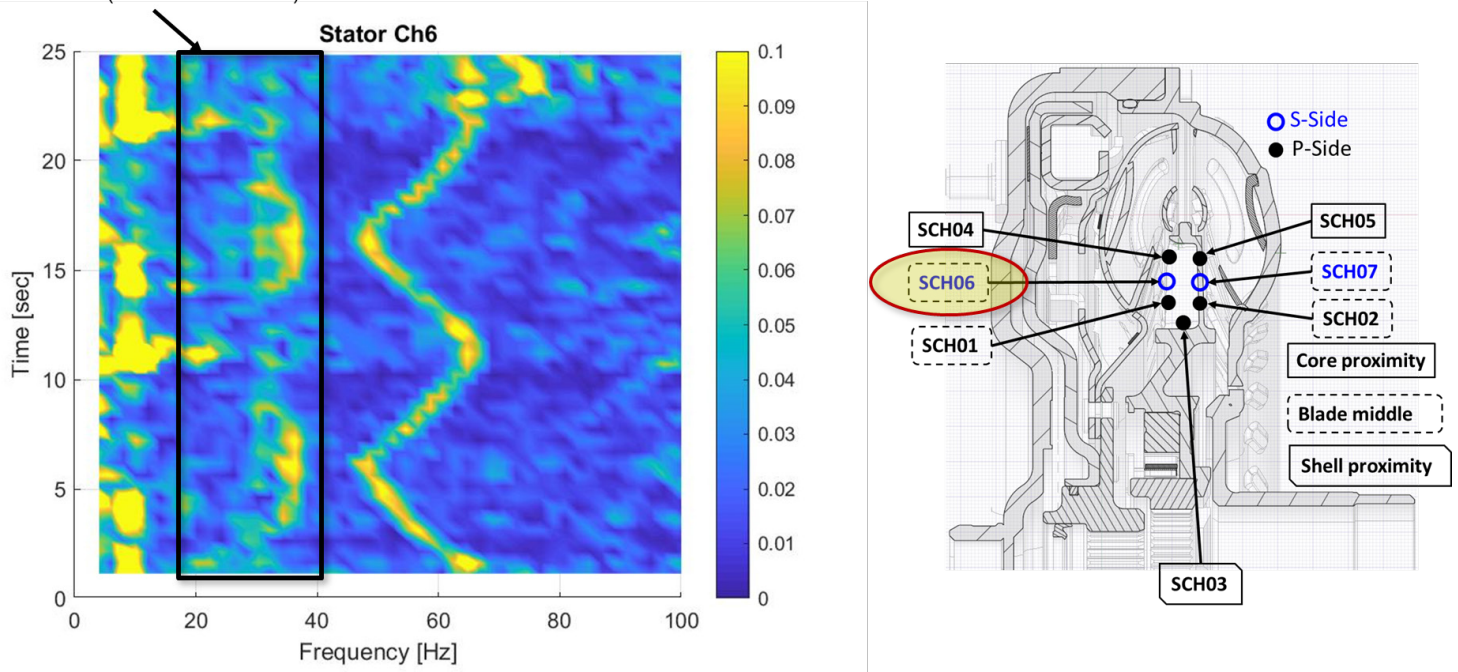

Stator Primary Frequency
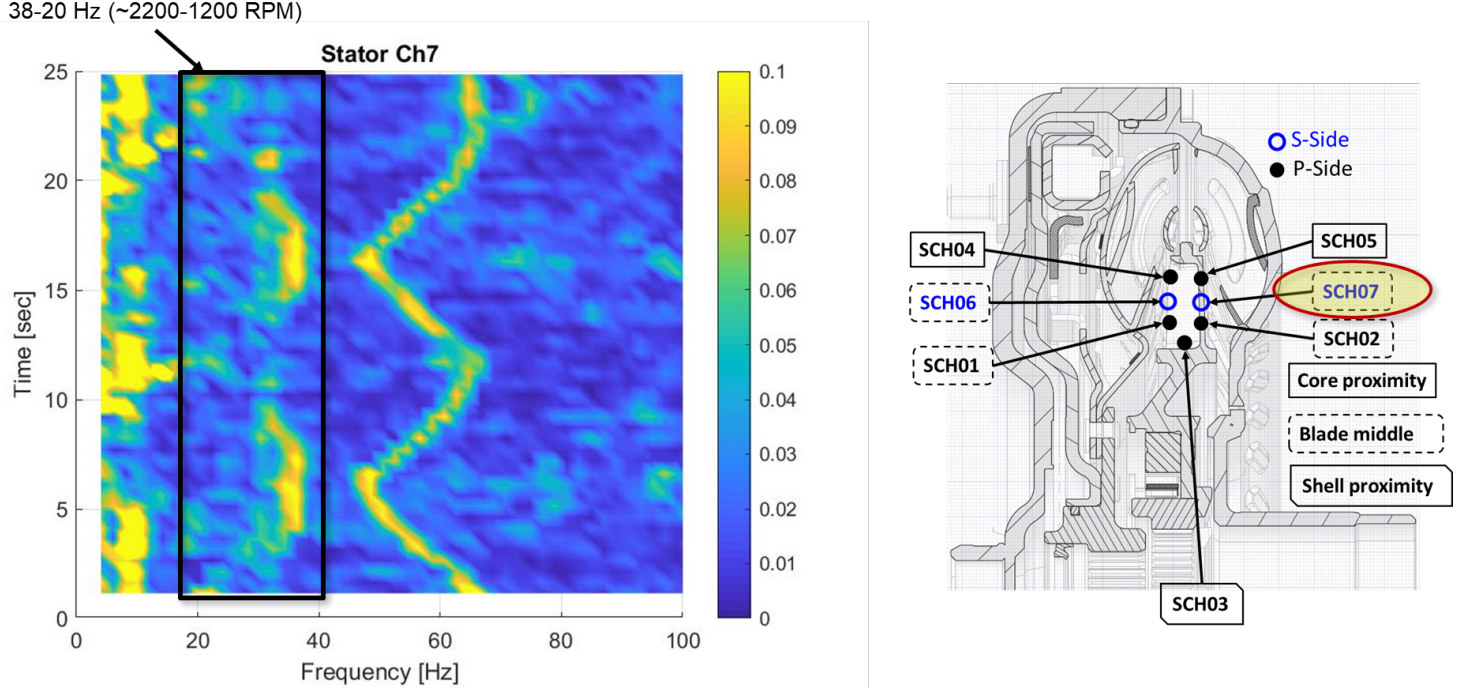


\section{N.3 Turbine Color Maps}
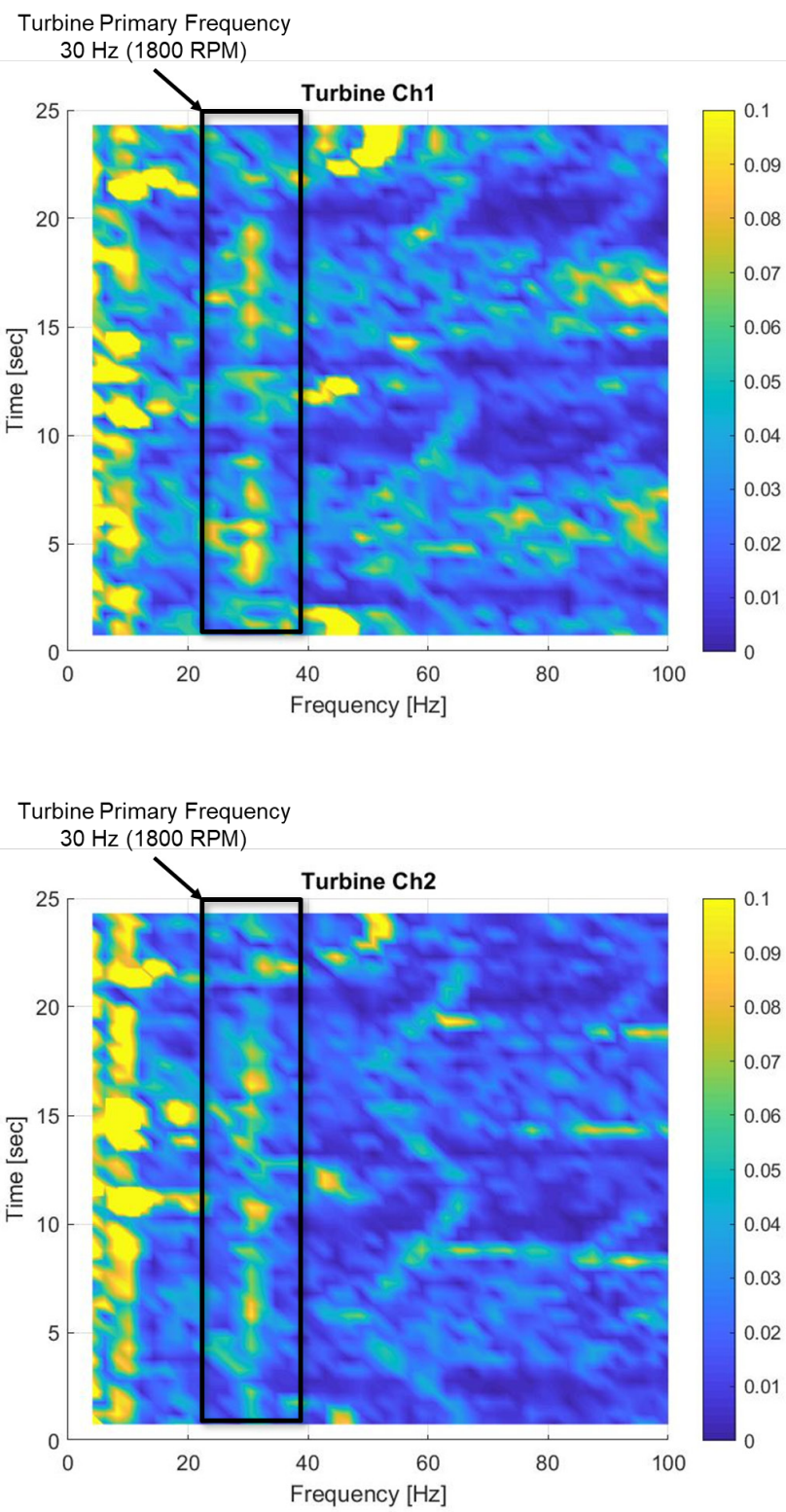
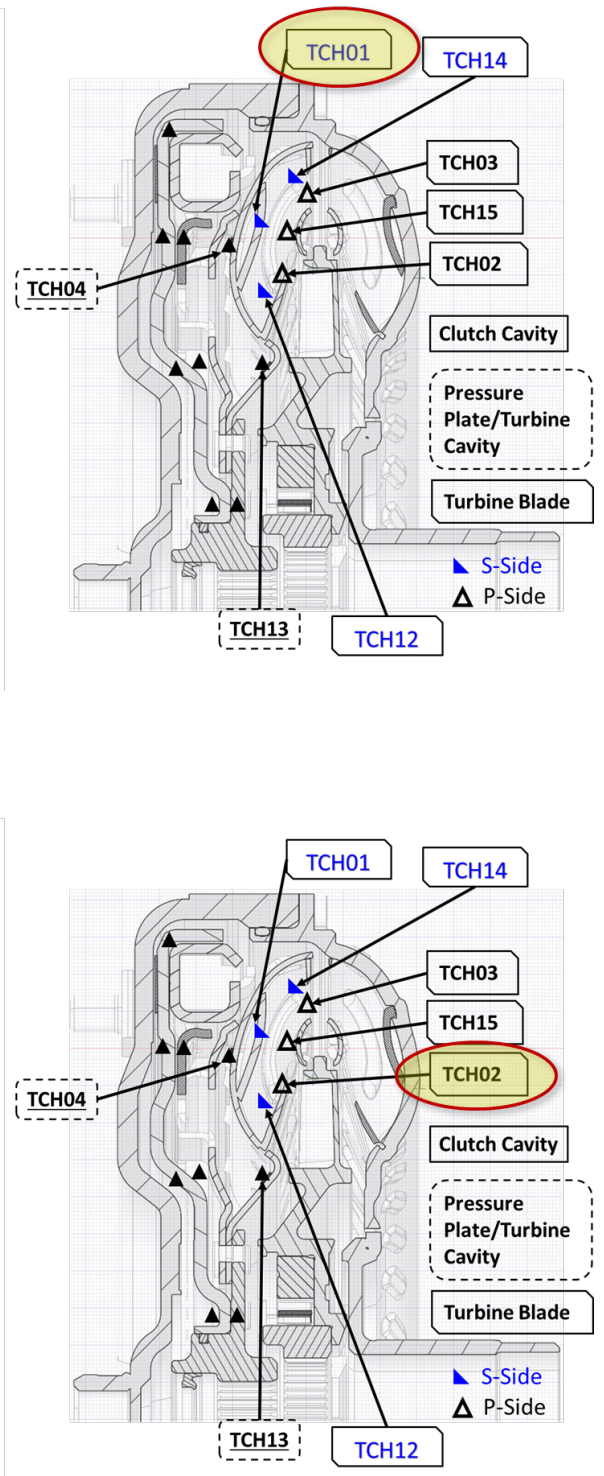

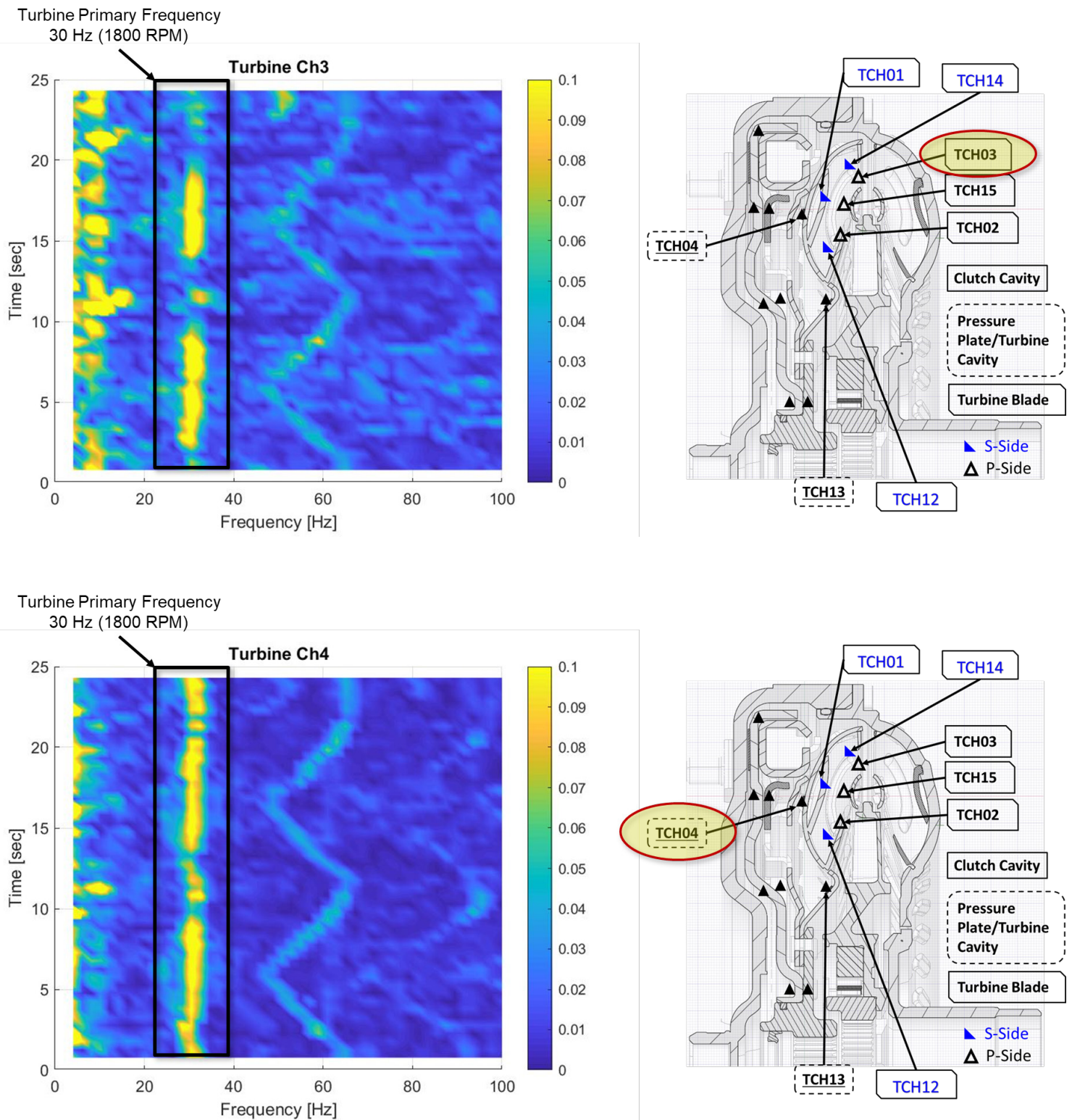

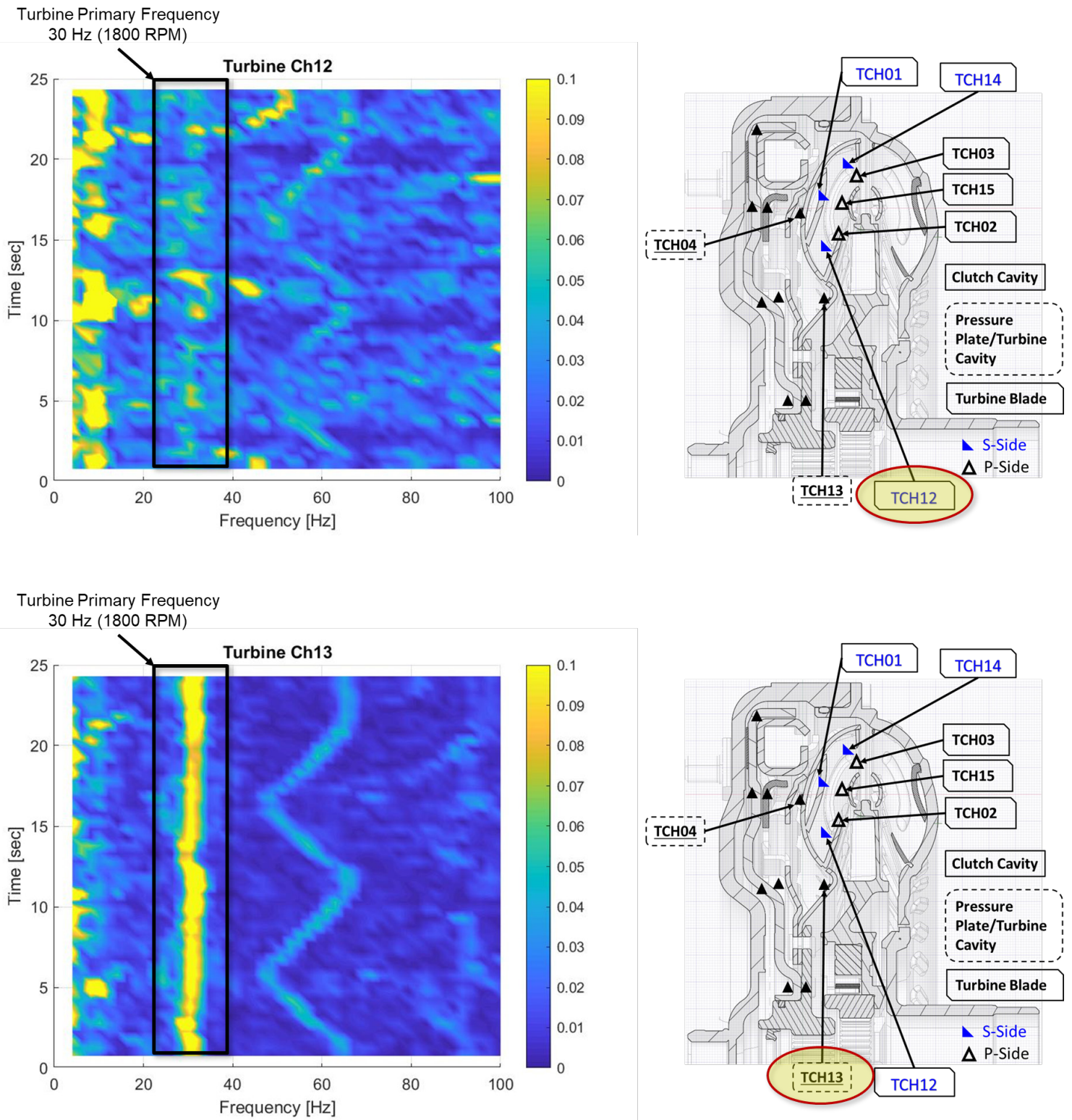

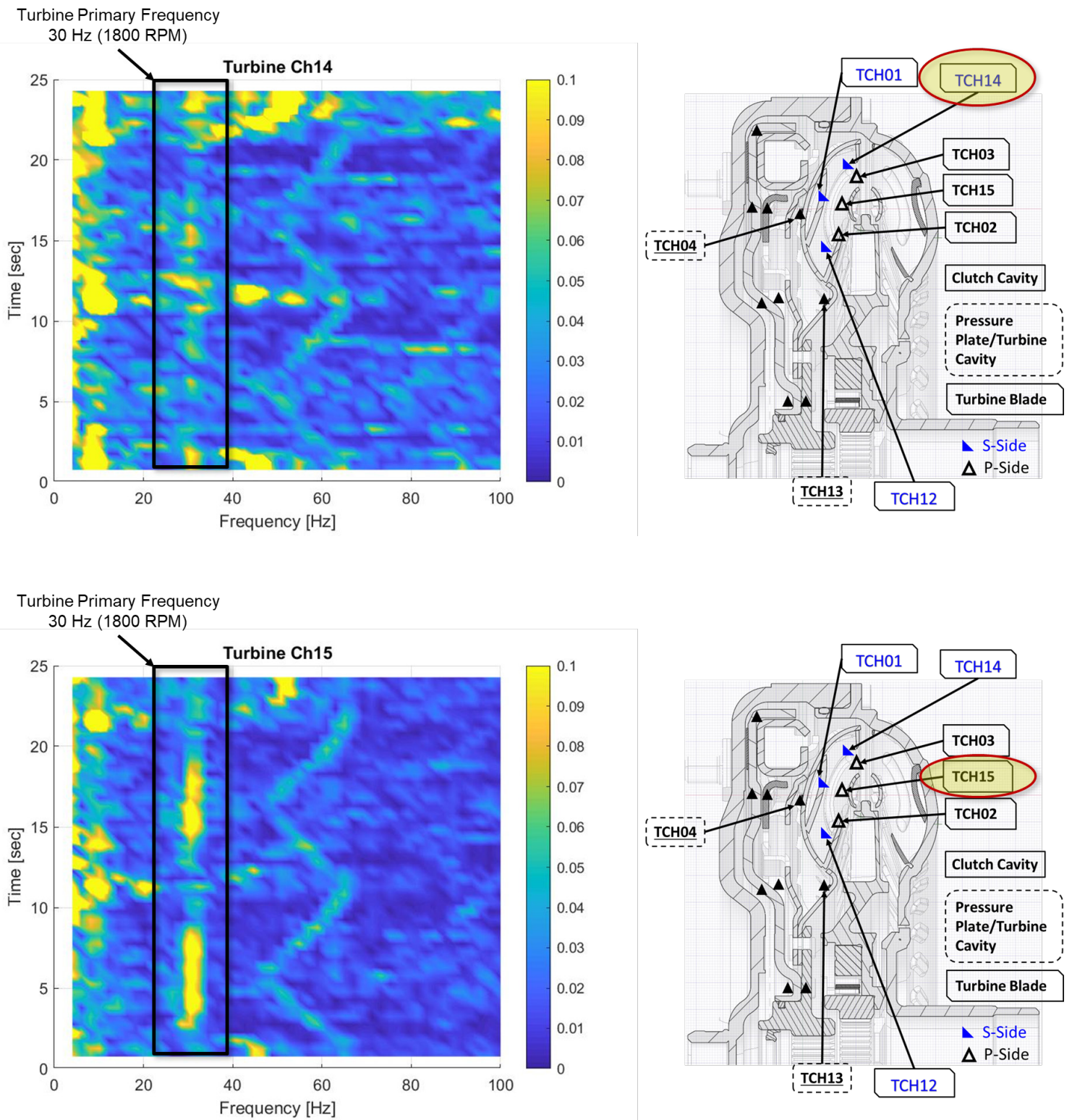

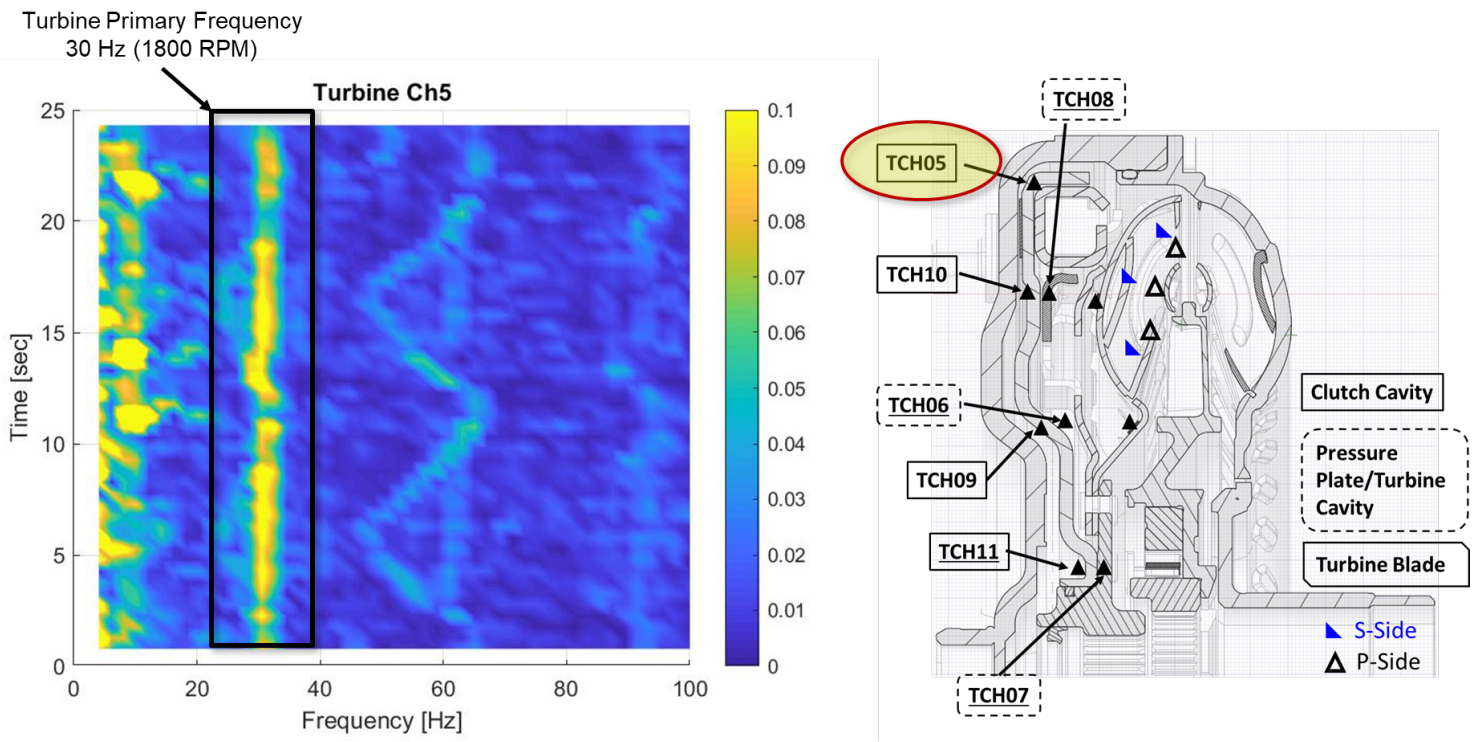

Turbine Primary Frequency
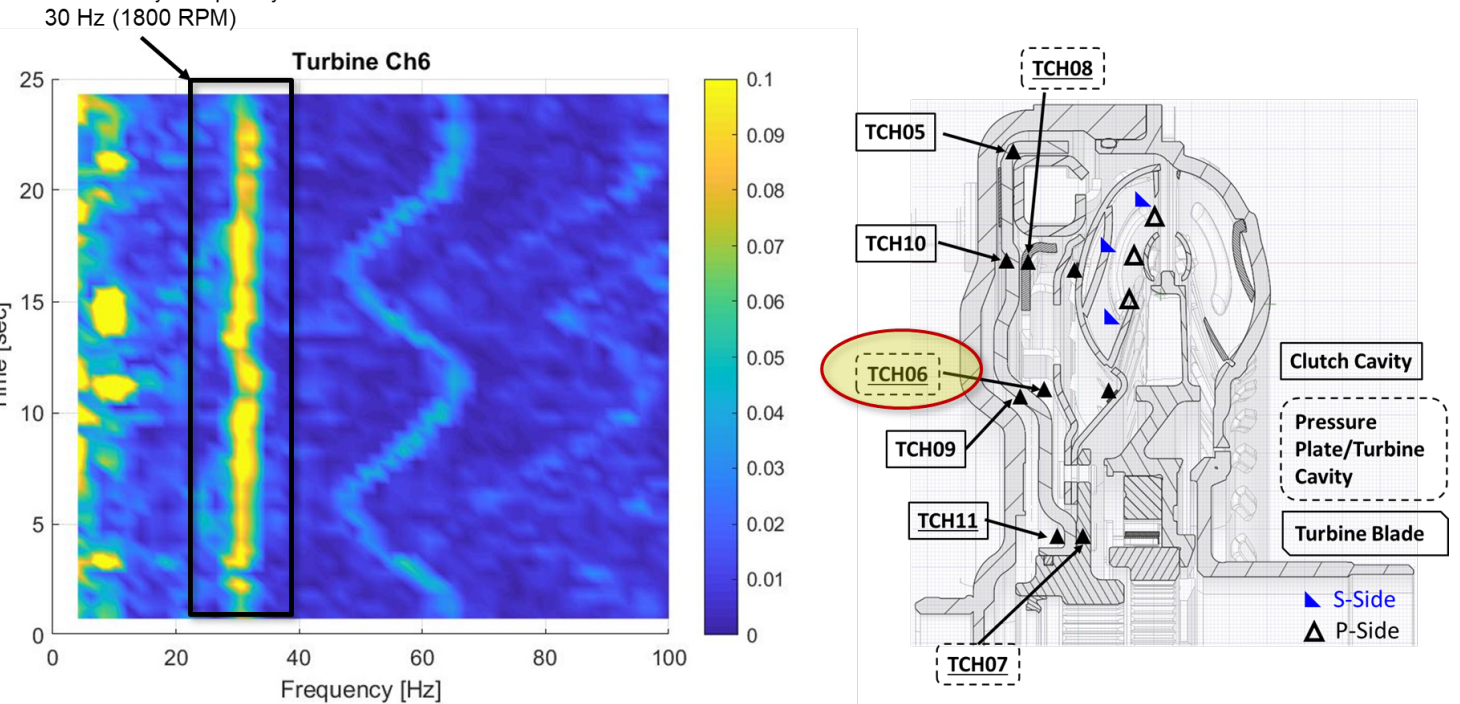

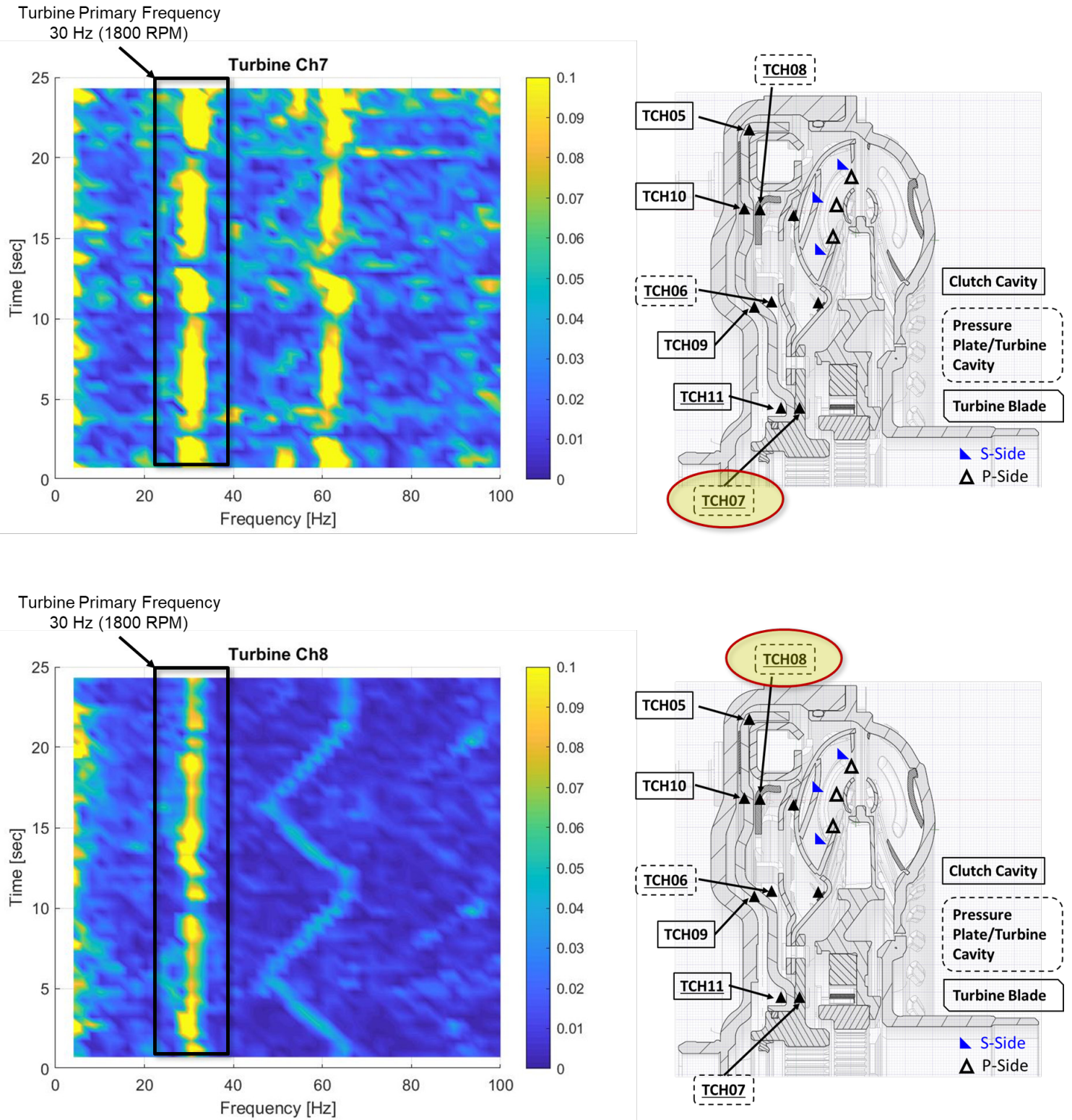

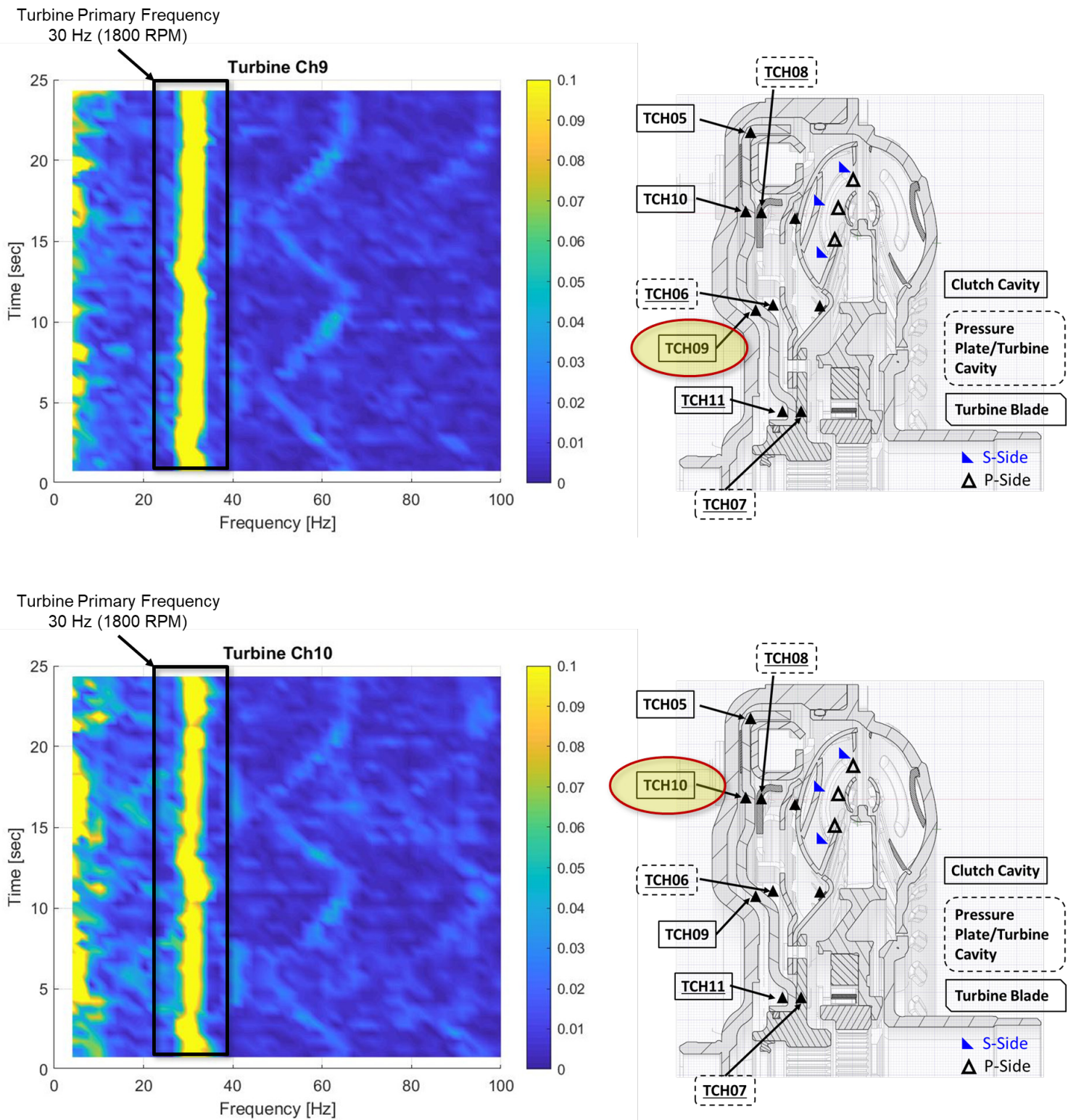

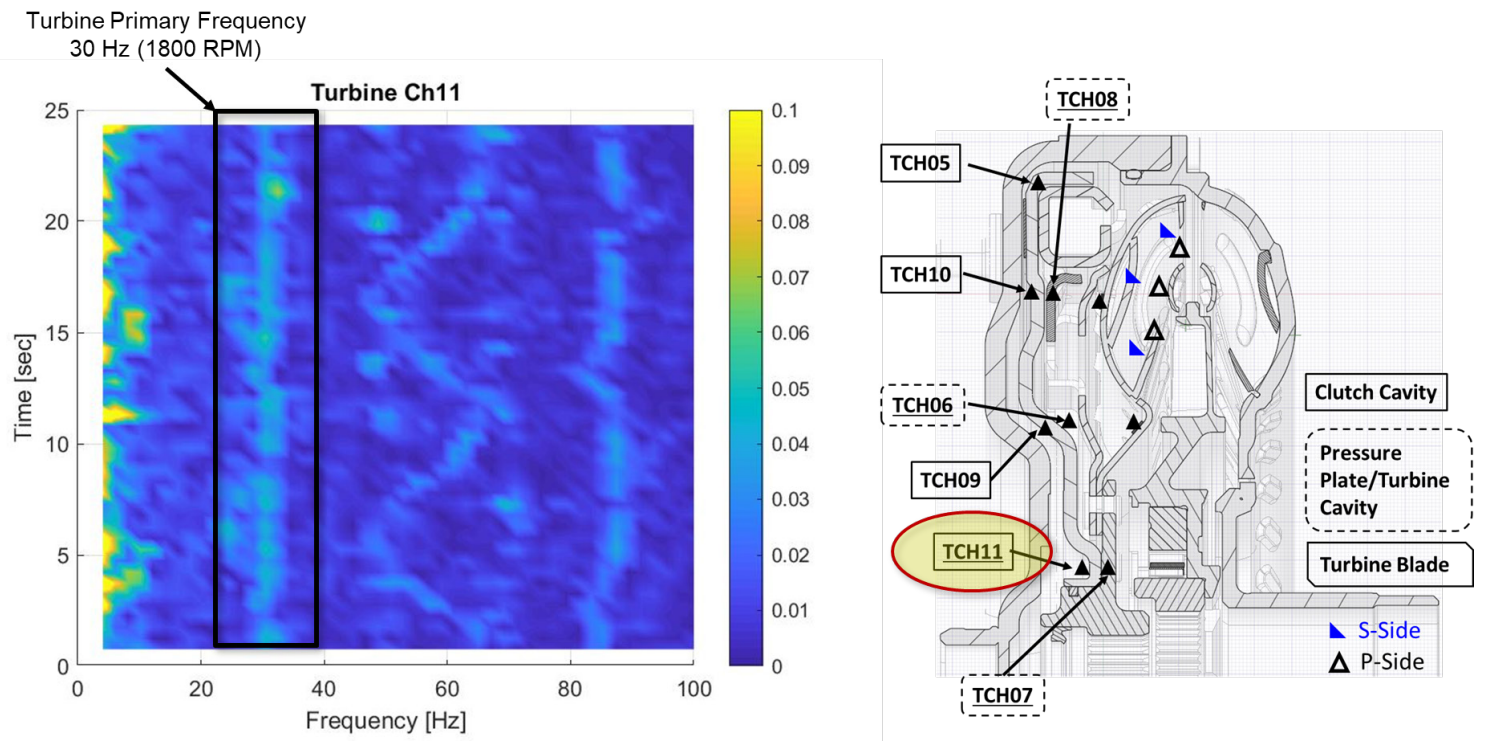


\section{O Key Analysis Tools}

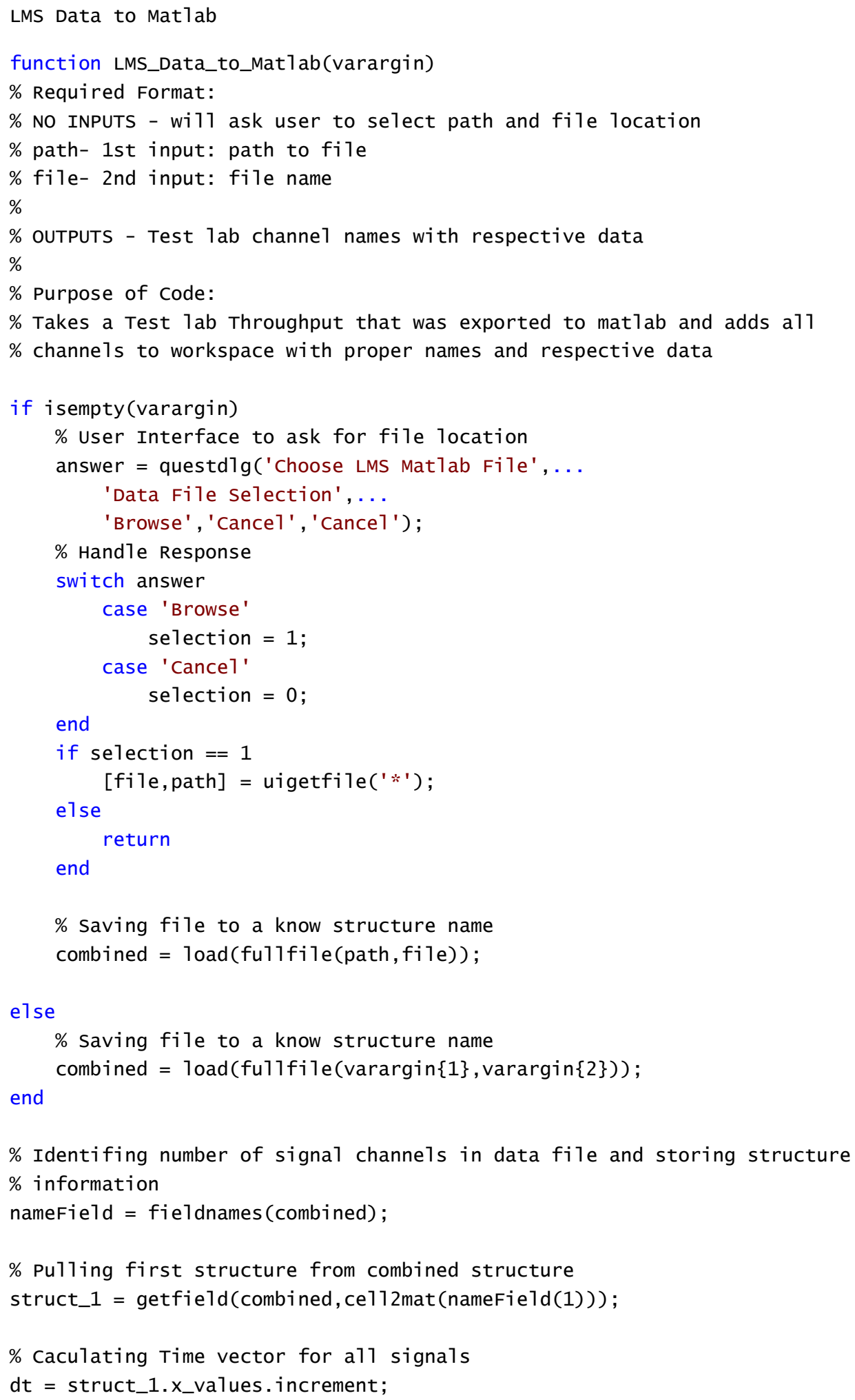




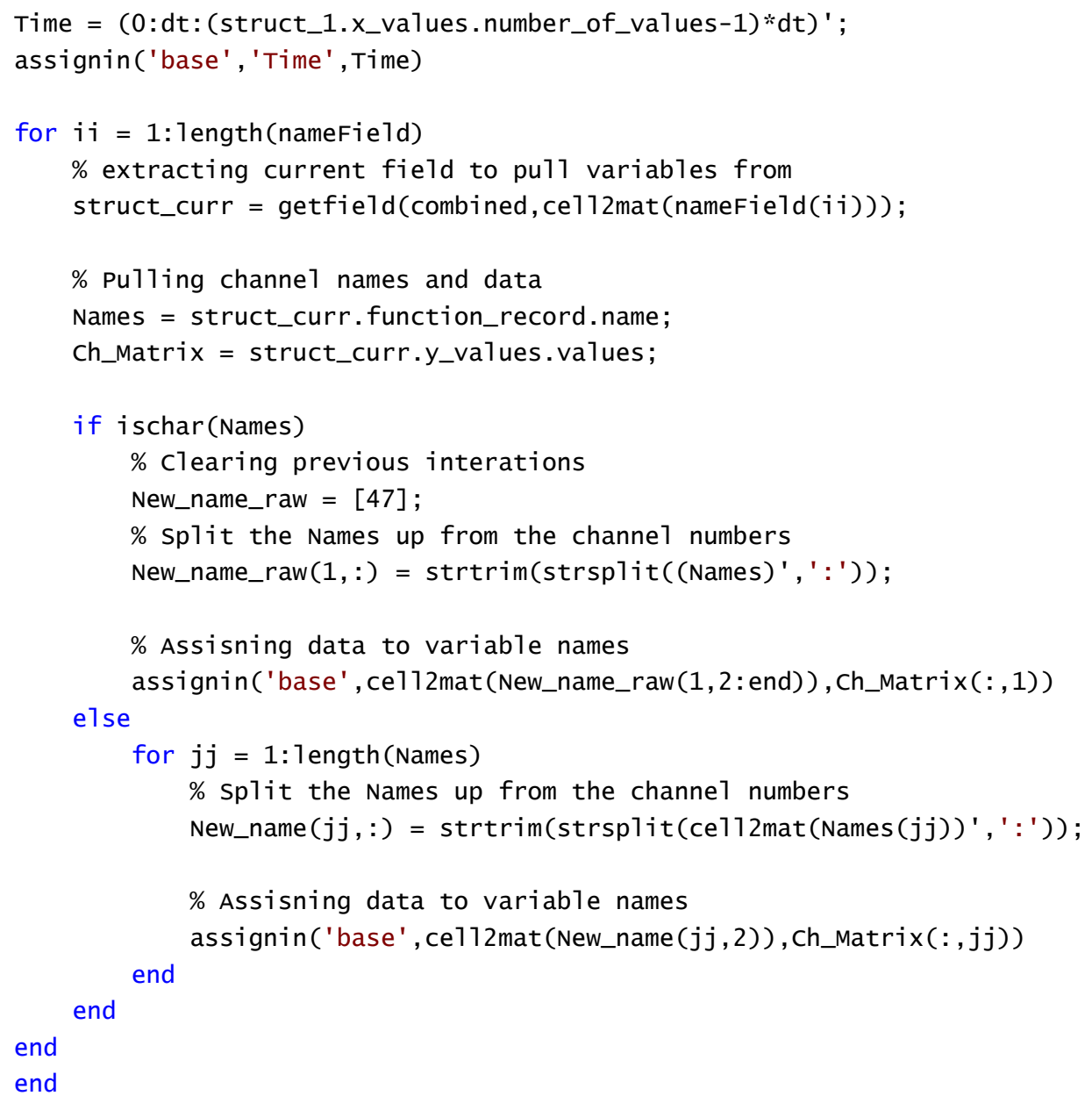

Published with MATLAB® R2018a

O.1 Telemetry Average Pressure

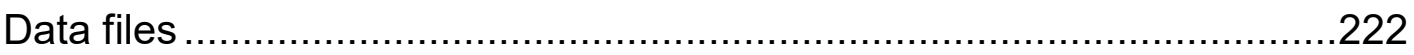

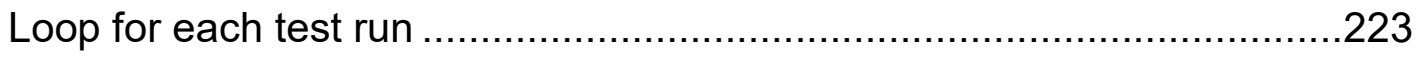

$\%$ Purpose of code:

$\%$ Takes .csv output files from telemetry and averages al1 the same test run

$\%$ values and output an .xlsx file with pressures, channel name, and run

$\%$ name

\section{Data files}

clear

clc

\% selecting file with data to be processed 


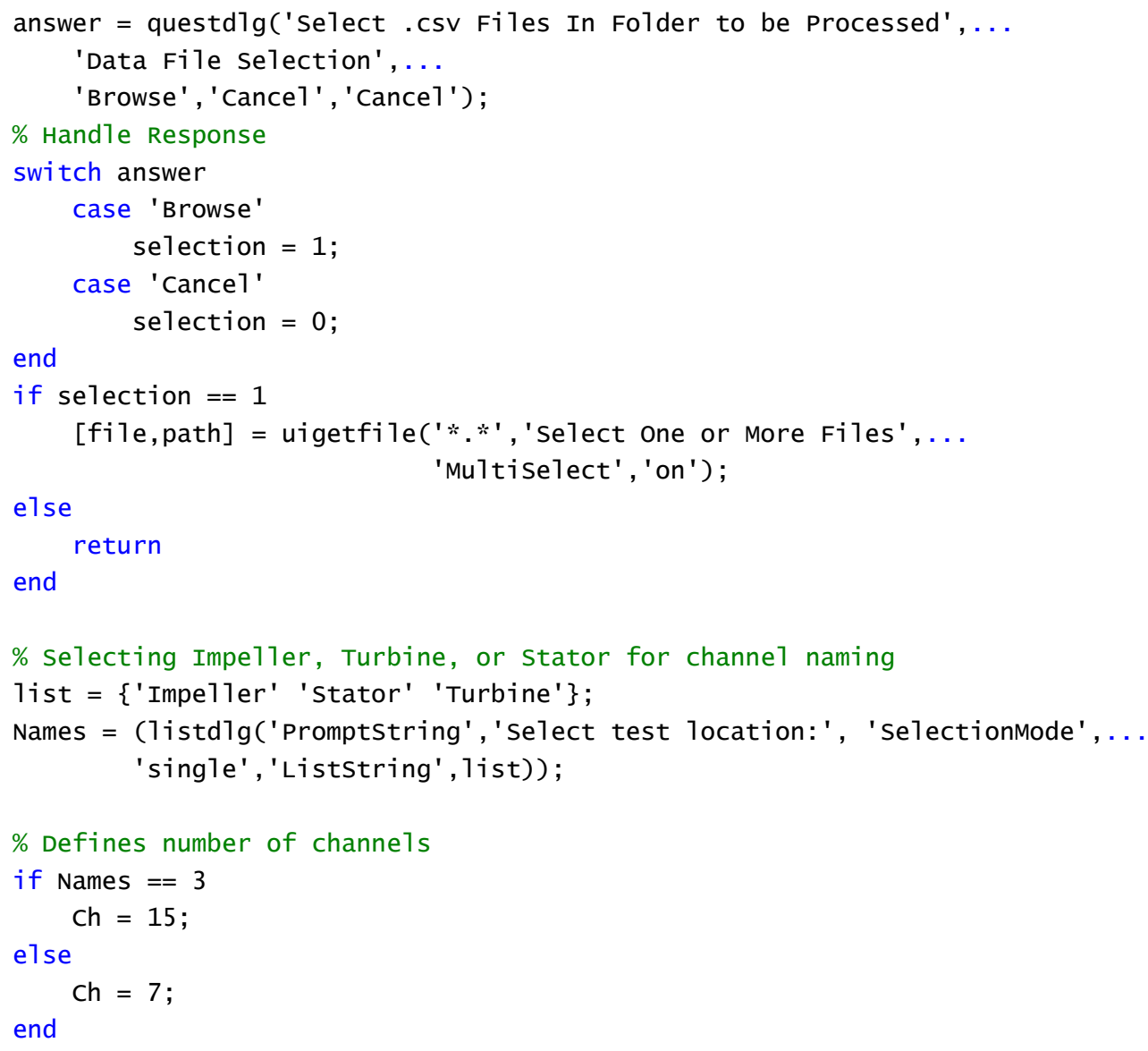

\section{Loop for each test run}

delete Telemetry_Pressure_Averaged_Results.x1sx \% Deletes file to ensure no data is from old processing

\% Splits each file name apart and determines number of test runs completed $A=\operatorname{cel1}(3,1$ ength $(f i 1 e))$;

for $i i=1:$ length $(\mathrm{file})$ 


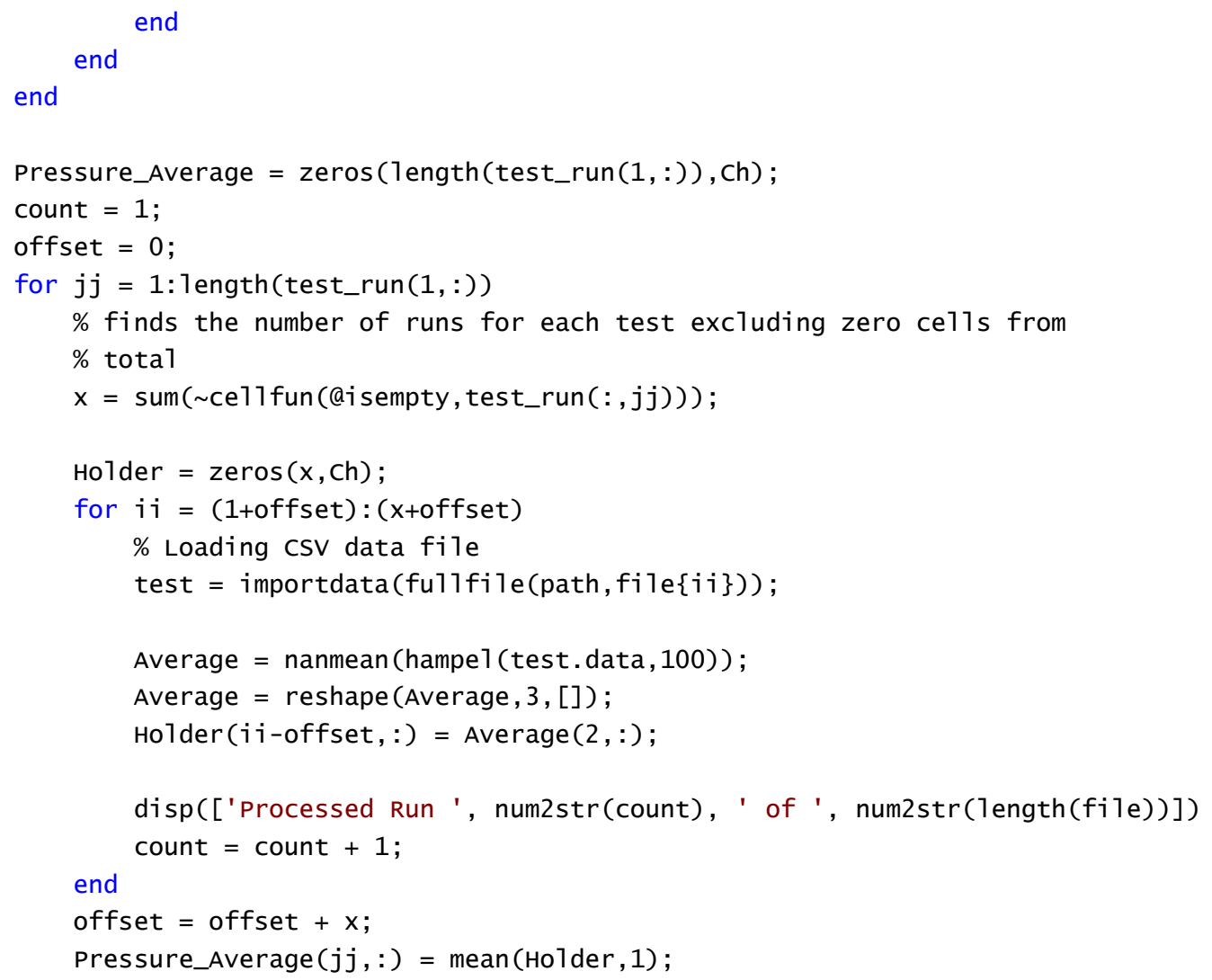

x1swrite('Te1emetry_Pressure_Averaged_Resu1ts.x1sx', test_run $(1, j j), \operatorname{strcat}\left({ }^{\prime} A\right.$ ' , num2str( $j j+$ 1) , ': $\left.\left.A^{\prime}, \operatorname{num} 2 \operatorname{str}(j j+1)\right)\right)$;

end

x1swrite('Te1emetry_Pressure_Averaged_Resu1ts.x1sx' , Pressure_Average,1, 'B2 ') ;

if Names $==1$

Titles $=\{$ 'Run Name', 'Ch1 In1et [PSI]', 'Ch2 Impe11er-Turbine OD [PSI]', 'Ch3 Exit [PSI]', 'Ch4 Middle [PSI]', ...

'Ch5 Cover OD [PSI]', 'Ch6 Cover Midd7e [PSI]', 'Ch7 cover ID [PSI]'\};

elseif Names $==2$

Titles $=$ \{'Run Name', 'Ch1 Pside Lead Mid [PSI]', 'Ch2 Pside Trai1 Mid [PSI]', 'Ch3 Pside Mid She11 [PSI]', 'Ch4 Pside Lead Core [PSI]',...

'Ch5 Pside Trai1 Core [PSI]', 'Ch6 Sside Lead Mid [PSI]', 'Ch7 Sside Trai1 Mid [PSI] '\};

e1se

Titles $=\{$ 'Run Name', 'Ch1 Sside Mid Mid [PSI]', 'Ch2 Pside Trai1 Mid [PSI]', 'Ch3 Pside Lead Mid [PSI]', 'Ch4 she11 outer OD [PSI]',...

'Ch5 Clutch side OD Past Friction Material [PSI]', 'Ch6 Turbine Side Middle [PSI]', 'Ch7 Turbine side ID [PSI]',...

'Ch8 Turbine side OD [PSI]', 'Ch9 clutch side Middle [PSI]', 'Ch10 Clutch side OD Before Friction Material [PSI]', ...

'Ch11 Turbine Side ID [PSI]', 'Ch12 Sside Trai1 Mid [PSI]', 'Ch13 she11 outer ID 
[PSI]', 'Ch14 Sside Lead Mid [PSI]', ...

'Ch15 Pside Mid Mid [PSI]'\};

end

x1swrite('Te1emetry_Pressure_Averaged_Resu1ts.x1sx',Tit1es);

disp('Processing Completed')

\section{Published with MATLAB® R2018a}

\section{O.2 Telemetry Stitcher}

Asking User to Define File Location ............................................... 225

Asking User to Define Impeller, Stator, or Turbine Data..................... 226

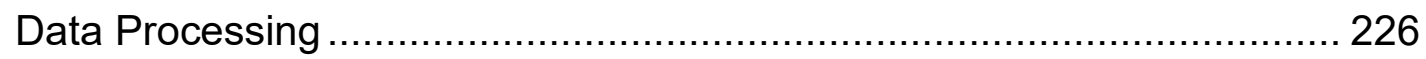

Sorting Time and Pressure Data ...................................................... 227

function [Time_Stitched,Pressure_Stitched,Sync] = Telemetry_Stitcher

\% Required Format:

\% Time- 1st input: 3D time matrix associated with the pressure matrix

\% Pressure- 2nd input: 3D pressure matrix

\% Time_stitched- 1st output: Time vector for each channe1

\% Pressure_stitched- 2nd output: Pressure vector for each channe1

$\%$

\% Purpose of Code:

$\%$ Takes each channel from a set of tests and stitches the data into a

\% single time trace for each channel

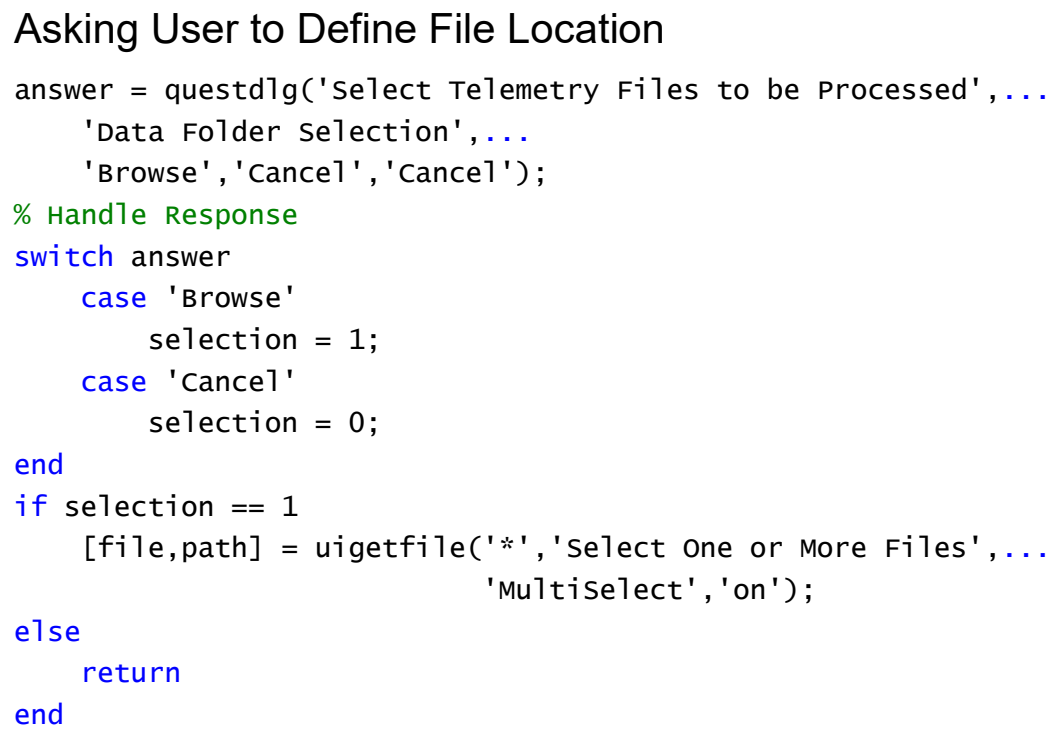




\section{Asking User to Define Impeller, Stator, or Turbine Data}

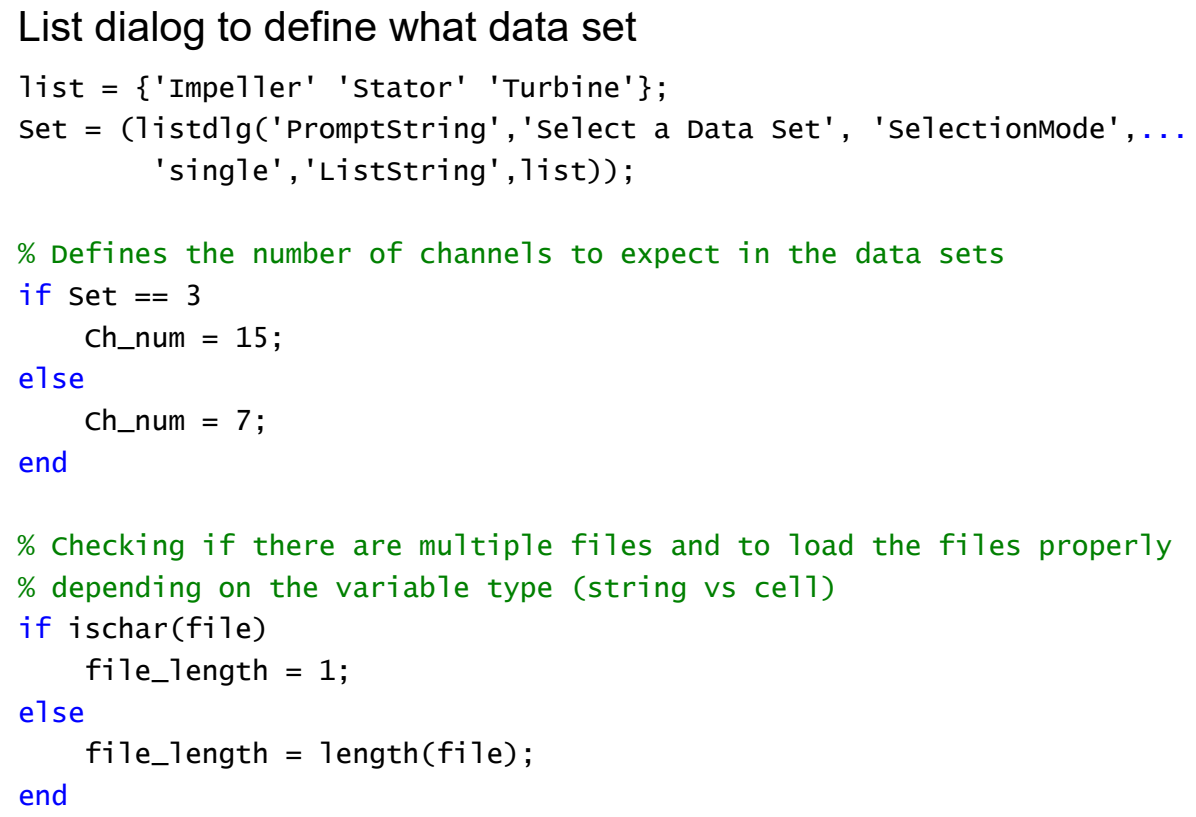

\section{Data Processing}

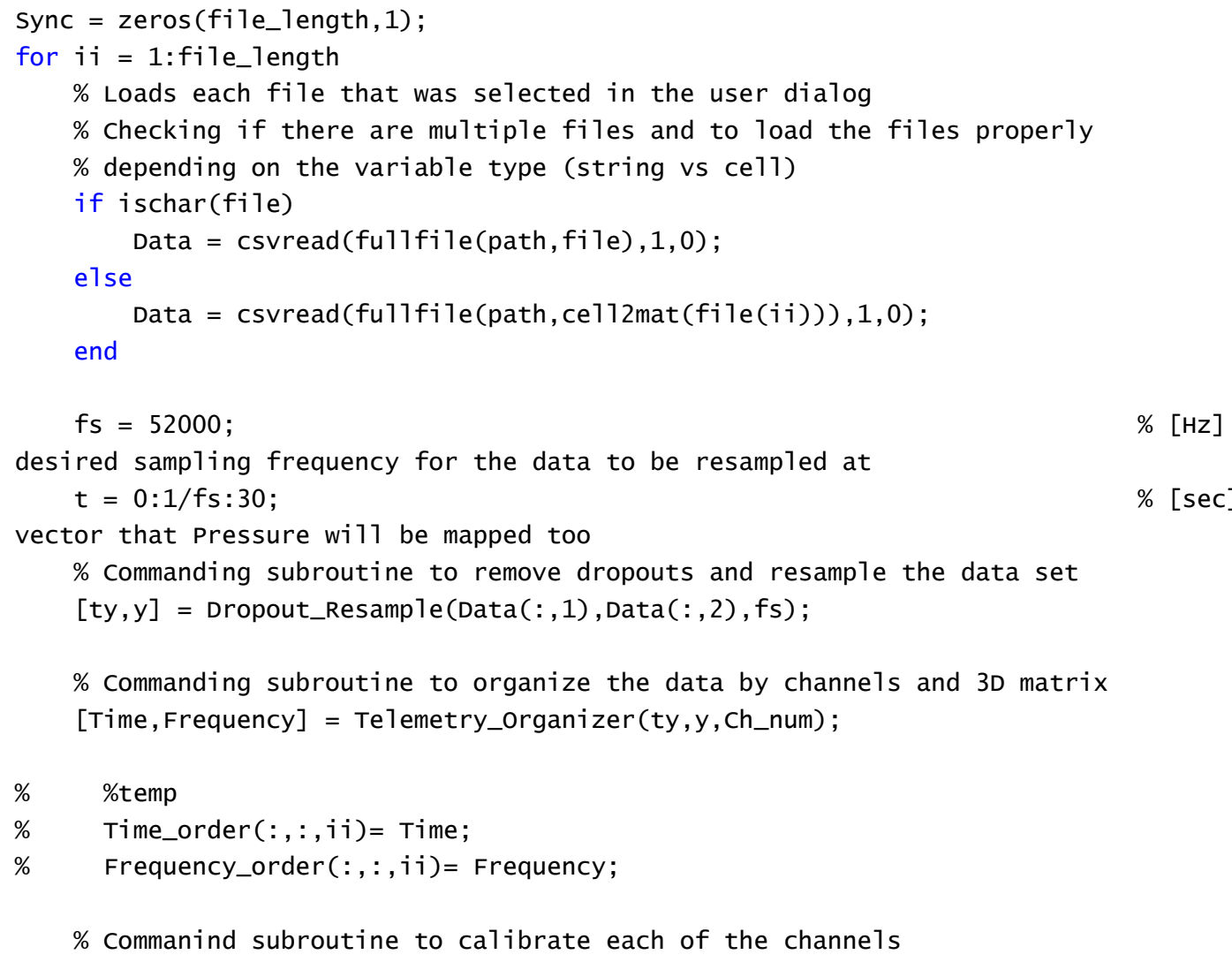




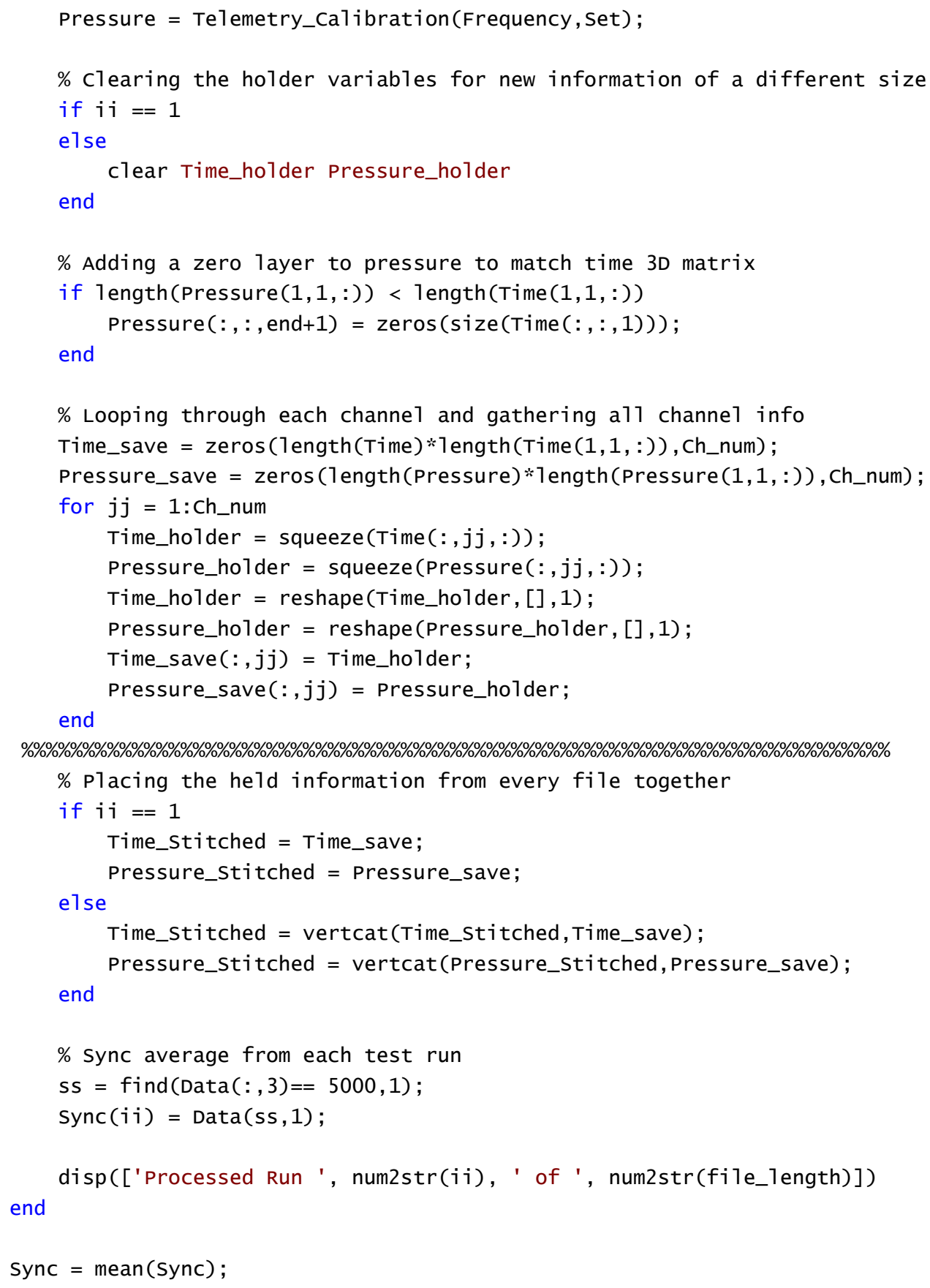

\section{Sorting Time and Pressure Data}

[Time_Stitched,index] = sort (Time_Stitched);

for $i i=1: 1$ ength $(i \operatorname{dex}(1,:))$

$A(:, i i)=$ Pressure_stitched $($ index $(:, i i), i i)$;

end

\% Replacing the sorted data over the unorganized values

$\%$ only saving the values that are not all zero rows 
Pressure_Stitched $=A($ any $(A, 2),:) ;$

Time_Stitched = Time_Stitched (any (Time_Stitched,2), : );

end

\section{Published with MATLAB® R2018a}

\section{O.3 Dropout Resample}

\section{Removing Dropouts}

function $[t y, y]=$ Dropout_Resample $(t, A, f s)$

$\%$ Required format:

$\% \mathrm{t}$ - 1st input: is the time vector associated with $\mathrm{A}$

\% A - 2nd input: is the vector to have dropouts removed and resampled

$\%$ fs - 3rd input: is desired sampling frequency for vector to be resampled at

$\%$ ty - 1st output: is the resampled time vector

$\%$ y - 2nd output: is the resampled, dropouts removed vector

$\%$

\%Purpose of code:

$\%$ Removes drop outs and resamples the data to a specified sampling

$\%$ frequency

\section{Removing Dropouts}

$B=\operatorname{hampel}(A, 1000)$;

$B=\operatorname{hampel}(B, 1000)$;

$\% p=5$, upsampling parameter, $q=10$, downsampling parameter

$y=\operatorname{resample}(B, t, f s, 5,10) ;$

ty $=1 / \mathrm{fs}: 1 / \mathrm{fs}:$ length $(\mathrm{y}) * 1 / \mathrm{fs}$;

end

$\underline{\text { Published with MATLAB® R2018a }}$

\section{O.4 Telemetry Organizer}

Finding Marker

Data Matrix.

function [Time,Frequency] = Telemetry_organizer(Time_raw,Freq_raw,Ch_num) 


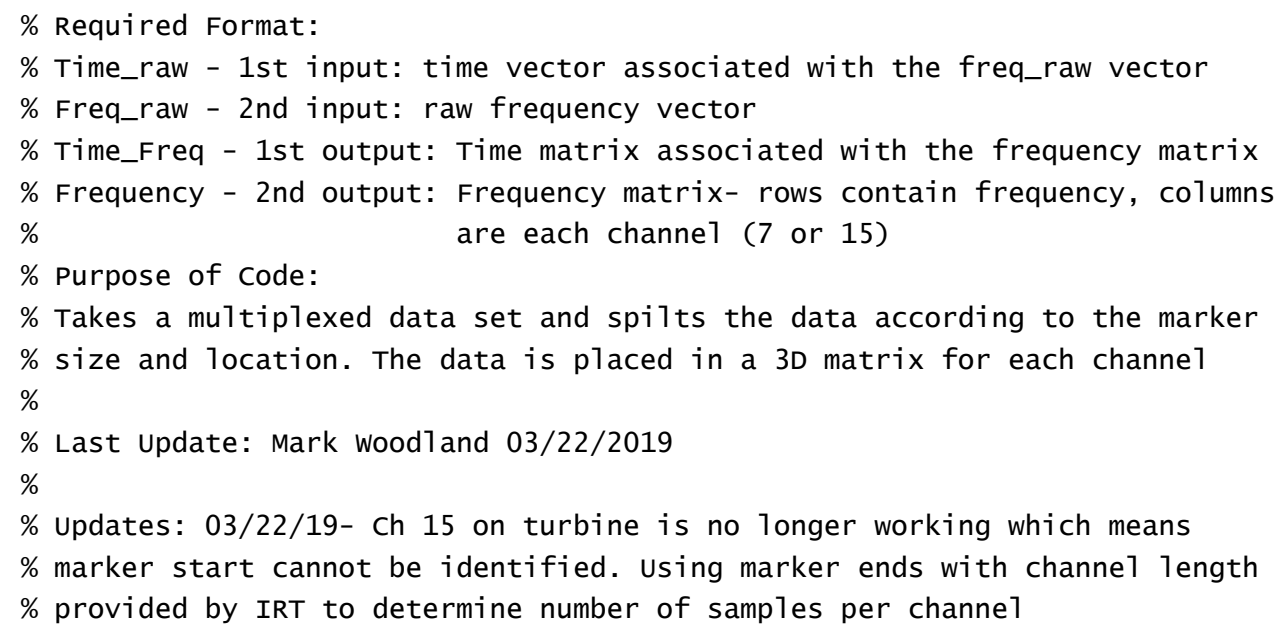

\section{Finding Marker}

thresh = 10000;

threshold 1evel for marker

$f s=1 /($ Time_raw(2)-Time_raw(1));

sampling frequency

Marker_start $=$ find $($ Freq_raw $(1:$ end-1) $>$ thresh..

marker 1ocation

Marker_end $=$ find $($ Freq_raw $(1$ : end -1$)<$ thresh...

\& Freq_raw $(2$ : end $)>$ thresh);

$\%$ End of

marker location

\% Removing all partial starting markers that can be at end of data set Marker_start(Time_raw(Marker_start) >Time_raw(end) -1$)=[]$;

\% Removing a11 parital ending markers that can be at beginning of data set Marker_end(Time_raw (Marker_end) $<$ Time_raw $(1)+1)=[]$;

\% Verifying is Marker start and Ends are Markers and not dropouts

\% Marker starting

Marker_remove $=\operatorname{zeros}(1,1$ ength $($ Marker_start $))$;

for $i \mathrm{i}=1$ : length(Marker_start)

\% checking values after the start of marker

if(mean(Freq_raw(Marker_start(ii):Marker_start(ii)+fs*.01))<thresh) \% Looking for

$1 \%$ of the sampling frequency as the number of points to verify marker

Marker_remove $(i i)=1$;

$\%$ Logic to

keep marker values

end

end

Marker_start (Marker_remove $<1)=[]$;

dropout values from

\% Looking for dropouts inside of marker and removing as marker starts count $=0$; 


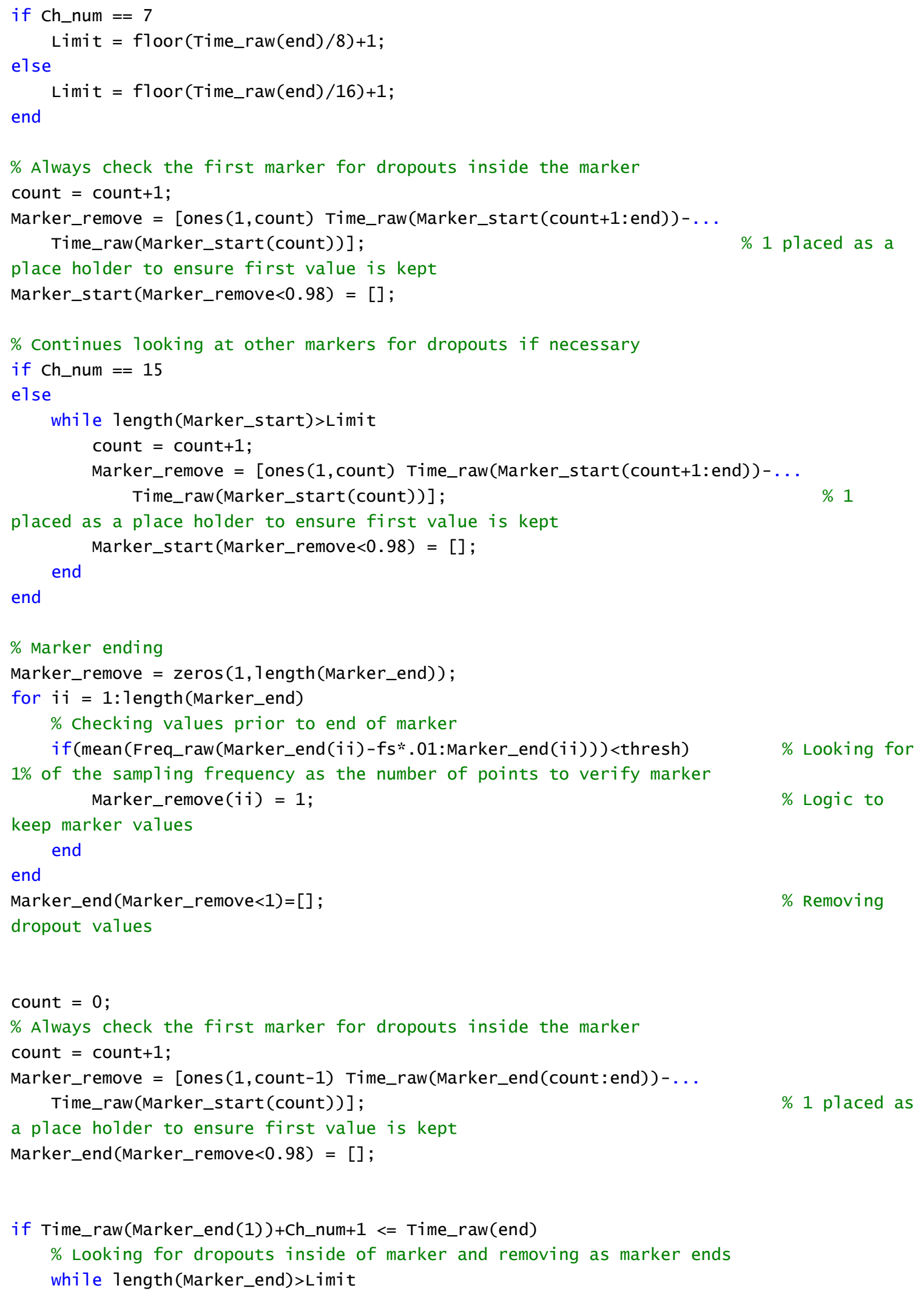




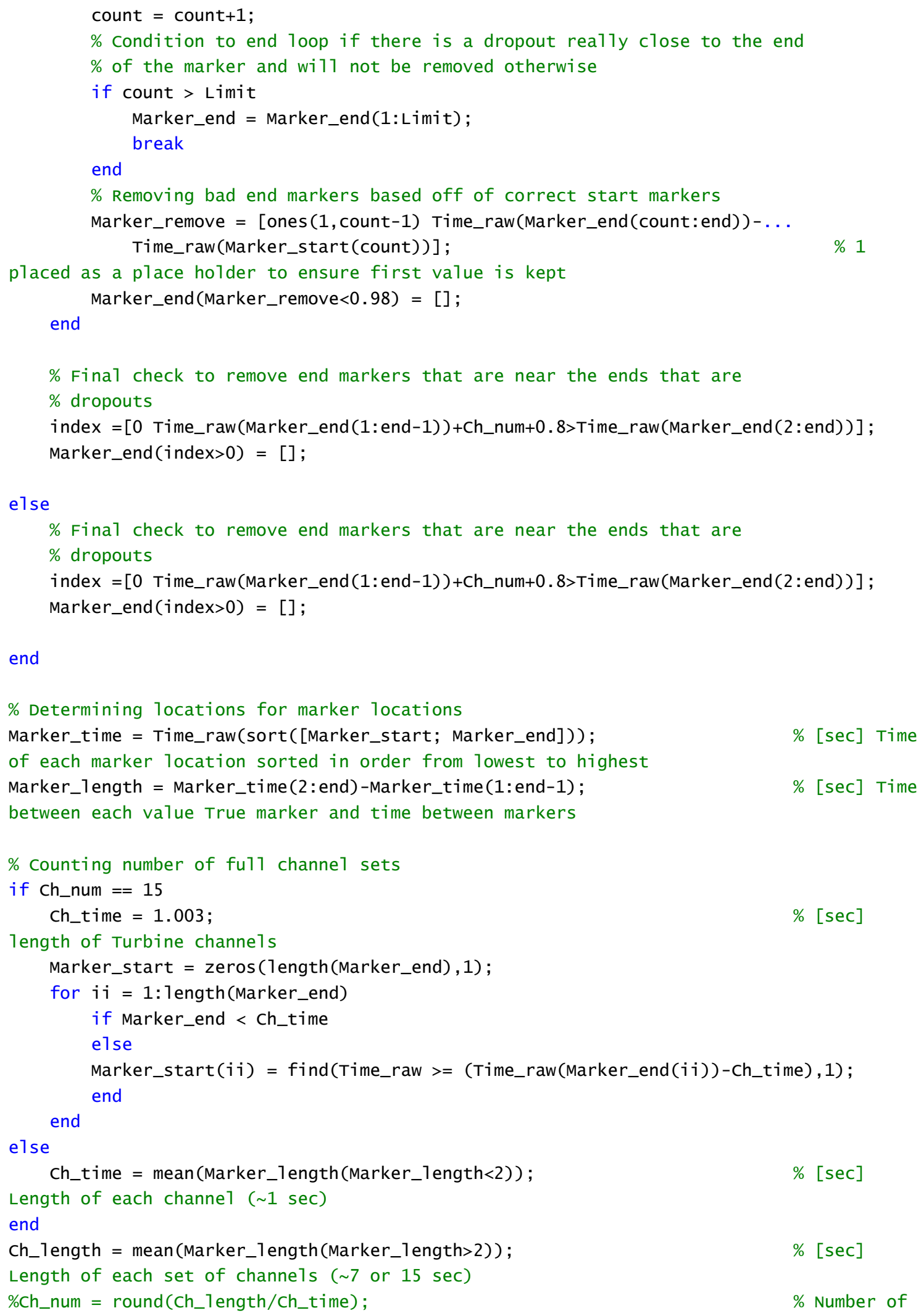


channels in each channe1 set

Ch_sets = 1ength (Marker_end) -1 ;

$\%$ Number of

fu11 channe1 sets

\% Counting number of data points per channe1

$v=$ find(Marker_end $>$ Marker_start $(1), 1)$;

\% Finding

first marker pair

Ch_point $=$ round $($ mean $($ Marker_end $(v$ :end $)-$ Marker_start $))$;

$\%$ Number of

data points in each channel

\section{Data Matrix}

\section{Creating 3D matrix for data}

Frequency $=$ zeros (Ch_point-1000,Ch_num,Ch_sets+2); \% Rows-

remove 500 data point for ends, Column- \# of $\mathrm{CH}$, Layers- Add two for possible partial data sets at begining and end

Time = Frequency;

\% Time matrix

associated with the Frequency Matrix

if Ch_sets $=0 \quad 0 \quad$ \% If there

are no full data sets just skip this portion of code and go to partial data sets code

else

for $i j=1:$ Ch_sets

$A=$ Freq_raw (Marker_start $(i i)+C h \_p o i n t: M a r k e r \_s t a r t(i i) \ldots$ +Ch_point*(Ch_num+1)-1); $\quad$ \% Pulling

ful1 channel set from data

$B=$ Time_raw (Marker_start $(i i)+C h \_p o i n t: M a r k e r \_s t a r t(i i) . .$. +Ch_point*(Ch_num+1)-1);

A_m = reshape $\left(A,[], C h \_n u m\right) ; \quad$ \% Reshaping

data to spli1t each channel

B_m = reshape $(B,[]$, Ch_num $)$;

A_m $(1: 500,:)=[]$;

\% Removing

first 500 data points

A_m(end-499: end, : ) $=[]$;

\% Removing

last 500 data points

B_m $(1: 500,:)=[]$;

B_m (end-499: end, : ) $=[]$;

Frequency $(:,:, i j+1)=$ A_m;

\% Assigning

values to 3D Results Matrix, Keep first layer open for possible partial data

Time $(:,:, i i+1)=$ B_m;

end

end

Partial Data Sets at Beginning and End

Finding if partial set at beginning of data 


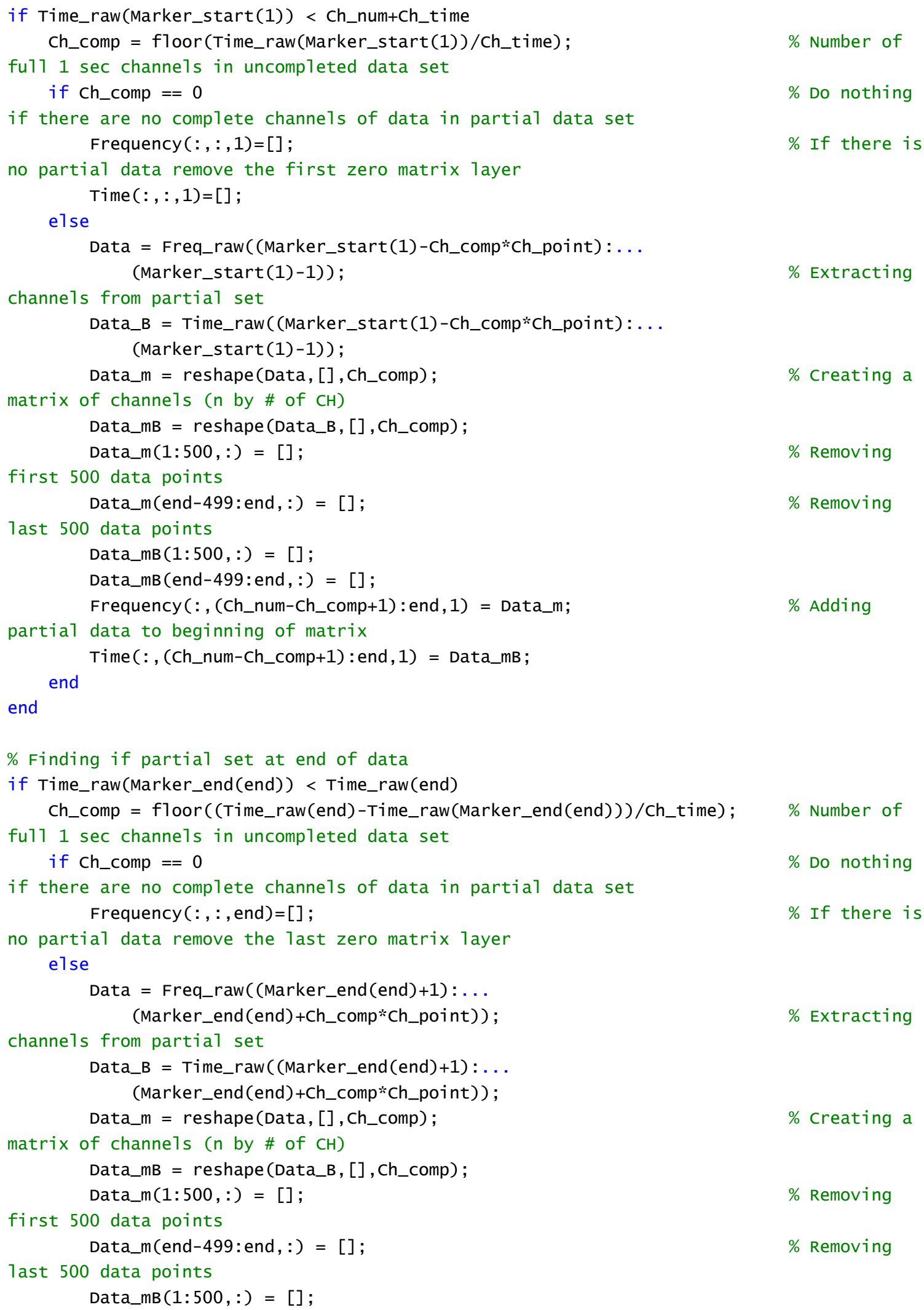




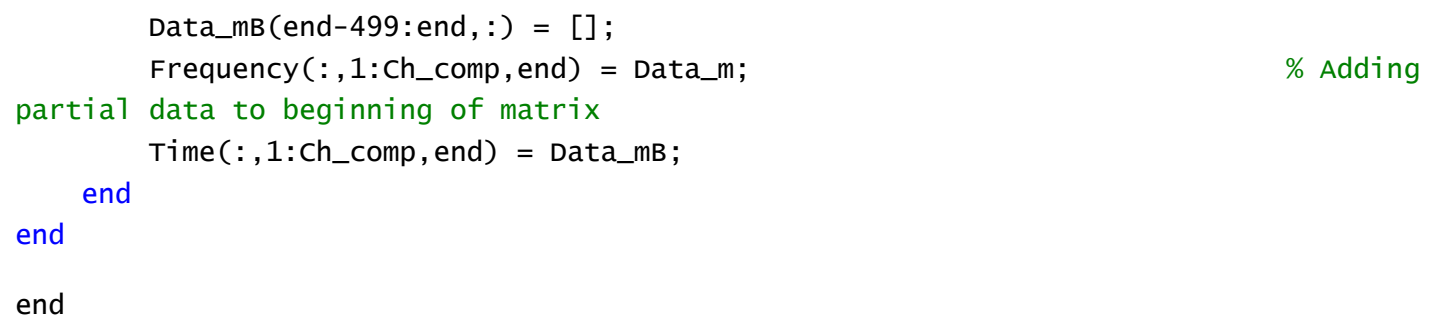

Calibration

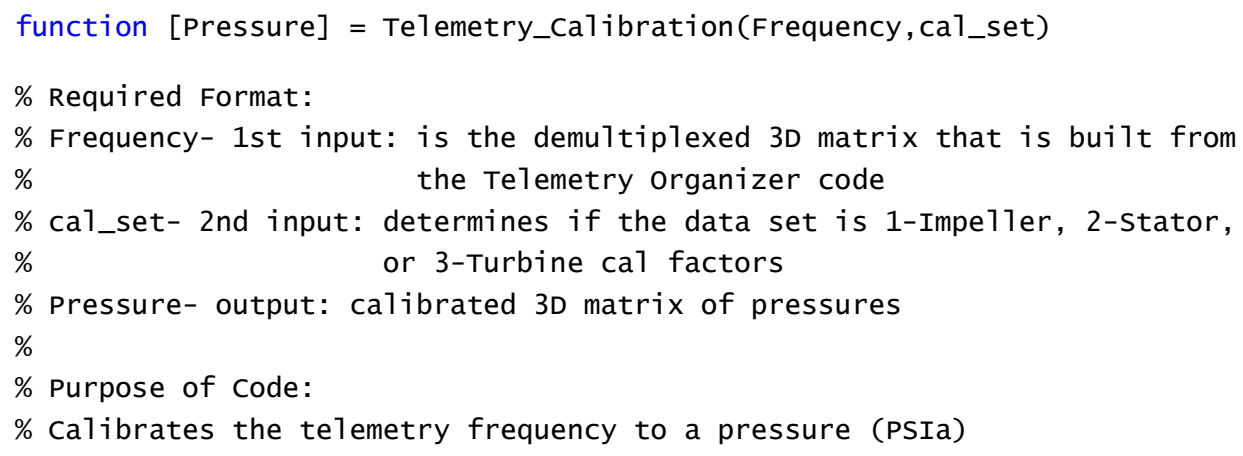

\section{Calibration}

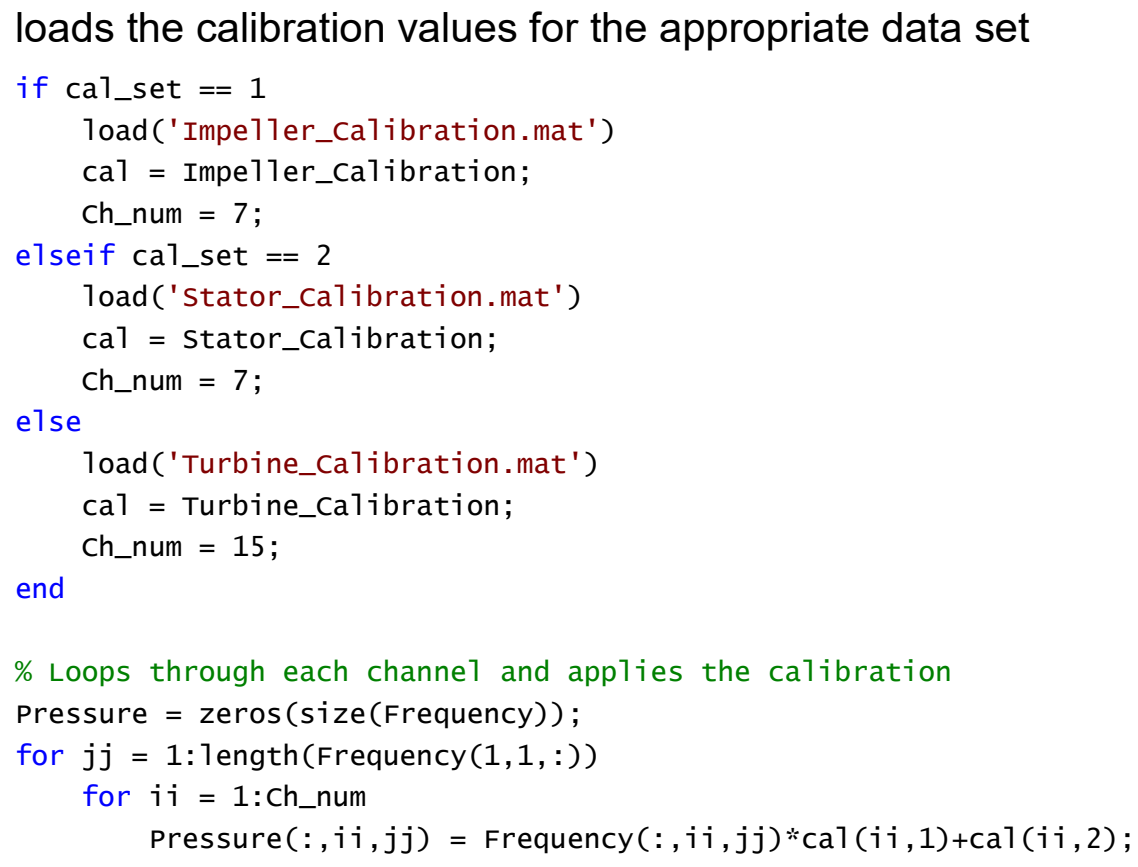




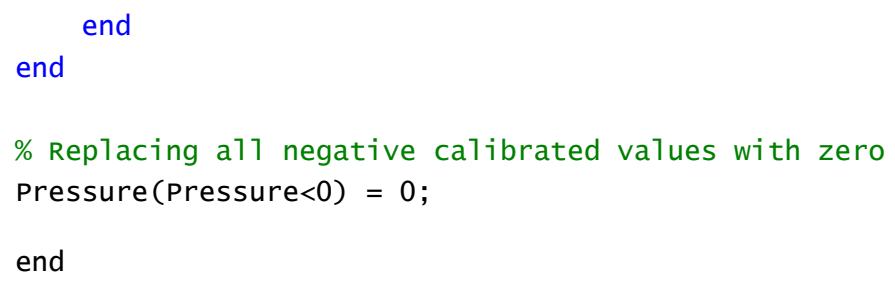

Published with MATLAB® R2018a

\section{O.6 Tach to RPM}

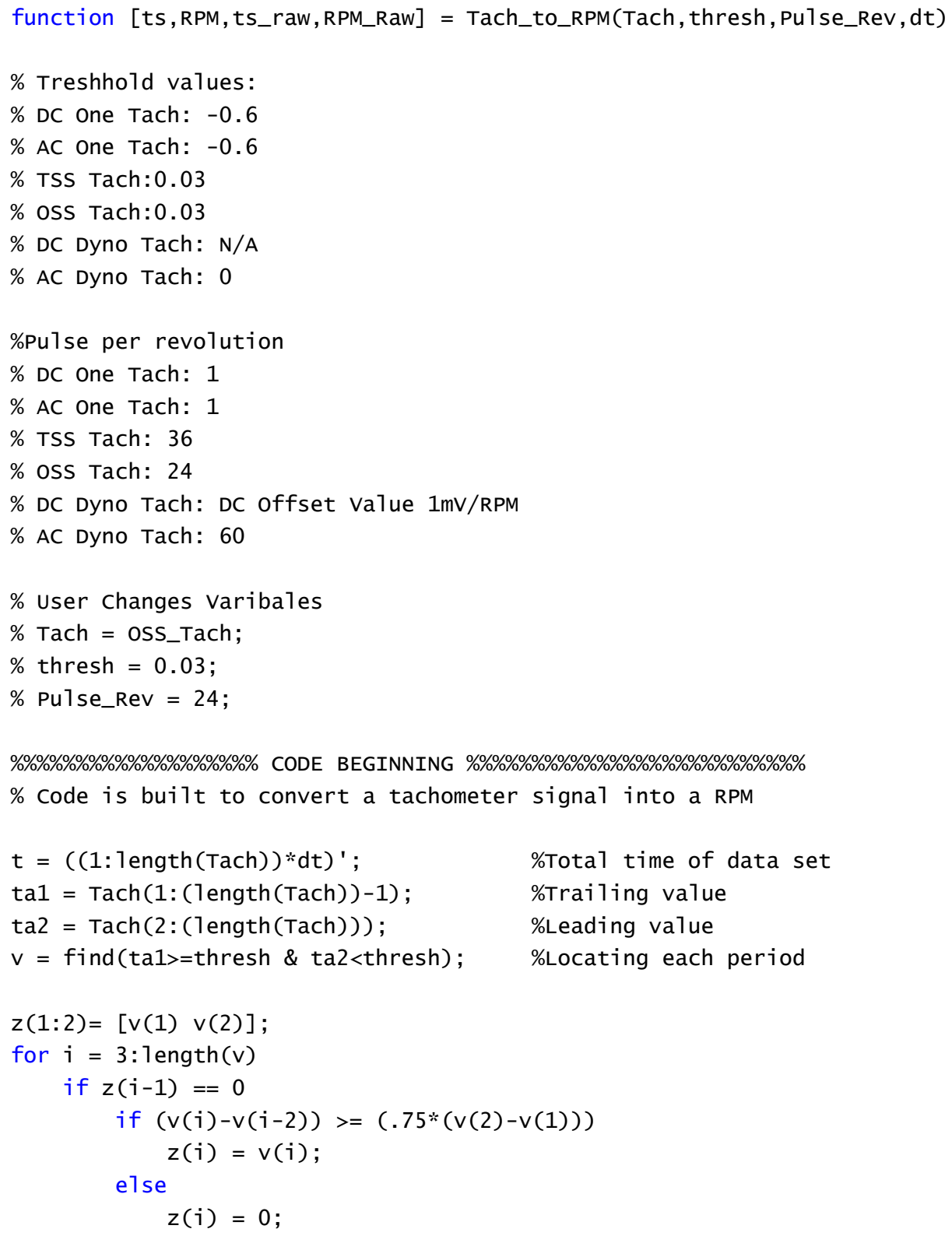




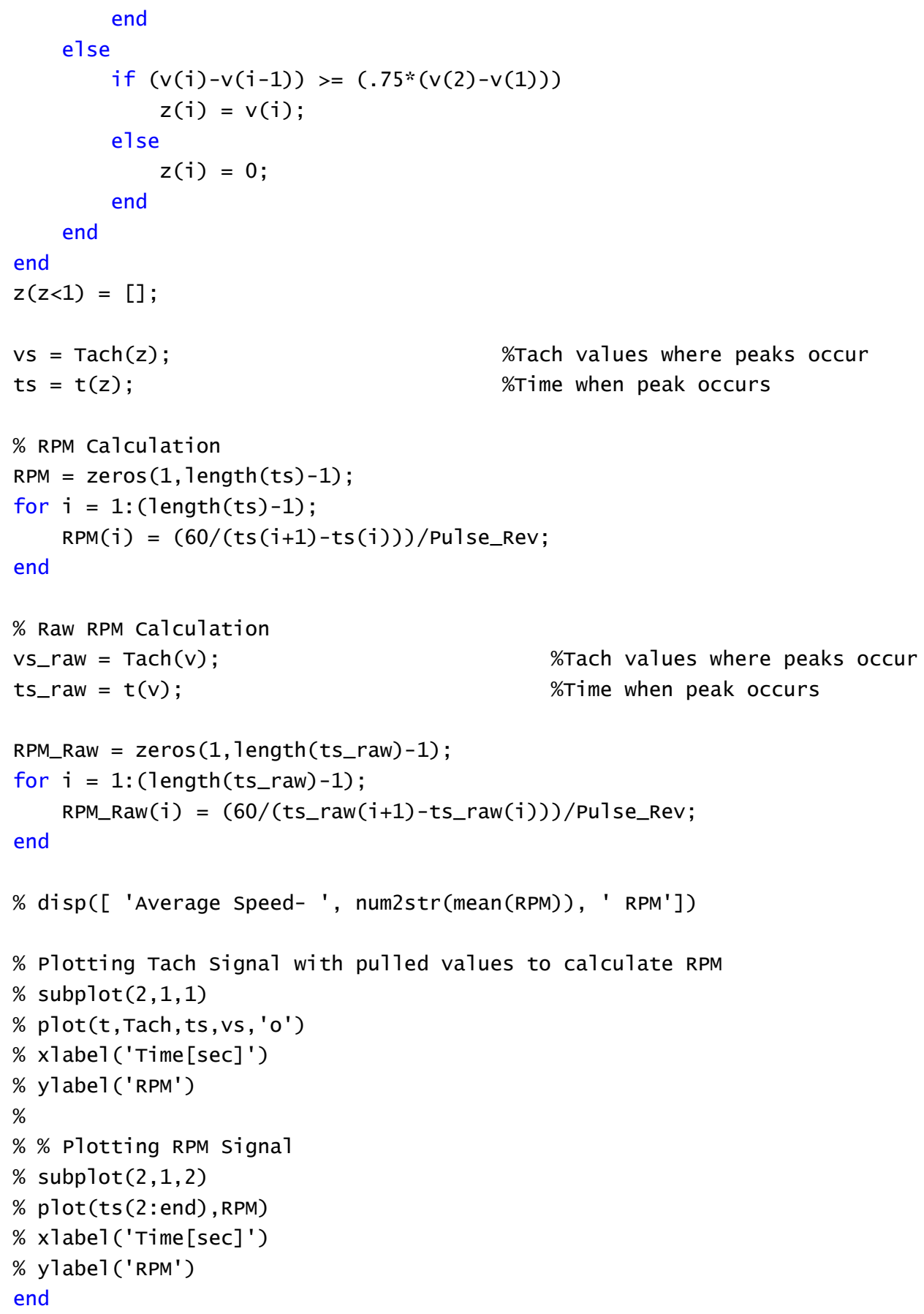

Published with MATLAB® R2018a

\section{O.7 Clutch Capacity}

Data files 
Calculations

$\%$ Purpose of code:

$\%$ Takes averaged pressure data and creates a clutch capacity curve

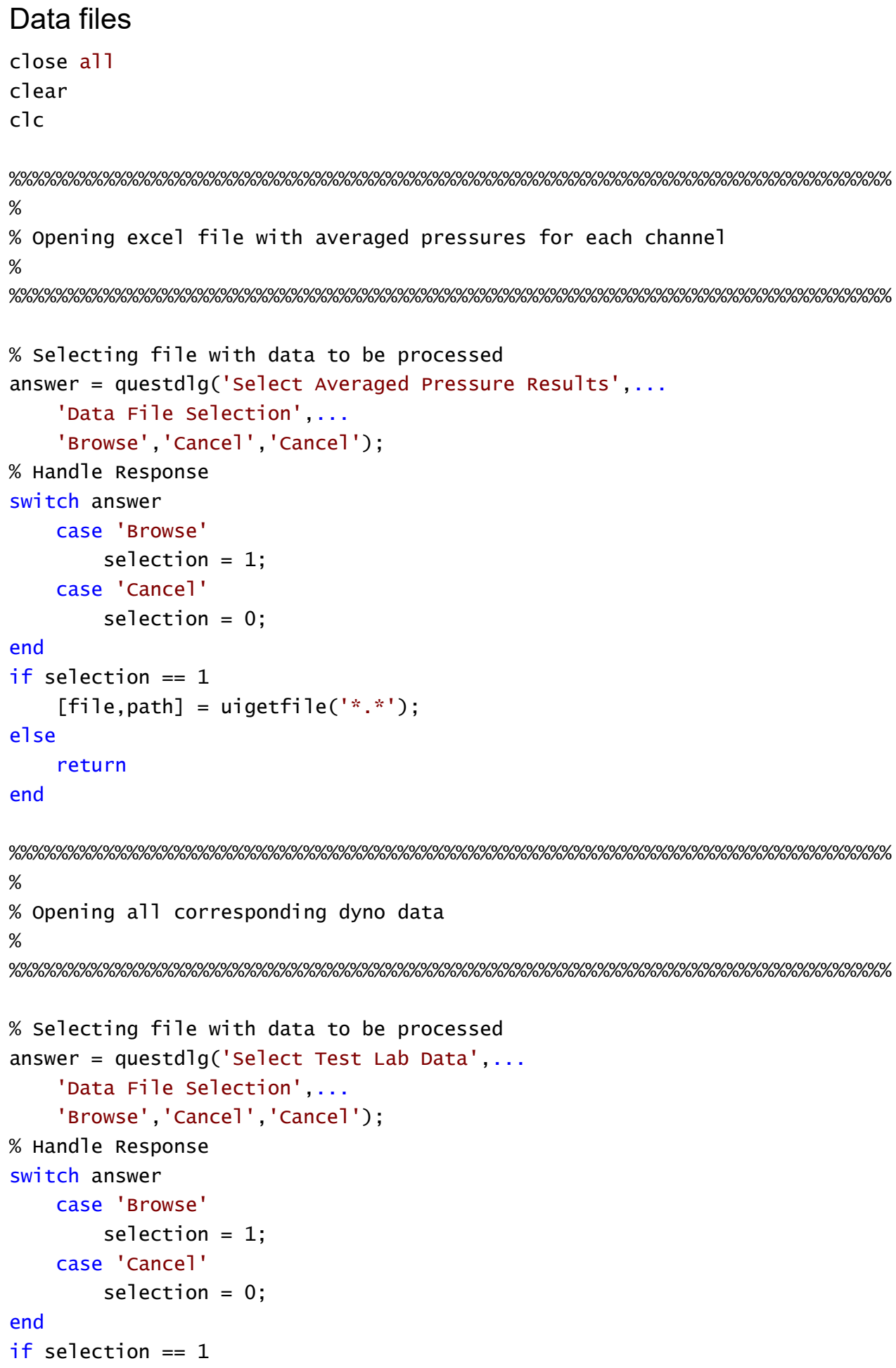


$\left[\right.$ file2, path2] $=$ uigetfile $\left({ }^{\prime} * *{ }^{\prime}\right.$, 'Select one or More Files',... 'Multiselect', 'on');

else

return

end

\% Selecting Impeller, Turbine, or Stator for channel naming

1ist $=\{$ 'Impe11er' 'Stator' 'Turbine' $\}$;

Names $=$ (1istdlg('PromptString', 'Select test 1ocation:', 'SelectionMode',... 'single' , 'Liststring', 1ist));

\section{Calculations}

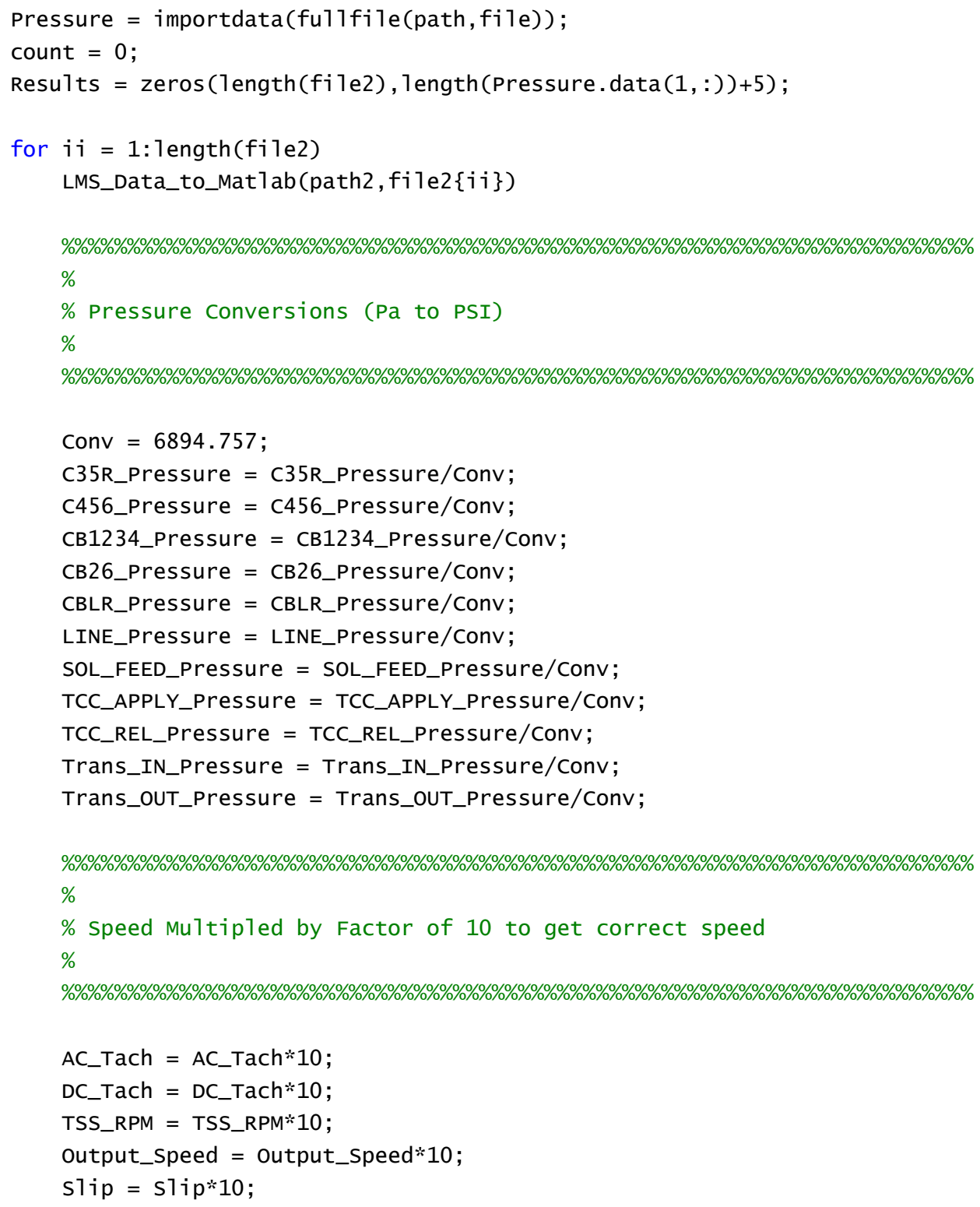




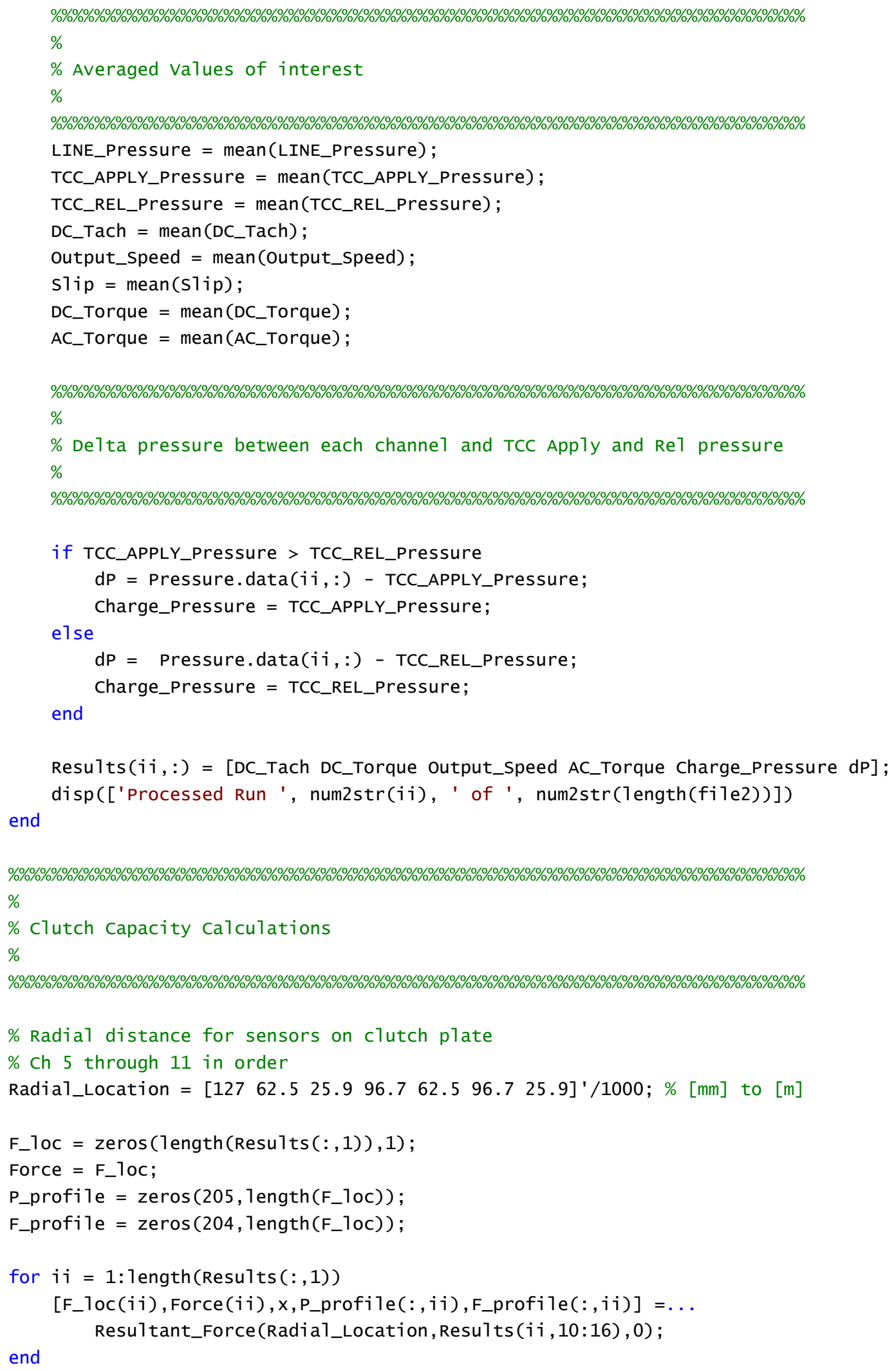




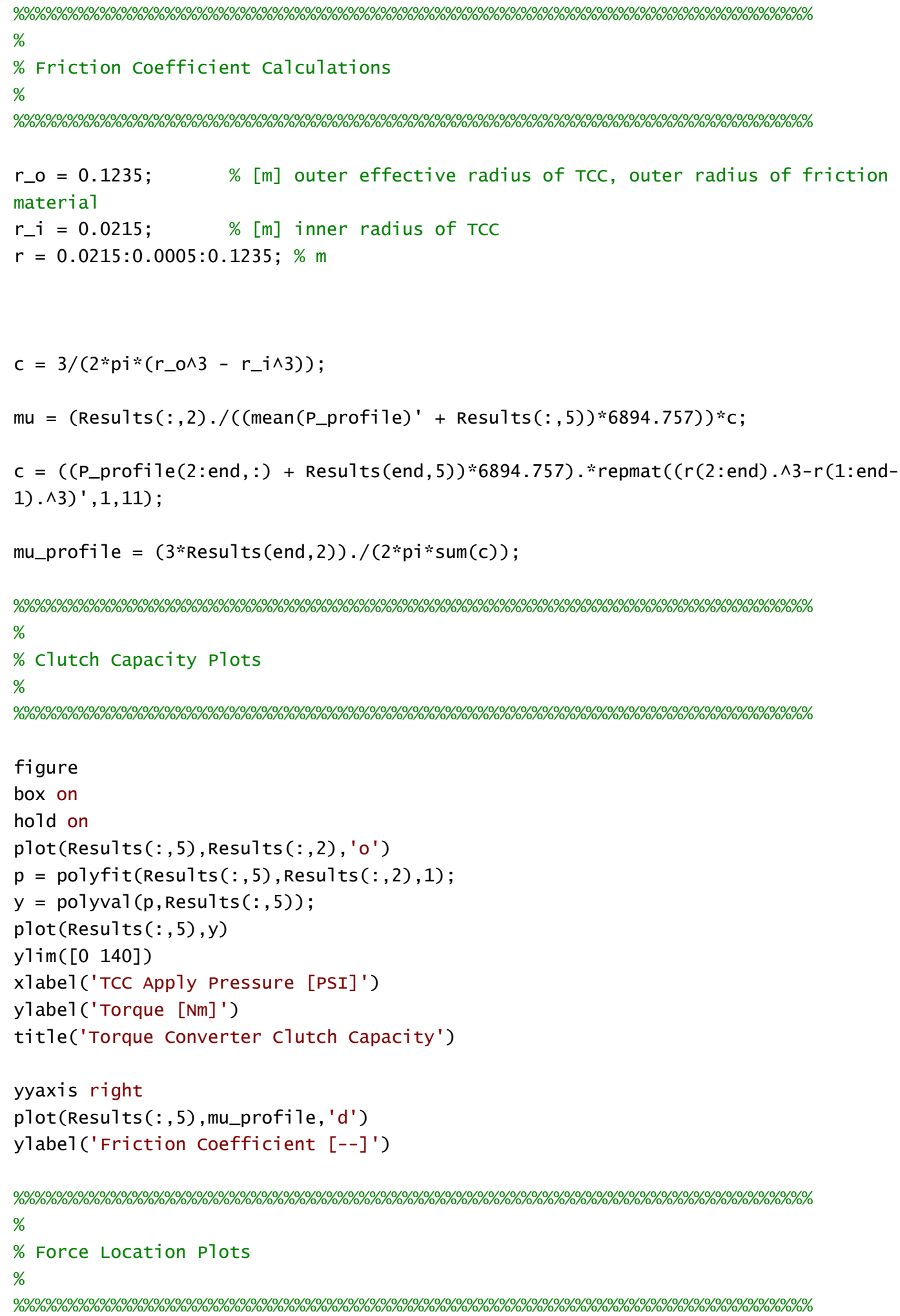




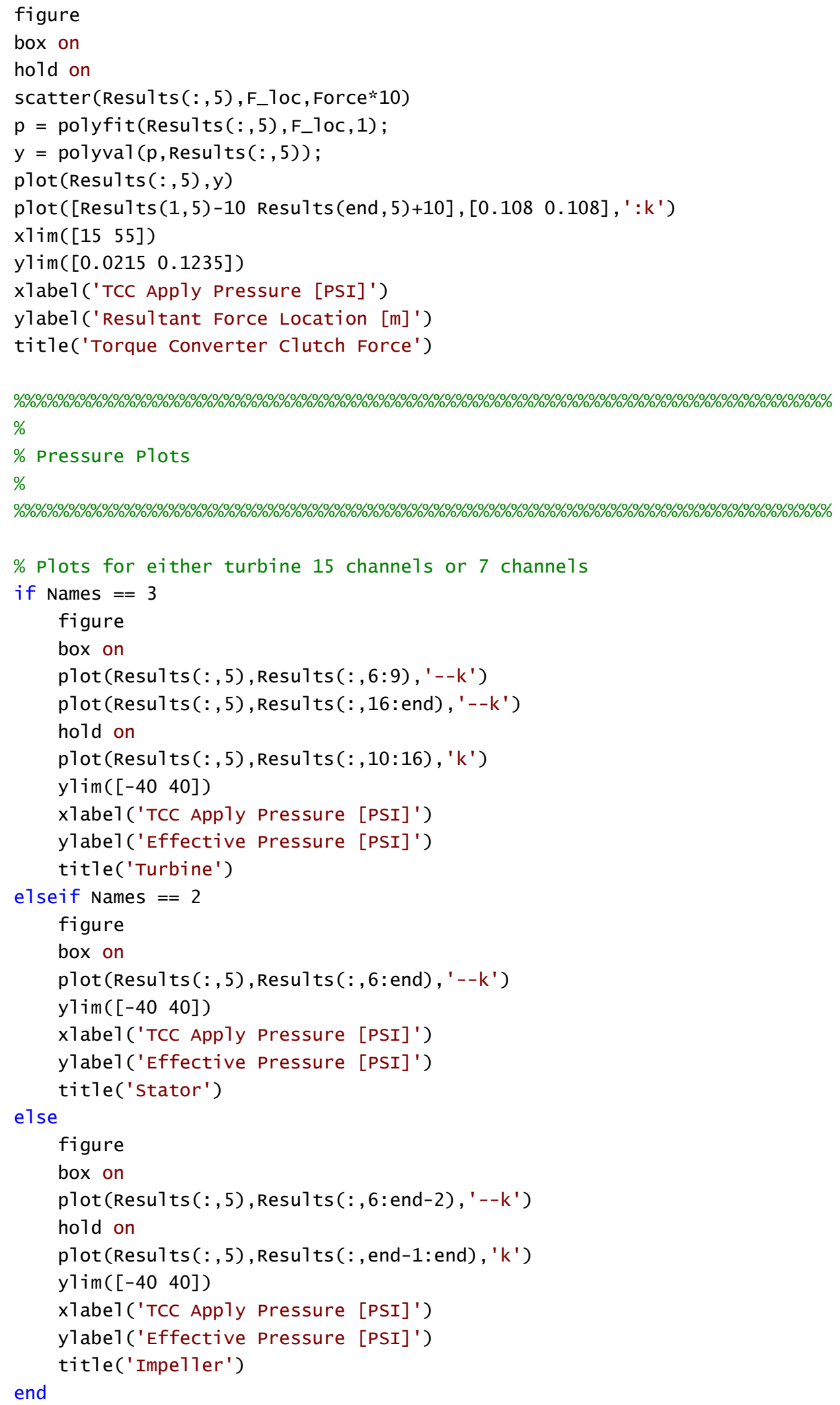




\section{O.8 Resultant Force}

function [F_1oc, Force, x1,P_profile,F_profi1e] = Resu1tant_Force(Radia1_Location, Data, on)

$\%$ Required Format:

\% Radial_Location - 1st input: radial distance on the clutch plate for each

$\%$ sensor

\% Data - 2nd input: open, Slip, or Locked Data

$\%$ on - 3rd input: on means the TCC is in the open condition

\% F_loc - 1st output: Radial location where the resultant force is acting

$\%$ Force - 2nd output: resultant force from the pressure in kN

$\%$

$\%$ Purpose of Code:

\% Finds the resultant force from experimental pressure data on clutch plate

$\%$ Back

\% Largest raduis of friction material on clutch plate is $123.5 \mathrm{~mm}$

$\%$ smallest radius of clutch plate is $21.5 \mathrm{~mm}$

$\mathrm{x} 1=0.0215: 0.0005: 0.1235 ; \% \mathrm{~m}$

$\mathrm{p}=$ polyfit(Radia1_Location $\left.(1: 4), \operatorname{Data}(1,1: 4)^{\prime}, 2\right)$;

$y 1=\operatorname{polyval}(p, x 1)$;

$\%$ Front

if on $==1$

$\mathrm{x} 2=0.0215: 0.0005: 0.1235 ; \% \mathrm{~m}$

e1se

\% Max radius to friction material is $108 \mathrm{~mm}$

$\mathrm{x} 2=0.0215: 0.0005: 0.108 ; \% \mathrm{~m}$

end

$\mathrm{p}=\operatorname{polyfit}($ Radial_Location (5: end), $\operatorname{Data}(1,5:$ end) ' , 2);

$y 2=\operatorname{polyval}(p, x 2)$;

\% Pressure profile acting on the clutch plate

P_profile = y1 (1: 1ength $(y 2))-y 2$;

P_profile $=[$ P_profile y1 (1ength $(y 2)+1$ : end $)]$;

$A=2 * p i * x 1(2$ : end $) . \wedge 2-2 * p i * x 1(1:$ end -1$) . \wedge 2 ; \% m \wedge 2$

F_profile $=$ P_profile(2:end).*6894.757.*A; \% N

Force $=\operatorname{cumsum}\left(F \_p r o f i 1 e\right)$;

$F_{-}$loc $=$find $($Force $>=\max ($ Force $) / 2,1)$;

$F_{-}$1oc $=x 1\left(F_{-}\right.$1oc $)$;

if isempty (F_loc)

$F_{-} 10 \mathrm{c}=\mathrm{x} 1(1)$;

end

Force $=\max ($ Force $) / 1000 ; \quad \% \mathrm{kN}$

end

Published with MATLAB® R2018a 


\section{O.9 Shape Graphing}

function RGB = Shape_Graphing $(I, x$, mag, mag_max $)$

\% Required Format:

$\%$ I - 1st input: imread('image name')

$\% x-2$ nd input: width of rectangles (default 25 for TC)

$\%$ mag - 3rd input: pressure mags of ch 5-11 for turbine

$\%$ mag_max - 4th input: maxium value for a11 pressures in maq matrix

\% RGB - output: Info for imshow(RGB)

$\%$

\% Purpose of Code:

\% create a frame of the pressures across the TC clutch plate

\%I = imread('TC Clutch.png');

$\% \mathrm{x}=25$

\% Bottom Right Channe1

if $\operatorname{mag}(1,3)<0$

RGB = insertshape (I, 'Fil1edRectangle ', [270 725-x abs(mag(1,3))/mag_max*100

$\mathrm{x}$ ] , 'Color' , 'cyan', 'Opacity', 1);

else

RGB = insertshape(I, 'Fil1edRectangle' , [270 725-x mag(1,3)/mag_max*100

$\mathrm{x}$ ] , 'Color' , 'red' , 'opacity', 1);

end

if $\operatorname{mag}(2,3)<0$

RGB = insertshape(RGB, 'Fil1edRectangle' , [270 725 abs (mag (2,3))/mag_max*100

$\mathrm{X}$ ] , 'Color' , 'blue' , 'Opacity' ,1);

else

RGB = insertshape(RGB, 'Fi11edRectangle ', [270 $725 \mathrm{mag}(2,3) /$ mag_max*100

$\mathrm{X}$ ] , 'Color' , 'green' , 'Opacity' ,1);

end

\% Middle Right Channel

if $\operatorname{mag}(1,2)<0$

RGB = insertshape (RGB, 'Fi11edRectangle ' , [220 485-x abs (mag (1,2))/mag_max*100

$\mathrm{x}$ ] , 'Color', 'cyan', 'opacity', 1);

else

RGB = insertshape (RGB, 'FilledRectangle' , [220 485-x mag $(1,2) /$ mag_max*100

$\mathrm{X}$ ] , 'Color' , 'red' , 'Opacity' ,1);

end

if $\operatorname{mag}(2,2)<0$

RGB = insertshape(RGB, 'Fi17edRectangle' , [220 485 abs (mag (2,2))/mag_max*100

$\mathrm{x}$ ] , 'Color' , 'blue' , 'opacity' ,1);

else

RGB = insertshape(RGB, 'Fi17edRectangle', [220 $485 \mathrm{mag}(2,2) /$ mag_max*100

$\mathrm{X}$ ] , 'Color' , 'green' , 'opacity' ,1);

end 


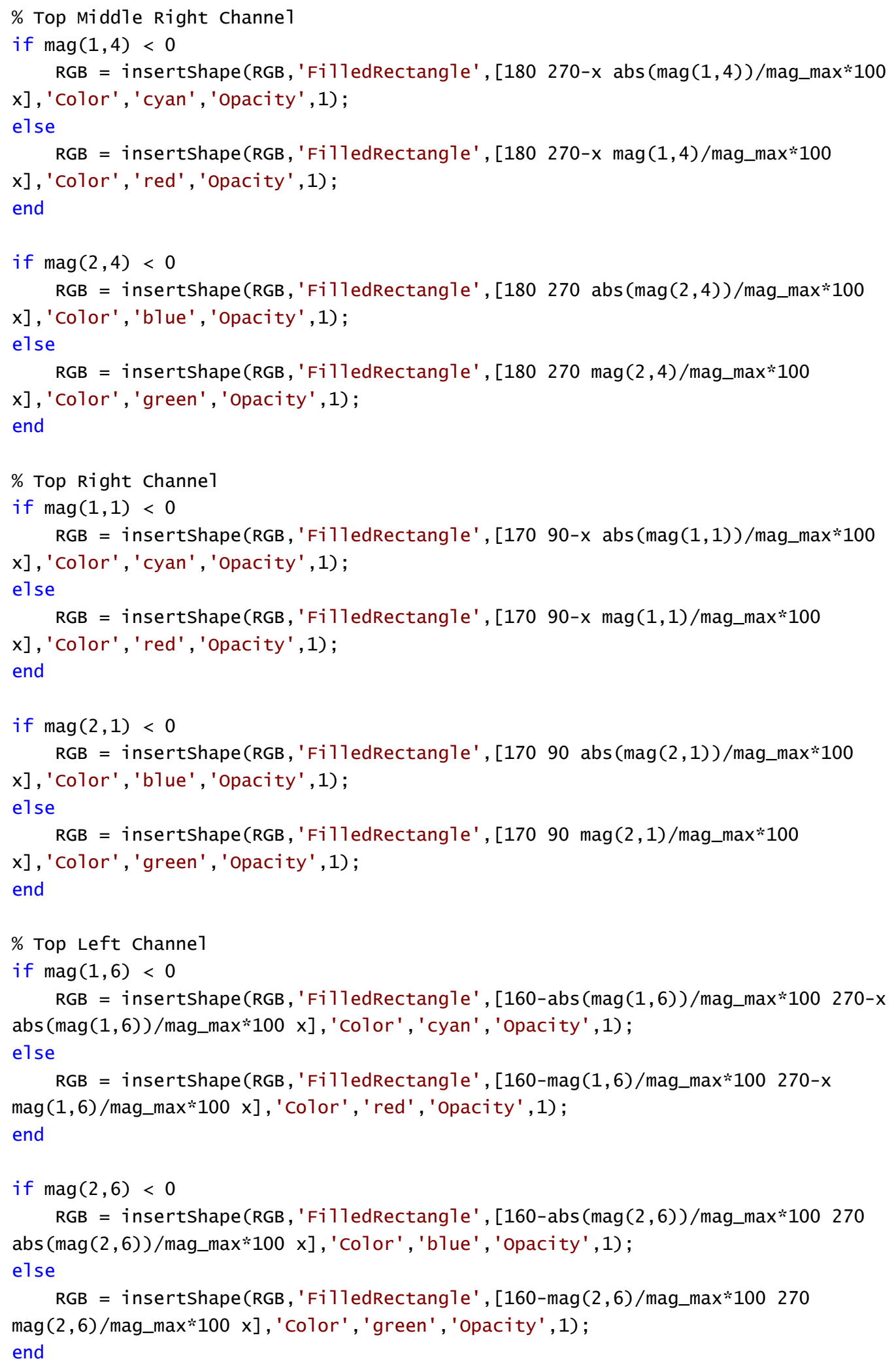




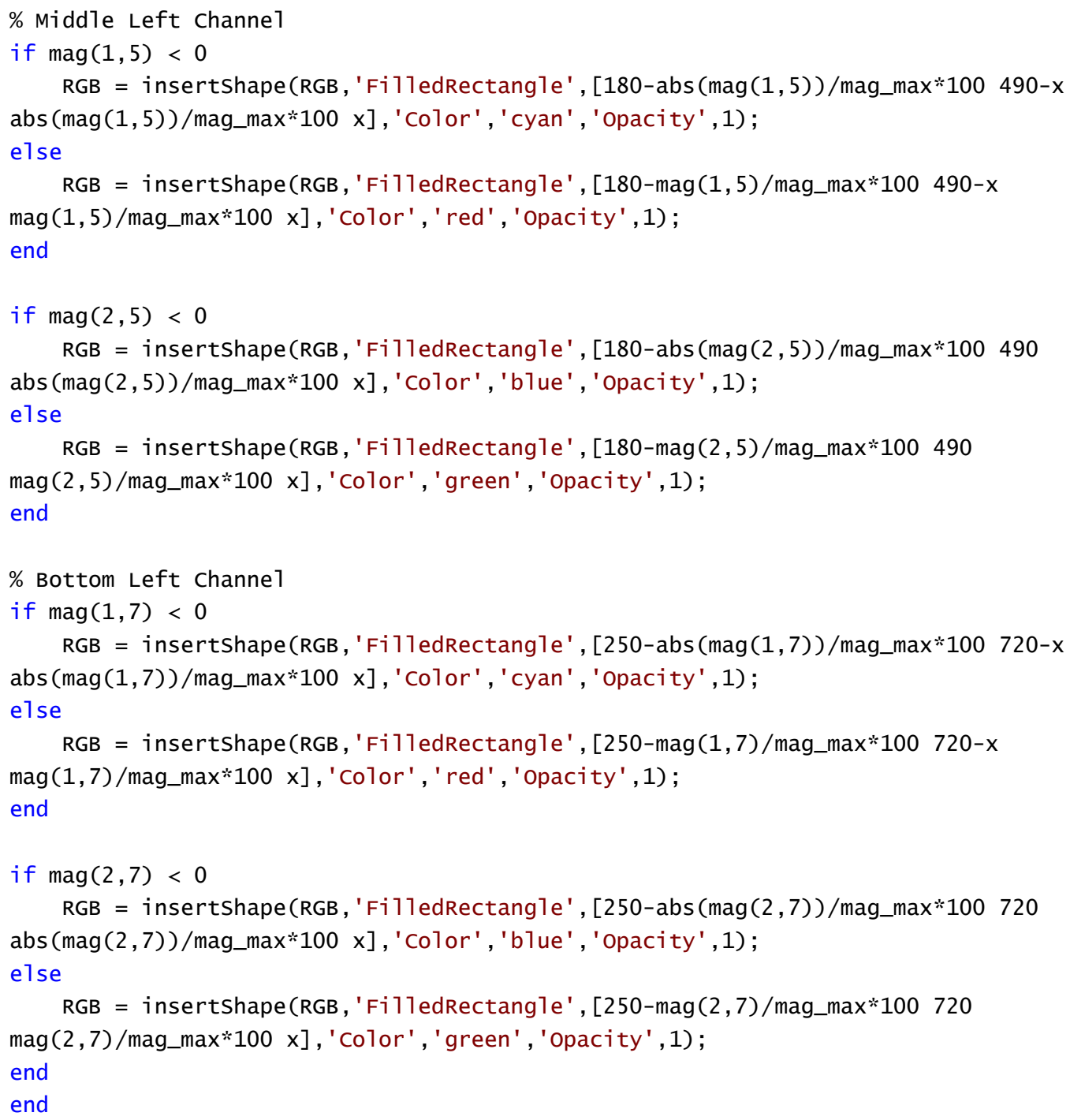

\section{Published with MATLAB® R2018a}

\section{O.10 Text Graphing}

function RGB = Text_Graphing ( $\mathrm{I}$, Data, Cond $)$

$\%$ Required Format:

\% I - 1st input: imread('image name')

$\%$ Data - open, slip, or Locked Data

$\%$ Cond - Condition the TC is in; open, slip, Locked

$\%$

$\%$ Purpose of Code:

$\%$ Add text to a frame with input, output, and charge pressure information 


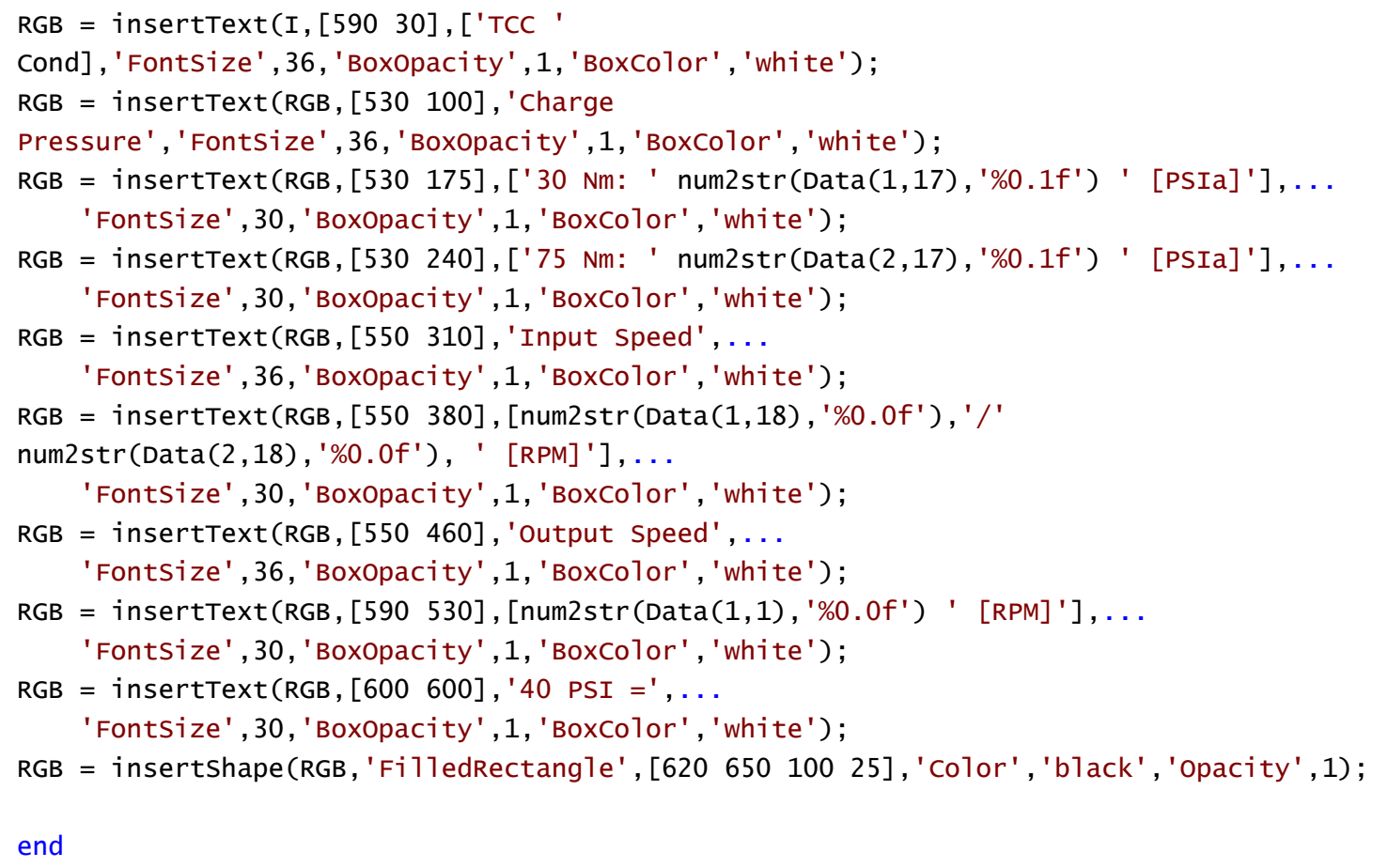

\section{$\underline{\text { Published with MATLAB® R2018a }}$}


